\title{
Writing for Success
}




\section{Writing for Success}

[Author removed at request of original publisher]

UNIVERSITY OF MINNESOTA LIBRARIES PUBLISHING EDITION, 2015. THIS EDITION ADAPTED FROM A WORK ORIGINALLY PRODUCED IN 2010 BY A PUBLISHER WHO HAS REQUESTED THAT IT NOT RECEIVE ATTRIBUTION.

MINNEAPOLIS, MN 


\section{() (1) (2) (2)}

Writing for Success by University of Minnesota is licensed under a Creative Commons Attribution-NonCommercial-ShareAlike 4.0 International License, except where otherwise noted. 



\section{Contents}

Publisher Information

Chapter 1: Introduction to Writing

1.1 Reading and Writing in College

1.2 Developing Study Skills

1.3 Becoming a Successful College Writer

1.4 Introduction to Writing: End-of-Chapter Exercises

\section{Chapter 2: Writing Basics: What Makes a Good Sentence?}

2.1 Sentence Writing

2.2 Subject-Verb Agreement

2.3 Verb Tense

2.4 Capitalization 75

2.5 Pronouns 80

2.6 Adjectives and Adverbs 89

2.7 Misplaced and Dangling Modifiers 96

2.8 Writing Basics: End-of-Chapter Exercises

\section{Chapter 3: Punctuation}

3.1 Commas

3.2 Semicolons

3.3 Colons

3.4 Quotes

3.5 Apostrophes

3.6 Parentheses

3.7 Dashes

Chapter 4: Working with Words: Which Word Is Right? 
4.3 Word Choice

4.4 Prefixes and Suffixes

4.5 Synonyms and Antonyms

4.6 Using Context Clues

4.7 Working with Words: End-of-Chapter Exercises

\section{Chapter 5: Help for English Language Learners}

5.1 Word Order

179

5.2 Negative Statements

185

5.3 Count and Noncount Nouns and Articles

5.4 Pronouns

5.5 Verb Tenses

200

5.6 Modal Auxiliaries

5.7 Prepositions

5.8 Slang and Idioms

5.9 Help for English Language Learners: End-of-Chapter Exercises

Chapter 6: Writing Paragraphs: Separating Ideas and Shaping Content

6.1 Purpose, Audience, Tone, and Content 232

$\begin{array}{ll}6.2 \text { Effective Means for Writing a Paragraph } & 248\end{array}$

6.3 Writing Paragraphs: End-of-Chapter Exercises $\quad 262$

Chapter 7: Refining Your Writing: How Do I Improve My Writing Technique?

7.1 Sentence Variety 265

$\begin{array}{ll}7.2 \text { Coordination and Subordination } & 281\end{array}$

$\begin{array}{ll}7.3 \text { Parallelism } & 290\end{array}$

7.4 Refining Your Writing: End-of-Chapter Exercises

Chapter 8: The Writing Process: How Do I Begin?

8.1 Apply Prewriting Models 300

$\begin{array}{ll}8.2 \text { Outlining } & 315\end{array}$

$\begin{array}{ll}\text { 8.3 Drafting } & 324\end{array}$

8.4 Revising and Editing 337

8.5 The Writing Process: End-of-Chapter Exercises 353 
Chapter 9: Writing Essays: From Start to Finish

9.1 Developing a Strong, Clear Thesis Statement 356

$\begin{array}{ll}9.2 \text { Writing Body Paragraphs } & 364\end{array}$

9.3 Organizing Your Writing 372

9.4 Writing Introductory and Concluding Paragraphs $\quad 377$

9.5 Writing Essays: End-of-Chapter Exercises 384

Chapter 10: Rhetorical Modes

10.1 Narration 386

$\begin{array}{ll}10.2 \text { Illustration } & 391\end{array}$

10.3 Description 395

10.4 Classification 398

10.5 Process Analysis $\quad 401$

10.6 Definition $\quad 404$

10.7 Comparison and Contrast $\quad 408$

10.8 Cause and Effect $\quad 413$

$\begin{array}{ll}10.9 \text { Persuasion } & 417\end{array}$

10.10 Rhetorical Modes: End-of-Chapter Exercises $\quad 425$

Chapter 11: Writing from Research: What Will I Learn?

11.1 The Purpose of Research Writing 427

11.2 Steps in Developing a Research Proposal 433

11.3 Managing Your Research Project $\quad 442$

11.4 Strategies for Gathering Reliable Information $\quad 447$

11.5 Critical Thinking and Research Applications $\quad 470$

11.6 Writing from Research: End-of-Chapter Exercises $\quad 479$

Chapter 12: Writing a Research Paper

12.1 Creating a Rough Draft for a Research Paper 481

12.2 Developing a Final Draft of a Research Paper 495

12.3 Writing a Research Paper: End-of-Chapter Exercises $\quad 516$

Chapter 13: APA and MLA Documentation and Formatting 
13.2 Citing and Referencing Techniques

13.3 Creating a References Section

13.4 Using Modern Language Association (MLA) Style

13.5 APA and MLA Documentation and Formatting: End-of-Chapter Exercises

Chapter 14: Creating Presentations: Sharing Your Ideas

14.1 Organizing a Visual Presentation

14.2 Incorporating Effective Visuals into a Presentation

595

14.3 Giving a Presentation

614

14.4 Creating Presentations: End-of-Chapter Exercises

625

Chapter 15: Readings: Examples of Essays

15.1 Introduction to Sample Essays

627

15.2 Narrative Essay

628

15.3 Illustration Essay

630

15.4 Descriptive Essay

632

15.5 Classification Essay

634

15.6 Process Analysis Essay

636

15.7 Definition Essay

638

15.8 Compare-and-Contrast Essay

640

15.9 Cause-and-Effect Essay

642

$\underline{15.10 \text { Persuasive Essay }}$

644 


\section{Publisher Information}

Writing for Success is adapted from a work produced and distributed under a Creative Commons license (CC BY-NC-SA) in 2011 by a

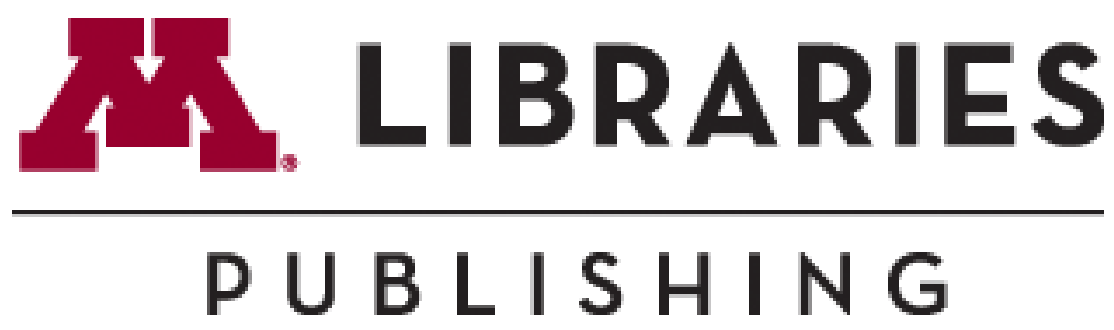
publisher who has requested that they and the original author not receive attribution. This adapted

\section{PUBLISHING}

edition is produced by the University of Minnesota Libraries Publishing through the eLearning Support Initiative.

This adaptation has reformatted the original text, and replaced some images and figures to make the resulting whole more shareable. This adaptation has not significantly altered or updated the original 2011 text. This work is made available under the terms of a Creative Commons Attribution-NonCommercialShareAlike license.

For questions about this textbook please contact textbookuse@umn.edu 


\section{Chapter 1: Introduction to Writing}

1.1 Reading and Writing in College

1.2 Developing Study Skills

1.3 Becoming a Successful College Writer

1.4 Introduction to Writing: End-of-Chapter Exercises 


\subsection{Reading and Writing in College}

\section{Learning Objectives}

1. Understand the expectations for reading and writing assignments in college courses.

2. Understand and apply general strategies to complete college-level reading assignments efficiently and effectively.

3. Recognize specific types of writing assignments frequently included in college courses.

4. Understand and apply general strategies for managing college-level writing assignments.

5. Determine specific reading and writing strategies that work best for you individually.

As you begin this chapter, you may be wondering why you need an introduction. After all, you have been writing and reading since elementary school. You completed numerous assessments of your reading and writing skills in high school and as part of your application process for college. You may write on the job, too. Why is a college writing course even necessary?

When you are eager to get started on the coursework in your major that will prepare you for your career, getting excited about an introductory college writing course can be difficult. However, regardless of your field of study, honing your writing skills_-and your reading and critical-thinking skills_-gives you a more solid academic foundation.

In college, academic expectations change from what you may have experienced in high school. The quantity of work you are expected to do is increased. When instructors expect you to read pages upon pages or study hours and hours for one particular course, managing your work load can be challenging. This chapter includes strategies for studying efficiently and managing your time.

The quality of the work you do also changes. It is not enough to understand course material and summarize it on an exam. You will also be expected to seriously engage with new ideas by reflecting on them, analyzing them, critiquing them, making connections, drawing conclusions, or finding new ways of thinking about a given subject. Educationally, you are moving into deeper waters. A good introductory writing course will help you swim.

Table 1.1 "High School versus College Assignments" summarizes some of the other major differences between high school and college assignments.

Table 1.1 High School versus College Assignments 
High School

Reading assignments are moderately long. Teachers may set aside some class time for reading and reviewing the material in depth.

Teachers often provide study guides and other aids to help you prepare for exams.

Your grade is determined by your performance on a wide variety of assessments, including minor and major assignments. Not all assessments are writing based.

Writing assignments include personal writing and creative writing in addition to expository writing.

The structure and format of writing assignments is generally stable over a four-year period.

Teachers often go out of their way to identify and try to help students who are performing poorly on exams, missing classes, not turning in assignments, or just struggling with the course. Often teachers will give students many "second chances."

\section{College}

Some reading assignments may be very long. You will be expected to come to class with a basic understanding of the material.

Reviewing for exams is primarily your responsibility.

Your grade may depend on just a few major assessments. Most assessments are writing based.

Outside of creative writing courses, most writing assignments are expository.

Depending on the course, you may be asked to master new forms of writing and follow standards within a particular professional field.

Although teachers want their students to succeed, they may not always realize when students are struggling. They also expect you to be proactive and take steps to help yourself. "Second chances" are less common.

This chapter covers the types of reading and writing assignments you will encounter as a college student. You will also learn a variety of strategies for mastering these new challenges — and becoming a more confident student and writer.

Throughout this chapter, you will follow a first-year student named Crystal. After several years of working as a saleswoman in a department store, Crystal has decided to pursue a degree in elementary education and become a teacher. She is continuing to work part-time, and occasionally she finds it challenging to balance the demands of work, school, and caring for her four-year-old son. As you read about Crystal, think about how you can use her experience to get the most out of your own college experience.

\section{Exercise 1}

Review Table 1.1 "High School versus College Assignments" and think about how you have found your college experience to be different from high school so far. Respond to the following questions:

1. In what ways do you think college will be more rewarding for you as a learner?

2. What aspects of college do you expect to find most challenging?

3. What changes do you think you might have to make in your life to ensure your success in college? 


\section{Reading Strategies}

Your college courses will sharpen both your reading and your writing skills. Most of your writing assignments-from brief response papers to in-depth research projects-will depend on your understanding of course reading assignments or related readings you do on your own. And it is difficult, if not impossible, to write effectively about a text that you have not understood. Even when you do understand the reading, it can be hard to write about it if you do not feel personally engaged with the ideas discussed.

This section discusses strategies you can use to get the most out of your college reading assignments. These strategies fall into three broad categories:

1. Planning strategies. To help you manage your reading assignments.

2. Comprehension strategies. To help you understand the material.

3. Active reading strategies. To take your understanding to a higher and deeper level.

\section{Planning Your Reading}

Have you ever stayed up all night cramming just before an exam? Or found yourself skimming a detailed memo from your boss five minutes before a crucial meeting? The first step in handling college reading successfully is planning. This involves both managing your time and setting a clear purpose for your reading.

\section{Managing Your Reading Time}

You will learn more detailed strategies for time management in Section 1.2 "Developing Study Skills", but for now, focus on setting aside enough time for reading and breaking your assignments into manageable chunks. If you are assigned a seventy-page chapter to read for next week's class, try not to wait until the night before to get started. Give yourself at least a few days and tackle one section at a time.

Your method for breaking up the assignment will depend on the type of reading. If the text is very dense and packed with unfamiliar terms and concepts, you may need to read no more than five or ten pages in one sitting so that you can truly understand and process the information. With more user-friendly texts, you will be able to handle longer sections - twenty to forty pages, for instance. And if you have a highly engaging reading assignment, such as a novel you cannot put down, you may be able to read lengthy passages in one sitting.

As the semester progresses, you will develop a better sense of how much time you need to allow for the reading assignments in different subjects. It also makes sense to preview each assignment well in advance to assess its difficulty level and to determine how much reading time to set aside. 


\section{Tip}

College instructors often set aside reserve readings for a particular course. These consist of articles, book chapters, or other texts that are not part of the primary course textbook. Copies of reserve readings are available through the university library; in print; or, more often, online. When you are assigned a reserve reading, download it ahead of time (and let your instructor know if you have trouble accessing it). Skim through it to get a rough idea of how much time you will need to read the assignment in full.

\section{Setting a Purpose}

The other key component of planning is setting a purpose. Knowing what you want to get out of a reading assignment helps you determine how to approach it and how much time to spend on it. It also helps you stay focused during those occasional moments when it is late, you are tired, and relaxing in front of the television sounds far more appealing than curling up with a stack of journal articles.

Sometimes your purpose is simple. You might just need to understand the reading material well enough to discuss it intelligently in class the next day. However, your purpose will often go beyond that. For instance, you might also read to compare two texts, to formulate a personal response to a text, or to gather ideas for future research. Here are some questions to ask to help determine your purpose:

- How did my instructor frame the assignment? Often your instructors will tell you what they expect you to get out of the reading:

- Read Chapter 2 and come to class prepared to discuss current teaching practices in elementary math.

- Read these two articles and compare Smith’s and Jones's perspectives on the 2010 health care reform bill.

- Read Chapter 5 and think about how you could apply these guidelines to running your own business.

- How deeply do I need to understand the reading? If you are majoring in computer science and you are assigned to read Chapter 1, "Introduction to Computer Science," it is safe to assume the chapter presents fundamental concepts that you will be expected to master. However, for some reading assignments, you may be expected to form a general understanding but not necessarily master the content. Again, pay attention to how your instructor presents the assignment.

- How does this assignment relate to other course readings or to concepts discussed in class? Your instructor may make some of these connections explicitly, but if not, try to draw connections on your own. (Needless to say, it helps to take detailed notes both when in class and when you read.)

- How might I use this text again in the future? If you are assigned to read about a topic that has always interested you, your reading assignment might help you develop ideas for a future 
research paper. Some reading assignments provide valuable tips or summaries worth bookmarking for future reference. Think about what you can take from the reading that will stay with you.

\section{Improving Your Comprehension}

You have blocked out time for your reading assignments and set a purpose for reading. Now comes the challenge: making sure you actually understand all the information you are expected to process. Some of your reading assignments will be fairly straightforward. Others, however, will be longer or more complex, so you will need a plan for how to handle them.

For any expository writing - that is, nonfiction, informational writing-your first comprehension goal is to identify the main points and relate any details to those main points. Because college-level texts can be challenging, you will also need to monitor your reading comprehension. That is, you will need to stop periodically and assess how well you understand what you are reading. Finally, you can improve comprehension by taking time to determine which strategies work best for you and putting those strategies into practice.

\section{Identifying the Main Points}

In college, you will read a wide variety of materials, including the following:

- Textbooks. These usually include summaries, glossaries, comprehension questions, and other study aids.

- Nonfiction trade books. These are less likely to include the study features found in textbooks.

- Popular magazine, newspaper, or web articles. These are usually written for a general audience.

- Scholarly books and journal articles. These are written for an audience of specialists in a given field.

Regardless of what type of expository text you are assigned to read, your primary comprehension goal is to identify the main point: the most important idea that the writer wants to communicate and often states early on. Finding the main point gives you a framework to organize the details presented in the reading and relate the reading to concepts you learned in class or through other reading assignments. After identifying the main point, you will find the supporting points, the details, facts, and explanations that develop and clarify the main point.

Some texts make that task relatively easy. Textbooks, for instance, include the aforementioned features as well as headings and subheadings intended to make it easier for students to identify core concepts. Graphic features, such as sidebars, diagrams, and charts, help students understand complex information and distinguish between essential and inessential points. When you are assigned to read from a textbook, 
7 [Author removed at request of original publisher]

be sure to use available comprehension aids to help you identify the main points.

Trade books and popular articles may not be written specifically for an educational purpose; nevertheless, they also include features that can help you identify the main ideas. These features include the following:

- Trade books. Many trade books include an introduction that presents the writer's main ideas and purpose for writing. Reading chapter titles (and any subtitles within the chapter) will help you get a broad sense of what is covered. It also helps to read the beginning and ending paragraphs of a chapter closely. These paragraphs often sum up the main ideas presented.

- Popular articles. Reading the headings and introductory paragraphs carefully is crucial. In magazine articles, these features (along with the closing paragraphs) present the main concepts. Hard news articles in newspapers present the gist of the news story in the lead paragraph, while subsequent paragraphs present increasingly general details.

At the far end of the reading difficulty scale are scholarly books and journal articles. Because these texts are written for a specialized, highly educated audience, the authors presume their readers are already familiar with the topic. The language and writing style is sophisticated and sometimes dense.

When you read scholarly books and journal articles, try to apply the same strategies discussed earlier. The introduction usually presents the writer's thesis, the idea or hypothesis the writer is trying to prove. Headings and subheadings can help you understand how the writer has organized support for his or her thesis. Additionally, academic journal articles often include a summary at the beginning, called an abstract, and electronic databases include summaries of articles, too.

For more information about reading different types of texts, see Chapter 12 "Writing a Research Paper".

\section{Monitoring Your Comprehension}

Finding the main idea and paying attention to text features as you read helps you figure out what you should know. Just as important, however, is being able to figure out what you do not know and developing a strategy to deal with it.

Textbooks often include comprehension questions in the margins or at the end of a section or chapter. As you read, stop occasionally to answer these questions on paper or in your head. Use them to identify sections you may need to reread, read more carefully, or ask your instructor about later.

Even when a text does not have built-in comprehension features, you can actively monitor your own comprehension. Try these strategies, adapting them as needed to suit different kinds of texts:

1. Summarize. At the end of each section, pause to summarize the main points in a few sentences. If you have trouble doing so, revisit that section.

2. Ask and answer questions. When you begin reading a section, try to identify two to three questions you should be able to answer after you finish it. Write down your questions and use them to test yourself on the reading. If you cannot answer a question, try to determine why. Is 
the answer buried in that section of reading but just not coming across to you? Or do you expect to find the answer in another part of the reading?

3. Do not read in a vacuum. Look for opportunities to discuss the reading with your classmates. Many instructors set up online discussion forums or blogs specifically for that purpose. Participating in these discussions can help you determine whether your understanding of the main points is the same as your peers'.

These discussions can also serve as a reality check. If everyone in the class struggled with the reading, it may be exceptionally challenging. If it was a breeze for everyone but you, you may need to see your instructor for help.

As a working mother, Crystal found that the best time to get her reading done was in the evening, after she had put her four-year-old to bed. However, she occasionally had trouble concentrating at the end of a long day. She found that by actively working to summarize the reading and asking and answering questions, she focused better and retained more of what she read. She also found that evenings were a good time to check the class discussion forums that a few of her instructors had created.

\section{Exercise 2}

Choose any text that that you have been assigned to read for one of your college courses. In your notes, complete the following tasks:

1. Summarize the main points of the text in two to three sentences.

2. Write down two to three questions about the text that you can bring up during class discussion.

Tip

Students are often reluctant to seek help. They feel like doing so marks them as slow, weak, or demanding. The truth is, every learner occasionally struggles. If you are sincerely trying to keep up with the course reading but feel like you are in over your head, seek out help. Speak up in class, schedule a meeting with your instructor, or visit your university learning center for assistance.

Deal with the problem as early in the semester as you can. Instructors respect students who are proactive about their own learning. Most instructors will work hard to help students who make the effort to help themselves.

\section{Taking It to the Next Level: Active Reading}

Now that you have acquainted (or reacquainted) yourself with useful planning and comprehension strategies, college reading assignments may feel more manageable. You know what you need to do to 
9 [Author removed at request of original publisher]

get your reading done and make sure you grasp the main points. However, the most successful students in college are not only competent readers but active, engaged readers.

\section{Using the SQ3R Strategy}

One strategy you can use to become a more active, engaged reader is the SQ3R strategy, a step-by-step process to follow before, during, and after reading. You may already use some variation of it. In essence, the process works like this:

1. Survey the text in advance.

2. Form questions before you start reading.

3. Read the text.

4. Recite and/or record important points during and after reading.

5. Review and reflect on the text after you read.

Before you read, you survey, or preview, the text. As noted earlier, reading introductory paragraphs and headings can help you begin to figure out the author's main point and identify what important topics will be covered. However, surveying does not stop there. Look over sidebars, photographs, and any other text or graphic features that catch your eye. Skim a few paragraphs. Preview any boldfaced or italicized vocabulary terms. This will help you form a first impression of the material.

Next, start brainstorming questions about the text. What do you expect to learn from the reading? You may find that some questions come to mind immediately based on your initial survey or based on previous readings and class discussions. If not, try using headings and subheadings in the text to formulate questions. For instance, if one heading in your textbook reads "Medicare and Medicaid," you might ask yourself these questions:

- When was Medicare and Medicaid legislation enacted? Why?

- What are the major differences between these two programs?

Although some of your questions may be simple factual questions, try to come up with a few that are more open-ended. Asking in-depth questions will help you stay more engaged as you read.

The next step is simple: read. As you read, notice whether your first impressions of the text were correct. Are the author's main points and overall approach about the same as what you predicted-or does the text contain a few surprises? Also, look for answers to your earlier questions and begin forming new questions. Continue to revise your impressions and questions as you read.

While you are reading, pause occasionally to recite or record important points. It is best to do this at the end of each section or when there is an obvious shift in the writer's train of thought. Put the book aside for a moment and recite aloud the main points of the section or any important answers you found there. You might also record ideas by jotting down a few brief notes in addition to, or instead of, reciting aloud. Either way, the physical act of articulating information makes you more likely to remember it. 
After you have completed the reading, take some time to review the material more thoroughly. If the textbook includes review questions or your instructor has provided a study guide, use these tools to guide your review. You will want to record information in a more detailed format than you used during reading, such as in an outline or a list.

As you review the material, reflect on what you learned. Did anything surprise you, upset you, or make you think? Did you find yourself strongly agreeing or disagreeing with any points in the text? What topics would you like to explore further? Jot down your reflections in your notes. (Instructors sometimes require students to write brief response papers or maintain a reading journal. Use these assignments to help you reflect on what you read.)

\section{Exercise 3}

Choose another text that that you have been assigned to read for a class. Use the SQ3R process to complete the reading. (Keep in mind that you may need to spread the reading over more than one session, especially if the text is long.)

Be sure to complete all the steps involved. Then, reflect on how helpful you found this process. On a scale of one to ten, how useful did you find it? How does it compare with other study techniques you have used?

\section{Using Other Active Reading Strategies}

The SQ3R process encompasses a number of valuable active reading strategies: previewing a text, making predictions, asking and answering questions, and summarizing. You can use the following additional strategies to further deepen your understanding of what you read.

- Connect what you read to what you already know. Look for ways the reading supports, extends, or challenges concepts you have learned elsewhere.

- Relate the reading to your own life. What statements, people, or situations relate to your personal experiences?

- Visualize. For both fiction and nonfiction texts, try to picture what is described. Visualizing is especially helpful when you are reading a narrative text, such as a novel or a historical account, or when you read expository text that describes a process, such as how to perform cardiopulmonary resuscitation (CPR).

- Pay attention to graphics as well as text. Photographs, diagrams, flow charts, tables, and other graphics can help make abstract ideas more concrete and understandable.

- Understand the text in context. Understanding context means thinking about who wrote the text, when and where it was written, the author's purpose for writing it, and what assumptions or agendas influenced the author's ideas. For instance, two writers might both address the subject of health care reform, but if one article is an opinion piece and one is a news story, the context is different. 
- Plan to talk or write about what you read. Jot down a few questions or comments in your notebook so you can bring them up in class. (This also gives you a source of topic ideas for papers and presentations later in the semester.) Discuss the reading on a class discussion board or blog about it.

As Crystal began her first semester of elementary education courses, she occasionally felt lost in a sea of new terms and theories about teaching and child development. She found that it helped to relate the reading to her personal observations of her son and other kids she knew.

\section{Writing at Work}

Many college courses require students to participate in interactive online components, such as a discussion forum, a page on a social networking site, or a class blog. These tools are a great way to reinforce learning. Do not be afraid to be the student who starts the discussion.

Remember that when you interact with other students and teachers online, you need to project a mature, professional image. You may be able to use an informal, conversational tone, but complaining about the work load, using off-color language, or "flaming" other participants is inappropriate.

Active reading can benefit you in ways that go beyond just earning good grades. By practicing these strategies, you will find yourself more interested in your courses and better able to relate your academic work to the rest of your life. Being an interested, engaged student also helps you form lasting connections with your instructors and with other students that can be personally and professionally valuable. In short, it helps you get the most out of your education.

\section{Common Writing Assignments}

College writing assignments serve a different purpose than the typical writing assignments you completed in high school. In high school, teachers generally focus on teaching you to write in a variety of modes and formats, including personal writing, expository writing, research papers, creative writing, and writing short answers and essays for exams. Over time, these assignments help you build a foundation of writing skills.

In college, many instructors will expect you to already have that foundation.

Your college composition courses will focus on writing for its own sake, helping you make the transition to college-level writing assignments. However, in most other college courses, writing assignments serve a different purpose. In those courses, you may use writing as one tool among many for learning how to think about a particular academic discipline.

Additionally, certain assignments teach you how to meet the expectations for professional writing in a given field. Depending on the class, you might be asked to write a lab report, a case study, a literary analysis, a business plan, or an account of a personal interview. You will need to learn and follow the 
standard conventions for those types of written products.

Finally, personal and creative writing assignments are less common in college than in high school. College courses emphasize expository writing, writing that explains or informs. Often expository writing assignments will incorporate outside research, too. Some classes will also require persuasive writing assignments in which you state and support your position on an issue. College instructors will hold you to a higher standard when it comes to supporting your ideas with reasons and evidence.

Table 1.2 "Common Types of College Writing Assignments" lists some of the most common types of college writing assignments. It includes minor, less formal assignments as well as major ones. Which specific assignments you encounter will depend on the courses you take and the learning objectives developed by your instructors.

Table 1.2 Common Types of College Writing Assignments 


\begin{tabular}{|c|c|c|}
\hline Assignment Type & Description & Example \\
\hline $\begin{array}{l}\text { Personal } \\
\text { Response Paper }\end{array}$ & $\begin{array}{l}\text { Expresses and explains your response to a } \\
\text { reading assignment, a provocative quote, } \\
\text { or a specific issue; may be very brief } \\
\text { (sometimes a page or less) or more } \\
\text { in-depth }\end{array}$ & $\begin{array}{l}\text { For an environmental science course, students } \\
\text { watch and write about President Obama's } \\
\text { June } 15,2010 \text {, speech about the BP oil spill } \\
\text { in the Gulf of Mexico. }\end{array}$ \\
\hline Summary & $\begin{array}{l}\text { Restates the main points of a longer } \\
\text { passage objectively and in your own } \\
\text { words }\end{array}$ & $\begin{array}{l}\text { For a psychology course, students write a } \\
\text { one-page summary of an article about a man } \\
\text { suffering from short-term memory loss. }\end{array}$ \\
\hline Position Paper & $\begin{array}{l}\text { States and defends your position on an } \\
\text { issue (often a controversial issue) }\end{array}$ & $\begin{array}{l}\text { For a medical ethics course, students state } \\
\text { and support their position on using stem cell } \\
\text { research in medicine. }\end{array}$ \\
\hline $\begin{array}{l}\text { Problem-Solution } \\
\text { Paper }\end{array}$ & $\begin{array}{l}\text { Presents a problem, explains its causes, } \\
\text { and proposes and explains a solution }\end{array}$ & $\begin{array}{l}\text { For a business administration course, a } \\
\text { student presents a plan for implementing an } \\
\text { office recycling program without increasing } \\
\text { operating costs. }\end{array}$ \\
\hline Literary Analysis & $\begin{array}{l}\text { States a thesis about a particular literary } \\
\text { work (or works) and develops the thesis } \\
\text { with evidence from the work and, } \\
\text { sometimes, from additional sources }\end{array}$ & $\begin{array}{l}\text { For a literature course, a student compares } \\
\text { two novels by the twentieth-century African } \\
\text { American writer Richard Wright. }\end{array}$ \\
\hline $\begin{array}{l}\text { Research Review } \\
\text { or Survey }\end{array}$ & $\begin{array}{l}\text { Sums up available research findings on a } \\
\text { particular topic }\end{array}$ & $\begin{array}{l}\text { For a course in media studies, a student } \\
\text { reviews the past twenty years of research on } \\
\text { whether violence in television and movies is } \\
\text { correlated with violent behavior. }\end{array}$ \\
\hline $\begin{array}{l}\text { Case Study or } \\
\text { Case Analysis }\end{array}$ & $\begin{array}{l}\text { Investigates a particular person, group, or } \\
\text { event in depth for the purpose of drawing } \\
\text { a larger conclusion from the analysis }\end{array}$ & $\begin{array}{l}\text { For an education course, a student writes a } \\
\text { case study of a developmentally disabled } \\
\text { child whose academic performance improved } \\
\text { because of a behavioral-modification } \\
\text { program. }\end{array}$ \\
\hline $\begin{array}{l}\text { Laboratory } \\
\text { Report }\end{array}$ & $\begin{array}{l}\text { Presents a laboratory experiment, } \\
\text { including the hypothesis, methods of data } \\
\text { collection, results, and conclusions }\end{array}$ & $\begin{array}{l}\text { For a psychology course, a group of students } \\
\text { presents the results of an experiment in which } \\
\text { they explored whether sleep deprivation } \\
\text { produced memory deficits in lab rats. }\end{array}$ \\
\hline Research Journal & $\begin{array}{l}\text { Records a student's ideas and findings } \\
\text { during the course of a long-term research } \\
\text { project }\end{array}$ & $\begin{array}{l}\text { For an education course, a student maintains } \\
\text { a journal throughout a semester-long research } \\
\text { project at a local elementary school. }\end{array}$ \\
\hline Research Paper & $\begin{array}{l}\text { Presents a thesis and supports it with } \\
\text { original research and/or other researchers' } \\
\text { findings on the topic; can take several } \\
\text { different formats depending on the subject } \\
\text { area }\end{array}$ & $\begin{array}{l}\text { For examples of typical research projects, see } \\
\text { Chapter } 12 \text { "Writing a Research Paper". }\end{array}$ \\
\hline
\end{tabular}




\section{Writing at Work}

Part of managing your education is communicating well with others at your university. For instance, you might need to e-mail your instructor to request an office appointment or explain why you will need to miss a class. You might need to contact administrators with questions about your tuition or financial aid. Later, you might ask instructors to write recommendations on your behalf.

Treat these documents as professional communications. Address the recipient politely; state your question, problem, or request clearly; and use a formal, respectful tone. Doing so helps you make a positive impression and get a quicker response.

\section{Key Takeaways}

- College-level reading and writing assignments differ from high school assignments not only in quantity but also in quality.

- Managing college reading assignments successfully requires you to plan and manage your time, set a purpose for reading, practice effective comprehension strategies, and use active reading strategies to deepen your understanding of the text.

- College writing assignments place greater emphasis on learning to think critically about a particular discipline and less emphasis on personal and creative writing. 


\subsection{Developing Study Skills}

\section{Learning Objectives}

1. Use strategies for managing time effectively as a college student.

2. Understand and apply strategies for taking notes efficiently.

3. Determine the specific time-management, study, and note-taking strategies that work best for you individually.

By now, you have a general idea of what to expect from your college courses. You have probably received course syllabi, started on your first few assignments, and begun applying the strategies you learned about in Section 1.1 "Reading and Writing in College".

At the beginning of the semester, your work load is relatively light. This is the perfect time to brush up on your study skills and establish good habits. When the demands on your time and energy become more intense, you will have a system in place for handling them.

This section covers specific strategies for managing your time effectively. You will also learn about different note-taking systems that you can use to organize and record information efficiently.

As you work through this section, remember that every student is different. The strategies presented here are tried and true techniques that work well for many people. However, you may need to adapt them slightly to develop a system that works well for you personally. If your friend swears by her smartphone, but you hate having to carry extra electronic gadgets around, then using a smartphone will not be the best organizational strategy for you.

Read with an open mind, and consider what techniques have been effective (or ineffective) for you in the past. Which habits from your high school years or your work life could help you succeed in college? Which habits might get in your way? What changes might you need to make?

\section{Understanding Yourself as a Learner}

To succeed in college - or any situation where you must master new concepts and skills-it helps to know what makes you tick. For decades, educational researchers and organizational psychologists have examined how people take in and assimilate new information, how some people learn differently than others, and what conditions make students and workers most productive. Here are just a few questions to think about: 
- What is your learning style? For the purposes of this chapter, learning style refers to the way you prefer to take in new information, by seeing, by listening, or through some other channel. For more information, see the section on learning styles.

- What times of day are you most productive? If your energy peaks early, you might benefit from blocking out early morning time for studying or writing. If you are a night owl, set aside a few evenings a week for schoolwork.

- How much clutter can you handle in your work space? Some people work fine at a messy desk and know exactly where to find what they need in their stack of papers; however, most people benefit from maintaining a neat, organized space.

- How well do you juggle potential distractions in your environment? If you can study at home without being tempted to turn on the television, check your e-mail, fix yourself a snack, and so on, you may make home your work space. However, if you need a less distracting environment to stay focused, you may be able to find one on your college's campus or in your community.

- Does a little background noise help or hinder your productivity? Some people work better when listening to background music or the low hum of conversation in a coffee shop. Others need total silence.

- When you work with a partner or group, do you stay on task? A study partner or group can sometimes be invaluable. However, working this way takes extra planning and effort, so be sure to use the time productively. If you find that group study sessions turn into social occasions, you may study better on your own.

- How do you manage stress? Accept that at certain points in the semester, you will feel stressed out. In your day-to-day routine, make time for activities that help you reduce stress, such as exercising, spending time with friends, or just scheduling downtime to relax.

\section{Learning Styles}

Most people have one channel that works best for them when it comes to taking in new information. Knowing yours can help you develop strategies for studying, time management, and note taking that work especially well for you.

To begin identifying your learning style, think about how you would go about the process of assembling a piece of furniture. Which of these options sounds most like you?

1. You would carefully look over the diagrams in the assembly manual first so you could picture each step in the process.

2. You would silently read the directions through, step by step, and then look at the diagrams afterward.

3. You would read the directions aloud under your breath. Having someone explain the steps to you would also help.

4. You would start putting the pieces together and figure out the process through trial and error, 
consulting the directions as you worked.

Now read the following explanations. Again, think about whether each description sounds like you.

- If you chose (a), you may be a visual learner. You understand ideas best when they are presented in a visual format, such as a flowchart, a diagram, or text with clear headings and many photos or illustrations.

- If you chose (b), you may be a verbal learner. You understand ideas best through reading and writing about them and taking detailed notes.

- If you chose (c), you may be an auditory learner. You understand ideas best through listening. You learn well from spoken lectures or books on tape.

- If you chose (d), you may be a kinesthetic learner. You learn best through doing and prefer hands-on activities. In long lectures, fidgeting may help you focus.

Your learning style does not completely define you as a student. Auditory learners can comprehend a flow chart, and kinesthetic learners can sit still long enough to read a book. However, if you do have one dominant learning style, you can work with it to get the most out of your classes and study time. Table 1.3 "Learning Style Strategies" lists some tips for maximizing your learning style.

Table 1.3 Learning Style Strategies 


\begin{tabular}{|c|c|}
\hline $\begin{array}{l}\text { Learning } \\
\text { Style }\end{array}$ & Strategies \\
\hline Visual & $\begin{array}{l}\text { - When possible, represent concepts visually-in charts, diagrams, or sketches. } \\
\text { - Use a visual format for taking notes on reading assignments or lectures. } \\
\text { - Use different-colored highlighters or pens to color-code information as you read. } \\
\text { - Use visual organizers, such as maps, flowcharts, and so forth, to help you plan writing } \\
\text { assignments. } \\
\text { - Use colored pens, highlighters, or the review feature of your word-processing program } \\
\text { to revise and edit writing. }\end{array}$ \\
\hline Verbal & $\begin{array}{l}\text { - Use the instructional features in course texts—summaries, chapter review questions, } \\
\text { glossaries, and so on-to aid your studying. } \\
\text { - Take notes on your reading assignments. } \\
\text { - Rewrite or condense reading notes and lecture notes to study. } \\
\text { - Summarize important ideas in your own words. } \\
\text { - Use informal writing techniques, such as brainstorming, freewriting, blogging, or } \\
\text { posting on a class discussion forum to generate ideas for writing assignments. } \\
\text { - Reread and take notes on your writing to help you revise and edit. }\end{array}$ \\
\hline Auditory & $\begin{array}{l}\text { - Ask your instructor's permission to tape-record lectures to supplement your notes. } \\
\text { - Read parts of your textbook or notes aloud when you study. } \\
\text { - If possible, obtain an audiobook version of important course texts. Make use of } \\
\text { supplemental audio materials, such as CDs or DVDs. } \\
\text { - Talk through your ideas with other students when studying or when preparing for a } \\
\text { writing assignment. } \\
\text { - Read your writing aloud to help you draft, revise, and edit. }\end{array}$ \\
\hline Kinesthetic & $\begin{array}{l}\text { - When you read or study, use techniques that will keep your hands in motion, such as } \\
\text { highlighting or taking notes. } \\
\text { - Use tactile study aids, such as flash cards or study guides you design yourself. } \\
\text { - Use self-stick notes to record ideas for writing. These notes can be physically } \\
\text { reorganized easily to help you determine how to shape your paper. } \\
\text { - Use a physical activity, such as running or swimming, to help you break through writing } \\
\text { blocks. } \\
\text { - Take breaks during studying to stand, stretch, or move around. }\end{array}$ \\
\hline
\end{tabular}


Tip

The material presented here about learning styles is just the tip of the iceberg. There are numerous other variations in how people learn. Some people like to act on information right away while others reflect on it first. Some people excel at mastering details and understanding concrete, tried and true ideas while others enjoy exploring abstract theories and innovative, even impractical ideas. For more information about how you learn, visit your school's academic resource center.

\section{Time Management}

In college you have increased freedom to structure your time as you please. With that freedom comes increased responsibility. High school teachers often take it upon themselves to track down students who miss class or forget assignments. College instructors, however, expect you to take full responsibility for managing yourself and getting your work done on time.

\section{Getting Started: Short- and Long-Term Planning}

At the beginning of the semester, establish a weekly routine for when you will study and write. A general guideline is that for every hour spent in class, students should expect to spend another two to three hours on reading, writing, and studying for tests. Therefore, if you are taking a biology course that meets three times a week for an hour at a time, you can expect to spend six to nine hours per week on it outside of class. You will need to budget time for each class just like an employer schedules shifts at work, and you must make that study time a priority.

That may sound like a lot when taking multiple classes, but if you plan your time carefully, it is manageable. A typical full-time schedule of fifteen credit hours translates into thirty to forty-five hours per week spent on schoolwork outside of class. All in all, a full-time student would spend about as much time on school each week as an employee spends on work. Balancing school and a job can be more challenging, but still doable.

In addition to setting aside regular work periods, you will need to plan ahead to handle more intense demands, such as studying for exams and writing major papers. At the beginning of the semester, go through your course syllabi and mark all major due dates and exam dates on a calendar. Use a format that you check regularly, such as your smartphone or the calendar feature in your e-mail. (In $\underline{\text { Section }}$ 1.3 "Becoming a Successful College Writer" you will learn strategies for planning out major writing assignments so you can complete them on time.) 


\section{Tip}

The two- to three-hour rule may sound intimidating. However, keep in mind that this is only a rule of thumb. Realistically, some courses will be more challenging than others, and the demands will ebb and flow throughout the semester. You may have trouble-free weeks and stressful weeks. When you schedule your classes, try to balance introductory-level classes with more advanced classes so that your work load stays manageable.

Crystal knew that to balance a job, college classes, and a family, it was crucial for her to get organized. For the month of September, she drew up a week-by-week calendar that listed not only her own class and work schedules but also the days her son attended preschool and the days her husband had off from work. She and her husband discussed how to share their day-to-day household responsibilities so she would be able to get her schoolwork done. Crystal also made a note to talk to her supervisor at work about reducing her hours during finals week in December.

\section{Exercise 1}

Now that you have learned some time-management basics, it is time to apply those skills. For this exercise, you will develop a weekly schedule and a semester calendar.

1. Working with your class schedule, map out a week-long schedule of study time. Try to apply the "two- to three-hour" rule. Be sure to include any other nonnegotiable responsibilities, such as a job or child care duties.

2. Use your course syllabi to record exam dates and due dates for major assignments in a calendar (paper or electronic). Use a star, highlighting, or other special marking to set off any days or weeks that look especially demanding.

\section{Staying Consistent: Time Management Dos and Don'ts}

Setting up a schedule is easy. Sticking with it, however, may create challenges. A schedule that looked great on paper may prove to be unrealistic. Sometimes, despite students' best intentions, they end up procrastinating or pulling all-nighters to finish a paper or study for an exam.

Keep in mind, however, that your weekly schedule and semester calendar are time-management tools. Like any tools, their effectiveness depends on the user: you. If you leave a tool sitting in the box unused (e.g., if you set up your schedule and then forget about it), it will not help you complete the task. And if, for some reason, a particular tool or strategy is not getting the job done, you need to figure out why and maybe try using something else.

With that in mind, read the list of time-management dos and don'ts. Keep this list handy as a reference 
you can use throughout the semester to "troubleshoot" if you feel like your schoolwork is getting off track.

\section{Dos}

1. Set aside time to review your schedule or calendar regularly and update or adjust them as needed.

2. Be realistic when you schedule study time. Do not plan to write your paper on Friday night when everyone else is out socializing. When Friday comes, you might end up abandoning your plans and hanging out with your friends instead.

3. Be honest with yourself about where your time goes. Do not fritter away your study time on distractions like e-mail and social networking sites.

4. Accept that occasionally your work may get a little off track. No one is perfect.

5. Accept that sometimes you may not have time for all the fun things you would like to do.

6. Recognize times when you feel overextended. Sometimes you may just need to get through an especially demanding week. However, if you feel exhausted and overworked all the time, you may need to scale back on some of your commitments.

7. Have a plan for handling high-stress periods, such as final exam week. Try to reduce your other commitments during those periods-for instance, by scheduling time off from your job. Build in some time for relaxing activities, too.

\section{Don'ts}

1. Do not procrastinate on challenging assignments. Instead, break them into smaller, manageable tasks that can be accomplished one at a time.

2. Do not fall into the trap of "all-or-nothing” thinking: "There is no way I can fit in a threehour study session today, so I will just wait until the weekend.” Extended periods of free time are hard to come by, so find ways to use small blocks of time productively. For instance, if you have a free half hour between classes, use it to preview a chapter or brainstorm ideas for an essay.

3. Do not fall into the trap of letting things slide and promising yourself, "I will do better next week." When next week comes, the accumulated undone tasks will seem even more intimidating, and you will find it harder to get them done.

4. Do not rely on caffeine and sugar to compensate for lack of sleep. These stimulants may temporarily perk you up, but your brain functions best when you are rested. 


\section{Exercise 2}

The key to managing your time effectively is consistency. Completing the following tasks will help you stay on track throughout the semester.

1. Establish regular times to "check in" with yourself to identify and prioritize tasks and plan how to accomplish them. Many people find it is best to set aside a few minutes for this each day and to take some time to plan at the beginning of each week.

2. For the next two weeks, focus on consistently using whatever time-management system you have set up. Check in with yourself daily and weekly, stick to your schedule, and take note of anything that interferes. At the end of the two weeks, review your schedule and determine whether you need to adjust it.

3. Review the preceeding list of dos and don'ts.

\section{Writing at Work}

If you are part of the workforce, you have probably established strategies for accomplishing job-related tasks efficiently. How could you adapt these strategies to help you be a successful student? For instance, you might sync up your school and work schedules on an electronic calendar. Instead of checking in with your boss about upcoming work deadlines, establish a buddy system where you check in with a friend about school projects. Give school the same priority you give to work.

\section{Note-Taking Methods}

One final valuable tool to have in your arsenal as a student is a good note-taking system. Just the act of converting a spoken lecture to notes helps you organize and retain information, and of course, good notes also help you review important concepts later. Although taking good notes is an essential study skill, many students enter college without having received much guidance about note taking.

These sections discuss different strategies you can use to take notes efficiently. No matter which system you choose, keep the note-taking guidelines in mind.

\section{General Note-Taking Guidelines}

1. Before class, quickly review your notes from the previous class and the assigned reading. Fixing key terms and concepts in your mind will help you stay focused and pick out the important points during the lecture. 
2. Come prepared with paper, pens, highlighters, textbooks, and any important handouts.

3. Come to class with a positive attitude and a readiness to learn. During class, make a point of concentrating. Ask questions if you need to. Be an active participant.

4. During class, capture important ideas as concisely as you can. Use words or phrases instead of full sentences and abbreviate when possible.

5. Visually organize your notes into main topics, subtopics, and supporting points, and show the relationships between ideas. Leave space if necessary so you can add more details under important topics or subtopics.

6. Record the following:

Review your notes regularly throughout the semester, not just before exams.

\section{Organizing Ideas in Your Notes}

A good note-taking system needs to help you differentiate among major points, related subtopics, and supporting details. It visually represents the connections between ideas. Finally, to be effective, your note-taking system must allow you to record and organize information fairly quickly. Although some students like to create detailed, formal outlines or concept maps when they read, these may not be good strategies for class notes, because spoken lectures may not allow time for elaborate notes.

Instead, focus on recording content simply and quickly to create organized, legible notes. Try one of the following techniques.

\section{Modified Outline Format}

A modified outline format uses indented spacing to show the hierarchy of ideas without including roman numerals, lettering, and so forth. Just use a dash or bullet to signify each new point unless your instructor specifically presents a numbered list of items.

The first example shows Crystal's notes from a developmental psychology class about an important theorist in this field. Notice how the line for the main topic is all the way to the left. Subtopics are indented, and supporting details are indented one level further. Crystal also used abbreviations for terms like development and example. 


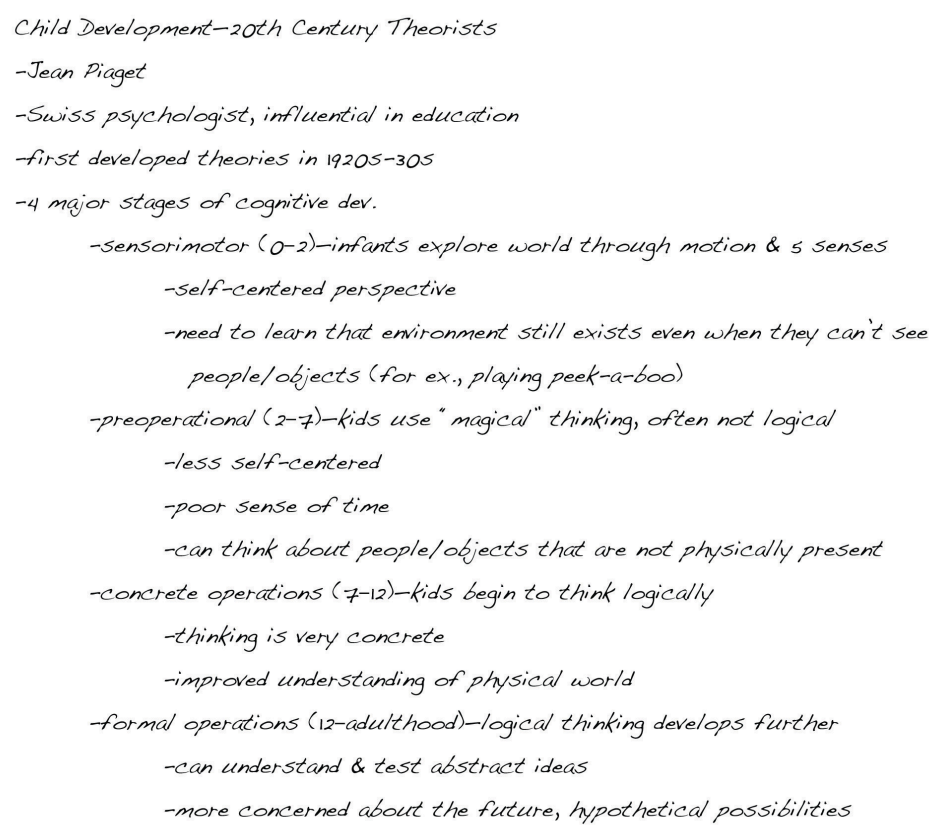

\section{Idea Mapping}

If you discovered in this section that you learn best with visual presentations, you may prefer to use a more graphic format for notes, such as an idea map. The next example shows how Crystal's lecture notes could be set up differently. Although the format is different, the content and organization are the same. 


\section{Child Development-20th Century Theorists}

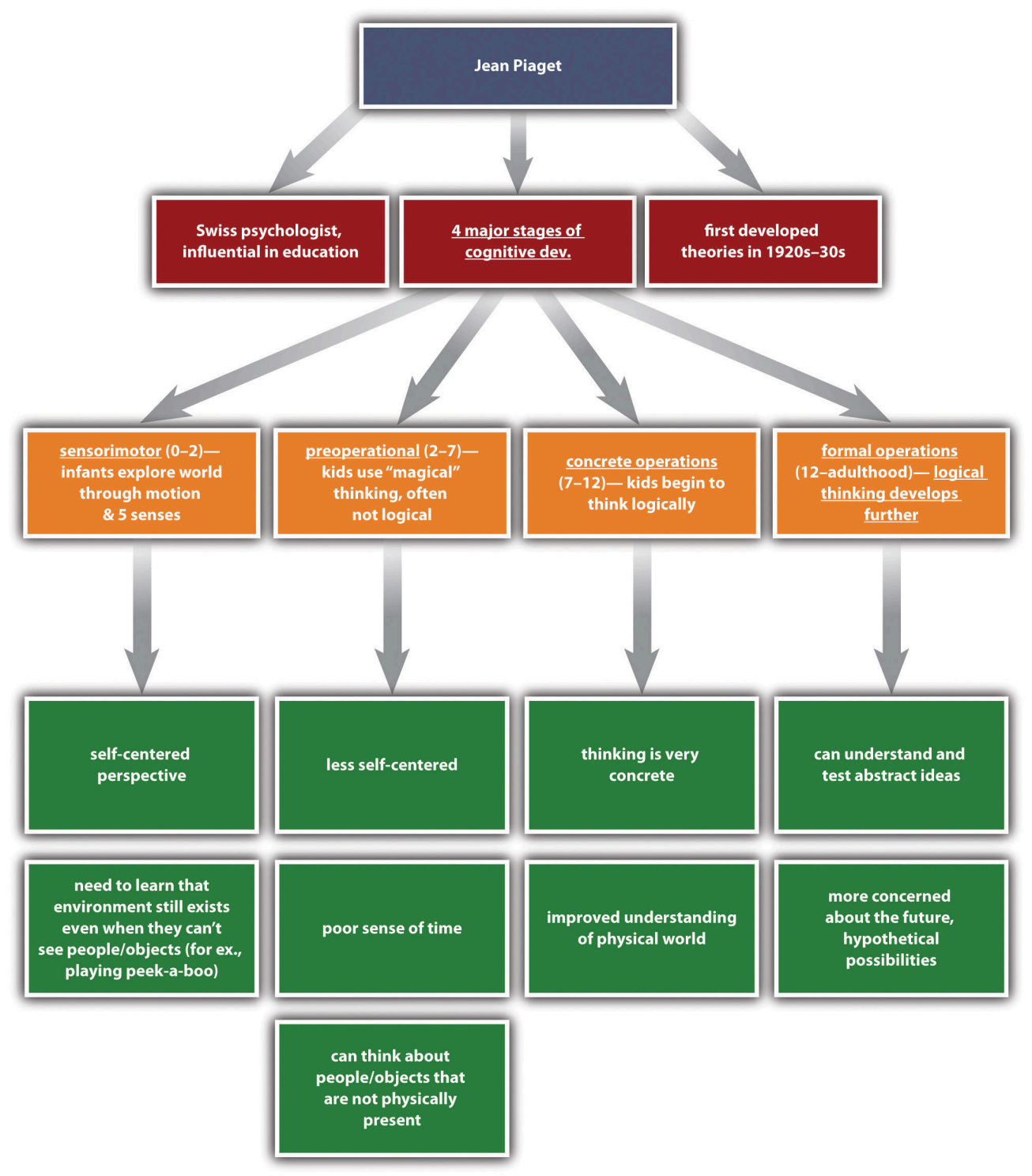

\section{Charting}

If the content of a lecture falls into a predictable, well-organized pattern, you might choose to use a chart or table to record your notes. This system works best when you already know, either before class or at the beginning of class, which categories you should include. The next figure shows how this system might be used. 


\begin{tabular}{|c|c|c|c|}
\hline THEORIST & COUNTRY OF ORIGIN & $\begin{array}{l}\text { YEARS } \\
\text { ACTIVE }\end{array}$ & $\begin{array}{l}\text { STAGES OF CHILD } \\
\text { DEVELOPMENT }\end{array}$ \\
\hline Jean Piaget & Switzerland & $\begin{array}{l}\text { 1920s } \\
\text { through } \\
\text { 1970s }\end{array}$ & $\begin{array}{l}\text { 1. sensorimotor }(0-2) \\
\text { 2. preoperational (2-7) } \\
\text { 3. concrete operational (7-12) } \\
\text { 4. formal operational } \\
\text { (12-adulthood) }\end{array}$ \\
\hline Erik Erikson & $\begin{array}{l}\text { Denmark (studied in Austria, emigrated } \\
\text { to US in 1930s) }\end{array}$ & $\begin{array}{l}\text { 1930s } \\
\text { through } \\
1980 s\end{array}$ & 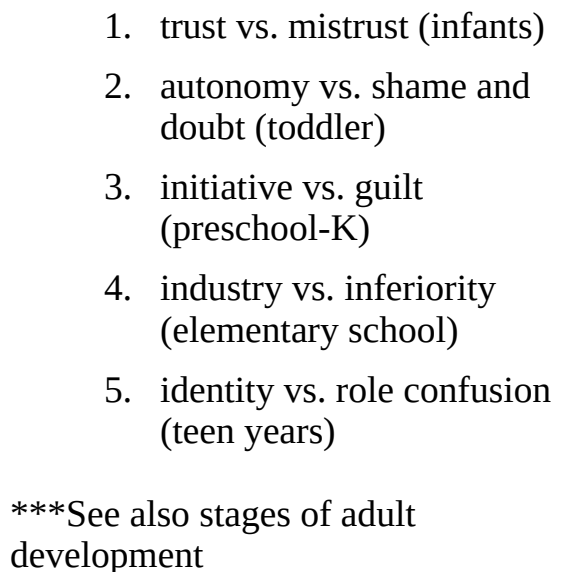 \\
\hline
\end{tabular}

\section{The Cornell Note-Taking System}

In addition to the general techniques already described, you might find it useful to practice a specific strategy known as the Cornell note-taking system. This popular format makes it easy not only to organize information clearly but also to note key terms and summarize content.

To use the Cornell system, begin by setting up the page with these components:

- The course name and lecture date at the top of the page

- A narrow column (about two inches) at the left side of the page

- A wide column (about five to six inches) on the right side of the page

- A space of a few lines marked off at the bottom of the page

During the lecture, you record notes in the wide column. You can do so using the traditional modified outline format or a more visual format if you prefer.

Then, as soon as possible after the lecture, review your notes and identify key terms. Jot these down in the narrow left-hand column. You can use this column as a study aid by covering the notes on the right-hand side, reviewing the key terms, and trying to recall as much as you can about them so that you can mentally restate the main points of the lecture. Uncover the notes on the right to check your 
understanding. Finally, use the space at the bottom of the page to summarize each page of notes in a few sentences.

Using the Cornell system, Crystal's notes would look like the following:

\begin{tabular}{|c|c|}
\hline Child Development & September 13, 2011 \\
\hline $\begin{array}{l}\text { Piaget } \\
\text { cognitive development } \\
\text { sensorimotor } \\
\text { preoperational } \\
\text { concrete operations } \\
\text { formal operations } \\
\text { concrete thinking } \\
\text { abstract thinking }\end{array}$ & $\begin{array}{l}\text { Child Development-20th Century Theorists } \\
\text {-Jean Piaget } \\
\text {-Swiss psychologist, influential in education } \\
\text {-first developed theories in 1920s-30s } \\
-4 \text { major stages of cognitive dev. } \\
\text {-sensorimotor (0-2) -infants explore world through motion \& } 5 \text { senses } \\
\text {-self-centered perspective } \\
\text {-need to learn that environment still exists even when } \\
\text { they can't see people/objects (for ex., playing } \\
\text { peek-a-boo) } \\
\text {-preoperational (2-7)-kids use "magical" thinking, often } \\
\text { not logical } \\
\text {-less self-centered } \\
\text {-poor sense of time } \\
\text {-can think about people/objects that are not } \\
\text { physically present } \\
\text {-concrete operations (7-12) -kids begin to think logically } \\
\text { - thinking is very concrete } \\
\text {-improved understanding of physical world } \\
\text {-formal operations (12-adulthood)-logical thinking } \\
\text { develops further } \\
\text {-can understand \& test abstract ideas } \\
\text {-more concerned about the future, hypothetical possibilities }\end{array}$ \\
\hline \multicolumn{2}{|c|}{$\begin{array}{l}\text { Piaget believed children go through four stages of cognitive development-sensorimotor, preoperational, } \\
\text { concrete operations, and formal operations. Gradually they progress from having a very limited } \\
\text { understanding of the world (infants and young children), to being more logical (older kids), to being able } \\
\text { to think abstractly (preteens and teens). }\end{array}$} \\
\hline
\end{tabular}

\section{Writing at Work}

Often, at school or in the workplace, a speaker will provide you with pregenerated notes summarizing electronic presentation slides. You may be tempted not to take notes at all because much of the content is already summarized for you. However, it is a good idea to jot down at least a few notes. Doing so keeps you focused during the presentation, allows you to record details you might otherwise forget, and gives you the opportunity to jot down questions or reflections to personalize the content.

\section{Exercise 3}

Over the next few weeks, establish a note-taking system that works for you.

1. If you are not already doing so, try using one of the aforementioned techniques. (Remember that the Cornell system can be combined with other note-taking formats.) 
2. It can take some trial and error to find a note-taking system that works for you. If you find that you are struggling to keep up with lectures, consider whether you need to switch to a different format or be more careful about distinguishing key concepts from unimportant details.

3. If you find that you are having trouble taking notes effectively, set up an appointment with your school's academic resource center.

\section{Key Takeaways}

- Understanding your individual learning style and preferences can help you identify the study and time-management strategies that will work best for you.

- To manage your time effectively, it is important to look at the short term (daily and weekly schedules) and the long term (major semester deadlines).

- To manage your time effectively, be consistent about maintaining your schedule. If your schedule is not working for you, make adjustments.

- A good note-taking system must differentiate among major points, related subtopics, and supporting details, and it must allow you to record and organize information fairly quickly. Choose the format that is most effective for you. 


\subsection{Becoming a Successful College Writer}

\section{Learning Objectives}

1. Identify strategies for successful writing.

2. Demonstrate comprehensive writing skills.

3. Identify writing strategies for use in future classes.

In the preceding sections, you learned what you can expect from college and identified strategies you can use to manage your work. These strategies will help you succeed in any college course. This section covers more about how to handle the demands college places upon you as a writer. The general techniques you will learn will help ensure your success on any writing task, whether you complete a bluebook exam in an hour or an in-depth research project over several weeks.

\section{Putting It All Together: Strategies for Success}

Writing well is difficult. Even people who write for a living sometimes struggle to get their thoughts on the page. Even people who generally enjoy writing have days when they would rather do anything else. For people who do not like writing or do not think of themselves as good writers, writing assignments can be stressful or even intimidating. And of course, you cannot get through college without having to write — sometimes a lot, and often at a higher level than you are used to.

No magic formula will make writing quick and easy. However, you can use strategies and resources to manage writing assignments more easily. This section presents a broad overview of these strategies and resources. The remaining chapters of this book provide more detailed, comprehensive instruction to help you succeed at a variety of assignments. College will challenge you as a writer, but it is also a unique opportunity to grow.

\section{Using the Writing Process}

To complete a writing project successfully, good writers use some variation of the following process. 


\section{The Writing Process}

- Prewriting. In this step, the writer generates ideas to write about and begins developing these ideas.

- Outlining a structure of ideas. In this step, the writer determines the overall organizational structure of the writing and creates an outline to organize ideas. Usually this step involves some additional fleshing out of the ideas generated in the first step.

- Writing a rough draft. In this step, the writer uses the work completed in prewriting to develop a first draft. The draft covers the ideas the writer brainstormed and follows the organizational plan that was laid out in the first step.

- Revising. In this step, the writer revisits the draft to review and, if necessary, reshape its content. This stage involves moderate and sometimes major changes: adding or deleting a paragraph, phrasing the main point differently, expanding on an important idea, reorganizing content, and so forth.

- Editing. In this step, the writer reviews the draft to make additional changes. Editing involves making changes to improve style and adherence to standard writing conventions-for instance, replacing a vague word with a more precise one or fixing errors in grammar and spelling. Once this stage is complete, the work is a finished piece and ready to share with others.

Chances are, you have already used this process as a writer. You may also have used it for other types of creative projects, such as developing a sketch into a finished painting or composing a song. The steps listed above apply broadly to any project that involves creative thinking. You come up with ideas (often vague at first), you work to give them some structure, you make a first attempt, you figure out what needs improving, and then you refine it until you are satisfied.

Most people have used this creative process in one way or another, but many people have misconceptions about how to use it to write. Here are a few of the most common misconceptions students have about the writing process:

- “I do not have to waste time on prewriting if I understand the assignment." Even if the task is straightforward and you feel ready to start writing, take some time to develop ideas before you plunge into your draft. Freewriting - writing about the topic without stopping for a set period of time- -is one prewriting technique you might try in that situation.

- "It is important to complete a formal, numbered outline for every writing assignment." For some assignments, such as lengthy research papers, proceeding without a formal outline can be very difficult. However, for other assignments, a structured set of notes or a detailed graphic organizer may suffice. The important thing is that you have a solid plan for organizing ideas and details.

- “My draft will be better if I write it when I am feeling inspired.” By all means, take advantage of those moments of inspiration. However, understand that sometimes you will have to write when you are not in the mood. Sit down and start your draft even if you do not feel like it. If necessary, force yourself to write for just one hour. By the end of the hour, you may be far more engaged and motivated to continue. If not, at least you will have 
accomplished part of the task.

- “My instructor will tell me everything I need to revise.” If your instructor chooses to review drafts, the feedback can help you improve. However, it is still your job, not your instructor's, to transform the draft to a final, polished piece. That task will be much easier if you give your best effort to the draft before submitting it. During revision, do not just go through and implement your instructor's corrections. Take time to determine what you can change to make the work the best it can be.

- “I am a good writer, so I do not need to revise or edit.” Even talented writers still need to revise and edit their work. At the very least, doing so will help you catch an embarrassing typo or two. Revising and editing are the steps that make good writers into great writers.

For a more thorough explanation of the steps of the writing process as well as for specific techniques you can use for each step, see Chapter 8 “The Writing Process: How Do I Begin?”.

Tip

The writing process also applies to timed writing tasks, such as essay exams. Before you begin writing, read the question thoroughly and think about the main points to include in your response. Use scrap paper to sketch out a very brief outline. Keep an eye on the clock as you write your response so you will have time to review it and make any needed changes before turning in your exam.

\section{Managing Your Time}

In Section 1.2 “Developing Study Skills”, you learned general time-management skills. By combining those skills with what you have learned about the writing process, you can make any writing assignment easier to manage.

When your instructor gives you a writing assignment, write the due date on your calendar. Then work backward from the due date to set aside blocks of time when you will work on the assignment. Always plan at least two sessions of writing time per assignment, so that you are not trying to move from step 1 to step 5 in one evening. Trying to work that fast is stressful, and it does not yield great results. You will plan better, think better, and write better if you space out the steps.

Ideally, you should set aside at least three separate blocks of time to work on a writing assignment: one for prewriting and outlining, one for drafting, and one for revising and editing. Sometimes those steps may be compressed into just a few days. If you have a couple of weeks to work on a paper, space out the five steps over multiple sessions. Long-term projects, such as research papers, require more time for each step. 


\section{Tip}

In certain situations you may not be able to allow time between the different steps of the writing process. For instance, you may be asked to write in class or complete a brief response paper overnight. If the time available is very limited, apply a modified version of the writing process (as you would do for an essay exam). It is still important to give the assignment thought and effort. However, these types of assignments are less formal, and instructors may not expect them to be as polished as formal papers. When in doubt, ask the instructor about expectations, resources that will be available during the writing exam, and if they have any tips to prepare you to effectively demonstrate your writing skills.

Each Monday in Crystal's Foundations of Education class, the instructor distributed copies of a current news article on education and assigned students to write a one-and-one-half- to two-page response that was due the following Monday. Together, these weekly assignments counted for 20 percent of the course grade. Although each response took just a few hours to complete, Crystal found that she learned more from the reading and got better grades on her writing if she spread the work out in the following way:

\begin{tabular}{|c|c|c|c|c|c|c|}
\hline MONDAY & TUESDAY & WEDNESDAY & THURSDAY & FRIDAY & SATURDAY & SUNDAY \\
\hline $\begin{array}{l}\text { Article } \\
\text { response } \\
\text { assigned. }\end{array}$ & & $\begin{array}{l}\text { Read article, } \\
\text { prewrite, and } \\
\text { outline response } \\
\text { paper. }\end{array}$ & & $\begin{array}{l}\text { Draft } \\
\text { response. }\end{array}$ & & $\begin{array}{l}\text { Revise } \\
\text { and edit } \\
\text { response. }\end{array}$ \\
\hline
\end{tabular}

For more detailed guidelines on how to plan for a long-term writing project, see Chapter 11 "Writing from Research: What Will I Learn?”.

\section{Setting Goals}

One key to succeeding as a student and as a writer is setting both short- and long-term goals for yourself. You have already glimpsed the kind of short-term goals a student might set. Crystal wanted to do well in her Foundations of Education course, and she realized that she could control how she handled her weekly writing assignments. At 20 percent of her course grade, she reasoned, those assignments might mean the difference between a $\mathrm{C}$ and a B or between a B and an $\mathrm{A}$.

By planning carefully and following through on her daily and weekly goals, Crystal was able to fulfill one of her goals for the semester. Although her exam scores were not as high as she had hoped, her consistently strong performance on writing assignments tipped her grade from a $\mathrm{B}+$ to an $\mathrm{A}-$. She was pleased to have earned a high grade in one of the required courses for her major. She was also glad to have gotten the most out of an introductory course that would help her become an effective teacher.

How does Crystal's experience relate to your own college experience?

To do well in college, it is important to stay focused on how your day-to-day actions determine your long-term success. You may not have defined your career goals or chosen a major yet. Even so, you 
surely have some overarching goals for what you want out of college: to expand your career options, to increase your earning power, or just to learn something new. In time, you will define your long-term goals more explicitly. Doing solid, steady work, day by day and week by week, will help you meet those goals.

\section{Exercise 1}

In this exercise, make connections between short- and long-term goals.

1. For this step, identify one long-term goal you would like to have achieved by the time you complete your degree. For instance, you might want a particular job in your field or hope to graduate with honors.

2. Next, identify one semester goal that will help you fulfill the goal you set in step one. For instance, you may want to do well in a particular course or establish a connection with a professional in your field.

3. Review the goal you determined in step two. Brainstorm a list of stepping stones that will help you meet that goal, such as "doing well on my midterm and final exams" or "talking to Professor Gibson about doing an internship.” Write down everything you can think of that would help you meet that semester goal.

4. Review your list. Choose two to three items, and for each item identify at least one concrete action you can take to accomplish it. These actions may be recurring (meeting with a study group each week) or one time only (calling the professor in charge of internships).

5. Identify one action from step four that you can do today. Then do it.

\section{Using College Resources}

One reason students sometimes find college overwhelming is that they do not know about, or are reluctant to use, the resources available to them. Some aspects of college will be challenging. However, if you try to handle every challenge alone, you may become frustrated and overwhelmed.

Universities have resources in place to help students cope with challenges. Your student fees help pay for resources such as a health center or tutoring, so use these resources if you need them. The following are some of the resources you might use if you find you need help:

- Your instructor. If you are making an honest effort but still struggling with a particular course, set up a time to meet with your instructor and discuss what you can do to improve. He or she may be able to shed light on a confusing concept or give you strategies to catch up.

- Your academic counselor. Many universities assign students an academic counselor who can help you choose courses and ensure that you fulfill degree and major requirements.

- The academic resource center. These centers offer a variety of services, which may range from general coaching in study skills to tutoring for specific courses. Find out what is offered 
at your school and use the services that you need.

- The writing center. These centers employ tutors to help you manage college-level writing assignments. They will not write or edit your paper for you, but they can help you through the stages of the writing process. (In some schools, the writing center is part of the academic resource center.)

- The career resource center. Visit the career resource center for guidance in choosing a career path, developing a résumé, and finding and applying for jobs.

- Counseling services. Many universities offer psychological counseling for free or for a low fee. Use these services if you need help coping with a difficult personal situation or managing depression, anxiety, or other problems.

Students sometimes neglect to use available resources due to limited time, unwillingness to admit there is a problem, or embarrassment about needing to ask for help. Unfortunately, ignoring a problem usually makes it harder to cope with later on. Waiting until the end of the semester may also mean fewer resources are available, since many other students are also seeking last-minute help.

\section{Exercise 2}

Identify at least one college resource that you think could be helpful to you and you would like to investigate further. Schedule a time to visit this resource within the next week or two so you can use it throughout the semester.

\section{Overview: College Writing Skills}

You now have a solid foundation of skills and strategies you can use to succeed in college. The remainder of this book will provide you with guidance on specific aspects of writing, ranging from grammar and style conventions to how to write a research paper.

For any college writing assignment, use these strategies:

- Plan ahead. Divide the work into smaller, manageable tasks, and set aside time to accomplish each task in turn.

- Make sure you understand the assignment requirements, and if necessary, clarify them with your instructor. Think carefully about the purpose of the writing, the intended audience, the topics you will need to address, and any specific requirements of the writing form.

- Complete each step of the writing process. With practice, using this process will come automatically to you.

- Use the resources available to you. Remember that most colleges have specific services to help students with their writing. 
For help with specific writing assignments and guidance on different aspects of writing, you may refer to the other chapters in this book. The table of contents lists topics in detail. As a general overview, the following paragraphs discuss what you will learn in the upcoming chapters.

Chapter 2 "Writing Basics: What Makes a Good Sentence?" through Chapter 7 "Refining Your Writing: How Do I Improve My Writing Technique?" will ground you in writing basics: the "nuts and bolts” of grammar, sentence structure, and paragraph development that you need to master to produce competent college-level writing. Chapter 2 "Writing Basics: What Makes a Good Sentence?" reviews the parts of speech and the components of a sentence. Chapter 3 "Punctuation" explains how to use punctuation correctly. Chapter 4 "Working with Words: Which Word Is Right?" reviews concepts that will help you use words correctly, including everything from commonly confused words to using context clues.

Chapter 5 "Help for English Language Learners" provides guidance for students who have learned English as a second language. Then, Chapter 6 "Writing Paragraphs: Separating Ideas and Shaping Content" guides you through the process of developing a paragraph while Chapter 7 "Refining Your Writing: How Do I Improve My Writing Technique?” has tips to help you refine and improve your sentences.

Chapter 8 “The Writing Process: How Do I Begin?” through Chapter 10 "Rhetorical Modes” are geared to help you apply those basics to college-level writing assignments. Chapter 8 "The Writing Process: How Do I Begin?" shows the writing process in action with explanations and examples of techniques you can use during each step of the process. Chapter 9 "Writing Essays: From Start to Finish" provides further discussion of the components of college essays-how to create and support a thesis and how to organize an essay effectively. Chapter 10 "Rhetorical Modes" discusses specific modes of writing you will encounter as a college student and explains how to approach these different assignments.

Chapter 11 "Writing from Research: What Will I Learn?” through Chapter 14 "Creating Presentations: Sharing Your Ideas" focus on how to write a research paper. Chapter 11 "Writing from Research: What Will I Learn?" guides students through the process of conducting research, while Chapter 12 "Writing a Research Paper" explains how to transform that research into a finished paper. Chapter 13 "APA and MLA Documentation and Formatting" explains how to format your paper and use a standard system for documenting sources. Finally, Chapter 14 "Creating Presentations: Sharing Your Ideas" discusses how to transform your paper into an effective presentation.

Many of the chapters in this book include sample student writing-not just the finished essays but also the preliminary steps that went into developing those essays. Chapter 15 "Readings: Examples of Essays” of this book provides additional examples of different essay types.

\section{Key Takeaways}

- Following the steps of the writing process helps students complete any writing assignment more successfully.

- To manage writing assignments, it is best to work backward from the due date, allotting appropriate time to complete each step of the writing process. 
- Setting concrete long- and short-term goals helps students stay focused and motivated.

- A variety of university resources are available to help students with writing and with other aspects of college life. 


\subsection{Introduction to Writing: End-of-Chapter Exercises}

\section{Exercises}

1. Find out more about your learning style by visiting your academic resource center or doing Internet research. Take note of strategies that are recommended for different types of learners. Which strategies do you already use? Which strategies could you incorporate into your routine?

2. Apply the following comprehension and active reading strategies to an assigned reading:

- Locate the writer's main idea and major supporting points. (Use text features to gather clues.)

- Apply the SQ3R strategy: Survey, Question, Read, Recite and Record, and Review and Reflect.

- Apply at least one other active reading strategy appropriate for the text, such as visualizing or connecting the text to personal experiences.

3. After reviewing your syllabus, map out a timeline of major assignments in the course. Describe the steps you anticipate needing to follow in order to complete these assignments.

4. Take a few minutes to skim through the remaining chapters of this book, whose contents are described in Section 1.3 "Becoming a Successful College Writer". Use self-stick notes or flags to mark any sections that you expect to consult frequently when you write, such as a grammar guide or guidelines for a particular essay format. You may wish to similarly make notes in other writing handbooks you own and any other reference books you will need to use frequently. 


\section{Chapter 2: Writing Basics: What Makes a Good Sentence?}

2.1 Sentence Writing

2.2 Subject-Verb Agreement

2.3 Verb Tense

2.4 Capitalization

2.5 Pronouns

2.6 Adjectives and Adverbs

2.7 Misplaced and Dangling Modifiers

2.8 Writing Basics: End-of-Chapter Exercises 


\subsection{Sentence Writing}

\section{Learning Objectives}

1. Identify the components of a basic sentence.

2. Identify the four most serious writing errors.

Imagine you are reading a book for school. You need to find important details that you can use for an assignment. However, when you begin to read, you notice that the book has very little punctuation. Sentences fail to form complete paragraphs and instead form one block of text without clear organization. Most likely, this book would frustrate and confuse you. Without clear and concise sentences, it is difficult to find the information you need.

For both students and professionals, clear communication is important. Whether you are typing an email or writing a report, it is your responsibility to present your thoughts and ideas clearly and precisely. Writing in complete sentences is one way to ensure that you communicate well. This section covers how to recognize and write basic sentence structures and how to avoid some common writing errors.

\section{Components of a Sentence}

Clearly written, complete sentences require key information: a subject, a verb and a complete idea. A sentence needs to make sense on its own. Sometimes, complete sentences are also called independent clauses. A clause is a group of words that may make up a sentence. An independent clause is a group of words that may stand alone as a complete, grammatically correct thought. The following sentences show independent clauses.

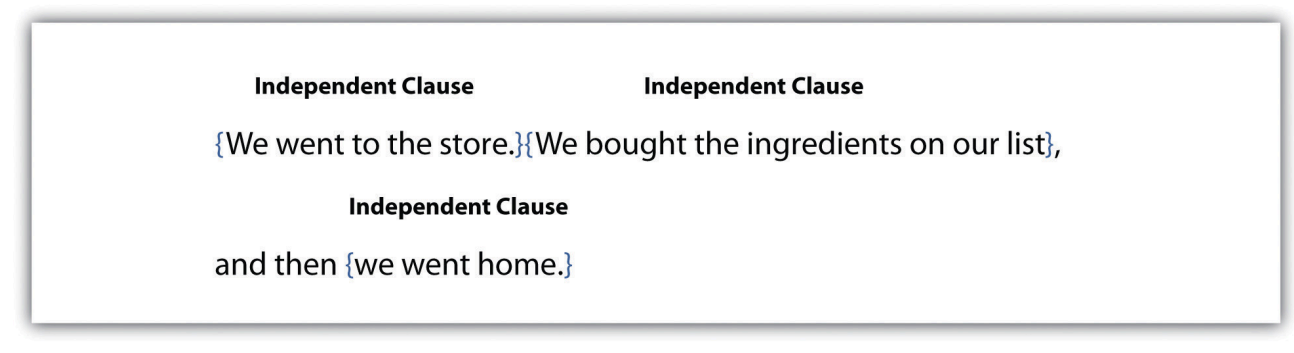

All complete sentences have at least one independent clause. You can identify an independent clause by reading it on its own and looking for the subject and the verb. 


\section{Subjects}

When you read a sentence, you may first look for the subject, or what the sentence is about. The subject usually appears at the beginning of a sentence as a noun or a pronoun. A noun is a word that identifies a person, place, thing, or idea. A pronoun is a word that replaces a noun. Common pronouns are $I$, he, she, it, you, they, and we. In the following sentences, the subject is underlined once.

Malik is the project manager for this project. $\underline{\text { He }}$ will give us our assignments.

In these sentences, the subject is a person: Malik. The pronoun He replaces and refers back to Malik.

The computer lab is where we will work. It will be open twenty-four hours a day.

In the first sentence, the subject is a place: computer lab. In the second sentence, the pronoun It substitutes for computer lab as the subject.

The project will run for three weeks. It will have a quick turnaround.

In the first sentence, the subject is a thing: project. In the second sentence, the pronoun It stands in for the project.

\section{Tip}

In this chapter, please refer to the following grammar key:

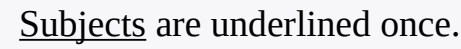

Verbs are underlined twice.

LV means linking verb, HV means helping verb, and V means action verb.

\section{Compound Subjects}

A sentence may have more than one person, place, or thing as the subject. These subjects are called compound subjects. Compound subjects are useful when you want to discuss several subjects at once.

Desmond and Maria have been working on that design for almost a year. Books, magazines, and online $\underline{\text { articles }}$ are all good resources. 


\section{Prepositional Phrases}

You will often read a sentence that has more than one noun or pronoun in it. You may encounter a group of words that includes a preposition with a noun or a pronoun. Prepositions connect a noun, pronoun, or verb to another word that describes or modifies that noun, pronoun, or verb. Common prepositions include in, on, under, near, by, with, and about. A group of words that begin with a preposition is called a prepositional phrase. A prepositional phrase begins with a preposition and modifies or describes a word. It cannot act as the subject of a sentence. The following circled phrases are examples of prepositional phrases.

We went on a business trip That restaurant with the famous pizza was on the way. We stopped(for lunch.)

\section{Exercise 1}

Read the following sentences. Underline the subjects, and circle the prepositional phrases.

1. The gym is open until nine o'clock tonight.

2. We went to the store to get some ice.

3. The student with the most extra credit will win a homework pass.

4. Maya and Tia found an abandoned cat by the side of the road.

5. The driver of that pickup truck skidded on the ice.

6. Anita won the race with time to spare.

7. The people who work for that company were surprised about the merger.

8. Working in haste means that you are more likely to make mistakes.

9. The soundtrack has over sixty songs in languages from around the world.

10. His latest invention does not work, but it has inspired the rest of us.

\section{Verbs}

Once you locate the subject of a sentence, you can move on to the next part of a complete sentence: the verb. A verb is often an action word that shows what the subject is doing. A verb can also link the subject to a describing word. There are three types of verbs that you can use in a sentence: action verbs, linking verbs, or helping verbs. 


\section{Action Verbs}

A verb that connects the subject to an action is called an action verb. An action verb answers the question what is the subject doing? In the following sentences, the action verbs are in italics.

The dog barked at the jogger.

He gave a short speech before we ate.

\section{Linking Verbs}

A verb can often connect the subject of the sentence to a describing word. This type of verb is called a linking verb because it links the subject to a describing word. In the following sentences, the linking verbs are in italics.

The coat was old and dirty.

The clock seemed broken.

If you have trouble telling the difference between action verbs and linking verbs, remember that an action verb shows that the subject is doing something, whereas a linking verb simply connects the subject to another word that describes or modifies the subject. A few verbs can be used as either action verbs or linking verbs.

Action Verb: The boy looked for his glove.

Linking Verb: The boy looked tired.

Although both sentences use the same verb, the two sentences have completely different meanings. In the first sentence, the verb describes the boy's action. In the second sentence, the verb describes the boy's appearance.

\section{Helping Verbs}

A third type of verb you may use as you write is a helping verb. Helping verbs are verbs that are used with the main verb to describe a mood or tense. Helping verbs are usually a form of be, do, or have. The word can is also used as a helping verb.

The restaurant is known for its variety of dishes.

She does speak up when prompted in class. 
We have seen that movie three times.

She can tell when someone walks on her lawn.

(is, does, have, and can are helping verbs and known, speak up, seen, and tell are verbs)

\section{Tip}

Whenever you write or edit sentences, keep the subject and verb in mind. As you write, ask yourself these questions to keep yourself on track:

Subject: Who or what is the sentence about?

Verb: Which word shows an action or links the subject to a description?

\section{Exercise 2}

Copy each sentence onto your own sheet of paper and underline the verb(s) twice. Name the type of verb(s) used in the sentence in the space provided ( $\mathrm{LV}, \mathrm{HV}$, or $\mathrm{V}$ ).

1. The cat sounds ready to come back inside.

2. We have not eaten dinner yet.

3. It took four people to move the broken-down car.

4. The book was filled with notes from class.

5. We walked from room to room, inspecting for damages.

6. Harold was expecting a package in the mail.

7. The clothes still felt damp even though they had been through the dryer twice.

8. The teacher who runs the studio is often praised for his restoration work on old masterpieces.

\section{Sentence Structure, Including Fragments and Run-ons}

Now that you know what makes a complete sentence-a subject and a verb-you can use other parts of speech to build on this basic structure. Good writers use a variety of sentence structures to make their work more interesting. This section covers different sentence structures that you can use to make longer, more complex sentences. 


\title{
Sentence Patterns
}

Six basic subject-verb patterns can enhance your writing. A sample sentence is provided for each pattern. As you read each sentence, take note of where each part of the sentence falls. Notice that some sentence patterns use action verbs and others use linking verbs.

\section{Subject-Verb}

Computers (subject) hum (verb)

\section{Subject-Linking Verb-Noun}

\author{
Computers (subject) are (linking verb) tool (noun)
}

\section{Subject-Linking Verb-Adjective}

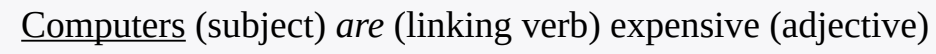

\section{Subject-Verb-Adverb}

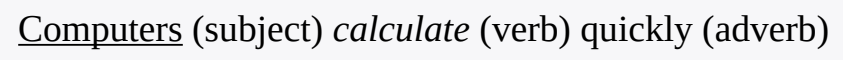

\section{Subject-Verb-Direct Object}

When you write a sentence with a direct object (DO), make sure that the DO receives the action of the verb. 


\section{Subject-Verb-Indirect Object-Direct Object}

In this sentence structure, an indirect object explains to whom or to what the action is being done. The indirect object is a noun or pronoun, and it comes before the direct object in a sentence.

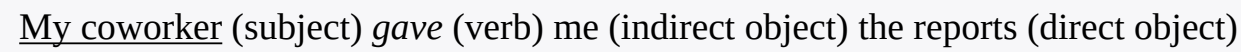

\section{Exercise 3}

Use what you have learned so far to bring variety in your writing. Use the following lines or your own sheet of paper to write six sentences that practice each basic sentence pattern. When you have finished, label each part of the sentence (S, V, LV, N, Adj, Adv, DO, IO).

1.

2.

3.

4.

5.

6.

\section{Collaboration}

Find an article in a newspaper, a magazine, or online that interests you. Bring it to class or post it online.

Then, looking at a classmate's article, identify one example of each part of a sentence (S, V, LV, N, Adj, Adv, DO, IO). Please share or post your results.

\section{Fragments}

The sentences you have encountered so far have been independent clauses. As you look more closely at your past writing assignments, you may notice that some of your sentences are not complete. A sentence that is missing a subject or a verb is called a fragment. A fragment may include a description or may express part of an idea, but it does not express a complete thought. 
Fragment: Children helping in the kitchen.

Complete sentence: Children helping in the kitchen often make a mess.

You can easily fix a fragment by adding the missing subject or verb. In the example, the sentence was missing a verb. Adding often make a mess creates an S-V-N sentence structure.

Figure 2.1 Editing Fragments That Are Missing a Subject or a Verb

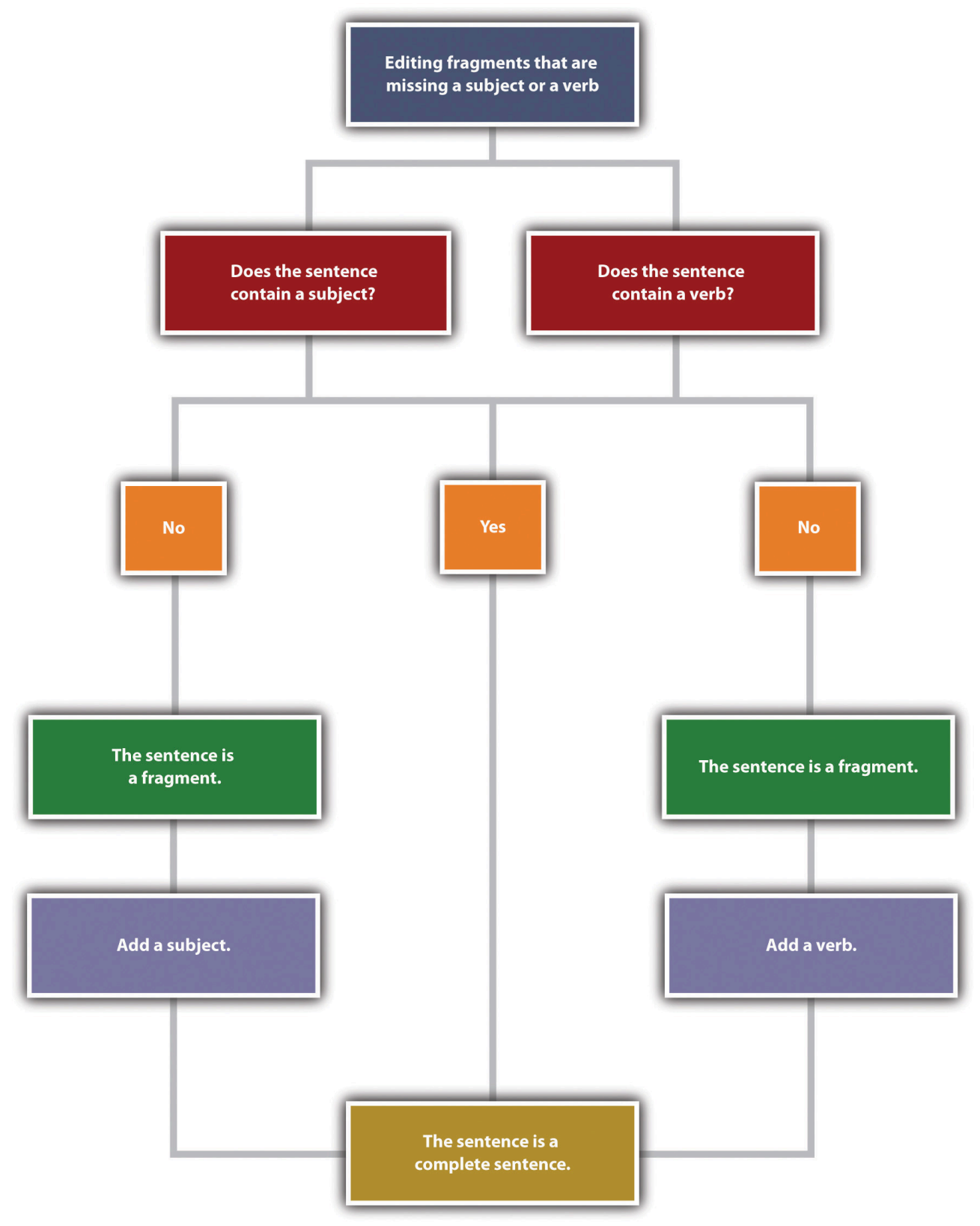

See whether you can identify what is missing in the following fragments. 
Fragment: Told her about the broken vase.

Complete sentence: I told her about the broken vase.

Fragment: The store down on Main Street.

Complete sentence: The store down on Main Street sells music.

\section{Common Sentence Errors}

Fragments often occur because of some common error, such as starting a sentence with a preposition, a dependent word, an infinitive, or a gerund. If you use the six basic sentence patterns when you write, you should be able to avoid these errors and thus avoid writing fragments.

When you see a preposition, check to see that it is part of a sentence containing a subject and a verb. If it is not connected to a complete sentence, it is a fragment, and you will need to fix this type of fragment by combining it with another sentence. You can add the prepositional phrase to the end of the sentence. If you add it to the beginning of the other sentence, insert a comma after the prepositional phrase.

Figure 2.2 Editing Fragments That Begin with a Preposition 


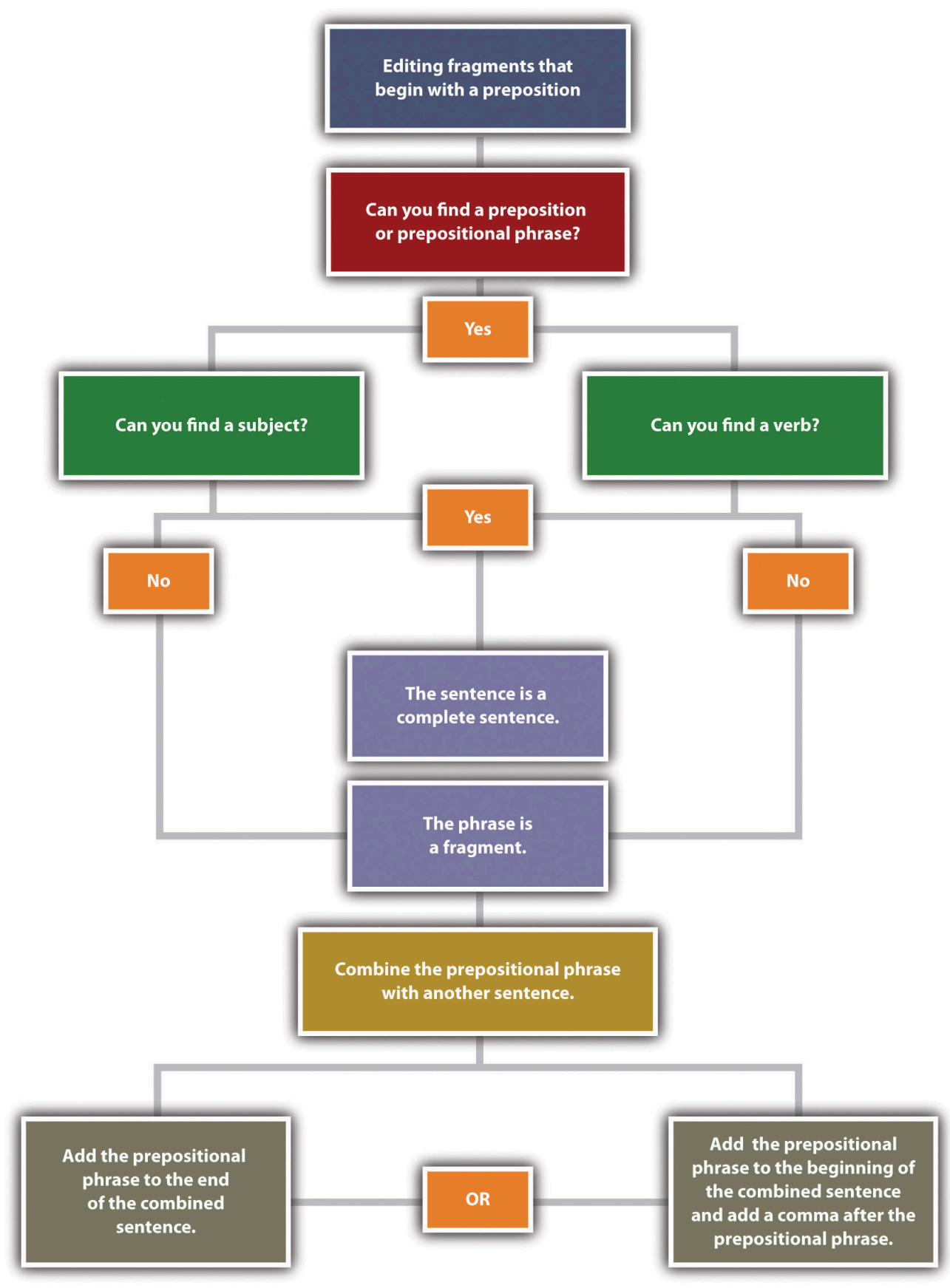

\section{Example A}

Incorrect: After walking over two miles. John remembered his wallet.

Correct: After walking over two miles, John remembered his wallet.

Correct: John remembered his wallet After after walking over two miles.

Example B

Incorrect: The dog growled at the vacuum cleaner. When it was switched on.

Correct: When the vacuum cleaner was switched on, the dog growled.

Correct: The dog growled at the vacuum cleaner When when it was switched on. 
Clauses that start with a dependent word-such as since, because, without, or unless-are similar to prepositional phrases. Like prepositional phrases, these clauses can be fragments if they are not connected to an independent clause containing a subject and a verb. To fix the problem, you can add such a fragment to the beginning or end of a sentence. If the fragment is added at the beginning of a sentence, add a comma.

Incorrect: Because we lost power. The entire family overslept.

Correct: Because we lost power, the entire family overslept.

Correct: The entire family overslept Because because we lost power.

Incorrect: He has been seeing a physical therapist. Since his accident.

Correct: Since his accident, he has been seeing a physical therapist.

Correct: He has been seeing a physical therapist Since since his accident.

When you encounter a word ending in -ing in a sentence, identify whether or not this word is used as a verb in the sentence. You may also look for a helping verb. If the word is not used as a verb or if no helping verb is used with the -ing verb form, the verb is being used as a noun. An -ing verb form used as a noun is called a gerund.

Verb: I was (helping verb) working (verb) on homework until midnight.

Noun: Working until midnight makes me tired the next morning.

Once you know whether the -ing word is acting as a noun or a verb, look at the rest of the sentence. Does the entire sentence make sense on its own? If not, what you are looking at is a fragment. You will need to either add the parts of speech that are missing or combine the fragment with a nearby sentence. 


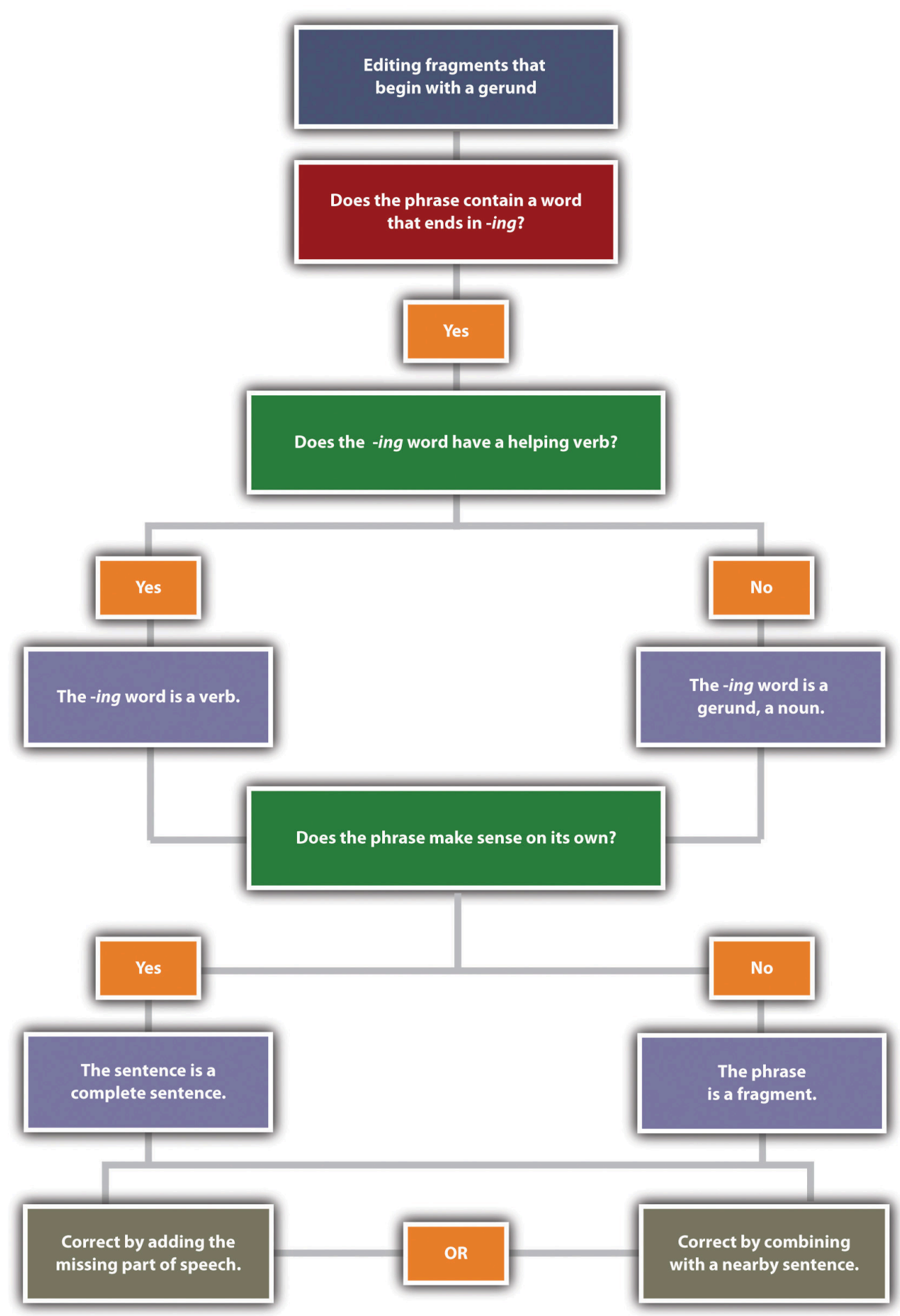

Incorrect: Taking deep breaths. Saul prepared for his presentation.

Correct: Taking deep breaths, Saul prepared for his presentation.

Correct: Saul prepared for his presentation. He was taking deep breaths. 
Incorrect: Congratulating the entire team. Sarah raised her glass to toast their success.

Correct: She was congratulating the entire team. Sarah raised her glass to toast their success.

Correct: Congratulating the entire team, Sarah raised her glass to toast their success.

Another error in sentence construction is a fragment that begins with an infinitive. An infinitive is a verb paired with the word to; for example, to run, to write, or to reach. Although infinitives are verbs, they can be used as nouns, adjectives, or adverbs. You can correct a fragment that begins with an infinitive by either combining it with another sentence or adding the parts of speech that are missing.

Incorrect: We needed to make three hundred more paper cranes. To reach the one thousand mark.

Correct: We needed to make three hundred more paper cranes to reach the one thousand mark.

Correct: We needed to make three hundred more paper cranes. We wanted to reach the one thousand mark.

\section{Exercise 4}

Copy the following sentences onto your own sheet of paper and circle the fragments. Then combine the fragment with the independent clause to create a complete sentence.

1. Working without taking a break. We try to get as much work done as we can in an hour.

2. I needed to bring work home. In order to meet the deadline.

3. Unless the ground thaws before spring break. We won't be planting any tulips this year.

4. Turning the lights off after he was done in the kitchen. Robert tries to conserve energy whenever possible.

5. You'll find what you need if you look. On the shelf next to the potted plant.

6. To find the perfect apartment. Deidre scoured the classifieds each day.

\section{Run-on Sentences}

Just as short, incomplete sentences can be problematic, lengthy sentences can be problematic too. Sentences with two or more independent clauses that have been incorrectly combined are known as runon sentences. A run-on sentence may be either a fused sentence or a comma splice. 
Fused sentence: A family of foxes lived under our shed young foxes played all over the yard.

Comma splice: We looked outside, the kids were hopping on the trampoline.

When two complete sentences are combined into one without any punctuation, the result is a fused sentence. When two complete sentences are joined by a comma, the result is a comma splice. Both errors can easily be fixed.

\section{Punctuation}

One way to correct run-on sentences is to correct the punctuation. For example, adding a period will correct the run-on by creating two separate sentences.

Run-on: There were no seats left, we had to stand in the back.

Correct: There were no seats left. we We had to stand in the back.

Using a semicolon between the two complete sentences will also correct the error. A semicolon allows you to keep the two closely related ideas together in one sentence. When you punctuate with a semicolon, make sure that both parts of the sentence are independent clauses. For more information on semicolons, see Section 2.4.2 “Capitalize Proper Nouns”.

Run-on: The accident closed both lanes of traffic we waited an hour for the wreckage to be cleared.

Complete sentence: The accident closed both lanes of traffic; we waited an hour for the wreckage to be cleared.

When you use a semicolon to separate two independent clauses, you may wish to add a transition word to show the connection between the two thoughts. After the semicolon, add the transition word and follow it with a comma. For more information on transition words, see Chapter 8 "The Writing Process: How Do I Begin?”.

Run-on: The project was put on hold we didn't have time to slow down, so we kept working.

Complete sentence: The project was put on hold; however, we didn't have time to slow down, so we kept working. 


\section{Coordinating Conjunctions}

You can also fix run-on sentences by adding a comma and a coordinating conjunction. A coordinating conjunction acts as a link between two independent clauses.

\section{Tip}

These are the seven coordinating conjunctions that you can use: for, and, nor, but, or, yet, and so. Use these words appropriately when you want to link the two independent clauses. The acronym FANBOYS will help you remember this group of coordinating conjunctions.

Run-on: The new printer was installed, no one knew how to use it.

Complete sentence: The new printer was installed, but no one knew how to use it.

\section{Dependent Words}

Adding dependent words is another way to link independent clauses. Like the coordinating conjunctions, dependent words show a relationship between two independent clauses.

Run-on: We took the elevator, the others still got there before us.

Complete sentence: Although we took the elevator, the others got there before us.

Run-on: Cobwebs covered the furniture, the room hadn't been used in years.

Complete sentence: Cobwebs covered the furniture because the room hadn't been used in years.

Writing at Work

Figure 2.4 Sample e-mail 


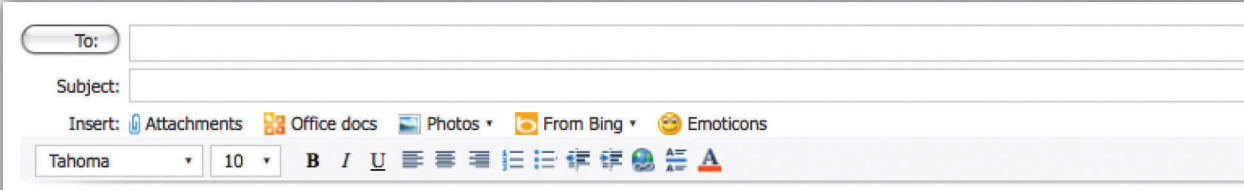

Dear Mr. Blankenship:

The invoice we received yesterday. From your office was dated February 25 . This date is incorrect, the date should read February 28, attached is the original invoice with the incorrect date. Please correct the date and resend the invoice. We will be able to send the funds promptly. By the end of the day.

Sincerely,

Isabelle

Isabelle's e-mail opens with two fragments and two run-on sentences containing comma splices. The e-mail ends with another fragment. What effect would this e-mail have on Mr. Blankenship or other readers? Mr. Blankenship or other readers may not think highly of Isaebelle's communication skills or-worse-may not understand the message at all! Communications written in precise, complete sentences are not only more professional but also easier to understand. Before you hit the "send" button, read your e-mail carefully to make sure that the sentences are complete, are not run together, and are correctly punctuated.

\section{Exercise 5}

A reader can get lost or lose interest in material that is too dense and rambling. Use what you have learned about run-on sentences to correct the following passages:

1. The report is due on Wednesday but we're flying back from Miami that morning. I told the project manager that we would be able to get the report to her later that day she suggested that we come back a day early to get the report done and I told her we had meetings until our flight took off. We e-mailed our contact who said that they would check with his boss, she said that the project could afford a delay as long as they wouldn't have to make any edits or changes to the file our new deadline is next Friday.

2. Anna tried getting a reservation at the restaurant, but when she called they said that there was a waiting list so she put our names down on the list when the day of our reservation arrived we only had to wait thirty minutes because a table opened up unexpectedly which was good because we were able to catch a movie after dinner in the time we'd expected to wait to be seated. 
3. Without a doubt, my favorite artist is Leonardo da Vinci, not because of his paintings but because of his fascinating designs, models, and sketches, including plans for scuba gear, a flying machine, and a life-size mechanical lion that actually walked and moved its head. His paintings are beautiful too, especially when you see the computer enhanced versions researchers use a variety of methods to discover and enhance the paintings' original colors, the result of which are stunningly vibrant and yet delicate displays of the man's genius.

\section{Key Takeaways}

- A sentence is complete when it contains both a subject and verb. A complete sentence makes sense on its own.

- Every sentence must have a subject, which usually appears at the beginning of the sentence. A subject may be a noun (a person, place, or thing) or a pronoun.

- A compound subject contains more than one noun.

- A prepositional phrase describes, or modifies, another word in the sentence but cannot be the subject of a sentence.

- A verb is often an action word that indicates what the subject is doing. Verbs may be action verbs, linking verbs, or helping verbs.

- Variety in sentence structure and length improves writing by making it more interesting and more complex.

- Focusing on the six basic sentence patterns will enhance your writing.

- Fragments and run-on sentences are two common errors in sentence construction.

- Fragments can be corrected by adding a missing subject or verb. Fragments that begin with a preposition or a dependent word can be corrected by combining the fragment with another sentence.

- Run-on sentences can be corrected by adding appropriate punctuation or adding a coordinating conjunction.

\section{Writing Application}

Using the six basic sentence structures, write one of the following:

1. A work e-mail to a coworker about a presentation.

2. A business letter to a potential employer.

3. A status report about your current project.

4. A job description for your résumé. 


\subsection{Subject-Verb Agreement}

\section{Learning Objectives}

1. Define subject-verb agreement.

2. Identify common errors in subject-verb agreement.

In the workplace, you want to present a professional image. Your outfit or suit says something about you when meeting face-to-face, and your writing represents you in your absence. Grammatical mistakes in your writing or even in speaking make a negative impression on coworkers, clients, and potential employers. Subject-verb agreement is one of the most common errors that people make. Having a solid understanding of this concept is critical when making a good impression, and it will help ensure that your ideas are communicated clearly.

\section{Agreement}

Agreement in speech and in writing refers to the proper grammatical match between words and phrases. Parts of sentences must agree, or correspond with other parts, in number, person, case, and gender.

- Number. All parts must match in singular or plural forms.

- Person. All parts must match in first person (I), second person (you), or third person (he, she, it, they) forms.

- Case. All parts must match in subjective (I, you, he, she, it, they, we), objective (me, her, him, them, us), or possessive (my, mine, your, yours, his, her, hers, their, theirs, our, ours) forms. For more information on pronoun case agreement, see Section 2.5.1 "Pronoun Agreement".

- Gender. All parts must match in male or female forms.

Subject-verb agreement describes the proper match between subjects and verbs.

Because subjects and verbs are either singular or plural, the subject of a sentence and the verb of a sentence must agree with each other in number. That is, a singular subject belongs with a singular verb form, and a plural subject belongs with a plural verb form. For more information on subjects and verbs, see Section 2.1 "Sentence Writing”. 
Singular: The cat jumps over the fence.

Plural: The cats jump over the fence.

\section{Regular Verbs}

Regular verbs follow a predictable pattern. For example, in the third person singular, regular verbs always end in -s. Other forms of regular verbs do not end in -s. Study the following regular verb forms in the present tense.

\begin{tabular}{|l|l|l|}
\hline First Person & I live. & We live. \\
\hline Second Person & You live. & You live. \\
\hline Third Person & He/She/It lives. & They live. \\
\hline
\end{tabular}

Tip

Add an -es to the third person singular form of regular verbs that end in -sh, $-x$, -ch, and -s. (I wish/He wishes, I fix/She fixes, I watch/It watches, I kiss/He kisses.)

Singular: I read every day.

Plural: We read every day.

In these sentences, the verb form stays the same for the first person singular and the first person plural.

Singular: You stretch before you go to bed.

Plural: You stretch before every game.

In these sentences, the verb form stays the same for the second person singular and the second person plural. In the singular form, the pronoun you refers to one person. In the plural form, the pronoun you refers to a group of people, such as a team.

Singular: My mother walks to work every morning.

In this sentence, the subject is mother. Because the sentence only refers to one mother, the subject is 
singular. The verb in this sentence must be in the third person singular form.

Plural: My friends like the same music as I do.

In this sentence, the subject is friends. Because this subject refers to more than one person, the subject is plural. The verb in this sentence must be in the third person plural form.

Tip

Many singular subjects can be made plural by adding an -s. Most regular verbs in the present tense end with an $-s$ in the third person singular. This does not make the verbs plural.

Singular subject, singular verb: The cat races across the yard.

Plural subject, plural verb: The cats race across the yard.

\section{Exercise 1}

On your own sheet of paper, write the correct verb form for each of the following sentences.

1. I (brush/brushes) my teeth twice a day.

2. You (wear/wears) the same shoes every time we go out.

3. He (kick/kicks) the soccer ball into the goal.

4. She (watch/watches) foreign films.

5. Catherine (hide/hides) behind the door.

6. We (want/wants) to have dinner with you.

7. You (work/works) together to finish the project.

8. They (need/needs) to score another point to win the game.

9. It (eat/eats) four times a day.

10. David (fix/fixes) his own motorcycle.

\section{Irregular Verbs}

Not all verbs follow a predictable pattern. These verbs are called irregular verbs. Some of the most common irregular verbs are be, have, and do. Learn the forms of these verbs in the present tense to avoid 
59 [Author removed at request of original publisher]

errors in subject-verb agreement.

$\mathrm{Be}$

Study the different forms of the verb to be in the present tense.

\begin{tabular}{|l|l|l|}
\hline First Person & I am. & We are. \\
\hline Second Person & You are. & You are. \\
\hline Third Person & He/She/It is. & They are. \\
\hline
\end{tabular}

\section{Have}

Study the different forms of the verb to have in the present tense.

\begin{tabular}{|l|l|l|}
\hline First Person & I have. & We have. \\
\hline Second Person & You have. & You have. \\
\hline Third Person & He/She/It has. & They have. \\
\hline
\end{tabular}

\section{Do}

Study the different forms of the verb to do in the present tense.

\begin{tabular}{|l|l|l|}
\hline & Singular Form & Plural Form \\
\hline First Person & I do. & We do. \\
\hline Second Person & You do. & You do. \\
\hline Third person & He/She/It does. & They do. \\
\hline
\end{tabular}




\section{Exercise 2}

Complete the following sentences by writing the correct present tense form of be, have, or do. Use your own sheet of paper to complete this exercise.

1. I sure that you will succeed.

2. They front-row tickets to the show.

3. $\mathrm{He}$ a great Elvis impersonation.

4. We so excited to meet you in person!

5. She a fever and a sore throat.

6. You not know what you are talking about.

7. You all going to pass this class.

8. She not going to like that.

9. It appear to be the right size.

10. They ready to take this job seriously.

\section{Errors in Subject-Verb Agreement}

Errors in subject-verb agreement may occur when

- a sentence contains a compound subject;

- the subject of the sentence is separate from the verb;

- the subject of the sentence is an indefinite pronoun, such as anyone or everyone;

- the subject of the sentence is a collective noun, such as team or organization;

- the subject appears after the verb.

Recognizing the sources of common errors in subject-verb agreement will help you avoid these errors in your writing. This section covers the subject-verb agreement errors in more detail.

\section{Compound Subjects}

A compound subject is formed by two or more nouns and the coordinating conjunctions and, or, or nor. A compound subject can be made of singular subjects, plural subjects, or a combination of singular and plural subjects.

Compound subjects combined with and take a plural verb form. 
Two singular subjects: Alicia and Miguel ride their bikes to the beach.

Two plural subjects: The girls and the boys ride their bikes to the beach.

Singular and plural subjects: Alicia and the boys ride their bikes to the beach.

Compound subjects combined with or and nor are treated separately. The verb must agree with the subject that is nearest to the verb.

Two singular subjects: Neither Elizabeth nor Rianna wants to eat at that restaurant. Two plural subjects: Neither the kids nor the adults want to eat at that restaurant.

Singular and plural subjects: Neither Elizabeth nor the kids want to eat at that restaurant.

Plural and singular subjects: Neither the kids nor Elizabeth wants to eat at that restaurant.

Two singular subjects: Either you or Jason takes the furniture out of the garage.

Two plural subjects: Either you or the twins take the furniture out of the garage.

Singular and plural subjects: Either Jason or the twins take the furniture out of the garage.

Plural and singular subjects: Either the twins or Jason takes the furniture out of the garage.

Tip

If you can substitute the word they for the compound subject, then the sentence takes the third person plural verb form.

\section{Separation of Subjects and Verbs}

As you read or write, you may come across a sentence that contains a phrase or clause that separates the subject from the verb. Often, prepositional phrases or dependent clauses add more information to the sentence and appear between the subject and the verb. However, the subject and the verb must still agree.

If you have trouble finding the subject and verb, cross out or ignore the phrases and clauses that begin with prepositions or dependent words. The subject of a sentence will never be in a prepositional phrase or dependent clause.

The following is an example of a subject and verb separated by a prepositional phrase:

The students with the best grades win the academic awards.

The puppy under the table is my favorite. 
The following is an example of a subject and verb separated by a dependent clause:

The car that I bought has power steering and a sunroof. The representatives who are courteous sell the most tickets.

\section{Indefinite Pronouns}

Indefinite pronouns refer to an unspecified person, thing, or number. When an indefinite pronoun serves as the subject of a sentence, you will often use a singular verb form.

However, keep in mind that exceptions arise. Some indefinite pronouns may require a plural verb form. To determine whether to use a singular or plural verb with an indefinite pronoun, consider the noun that the pronoun would refer to. If the noun is plural, then use a plural verb with the indefinite pronoun. View the chart to see a list of common indefinite pronouns and the verb forms they agree with.

\begin{tabular}{|l|l|}
\hline $\begin{array}{l}\text { Indefinite Pronouns That Always Take a } \\
\text { Singular Verb }\end{array}$ & $\begin{array}{l}\text { Indefinite Pronouns That Can Take a Singular or } \\
\text { Plural Verb }\end{array}$ \\
\hline anybody, anyone, anything & All \\
\hline each & Any \\
\hline everybody, everyone, everything & None \\
\hline much & Some \\
\hline many & \\
\hline nobody, no one, nothing & \\
\hline somebody, someone, something & \\
\hline
\end{tabular}

Singular: Everybody in the kitchen sings along when that song comes on the radio.

The indefinite pronoun everybody takes a singular verb form because everybody refers to a group performing the same action as a single unit.

Plural: All the people in the kitchen sing along when that song comes on the radio.

The indefinite pronoun all takes a plural verb form because all refers to the plural noun people. Because people is plural, all is plural. 
Singular: All the cake is on the floor.

In this sentence, the indefinite pronoun all takes a singular verb form because all refers to the singular noun cake. Because cake is singular, all is singular.

\section{Collective Nouns}

A collective noun is a noun that identifies more than one person, place, or thing and considers those people, places, or things one singular unit. Because collective nouns are counted as one, they are singular and require a singular verb. Some commonly used collective nouns are group, team, army, flock, family, and class.

Singular: The class is going on a field trip.

In this sentence, class is a collective noun. Although the class consists of many students, the class is treated as a singular unit and requires a singular verb form.

\section{The Subject Follows the Verb}

You may encounter sentences in which the subject comes after the verb instead of before the verb. In other words, the subject of the sentence may not appear where you expect it to appear. To ensure proper subject-verb agreement, you must correctly identify the subject and the verb.

\section{Here or There}

In sentences that begin with here or there, the subject follows the verb.

Here is my wallet!

There are thirty dolphins in the water.

If you have trouble identifying the subject and the verb in sentences that start with here or there; it may help to reverse the order of the sentence so the subject comes first.

My wallet is here!

Thirty dolphins are in the water. 


\section{Questions}

When you ask questions, a question word (who, what, where, when, why, or how) appears first. The verb and then the subject follow.

Who are the people you are related to?

When am I going to go to the grocery store?

Tip

If you have trouble finding the subject and the verb in questions, try answering the question being asked.

When am I going to the grocery store? I am going to the grocery store tonight!

\section{Exercise 3}

Correct the errors in subject-verb agreement in the following sentences. If there are no errors in subject-verb agreement, write $O K$. Copy the corrected sentence or the word $O K$ on your own sheet of notebook paper.

1. My dog and cats chases each other all the time.

2. The books that are in my library is the best I have ever read.

3. Everyone are going to the concert except me.

4. My family are moving to California.

5. Here is the lake I told you about.

6. There is the newspapers I was supposed to deliver. 
7. Which room is bigger?

8. When are the movie going to start?

9. My sister and brother cleans up after themselves.

10. Some of the clothes is packed away in the attic.

\section{Exercise 4}

Correct the errors in subject-verb agreement in the following paragraph. Copy the paragraph on a piece of notebook paper and make corrections.

Dear Hiring Manager,

I feels that I am the ideal candidate for the receptionist position at your company. I has three years of experience as a receptionist in a company that is similar to yours. My phone skills and written communication is excellent. These skills, and others that I have learned on the job, helps me understand that every person in a company helps make the business a success. At my current job, the team always say that I am very helpful. Everyone appreciate when I go the extra mile to get the job done right. My current employer and coworkers feels that I am an asset to the team. I is efficient and organized. Is there any other details about me that you would like to know? If so, please contact me. Here are my résumé. You can reach me by e-mail or phone. I looks forward to speaking with you in person.

Thanks,

Felicia Fellini

\section{Writing at Work}

Figure 2.5 Advertisement 


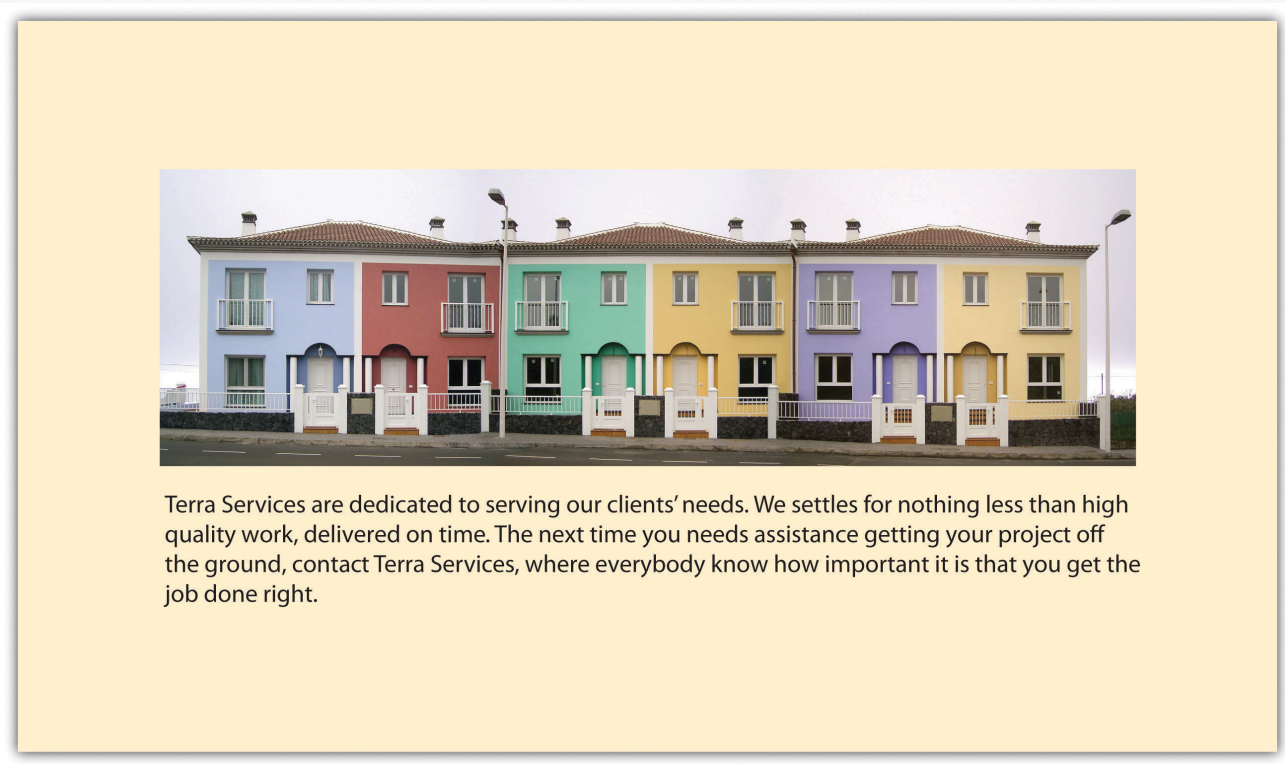

Imagine that you are a prospective client and that you saw this ad online. Would you call Terra Services to handle your next project? Probably not! Mistakes in subject-verb agreement can cost a company business. Paying careful attention to grammatical details ensures professionalism that clients will recognize and respect.

\section{Key Takeaways}

- Parts of sentences must agree in number, person, case, and gender.

- A verb must always agree with its subject in number. A singular subject requires a singular verb; a plural subject requires a plural verb.

- Irregular verbs do not follow a predictable pattern in their singular and plural forms. Common irregular verbs are to be, to have, and to do.

- A compound subject is formed when two or more nouns are joined by the words and, or, or nor.

- In some sentences, the subject and verb may be separated by a phrase or clause, but the verb must still agree with the subject.

- Indefinite pronouns, such as anyone, each, everyone, many, no one, and something, refer to unspecified people or objects. Most indefinite pronouns are singular.

- A collective noun is a noun that identifies more than one person, place, or thing and treats those people, places, or things one singular unit. Collective nouns require singular verbs.

- In sentences that begin with here and there, the subject follows the verb.

- In questions, the subject follows the verb. 


\section{Writing Application}

Use your knowledge of subject-verb agreement to write one of the following:

1. An advertisement for a potential company

2. A memo to all employees of a particular company

3. A cover letter describing your qualifications to a potential employer

Be sure to include at least the following:

- One collective noun

- One irregular verb

- One question 


\subsection{Verb Tense}

\section{Learning Objectives}

1. Use the correct regular verb tense in basic sentences.

2. Use the correct irregular verb tense in basic sentences.

Suppose you must give an oral presentation about what you did last summer. How do you make it clear that you are talking about the past and not about the present or the future? Using the correct verb tense can help you do this.

It is important to use the proper verb tense. Otherwise, your listener might judge you harshly. Mistakes in tense often leave a listener or reader with a negative impression.

\section{Regular Verbs}

Verbs indicate actions or states of being in the past, present, or future using tenses. Regular verbs follow regular patterns when shifting from the present to past tense. For example, to form a past-tense or pastparticiple verb form, add -ed or $-d$ to the end of a verb. You can avoid mistakes by understanding this basic pattern.

Verb tense identifies the time of action described in a sentence. Verbs take different forms to indicate different tenses. Verb tenses indicate

- an action or state of being in the present,

- an action or state of being in the past,

- an action or state of being in the future.

Helping verbs, such as be and have, also work to create verb tenses, such as the future tense.

Present Tense: Time walks to the store. (Singular subject)

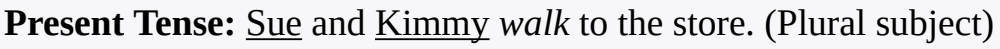

Past Tense: Yesterday, they walked to the store to buy some bread. (Singular subject) 


\section{Exercise 1}

Complete the following sentences by selecting the correct form of the verb in simple present, simple past, or simple future tenses. Write the corrected sentence on your own sheet of paper.

1. The Dust Bowl (is, was, will be) a name given to a period of very destructive dust storms that occurred in the United States during the 1930s.

2. Historians today (consider, considered, will consider) The Dust Bowl to be one of the worst weather of events in American history.

3. The Dust Bowl mostly (affects, affected, will affect) the states of Kansas, Colorado, Oklahoma, Texas, and New Mexico.

4. Dust storms (continue, continued, will continue) to occur in these dry regions, but not to the devastating degree of the 1930s.

5. The dust storms during The Dust Bowl (cause, caused, will cause) irreparable damage to farms and the environment for a period of several years.

6. When early settlers (move, moved, will move) into this area, they (remove, removed, will remove) the natural prairie grasses in order to plant crops and graze their cattle.

7. They did not (realize, realized, will realize) that the grasses kept the soil in place.

8. There (is, was, will be) also a severe drought that (affects, affected, will affect) the region.

9. The worst dust storm (happens, happened, will happen) on April 14, 1935, a day called Black Sunday.

10. The Dust Bowl era finally came to end in 1939 when the rains (arrive, arrived, will arrive).

11. Dust storms (continue, continued, will continue) to affect the region, but hopefully they will not be as destructive as the storms of the 1930s.

\section{Irregular Verbs}

The past tense of irregular verbs is not formed using the patterns that regular verbs follow. Study Table 2.1 "Irregular Verbs", which lists the most common irregular verbs.

\section{Tip}

The best way to learn irregular verbs is to memorize them. With the help of a classmate, create flashcards of irregular verbs and test yourselves until you master them. 


\begin{tabular}{|c|c|c|c|}
\hline Simple Present & Past & Simple Present & Past \\
\hline be & was, were & lose & lost \\
\hline become & became & make & made \\
\hline begin & began & mean & meant \\
\hline blow & blew & meet & met \\
\hline break & broke & pay & paid \\
\hline bring & brought & put & put \\
\hline build & built & quit & quit \\
\hline burst & burst & read & read \\
\hline buy & bought & ride & rode \\
\hline catch & caught & ring & rang \\
\hline choose & chose & rise & rose \\
\hline come & came & run & ran \\
\hline cut & cut & say & said \\
\hline dive & dove (dived) & see & saw \\
\hline do & did & seek & sought \\
\hline draw & drew & sell & sold \\
\hline drink & drank & send & sent \\
\hline drive & drove & set & set \\
\hline eat & ate & shake & shook \\
\hline fall & fell & shine & shone (shined) \\
\hline feed & fed & shrink & shrank (shrunk) \\
\hline feel & felt & sing & sang \\
\hline fight & fought & sit & sat \\
\hline find & found & sleep & slept \\
\hline fly & flew & speak & spoke \\
\hline forget & forgot & spend & spent \\
\hline forgive & forgave & spring & sprang \\
\hline freeze & froze & stand & stood \\
\hline get & got & steal & stole \\
\hline
\end{tabular}




\begin{tabular}{|l|l|l|l|}
\hline Simple Present & Past & Simple Present & Past \\
\hline give & gave & strike & struck \\
\hline go & went & swim & swam \\
\hline grow & grew & swing & swung \\
\hline have & heard & take & took \\
\hline hear & hid & tear & taught \\
\hline hide & held & tell & tore \\
\hline hold & hurt & think & told \\
\hline hurt & kept & throw & thought \\
\hline keep & knew & understand & understood \\
\hline know & laid & wake & woke \\
\hline lay & led & wear & wore \\
\hline lead & left & win & won \\
\hline leave & let & wind & wound \\
\hline let & & & \\
\hline & & & \\
\hline
\end{tabular}

Here we consider using irregular verbs.

Present Tense: Lauren keeps all her letters.

Past Tense: Lauren kept all her letters.

Future Tense: Lauren will keep all her letters.

\section{Exercise 2}

Complete the following sentences by selecting the correct form of the irregular verb in simple present, simple past, or simple future tense. Copy the corrected sentence onto your own sheet of paper.

1. Marina finally (forgived, forgave, will forgive) her sister for snooping around her room.

2. The house (shook, shaked, shakes) as the airplane rumbled overhead.

3. I (buyed, bought, buy) several items of clothing at the thrift store on Wednesday.

4. She (put, putted, puts) the lotion in her shopping basket and proceeded to the checkout line.

5. The prized goose (layed, laid, lay) several golden eggs last night.

6. Mr. Batista (teached, taught, taughted) the class how to use correct punctuation. 
7. I (drink, drank, will drink) several glasses of sparkling cider instead of champagne on New Year's Eve next year.

8. Although Hector (growed, grew, grows) three inches in one year, we still called him "Little Hector.”

9. Yesterday our tour guide (lead, led, will lead) us through the maze of people in Times Square.

10. The rock band (burst, bursted, bursts) onto the music scene with their catchy songs.

\section{Exercise 3}

On your own sheet of paper, write a sentence using the correct form of the verb tense shown below.

1. Throw (past)

2. Paint (simple present)

3. Smile (future)

4. Tell (past)

5. Share (simple present)

\section{Maintaining Consistent Verb Tense}

Consistent verb tense means the same verb tense is used throughout a sentence or a paragraph. As you write and revise, it is important to use the same verb tense consistently and to avoid shifting from one tense to another unless there is a good reason for the tense shift. In the following box, see whether you notice the difference between a sentence with consistent tense and one with inconsistent tense.

\section{Inconsistent tense:}

The crowd starts cheering as Melina approached the finish line.

\section{Consistent tense:}

The crowd started cheering as Melina approached the finish line.

\section{Consistent tense:}

The crowd starts cheering as Melina approaches the finish line. 


\section{Tip}

In some cases, clear communication will call for different tenses. Look at the following example:

When I was a teenager, I wanted to be a fire fighter, but not I am studying computer science.

If the time frame for each action or state is different, a tense shift is appropriate.

\section{Exercise 4}

Edit the following paragraph by correcting the inconsistent verb tense. Copy the corrected paragraph onto your own sheet of paper.

In the Middle Ages, most people lived in villages and work as agricultural laborers, or peasants. Every village has a "lord," and the peasants worked on his land. Much of what they produce go to the lord and his family. What little food was leftover goes to support the peasants' families. In return for their labor, the lord offers them protection. A peasant's day usually began before sunrise and involves long hours of backbreaking work, which includes plowing the land, planting seeds, and cutting crops for harvesting. The working life of a peasant in the Middle Ages is usually demanding and exhausting.

\section{Writing at Work}

Read the following excerpt from a work e-mail:

I would like to highlight an important concern that comes up after our meeting last week. During the meeting, we agree to conduct a series of interviews over the next several months in which we hired new customer service representatives. Before we do that, however, I would like to review your experiences with the Customer Relationship Management Program. Please suggest a convenient time next week for us to meet so that we can discuss this important matter.

The inconsistent tense in the e-mail will very likely distract the reader from its overall point. Most likely, your coworkers will not correct your verb tenses or call attention to grammatical errors, but it is important to keep in mind that errors such as these do have a subtle negative impact in the workplace. 


\section{Key Takeaways}

- Verb tense helps you express when an event takes place.

- Regular verbs follow regular patterns when shifting from present to past tense.

- Irregular verbs do not follow regular, predictable patterns when shifting from present to past tense.

- Using consistent verb tense is a key element to effective writing.

\section{Writing Application}

Tell a family story. You likely have several family stories to choose from, but pick the one that you find most interesting to write about. Use as many details as you can in the telling. As you write and proofread, make sure your all your verbs are correct and the tenses are consistent. 


\subsection{Capitalization}

\section{Learning Objectives}

1. Learn the basic rules of capitalization.

2. Identify common capitalization errors.

Text messages, casual e-mails, and instant messages often ignore the rules of capitalization. In fact, it can seem unnecessary to capitalize in these contexts. In other, more formal forms of communication, however, knowing the basic rules of capitalization and using capitalization correctly gives the reader the impression that you choose your words carefully and care about the ideas you are conveying.

\section{Capitalize the First Word of a Sentence}

Incorrect: the museum has a new butterfly exhibit.

Correct: The museum has a new butterfly exhibit.

Incorrect: cooking can be therapeutic.

Correct: Cooking can be therapeutic.

\section{Capitalize Proper Nouns}

Proper nouns - the names of specific people, places, objects, streets, buildings, events, or titles of individuals — are always capitalized.

Incorrect: He grew up in harlem, new york.

Correct: He grew up in $\underline{\text { Harlem, }} \underline{\text { New }} \underline{\text { York. }}$

Incorrect: The sears tower in chicago has a new name.

Correct: The Sears $\underline{\text { Tower in }}$ Chicago has a new name. 
Tip

Always capitalize nationalities, races, languages, and religions. For example, American, African American, Hispanic, Catholic, Protestant, Jewish, Muslim, Hindu, Buddhist, and so on.

Do not capitalize nouns for people, places, things, streets, buildings, events, and titles when the noun is used in general or common way. See the following chart for the difference between proper nouns and common nouns.

\begin{tabular}{|l|l|}
\hline Common Noun & Proper Noun \\
\hline museum & The Art Institute of Chicago \\
\hline theater & Apollo Theater \\
\hline country & Malaysia \\
\hline uncle & Uncle Javier \\
\hline doctor & Dr. Jackson \\
\hline book & Pride and Prejudice \\
\hline college & Smith College \\
\hline war & the Spanish-American War \\
\hline historical event & The Renaissance \\
\hline
\end{tabular}

\section{Exercise 1}

On your own sheet of paper, write five proper nouns for each common noun that is listed. The first one has been done for you.

Common noun: river

1. Nile River

2.

3.

4.

5.

Common noun: musician

1. 
2.

3.

4.

5.

Common noun: magazine

1.

2.

3.

4.

5.

\section{Collaboration}

Please share with a classmate and compare your answers.

\section{Capitalize Days of the Week, Months of the Year, and Holidays}

Incorrect: On wednesday, I will be traveling to Austin for a music festival.

Correct: On Wednesday, I will be traveling to Austin for a music festival.

Incorrect: The fourth of july is my favorite holiday.

Correct: The Fourth of July is my favorite holiday.

\section{Capitalize Titles}

Incorrect: The play, fences, by August Wilson is one of my favorites.

Correct: The play, Fences, by August Wilson is one of my favorites.

Incorrect: The president of the united states will be speaking at my university.

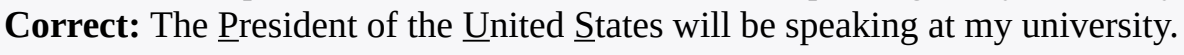

Tip

Computer-related words such as "Internet" and "World Wide Web” are usually capitalized; however, "e-mail” and "online” are never capitalized. 


\section{Exercise 2}

Edit the following sentences by correcting the capitalization of the titles or names.

1. The prince of england enjoys playing polo.

2. "Ode to a nightingale" is a sad poem.

3. My sister loves to read magazines such as the new yorker.

4. The house on Mango street is an excellent novel written by Sandra Cisneros.

5. My physician, dr. alvarez, always makes me feel comfortable in her office.

\section{Exercise 3}

Edit the following paragraphs by correcting the capitalization.

david grann's the lost City of $Z$ mimics the snake-like winding of the amazon River. The three distinct Stories that are introduced are like twists in the River. First, the Author describes his own journey to the amazon in the present day, which is contrasted by an account of percy fawcett's voyage in 1925 and a depiction of James Lynch's expedition in 1996. Where does the river lead these explorers? the answer is one that both the Author and the reader are hungry to discover.

The first lines of the preface pull the reader in immediately because we know the author, david grann, is lost in the amazon. It is a compelling beginning not only because it's thrilling but also because this is a true account of grann's experience. grann has dropped the reader smack in the middle of his conflict by admitting the recklessness of his decision to come to this place. the suspense is further perpetuated by his unnerving observation that he always considered himself A Neutral Witness, never getting personally involved in his stories, a notion that is swiftly contradicted in the opening pages, as the reader can clearly perceive that he is in a dire predicament-and frighteningly involved.

\section{Writing at Work}

Did you know that, if you use all capital letters to convey a message, the capital letters come across like shouting? In addition, all capital letters are actually more difficult to read and may annoy the reader. To avoid "shouting" at or annoying your reader, follow the rules of capitalization and find other ways to emphasize your point. 


\section{Key Takeaways}

- Learning and applying the basic rules of capitalization is a fundamental aspect of good writing.

- Identifying and correcting errors in capitalization is an important writing skill.

\section{Writing Application}

Write a one-page biography. Make sure to identify people, places, and dates and use capitalization correctly. 


\subsection{Pronouns}

\section{Learning Objectives}

1. Identify pronouns and their antecedents.

2. Use pronouns and their antecedents correctly.

If there were no pronouns, all types of writing would be quite tedious to read. We would soon be frustrated by reading sentences like Bob said that Bob was tired or Christina told the class that Christina received an $A$. Pronouns help a writer avoid constant repetition. Knowing just how pronouns work is an important aspect of clear and concise writing.

\section{Pronoun Agreement}

A pronoun is a word that takes the place of (or refers back to) a noun or another pronoun. The word or words a pronoun refers to is called the antecedent of the pronoun.

1. Lani complained that she was exhausted.

- She refers to Lani.

- Lani is the antecedent of she.

2. Jeremy left the party early, so I did not see him until Monday at work.

- Him refers to Jeremy.

- Jeremy is the antecedent of him.

3. Crina and Rosalie have been best friends ever since they were freshman in high school.

- They refers to Crina and Rosalie.

- Crina and Rosalie is the antecedent of they.

Pronoun agreement errors occur when the pronoun and the antecedent do not match or agree with each other. There are several types of pronoun agreement. 


\section{Agreement in Number}

If the pronoun takes the place of or refers to a singular noun, the pronoun must also be singular.

Incorrect: If a student (sing.) wants to return a book to the bookstore, they (plur.) must have a receipt.

Correct: If a student (sing.) wants to return a book to the bookstore, he or she (sing.) must have a receipt.

*If it seems too wordy to use he or she, change the antecedent to a plural noun.

Correct: If students (plur.) want to return a book to the bookstore, they (plur.) must have a receipt.

\section{Agreement in Person}

\begin{tabular}{|l|l|l|l|l|l|l|l|}
\hline \multicolumn{4}{|c|}{ Singular Pronouns } & \multicolumn{3}{c|}{ Plural Pronouns } \\
\hline First Person & I & me & my (mine) & we & us & our (ours) \\
\hline Second Person & you & you & your (yours) & you & you & your (your) \\
\hline Third Person & he, she, it & him, her, it & his, her, its & they & them & their (theirs) \\
\hline
\end{tabular}

If you use a consistent person, your reader is less likely to be confused.

Incorrect: When a person (3rd) goes to a restaurant, you (2nd) should leave a tip.

Correct: When a person (3rd) goes to a restaurant, he or she (3rd) should leave a tip.

Correct: When we (1st) go to a restaurant, I should (1st) should leave a tip.

\section{Exercise 1}

Edit the following paragraph by correcting pronoun agreement errors in number and person.

Over spring break I visited my older cousin, Diana, and they took me to a butterfly exhibit at a museum. Diana and I have been close ever since she was young. Our mothers are twin sisters, and she is inseparable! Diana knows how much I love butterflies, so it was their special present to me. I have a soft spot for caterpillars too. I love them because something about the way it transforms is so interesting to me. One summer my grandmother gave me a butterfly growing kit, and you got to see the entire life cycle of five Painted Lady butterflies. I even got to set it free. So when my cousin said they wanted to take me to the butterfly exhibit, I was really excited! 


\section{Indefinite Pronouns and Agreement}

Indefinite pronouns do not refer to a specific person or thing and are usually singular. Note that a pronoun that refers to an indefinite singular pronoun should also be singular. The following are some common indefinite pronouns.

\begin{tabular}{|l|l|l|l|l|}
\hline \multicolumn{5}{|l}{ Common Indefinite Pronouns } \\
\hline all & each one & few & nothing & several \\
\hline any & each other & many & one & some \\
\hline anybody & either & neither & one another & somebody \\
\hline anything & everybody & nobody & oneself & someone \\
\hline both & everyone & none & other & something \\
\hline each & everything & no one & others & anyone \\
\hline
\end{tabular}

\section{Indefinite pronoun agreement}

Incorrect: Everyone (sing.) should do what they (plur.) can to help.

Correct: Everyone (sing.) should do what he or she (sing.) can to help.

Incorrect: Someone (sing.) left their (plur.) backpack in the library.

Correct: Someone (sing.) left his or her (sing.) backpack in the library.

\section{Collective Nouns}

Collective nouns suggest more than one person but are usually considered singular. Look over the following examples of collective nouns.

\begin{tabular}{|l|l|l|}
\hline \multicolumn{3}{|c|}{ Common Collective Nouns } \\
\hline audience & faculty & public \\
\hline band & family & school \\
\hline class & government & society \\
\hline committee & group & team \\
\hline company & jury & tribe \\
\hline
\end{tabular}

\section{Collective noun agreement}


Incorrect: Lara's company (sing.) will have their (plur.) annual picnic next week.

Correct: Lara's company (sing.) will have its (sing.) annual picnic next week.

Complete the following sentences by selecting the correct pronoun. Copy the completed sentence onto your own sheet of paper. Then circle the noun the pronoun replaces.

1. In the current economy, nobody wants to waste money on frivolous things.

2. If anybody chooses to go to medical school, must be prepared to work long hours.

3. The plumbing crew did best to repair the broken pipes before the next ice storm.

4. If someone is rude to you, try giving a smile in return.

5. My family has faults, but I still love them no matter what.

6. The school of education plans to train students to be literacy tutors.

7. The commencement speaker said that each student has a responsibility toward

8. My mother's singing group has rehearsals on Thursday evenings.

9. No one should suffer pains alone.

10. I thought the flock of birds lost way in the storm.

\section{Subject and Object Pronouns}

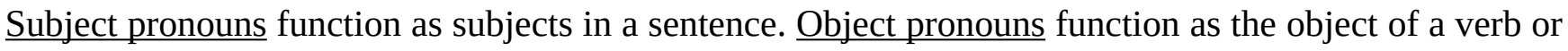
of a preposition.

\begin{tabular}{|c|c|c|c|}
\hline \multicolumn{2}{|c|}{ Singular Pronouns } & \multicolumn{2}{|c|}{ Plural Pronouns } \\
\hline Subject & Object & Subject & Object \\
\hline $\mathrm{I}$ & me & we & us \\
\hline you & you & you & you \\
\hline he, she, it & him, her, it & they & them \\
\hline
\end{tabular}

The following sentences show pronouns as subjects:

1. She loves the Blue Ridge Mountains in the fall.

2. Every summer, they picked up litter from national parks. 
The following sentences show pronouns as objects:

1. Marie leaned over and kissed him.

2. Jane moved it to the corner.

\section{Tip}

Note that a pronoun can also be the object of a preposition.

Near them, the children played.

My mother stood between us.

The pronouns us and them are objects of the prepositions near and between. They answer the questions near whom? And between whom?

Compound subject pronouns are two or more pronouns joined by a conjunction or a preposition that function as the subject of the sentence.

The following sentences show pronouns with compound subjects:

Incorrect: Me and Harriet visited the Grand Canyon last summer.

Correct: Harriet and I visited the Grand Canyon last summer.

Correct: Jenna accompanied Harriet and me on our trip.

Tip

Note that object pronouns are never used in the subject position. One way to remember this rule is to remove the other subject in a compound subject, leave only the pronoun, and see whether the sentence makes sense. For example, Me visited the Grand Canyon last summer sounds immediately incorrect.

Compound object pronouns are two or more pronouns joined by a conjunction or a preposition that function as the object of the sentence.

Incorrect: I have a good feeling about Janice and I.

Correct: I have a good feeling about Janice and me. 


\section{Tip}

It is correct to write Janice and me, as opposed to me and Janice. Just remember it is more polite to refer to yourself last.

\section{Writing at Work}

In casual conversation, people sometimes mix up subject and object pronouns. For instance, you might say, "Me and Donnie went to a movie last night." However, when you are writing or speaking at work or in any other formal situation, you need to remember the distinctions between subject and object pronouns and be able to correct yourself. These subtle grammar corrections will enhance your professional image and reputation.

\section{Exercise 3}

Revise the following sentences in which the subject and object pronouns are used incorrectly. Copy the revised sentence onto your own sheet of paper. Write a $\mathrm{C}$ for each sentence that is correct.

1. Meera and me enjoy doing yoga together on Sundays.

2. She and him have decided to sell their house.

3. Between you and I, I do not think Jeffrey will win the election.

4. Us and our friends have game night the first Thursday of every month.

5. They and I met while on vacation in Mexico.

6. Napping on the beach never gets boring for Alice and I.

7. New Year's Eve is not a good time for she and I to have a serious talk. 
8. You exercise much more often than me.

9. I am going to the comedy club with Yolanda and she.

10. The cooking instructor taught her and me a lot.

\section{Who versus Whom}

Who or whoever is always the subject of a verb. Use who or whoever when the pronoun performs the action indicated by the verb.

Who won the marathon last Tuesday?

I wonder who came up with that terrible idea!

On the other hand, whom and whomever serve as objects. They are used when the pronoun does not perform an action. Use whom or whomever when the pronoun is the direct object of a verb or the object of a preposition.

Whom did Frank marry the third time? (direct object of verb)

From whom did you buy that old record player? (object of preposition)

\section{Tip}

If you are having trouble deciding when to use who and whom, try this trick. Take the following sentence:

Who/Whom do I consider my best friend?

Reorder the sentence in your head, using either he or him in place of who or whom.

I consider him my best friend.

I consider he my best friend.

Which sentence sounds better? The first one, of course. So the trick is, if you can use him, you should use 
whom.

\section{Exercise 4}

Complete the following sentences by adding who or whom. Copy the completed sentence onto your own sheet of paper.

1. hit the home run?

2. I remember won the Academy Award for Best Actor last year.

3. To is the letter addressed?

4. I have no idea left the iron on, but I am going to find out.

5. are you going to recommend for the internship?

6. With are you going to Hawaii?

7. No one knew the famous actor was.

8. in the office knows how to fix the copy machine?

9. From did you get the concert tickets?

10. No one knew ate the cake mom was saving.

\section{Key Takeaways}

- Pronouns and their antecedents need to agree in number and person.

- Most indefinite pronouns are singular.

- Collective nouns are usually singular.

- Pronouns can function as subjects or objects.

- Subject pronouns are never used as objects, and object pronouns are never used as subjects.

- Who serves as a subject of a verb.

- Whom serves as an object of a sentence or the object of a preposition.

\section{Writing Application}

Write about what makes an ideal marriage or long-term relationship. Provide specific details to back up your assertions. After you have written a few paragraphs, go back and proofread your paper for correct pronoun 
Writing for Success 88

usage. 


\subsection{Adjectives and Adverbs}

\section{Learning Objectives}

1. Identify adjectives and adverbs.

2. Use adjectives and adverbs correctly.

Adjectives and adverbs are descriptive words that bring your writing to life.

\section{Adjectives and Adverbs}

An adjective is a word that describes a noun or a pronoun. It often answers questions such as which one, what kind, or how many?

1. The green sweater belongs to Iris.

2. She looks beautiful.

- In sentence 1 , the adjective green describes the noun sweater.

- In sentence 2, the adjective beautiful describes the pronoun she.

An adverb is a word that describes a verb, an adjective, or another adverb. Adverbs frequently end in -ly. They answer questions such as how, to what extent, why, when, and where.

3. Bertrand sings horribly.

4. My sociology instructor is extremely wise.

5. He threw the ball very accurately.

- In sentence 3, horribly describes the verb sings. How does Bertrand sing? He sings horribly.

- In sentence 4, extremely describes the adjective wise. How wise is the instructor? Extremely wise.

- In sentence 5, very describes the adverb accurately. How accurately did he throw the ball? Very accurately. 


\section{Exercise 1}

Complete the following sentences by adding the correct adjective or adverb from the list in the previous section. Identify the word as an adjective or an adverb (Adj, Adv).

1. Frederick choked on the piece of chicken when he saw Margaret walk through the door.

2. His eyes looked at everyone and everything as if they were specimens in a biology lab.

3. Despite her pessimistic views on life, Lauren believes that most people have hearts.

4. Although Stefan took the criticism he remained calm.

5. The child developed a imagination because he read a lot of books.

6. Madeleine spoke while she was visiting her grandmother in the hospital.

7. Hector's most possession was his father's bass guitar from the 1970s.

8. My definition of a afternoon is walking to the park on a beautiful day, spreading out my blanket, and losing myself in a good book.

9. She eyed her new coworker and wondered if he was single.

10. At the party, Denise devoured two pieces of pepperoni pizza and a several slices of ripe watermelon.

\section{Comparative versus Superlative}

Comparative adjectives and adverbs are used to compare two people or things.

1. Jorge is thin.

2. Steven is thinner than Jorge.

- Sentence 1 describes Jorge with the adjective thin.

- Sentence 2 compares Jorge to Steven, stating that Steven is thinner. So thinner is the comparative form of thin.

Form comparatives in one of the following two ways:

1. If the adjective or adverb is a one syllable word, add -er to it to form the comparative. For example, big, fast, and short would become bigger, faster, and shorter in the comparative form.

2. If the adjective or adverb is a word of two or more syllables, place the word more in front of it to form the comparative. For example, happily, comfortable, and jealous would become more happily, more comfortable, and more jealous in the comparative. 
Superlative adjectives and adverbs are used to compare more than two people or two things.

1. Jackie is the loudest cheerleader on the squad.

2. Kenyatta was voted the most confident student by her graduating class.

- Sentence 1 shows that Jackie is not just louder than one other person, but she is the loudest of all the cheerleaders on the squad.

- Sentence 2 shows that Kenyatta was voted the most confident student of all the students in her class.

Form superlatives in one of the following two ways:

1. If the adjective or adverb is a one-syllable word, add -est to form the superlative. For example, big, fast, and short would become biggest, fastest, and shortest in the superlative form.

2. If the adjective or adverb is a word of two or more syllables, place the word most in front of it. For example, happily, comfortable, and jealous would become most happily, most comfortable, and most jealous in the superlative form.

\section{Tip}

Remember the following exception: If the word has two syllables and ends in $-y$, change the $-y$ to an $-i$ and add -est. For example, happy would change to happiest in the superlative form; healthy would change to healthiest.

\section{Exercise 2}

Edit the following paragraph by correcting the errors in comparative and superlative adjectives.

Our argument started on the most sunny afternoon that I have ever experienced. Max and I were sitting on my front stoop when I started it. I told him that my dog, Jacko, was more smart than his dog, Merlin. I could not help myself. Merlin never came when he was called, and he chased his tail and barked at rocks. I told Max that Merlin was the most dumbest dog on the block. I guess I was angrier about a bad grade that I received, so I decided to pick on poor little Merlin. Even though Max insulted Jacko too, I felt I had been more mean. The next day I apologized to Max and brought Merlin some of Jacko's treats. When Merlin placed his paw on my knee and licked my hand, I was the most sorry person on the block.

Collaboration

Share and compare your answers with a classmate. 


\section{Irregular Words: Good, Well, Bad, and Badly}

Good, well, bad, and badly are often used incorrectly. Study the following chart to learn the correct usage of these words and their comparative and superlative forms.

\begin{tabular}{|l|l|l|l|}
\hline \multicolumn{2}{|c|}{ Comparative } & Superlative \\
\hline Adjective & good & better & best \\
\hline Adverb & well & better & best \\
\hline Adjective & bad & worse & worst \\
\hline Adverb & badly & worse & worst \\
\hline
\end{tabular}

\section{Good versus Well}

Good is always an adjective- - that is, a word that describes a noun or a pronoun. The second sentence is correct because well is an adverb that tells how something is done.

Incorrect: Cecilia felt that she had never done so good on a test.

Correct: Cecilia felt that she had never done so well on a test.

Well is always an adverb that describes a verb, adverb, or adjective. The second sentence is correct because good is an adjective that describes the noun score.

Incorrect: Cecilia's team received a well score.

Correct: Cecilia’s team received a good score.

\section{Bad versus Badly}

Bad is always an adjective. The second sentence is correct because badly is an adverb that tells how the speaker did on the test. 
Incorrect: I did bad on my accounting test because I didn’t study.

Correct: I did badly on my accounting test because I didn’t study.

Badly is always an adverb. The second sentence is correct because bad is an adjective that describes the noun thunderstorm.

Incorrect: The coming thunderstorm looked badly.

Correct: The coming thunderstorm looked bad.

\section{Better and Worse}

The following are examples of the use of better and worse:

Tyra likes sprinting better than long distance running.

The traffic is worse in Chicago than in Atlanta.

\section{Best and Worst}

The following are examples of the use of best and worst:

Tyra sprints best of all the other competitors.

Peter finished worst of all the runners in the race.

\section{Tip}

Remember better and worse compare two persons or things. Best and worst compare three or more persons or things. 


\section{Exercise 3}

Write good, well, bad, or badly to complete each sentence. Copy the completed sentence onto your own sheet of paper.

1. Donna always felt if she did not see the sun in the morning.

2. The school board president gave a speech for once.

3. Although my dog, Comet, is mischievous, he always behaves at the dog park.

4. I thought my back injury was at first, but it turned out to be minor.

5. Steve was shaking from the extreme cold.

6. Apple crisp is a very dessert that can be made using whole grains instead of white flour.

7. The meeting with my son's math teacher went very

8. Juan has a appetite, especially when it comes to dessert.

9. Magritte thought the guests had a time at the party because most people left early.

10. She wanted to win the writing contest prize, which included a trip to New York.

\section{Exercise 4}

Write the correct comparative or superlative form of the word in parentheses. Copy the completed sentence onto your own sheet of paper.

1. This research paper is (good) than my last one.

2. Tanaya likes country music (well) of all.

3. My motorcycle rides (bad) than it did last summer.

4. That is the (bad) joke my father ever told.

5. The hockey team played (badly) than it did last season.

6. Tracey plays guitar (well) than she plays the piano.

7. It will go down as one of the (bad) movies I have ever seen.

8. The deforestation in the Amazon is (bad) than it was last year.

9. Movie ticket sales are (good) this year than last.

10. My husband says mystery novels are the (good) types of books. 


\section{Writing at Work}

The irregular words good, well, bad, and badly are often misused along with their comparative and superlative forms better, best, worse, and worst. You may not hear the difference between worse and worst, and therefore type it incorrectly. In a formal or business-like tone, use each of these words to write eight separate sentences. Assume these sentences will be seen and judged by your current or future employer.

\section{Key Takeaways}

- Adjectives describe a noun or a pronoun.

- Adverbs describe a verb, adjective, or another adverb.

- Most adverbs are formed by adding -ly to an adjective.

- Comparative adjectives and adverbs compare two persons or things.

- Superlative adjectives or adverbs compare more than two persons or things.

- The adjectives good and bad and the adverbs well and badly are unique in their comparative and superlative forms and require special attention.

\section{Writing Application}

Using the exercises as a guide, write your own ten-sentence quiz for your classmate(s) using the concepts covered in this section. Try to include two questions from each subsection in your quiz. Exchange papers and see whether you can get a perfect score. 


\subsection{Misplaced and Dangling Modifiers}

\section{Learning Objectives}

1. Identify modifiers.

2. Learn how to correct misplaced and dangling modifiers.

A modifier is a word, phrase, or clause that clarifies or describes another word, phrase, or clause. Sometimes writers use modifiers incorrectly, leading to strange and unintentionally humorous sentences. The two common types of modifier errors are called misplaced modifiers and dangling modifiers. If either of these errors occurs, readers can no longer read smoothly. Instead, they become stumped trying to figure out what the writer meant to say. A writer's goal must always be to communicate clearly and to avoid distracting the reader with strange sentences or awkward sentence constructions. The good news is that these errors can be easily overcome.

\section{Misplaced Modifiers}

A misplaced modifier is a modifier that is placed too far from the word or words it modifies. Misplaced modifiers make the sentence awkward and sometimes unintentionally humorous.

Incorrect: She wore a bicycle helmet on her head that was too large.

Correct: She wore a bicycle helmet that was too large on her head.

- Notice in the incorrect sentence it sounds as if her head was too large! Of course, the writer is referring to the helmet, not to the person's head. The corrected version of the sentence clarifies the writer's meaning.

Look at the following two examples:

Incorrect: They bought a kitten for my brother they call Shadow.

Correct: They bought a kitten they call Shadow for my brother. 
- In the incorrect sentence, it seems that the brother's name is Shadow. That's because the modifier is too far from the word it modifies, which is kitten.

Incorrect: The patient was referred to the physician with stomach pains.

Correct: The patient with stomach pains was referred to the physician.

- The incorrect sentence reads as if it is the physician who has stomach pains! What the writer means is that the patient has stomach pains.

\section{Tip}

Simple modifiers like only, almost, just, nearly, and barely often get used incorrectly because writers often stick them in the wrong place.

Confusing: Tyler almost found fifty cents under the sofa cushions.

Repaired: Tyler found almost fifty cents under the sofa cushions.

- How do you almost find something? Either you find it or you do not. The repaired sentence is much clearer.

\section{Exercise 1}

On a separate sheet of paper, rewrite the following sentences to correct the misplaced modifiers.

1. The young lady was walking the dog on the telephone.

2. I heard that there was a robbery on the evening news.

3. Uncle Louie bought a running stroller for the baby that he called "Speed Racer."

4. Rolling down the mountain, the explorer stopped the boulder with his powerful foot.

5. We are looking for a babysitter for our precious six-year-old who doesn't drink or smoke and owns a car.

6. The teacher served cookies to the children wrapped in aluminum foil.

7. The mysterious woman walked toward the car holding an umbrella.

8. We returned the wine to the waiter that was sour.

9. Charlie spotted a stray puppy driving home from work.

10. I ate nothing but a cold bowl of noodles for dinner. 


\section{Dangling Modifiers}

A dangling modifier is a word, phrase, or clause that describes something that has been left out of the sentence. When there is nothing that the word, phrase, or clause can modify, the modifier is said to dangle.

Incorrect: Riding in the sports car, the world whizzed by rapidly.

Correct: As Jane was riding in the sports car, the world whizzed by rapidly.

- In the incorrect sentence, riding in the sports car is dangling. The reader is left wondering who is riding in the sports car. The writer must tell the reader!

Incorrect: Walking home at night, the trees looked like spooky aliens.

Correct: As Jonas was walking home at night, the trees looked like spooky aliens.

Correct: The trees looked like spooky aliens as Jonas was walking home at night.

- In the incorrect sentence walking home at night is dangling. Who is walking home at night? Jonas. Note that there are two different ways the dangling modifier can be corrected.

Incorrect: To win the spelling bee, Luis and Gerard should join our team.

Correct: If we want to win the spelling bee this year, Luis and Gerard should join our team.

- In the incorrect sentence, to win the spelling bee is dangling. Who wants to win the spelling bee? We do!

Tip

The following three steps will help you quickly spot a dangling modifier:

1. Look for an -ing modifier at the beginning of your sentence or another modifying phrase:

Painting for three hours at night, the kitchen was finally finished by Maggie. (Painting is the -ing modifier.)

2. Underline the first noun that follows it: 
Painting for three hours at night, the kitchen was finally finished by Maggie.

3. Make sure the modifier and noun go together logically. If they do not, it is very likely you have a dangling modifier.

After identifying the dangling modifier, rewrite the sentence.

Painting for three hours at night, Maggie finally finished the kitchen.

\section{Exercise 2}

Rewrite the following the sentences onto your own sheet of paper to correct the dangling modifiers.

1. Bent over backward, the posture was very challenging.

2. Making discoveries about new creatures, this is an interesting time to be a biologist.

3. Walking in the dark, the picture fell off the wall.

4. Playing a guitar in the bedroom, the cat was seen under the bed.

5. Packing for a trip, a cockroach scurried down the hallway.

6. While looking in the mirror, the towel swayed in the breeze.

7. While driving to the veterinarian's office, the dog nervously whined.

8. The priceless painting drew large crowds when walking into the museum.

9. Piled up next to the bookshelf, I chose a romance novel.

10. Chewing furiously, the gum fell out of my mouth.

\section{Exercise 3}

Rewrite the following paragraph correcting all the misplaced and dangling modifiers.

I bought a fresh loaf of bread for my sandwich shopping in the grocery store. Wanting to make a delicious sandwich, the mayonnaise was thickly spread. Placing the cold cuts on the bread, the lettuce was placed on top. I cut the sandwich in half with a knife turning on the radio. Biting into the sandwich, my favorite song blared loudly in my ears. Humming and chewing, my sandwich went down smoothly. Smiling, my sandwich will be made again, but next time I will add cheese.

\section{Collaboration}

Please share with a classmate and compare your answers. 


\section{Key Takeaways}

- Misplaced and dangling modifiers make sentences difficult to understand.

- Misplaced and dangling modifiers distract the reader.

- There are several effective ways to identify and correct misplaced and dangling modifiers.

\section{Writing Application}

See how creative and humorous you can get by writing ten sentences with misplaced and dangling modifiers. This is a deceptively simple task, but rise to the challenge. Your writing will be stronger for it. Exchange papers with a classmate, and rewrite your classmate's sentences to correct any misplaced modifiers. 


\subsection{Writing Basics: End-of-Chapter Exercises}

\section{Learning Objectives}

1. Use the skills you have learned in the chapter.

2. Work collaboratively with other students.

\section{Exercises}

1. On your own sheet of paper, identify each sentence as a fragment, a run-on, or correct (no error). Then rewrite the paragraph by correcting the sentence fragments and run-ons.

My favorite book is Brave New World by Aldous Huxley, he was born in 1894 and died in 1963 . Written in 1931 . A futuristic society where humans are born out of test tubes and kept in rigid social classes . This may not seem like a humorous premise for a novel, but Huxley uses satire, which is a type of humor that is used to make a serious point . The humans in Brave New World learn through sleep teaching, Huxley calls this "hypnopedia" . Everyone is kept "happy" in the brave new world by taking a pill called soma, there is one character named John the Savage who does not take soma __ because he comes from a different part of the world where there is no technology, and he believes in natural ways of living big problem with the brave new world and how people live there It turns out that John has a to survive living there, well you will have to read the novel to find out Will he be able World is considered a classic in English literature, it is one of the best novels I have ever read

2. Each sentence contains an error in subject-verb agreement, irregular verb form, or consistent verb tense. Identify the type of error. Then, on your own sheet of paper, rewrite the sentence correctly.

a. Maria and Ty meets me at the community center for cooking classes on Tuesdays.

b. John's ability to laugh at almost anything amaze me.

c. Samantha and I were walking near the lake when the large, colorful bird appears.

d. I builded my own telescope using materials I bought at the hardware store. 
e. My mother freezed the remaining tomatoes from her garden so that she could use them during the winter.

f. Bernard asked the stranger sitting next to him for the time, and she says it was past midnight.

g. My mother and brother wears glasses, but my father and sister do not.

h. We held our noses as the skunk runs away.

i. Neither Soren nor Andrew are excited about the early morning swim meet.

j. My hands hurted at the thought of transcribing all those notes.

k. The police questioned the suspect for hours but she gives them no useful information.

l. Terry takes short weekend trips because her job as a therapist was very emotionally draining.

m. She criticize delicately, making sure not to hurt anyone’s feelings.

n. Davis winded the old clock and set it atop his nightstand.

o. Cherie losed four poker hands in a row before realizing that she was playing against professionals.

p. Janis and Joan describes their trip to the Amazon in vivid detail.

q. You should decides for yourself whether or not to reduce the amount of processed foods in your diet.

r. The oil rig exploded and spills millions of gallons of oil into the ocean.

s. The handsome vampire appeared out of nowhere and smiles at the smitten woman.

t. The batter swinged at the ball several times but never hit it. 
3. Correct the capitalization errors in the following fictional story. Copy the corrected paragraph onto your own sheet of paper.

lance worthington signed a Recording Contract with Capitol records on june 15, 2007. Despite selling two million copies of his Debut Album, nothing to lose, lance lost quite a bit as his tax returns from the irs revealed. lance did not think it was fair that the Record Company kept so much of his earnings, so he decided to hire robert bergman, a prominent music Attorney with a Shark-like reputation. bergman represented lance all the way to the supreme court, where lance won the case against capitol records. Lance worthington was instrumental in changing intellectual property rights and long standing Record Company practices. All artists and musicians can thank him for his brave stance against record companies. Lance subsequently formed his own independent record label called worthy records. worthy is now a successful Label based out of chicago, illinois, and its Artists have appeared on well known shows such as The tonight show and Saturday night live. Lance worthington is a model for success in the do-it-yourself World that has become the Music Industry.

Collaboration

Please share with a classmate and compare your answers.

4. Complete the following sentences by selecting the correct comparative or superlative adjective or adverb. Then copy the completed sentence onto your own sheet of paper.

a. Denise has a (cheerful) ___ outlook on life than her husband.

b. I don't mean to brag, but I think I am the (good)___ cook in my family.

c. Lydia is the (thoughtful) person I know.

d. Italy experienced the (bad)___ heat wave in its history last year.

e. My teacher, Ms. Beckett, is the (strange) ___ person I know, and I like that.

f. Dorian's drawing skills are (good) ___ this semester than last.

g. My handwriting is the (sloppy)___ of all my classmates.

h. Melvin's soccer team played (badly) ___ than it did last season.

i. Josie's pen writes (smooth) ___ than mine.

j. I felt (lucky) ___ than my sister because I got in to the college of my choice. 


\section{Chapter 3: Punctuation}

\subsection{Commas}

3.2 Semicolons

3.3 Colons

3.4 Quotes

3.5 Apostrophes

3.6 Parentheses

3.7 Dashes

3.8 Hyphens

3.9 Punctuation: End-of-Chapter Exercises 


\subsection{Commas}

\section{Learning Objectives}

1. Identify the uses of commas.

2. Correctly use commas in sentences.

One of the punctuation clues to reading you may encounter is the comma. The comma is a punctuation mark that indicates a pause in a sentence or a separation of things in a list. Commas can be used in a variety of ways. Look at some of the following sentences to see how you might use a comma when writing a sentence.

- Introductory word: Personally, I think the practice is helpful.

- Lists: The barn, the tool shed, and the back porch were destroyed by the wind.

- Coordinating adjectives: He was tired, hungry, and late.

- Conjunctions in compound sentences: The bedroom door was closed, so the children knew their mother was asleep.

- Interrupting words: I knew where it was hidden, of course, but I wanted them to find it themselves.

- Dates, addresses, greetings, and letters: The letter was postmarked December 8, 1945.

\section{Commas after an Introductory Word or Phrase}

You may notice a comma that appears near the beginning of the sentence, usually after a word or phrase. This comma lets the reader know where the introductory word or phrase ends and the main sentence begins.

Without spoiling the surprise, we need to tell her to save the date.

In this sentence, without spoiling the surprise is an introductory phrase, while we need to tell her to save the date is the main sentence. Notice how they are separated by a comma. When only an introductory word appears in the sentence, a comma also follows the introductory word. 
Ironically, she already had plans for that day.

\section{Exercise 1}

Look for the introductory word or phrase. On your own sheet of paper, copy the sentence and add a comma to correct the sentence.

1. Suddenly the dog ran into the house.

2. In the blink of an eye the kids were ready to go to the movies.

3. Confused he tried opening the box from the other end.

4. Every year we go camping in the woods.

5. Without a doubt green is my favorite color.

6. Hesitating she looked back at the directions before proceeding.

7. Fortunately the sleeping baby did not stir when the doorbell rang.

8. Believe it or not the criminal was able to rob the same bank three times.

\section{Commas in a List of Items}

When you want to list several nouns in a sentence, you separate each word with a comma. This allows the reader to pause after each item and identify which words are included in the grouping. When you list items in a sentence, put a comma after each noun, then add the word and before the last item. However, you do not need to include a comma after the last item.

We'll need to get flour, tomatoes, and cheese at the store.

The pizza will be topped with olives, peppers, and pineapple chunks.

\section{Commas and Coordinating Adjectives}

You can use commas to list both adjectives and nouns. A string of adjectives that describe a noun are called coordinating adjectives. These adjectives come before the noun they modify and are separated by commas. One important thing to note, however, is that unlike listing nouns, the word and does not always need to be before the last adjective. 
It was a bright, windy, clear day.

Our kite glowed red, yellow, and blue in the morning sunlight.

\section{Exercise 2}

On your own sheet of paper, use what you have learned so far about comma use to add commas to the following sentences.

1. Monday Tuesday and Wednesday are all booked with meetings.

2. It was a quiet uneventful unproductive day.

3. We'll need to prepare statements for the Franks Todds and Smiths before their portfolio reviews next week.

4. Michael Nita and Desmond finished their report last Tuesday.

5. With cold wet aching fingers he was able to secure the sails before the storm.

6. He wrote his name on the board in clear precise delicate letters.

\section{Commas before Conjunctions in Compound Sentences}

Commas are sometimes used to separate two independent clauses. The comma comes after the first independent clause and is followed by a conjunction, such as for, and, or but. For a full list of conjunctions, see Chapter 2 "Writing Basics: What Makes a Good Sentence?”.

He missed class today, and he thinks he will be out tomorrow, too.

He says his fever is gone, but he is still very tired.

\section{Exercise 3}

On your own sheet of paper, create a compound sentence by combining the two independent clauses with a comma and a coordinating conjunction.

1. The presentation was scheduled for Monday. The weather delayed the presentation for four days. 
2. He wanted a snack before bedtime. He ate some fruit.

3. The patient is in the next room. I can hardly hear anything.

4. We could go camping for vacation. We could go to the beach for vacation.

5. I want to get a better job. I am taking courses at night.

6. I cannot move forward on this project. I cannot afford to stop on this project.

7. Patrice wants to stop for lunch. We will take the next exit to look for a restaurant.

8. I've got to get this paper done. I have class in ten minutes.

9. The weather was clear yesterday. We decided to go on a picnic.

10. I have never dealt with this client before. I know Leonardo has worked with them. Let's ask Leonardo for his help.

\section{Commas before and after Interrupting Words}

In conversations, you might interrupt your train of thought by giving more details about what you are talking about. In a sentence, you might interrupt your train of thought with a word or phrase called interrupting words. Interrupting words can come at the beginning or middle of a sentence. When the interrupting words appear at the beginning of the sentence, a comma appears after the word or phrase.

If you can believe it, people once thought the sun and planets orbited around Earth.

Luckily, some people questioned that theory. 
When interrupting words come in the middle of a sentence, they are separated from the rest of the sentence by commas. You can determine where the commas should go by looking for the part of the sentence that is not essential for the sentence to make sense.

An Italian astronomer, Galileo, proved that Earth orbited the sun.

We have known, for hundreds of years now, that the Earth and other planets exist in a solar system.

\section{Exercise 4}

On your own sheet of paper, copy the sentence and insert commas to separate the interrupting words from the rest of the sentence.

1. I asked my neighbors the retired couple from Florida to bring in my mail.

2. Without a doubt his work has improved over the last few weeks.

3. Our professor Mr. Alamut drilled the lessons into our heads.

4. The meeting is at noon unfortunately which means I will be late for lunch.

5. We came in time for the last part of dinner but most importantly we came in time for dessert.

6. All of a sudden our network crashed and we lost our files.

7. Alex hand the wrench to me before the pipe comes loose again.

\section{Collaboration}

Please share with a classmate and compare your answers.

\section{Commas in Dates, Addresses, and the Greetings and Closings of Letters}

You also use commas when you write the date, such as in cover letters and e-mails. Commas are used when you write the date, when you include an address, and when you greet someone.

If you are writing out the full date, add a comma after the day and before the year. You do not need to add a comma when you write the month and day or when you write the month and the year. If you need to continue the sentence after you add a date that includes the day and year, add a comma after the end of the date.

The letter is postmarked May 4, 2001. 
Her birthday is May 5.

He visited the country in July 2009.

I registered for the conference on March 7, 2010, so we should get our tickets soon.

You also use commas when you include addresses and locations. When you include an address in a sentence, be sure to place a comma after the street and after the city. Do not place a comma between the state and the zip code. Like a date, if you need to continue the sentence after adding the address, simply add a comma after the address.

We moved to 4542 Boxcutter Lane, Hope, Missouri 70832.

After moving to Boston, Massachusetts, Eric used public transportation to get to work.

Greetings are also separated by commas. When you write an e-mail or a letter, you add a comma after the greeting word or the person's name. You also need to include a comma after the closing, which is the word or phrase you put before your signature.

Hello,

I would like more information about your job posting.

Thank you,

Anita Al-Sayf

Dear Mrs. Al-Sayf,

Thank you for your letter. Please read the attached document for details.

Sincerely,

Jack Fromont

\section{Exercise 5}

On your own sheet of paper, use what you have learned about using commas to edit the following letter.

March 272010

Alexa Marché

14 Taylor Drive Apt. 6

New Castle Maine 90342

Dear Mr. Timmons

Thank you for agreeing to meet with me. I am available on Monday the fifth. I can stop by your office at any 
time. Is your address still 7309 Marcourt Circle \#501? Please get back to me at your earliest convenience. Thank you

Alexa

\section{Exercise 6}

On your own sheet of paper, use what you have learned about comma usage to edit the following paragraphs.

1. My brother Nathaniel is a collector of many rare unusual things. He has collected lunch boxes limited edition books and hatpins at various points of his life. His current collection of unusual bottles has over fifty pieces. Usually he sells one collection before starting another.

2. Our meeting is scheduled for Thursday March 20. In that time we need to gather all our documents together. Alice is in charge of the timetables and schedules. Tom is in charge of updating the guidelines. I am in charge of the presentation. To prepare for this meeting please print out any e-mails faxes or documents you have referred to when writing your sample.

3. It was a cool crisp autumn day when the group set out. They needed to cover several miles before they made camp so they walked at a brisk pace. The leader of the group Garth kept checking his watch and their GPS location. Isabelle Raoul and Maggie took turns carrying the equipment while Carrie took notes about the wildlife they saw. As a result no one noticed the darkening sky until the first drops of rain splattered on their faces.

4. Please have your report complete and filed by April 15 2010. In your submission letter please include your contact information the position you are applying for and two people we can contact as references. We will not be available for consultation after April 10 but you may contact the office if you have any questions. Thank you HR Department.

\section{Collaboration}

Please share with a classmate and compare your answers.

\section{Key Takeaways}

- Punctuation marks provide visual cues to readers to tell them how to read a sentence. Punctuation marks convey meaning.

- Commas indicate a pause or a list in a sentence.

- A comma should be used after an introductory word to separate this word from the main sentence.

- A comma comes after each noun in a list. The word and is added before the last noun, which is not followed by a comma.

- A comma comes after every coordinating adjective except for the last adjective. 
- Commas can be used to separate the two independent clauses in compound sentences as long as a conjunction follows the comma.

- Commas are used to separate interrupting words from the rest of the sentence.

- When you write the date, you add a comma between the day and the year. You also add a comma after the year if the sentence continues after the date.

- When they are used in a sentence, addresses have commas after the street address, and the city. If a sentence continues after the address, a comma comes after the zip code.

- When you write a letter, you use commas in your greeting at the beginning and in your closing at the end of your letter. 


\subsection{Semicolons}

\section{Learning Objectives}

1. Identify the uses of semicolons.

2. Properly use semicolons in sentences.

Another punctuation mark that you will encounter is the semicolon (;). Like most punctuation marks, the semicolon can be used in a variety of ways. The semicolon indicates a break in the flow of a sentence, but functions differently than a period or a comma. When you encounter a semicolon while reading aloud, this represents a good place to pause and take a breath.

\section{Semicolons to Join Two Independent Clauses}

Use a semicolon to combine two closely related independent clauses. Relying on a period to separate the related clauses into two shorter sentences could lead to choppy writing. Using a comma would create an awkward run-on sentence.

Correct: Be sure to wear clean, well-pressed clothes to the interview; appearances are important.

Choppy: Be sure to wear clean, well-pressed clothes to the interview. Appearances are important.

Incorrect: Be sure to wear clean, well-pressed clothes to the interview, appearances are important.

In this case, writing the independent clauses as two sentences separated by a period is correct. However, using a semicolon to combine the clauses can make your writing more interesting by creating a variety of sentence lengths and structures while preserving the flow of ideas.

\section{Semicolons to Join Items in a List}

You can also use a semicolon to join items in a list when the items in the list already require commas. Semicolons help the reader distinguish between items in the list. 
Correct: The color combinations we can choose from are black, white, and grey; green, brown, and black; or red, green, and brown.

Incorrect: The color combinations we can choose from are black, white, and grey, green, brown, and black, or red, green, and brown.

By using semicolons in this sentence, the reader can easily distinguish between the three sets of colors.

Tip

Use semicolons to join two main clauses. Do not use semicolons with coordinating conjunctions such as and, or, and but.

\section{Exercise 1}

On your own sheet of paper, correct the following sentences by adding semicolons. If the sentence is correct as it is, write $O K$.

1. I did not notice that you were in the office I was behind the front desk all day.

2. Do you want turkey, spinach, and cheese roast beef, lettuce, and cheese or ham, tomato, and cheese?

3. Please close the blinds there is a glare on the screen.

4. Unbelievably, no one was hurt in the accident.

5. I cannot decide if I want my room to be green, brown, and purple green, black, and brown or green, brown, and dark red.

6. Let's go for a walk the air is so refreshing.

\section{Key Takeaways}

- Use a semicolon to join two independent clauses.

- Use a semicolon to separate items in a list when those items already require a comma. 


\subsection{Colons}

\section{Learning Objectives}

1. Identify the uses of colons.

2. Properly use colons in sentences.

The colon (:) is another punctuation mark used to indicate a full stop. Use a colon to introduce lists, quotes, examples, and explanations. You can also use a colon after the greeting in business letters and memos.

Dear Hiring Manager:

To: Human Resources

From: Deanna Dean

\section{Colons to Introduce a List}

Use a colon to introduce a list of items. Introduce the list with an independent clause.

\section{Colons to Introduce a Quote}

You can use a colon to introduce a quote.

Mark Twain said it best: "When in doubt, tell the truth.” 
If a quote is longer than forty words, skip a line after the colon and indent the left margin of the quote five spaces. Because quotations longer than forty words use line spacing and indentation to indicate a quote, quotation marks are not necessary.

My father always loved Mark Twain’s words:

There are basically two types of people. People who accomplish things, and people who claim to have accomplished things. The first group is less crowded.

Tip

Long quotations, which are forty words or more, are called block quotations. Block quotations frequently appear in longer essays and research papers. For more information about block quotations, see Chapter 11 "Writing from Research: What Will I Learn?”.

\section{Colons to Introduce Examples or Explanations}

Use a colon to introduce an example or to further explain an idea presented in the first part of a sentence. The first part of the sentence must always be an independent clause; that is, it must stand alone as a complete thought with a subject and verb. Do not use a colon after phrases like such as or for example.

Correct: Our company offers many publishing services: writing, editing, and reviewing.

Incorrect: Our company offers many publishing services, such as: writing, editing, and reviewing.

Tip

Capitalize the first letter following a colon for a proper noun, the beginning of a quote, or the first letter of another independent clause. Do NOT capitalize if the information following the colon is not a complete sentence.

Proper noun: We visited three countries: Belize, Honduras, and El Salvador.

Beginning of a quote: My mother loved this line from Hamlet: "To thine own self be true.”

Two independent clauses: There are drawbacks to modern technology: My brother's cell phone died and he lost a lot of phone numbers. 
Incorrect: The recipe is simple: Tomato, basil, and avocado.

\section{Exercise 1}

On your own sheet of paper, correct the following sentences by adding semicolons or colons where needed. If the sentence does not need a semicolon or colon, write $O K$.

1. Don’t give up you never know what tomorrow brings.

2. Our records show that the patient was admitted on March 9, 2010 January 13, 2010 and November 16, 2009.

3. Allow me to introduce myself I am the greatest ice-carver in the world.

4. Where I come from there are three ways to get to the grocery store by car, by bus, and by foot.

5. Listen closely you will want to remember this speech.

6. I have lived in Sedona, Arizona Baltimore, Maryland and Knoxville, Tennessee.

7. The boss's message was clear Lateness would not be tolerated.

8. Next semester, we will read some more contemporary authors, such as Vonnegut, Miller, and Orwell.

9. My little sister said what we were all thinking "We should have stayed home."

10. Trust me I have done this before. 


\section{Key Takeaways}

- Use a colon to introduce a list, quote, or example.

- Use a colon after a greeting in business letters and memos. 


\subsection{Quotes}

\section{Learning Objectives}

1. Identify the uses of quotes.

2. Correctly use quotes in sentences.

Quotation marks (“”) set off a group of words from the rest of the text. Use quotation marks to indicate direct quotations of another person's words or to indicate a title. Quotation marks always appear in pairs.

\section{Direct Quotations}

A direct quotation is an exact account of what someone said or wrote. To include a direct quotation in your writing, enclose the words in quotation marks. An indirect quotation is a restatement of what someone said or wrote. An indirect quotation does not use the person's exact words. You do not need to use quotation marks for indirect quotations.

Direct quotation: Carly said, “I'm not ever going back there again.”

Indirect quotation: Carly said that she would never go back there.

\section{Writing at Work}

Most word processsing software is designed to catch errors in grammar, spelling, and punctuation. While this can be a useful tool, it is better to be well acquainted with the rules of punctuation than to leave the thinking to the computer. Properly punctuated writing will convey your meaning clearly. Consider the subtle shifts in meaning in the following sentences:

- The client said he thought our manuscript was garbage.

- The client said, "He thought our manuscript was garbage."

The first sentence reads as an indirect quote in which the client does not like the manuscript. But did he actually use the word "garbage”? (This would be alarming!) Or has the speaker paraphrased (and exaggerated) the client's words? 
The second sentence reads as a direct quote from the client. But who is "he" in this sentence? Is it a third party?

Word processing software would not catch this because the sentences are not grammatically incorrect. However, the meanings of the sentences are not the same. Understanding punctuation will help you write what you mean, and in this case, could save a lot of confusion around the office!

\section{Punctuating Direct Quotations}

Quotation marks show readers another person's exact words. Often, you will want to identify who is speaking. You can do this at the beginning, middle, or end of the quote. Notice the use of commas and capitalized words.

Beginning: Madison said, “Let’s stop at the farmers market to buy some fresh vegetables for dinner.”

Middle: “Let’s stop at the farmers market,” Madison said, “to buy some fresh vegetables for dinner.”

End: “Let’s stop at the farmers market to buy some fresh vegetables for dinner,” Madison said.

Speaker not identified: “Let’s stop at the farmers market to buy some fresh vegetables for dinner.”

Always capitalize the first letter of a quote even if it is not the beginning of the sentence. When using identifying words in the middle of the quote, the beginning of the second part of the quote does not need to be capitalized.

Use commas between identifying words and quotes. Quotation marks must be placed after commas and periods. Place quotation marks after question marks and exclamation points only if the question or exclamation is part of the quoted text.

Question is part of quoted text: The new employee asked, “When is lunch?”

Question is not part of quoted text: Did you hear her say you were “the next Picasso”?

Exclamation is part of quoted text: My supervisor beamed, “Thanks for all of your hard work!”

Exclamation is not part of quoted text: He said I "single-handedly saved the company thousands of dollars"!

\section{Quotations within Quotations}

Use single quotation marks (' ') to show a quotation within in a quotation. 
Theresa said, "I wanted to take my dog to the festival, but the man at the gate said, 'No dogs allowed.””

“When you say, 'I can’t help it,' what exactly does that mean?”

“The instructions say, 'Tighten the screws one at a time.”

\section{Titles}

Use quotation marks around titles of short works of writing, such as essays, songs, poems, short stories, and chapters in books. Usually, titles of longer works, such as books, magazines, albums, newspapers, and novels, are italicized.

“Annabelle Lee” is one of my favorite romantic poems.

The New York Times has been in publication since 1851.

\section{Writing at Work}

In many businesses, the difference between exact wording and a paraphrase is extremely important. For legal purposes, or for the purposes of doing a job correctly, it can be important to know exactly what the client, customer, or supervisor said. Sometimes, important details can be lost when instructions are paraphrased. Use quotes to indicate exact words where needed, and let your coworkers know the source of the quotation (client, customer, peer, etc.).

\section{Exercise 1}

Copy the following sentences onto your own sheet of paper, and correct them by adding quotation marks where necessary. If the sentence does not need any quotation marks, write $O K$.

1. Yasmin said, I don’t feel like cooking. Let's go out to eat.

2. Where should we go? said Russell.

3. Yasmin said it didn’t matter to her. 
4. I know, said Russell, let's go to the Two Roads Juice Bar.

5. Perfect! said Yasmin.

6. Did you know that the name of the Juice Bar is a reference to a poem? asked Russell.

7. I didn’t! exclaimed Yasmin. Which poem?

8. The Road Not Taken, by Robert Frost Russell explained.

9. Oh! said Yasmin, Is that the one that starts with the line, Two roads diverged in a yellow wood?

10. That's the one said Russell.

\section{Key Takeaways}

- Use quotation marks to enclose direct quotes and titles of short works.

- Use single quotation marks to enclose a quote within a quote.

- Do not use any quotation marks for indirect quotations. 


\subsection{Apostrophes}

\section{Learning Objectives}

1. Identify the uses of apostrophes.

2. Correctly use apostrophes in sentences.

An apostrophe (') is a punctuation mark that is used with a noun to show possession or to indicate where a letter has been left out to form a contraction.

\section{Possession}

An apostrophe and the letter $s$ indicate who or what owns something. To show possession with a singular noun, add 's.

Jen's dance routine mesmerized everyone in the room.

The dog's leash is hanging on the hook beside the door.

Jess's sister is also coming to the party.

Notice that singular nouns that end in $s$ still take the apostrophe $s$ ('s) ending to show possession.

To show possession with a plural noun that ends in $s$, just add an apostrophe ('). If the plural noun does not end in s, add an apostrophe and an s ('s).

Plural noun that ends in $s$ : The drummers' sticks all moved in the same rhythm, like a machine.

Plural noun that does not end in $s$ : The people's votes clearly showed that no one supported the management decision. 


\section{Contractions}

A contraction is a word that is formed by combining two words. In a contraction, an apostrophe shows where one or more letters have been left out. Contractions are commonly used in informal writing but not in formal writing.

I do not like ice cream.

I don't like ice cream.

Notice how the words do and not have been combined to form the contraction don't. The apostrophe shows where the $o$ in not has been left out.

We will see you later.

We'll see you later.

Look at the chart for some examples of commonly used contractions.

\begin{tabular}{|l|l|}
\hline aren't & are not \\
\hline can't & cannot \\
\hline doesn't & does not \\
\hline don't & do not \\
\hline isn't & is not \\
\hline he'll & he will \\
\hline I'll & I will \\
\hline she'll & she will \\
\hline they'll & they will \\
\hline you'll & you will \\
\hline it's & it is, it has \\
\hline let's & let us \\
\hline she's & she is, she has \\
\hline there's & there is, there has \\
\hline who's & who is, who has \\
\hline
\end{tabular}




\section{Tip}

Be careful not to confuse it's with its. It's is a contraction of the words it and is. Its is a possessive pronoun. It's cold and rainy outside. (It is cold and rainy outside.)

The cat was chasing its tail. (Shows that the tail belongs to the cat.)

When in doubt, substitute the words it is in a sentence. If sentence still makes sense, use the contraction it's.

\section{Exercise 1}

On your own sheet of paper, correct the following sentences by adding apostrophes. If the sentence is correct as it is, write $O K$.

1. "What a beautiful child! She has her mothers eyes."

2. My brothers wife is one of my best friends.

3. I couldnt believe it when I found out that I got the job!

4. My supervisors informed me that I wouldnt be able to take the days off.

5. Each of the students responses were unique.

6. Wont you please join me for dinner tonight?

\section{Key Takeaways}

- Use apostrophes to show possession. Add 's to singular nouns and plural nouns that do not end in s. Add ' to plural nouns that end in $s$.

- Use apostrophes in contractions to show where a letter or letters have been left out. 


\subsection{Parentheses}

\section{Learning Objectives}

1. Identify the uses of parentheses.

2. Properly use parentheses in sentences.

Parentheses ( ) are punctuation marks that are always used in pairs and contain material that is secondary to the meaning of a sentence. Parentheses must never contain the subject or verb of a sentence. A sentence should make sense if you delete any text within parentheses and the parentheses.

Attack of the Killer Potatoes has to be the worst movie I have seen (so far).

Your spinach and garlic salad is one of the most delicious (and nutritious) foods I have ever tasted!

\section{Exercise 1}

On your own sheet of paper, clarify the following sentences by adding parentheses. If the sentence is clear as it is, write $O K$.

1. Are you going to the seminar this weekend I am?

2. I recommend that you try the sushi bar unless you don't like sushi.

3. I was able to solve the puzzle after taking a few moments to think about it.

4. Please complete the questionnaire at the end of this letter.

5. Has anyone besides me read the assignment?

6. Please be sure to circle not underline the correct answers.

\section{Key Takeaways}

- Parentheses enclose information that is secondary to the meaning of a sentence. 
127 [Author removed at request of original publisher]

- Parentheses are always used in pairs. 


\subsection{Dashes}

\section{Learning Objectives}

1. Identify the uses of dashes.

2. Correctly use dashes in sentences.

A dash (-) is a punctuation mark used to set off information in a sentence for emphasis. You can enclose text between two dashes, or use just one dash. To create a dash in Microsoft Word, type two hyphens together. Do not put a space between dashes and text.

Arrive to the interview early—but not too early.

Any of the suits-except for the purple one-should be fine to wear.

\section{Exercise 1}

On your own sheet of paper, clarify the following sentences by adding dashes. If the sentence is clear as it is, write $O K$.

1. Which hairstyle do you prefer short or long?

2. I don't know I hadn't even thought about that.

3. Guess what I got the job!

4. I will be happy to work over the weekend if I can have Monday off.

5. You have all the qualities that we are looking for in a candidate intelligence, dedication, and a strong work ethic.

\section{Key Takeaways}

- Dashes indicate a pause in text. 
129 [Author removed at request of original publisher]

- Dashes set off information in a sentence to show emphasis. 


\subsection{Hyphens}

\section{Learning Objectives}

1. Identify the uses of hyphens.

2. Properly use hyphens in sentences.

A hyphen (-) looks similar to a dash but is shorter and used in different ways.

\section{Hyphens between Two Adjectives That Work as One}

Use a hyphen to combine words that work together to form a single description.

The fifty-five-year-old athlete was just as qualified for the marathon as his younger opponents.

My doctor recommended against taking the medication, since it can be habit-forming.

My study group focused on preparing for the midyear review.

\section{Hyphens When a Word Breaks at the End of a Line}

Use a hyphen to divide a word across two lines of text. You may notice that most word-processing programs will do this for you. If you have to manually insert a hyphen, place the hyphen between two syllables. If you are unsure of where to place the hyphen, consult a dictionary or move the entire word to the next line.

My supervisor was concerned that the team meet-

ing would conflict with the client meeting. 


\section{Key Takeaways}

- Hyphens join words that work as one adjective.

- Hyphens break words across two lines of text. 


\subsection{Punctuation: End-of-Chapter Exercises}

\section{Learning Objectives}

1. Use the skills you have learned in this chapter.

2. Work collaboratively with other students.

\section{Exercises}

1. Each sentence contains a punctuation error. On your own sheet of paper, correct each sentence by adding the correct punctuation. The headings will let you know which type of punctuation mistakes to look for. If the sentence does not need corrections, write $O K$.

\section{Commas}

a. The wedding will be July 132012.

b. The date by the way is the anniversary of the day that they met.

c. The groom the bride and their parents are all planning the event.

d. Actually all of their friends and relatives are involved in the planning.

e. The bride is a baker so she will be making the wedding cake herself.

f. The photography the catering and the music will all be friends.

\section{Semicolons}

a. Some people spend a lot of money hiring people for wedding services they are lucky to have such talented friends.

b. The flowers will be either roses, daisies, and snapdragons orchids, tulips, and irises or peonies and lilies.

\section{Colons}

a. There will be three colors for the wedding: white, black, and gold.

b. They've finally narrowed down the dinner choices salmon, steak, and a vegan stew.

c. Their wedding invitations contained the following quote from the Roman poet Ovid If you want to be loved, be lovable.

\section{Quotes}

a. The invitations said that the wedding would be "outdoor casual."

b. "What exactly does 'outdoor casual' mean?" I asked the bride.

c. She told me to dress comfortably and wear shoes that do not sink into the ground.

\section{Apostrophes}

a. On the day of the wedding, were going to rent a limo. 
b. My brothers wife will make the arrangements.

c. Shes a great party organizer.

\section{Parentheses}

a. On the day of the wedding, the bride looked more beautiful than ever and I've known her for fifteen years.

b. All the details were perfect in my opinion.

\section{Dashes}

a. Everyone danced at the wedding except my mother.

b. It was to be expected she just had hip surgery.

\section{Hyphens}

a. The groom danced with his new mother in law.

b. It was a spectacular, fun filled day for everyone.

2. Each sentence contains a punctuation error. On your own sheet of paper, correct each sentence by adding commas, semicolons, colons, apostrophes, parentheses, hyphens, and dashes as needed.

a. My mothers garden is full of beautiful flowers.

b. She has carefully planted several species of roses peonies and irises.

c. She is especially proud of her thirty year old Japanese maple tree.

d. I am especially proud of the sunflowers I planted them!

e. You should see the birds that are attracted to the garden hummingbirds, finches, robins, and sparrows.

f. I like to watch the hummingbirds they are my favorite.

g. We spend a lot of time in the garden planting weeding and just enjoying the view.

h. Each flower has its own personality some seem shy and others seem bold.

i. Arent gardens wonderful?

j. You should come visit sometime Do you like to garden?

3. The following paragraph contains errors in punctuation. On your own sheet of paper, correct the paragraph by adding commas, semicolons, colons, apostrophes, parentheses, hyphens, and dashes as needed. There may be more than one way to correct the paragraph.

May 182011

Dear Hiring Manager

Allow me to introduce myself in my previous position I was known as the King of Sales. I hope to earn the same title within your company. My name is Frances Fortune. I have thirteen years experience in corporate sales and account management. I have been the top rated seller for two years in a row in my previous position. Clients recognize me as dependable honest and resourceful. I have a strong work ethic and great interpersonal skills. I excel at goal setting and time management. However you don't have to take my word for it I will be happy to provide personal and professional references upon request. Youre welcome to contact my previous employer to inquire about my work performance. I look forward to speaking with you in person in the near future.

Sincerely

Frances Fortune 
4. Read the following paragraph. Edit by adding apostrophes, parentheses, dashes, and hyphens where needed. There may be more than one correct way to edit some sentences. Consider how the punctuation you choose affects the meaning of the sentence.

I was a little nervous about the interview it was my first in years. I had to borrow my roommates suit, but it fit me well. A few days ago, I started to research the companys history and mission. I felt like I was well qualified for the job. When I arrived, I shook hands with the interviewer she had a strong grip! It nearly caught me off guard, but I did my best to smile and relax. I was a little distracted by all the books in the womans office she must have had a hundred books in that tiny room. However, I think my responses to her questions were good. Ill send her an e-mail to thank her for her time. Hopefully shell call me soon about the position.

\section{Collaboration}

Please share with a classmate and compare your answers.

\section{Writing Application}

Review some of the recent or current assignments you have completed for school or work. Look through recent business and personal e-mails. Does your work contain any errors in punctuation? Correct the errors and compile a list of the types of errors you are correcting (commas, semicolons, colons, apostrophes, quotation marks, parentheses, dashes, hyphens, etc.). Use this list as a reference for the types of punctuation marks that you should review and practice.

If you do not find many errors-great! You can still look for ways to add interest to your writing by using dashes, semicolons, colons, and parentheses to create a variety of sentence lengths and structures. 


\title{
Chapter 4: Working with Words: Which Word Is Right?
}

\author{
4.1 Commonly Confused Words \\ 4.2 Spelling \\ 4.3 Word Choice \\ 4.4 Prefixes and Suffixes \\ 4.5 Synonyms and Antonyms \\ 4.6 Using Context Clues \\ 4.7 Working with Words: End-of-Chapter Exercises
}




\subsection{Commonly Confused Words}

\section{Learning Objectives}

1. Identify commonly confused words.

2. Use strategies to avoid commonly confused words.

Just as a mason uses bricks to build sturdy homes, writers use words to build successful documents. Consider the construction of a building. Builders need to use tough, reliable materials to build a solid and structurally sound skyscraper. From the foundation to the roof and every floor in between, every part is necessary. Writers need to use strong, meaningful words from the first sentence to the last and in every sentence in between.

You already know many words that you use everyday as part of your writing and speaking vocabulary. You probably also know that certain words fit better in certain situations. Letters, e-mails, and even quickly jotted grocery lists require the proper selection of vocabulary. Imagine you are writing a grocery list to purchase the ingredients for a recipe but accidentally write down cilantro when the recipe calls for parsley. Even though cilantro and parsley look remarkably alike, each produces a very different effect in food. This seemingly small error could radically alter the flavor of your dish!

Having a solid everyday vocabulary will help you while writing, but learning new words and avoiding common word errors will make a real impression on your readers. Experienced writers know that deliberate, careful word selection and usage can lead to more polished, more meaningful work. This chapter covers word choice and vocabulary-building strategies that will improve your writing.

\section{Commonly Confused Words}

Some words in English cause trouble for speakers and writers because these words share a similar pronunciation, meaning, or spelling with another word. These words are called commonly confused words. For example, read aloud the following sentences containing the commonly confused words new and knew:

I liked her new sweater.

I knew she would wear that sweater today. 
These words may sound alike when spoken, but they carry entirely different usages and meanings. New is an adjective that describes the sweater, and knew is the past tense of the verb to know. To read more about adjectives, verbs, and other parts of speech see Chapter 2 "Writing Basics: What Makes a Good Sentence?".

\section{Recognizing Commonly Confused Words}

New and knew are just two of the words that can be confusing because of their similarities. Familiarize yourself with the following list of commonly confused words. Recognizing these words in your own writing and in other pieces of writing can help you choose the correct word.

\section{Commonly Confused Words}

A, An, And

- A (article). Used before a word that begins with a consonant.

a key, a mouse, a screen

- An (article). Used before a word that begins with a vowel.

an airplane, an ocean, an igloo

- And (conjunction). Connects two or more words together.

peanut butter and jelly, pen and pencil, jump and shout

Accept, Except

- Accept (verb). Means to take or agree to something offered.

They accepted our proposal for the conference.

- Except (conjunction). Means only or but.

We could fly there except the tickets cost too much.

Affect, Effect

- Affect (verb). Means to create a change.

Hurricane winds affect the amount of rainfall.

- Effect (noun). Means an outcome or result.

The heavy rains will have an effect on the crop growth.

Are, Our

- Are (verb). A conjugated form of the verb to be. 
My cousins are all tall and blonde.

- Our (pronoun). Indicates possession, usually follows the pronoun we.

We will bring our cameras to take pictures.

By, Buy

- By (preposition). Means next to.

My glasses are by the bed.

- Buy (verb). Means to purchase.

I will buy new glasses after the doctor's appointment.

Its, It's

- Its (pronoun). A form of it that shows possession.

The butterfly flapped its wings.

- It's (contraction). Joins the words it and is.

It's the most beautiful butterfly I have ever seen.

Know, No

- Know (verb). Means to understand or possess knowledge.

I know the male peacock sports the brilliant feathers.

- No. Used to make a negative.

I have no time to visit the zoo this weekend.

Loose, Lose

- Loose (adjective). Describes something that is not tight or is detached.

Without a belt, her pants are loose on her waist.

- Lose (verb). Means to forget, to give up, or to fail to earn something.

She will lose even more weight after finishing the marathon training.

Of, Have

- Of (preposition). Means from or about.

I studied maps of the city to know where to rent a new apartment.

- Have (verb). Means to possess something.

I have many friends to help me move.

- Have (linking verb). Used to connect verbs. 
I should have helped her with that heavy box.

Quite, Quiet, Quit

- Quite (adverb). Means really or truly.

My work will require quite a lot of concentration.

- Quiet (adjective). Means not loud.

I need a quiet room to complete the assignments.

- Quit (verb). Means to stop or to end.

I will quit when I am hungry for dinner.

Right, Write

- Right (adjective). Means proper or correct.

When bowling, she practices the right form.

- Right (adjective). Also means the opposite of left.

The ball curved to the right and hit the last pin.

- Write (verb). Means to communicate on paper.

After the team members bowl, I will write down their scores.

Set, Sit

- Set (verb). Means to put an item down.

She set the mug on the saucer.

- Set (noun). Means a group of similar objects.

All the mugs and saucers belonged in a set.

- Sit (verb). Means to lower oneself down on a chair or another place

I'll sit on the sofa while she brews the tea.

Suppose, Supposed

- Suppose (verb). Means to think or to consider

I suppose I will bake the bread, because no one else has the recipe.

- Suppose (verb). Means to suggest.

Suppose we all split the cost of the dinner.

- Supposed (verb). The past tense form of the verb suppose, meaning required or allowed.

She was supposed to create the menu.

Than, Then 
- Than (conjunction). Used to connect two or more items when comparing

Registered nurses require less schooling than doctors.

- Then (adverb). Means next or at a specific time.

Doctors first complete medical school and then obtain a residency.

Their, They're, There

- Their (pronoun). A form of they that shows possession.

The dog walker feeds their dogs everyday at two o’clock.

- They're (contraction). Joins the words they and are.

They're the sweetest dogs in the neighborhood.

- There (adverb). Indicates a particular place.

The dogs' bowls are over there, next to the pantry.

- There (pronoun). Indicates the presence of something

There are more treats if the dogs behave.

To, Two, Too

- To (preposition). Indicates movement.

Let's go to the circus.

- To. A word that completes an infinitive verb.

to play, to ride, to watch.

- Two. The number after one. It describes how many.

Two clowns squirted the elephants with water.

- Too (adverb). Means also or very.

The tents were too loud, and we left.

Use, Used

- Use (verb). Means to apply for some purpose.

We use a weed whacker to trim the hedges.

- Used. The past tense form of the verb to use

He used the lawnmower last night before it rained.

- Used to. Indicates something done in the past but not in the present

He used to hire a team to landscape, but now he landscapes alone.

Who's, Whose 
- Who's (contraction). Joins the words who and either is or has.

Who's the new student? Who's met him?

- Whose (pronoun). A form of who that shows possession.

Whose schedule allows them to take the new student on a campus tour?

Your, You're

- Your (pronoun). A form of you that shows possession.

Your book bag is unzipped.

- You're (contraction). Joins the words you and are.

You're the girl with the unzipped book bag.

The English language contains so many words; no one can say for certain how many words exist. In fact, many words in English are borrowed from other languages. Many words have multiple meanings and forms, further expanding the immeasurable number of English words. Although the list of commonly confused words serves as a helpful guide, even these words may have more meanings than shown here. When in doubt, consult an expert: the dictionary!

\section{Exercise 1}

Complete the following sentences by selecting the correct word.

1. My little cousin turns (to, too, two) years old tomorrow.

2. The next-door neighbor's dog is (quite, quiet, quit) loud. He barks constantly throughout the night.

3. (Your, You're) mother called this morning to talk about the party.

4. I would rather eat a slice of chocolate cake (than, then) eat a chocolate muffin.

5. Before the meeting, he drank a cup of coffee and (than, then) brushed his teeth.

6. Do you have any (loose, lose) change to pay the parking meter?

7. Father must (have, of) left his briefcase at the office.

8. Before playing ice hockey, I was (suppose, supposed) to read the contract, but I only skimmed it and signed my name quickly, which may of the rules.

9. Tonight she will her résumé and job application. (set, sit) down and (affect, effect) my understanding

It must be fall, because the leaves darker earlier. (right, write) a cover letter to accompany (are, our) changing, and (it’s, its) getting 


\section{Strategies to Avoid Commonly Confused Words}

When writing, you need to choose the correct word according to its spelling and meaning in the context. Not only does selecting the correct word improve your vocabulary and your writing, but it also makes a good impression on your readers. It also helps reduce confusion and improve clarity. The following strategies can help you avoid misusing confusing words.

1. Use a dictionary. Keep a dictionary at your desk while you write. Look up words when you are uncertain of their meanings or spellings. Many dictionaries are also available online, and the Internet's easy access will not slow you down. Check out your cell phone or smartphone to see if a dictionary app is available.

2. Keep a list of words you commonly confuse. Be aware of the words that often confuse you. When you notice a pattern of confusing words, keep a list nearby, and consult the list as you write. Check the list again before you submit an assignment to your instructor.

3. Study the list of commonly confused words. You may not yet know which words confuse you, but before you sit down to write, study the words on the list. Prepare your mind for working with words by reviewing the commonly confused words identified in this chapter.

Tip

Figure 4.1 A Commonly Misused Word on a Public Sign

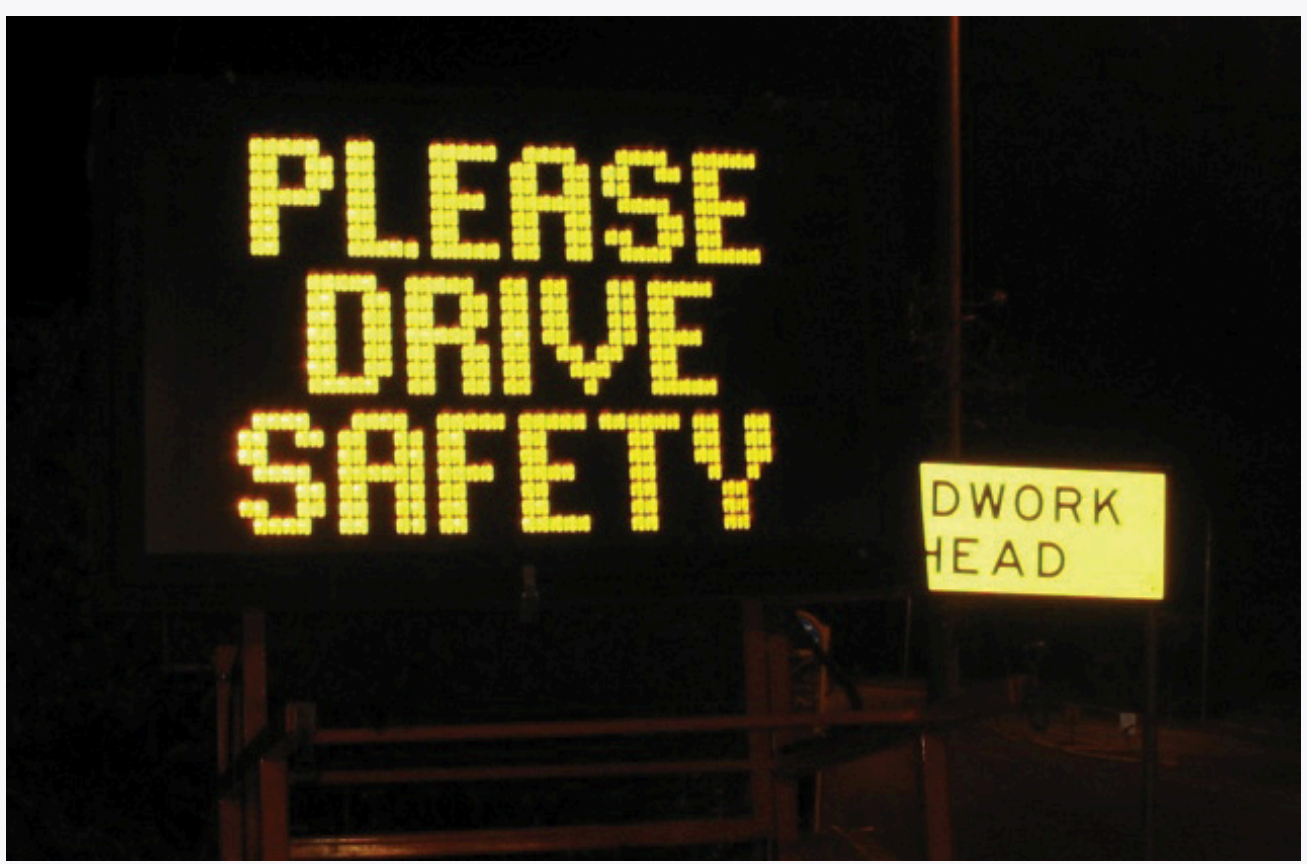

Commonly confused words appear in many locations, not just at work or at school. Be on the lookout for 
misused words wherever you find yourself throughout the day. Make a mental note of the error and remember its correction for your own pieces of writing.

\section{Writing at Work}

All employers value effective communication. From an application to an interview to the first month on the job, employers pay attention to your vocabulary. You do not need a large vocabulary to succeed, but you do need to be able to express yourself clearly and avoid commonly misused words.

When giving an important presentation on the effect of inflation on profit margins, you must know the difference between effect and affect and choose the correct word. When writing an e-mail to confirm deliveries, you must know if the shipment will arrive in to days, too days, or two days. Confusion may arise if you choose the wrong word.

Consistently using the proper words will improve your communication and make a positive impression on your boss and colleagues.

\section{Exercise 2}

The following paragraph contains eleven errors. Find each misused word and correct it by adding the proper word.

The original United States Declaration of Independence sets in a case at the Rotunda for the Charters of Freedom as part of the National Archives in Washington, DC. Since 1952, over one million visitors each year of passed through the Rotunda too snap a photograph to capture they're experience. Although signs state, "No Flash Photography," forgetful tourists leave the flash on, an a bright light flickers for just a millisecond. This millisecond of light may not seem like enough to effect the precious document, but supposed how much light could be generated when all those milliseconds are added up. According to the National Archives administrators, its enough to significantly damage the historic document. So, now, the signs display quit a different message: "No Photography." Visitors continue to travel to see the Declaration that began are country, but know longer can personal pictures serve as mementos. The administrators' compromise, they say, is a visit to the gift shop for a preprinted photograph.

Collaboration

Please share with a classmate and compare your answers.

\section{Key Takeaways}

- In order to write accurately, it is important for writers to be aware of commonly confused words. 
- Although commonly confused words may look alike or sound alike, their meanings are very different.

- Consulting the dictionary is one way to make sure you are using the correct word in your writing. You may also keep a list of commonly confused words nearby when you write or study the chart in this book.

- Choosing the proper words leaves a positive impression on your readers.

\section{Writing Application}

Review the latest assignment you completed for school or for work. Does it contain any commonly confused words? Circle each example and use the circled words to begin your own checklist of commonly confused words. Continue to add to your checklist each time you complete an assignment and find a misused word. 


\subsection{Spelling}

\section{Learning Objectives}

1. Identify common spelling rules.

2. Identify commonly misused homonyms.

3. Identify commonly misspelled words.

One essential aspect of good writing is accurate spelling. With computer spell checkers, spelling may seem simple, but these programs fail to catch every error. Spell checkers identify some errors, but writers still have to consider the flagged words and suggested replacements. Writers are still responsible for the errors that remain.

For example, if the spell checker highlights a word that is misspelled and gives you a list of alternative words, you may choose a word that you never intended even though it is spelled correctly. This can change the meaning of your sentence. It can also confuse readers, making them lose interest. Computer spell checkers are useful editing tools, but they can never replace human knowledge of spelling rules, homonyms, and commonly misspelled words.

\section{Common Spelling Rules}

The best way to master new words is to understand the key spelling rules. Keep in mind, however, that some spelling rules carry exceptions. A spell checker may catch these exceptions, but knowing them yourself will prepare you to spell accurately on the first try. You may want to try memorizing each rule and its exception like you would memorize a rhyme or lyrics to a song.

Write $i$ before $e$ except after $c$, or when pronounced ay like "neighbor" or "weigh."

- achieve, niece, alien

- receive, deceive

When words end in a consonant plus $y$, drop the $y$ and add an $i$ before adding another ending. 
- happy + er = happier

- $\quad$ cry + ed = cried

When words end in a vowel plus $y$, keep the $y$ and add the ending.

- delay + ed $=$ delayed

Memorize the following exceptions to this rule: day, lay, say, pay = daily, laid, said, paid

When adding an ending that begins with a vowel, such as -able,-ence, -ing, or -ity, drop the last $e$ in a word.

- $\quad$ write + ing $=$ writing

- pure + ity = purity

When adding an ending that begins with a consonant, such as -less, -ment, or -ly, keep the last $e$ in a word.

- hope + less $=$ hopeless

- advertise + ment $=$ advertisement

For many words ending in a consonant and an $o$, add $-s$ when using the plural form.

- photo $+\mathrm{s}=$ photos

- soprano $+\mathrm{s}=$ sopranos

Add - es to words that end in $s, c h, s h$, and $x$.

- church + es $=$ churches

- fax + es $=$ faxes 


\section{Exercise 1}

Identify and correct the nine misspelled words in the following paragraph.

Sherman J. Alexie Jr. was born in October 1966. He is a Spokane/Coeur d'Alene Indian and an American writer, poet, and filmmaker. Alexie was born with hydrocephalus, or water on the brain. This condition led doctors to predict that he would likly suffer long-term brain damage and possibly mental retardation. Although Alexie survived with no mental disabilitys, he did suffer other serious side effects from his condition that plagud him throughout his childhood. Amazingly, Alexie learned to read by the age of three, and by age five he had read novels such as John Steinbeck's The Grapes of Wrath. Raised on an Indian reservation, Alexie often felt aleinated from his peers due to his avid love for reading and also from the long-term effects of his illness, which often kept him from socializeing with his peers on the reservation. The reading skills he displaid at such a young age foreshadowed what he would later become. Today Alexie is a prolific and successful writer with several story anthologeis to his credit, noteably The Lone Ranger and Tonto Fistfight in Heaven and The Toughest Indian in the World. Most of his fiction is about contemporary Native Americans who are influenced by pop culture and pow wows and everything in between. His work is sometimes funny but always thoughtful and full of richness and depth. Alexie also writes poetry, novels, and screenplays. His latest collection of storys is called War Dances, which came out in 2009.

Collaboration

Please share with a classmate and compare your answers.

Tip

Eight Tips to Improve Spelling Skills

1. Read the words in your assignment carefully, and avoid skimming over the page. Focusing on your written assignment word by word will help you pay close attention to each word's spelling. Skimming quickly, you may overlook misspelled words.

2. Use mnemonic devices to remember the correct spelling of words. Mnemonic devices, or memory techniques and learning aids, include inventive sayings or practices that help you remember. For example, the saying "It is important to be a beautiful person inside and out" may help you remember that beautiful begins with "be a." The practice of pronouncing the word Wednesday Wed-nes-day may help you remember how to spell the word correctly.

3. Use a dictionary. Many professional writers rely on the dictionary-either in print or online. If you find it difficult to use a regular dictionary, ask your instructor to help you find a "poor speller's dictionary."

4. Use your computer's spell checker. The spell checker will not solve all your spelling problems, but it is a useful tool. See the introduction to this section for cautions about spell checkers.

5. Keep a list of frequently misspelled words. You will often misspell the same words again and again, but do not let this discourage you. All writers struggle with the spellings of certain words; they become aware of their spelling weaknesses and work to improve. Be aware of which words you commonly misspell, and you can add them to a list to learn to spell them correctly. 
6. Look over corrected papers for misspelled words. Add these words to your list and practice writing each word four to five times each. Writing teachers will especially notice which words you frequently misspell, and it will help you excel in your classes if they see your spelling improve.

7. Test yourself with flashcards. Sometimes the old-fashioned methods are best, and for spelling, this tried and true technique has worked for many students. You can work with a peer or alone.

8. Review the common spelling rules explained in this chapter. Take the necessary time to master the material; you may return to the rules in this chapter again and again, as needed.

Tip

Remember to focus on spelling during the editing and revising step of the writing process. Start with the big ideas such as organizing your piece of writing and developing effective paragraphs, and then work your way down toward the smaller-but equally important-details like spelling and punctuation. To read more about the writing process and editing and revising, see Chapter 8 “The Writing Process: How Do I Begin?”.

\section{Homonyms}

Homonyms are words that sound like one another but have different meanings.

\section{Commonly Misused Homonyms}

Principle, Principal

- Principle (noun). A fundamental concept that is accepted as true.

The principle of human equality is an important foundation for all nations.

- Principal (noun). The original amount of debt on which interest is calculated.

The payment plan allows me to pay back only the principal amount, not any compounded interest.

- Principal (noun). A person who is the main authority of a school.

The principal held a conference for both parents and teachers.

Where, Wear, Ware

- Where (adverb). The place in which something happens. 
Where is the restaurant?

- Wear (verb). To carry or have on the body.

I will wear my hiking shoes when go on a climb tomorrow morning.

- Ware (noun). Articles of merchandise or manufacture (usually, wares).

When I return from shopping, I will show you my wares.

Lead, Led

- Lead (noun). A type of metal used in pipes and batteries.

The lead pipes in my homes are old and need to be replaced.

- Led (verb). The past tense of the verb lead.

After the garden, she led the patrons through the museum.

Which, Witch

- Which (pronoun). Replaces one out of a group.

Which apartment is yours?

- Witch (noun). A person who practices sorcery or who has supernatural powers.

She thinks she is a witch, but she does not seem to have any powers.

Peace, Piece

- Peace (noun). A state of tranquility or quiet.

For once, there was peace between the argumentative brothers.

- Piece (noun). A part of a whole.

I would like a large piece of cake, thank you.

Passed, Past

- Passed (verb). To go away or move.

He passed the slower cars on the road using the left lane.

- Past (noun). Having existed or taken place in a period before the present.

The argument happened in the past, so there is no use in dwelling on it.

Lessen, Lesson

- Lessen (verb). To reduce in number, size, or degree.

My dentist gave me medicine to lessen the pain of my aching tooth.

- Lesson (noun). A reading or exercise to be studied by a student. 
Today’s lesson was about mortgage interest rates.

Patience, Patients

- Patience (noun). The capacity of being patient (waiting for a period of time or enduring pains and trials calmly).

The novice teacher's patience with the unruly class was astounding.

- Patients (plural noun). Individuals under medical care.

The patients were tired of eating the hospital food, and they could not wait for a home-cooked meal.

Sees, Seas, Seize

- Sees (verb). To perceive with the eye.

He sees a whale through his binoculars.

- Seas (plural noun). The plural of sea, a great body of salt water.

The tidal fluctuation of the oceans and seas are influenced by the moon.

- Seize (verb). To possess or take by force.

The king plans to seize all the peasants' land.

Threw, Through

- Threw (verb). The past tense of throw.

She threw the football with perfect form.

- Through (preposition). A word that indicates movement.

She walked through the door and out of his life.

\section{Exercise 2}

Complete the following sentences by selecting the correct homonym.

1. Do you agree with the underlying (principle, principal) that ensures copyrights are protected in the digital age?

2. I like to (where, wear, ware) unique clothing from thrift stores that do not have company logos on them.

3. Marjorie felt like she was being one bit. (led, lead) on a wild goose chase, and she did not like it

4. Serina described (witch, which) house was hers, but now that I am here, they all look 
the same.

5. Seeing his friend without a lunch, Miguel gave her a (peace, piece) of his apple.

6. Do you think that it is healthy for mother to talk about the (passed, past) all the time?

7. Eating healthier foods will (lessen, lesson) the risk of heart disease.

8. I know it sounds cliché, but my father had the (patients, patience) of a saint.

9. Daniela (sees, seas, seize) possibilities in the bleakest situations, and that it is why she is successful.

10. Everyone goes (through, threw) hardships in life regardless of who they are.

\section{Commonly Misspelled Words}

Below is a list of commonly misspelled words. You probably use these words every day in either speaking or writing. Each word has a segment in bold type, which indicates the problem area of the word that is often spelled incorrectly. If you can, use this list as a guide before, during, and after you write.

\section{Tip}

Use the following two tricks to help you master these troublesome words:

1. Copy each word a few times and underline the problem area.

2. Copy the words onto flash cards and have a friend test you. 


\begin{tabular}{|l|l|l|l|l|}
\hline across & disappoint & integration & particular & separate \\
\hline address & disapprove & intelligent & perform & similar \\
\hline answer & doesn't & interest & perhaps & since \\
\hline argument & eighth & interfere & personnel & speech \\
\hline athlete & embarrass & jewelry & possess & strength \\
\hline beginning & environment & judgment & possible & success \\
\hline behavior & exaggerate & knowledge & prefer & surprise \\
\hline calendar & familiar & maintain & prejudice & taught \\
\hline career & finally & mathematics & privilege & temperature \\
\hline conscience & government & meant & probably & thorough \\
\hline crowded & grammar & necessary & psychology & thought \\
\hline definite & height & nervous & pursue & tired \\
\hline describe & illegal & occasion & reference & until \\
\hline desperate & immediately & opinion & rhythm & weight \\
\hline different & important & optimist & ridiculous & written \\
\hline & & & \\
\hline
\end{tabular}

\section{Exercise 3}

Identify and correct the ten commonly misspelled words in the following paragraph.

Brooklyn is one of the five boroughs that make up New York City. It is located on the eastern shore of Long Island directly accross the East River from the island of Manhattan. Its beginings stretch back to the sixteenth century when it was founded by the Dutch who originally called it "Breuckelen.” Immedietely after the Dutch settled Brooklyn, it came under British rule. However, neither the Dutch nor the British were Brooklyn's first inhabitants. When European settlers first arrived, Brooklyn was largely inhabited by the Lenapi, a collective name for several organized bands of Native American people who settled a large area of land that extended from upstate New York through the entire state of New Jersey. They are sometimes referred to as the Delaware Indians. Over time, the Lenapi succumbed to European diseases or conflicts between European settlers or other Native American enemies. Finalley they were pushed out of Brooklyn completely by the British.

In 1776, Brooklyn was the site of the first importent battle of the American Revolution known as the Battle of Brooklyn. The colonists lost this battle, which was led by George Washington, but over the next two years they would win the war, kicking the British out of the colonies once and for all.

By the end of the nineteenth century, Brooklyn grew to be a city in its own right. The completion of the Brooklyn Bridge was an ocasion for celebration; transportation and commerce between Brooklyn and Manhattan now became much easier. Eventually, in 1898, Brooklyn lost its seperate identity as an independent city and became one of five boroughs of New York City. However, in some people's opinien, the intagration into New York City should have never happened; they though Brooklyn should have 
remained an independent city.

Collaboration

Please share with a classmate and compare your answers.

\section{Writing at Work}

In today's job market, writing e-mails has become a means by which many people find employment. E-mails to prospective employers require thoughtful word choice, accurate spelling, and perfect punctuation.

Employers' inboxes are inundated with countless e-mails daily. If even the subject line of an e-mail contains a spelling error, it will likely be overlooked and someone else's e-mail will take priority.

The best thing to do after you proofread an e-mail to an employer and run the spell checker is to have an additional set of eyes go over it with you; one of your teachers may be able to read the e-mail and give you suggestions for improvement. Most colleges and universities have writing centers, which may also be able to assist you.

\section{Key Takeaways}

- Accurate, error-free spelling enhances your credibility with the reader.

- Mastering the rules of spelling may help you become a better speller.

- Knowing the commonly misused homonyms may prevent spelling errors.

- Studying the list of commonly misspelled words in this chapter, or studying a list of your own, is one way to improve your spelling skills.

\section{Writing Application}

What is your definition of a successful person? Is it based on a person's profession or is it based on his or her character? Perhaps success means a combination of both. In one paragraph, describe in detail what you think makes a person successful. When you are finished, proofread your work for spelling errors. Exchange papers with a partner and read each other's work. See if you catch any spelling errors that your partner missed. 


\subsection{Word Choice}

\section{Learning Objectives}

1. Identify the reasons why using a dictionary and thesaurus is important when writing.

2. Identify how to use proper connotations.

3. Identify how to avoid using slang, clichés, and overly general words in your writing.

Effective writing involves making conscious choices with words. When you prepare to sit down to write your first draft, you likely have already completed some freewriting exercises, chosen your topic, developed your thesis statement, written an outline, and even selected your sources. When it is time to write your first draft, start to consider which words to use to best convey your ideas to the reader.

Some writers are picky about word choice as they start drafting. They may practice some specific strategies, such as using a dictionary and thesaurus, using words and phrases with proper connotations, and avoiding slang, clichés, and overly general words.

Once you understand these tricks of the trade, you can move ahead confidently in writing your assignment. Remember, the skill and accuracy of your word choice is a major factor in developing your writing style. Precise selection of your words will help you be more clearly understood—in both writing and speaking.

\section{Using a Dictionary and Thesaurus}

Even professional writers need help with the meanings, spellings, pronunciations, and uses of particular words. In fact, they rely on dictionaries to help them write better. No one knows every word in the English language and their multiple uses and meanings, so all writers, from novices to professionals, can benefit from the use of dictionaries.

Most dictionaries provide the following information:

- Spelling. How the word and its different forms are spelled.

- Pronunciation. How to say the word.

- Part of speech. The function of the word.

- Definition. The meaning of the word.

- Synonyms. Words that have similar meanings. 
- Etymology. The history of the word.

Look at the following sample dictionary entry and see which of the preceeding information you can identify:

myth, mith, $n$. [Gr. mythos, a word, a fable, a legend.] A fable or legend embodying the convictions of a people as to their gods or other divine beings, their own beginnings and early history and the heroes connected with it, or the origin of the world; any invented story; something or someone having no existence in fact.—myth • ic, myth $\bullet$ i $\bullet$ cal

Like a dictionary, a thesaurus is another indispensable writing tool. A thesaurus gives you a list of synonyms, words that have the same (or very close to the same) meaning as another word. It also lists antonyms, words with the opposite meaning of the word. A thesaurus will help you when you are looking for the perfect word with just the right meaning to convey your ideas. It will also help you learn more words and use the ones you already know more correctly.

precocious adj, She's such a precocious little girl!: uncommonly smart, mature, advanced, smart, bright, brilliant, gifted, quick, clever, apt.

Ant. slow, backward, stupid.

\section{Using Proper Connotations}

A denotation is the dictionary definition of a word. A connotation, on the other hand, is the emotional or cultural meaning attached to a word. The connotation of a word can be positive, negative, or neutral. Keep in mind the connotative meaning when choosing a word.

\section{Scrawny}

- Denotation: Exceptionally thin and slight or meager in body or size.

- Word used in a sentence: Although he was a premature baby and a scrawny child, Martin has developed into a strong man.

- Connotation: (Negative) In this sentence the word scrawny may have a negative connotation in the readers' minds. They might find it to mean a weakness or a personal flaw; however, the word fits into the sentence appropriately.

Skinny

- Denotation: Lacking sufficient flesh, very thin. 
- Word used in a sentence: Skinny jeans have become very fashionable in the past couple of years.

- Connotation: (Positive) Based on cultural and personal impressions of what it means to be skinny, the reader may have positive connotations of the word skinny.

Lean

- Denotation: Lacking or deficient in flesh; containing little or no fat.

- Word used in a sentence: My brother has a lean figure, whereas I have a more muscular build.

- Connotation: (Neutral) In this sentence, lean has a neutral connotation. It does not call to mind an overly skinny person like the word scrawny, nor does imply the positive cultural impressions of the word skinny. It is merely a neutral descriptive word.

Notice that all the words have a very similar denotation; however, the connotations of each word differ.

\section{Exercise 1}

In each of the following items, you will find words with similar denotations. Identify the words' connotations as positive, negative, or neutral by writing the word in the appropriate box. Copy the chart onto your own piece of paper.

1. curious, nosy, interested

2. lazy, relaxed, slow

3. courageous, foolhardy, assured

4. new, newfangled, modern

5. mansion, shack, residence

6. spinster, unmarried woman, career woman

7. giggle, laugh, cackle

8. boring, routine, prosaic

9. noted, notorious, famous

10. assertive, confident, pushy 


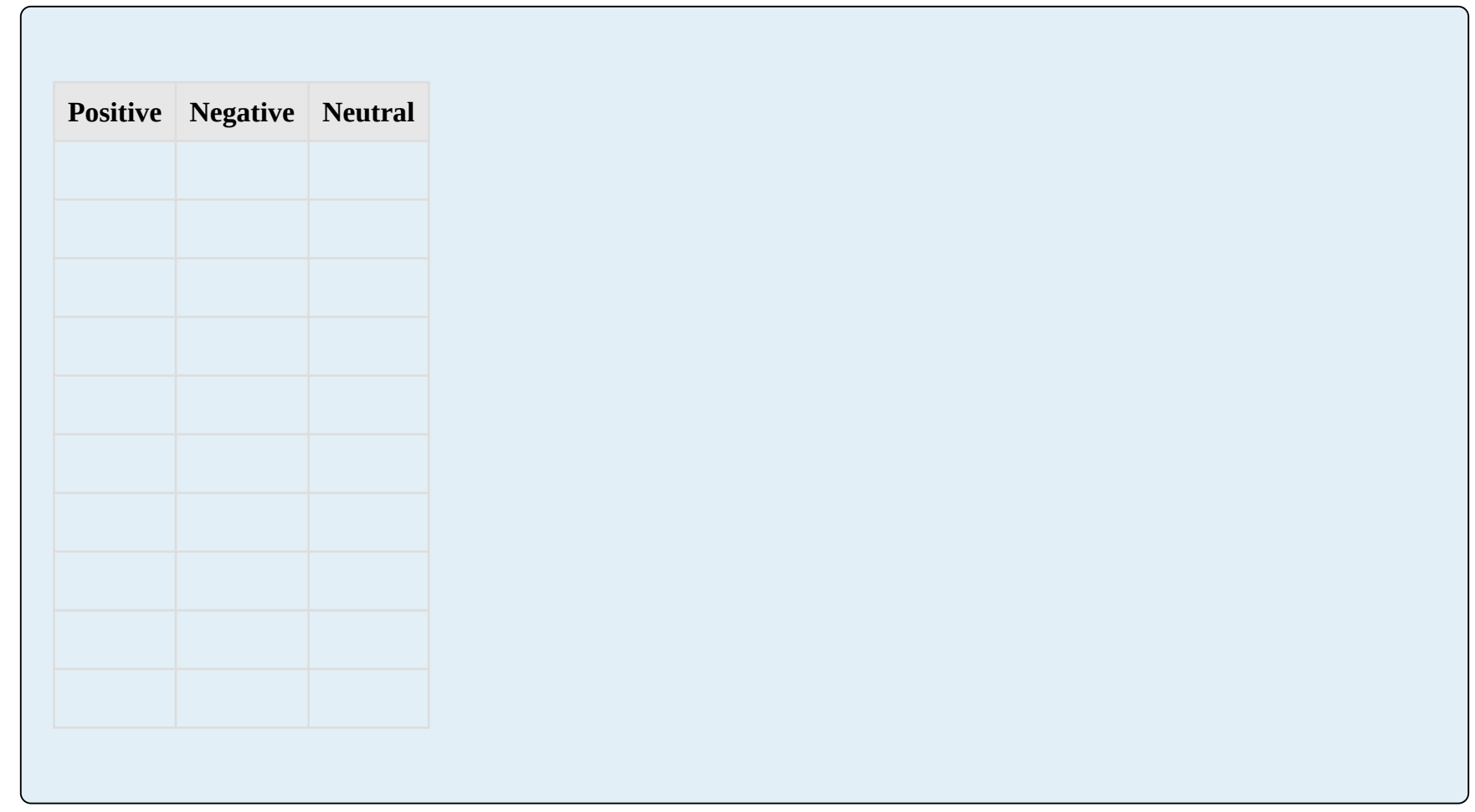

\section{Avoiding Slang}

Slang describes informal words that are considered nonstandard English. Slang often changes with passing fads and may be used by or familiar to only a specific group of people. Most people use slang when they speak and in personal correspondences, such as e-mails, text messages, and instant messages. Slang is appropriate between friends in an informal context but should be avoided in formal academic writing.

\section{Writing at Work}

Frequent exposure to media and popular culture has desensitized many of us to slang. In certain situations, using slang at work may not be problematic, but keep in mind that words can have a powerful effect. Slang in professional e-mails or during meetings may convey the wrong message or even mistakenly offend someone.

\section{Exercise 2}

Edit the following paragraph by replacing the slang words and phrases with more formal language. Rewrite the paragraph on your own sheet of paper. 
I felt like such an airhead when I got up to give my speech. As I walked toward the podium, I banged my knee on a chair. Man, I felt like such a klutz. On top of that, I kept saying "like" and "um," and I could not stop fidgeting. I was so stressed out about being up there. I feel like I've been practicing this speech 24/7, and I still bombed. It was ten minutes of me going off about how we sometimes have to do things we don't enjoy doing. Wow, did I ever prove my point. My speech was so bad I'm surprised that people didn't boo. My teacher said not to sweat it, though. Everyone gets nervous his or her first time speaking in public, and she said, with time, I would become a whiz at this speech giving stuff. I wonder if I have the guts to do it again.

Collaboration

Please share with a classmate and compare your answers.

\section{Avoiding Clichés}

Clichés are descriptive expressions that have lost their effectiveness because they are overused. Writing that uses clichés often suffers from a lack of originality and insight. Avoiding clichés in formal writing will help you write in original and fresh ways.

- Clichéd: Whenever my brother and I get into an argument, he always says something that makes my blood boil.

- Plain: Whenever my brother and I get into an argument, he always says something that makes me really angry.

- Original: Whenever my brother and I get into an argument, he always says something that makes me want to go to the gym and punch the bag for a few hours.

\section{Tip}

Think about all the cliché phrases that you hear in popular music or in everyday conversation. What would happen if these clichés were transformed into something unique?

\section{Exercise 3}

On your own sheet of paper, revise the following sentences by replacing the clichés with fresh, original descriptions. 
1. She is writing a memoir in which she will air her family's dirty laundry.

2. Fran had an ax to grind with Benny, and she planned to confront him that night at the party.

3. Mr. Muller was at his wit's end with the rowdy class of seventh graders.

4. The bottom line is that Greg was fired because he missed too many days of work.

5. Sometimes it is hard to make ends meet with just one paycheck.

6. My brain is fried from pulling an all-nighter.

7. Maria left the dishes in the sink all week to give Jeff a taste of his own medicine.

8. While they were at the carnival Janice exclaimed, “Time sure does fly when you are having fun!”

9. Jeremy became tongue-tied after the interviewer asked him where he saw himself in five years.

10. Jordan was dressed to the nines that night.

\section{Avoiding Overly General Words}

Specific words and images make your writing more interesting to read. Whenever possible, avoid overly general words in your writing; instead, try to replace general language with particular nouns, verbs, and modifiers that convey details and that bring yours words to life. Add words that provide color, texture, sound, and even smell to your writing.

- General: My new puppy is cute.

- Specific: My new puppy is a ball of white fuzz with the biggest black eyes I have ever seen.

- General: My teacher told us that plagiarism is bad.

- Specific: My teacher, Ms. Atwater, created a presentation detailing exactly how plagiarism is illegal and unethical.

\section{Exercise 4}

Revise the following sentences by replacing the overly general words with more precise and attractive language. Write the new sentences on your own sheet of paper.

1. Reilly got into her car and drove off.

2. I would like to travel to outer space because it would be amazing.

3. Jane came home after a bad day at the office. 
4. I thought Milo's essay was fascinating.

5. The dog walked up the street.

6. The coal miners were tired after a long day.

7. The tropical fish are pretty.

8. I sweat a lot after running.

9. The goalie blocked the shot.

10. I enjoyed my Mexican meal.

\section{Key Takeaways}

- Using a dictionary and thesaurus as you write will improve your writing by improving your word choice.

- Connotations of words may be positive, neutral, or negative.

- Slang, clichés, and overly general words should be avoided in academic writing.

\section{Writing Application}

Review a piece of writing that you have completed for school. Circle any sentences with slang, clichés, or overly general words and rewrite them using stronger language. 


\subsection{Prefixes and Suffixes}

\section{Learning Objectives}

1. Identify the meanings of common prefixes.

2. Become familiar with common suffix rules.

The English language contains an enormous and ever-growing number of words. Enhancing your vocabulary by learning new words can seem overwhelming, but if you know the common prefixes and suffixes of English, you will understand many more words.

Mastering common prefixes and suffixes is like learning a code. Once you crack the code, you can not only spell words more correctly but also recognize and perhaps even define unfamiliar words.

\section{Prefixes}

A prefix is a word part added to the beginning of a word to create a new meaning. Study the common prefixes in Table 4.2 "Common Prefixes".

\section{Tip}

The main rule to remember when adding a prefix to a word is not to add letters or leave out any letters. See Table 4.2 "Common Prefixes" for examples of this rule.

Table 4.2 Common Prefixes 


\begin{tabular}{|l|l|l|}
\hline Prefix & Meaning & Example \\
\hline dis & not, opposite of & dis + satisfied = dissatisfied \\
\hline mis & wrongly & mis + spell = misspell \\
\hline un & not & un + acceptable = unacceptable \\
\hline re & again & re + election = reelection \\
\hline inter & between & inter + related = interrelated \\
\hline pre & before & pre + pay = prepay \\
\hline non & not & non + sense = nonsense \\
\hline super & above & super + script = superscript \\
\hline sub & under & sub + merge = submerge \\
\hline anti & against, opposing & anti + bacterial = antibacterial \\
\hline
\end{tabular}

\section{Exercise 1}

Identify the five words with prefixes in the following paragraph, and write their meanings on a separate sheet of paper.

At first, I thought one of my fuzzy, orange socks disappeared in the dryer, but I could not find it in there. Because it was my favorite pair, nothing was going to prevent me from finding that sock. I looked all around my bedroom, under the bed, on top of the bed, and in my closet, but I still could not find it. I did not know that I would discover the answer just as I gave up my search. As I sat down on the couch in the family room, my Dad was reclining on his chair. I laughed when I saw that one of his feet was orange and the other blue! I forgot that he was color-blind. Next time he does laundry I will have to supervise him while he folds the socks so that he does not accidentally take one of mine!

Collaboration

Please share with a classmate and compare your answers.

\section{Exercise 2}

Add the correct prefix to the word to complete each sentence. Write the word on your own sheet of paper.

1. I wanted to ease my stomach comfort, so I drank some ginger root tea.

2. Lenny looked funny in his matched shirt and pants.

3. Penelope felt glamorous at the party because she was the only one not wearing a dress. 
4. My mother said those aging creams do not work, so I should not waste my money on them.

5. The child's standard performance on the test alarmed his parents.

6. When my sister first saw the meteor, she thought it was a natural phenomenon.

7. Even though she got an excellent job offer, Cherie did not want to locate to a different country.

8. With a small class size, the students get to act with the teacher more frequently.

9. I slipped on the ice because I did not heed the cautions about watching my step.

10. A combatant is another word for civilian.

\section{Suffixes}

A suffix is a word part added to the end of a word to create a new meaning. Study the suffix rules in the following boxes.

\section{Rule 1}

When adding the suffixes - ness and -ly to a word, the spelling of the word does not change.

\section{Examples:}

- dark + ness $=$ darkness

- scholar + ly = scholarly

Exceptions to Rule 1

When the word ends in $y$, change the $y$ to $i$ before adding -ness and -ly.

\section{Examples:}

- ready + ly = readily

- happy + ness $=$ happiness

\section{Rule 2}

When the suffix begins with a vowel, drop the silent $e$ in the root word.

\section{Examples:}

- $\quad$ care + ing $=$ caring 
- use + able $=$ usable

Exceptions to Rule 2

When the word ends in ce or ge, keep the silent $e$ if the suffix begins with $a$ or $o$.

Examples:

- replace + able $=$ replaceable

- courage + ous $=$ courageous

Rule 3

When the suffix begins with a consonant, keep the silent $e$ in the original word.

\section{Examples:}

- care + ful $=$ careful

- care + less $=$ careless

Exceptions to Rule 3

Examples:

- true + ly = truly

- argue + ment $=$ argument

Rule 4

When the word ends in a consonant plus $y$, change the $y$ to $i$ before any suffix not beginning with $i$.

\section{Examples:}

- sunny + er = sunnier

- hurry + ing = hurrying

\section{Rule 5}

When the suffix begins with a vowel, double the final consonant only if (1) the word has only one syllable or is accented on the last syllable and (2) the word ends in a single vowel followed by a single consonant.

\section{Examples:}

- $\tan +$ ing $=$ tanning $($ one syllable word $)$ 
- regret + ing = regretting (The accent is on the last syllable; the word ends in a single vowel followed by a single consonant.)

- cancel + ed $=$ canceled (The accent is not on the last syllable.)

- prefer + ed $=$ preferred

\section{Exercise 3}

On your own sheet of paper, write correctly the forms of the words with their suffixes.

1. refer + ed

2. refer + ence

3. mope + ing

4. approve $+\mathrm{al}$

5. green + ness

6. benefit + ed

7. resubmit + ing

8. use + age

9. greedy + ly

10. excite + ment

\section{Key Takeaways}

- A prefix is a word part added to the beginning of a word that changes the word's meaning.

- A suffix is a word part added to the end of a word that changes the word's meaning.

- Learning the meanings of prefixes and suffixes will help expand your vocabulary, which will help improve your writing.

\section{Writing Application}

Write a paragraph describing one of your life goals. Include five words with prefixes and five words with suffixes. Exchange papers with a classmate and circle the prefixes and suffixes in your classmate's paper. 
Correct each prefix or suffix that is spelled incorrectly. 


\subsection{Synonyms and Antonyms}

\section{Learning Objectives}

1. Recognize how synonyms improve writing.

2. Identify common antonyms to increase your vocabulary.

As you work with your draft, you will want to pay particular attention to the words you have chosen. Do they express exactly what you are trying to convey? Can you choose better, more effective words? Familiarity with synonyms and antonyms can be helpful in answering these questions.

\section{Synonyms}

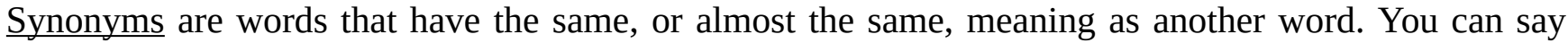
an "easy task" or a "simple task" because easy and simple are synonyms. You can say Hong Kong is a "large city" or a "metropolis" because city and metropolis are synonyms.

However, it is important to remember that not all pairs of words in the English language are so easily interchangeable. The slight but important differences in meaning between synonyms can make a big difference in your writing. For example, the words boring and insipid may have similar meanings, but the subtle differences between the two will affect the message your writing conveys. The word insipid evokes a scholarly and perhaps more pretentious message than boring.

The English language is full of pairs of words that have subtle distinctions between them. All writers, professionals and beginners alike, face the challenge of choosing the most appropriate synonym to best convey their ideas. When you pay particular attention to synonyms in your writing, it comes across to your reader. The sentences become much more clear and rich in meaning.

\section{Writing at Work}

Any writing you do at work involves a careful choice of words. For example, if you are writing an e-mail to your employer regarding your earnings, you can use the word pay, salary, or hourly wage. There are also other synonyms to choose from. Just keep in mind that the word you choose will have an effect on the reader, so you want to choose wisely to get the desired effect. 


\section{Exercise 1}

Replace the underlined words in the paragraph with appropriate synonyms. Write the new paragraph on your own sheet of paper.

When most people think of the Renaissance, they might think of artists like Michelangelo, Raphael, or Leonardo da Vinci, but they often overlook one of the very important figures of the Renaissance: Filippo Brunelleschi. Brunelleschi was born in Florence, Italy in 1377. He is considered the very best architect and engineer of the Renaissance. His impressive accomplishments are a testament to following one's dreams, persevering in the face of obstacles, and realizing one's vision.

The most difficult undertaking of Brunelleschi's career was the dome of Florence Cathedral, which took sixteen years to construct. A major blow to the progress of the construction happened in 1428. Brunelleschi had designed a special ship to carry the one hundred tons of marble needed for the dome. He felt this would be the most inexpensive way to transport the marble, but the unthinkable happened. The ship went down to the bottom of the water, taking all the marble with it to the bottom of the river. Brunelleschi was really sad. Nevertheless, he did not give up. He held true to his vision of the completed dome. Filippo Brunelleschi completed construction of the dome of Florence Cathedral in 1446. His influence on artists and architects alike was felt strongly during his lifetime and can still be felt in this day and age.

Collaboration

Please share with a classmate and compare your answers.

\section{Exercise 2}

On your own sheet of paper, write a sentence with each of the following words that illustrates the specific meaning of each synonym.

1. leave, abandon

2. mad, insane

3. outside, exterior

4. poor, destitute

5. quiet, peaceful

6. riot, revolt

7. rude, impolite

8. talk, conversation

9. hug, embrace

10. home, residence

\section{Collaboration}

Please share with a classmate and compare your answers. 


\section{Antonyms}

Antonyms are words that have the opposite meaning of a given word. The study of antonyms will not only help you choose the most appropriate word as you write; it will also sharpen your overall sense of language. Table 4.3 "Common Antonyms" lists common words and their antonyms.

Table 4.3 Common Antonyms

\begin{tabular}{|c|c|c|c|}
\hline Word & Antonym & Word & Antonym \\
\hline absence & presence & frequent & seldom \\
\hline accept & refuse & harmful & harmless \\
\hline accurate & inaccurate & horizontal & vertical \\
\hline advantage & disadvantage & imitation & genuine \\
\hline ancient & modern & inhabited & uninhabited \\
\hline abundant & scarce & inferior & superior \\
\hline artificial & natural & intentional & accidental \\
\hline attractive & repulsive & justice & injustice \\
\hline borrow & lend & knowledge & ignorance \\
\hline bravery & cowardice & landlord & tenant \\
\hline create & destroy, demolish & likely & unlikely \\
\hline bold & timid, meek & minority & majority \\
\hline capable & incapable & miser & spendthrift \\
\hline combine & separate & obedient & disobedient \\
\hline conceal & reveal & optimist & pessimist \\
\hline common & rare & permanent & temporary \\
\hline decrease & increase & plentiful & scarce \\
\hline definite & indefinite & private & public \\
\hline despair & hope & prudent & imprudent \\
\hline discourage & encourage & qualified & unqualified \\
\hline employer & employee & satisfactory & unsatisfactory \\
\hline expand & contract & tame & wild \\
\hline forget & remember & vacant & occupied \\
\hline
\end{tabular}




\section{Tip}

Learning antonyms is an effective way to increase your vocabulary. Memorizing words in combination with or in relation to other words often helps us retain them.

\section{Exercise 3}

Correct the following sentences by replacing the underlined words with an antonym. Write the antonym on your own sheet of paper.

1. The pilot who landed the plane was a coward because no one was injured.

2. Even though the botany lecture was two hours long, Gerard found it incredibly dull.

3. My mother says it is impolite to say thank you like you really mean it.

4. Although I have learned a lot of information through textbooks, it is life experience that has given me ignorance.

5. When our instructor said the final paper was compulsory, it was music to my ears!

6. My only virtues are coffee, video games, and really loud music.

7. Elvin was so bold when he walked in the classroom that he sat in the back row and did not participate.

8. Maria thinks elephants who live in freedom have a sad look in their eyes.

9. The teacher filled her students' minds with gloomy thoughts about their futures.

10. The guest attended to every one of our needs.

\section{Key Takeaways}

- Synonyms are words that have the same, or almost the same, meaning as another word.

- Antonyms are words that have the opposite meaning of another word.

- Choosing the right synonym refines your writing.

- Learning common antonyms sharpens your sense of language and expands your vocabulary. 
171 [Author removed at request of original publisher]

\section{Writing Application}

Write a paragraph that describes your favorite dish or food. Use as many synonyms as you can in the description, even if it seems too many. Be creative. Consult a thesaurus, and take this opportunity to use words you have never used before. Be prepared to share your paragraph. 


\subsection{Using Context Clues}

\section{Learning Objectives}

1. Identify the different types of context clues.

2. Practice using context clues while reading.

Context clues are bits of information within a text that will assist you in deciphering the meaning of unknown words. Since most of your knowledge of vocabulary comes from reading, it is important that you recognize context clues. By becoming more aware of particular words and phrases surrounding a difficult word, you can make logical guesses about its meaning. The following are the different types of context clues:

- Brief definition or restatement

- Synonyms and antonyms

- Examples

\section{Brief Definition or Restatement}

Sometimes a text directly states the definition or a restatement of the unknown word. The brief definition or restatement is signaled by a word or a punctuation mark. Consider the following example:

If you visit Alaska, you will likely see many glaciers, or slow moving masses of ice.

In this sentence, the word glaciers is defined by the phrase that follows the signal word or, which is slow moving masses of ice.

In other instances, the text may restate the meaning of the word in a different way, by using punctuation as a signal. Look at the following example:

Marina was indignant—fuming mad—when she discovered her brother had left for the party without her. 
Although fuming mad is not a formal definition of the word indignant, it does serve to define it. These two examples use signals - the word or and the punctuation dashes - to indicate the meaning of the unfamiliar word. Other signals to look for are the words is, as, means, known as, and refers to.

\section{Synonyms and Antonyms}

Sometimes a text gives a synonym of the unknown word to signal the meaning of the unfamiliar word:

When you interpret an image, you actively question and examine what the image connotes and suggests.

In this sentence the word suggests is a synonym of the word connotes. The word and sometimes signals synonyms.

Likewise, the word but may signal a contrast, which can help you define a word by its antonym.

I abhor clothes shopping, but I adore grocery shopping.

The word abhor is contrasted with its opposite: adore. From this context, the reader can guess that abhor means to dislike greatly.

\section{Examples}

Sometimes a text will give you an example of the word that sheds light on its meaning:

I knew Mark’s ailurophobia was in full force because he began trembling and stuttering when he saw my cat, Ludwig, slink out from under the bed.

Although ailurophobia is an unknown word, the sentence gives an example of its effects. Based on this example, a reader could confidently surmise that the word means a fear of cats.

Tip

Look for signal words like such as, for instance, and for example. These words signal that a word's meaning 
may be revealed through an example.

\section{Exercise 1}

Identify the context clue that helps define the underlined words in each of the following sentences. Write the context clue on your own sheet of paper.

1. Lucinda is very adroit on the balance beam, but Constance is rather clumsy.

2. I saw the entomologist, a scientist who studies insects, cradle the giant dung beetle in her palm.

3. Lance's comments about politics were irrelevant and meaningless to the botanist's lecture on plant reproduction.

4. Before I left for my trip to the Czech Republic, I listened to my mother's sage advice and made a copy of my passport.

5. His rancor, or hatred, for socializing resulted in a life of loneliness and boredom.

6. Martin was mortified, way beyond embarrassment, when his friends teamed up to shove him into the pool.

7. The petulant four-year-old had a baby sister who was, on the contrary, not grouchy at all.

8. The philosophy teacher presented the students with several conundrums, or riddles, to solve.

9. Most Americans are omnivores, people that eat both plants and animals.

10. Elena is effervescent, as excited as a cheerleader, for example, when she meets someone for the first time.

\section{Exercise 2}

On your own sheet of paper, write the name of the context clue that helps to define the underlined words.

Maggie was a precocious child to say the least. She produced brilliant watercolor paintings by the age of three. At first, her parents were flabbergasted — utterly blown away-by their daughter's ability, but soon they got used to their little painter. Her preschool teacher said that Maggie's dexterity, or ease with which she used her hands, was something she had never before seen in such a young child. Little Maggie never gloated or took pride in her paintings; she just smiled contentedly when she finished one and requested her parents give it to someone as a gift. Whenever people met Maggie for the first time they often watched her paint with their mouths agape, but her parents always kept their mouths closed and simply smiled over their "little Monet."

\section{Collaboration}

Please share with a classmate and compare your answers. 


\section{Tip}

In addition to context clues to help you figure out the meaning of a word, examine the following word parts: prefixes, roots, and suffixes.

\section{Writing at Work}

Jargon a type of shorthand communication often used in the workplace. It is the technical language of a special field. Imagine it is your first time working as a server in a restaurant and your manager tells you he is going to "eighty-six" the roasted chicken. If you do not realize that "eighty-six" means to remove an item from the menu, you could be confused.

When you first start a job, no matter where it may be, you will encounter jargon that will likely be foreign to you. Perhaps after working the job for a short time, you too will feel comfortable enough to use it. When you are first hired, however, jargon can be baffling and make you feel like an outsider. If you cannot decipher the jargon based on the context, it is always a good policy to ask.

\section{Key Takeaways}

- Context clues are words or phrases within a text that help clarify vocabulary that is unknown to you.

- There are several types of context clues including brief definition and restatement, synonyms and antonyms, and example.

\section{Writing Application}

Write a paragraph describing your first job. In the paragraph, use five words previously unknown to you. These words could be jargon words or you may consult a dictionary or thesaurus to find a new word. Make sure to provide a specific context clue for understanding each word. Exchange papers with a classmate and try to decipher the meaning of the words in each other's paragraphs based on the context clues. 


\subsection{Working with Words: End-of-Chapter Exercises}

\section{Learning Objectives}

1. Use the skills you have learned in the chapter.

2. Work collaboratively with other students.

\section{Exercises}

1. Proofread the paragraph and correct any commonly confused words and misspelled words.

Grunge, or the Seattle sound, is a type of rock music that became quiet popular in the late 1980s and early 1990s. It began in Seattle, Washington. Grunge musicians rejected the dramatic an expensive stage productions that were trendy at the time. There music was striped down with an emphasis on distorted electric guitars. Grunge musicians did not ware makeup or sport extravagent hairstyles like many of the day's rock musicians and bands. Many grunge musicians would by they're clothes from secondhand stores. The lyrics too grunge songs were also quit different compared two what was populer at the time. Grunge lyrics are charecterized by dark or socially conscience themes. Grunge music is still admired today buy music lovers of all ages.

2. Complete the following sentences by filling in the blank line with the correct homonym or frequently misspelled word.

a. Kevin asked me a serious question and (then, than) interrupted me when I attempted to answer.

b. A hot compress will

c. Jason was not a graceful

(lessen, lesson) the pain of muscle cramps. stormed off the basketball court.

d. Please consider the (looser, loser) because he knocked his chair over and diet.

e. _ (Except, Accept) for Ajay, we all had our tickets to the play.

f. I am ___ (threw, through) with this magazine, so you can read it if you like.

g. I don't care ___ (whose, who's) coming to the party and (whose, who's) not.

h. Crystal could (sea, see) the soaring hawk through her binoculars.

i. The (principal, principle) gave the students a very long lecture about peer pressure. j. Dr. Frankl nearly lost his (patience, patients) with one of his (patience, patients).

3. Rewrite the following personal essay by replacing the slang, clichés, and overly general language 
with stronger, more precise language.

My biggest regret happened in high school. I had always felt like a fish out of water, so during my sophomore year I was determined to fit in with the cool people. Man, was that an uphill battle. I don't even know why I tried, but hindsight is 20/20 I guess. The first thing I did was change the way I dressed. I went from wearing clothes I was comfortable in to wearing stuff that was so not me. Then I started wearing a ton of makeup, and my brother was all like, "What happened to your face?” Not only did my looks change, my personality changed a lot too. I started to act all stuck up and bossy with my friends, and they didn’t know how to respond to this person that used to be me. Luckily, this phase didn’t last more than a couple of months. I decided it was more fun to be me than to try to be someone else. I guess you can't fit a square peg in a round hole after all.

4. Write the correct synonym for each word.
a. lenient
(relaxed, callous)
b. abandon (vacate, deceive)
c. berate (criticize, encourage)
d. experienced (callow, matured)
e. spiteful (malevolent, mellow)
f. tame (subdued, wild)
g. tasty (savory, bland)
h. banal (common, interesting)
i. contradict (deny, revolt)
j. vain (boastful, simple) 


\section{Chapter 5: Help for English Language Learners}

5.1 Word Order

5.2 Negative Statements

5.3 Count and Noncount Nouns and Articles

5.4 Pronouns

5.5 Verb Tenses

5.6 Modal Auxiliaries

5.7 Prepositions

5.8 Slang and Idioms

5.9 Help for English Language Learners: End-of-Chapter Exercises 


\subsection{Word Order}

\section{Learning Objectives}

1. Identify the basic structures of sentences.

2. Determine ways to turn sentences into questions.

3. Define adjectives and how they are used.

If your first language is not English, you will most likely need some extra help when writing in Standard, or formal, English. New students of Standard English often make similar kinds of errors. Even if you have been speaking English for a long time, you may not feel as confident in your written English skills. This chapter covers the most common errors made by English language learners and helps you avoid similar mistakes in your writing.

\section{Basic Sentence Structures}

The most basic sentence structure in English is a subject plus a verb. A subject performs the action in the sentence, and the verb identifies the action. Keep in mind that in some languages, such as Spanish and Italian, an obvious subject does not always perform the action in a sentence; the subject is often implied by the verb. However, every sentence in English must have a subject and a verb to express a complete thought.

subject + verb

Samantha sleeps.

Not all sentences are as simple as a subject plus a verb. To form more complex sentences, writers build upon this basic structure. Adding a prepositional phrase to the basic sentence creates a more complex sentence. A preposition is a part of speech that relates a noun or a pronoun to another word in a sentence. It also introduces a prepositional phrase. If you can identify a preposition, you will be able to identify a prepositional phrase.

subject + verb + prepositional phrase

Samantha sleeps on the couch.

On is the preposition. On the couch is the prepositional phrase. 


\begin{tabular}{|l|l|l|}
\hline \multicolumn{3}{|c|}{ Common Prepositions } \\
\hline about & beside & off \\
\hline above & between & on \\
\hline across & by & over \\
\hline after & during & through \\
\hline against & except & to \\
\hline along & for & toward \\
\hline among & from & under \\
\hline around & in & until \\
\hline at & into & up \\
\hline before & like & with \\
\hline behind & of & without \\
\hline
\end{tabular}

\section{Exercise 1}

Copy the following sentences onto your own sheet of paper and underline the prepositional phrases.

1. Linda and Javier danced under the stars.

2. Each person has an opinion about the topic.

3. The fans walked through the gates.

4. Jamyra ran around the track.

5. Maria celebrated her birthday in January.

Another sentence structure that is important to understand is subject + verb + object. There are two types of objects: direct objects and indirect objects.

A direct object receives the action of the verb.

subject + verb + direct object

Janice writes a letter.

The letter directly receives the action of the verb writes. 


\section{Tip}

A quick way to find the direct object is to ask what? or who?

Sentence: Maurice kicked the ball.

What did Maurice kick? The direct object, ball.

Sentence: Maurice kicked Tom by accident.

Who did Maurice kick? The direct object, Tom.

An indirect object does not receive the action of the verb.

subject + verb + indirect object

Janice writes me a letter

The action (writes) is performed for or to the indirect object (me).

\section{Tip}

Even though the indirect object is not found after a preposition in English, it can be discovered by asking to whom? or for whom? after the verb.

Sentence: Dad baked the children some cookies.

For whom did Dad bake the cookies? The indirect object, children.

\section{Exercise 2}

On a separate sheet of paper, identify the subject, verb, direct object, and indirect object in the following sentences.

1. Captain Kirk told the crew a story.

2. Jermaine gave his girlfriend a dozen yellow tulips.

3. That hospital offers nurses better pay.

4. Dad served Grandma a delicious dinner.

5. Mom bought herself a new car. 


\section{Exercise 3}

On a separate sheet of paper, rewrite the sentences in the correct order. If the sentence is correct as it is, write OK.

1. The pizza Jeannine burnt.

2. To the Mexican restaurant we had to go for dinner.

3. Jeannine loved the food.

4. So full were we during the walk home.

5. I will make the pizza next time.

\section{Questions}

English speakers rely on the following two common ways to turn sentences into questions:

1. Move the helping verb and add a question mark.

2. Add the verb do, does, or did and add a question mark.

Move the helping verb and add a question mark.

Sentence: Sierra can pack these boxes.

Question: Can Sierra pack these boxes?

Add the verb do, does, or did, and add a question mark:

Sentence: Jolene skated across the pond.

Question: Did Jolene skate across the pond?

\section{Exercise 4}

On a separate sheet of paper, create questions from the following sentences.

1. Slumdog Millionaire is a film directed by Danny Boyle.

2. The story centers on a character named Jamal Malik.

3. He and his older brother find different ways to escape the slums.

4. His brother, Salim, pursues a life of crime. 
5. Jamal ends up on the game show Who Wants to Be a Millionaire?

\section{Adjectives}

An adjective is a kind of descriptive word that describes a noun or a pronoun. It tells which one, what kind, and how many. Adjectives make your writing more lively and interesting. Keep in mind, a common error that English language learners make is misplacing the adjectives in a sentence. It is important to know where to place the adjective in a sentence so that readers are not confused.

If you are using more than one adjective to describe a noun, place the adjectives in the following order before the noun:

1. Opinion: an interesting book, a boring movie, a fun ride

2. Size: a large box, a tiny turtle, a tall woman

3. Shape: a round ball, a long hose, a square field

4. Age: a new day, an old horse, a modern building

5. Color: an orange sunset, a green jacket, a red bug

6. Ethnicity: Italian cheese, French wine, Chinese tea

7. Material: silk shirt, wool socks, a cotton dress

Tip

Adjectives can also be placed at the end of a sentence if they describe the subject of a sentence and appear after the verb.

Sentence: My English teacher is excellent.

\section{Exercise 5}

On a separate sheet of paper, place the following sets of adjectives in the correct order before the noun. The first one has been done for you.

1. book: old, small, Spanish 
a small old Spanish book (age, size, ethnicity)

2. photograph: new, strange

3. suit: wool, green, funny

4. opinion: refreshing, new

5. dress: fashionable, purple

\section{Key Takeaways}

- The most basic sentence structure is a subject plus a verb that expresses a complete thought.

- Adding a prepositional phrase or a direct or indirect object to a sentence makes it more complex.

- English speakers change a sentence into a question in one of the following two ways: moving the helping verb and adding a question mark or adding the verb $d o$, does, or did and adding a question mark.

- Adjectives follow a particular order before the noun they describe. The order is opinion, size, shape, age, color, ethnicity, and material.

\section{Writing Application}

Write a paragraph about a memorable family trip. Use at least two adjectives to describe each noun in your paragraph. Proofread your paragraph, and then exchange papers with a classmate. Check your classmate's use of adjectives to make sure they are correct. 


\subsection{Negative Statements}

\section{Learning Objectives}

1. Identify a negative statement.

2. Write negative statements.

Negative statements are the opposite of positive statements and are necessary to express an opposing idea. The following charts list negative words and helping verbs that can be combined to form a negative statement.

\begin{tabular}{|l|l|l|}
\hline \multicolumn{2}{|l|}{ Negative Words } \\
\hline never & no & hardly \\
\hline nobody & none & scarcely \\
\hline no one & not & barely \\
\hline nowhere & & rarely \\
\hline
\end{tabular}

\begin{tabular}{|l|l|l|}
\hline \multicolumn{3}{|c|}{ Common Helping Verbs } \\
\hline am & is & are \\
\hline was & were & be \\
\hline being & been & have \\
\hline has & had & do \\
\hline does & did & can \\
\hline could & may & might \\
\hline must & will & should \\
\hline would & ought to & used to \\
\hline
\end{tabular}

The following examples show several ways to make a sentence negative in the present tense. 
1. A helping verb used with the negative word not.

Sentence: My guests are arriving now.

Negative: My guests are not arriving now.

2. The negative word no.

Sentence: Jennie has money.

Negative: Jennie has no money.

3. The contraction $n$ 't.

Sentence: Janetta does miss her mom.

Negative: Janetta doesn't miss her mom.

4. The negative adverb rarely.

Sentence: I always go to the gym after work.

Negative: I rarely go to the gym after work.

5. The negative subject nobody.

Sentence: Everybody gets the day off.

Negative: Nobody gets the day off.

\section{Exercise 1}

On a separate sheet of paper, rewrite the positive sentences as negative sentences. Be sure to keep the sentences in the present tense.

1. Everybody is happy about the mandatory lunch.

2. Deborah likes to visit online dating sites.

3. Jordan donates blood every six months.

4. Our writing instructor is very effective.

5. That beautiful papaya is cheap.

The following sentences show you the ways to make a sentence negative in the past tense.

Sentence: Paul called me yesterday.

Negative: Paul did not call me yesterday. 
Sentence: Jamilee went to the grocery store.

Negative: Jamilee never went to the grocery store.

Sentence: Gina laughed when she saw the huge pile of laundry.

Negative: Gina did not laugh when she saw the huge pile of laundry.

Notice that when forming a negative in the past tense, the helping verb did is what signals the past tense, and the main verb laugh does not have an -ed ending.

\section{Exercise 2}

Rewrite the following paragraph by correcting the errors in the past-tense negative sentences.

Celeste no did call me when she reached North Carolina. I was worried because she not drove alone before. She was going to meet her friend, Terry, who lived in a town called Asheville, North Carolina. I did never want to worry, but she said she was going to call when she reached there. Finally, four hours later, she called and said, “Mom, I’m sorry I did not call. I lost track of time because I was so happy to see Terry!” I was relieved.

Collaboration

Once you have found all the errors you can, please share with a classmate and compare your answers. Did your partner find an error you missed? Did you find an error your partner missed? Compare with your instructor's answers.

Double negatives are two negatives used in the same phrase or sentence. They are considered incorrect in Standard English. You should avoid using double negatives in all formal writing. If you want to say something negative, use only one negative word in the sentence. Return to the beginning of this section for a list of negative words, and then study the following examples.

\begin{tabular}{|l|l|}
\hline Double negative (incorrect) & Single negative (correct) \\
\hline $\begin{array}{l}\text { neg. + neg. } \\
\text { I couldn't find no paper }\end{array}$ & $\begin{array}{l}\text { neg. } \\
\text { I couldn't find any paper. }\end{array}$ \\
\hline $\begin{array}{l}\text { neg. + neg. } \\
\text { I don't want nothing. }\end{array}$ & $\begin{array}{l}\text { neg. } \\
\text { I don't want anything. }\end{array}$ \\
\hline
\end{tabular}

\section{Tip}

Ain't is considered a contraction of am not. Although some may use it in everyday speech, it is considered incorrect in Standard English. Avoid using it when speaking and writing in formal contexts. 


\section{Exercise 3}

On your own sheet of paper, correct the double negatives and rewrite the following sentences.

1. Jose didn't like none of the choices on the menu.

2. Brittany can't make no friends with nobody.

3. The Southwest hardly had no rain last summer.

4. My kids never get into no trouble.

5. I could not do nothing about the past.

\section{Key Takeaways}

- Negatives are usually formed using a negative word plus a helping verb.

- Double negatives are considered incorrect in Standard English.

- Only one negative word is used to express a negative statement.

\section{Writing Application}

Write a paragraph describing your favorite meal. Use rich, colorful language to describe the meal. Exchange papers with a classmate and read his or her paragraph. Then rewrite each sentence of your classmate's paragraph using negatives. Be sure to avoid double negatives. Share your negative paragraphs with each other. 


\subsection{Count and Noncount Nouns and Articles}

\section{Learning Objectives}

1. Define and use count and noncount nouns.

2. Recognize and use definite and indefinite articles.

Nouns are words that name things, places, people, and ideas. Right now, you may be surrounded by desks, computers, and notebooks. These are called count nouns because you can count the exact number of desks, computers, and notebooks—-three desks, one computer, and six notebooks, for example.

On the other hand, you may be carrying a small amount of money in your wallet and sitting on a piece of furniture. These are called noncount nouns. Although you can count the pieces of furniture or the amount of money, you cannot add a number in front of money or furniture and simply add $-s$ to the end of the noun. Instead, you must use other words and phrases to indicate the quantity of money and furniture.

Incorrect: five moneys, two furnitures

Correct: some money, two pieces of furniture

By the end of Section 5.3.1 "Count and Noncount Nouns", you will grasp the difference between the two types of nouns and be able to use them confidently in speaking and writing.

\section{Count and Noncount Nouns}

A count noun refers to people, places, and things that are separate units. You make count nouns plural by adding $-s$.

Table 5.1 Count Nouns 


\begin{tabular}{|l|l|} 
Count Noun & Sentence \\
\hline Quarter & It takes six quarters to do my laundry. \\
\hline Chair & Make sure to push in your chairs before leaving class. \\
\hline Candidate & The two candidates debated the issue. \\
\hline Adult & The three adults in the room acted like children. \\
\hline Comedian & The two comedians made the audience laugh. \\
\hline
\end{tabular}

A noncount noun identifies a whole object that cannot separate and count individually. Noncount nouns may refer to concrete objects or abstract objects. A concrete noun identifies an object you can see, taste, touch, or count. An abstract noun identifies an object that you cannot see, touch, or count. There are some exceptions, but most abstract nouns cannot be made plural, so they are noncount nouns. Examples of abstract nouns include anger, education, melancholy, softness, violence, and conduct.

Table 5.2 Types of Noncount Nouns

\begin{tabular}{|l|l|l|}
\hline $\begin{array}{l}\text { Type of Noncount } \\
\text { Noun }\end{array}$ & Examples & Sentence \\
\hline Food & sugar, salt, pepper, lettuce, rice & Add more sugar to my coffee, please. \\
\hline Solids & concrete, chocolate, silver, soap & $\begin{array}{l}\text { The ice cream was covered in creamy } \\
\text { chocolate. }\end{array}$ \\
\hline Abstract Nouns & $\begin{array}{l}\text { peace, warmth, hospitality, } \\
\text { information }\end{array}$ & $\begin{array}{l}\text { I need more information about the insurance } \\
\text { policy. }\end{array}$ \\
\hline
\end{tabular}

\section{Exercise 1}

On a separate sheet of paper, label each of the following nouns as count or noncount.

1. Electricity

2. Water

3. Book

4. Sculpture

5. Advice 


\section{Exercise 2}

On a separate sheet of paper, identify whether the italicized noun in the sentence is a count or noncount noun by writing $\mathbf{C}$ or $\mathbf{N C}$ above the noun.

1. The amount of traffic on the way home was terrible.

2. Forgiveness is an important part of growing up.

3. I made caramel sauce for the organic apples I bought.

4. I prefer film cameras instead of digital ones.

5. My favorite subject is history.

\section{Definite and Indefinite Articles}

The word the is a definite article. It refers to one or more specific things. For example, the woman refers to not any woman but a particular woman. The definite article the is used before singular and plural count nouns.

The words $a$ and an are indefinite articles. They refer to one nonspecific thing. For example, $a$ woman refers to any woman, not a specific, particular woman. The indefinite article $a$ or an is used before a singular count noun.

Definite Articles (The) and Indefinite Articles (A/An) with Count Nouns

I saw the concert. (singular, refers to a specific concert)

I saw the concerts. (plural, refers to more than one specific concert)

I saw the U2 concert last night. (singular, refers to a specific concert)

I saw a concert. (singular, refers to any nonspecific concert)

\section{Exercise 3}

On a separate sheet of paper, write the correct article in the blank for each of the following sentences. Write $O K$ if the sentence is correct.

1. (A/An/The) camel can live for days without water.

2. I enjoyed (a/an/the) pastries at the Bar Mitzvah. 
3. (A/An/The) politician spoke of many important issues.

4. I really enjoyed (a/an/the) actor's performance in the play.

5. (A/An/The) goal I have is to run a marathon this year.

\section{Exercise 4}

Correct the misused or missing articles and rewrite the paragraph.

Stars are large balls of spinning hot gas like our sun. The stars look tiny because they are far away. Many of them are much larger than sun. Did you know that a Milky Way galaxy has between two hundred billion and four hundred billion stars in it? Scientists estimate that there may be as many as five hundred billion galaxies in an entire universe! Just like a human being, the star has a life cycle from birth to death, but its lifespan is billions of years long. The star is born in a cloud of cosmic gas and dust called a nebula. Our sun was born in the nebula nearly five billion years ago. Photographs of the star-forming nebulas are astonishing.

\section{Collaboration}

Once you have found all the errors you can, share with a classmate and compare your answers. Did your partner find an error you missed? Did you find an error your partner missed? Compare with your instructor's answers.

\section{Key Takeaways}

- You can make count nouns plural by adding -s.

- Count nouns are individual people, places, or things that can be counted, such as politicians, deserts, or candles.

- Noncount nouns refer to whole things that cannot be made plural, such as salt, peace, or happiness.

- The is a definite article and is used to refer to a specific person, place, or thing, such as the Queen of England.

- A and an are indefinite articles, and they refer to nonspecific people, places, or things, such as an apple or a bicycle.

\section{Writing Application}

Write five sentences using the definite article the. Write five sentences using the indefinite article $a$ or $a n$. 
193 [Author removed at request of original publisher]

Exchange papers with a classmate and check each other's work. 


\subsection{Pronouns}

\section{Learning Objectives}

1. Recognize subject and object pronouns.

2. Identify possessive pronouns.

3. Determine common pronoun errors.

A pronoun is a word that can be used in place of the noun. We use pronouns so we do not have to repeat words. For example, imagine writing the following sentence: Afrah put her scarf on because Afrah was cold. The sentence sounds a bit strange because Afrah is named twice; however, if you use a pronoun, the sentence will be shorter and less repetitive. You might rewrite the sentence to something similar to the following: Afrah put her scarf on because she was cold. She refers to Afrah, so you do not have to write the name twice.

\section{Types of Pronouns}

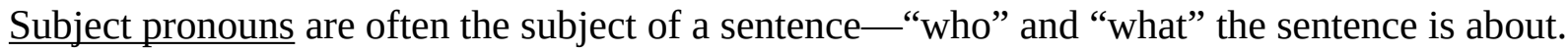

Sentence: She loves the desserts in France.

She is the subject.

Sentence: By lunch time, they were hungry.

They is the subject.

Object pronouns are often the object of the verb— "who" or "what" was acted upon.

Sentence: Melanie's thoughtfulness touched him.

Him is the object of the verb touched.

Sentence: We lifted it.

It is the object of the verb lifted. 


\section{Tip}

The masculine subject pronoun is he, and the masculine object pronoun is him. The feminine subject pronoun is she, and the feminine object pronoun is her.

A pronoun that shows possession or ownership is called a possessive pronoun.

Sentence: The teacher took her apple and left.

The pronoun her shows the teacher owns the apple.

Sentence: The hikers spotted their guide on the trail.

The pronoun their shows the hikers follow the guide who was assigned to the hikers.

Table 5.3 Pronouns

\begin{tabular}{|l|l|}
\hline Subject Pronouns & I, you, he, she, it, we, they \\
\hline Object Pronouns & me, you, him, her, it, us, them \\
\hline Possessive Pronouns & my (mine), your(s), his, hers, its, our(s), their(s) \\
\hline
\end{tabular}

\section{Exercise 1}

On a separate sheet of paper, complete the following sentences by circling the correct pronoun.

1. Unfortunately, the house was too expensive for (we, us, they).

2. I completed (mine, my, your) research paper, and she completed (his, hers, theirs).

3. My dog Buster is old, but (he, it, them) is very playful.

4. That ring belongs to my father, so it is (hers, his, theirs).

5. I cannot find my textbook, so I think (they, it, he) is lost.

\section{Common Pronoun Errors}

English language learners often make the same errors when using pronouns. The following examples illustrate common errors. 
Incorrect: Me and Daniela went to the restaurant for lunch.

This sentence is incorrect because an object pronoun (me) is used instead of a subject pronoun.

Correct: Daniela and I went to the restaurant for lunch.

This sentence is now correct because a subject pronoun $(I)$ is used.

Incorrect: Mark put her grocery bag on the counter.

This sentence is incorrect because the pronoun her refers to a female, and Mark is a male.

Correct: Mark put his grocery bag on the counter.

This sentence is now correct because the male pronoun his refers to the male person, Mark.

Incorrect: The woman she went to work earlier than usual.

This sentence is incorrect because the subject the woman is repeated by the pronoun she.

Correct: The woman went to work earlier than usual.

Correct: She went to work earlier than usual.

These sentences are now correct because the unnecessary repeated subject has been removed.

\section{Exercise 2}

On a separate sheet of paper, correct the following sentences that have pronoun errors. If the sentence is correct as it is, write $O K$.

1. Us are going to the county fair this weekend.

2. Steven did not want to see a movie because she had a headache.

3. The teacher congratulated Maria and me.

4. The eighth grade students they were all behaving mysteriously well.

5. Derrick and he received the best grade on the grammar test.

\section{Relative Pronouns}

A relative pronoun is a type of pronoun that helps connect details to the subject of the sentence and may 
197 [Author removed at request of original publisher]

often combine two shorter sentences. The relative pronouns are who, whom, whose, which or that.

Sentence: A relative pronoun is a type of pronoun.

The subject of this sentence is a relative pronoun. The clause is a type of pronoun gives some information about the subject.

The relative pronoun that may be added to give more details to the subject.

Sentence using a relative pronoun: A relative pronoun is a type of pronoun that helps connect details to the subject of the sentence.

Tip

Remember the following uses of relative pronouns:

- Who, whom, and whose refer only to people.

- Which refers to things.

- That refers to people or things.

The following examples show how a relative pronoun may be used to connect two sentences and to connect details to the subject.

Sentence 1: Gossip is a form of communication.

Sentence 2: It is a waste of time and energy.

Combination of 1 and 2: Gossip is a form of communication that is a waste of time and energy.

Notice how the relative pronoun that replaces the subject it in sentence 2.

That is called a relative pronoun because it connects the details (is a waste of time and energy) to the subject (Gossip).

Sentence 1: My grandmother is eighty years old.

Sentence 2: She collects seashells.

Combination of 1 and 2: My grandmother, who is eighty years old, collects seashells.

Notice how the relative pronoun who replaces the subject she in sentence 2.

Who is called a relative pronoun because it connects the details (is eighty years old) to the subject (My 
grandmother).

\section{Exercise 3}

On a separate sheet of paper, complete the following sentences by selecting the correct relative pronoun.

1. He showed me a photo (who, that) upset me.

2. Soccer is a fast moving game (who, that) has many fans worldwide.

3. Juan is a man (which, who) has high standards for everything.

4. Jamaica is a beautiful country (that, who) I would like to visit next year.

5. My mother only eats bananas (who, that) are green.

\section{Exercise 4}

On a separate sheet of paper, combine the two sentences into one sentence using a relative pronoun.

1. Jeff is a dependable person. He will never let you down.

2. I rode a roller coaster. It was scary.

3. At the beach, I always dig my feet into the sand. It protects them from the hot sun.

4. Jackie is trying not to use so many plastic products. They are not good for the environment.

5. My Aunt Sherry is teaching me how to drive. She has never been in accident or gotten a ticket.

\section{Key Takeaways}

- A pronoun is used in place of a noun.

- There are several types of pronouns, including subject and object pronouns, possessive pronouns, and relative pronouns.

- Subject pronouns are the "who" and "what" the sentence is about.

- Object pronouns are the "who" and "what" that receives the action.

- A possessive pronoun is a pronoun showing ownership.

- Common pronoun errors include mixing up subject, object, and gender pronouns, and repeating the subject of a sentence with a pronoun. 
199 [Author removed at request of original publisher]

- Relative pronouns help combine two separate sentences.

\section{Writing Application}

Proofread a piece of your writing for the types of pronoun errors discussed in this section. Correct any errors you come across. 


\subsection{Verb Tenses}

\section{Learning Objectives}

1. Identify simple verb tenses.

2. Recognize to be, to have, and to do verbs.

3. Use perfect verb tenses.

4. Apply progressive verb tenses.

5. Define gerunds and infinitives.

You must always use a verb in every sentence you write. Verbs are parts of speech that indicate actions or states of being. The most basic sentence structure is a subject followed by a verb.

\section{Simple Verb Tenses}

Verb tenses tell the reader when the action takes place. The action could be in the past, present, or future.

\begin{tabular}{|l|l|l|}
\hline Past & $\leftarrow$ Present $\rightarrow$ & Future \\
\hline Yesterday I jumped. & Today I jump. & Tomorrow I will jump. \\
\hline
\end{tabular}

Simple present verbs are used in the following situations:

1. When the action takes place now

I drink the water greedily.

2. When the action is something that happens regularly

I always cross my fingers for good luck.

3. When describing things that are generally true

College tuition is very costly.

Table 5.4 Regular Simple Present Tense Verbs 
201 [Author removed at request of original publisher]

\begin{tabular}{|l|l|l|l|l|l|}
\hline Verb & I & He/She/It & You & We & They \\
\hline ask & ask & asks & ask & ask & ask \\
\hline bake & bake & bakes & bake & bake & bake \\
\hline cook & cook & cooks & cook & cook & cook \\
\hline cough & cough & coughs & cough & cough & cough \\
\hline clap & clap & claps & clap & clap & clap \\
\hline dance & dance & dances & dance & dance & dance \\
\hline erase & erase & erases & erase & erase & erase \\
\hline kiss & kiss & kisses & kiss & kiss & kiss \\
\hline push & push & pushes & push & push & push \\
\hline wash & wash & washes & wash & wash & wash \\
\hline
\end{tabular}

When it is he, she, or it doing the present tense action, remember to add $-s$, or -es to the end of the verb or to change the $y$ to -ies.

Simple past verbs are used when the action has already taken place and is now finished:

- I washed my uniform last night.

- I asked for more pie.

- I coughed loudly last night.

Table 5.5 Regular Simple Past Tense Verbs

\begin{tabular}{|l|l|l|l|l|l|}
\hline Verb & I & He/She/It & You & We & They \\
\hline ask & asked & asked & asked & asked & asked \\
\hline bake & baked & baked & baked & baked & baked \\
\hline cook & cooked & cooked & cooked & cooked & cooked \\
\hline cough & coughed & coughed & coughed & coughed & coughed \\
\hline clap & clapped & clapped & clapped & clapped & clapped \\
\hline dance & danced & danced & danced & danced & danced \\
\hline erase & erased & erased & erased & erased & erased \\
\hline kiss & kissed & kissed & kissed & kissed & kissed \\
\hline push & pushed & pushed & pushed & pushed & pushed \\
\hline wash & washed & washed & washed & washed & washed \\
\hline
\end{tabular}


When he, she, or it is doing the action in the past tense, remember to add $-d$ or $-e d$ to the end of regular verbs.

Simple future verbs are used when the action has not yet taken place:

- I will work late tomorrow.

- I will kiss my boyfriend when I see him.

- I will erase the board after class.

Table 5.6 Regular Simple Future Tense Verbs

\begin{tabular}{|l|l|l|l|l|l|}
\hline Verb & I & He/She/It & You & We & They \\
\hline ask & will ask & will ask & will ask & will ask & will ask \\
\hline bake & will bake & will bake & will bake & will bake & will bake \\
\hline cook & will cook & will cook & will cook & will cook & will cook \\
\hline cough & will cough & will cough & will cough & will cough & will cough \\
\hline clap & will clap & will clap & will clap & will clap & will clap \\
\hline dance & will dance & will dance & will dance & will dance & will dance \\
\hline erase & will erase & will erase & will erase & will erase & will erase \\
\hline kiss & will kiss & will kiss & will kiss & will kiss & will kiss \\
\hline push & will push & will push & will push & will push & will push \\
\hline wash & will wash & will wash & will wash & will wash & will wash \\
\hline
\end{tabular}

Going to can also be added to the main verb to make it future tense:

- I am going to go to work tomorrow.

\section{Exercise 1}

On a separate sheet of paper, complete the following sentences by adding the verb in the correct simple tense.

1. Please do not (erase, erased, will erase) what I have written on the board.

2. They (dance, danced, will dance) for hours after the party was over.

3. Harrison (wash, washed, will wash) his laundry after several weeks had passed.

4. Yesterday Mom (ask, asked, will ask) me about my plans for college.

5. I (bake, baked, will bake) several dozen cookies for tomorrow's bake sale. 


\section{Exercise 2}

Correct the verb tense mistakes in the following paragraph.

Last summer, I walk around Walden Pond. Walden Pond is in Concord, Massachusetts. It is where the philosopher Henry David Thoreau will live during the mid-nineteenth century. During his time there, he wrote a book called Walden. Walden is a book of Thoreau's reflections on the natural environment. It will be consider a classic in American literature. I did not know that Walden Pond is consider the birthplace of the environmental movement. It was very relaxing there. I will listen to birds, frogs, and crickets, not to mention the peaceful sound of the pond itself.

Collaboration

Once you have found all the errors you can, please share with a classmate and compare your answers. Did your partner find an error you missed? Did you find an error your partner missed? Compare with your instructor's answers.

\section{To Be, To Do, and To Have}

There are some irregular verbs in English that are formed in special ways. The most common of these are the verbs to be, to have, and to do.

Table 5.7 Verb Forms of To Be, To Do, and To Have

\begin{tabular}{|l|l|l|l|}
\hline Base Form & Present Tense Form & Past Tense Form & Future Tense Form \\
\hline be & am/is/are & was/were & will be \\
\hline do & do/does & did & will do \\
\hline have & have/has & had & will have \\
\hline
\end{tabular}

\section{Tip}

Memorize the present tense forms of to be, to do, and to have. A song or rhythmic pattern will make them easier to memorize.

Review these examples of to be, to do, and to have used in sentences. 


\begin{tabular}{|l|l|l|}
\hline Past & $\leftarrow$ Present $\rightarrow$ & Future \\
\hline To Be & \multicolumn{2}{|l|}{} \\
\hline Yesterday I was angry. & Today I am not angry. & Tomorrow I will be angry. \\
\hline To Do & \multicolumn{2}{|l|}{} \\
\hline I did my best yesterday. & I do my best every day. & Tomorrow I will do my best. \\
\hline To Have & \multicolumn{2}{|l|}{} \\
\hline Yesterday I had ten dollars. & Today I have ten dollars. & Tomorrow I will have ten dollars. \\
\hline
\end{tabular}

Remember the following uses of to be, to have and to do:

To Be

- $\mathrm{I} \rightarrow$ am/was/will be

- you/we/they $\rightarrow$ are/were/will be

- he/she/it $\rightarrow$ is/was/will be

To Have

- I/you/we/they $\rightarrow$ have/had/will have

- he/she/it $\rightarrow$ has/had/will have

To Do

- I/you/we/they $\rightarrow$ do/did/will do

- he/she/it $\rightarrow$ does/did/will do

\section{Tip}

Remember, if you have a compound subject like Marie and Jennifer, think of the subject as they to determine the correct verb form.

- Marie and Jennifer (they) have a house on Bainbridge Island.

Similarly, single names can be thought of as he, she, or it.

- LeBron (he) has scored thirty points so far. 


\section{Exercise 3}

On a separate sheet of paper, complete the following sentences by circling the correct form of the verbs to be, to have, and to do in the three simple tenses.

1. Stefan always (do, does, will do) his taxes the day before they are due.

2. We (are, is, was) planning a surprise birthday party for my mother.

3. Turtles (have, had, has) the most beautiful patterns on their shells.

4. I always (do, did, will do) my homework before dinner, so I can eat in peace.

5. You (is, are, was) so much smarter than you think!

\section{Perfect Verb Tenses}

Up to this point, we have studied the three simple verb tenses-simple present, simple past, and simple future. Now we will add three more tenses, which are called perfect tenses. They are present perfect, past perfect, and future perfect. These are the three basic tenses of English. A past participle is often called the $-e d$ form of a verb because it is formed by adding $-d$ or $-e d$ to the base form of regular verbs. Past participles can also end in -t or -en. Keep in mind, however, the past participle is also formed in various other ways for irregular verbs. The past participle can be used to form the present perfect tense.

Review the following basic formula for the present perfect tense:

$$
\begin{array}{|l|l|l|}
\hline \text { Subject } & + & \text { has or have } \\
\hline \text { I } & \text { have } & \text { past participle } \\
\hline
\end{array}
$$

The present perfect tense has a connection with the past and the present.

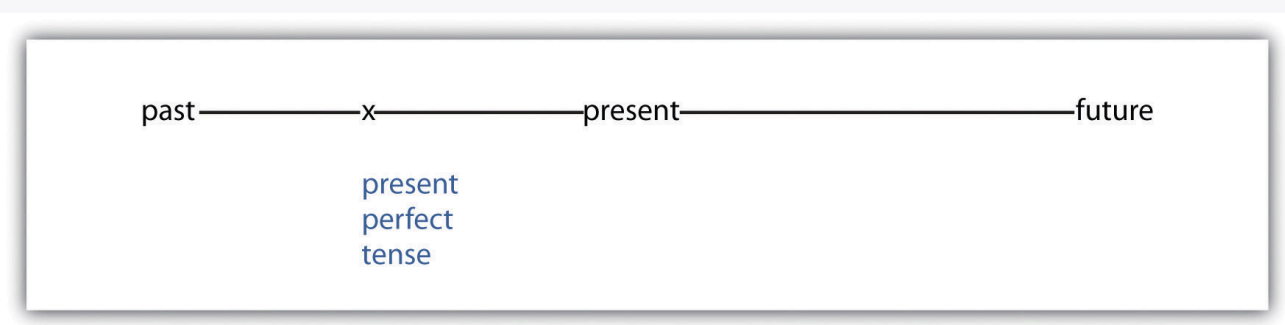

Use the present perfect tense to describe a continuing situation and to describe an action that has just happened.

- I have worked as a caretaker since June. 
This sentence tells us that the subject has worked as a caretaker in the past and is still working as a caretaker in the present.

- Dmitri has just received an award from the Dean of Students.

This sentence tells us that Dmitri has very recently received the award. The word just emphasizes that the action happened very recently.

Study the following basic formula for the past perfect tense:

\begin{tabular}{|c|c|c|c|c|}
\hline Subject & + & had or have & + & past participle \\
\hline I & & had & & listened \\
\hline
\end{tabular}

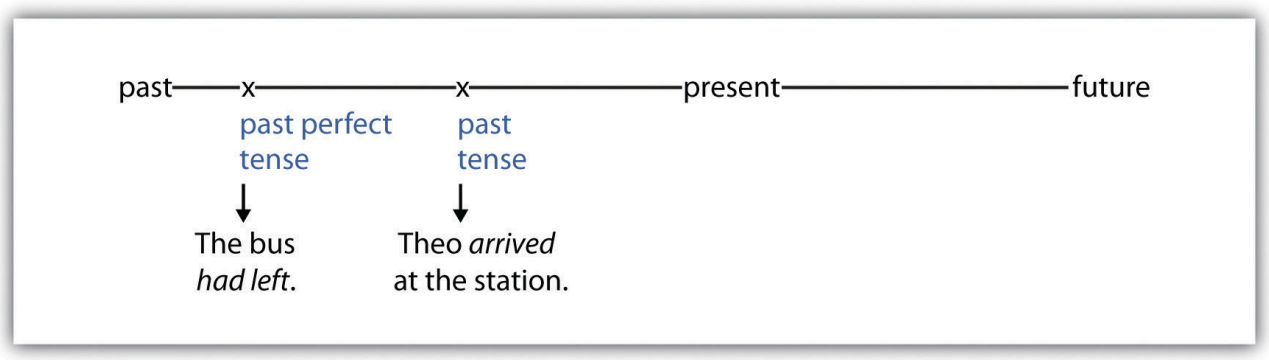

- The bus had left by the time Theo arrived at the station.

Notice that both actions occurred entirely in the past, but one action occurred before the other. At some time in the past, Theo arrived (simple past tense) at the station, but at some time before that, the bus had left (past perfect).

Look at the following basic formula for the future perfect tense:

$$
\begin{array}{|l|l|l|l|}
\hline \text { Subject } & + \text { will have } & + & \text { past participle } \\
\hline \text { I } & \text { will have } & \text { graduated } \\
\hline
\end{array}
$$




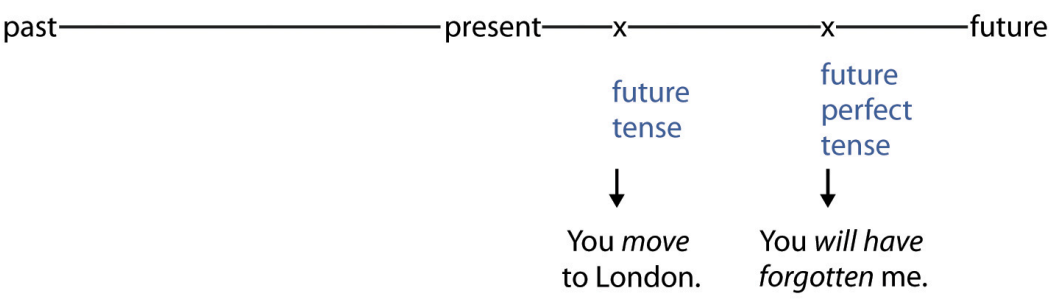

The future perfect tense describes an action from the past in the future, as if the past event has already occurred. Use the future perfect tense when you anticipate completing an event in the future, but you have not completed it yet.

- You will have forgotten me after you move to London.

Notice that both actions occur in the future, but one action will occur before the other. At some time in the future, the subject (you) will move (future tense) to London, and at some time after that, the subject will have forgotten (future perfect tense) the speaker, me.

\section{Exercise 4}

On a separate sheet of paper, complete the following sentences by using the correct perfect verb tense for the verb in parentheses.

1. I plan to start a compost bin because I (to want) one for a long time now.

2. My brother told me he (to argue) with his friend about politics.

3. By the time we reach the mountain top the sun (to set).

4. Denise (to walk) several miles in the past three hours.

5. His mother (to offer) to pay him to work in her office.

\section{Progressive Verb Tenses}

Progressive verb tenses describe a continuing or unfinished action, such as I am going, I was going, or I will be going.

The present progressive tense describes an action or state of being that takes place in the present and that continues to take place. 
To make verbs in the present progressive tense, combine these two parts:

\begin{tabular}{|l|l|l|}
\hline Present tense form of to be & + & -ing (present participle) \\
\hline am/is/are & help & helping \\
\hline
\end{tabular}

You should use the present progressive tense to describe a planned activity, to describe an activity that is recurring right now, and to describe an activity that is in progress, although not actually occurring at the time of speaking:

- Preeti is starting school on Tuesday.

This sentence describes a planned activity.

- Janetta is getting her teeth cleaned right now.

This sentence describes an activity that is occurring right now.

- I am studying ballet at school.

This sentence describes an activity that is in progress but not actually occurring at the time of speaking.

The past progressive tense describes an action or state of being that took place in the past and that continues to take place.

To make verbs in the past progressive tense, combine these two parts:

\begin{tabular}{|l|l|l|}
\hline Past tense form of to be & + & -ing (present participle) \\
\hline was/were & helping \\
\hline
\end{tabular}

You should use the past progressive tense to describe a continuous action in the past, to describe a past activity in progress while another activity occurred, or to describe two past activities in progress at the same time:

- Ella and I were planning a vacation.

This sentence describes a continuous action in the past.

- I was helping a customer when I smelled delicious fried chicken.

This sentence describes a past activity in progress while another activity occurred.

- While I was finishing my homework, my wife was talking on the phone.

This sentence describes two past activities in progress at the same time. 
The future progressive tense describes an action or state of being that will take place in the future and that will continue to take place. The action will have started at that future moment, but it will not have finished at that moment.

To make verbs in the future progressive tense, combine these parts:

\begin{tabular}{|l|l|l|}
\hline Future tense form of to be & + & -ing (present participle) \\
\hline will be & helping \\
\hline
\end{tabular}

Use the future progressive tense to describe an activity that will be in progress in the future:

- Samantha and I will be dancing in the school play next week.

- Tomorrow Agnes will be reading two of her poems.

\section{Exercise 5}

On a separate sheet of paper, revise the following sentences, written in simple tenses, using the progressive tenses indicated in parentheses.

1. He prepared the food while I watched. (past progressive tense)

2. Jonathan will speak at the conference. (future progressive)

3. Josie traveled to Egypt last July. (past progressive tense)

4. My foot aches, so I know it will rain. (present progressive tense)

5. Micah will talk a lot when I see him. (future progressive)

6. I yawn a lot because I feel tired. (present progressive tense)

Similar to the present perfect tense, the present perfect progressive tense is used to indicate an action that was begun in the past and continues into the present. However, the present perfect progressive is used when you want to stress that the action is ongoing.

To make verbs in the present perfect progressive tense, combine the following parts:

\begin{tabular}{|c|c|c|c|c|}
\hline Present tense form of to have & + & Been & + & -ing (present participle) \\
\hline has or have & & been & & helping \\
\hline
\end{tabular}

- She has been talking for the last hour.

This sentence indicates that she started talking in the past and is continuing to talk in the present. 
- I have been feeling tired lately.

This sentence indicates that $I$ started feeling tired in the past, and $I$ continue to feel tired in the present. Instead of indicating time, as in the first sentence, the second sentence uses the adverb lately. You can also use the adverb recently when using the present perfect progressive tense.

Similar to the past perfect tense, the past perfect progressive tense is used to indicate an action that was begun in the past and continued until another time in the past. The past perfect progressive does not continue into the present but stops at a designated moment in the past.

To make verbs in the past perfect progressive tense, combine the following parts:

\begin{tabular}{|c|c|c|c|c|}
\hline Past tense form of to have & + & been & + & -ing (present participle) \\
\hline had & & been & & helping \\
\hline
\end{tabular}

- The employees had been talking until their boss arrived.

This sentence indicates that the employees were talking in the past and they stopped talking when their boss arrived, which also happened in the past.

- I had been working all day.

This sentence implies that $I$ was working in the past. The action does not continue into the future, and the sentence implies that the subject stopped working for unstated reasons.

The future perfect progressive tense is rarely used. It is used to indicate an action that will begin in the future and will continue until another time in the future.

To make verbs in the future perfect progressive tense, combine the following parts:

\begin{tabular}{|c|c|c|c|c|}
\hline Future tense form of to have & + & been & + & -ing (present participle) \\
\hline will have & & Been & & helping \\
\hline
\end{tabular}

- By the end of the meeting, I will have been hearing about mortgages and taxes for eight hours.

This sentence indicates that in the future $I$ will hear about mortgages and taxes for eight hours, but it has not happened yet. It also indicates the action of hearing will continue until the end of the meeting, something that is also in the future. 


\section{Gerunds}

A gerund is a form of a verb that is used as a noun. All gerunds end in -ing. Since gerunds function as nouns, they occupy places in a sentence that a noun would, such as the subject, direct object, and object of a preposition.

You can use a gerund in the following ways:

\section{As a subject}

Traveling is Cynthia’s favorite pastime.

2. As a direct object

I enjoy jogging.

\section{As an object of a proposition}

The librarian scolded me for laughing.

Often verbs are followed by gerunds. Study Table 5.8 “Gerunds and Verbs” for examples.

Table 5.8 Gerunds and Verbs

\begin{tabular}{|l|l|}
\hline Gerund & Verb Followed by a Gerund \\
\hline moving & Denise considered moving to Paris. \\
\hline cleaning & I hate cleaning the bathroom. \\
\hline winning & Nate imagines winning an Oscar one day. \\
\hline worrying & Mom says she has stopped worrying. \\
\hline taking & She admitted taking the pumpkin. \\
\hline
\end{tabular}

\section{Infinitives}

An infinitive is a form of a verb that comes after the word to and acts as a noun, adjective, or adverb.

to + verb $=$ infinitive

Examples of infinitives include to move, to sleep, to look, to throw, to read, and to sneeze.

Often verbs are followed by infinitives. Study Table 5.9 “Infinitives and Verbs” for examples. 


\begin{tabular}{|l|l|}
\hline Infinitive & Verb Followed by Infinitive \\
\hline to help & Jessica offered to help her move. \\
\hline to arrive & Mick expects to arrive early. \\
\hline to win & Sunita wants to win the writing contest. \\
\hline to close & He forgot to close the curtains. \\
\hline to eat & She likes to eat late. \\
\hline
\end{tabular}

You may wonder which verbs can be followed by gerunds and which verbs can be followed by infinitives. With the following verbs, you can use either a gerund or an infinitive.

Table 5.10 Infinitives and Gerunds Verbs

\begin{tabular}{|l|l|}
\hline Base Form of Verb & Sentences with Verbs Followed by Gerunds and Infinitives \\
\hline begin & 1. John began crying. \\
\hline 2. John began to cry. \\
\hline hate & 1. Marie hated talking on the phone. \\
\hline 2. Marie hated to talk on the phone. \\
\hline forget & 1. Wendell forgot paying the bills. \\
\hline like & 1. Wendell forgot to pay the bills. \\
\hline 2. I liked leaving messages. \\
\hline continue & 1. He continued listening to the news. \\
\hline 2. He continued to listen to the news. \\
\hline start & 1. I will start recycling immediately. \\
\hline 2. I will start to recycle immediately.
\end{tabular}




\section{Exercise 6}

On your own sheet of paper, complete the following sentences by choosing the correct infinitive or gerund.

1. I meant (to kiss, kissing) my kids before they left for school.

2. The children hoped (to go, going) to a restaurant for dinner.

3. Do you intend (to eat, eating) the entire pie?

4. Crystal postponed (to get dressed, getting dressed) for the party.

5. When we finish (to play, playing) this game, we will go home.

\section{Key Takeaways}

- Verb tenses tell the reader when the action takes place.

- Actions could be in the past, present, or future.

- There are some irregular verbs in English that are formed in special ways. The most common of these irregular verbs are the verbs to be, to have, and to do.

- There are six main verb tenses in English: simple present, simple past, simple future, present perfect, past perfect, and future perfect.

- Verbs can be followed by either gerunds or infinitives.

\section{Writing Application}

Write about a lively event that is either remembered or imagined. Ask yourself the following three questions: What happened during the event? What happened after the event? Looking back, what do you think of the event now? Answer each question in a separate paragraph to keep the present, past, and future tense verbs separate. 


\subsection{Modal Auxiliaries}

\section{Learning Objectives}

1. Define and identify modal auxiliaries.

2. Learn how and when to use modal auxiliaries.

We all need to express our moods and emotions, both in writing and in our everyday life. We do this by using modal auxiliaries.

\section{Modal Auxiliaries}

Modal auxiliaries are a type of helping verb that are used only with a main verb to help express its mood.

The following is the basic formula for using a modal auxiliary:

\begin{tabular}{|l|l|l|l|l|}
\hline Subject & + & modal auxiliary & + & main verb \\
\hline James & & may & & call \\
\hline
\end{tabular}

There are ten main modal auxiliaries in English.

Table 5.11 Modal Auxiliaries 


\begin{tabular}{|c|c|c|}
\hline $\begin{array}{l}\text { Modal } \\
\text { Auxiliary }\end{array}$ & Use & Modal Auxiliary + Main Verb \\
\hline \multirow[b]{2}{*}{ can } & \multirow[b]{2}{*}{ Expresses an ability or possibility } & I can lift this forty-pound box. (ability) \\
\hline & & $\begin{array}{l}\text { We can embrace green sources of energy. } \\
\text { (possibility) }\end{array}$ \\
\hline \multirow{3}{*}{ could } & \multirow{3}{*}{$\begin{array}{l}\text { Expresses an ability in the past; a present possibility; } \\
\text { a past or future permission }\end{array}$} & $\begin{array}{l}\text { I could beat you at chess when we were } \\
\text { kids. (past ability) }\end{array}$ \\
\hline & & We could bake a pie! (present possibility) \\
\hline & & $\begin{array}{l}\text { Could we pick some flowers from the } \\
\text { garden? (future permission) }\end{array}$ \\
\hline \multirow{3}{*}{ may } & \multirow{3}{*}{$\begin{array}{l}\text { Expresses uncertain future action; permission; ask a } \\
\text { yes-no question }\end{array}$} & $\begin{array}{l}\text { I may attend the concert. (uncertain future } \\
\text { action) }\end{array}$ \\
\hline & & You may begin the exam. (permission) \\
\hline & & $\begin{array}{l}\text { May I attend the concert? (yes-no } \\
\text { questions) }\end{array}$ \\
\hline might & Expresses uncertain future action & $\begin{array}{l}\text { I might attend the concert (uncertain future } \\
\text { action—same as may) }\end{array}$ \\
\hline shall & Expresses intended future action & $\begin{array}{l}\text { I shall go to the opera. (intended future } \\
\text { action) }\end{array}$ \\
\hline \multirow{2}{*}{ should } & \multirow{2}{*}{ Expresses obligation; ask if an obligation exists } & $\begin{array}{l}\text { I should mail my RSVP. (obligation, same } \\
\text { as ought to) }\end{array}$ \\
\hline & & $\begin{array}{l}\text { Should I call my mother? (asking if an } \\
\text { obligation exists) }\end{array}$ \\
\hline \multirow{3}{*}{ will } & \multirow{3}{*}{$\begin{array}{l}\text { Expresses intended future action; ask a favor; ask for } \\
\text { information }\end{array}$} & $\begin{array}{l}\text { I will get an A in this class. (intended future } \\
\text { action) }\end{array}$ \\
\hline & & Will you buy me some chocolate? (favor) \\
\hline & & Will you be finished soon? (information) \\
\hline \multirow{4}{*}{ would } & \multirow{4}{*}{$\begin{array}{l}\text { States a preference; request a choice politely; explain } \\
\text { an action; introduce habitual past actions }\end{array}$} & I would like the steak, please. (preference) \\
\hline & & $\begin{array}{l}\text { Would you like to have breakfast in bed? } \\
\text { (request a choice politely) }\end{array}$ \\
\hline & & $\begin{array}{l}\text { I would go with you if I didn't have to } \\
\text { babysit tonight. (explain an action) }\end{array}$ \\
\hline & & $\begin{array}{l}\text { He would write to me every week when we } \\
\text { were dating. (habitual past action) }\end{array}$ \\
\hline must & Expresses obligation & We must be on time for class. \\
\hline ought to & Expresses obligation & $\begin{array}{l}\text { I ought to mail my RSVP. (obligation, } \\
\text { same as may) }\end{array}$ \\
\hline
\end{tabular}


Tip

Use the following format to form a yes-no question with a modal auxiliary:

\begin{tabular}{|c|c|c|c|c|}
\hline Modal auxiliary & + & subject & + & main verb \\
\hline Should & & I & & drive? \\
\hline
\end{tabular}

Be aware of these four common errors when using modal auxiliaries:

1. Using an infinitive instead of a base verb after a modal

Incorrect: I can to move this heavy table.

Correct: I can move this heavy table.

2. Using a gerund instead of an infinitive or a base verb after a modal

Incorrect: I could moving to the United States.

Correct: I could move to the United States.

3. Using two modals in a row

Incorrect: I should must renew my passport.

Correct: I must renew my passport.

Correct: I should renew my passport.

4. Leaving out a modal

Incorrect: I renew my passport.

Correct: I must renew my passport.

\section{Exercise 1}

Edit the following paragraph by correcting the common modal auxiliary errors.

I may to go to France on vacation next summer. I shall might visit the Palace of Versailles. I would to drive around the countryside. I could imagining myself living there; however, I will not move to France because 


\section{Modals and Present Perfect Verbs}

In the previous section, we defined present perfect verb tense as describing a continuing situation or something that has just happened.

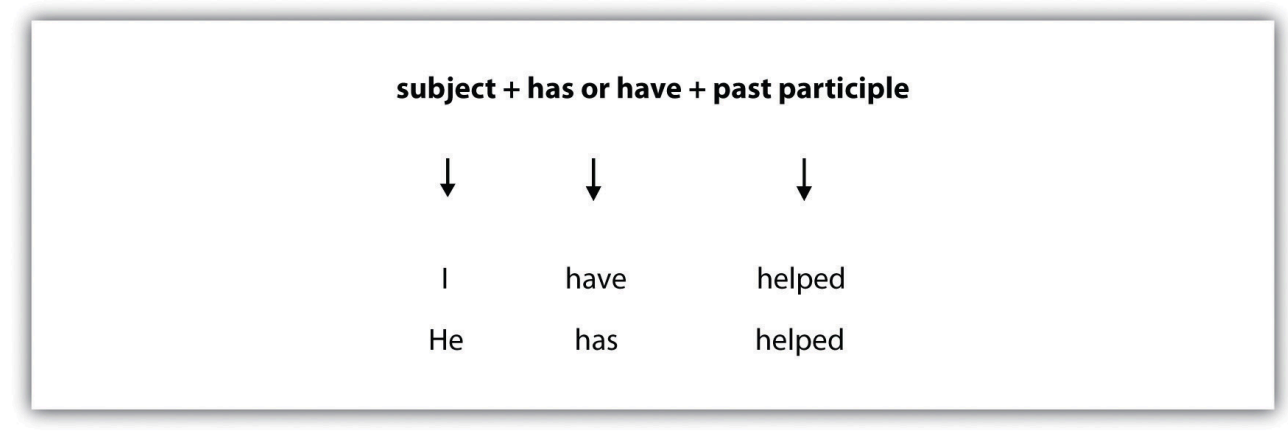

Remember, when a sentence contains a modal auxiliary before the verb, the helping verb is always have.

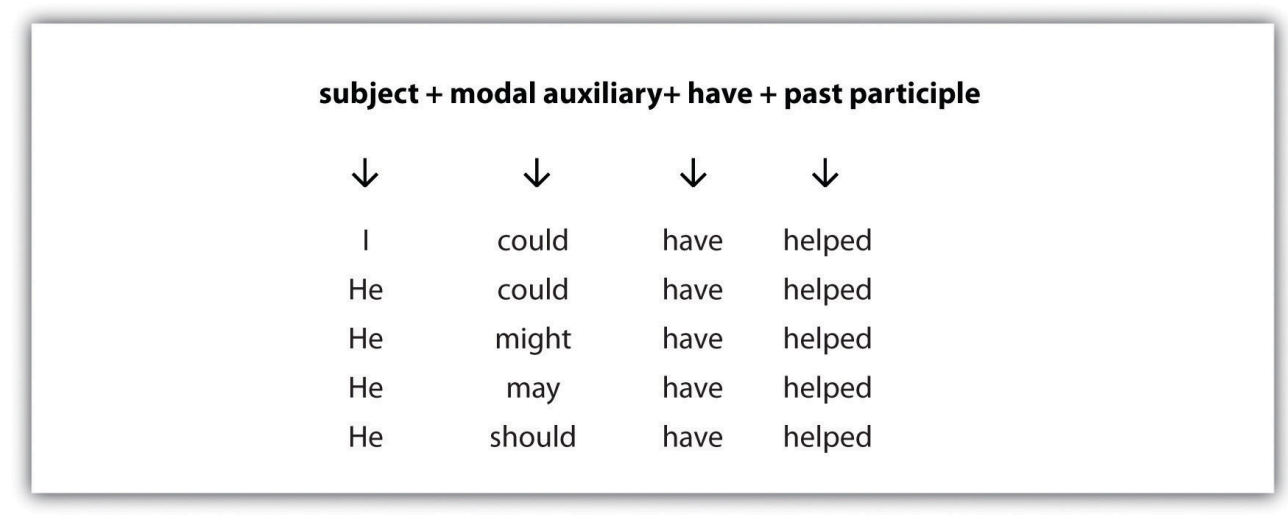

Be aware of the following common errors when using modal auxiliaries in the present perfect tense:

1. Using had instead of have

Incorrect: Jamie would had attended the party, but he was sick.

Correct: Jamie would have attended the party, but he was sick.

2. Leaving out have

Incorrect: Jamie would attended the party, but he was sick. 
Correct: Jamie would have attended the party, but he was sick.

\section{Exercise 2}

On a separate sheet of paper, complete the following sentences by changing the given verb form to a modal auxiliary in present perfect tense.

1. The man (laugh).

2. The frogs (croak).

3. My writing teacher (smile).

4. The audience (cheer) all night.

5. My best friend (giggled).

\section{Key Takeaways}

- The basic formula for using a modal auxiliary is

$$
\text { subject }+ \text { modal auxiliary }+ \text { main verb }
$$

- There are ten main modal auxiliaries in English: can, could, may, might, shall, should, will, would, must, and ought to.

- The four common types of errors when using modals include the following: using an infinitive instead of a base verb after a modal, using a gerund instead of an infinitive or a base verb after a modal, using two modals in a row, and leaving out a modal.

- In the present perfect tense, when a sentence has a modal auxiliary before the verb, the helping verb is always have.

- The two common errors when using modals in the present perfect tense include using had instead of have and leaving out have.

\section{Writing Application}

On a separate sheet of paper, write ten original sentences using modal auxiliaries. 


\subsection{Prepositions}

\section{Learning Objectives}

1. Identify prepositions.

2. Learn how and when to use prepositions.

A preposition is a word that connects a noun or a pronoun to another word in a sentence. Most prepositions such as above, below, and behind usually indicate a location in the physical world, but some prepositions such as during, after, and until show location in time.

\section{In, At, and On}

The prepositions in, at, and on are used to indicate both location and time, but they are used in specific ways. Study Table 5.12, Table 5.13, and Table 5.14 to learn when to use each one.

Table 5.12 In

\begin{tabular}{|l|l|l|l|l|}
\hline Preposition & Time & Example & Place & Example \\
\hline \multirow{2}{*}{ in } & year & in 1942 & country & in Zimbabwe \\
\hline month & in August & state & in California \\
\hline & season & in the summer & city & in Chicago \\
\hline & time of day (not with night) & in the afternoon & & \\
\hline
\end{tabular}

Table 5.13 On

\begin{tabular}{|l|l|l|l|l|}
\hline Preposition & Time & Example & Place & Example \\
\hline \multirow{2}{*}{ on } & day & on Monday & surfaces & on the table \\
\hline & date & on May 23 & streets & on 124th Street \\
\hline & specific days/dates & on Monday & modes of transportation & on the bus \\
\hline
\end{tabular}




\begin{tabular}{|l|l|l|l|l|}
\hline Preposition & Time & Example & Place & Example \\
\hline \multirow{2}{*}{ at } & time & at five o'clock & addresses & at 1600 Pennsylvania Avenue \\
\hline & with night & at night & location & at Rooney's Grill \\
\hline
\end{tabular}

\section{Exercise 1}

Edit the following letter from a resident to her landlord by correcting errors with in, at, and on.

Dear Mrs. Salazar,

I am writing this letter to inform you that I will be vacating apartment 2A in 356 Maple Street at Wednesday, June 30, 2010. I will be cleaning the apartment at the Monday before I leave. I will return the keys to you on 5 p.m., sharp, at June 30. If you have any questions or specific instructions for me, please contact me in my office. I have enjoyed living at Austin, Texas, but I want to explore other parts of the country now.

Sincerely,

Milani Davis

\section{Prepositions after Verbs}

Prepositions often follow verbs to create expressions with distinct meanings. These expressions are sometimes called prepositional verbs. It is important to remember that these expressions cannot be separated.

Table 5.15 Verbs + Prepositions 


\begin{tabular}{|l|l|l|}
$\begin{array}{l}\text { Verb }+ \\
\text { Preposition }\end{array}$ & Meaning & Example \\
\hline agree with & to agree with something or someone & My husband always agrees with me. \\
\hline apologize for & $\begin{array}{l}\text { to express regret for something, to say sorry about } \\
\text { something }\end{array}$ & I apologize for being late. \\
\hline apply for & to ask for something formally & I will apply for that job. \\
\hline believe in & $\begin{array}{l}\text { to have a firm conviction in something; to believe in the } \\
\text { existence of something }\end{array}$ & $\begin{array}{l}\text { I believe in educating the world's } \\
\text { women. }\end{array}$ \\
\hline care about & to think that someone or something is important & $\begin{array}{l}\text { I care about the health of our } \\
\text { oceans. }\end{array}$ \\
\hline hear about & to be told about something or someone & I heard about the teachers' strike. \\
\hline look after & to watch or to protect someone or something & $\begin{array}{l}\text { Will you look after my dog while I } \\
\text { am on vacation? }\end{array}$ \\
\hline talk about & to discuss something & $\begin{array}{l}\text { We will talk about the importance } \\
\text { of recycling. }\end{array}$ \\
\hline $\begin{array}{l}\text { speak to, } \\
\text { with }\end{array}$ & to talk to/with someone & I will speak to his teacher tomorrow. \\
\hline wait for & to await the arrival of someone or something & I will wait for my package to arrive. \\
\hline
\end{tabular}

\section{Tip}

It is a good idea to memorize these combinations of verbs plus prepositions. Write them down in a notebook along with the definition and practice using them when you speak.

\section{Exercise 2}

On a separate sheet of paper, complete the following sentences by writing the correct preposition after the verb.

1. Charlotte does not (apologize for, believe in) aliens or ghosts.

2. It is impolite to (hear about, talk about) people when they are not here.

3. Herman said he was going to (believe in, apply for) the internship.

4. Jonas would not (talk about, apologize for) eating the last piece of cake.

5. I (care about, agree with) the environment very much. 


\section{Prepositions after Adjectives}

Similar to prepositions after verbs, prepositions after adjectives create expressions with distinct meanings unique to English. Remember, like prepositional verbs, these expressions also cannot be separated.

Table 5.16 Adjectives + Prepositions

\begin{tabular}{|c|c|c|}
\hline $\begin{array}{l}\text { Adjective + } \\
\text { Preposition }\end{array}$ & Meaning & Example \\
\hline $\begin{array}{l}\text { angry at, } \\
\text { about }\end{array}$ & $\begin{array}{l}\text { to feel or show anger toward (or about) someone or } \\
\text { something }\end{array}$ & $\begin{array}{l}\text { I am angry about the oil spill in the } \\
\text { ocean. }\end{array}$ \\
\hline $\begin{array}{l}\text { confused } \\
\text { about }\end{array}$ & $\begin{array}{l}\text { to be unable to think with clarity about someone or } \\
\text { something. }\end{array}$ & $\begin{array}{l}\text { Shawn was confused about the } \\
\text { concepts presented at the meeting. }\end{array}$ \\
\hline $\begin{array}{l}\text { disappointed } \\
\text { in, with }\end{array}$ & to feel dissatisfaction with someone or something & $\begin{array}{l}\text { I was disappointed in my husband } \\
\text { because he voted for that candidate. }\end{array}$ \\
\hline dressed in & to clothe the body & He was dressed in a pin-striped suit. \\
\hline happy for & to show happiness for someone or something & $\begin{array}{l}\text { I was happy for my sister who } \\
\text { graduated from college. }\end{array}$ \\
\hline interested in & giving attention to something, expressing interest & I am interested in musical theater. \\
\hline jealous of & $\begin{array}{l}\text { to feel resentful or bitter toward someone or something } \\
\text { (because of their status, possessions, or ability) }\end{array}$ & $\begin{array}{l}\text { I was jealous of her because she } \\
\text { always went on vacation. }\end{array}$ \\
\hline thankful for & to express thanks for something & $\begin{array}{l}\text { I am thankful for my wonderful } \\
\text { friends. }\end{array}$ \\
\hline tired of & to be disgusted with, have a distaste for & $\begin{array}{l}\text { I was tired of driving for hours } \\
\text { without end. }\end{array}$ \\
\hline $\begin{array}{l}\text { worried } \\
\text { about }\end{array}$ & to express anxiety or worry about something & $\begin{array}{l}\text { I am worried about my father's } \\
\text { health. }\end{array}$ \\
\hline
\end{tabular}

\section{Exercise 3}

On a separate sheet of paper, complete the following sentences by writing the correct preposition after the verb.

1. Meera was deeply (interested in, thankful for) marine biology.

2. I was (jealous of, disappointed in) the season finale of my favorite show.

3. Jordan won the race, and I am (happy for, interested in) him. 
4. The lawyer was (thankful for, confused about) the details of the case.

5. Chloe was (dressed in, tired of) a comfortable blue tunic.

Tip

The following adjectives are always followed by the preposition at:

- Good

She is really good at chess.

- Excellent

Henry is excellent at drawing.

- Brilliant

Mary Anne is brilliant at playing the violin.

\section{Key Takeaways}

- The prepositions in, at, and on are used to indicate both location and time, but they are used in specific ways.

- The preposition in is used when expressing the following: year, month, season, time of day (not with night), country, state, and city.

- The preposition on is used to express day, date, and specific days or dates and surfaces, streets, and transportation modes.

- The preposition at is used for expressions of time, with night, and with addresses and locations.

- Prepositions often follow verbs to create expressions with distinct meanings that are unique to English.

- Prepositions also follow adjectives to create expressions with distinct meanings that are unique to English.

\section{Writing Application}

Write about a happy childhood memory using as many prepositions followed by verbs and adjectives as you 
can. Use at least ten. When you are finished, exchange papers with a classmate and correct any preposition errors you find. 


\subsection{Slang and Idioms}

\section{Learning Objectives}

1. Recognize slang and idioms.

2. Learn to avoid using slang and idioms in formal writing.

Words are the basis of how a reader or listener judges you, the writer and speaker. When you write an academic paper or speak in a business interview, you want to be sure to choose your words carefully. In our casual, everyday talk, we often use a lot of "ums," "likes," “yeahs,” and so on. This everyday language is not appropriate for formal contexts, such as academic papers and business interviews. You should switch between different ways of speaking and writing depending on whether the context is formal or informal.

\section{Slang}

Hey guys, let's learn about slang and other cool stuff like that! It will be awesome, trust me. This section is off the hook!

What do you notice about the previous paragraph? You might notice that the language sounds informal, or casual, like someone might talk with a friend or family member. The paragraph also uses a lot of slang. Slang is a type of language that is informal and playful. It often changes over time. The slang of the past is different than the slang of today, but some slang has carried over into the present. Slang also varies by region and culture. The important thing to understand is that slang is casual talk, and you should avoid using it in formal contexts. There are literally thousands of slang words and expressions. Table 5.17 "Slang Expressions" explains just a few of the more common terms.

Table 5.17 Slang Expressions 


\begin{tabular}{|l|l|}
\hline Slang Word or Phrase & Meaning \\
\hline check it out, check this out & v. look at, watch, examine \\
\hline chocoholic, workaholic, shopaholic & n. a person who loves, is addicted to chocolate/work/shopping \\
\hline stuff & n. things (used as a singular, noncount noun) \\
\hline taking care of business & doing things that need to be done \\
\hline pro & n. a person who is a professional \\
\hline crack up & v. to laugh uncontrollably \\
\hline veg (sounds like the veg in vegetable) & v. relax and do nothing \\
\hline dude, man & n. person, man \\
\hline all-nighter & n. studying all night \\
\hline cool & adj. good, fashionable \\
\hline gross, nasty & adj. disgusting \\
\hline pig out & v. eat a lot, overeat \\
\hline screw up & v. make a mistake \\
\hline awesome & adj. great \\
\hline
\end{tabular}

\section{Exercise 1}

Edit the business e-mail by replacing any slang words and phrases with more formal language.

\section{Dear Ms. O’Connor:}

I am writing to follow up on my interview from last week. First of all, it was awesome to meet you. You are a really cool lady. I believe I would be a pro at all the stuff you mentioned that would be required of me in this job. I am not a workaholic, but I do work hard and "take care of business." Haha. Please contact me if you have any questions or concerns.

Sincerely,

M. Ernest Anderson

\section{Idioms}

Idioms are expressions that have a meaning different from the dictionary definitions of the individual words in the expression. Because English contains many idioms, nonnative English speakers have difficulties making logical sense of idioms and idiomatic expressions. The more you are exposed to English, however, the more idioms you will come to understand. Until then, memorizing the more 
common idioms may be of some help.

Table 5.18 Idioms

\begin{tabular}{|l|l|}
\hline Idiom & Definition \\
\hline a blessing in disguise & a good thing you do not recognize at first \\
\hline a piece of cake & easy to do \\
\hline better late than never & it is better to do something late than not at all \\
\hline get over it & recover from something (like a perceived insult) \\
\hline I have no idea & I don't know \\
\hline not a chance & it will definitely not happen \\
\hline on pins and needles & very nervous about something that is happening \\
\hline on top of the world & feeling great \\
\hline pulling your leg & making a joke by tricking another person \\
\hline the sky is the limit & the possibilities are endless \\
\hline
\end{tabular}

What if you come across an idiom that you do not understand? There are clues that can help you. They are called context clues. Context clues are words or phrases around the unknown word or phrase that may help you decipher its meaning.

1. Definition or explanation clue. An idiom may be explained immediately after its use.

Sentence: I felt like I was sitting on pins and needles I was so nervous.

2. Restatement or synonym clues. An idiom may be simplified or restated.

Sentence: The young girl felt as though she had been sent to the dog house when her mother punished her for fighting in school.

3. Contrast or Antonym clues. An idiom may be clarified by a contrasting phrase or antonym that is near it.

Sentence: Chynna thought the 5k marathon would be a piece of cake, but it turned out to be very difficult.

Pay attention to the signal word but, which tells the reader that an opposite thought or concept is occurring. 


\section{Key Takeaways}

- Informal language is not appropriate in formal writing or speaking contexts.

- Slang and idioms might not make logical sense to nonnative speakers of English.

- It is good to be aware of slang and idioms so they do not appear in your formal writing.

\section{Writing Application}

Write a short paragraph about yourself to a friend. Write another paragraph about yourself to an employer. Examine and discuss the differences in language between the two paragraphs. 


\subsection{Help for English Language Learners: End-of-Chapter Exercises}

\section{Learning Objectives}

1. Use the skills you have learned in the chapter.

2. Work collaboratively with other students.

\section{Exercises}

1. On a separate sheet of paper, create questions from the following sentences.
a. My daughter will have to think about her college options.
b. Otto is waiting in the car for his girlfriend.
c. The article talks about conserving energy.
d. We need to reduce our needs.
e. Rusha is always complaining about her work.

2. Underline the prepositional phrase in each of the following sentences.
a. Monica told us about her trip.
b. I hope we have sunshine throughout the summer.
c. The panther climbed up the tree.
d. The little boy was standing behind his mother's legs.
e. We stayed awake until dawn.

3. Place the following sets of adjectives in the correct order before the noun.
a. eyes: black, mesmerizing
b. jacket: vintage, orange, suede
c. pineapple: ripe, yellow, sweet
d. vacation: fun, skiing
e. movie: hilarious, independent

4. On a separate sheet of paper, rewrite the positive sentences as negative sentences. Be sure to keep the sentences in the present tense.
a. Sometimes I work on Saturdays.
b. The garden attracts butterflies and bees.
c. He breathes loudly at night.
d. I chew on blades of grass in the summer time.
e. I communicate well with my husband. 
5. On a separate sheet of paper, rewrite the following paragraph by correcting the double negatives.

That morning it was so hot Forrest felt like he couldn't hardly breathe. Ain't nothing would get him out the door into that scorching heat. Then he remembered his dog, Zeus, who started whining right then. Zeus was whining and barking so much that Forrest didn't have no choice but to get off the couch and face the day. That dog didn't do nothing but sniff around the bushes and try to stay in the shade while Forrest was sweating in the sun holding the leash. He couldn't not wait for winter to come.

\section{Collaboration}

Once you have found all the errors you can, please share with a classmate and compare your answers. Did your partner find an error you missed? Did you find an error your partner missed? Compare with your instructor's answers. 


\section{Chapter 6: Writing Paragraphs: Separating Ideas and Shaping Content}

6.1 Purpose, Audience, Tone, and Content

6.2 Effective Means for Writing a Paragraph

6.3 Writing Paragraphs: End-of-Chapter Exercises 


\subsection{Purpose, Audience, Tone, and Content}

\section{Learning Objectives}

1. Identify the four common academic purposes.

2. Identify audience, tone, and content.

3. Apply purpose, audience, tone, and content to a specific assignment.

Imagine reading one long block of text, with each idea blurring into the next. Even if you are reading a thrilling novel or an interesting news article, you will likely lose interest in what the author has to say very quickly. During the writing process, it is helpful to position yourself as a reader. Ask yourself whether you can focus easily on each point you make. One technique that effective writers use is to begin a fresh paragraph for each new idea they introduce.

Paragraphs separate ideas into logical, manageable chunks. One paragraph focuses on only one main idea and presents coherent sentences to support that one point. Because all the sentences in one paragraph support the same point, a paragraph may stand on its own. To create longer assignments and to discuss more than one point, writers group together paragraphs.

Three elements shape the content of each paragraph:

1. Purpose. The reason the writer composes the paragraph.

2. Tone. The attitude the writer conveys about the paragraph's subject.

3. Audience. The individual or group whom the writer intends to address. 


\section{Audience}

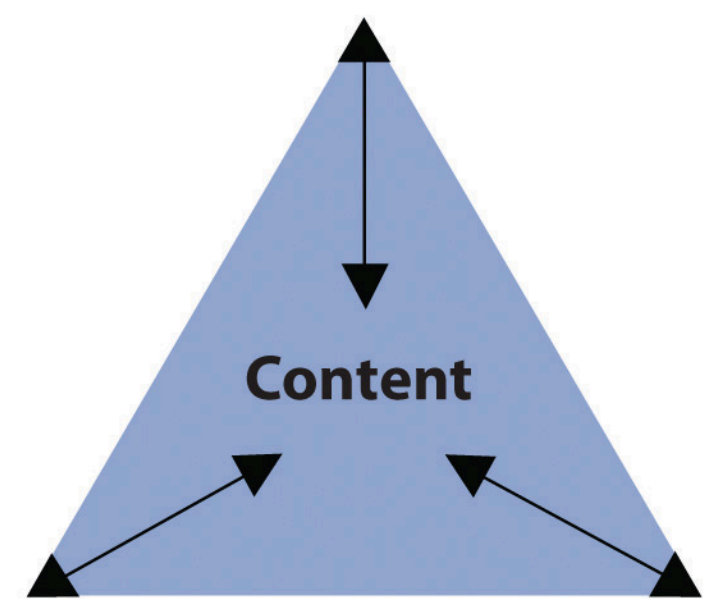

\section{Tone}

\section{Purpose}

The assignment's purpose, audience, and tone dictate what the paragraph covers and how it will support one main point. This section covers how purpose, audience, and tone affect reading and writing paragraphs.

\section{Identifying Common Academic Purposes}

The purpose for a piece of writing identifies the reason you write a particular document. Basically, the purpose of a piece of writing answers the question "Why?" For example, why write a play? To entertain a packed theater. Why write instructions to the babysitter? To inform him or her of your schedule and rules. Why write a letter to your congressman? To persuade him to address your community’s needs.

In academic settings, the reasons for writing fulfill four main purposes: to summarize, to analyze, to synthesize, and to evaluate. You will encounter these four purposes not only as you read for your classes but also as you read for work or pleasure. Because reading and writing work together, your writing skills will improve as you read. To learn more about reading in the writing process, see Chapter 8 “The Writing Process: How Do I Begin?”.

Eventually, your instructors will ask you to complete assignments specifically designed to meet one of the four purposes. As you will see, the purpose for writing will guide you through each part of the paper, helping you make decisions about content and style. For now, identifying these purposes by reading paragraphs will prepare you to write individual paragraphs and to build longer assignments. 


\section{Summary Paragraphs}

A summary shrinks a large amount of information into only the essentials. You probably summarize events, books, and movies daily. Think about the last blockbuster movie you saw or the last novel you read. Chances are, at some point in a casual conversation with a friend, coworker, or classmate, you compressed all the action in a two-hour film or in a two-hundred-page book into a brief description of the major plot movements. While in conversation, you probably described the major highlights, or the main points in just a few sentences, using your own vocabulary and manner of speaking.

Similarly, a summary paragraph condenses a long piece of writing into a smaller paragraph by extracting only the vital information. A summary uses only the writer's own words. Like the summary's purpose in daily conversation, the purpose of an academic summary paragraph is to maintain all the essential information from a longer document. Although shorter than the original piece of writing, a summary should still communicate all the key points and key support. In other words, summary paragraphs should be succinct and to the point. 
According to the Monitoring the Future Study, almost two-thirds of 10th-grade students reported having tried alcohol at least once in their lifetime, and two-fifths reported having been drunk at least once (Johnston et a1. 2006x). Among 12th-grade students. these rates had risen to over three-quarters who reported having tried alcohol at least once and nearly three-fifths who reported having been drunk at least once. In terms of current alcohol use. 33.2 percent of the Nation's 10th graders and 47.0 percent of 12 th graders reported having used alcohol at least once in the past 30 days: 17.6 percent and 30.2 percent, respectively, reported having been drunk in the past 30 days: 21.0 percent and 28.1 percent. respectively. reported having had five or more drinks in a row in the past 2 weeks (sometimes called binge drinking): and 1.3 percent and 3.1 percent, respectively, reported daily alcohol use (Johnston et al. 2006a).

Alcohol consumption continues to escalate after high school. In fact, eighteento twenty-four-year-olds have the highest levels of alcohol consumption and alcohol dependence of any age group. In the first 2 years after high school. 1ifetime prevalence of alcohol use (based on 2005 follow-up surveys from the Monitoring the Future Study) was 81.8 percent. 30 -day use prevalence was 59 percent, and binge-drinking prevalence was 36.3 percent (Johnston et a1. 2006b). Of note, college students on average drink more than their noncollege peers, even though they drank less during high school than those who did not go on to college (Johnston et a1. 2006a,b: Schulenberg and Maggs 2002). For example, in 2005, the rate of binge drinking for college students ( 1 to 4 years beyond high school) was 40.1 percent, whereas the rate for their noncollege age mates was 35.1 percent.

Alcohol use and problem drinking in late adolescence vary by sociodemographic characteristics. For example, the prevalence of alcohol use is higher for boys than for girls, higher for White and Hispanic adolescents than for African-American adolescents. and higher for those living in the north and north central United States than for those living in the South and West. Some of these relationships change with early adulthood. however. For example, although alcohol use in high school tends to be higher in areas with lower population density (i.e.. rural areas) than in more densely populated areas. this relationship reverses during early adulthood (Johnston et a1., 2006 a,b). Lower economic status (i.e., lower educational level of parents) is associated with more alcohol use during the early high school years; by the end of high school, and during the transition to adulthood, this relationship changes, and youth from higher socioeconomic backgrounds consume greater amounts of alcohol.

A summary of the report should present all the main points and supporting details in brief. Read the following summary of the report written by a student: 


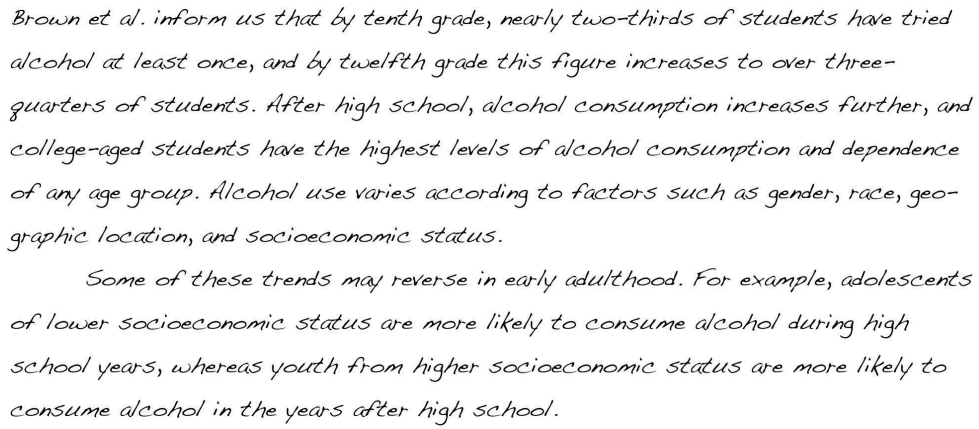

Notice how the summary retains the key points made by the writers of the original report but omits most of the statistical data. Summaries need not contain all the specific facts and figures in the original document; they provide only an overview of the essential information.

\section{Analysis Paragraphs}

An analysis separates complex materials in their different parts and studies how the parts relate to one another. The analysis of simple table salt, for example, would require a deconstruction of its parts - the elements sodium $(\mathrm{Na})$ and chloride $(\mathrm{Cl})$. Then, scientists would study how the two elements interact to create the compound $\mathrm{NaCl}$, or sodium chloride, which is also called simple table salt.

Analysis is not limited to the sciences, of course. An analysis paragraph in academic writing fulfills the same purpose. Instead of deconstructing compounds, academic analysis paragraphs typically deconstruct documents. An analysis takes apart a primary source (an essay, a book, an article, etc.) point by point. It communicates the main points of the document by examining individual points and identifying how the points relate to one another.

Take a look at a student's analysis of the journal report. 


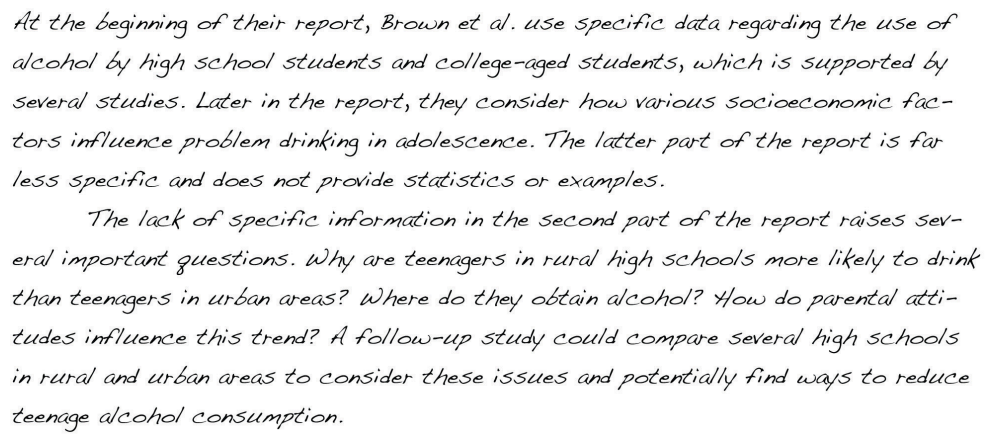

Notice how the analysis does not simply repeat information from the original report, but considers how the points within the report relate to one another. By doing this, the student uncovers a discrepancy between the points that are backed up by statistics and those that require additional information. Analyzing a document involves a close examination of each of the individual parts and how they work together.

\section{Synthesis Paragraphs}

A synthesis combines two or more items to create an entirely new item. Consider the electronic musical instrument aptly named the synthesizer. It looks like a simple keyboard but displays a dashboard of switches, buttons, and levers. With the flip of a few switches, a musician may combine the distinct sounds of a piano, a flute, or a guitar-or any other combination of instruments - to create a new sound. The purpose of the synthesizer is to blend together the notes from individual instruments to form new, unique notes.

The purpose of an academic synthesis is to blend individual documents into a new document. An academic synthesis paragraph considers the main points from one or more pieces of writing and links the main points together to create a new point, one not replicated in either document.

Take a look at a student's synthesis of several sources about underage drinking. 


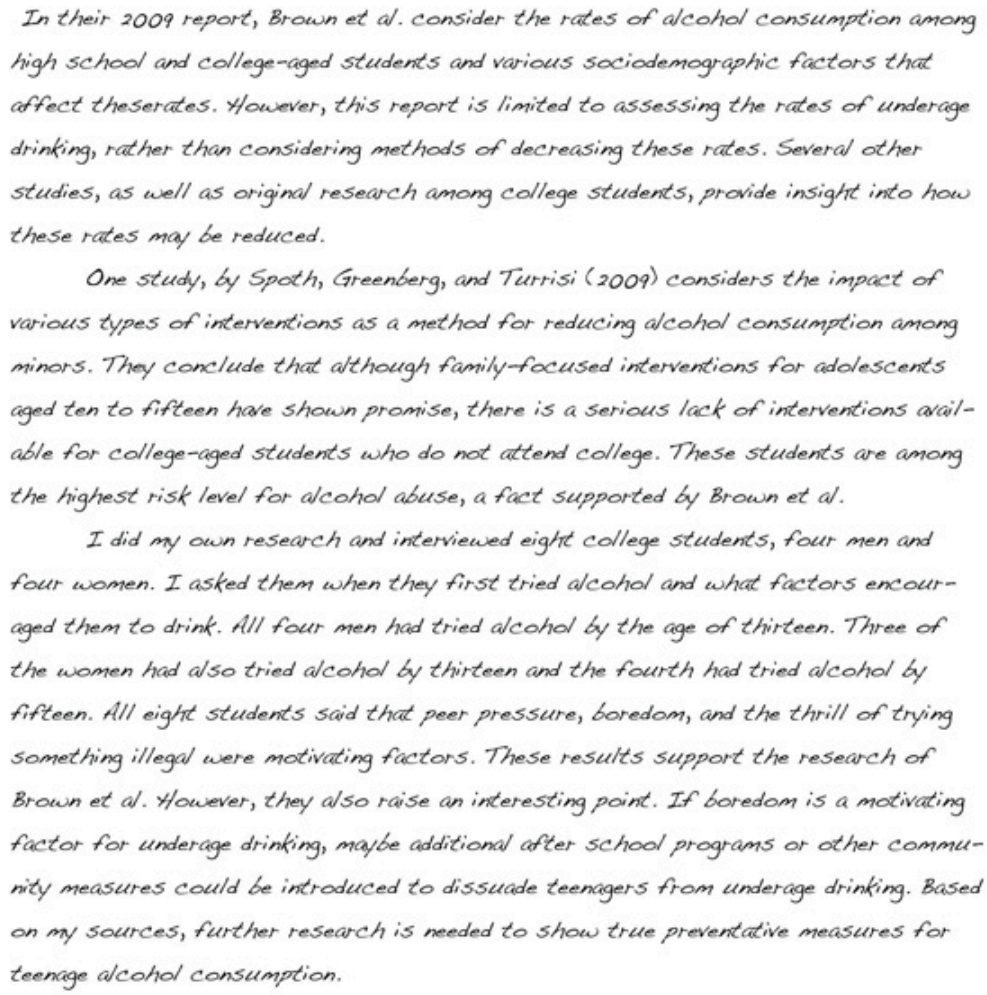

Notice how the synthesis paragraphs consider each source and use information from each to create a new thesis. A good synthesis does not repeat information; the writer uses a variety of sources to create a new idea.

\section{Evaluation Paragraphs}

An evaluation judges the value of something and determines its worth. Evaluations in everyday experiences are often not only dictated by set standards but also influenced by opinion and prior knowledge. For example, at work, a supervisor may complete an employee evaluation by judging his subordinate's performance based on the company's goals. If the company focuses on improving communication, the supervisor will rate the employee's customer service according to a standard scale. However, the evaluation still depends on the supervisor's opinion and prior experience with the employee. The purpose of the evaluation is to determine how well the employee performs at his or her job.

An academic evaluation communicates your opinion, and its justifications, about a document or a topic of discussion. Evaluations are influenced by your reading of the document, your prior knowledge, and 
your prior experience with the topic or issue. Because an evaluation incorporates your point of view and reasons for your point of view, it typically requires more critical thinking and a combination of summary, analysis, and synthesis skills. Thus evaluation paragraphs often follow summary, analysis, and synthesis paragraphs. Read a student's evaluation paragraph.

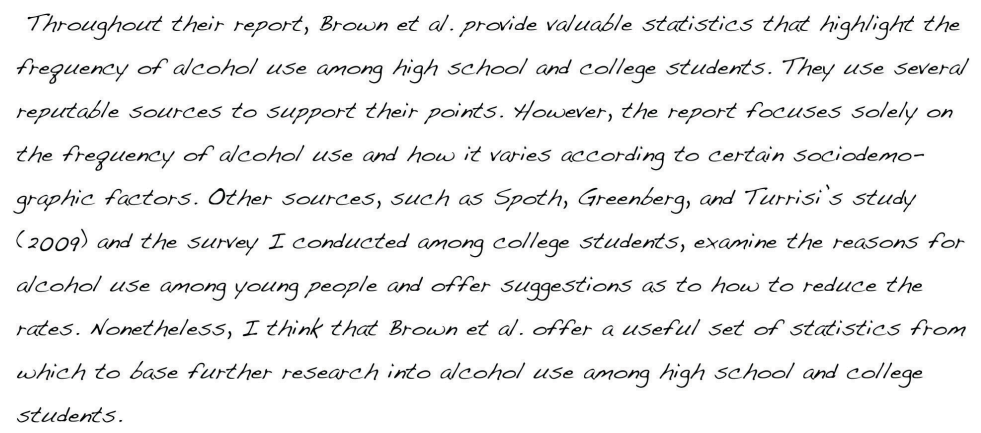

Notice how the paragraph incorporates the student's personal judgment within the evaluation. Evaluating a document requires prior knowledge that is often based on additional research.

\section{Tip}

When reviewing directions for assignments, look for the verbs summarize, analyze, synthesize, or evaluate. Instructors often use these words to clearly indicate the assignment's purpose. These words will cue you on how to complete the assignment because you will know its exact purpose.

\section{Exercise 1}

Read the following paragraphs about four films and then identify the purpose of each paragraph.

1. This film could easily have been cut down to less than two hours. By the final scene, I noticed that most of my fellow moviegoers were snoozing in their seats and were barely paying attention to what was happening on screen. Although the director sticks diligently to the book, he tries too hard to cram in all the action, which is just too ambitious for such a detail-oriented story. If you want my advice, read the book and give the movie a miss.

2. During the opening scene, we learn that the character Laura is adopted and that she has spent the past three years desperately trying to track down her real parents. Having exhausted all the usual options-adoption agencies, online searches, family trees, and so on-she is on the verge of 
giving up when she meets a stranger on a bus. The chance encounter leads to a complicated chain of events that ultimately result in Laura getting her lifelong wish. But is it really what she wants? Throughout the rest of the film, Laura discovers that sometimes the past is best left where it belongs.

3. To create the feeling of being gripped in a vice, the director, May Lee, uses a variety of elements to gradually increase the tension. The creepy, haunting melody that subtly enhances the earlier scenes becomes ever more insistent, rising to a disturbing crescendo toward the end of the movie. The desperation of the actors, combined with the claustrophobic atmosphere and tight camera angles create a realistic firestorm, from which there is little hope of escape. Walking out of the theater at the end feels like staggering out of a Roman dungeon.

4. The scene in which Campbell and his fellow prisoners assist the guards in shutting down the riot immediately strikes the viewer as unrealistic. Based on the recent reports on prison riots in both Detroit and California, it seems highly unlikely that a posse of hardened criminals will intentionally help their captors at the risk of inciting future revenge from other inmates. Instead, both news reports and psychological studies indicate that prisoners who do not actively participate in a riot will go back to their cells and avoid conflict altogether. Examples of this lack of attention to detail occur throughout the film, making it almost unbearable to watch.

\section{Collaboration}

Share with a classmate and compare your answers.

\section{Writing at Work}

Thinking about the purpose of writing a report in the workplace can help focus and structure the document. A summary should provide colleagues with a factual overview of your findings without going into too much specific detail. In contrast, an evaluation should include your personal opinion, along with supporting evidence, research, or examples to back it up. Listen for words such as summarize, analyze, synthesize, or evaluate when your boss asks you to complete a report to help determine a purpose for writing.

\section{Exercise 2}

Consider the essay most recently assigned to you. Identify the most effective academic purpose for the assignment.

My assignment:

My purpose: 


\section{Identifying the Audience}

Imagine you must give a presentation to a group of executives in an office. Weeks before the big day, you spend time creating and rehearsing the presentation. You must make important, careful decisions not only about the content but also about your delivery. Will the presentation require technology to project figures and charts? Should the presentation define important words, or will the executives already know the terms? Should you wear your suit and dress shirt? The answers to these questions will help you develop an appropriate relationship with your audience, making them more receptive to your message.

Now imagine you must explain the same business concepts from your presentation to a group of high school students. Those important questions you previously answered may now require different answers. The figures and charts may be too sophisticated, and the terms will certainly require definitions. You may even reconsider your outfit and sport a more casual look. Because the audience has shifted, your presentation and delivery will shift as well to create a new relationship with the new audience.

In these two situations, the audience-the individuals who will watch and listen to the presentation-plays a role in the development of presentation. As you prepare the presentation, you visualize the audience to anticipate their expectations and reactions. What you imagine affects the information you choose to present and how you will present it. Then, during the presentation, you meet the audience in person and discover immediately how well you perform.

Although the audience for writing assignments-your readers-may not appear in person, they play an equally vital role. Even in everyday writing activities, you identify your readers' characteristics, interests, and expectations before making decisions about what you write. In fact, thinking about audience has become so common that you may not even detect the audience-driven decisions.

For example, you update your status on a social networking site with the awareness of who will digitally follow the post. If you want to brag about a good grade, you may write the post to please family members. If you want to describe a funny moment, you may write with your friends' senses of humor in mind. Even at work, you send e-mails with an awareness of an unintended receiver who could intercept the message.

In other words, being aware of "invisible" readers is a skill you most likely already possess and one you rely on every day. Consider the following paragraphs. Which one would the author send to her parents? Which one would she send to her best friend?

\section{Example A}

Last Saturday, I volunteered at a local hospital. The visit was fun and rewarding. I even learned how to do cardiopulmonary resuscitation, or CPR. Unfortunately, I think caught a cold from one of the patients. This week, I will rest in bed and drink plenty of clear fluids. I hope I am well by next Saturday to volunteer again.

Example B

OMG! You won't believe this! My advisor forced me to do my community service hours at this hospital all weekend! We learned CPR but we did it on dummies, not even real peeps. And some kid sneezed on me and 
got me sick! I was so bored and sniffling all weekend; I hope I don’t have to go back next week. I def do NOT want to miss the basketball tournament!

Most likely, you matched each paragraph to its intended audience with little hesitation. Because each paragraph reveals the author's relationship with her intended readers, you can identify the audience fairly quickly. When writing your own paragraphs, you must engage with your audience to build an appropriate relationship given your subject. Imagining your readers during each stage of the writing process will help you make decisions about your writing. Ultimately, the people you visualize will affect what and how you write.

\section{Tip}

While giving a speech, you may articulate an inspiring or critical message, but if you left your hair a mess and laced up mismatched shoes, your audience would not take you seriously. They may be too distracted by your appearance to listen to your words.

Similarly, grammar and sentence structure serve as the appearance of a piece of writing. Polishing your work using correct grammar will impress your readers and allow them to focus on what you have to say.

Because focusing on audience will enhance your writing, your process, and your finished product, you must consider the specific traits of your audience members. Use your imagination to anticipate the readers’ demographics, education, prior knowledge, and expectations.

- Demographics. These measure important data about a group of people, such as their age range, their ethnicity, their religious beliefs, or their gender. Certain topics and assignments will require these kinds of considerations about your audience. For other topics and assignments, these measurements may not influence your writing in the end. Regardless, it is important to consider demographics when you begin to think about your purpose for writing.

- Education. Education considers the audience's level of schooling. If audience members have earned a doctorate degree, for example, you may need to elevate your style and use more formal language. Or, if audience members are still in college, you could write in a more relaxed style. An audience member's major or emphasis may also dictate your writing.

- Prior knowledge. This refers to what the audience already knows about your topic. If your readers have studied certain topics, they may already know some terms and concepts related to the topic. You may decide whether to define terms and explain concepts based on your audience's prior knowledge. Although you cannot peer inside the brains of your readers to discover their knowledge, you can make reasonable assumptions. For instance, a nursing major would presumably know more about health-related topics than a business major would.

- Expectations. These indicate what readers will look for while reading your assignment. Readers may expect consistencies in the assignment's appearance, such as correct grammar and traditional formatting like double-spaced lines and legible font. Readers may also have content-based 
expectations given the assignment's purpose and organization. In an essay titled "The Economics of Enlightenment: The Effects of Rising Tuition,” for example, audience members may expect to read about the economic repercussions of college tuition costs.

\section{Exercise 3}

On your own sheet of paper, generate a list of characteristics under each category for each audience. This list will help you later when you read about tone and content.

1. Your classmates

- Demographics

- Education

- Prior knowledge

- Expectations

2. Your instructor

- Demographics

- Education

- Prior knowledge

- Expectations

3. The head of your academic department

- Demographics

- Education

- Prior knowledge

- Expectations

4. Now think about your next writing assignment. Identify the purpose (you may use the same purpose listed in Note 6.12 "Exercise 2"), and then identify the audience. Create a list of characteristics under each category.

My assignment:

My purpose:

My audience:

- Demographics

- Education

- Prior knowledge

- Expectations 


\section{Collaboration}

Please share with a classmate and compare your answers.

Keep in mind that as your topic shifts in the writing process, your audience may also shift. For more information about the writing process, see Chapter 8 “The Writing Process: How Do I Begin?”.

Also, remember that decisions about style depend on audience, purpose, and content. Identifying your audience's demographics, education, prior knowledge, and expectations will affect how you write, but purpose and content play an equally important role. The next subsection covers how to select an appropriate tone to match the audience and purpose.

\section{Selecting an Appropriate Tone}

Tone identifies a speaker's attitude toward a subject or another person. You may pick up a person's tone of voice fairly easily in conversation. A friend who tells you about her weekend may speak excitedly about a fun skiing trip. An instructor who means business may speak in a low, slow voice to emphasize her serious mood. Or, a coworker who needs to let off some steam after a long meeting may crack a sarcastic joke.

Just as speakers transmit emotion through voice, writers can transmit through writing a range of attitudes, from excited and humorous to somber and critical. These emotions create connections among the audience, the author, and the subject, ultimately building a relationship between the audience and the text. To stimulate these connections, writers intimate their attitudes and feelings with useful devices, such as sentence structure, word choice, punctuation, and formal or informal language. Keep in mind that the writer's attitude should always appropriately match the audience and the purpose.

Read the following paragraph and consider the writer's tone. How would you describe the writer's attitude toward wildlife conservation?

Many species of plants and animals are disappearing right before our eyes. If we don't act fast, it might be too late to save them. Human activities, including pollution, deforestation, hunting, and overpopulation, are devastating the natural environment. Without our help, many species will not survive long enough for our children to see them in the wild. Take the tiger, for example. Today, tigers occupy just 7 percent of their historical range, and many local populations are already extinct. Hunted for their beautiful pelt and other body parts, the tiger population has plummeted from one hundred thousand in 1920 to just a few thousand. Contact your local wildlife conservation society today to find out how you can stop this terrible destruction. 


\section{Exercise 4}

Think about the assignment and purpose you selected in Note 6.12 "Exercise 2", and the audience you selected in Note 6.16 "Exercise 3". Now, identify the tone you would use in the assignment.

My assignment:

My purpose:

My audience:

My tone:

\section{Choosing Appropriate, Interesting Content}

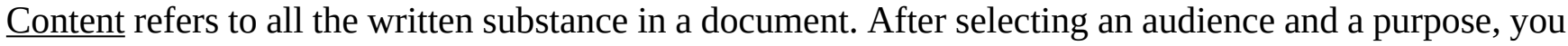
must choose what information will make it to the page. Content may consist of examples, statistics, facts, anecdotes, testimonies, and observations, but no matter the type, the information must be appropriate and interesting for the audience and purpose. An essay written for third graders that summarizes the legislative process, for example, would have to contain succinct and simple content.

Content is also shaped by tone. When the tone matches the content, the audience will be more engaged, and you will build a stronger relationship with your readers. Consider that audience of third graders. You would choose simple content that the audience will easily understand, and you would express that content through an enthusiastic tone. The same considerations apply to all audiences and purposes.

\section{Exercise 5}

Match the content in the box to the appropriate audience and purpose. On your own sheet of paper, write the correct letter next to the number.

1. Whereas economist Holmes contends that the financial crisis is far from over, the presidential advisor Jones points out that it is vital to catch the first wave of opportunity to increase market share. We can use elements of both experts' visions. Let me explain how.

2. In 2000, foreign money flowed into the United States, contributing to easy credit conditions. People bought larger houses than they could afford, eventually defaulting on their loans as interest rates rose.

3. The Emergency Economic Stabilization Act, known by most of us as the humungous government bailout, caused mixed reactions. Although supported by many political leaders, the statute provoked outrage among grassroots groups. In their opinion, the government was actually rewarding banks for their appalling behavior. 
1. Audience: An instructor

Purpose: To analyze the reasons behind the 2007 financial crisis

Content:

2. Audience: Classmates

Purpose: To summarize the effects of the $\$ 700$ billion government bailout

Content:

3. Audience: An employer

Purpose: To synthesize two articles on preparing businesses for economic recovery

Content:

\section{Collaboration}

Please share with a classmate and compare your answers.

\section{Exercise 6}

Using the assignment, purpose, audience, and tone from Note 6.18 "Exercise 4", generate a list of content ideas. Remember that content consists of examples, statistics, facts, anecdotes, testimonies, and observations. My assignment:

My purpose:

My audience:

My tone:

My content ideas:

\section{Key Takeaways}

- Paragraphs separate ideas into logical, manageable chunks of information.

- The content of each paragraph and document is shaped by purpose, audience, and tone.

- The four common academic purposes are to summarize, to analyze, to synthesize, and to evaluate.

- Identifying the audience's demographics, education, prior knowledge, and expectations will affect how and what you write.

- Devices such as sentence structure, word choice, punctuation, and formal or informal language communicate tone and create a relationship between the writer and his or her audience. 
247 [Author removed at request of original publisher]

- Content may consist of examples, statistics, facts, anecdotes, testimonies, and observations. All content must be appropriate and interesting for the audience, purpose and tone. 


\subsection{Effective Means for Writing a Paragraph}

\section{Learning Objectives}

1. Identify characteristics of a good topic sentence.

2. Identify the three parts of a developed paragraph.

3. Apply knowledge of topic sentences and parts of a developed paragraph in an assignment.

Now that you have identified common purposes for writing and learned how to select appropriate content for a particular audience, you can think about the structure of a paragraph in greater detail. Composing an effective paragraph requires a method similar to building a house. You may have the finest content, or materials, but if you do not arrange them in the correct order, then the final product will not hold together very well.

A strong paragraph contains three distinct components:

1. Topic sentence. The topic sentence is the main idea of the paragraph.

2. Body. The body is composed of the supporting sentences that develop the main point.

3. Conclusion. The conclusion is the final sentence that summarizes the main point.

The foundation of a good paragraph is the topic sentence, which expresses the main idea of the paragraph. The topic sentence relates to the thesis, or main point, of the essay (see Chapter 9 "Writing Essays: From Start to Finish" for more information about thesis statements) and guides the reader by signposting what the paragraph is about. All the sentences in the rest of the paragraph should relate to the topic sentence.

This section covers the major components of a paragraph and examines how to develop an effective topic sentence.

\section{Developing a Topic Sentence}

Pick up any newspaper or magazine and read the first sentence of an article. Are you fairly confident that you know what the rest of the article is about? If so, you have likely read the topic sentence. An effective topic sentence combines a main idea with the writer's personal attitude or opinion. It serves to orient the reader and provides an indication of what will follow in the rest of the paragraph. Read the following example. 
Creating a national set of standards for math and English education will improve student learning in many states.

This topic sentence declares a favorable position for standardizing math and English education. After reading this sentence, a reader might reasonably expect the writer to provide supporting details and facts as to why standardizing math and English education might improve student learning in many states. If the purpose of the essay is actually to evaluate education in only one particular state, or to discuss math or English education specifically, then the topic sentence is misleading.

\section{Tip}

When writing a draft of an essay, allow a friend or colleague to read the opening line of your first paragraph. Ask your reader to predict what your paper will be about. If he or she is unable to guess your topic accurately, you should consider revising your topic sentence so that it clearly defines your purpose in writing.

\section{Main Idea versus Controlling Idea}

Topic sentences contain both a main idea (the subject, or topic that the writer is discussing) and a controlling idea (the writer's specific stance on that subject). Just as a thesis statement includes an idea that controls a document's focus (as you will read about in Chapter 8 "The Writing Process: How Do I Begin?"), a topic sentence must also contain a controlling idea to direct the paragraph. Different writers may use the same main idea but can steer their paragraph in a number of different directions according to their stance on the subject. Read the following examples.

- Marijuana is a destructive influence on teens and causes long-term brain damage.

- The antinausea properties in marijuana are a lifeline for many cancer patients.

- Legalizing marijuana would create a higher demand for Class A and Class B drugs.

Although the main idea—marijuana—is the same in all three topic sentences, the controlling idea differs depending on the writer's viewpoint.

\section{Exercise 1}

Circle the main idea and underline the controlling idea in each of the following topic sentences. 
1. Exercising three times a week is the only way to maintain good physical health.

2. Sexism and racism are still rampant in today's workplace.

3. Raising the legal driving age to twenty-one would decrease road traffic accidents.

4. Owning a business is the only way to achieve financial success.

5. Dog owners should be prohibited from taking their pets on public beaches.

\section{Characteristics of a Good Topic Sentence}

Five characteristics define a good topic sentence:

1. A good topic sentence provides an accurate indication of what will follow in the rest of the paragraph.

Weak example. People rarely give firefighters the credit they deserve for such a physically and emotionally demanding job. (The paragraph is about a specific incident that involved firefighters; therefore, this topic sentence is too general.)

Stronger example. During the October riots, Unit 3B went beyond the call of duty. (This topic sentence is more specific and indicates that the paragraph will contain information about a particular incident involving Unit 3B.)

2. A good topic sentence contains both a topic and a controlling idea or opinion.

Weak example. In this paper, I am going to discuss the rising suicide rate among young professionals. (This topic sentence provides a main idea, but it does not present a controlling idea, or thesis.)

Stronger example. The rising suicide rate among young professionals is a cause for immediate concern. (This topic sentence presents the writer's opinion on the subject of rising suicide rates among young professionals.)

3. A good topic sentence is clear and easy to follow.

Weak example. In general, writing an essay, thesis, or other academic or nonacademic document is considerably easier and of much higher quality if you first construct an outline, of which there are many different types. (This topic sentence includes a main idea and a controlling thesis, but both are buried beneath the confusing sentence structure and unnecessary vocabulary. These obstacles make it difficult for the reader to follow.)

Stronger example. Most forms of writing can be improved by first creating an outline. (This topic sentence cuts out unnecessary verbiage and simplifies the previous statement, making it easier for the reader to follow.) 
4. A good topic sentence does not include supporting details.

Weak example. Salaries should be capped in baseball for many reasons, most importantly so we don't allow the same team to win year after year. (This topic sentence includes a supporting detail that should be included later in the paragraph to back up the main point.)

Stronger example. Introducing a salary cap would improve the game of baseball for many reasons. (This topic sentence omits the additional supporting detail so that it can be expanded upon later in the paragraph.)

5. A good topic sentence engages the reader by using interesting vocabulary.

Weak example. The military deserves better equipment. (This topic sentence includes a main idea and a controlling thesis, but the language is bland and unexciting.)

Stronger example. The appalling lack of resources provided to the military is outrageous and requires our immediate attention. (This topic sentence reiterates the same idea and controlling thesis, but adjectives such as appalling and immediate better engage the reader. These words also indicate the writer's tone.)

\section{Exercise 2}

Choose the most effective topic sentence from the following sentence pairs.

1. a. This paper will discuss the likelihood of the Democrats winning the next election.

b. To boost their chances of winning the next election, the Democrats need to listen to public opinion.

2. a. The unrealistic demands of union workers are crippling the economy for three main reasons.

b. Union workers are crippling the economy because companies are unable to remain competitive as a result of added financial pressure.

3. a. Authors are losing money as a result of technological advances.

b. The introduction of new technology will devastate the literary world.

4. a. Rap music is produced by untalented individuals with oversized egos.

b. This essay will consider whether talent is required in the rap music industry.

\section{Exercise 3}

Using the tips on developing effective topic sentences in this section, create a topic sentence on each of the 
following subjects. Remember to include a controlling idea as well as a main idea. Write your responses on your own sheet of paper.

1. An endangered species

2. The cost of fuel

3. The legal drinking age

4. A controversial film or novel

\section{Writing at Work}

When creating a workplace document, use the "top-down" approach-keep the topic sentence at the beginning of each paragraph so that readers immediately understand the gist of the message. This method saves busy colleagues precious time and effort trying to figure out the main points and relevant details.

Headings are another helpful tool. In a text-heavy document, break up each paragraph with individual headings. These serve as useful navigation aids, enabling colleagues to skim through the document and locate paragraphs that are relevant to them.

\section{Developing Paragraphs That Use Topic Sentences, Supporting Ideas, and Transitions Effectively}

Learning how to develop a good topic sentence is the first step toward writing a solid paragraph. Once you have composed your topic sentence, you have a guideline for the rest of the paragraph. To complete the paragraph, a writer must support the topic sentence with additional information and summarize the main point with a concluding sentence.

This section identifies the three major structural parts of a paragraph and covers how to develop a paragraph using transitional words and phrases. 


\section{Identifying Parts of a Paragraph}

An effective paragraph contains three main parts: a topic sentence, the body, and the concluding sentence. A topic sentence is often the first sentence of a paragraph. This chapter has already discussed its purpose - to express a main idea combined with the writer's attitude about the subject. The body of the paragraph usually follows, containing supporting details. Supporting sentences help explain, prove, or enhance the topic sentence. The concluding sentence is the last sentence in the paragraph. It reminds the reader of the main point by restating it in different words.

Figure 6.2 Paragraph Structure Graphic Organizer

\begin{tabular}{l} 
Paragraph Stucture Graphic Organizer \\
Topic Sentence \\
(main idea + personal opinion) \\
\hline Body \\
Supporting Sentence \\
\hline Supporting Sentence \\
\hline Supporting Sentence \\
\hline Supporting Sentence \\
\hline Conclusion \\
(summary of main idea + personal opinion) \\
\hline
\end{tabular}


Read the following paragraph. The topic sentence is underlined for you.

After reading the new TV guide this week I had just one thought—why are we still being bombarded with reality shows? This season, the plague of reality television continues to darken our airwaves. Along with the return of viewer favorites, we are to be cursed with yet another mindless creation. Prisoner follows the daily lives of eight suburban housewives who have chosen to be put in jail for the purposes of this fake psychological experiment. A preview for the first episode shows the usual tears and tantrums associated with reality television. I dread to think what producers will come up with next season, but if any of them are reading this blog—stop it! We’ve had enough reality television to last us a lifetime!

The first sentence of this paragraph is the topic sentence. It tells the reader that the paragraph will be about reality television shows, and it expresses the writer's distaste for these shows through the use of the word bombarded.

Each of the following sentences in the paragraph supports the topic sentence by providing further information about a specific reality television show. The final sentence is the concluding sentence. It reiterates the main point that viewers are bored with reality television shows by using different words from the topic sentence.

Paragraphs that begin with the topic sentence move from the general to the specific. They open with a general statement about a subject (reality shows) and then discuss specific examples (the reality show Prisoner). Most academic essays contain the topic sentence at the beginning of the first paragraph.

Now take a look at the following paragraph. The topic sentence is underlined for you.

Last year, a cat traveled 130 miles to reach its family, who had moved to another state and had left their pet behind. Even though it had never been to their new home, the cat was able to track down its former owners. A dog in my neighborhood can predict when its master is about to have a seizure. It makes sure that he does not hurt himself during an epileptic fit. Compared to many animals, our own senses are almost dull.

The last sentence of this paragraph is the topic sentence. It draws on specific examples (a cat that tracked down its owners and a dog that can predict seizures) and then makes a general statement that draws a conclusion from these examples (animals' senses are better than humans'). In this case, the supporting sentences are placed before the topic sentence and the concluding sentence is the same as the topic sentence.

This technique is frequently used in persuasive writing. The writer produces detailed examples as evidence to back up his or her point, preparing the reader to accept the concluding topic sentence as the truth.

Sometimes, the topic sentence appears in the middle of a paragraph. Read the following example. The topic sentence is underlined for you. 
For many years, I suffered from severe anxiety every time I took an exam. Hours before the exam, my heart would begin pounding, my legs would shake, and sometimes I would become physically unable to move. Last year, I was referred to a specialist and finally found a way to control my anxiety-breathing exercises. It seems so simple, but by doing just a few breathing exercises a couple of hours before an exam, I gradually got my anxiety under control. The exercises help slow my heart rate and make me feel less anxious. Better yet, they require no pills, no equipment, and very little time. It's amazing how just breathing correctly has helped me learn to manage my anxiety symptoms.

In this paragraph, the underlined sentence is the topic sentence. It expresses the main idea-that breathing exercises can help control anxiety. The preceding sentences enable the writer to build up to his main point (breathing exercises can help control anxiety) by using a personal anecdote (how he used to suffer from anxiety). The supporting sentences then expand on how breathing exercises help the writer by providing additional information. The last sentence is the concluding sentence and restates how breathing can help manage anxiety.

Placing a topic sentence in the middle of a paragraph is often used in creative writing. If you notice that you have used a topic sentence in the middle of a paragraph in an academic essay, read through the paragraph carefully to make sure that it contains only one major topic. To read more about topic sentences and where they appear in paragraphs, see Chapter 8 “The Writing Process: How Do I Begin?”.

\section{Implied Topic Sentences}

Some well-organized paragraphs do not contain a topic sentence at all. Instead of being directly stated, the main idea is implied in the content of the paragraph. Read the following example:

Heaving herself up the stairs, Luella had to pause for breath several times. She let out a wheeze as she sat down heavily in the wooden rocking chair. Tao approached her cautiously, as if she might crumble at the slightest touch. He studied her face, like parchment; stretched across the bones so finely he could almost see right through the skin to the decaying muscle underneath. Luella smiled a toothless grin.

Although no single sentence in this paragraph states the main idea, the entire paragraph focuses on one concept - that Luella is extremely old. The topic sentence is thus implied rather than stated. This technique is often used in descriptive or narrative writing. Implied topic sentences work well if the writer has a firm idea of what he or she intends to say in the paragraph and sticks to it. However, a paragraph loses its effectiveness if an implied topic sentence is too subtle or the writer loses focus. 
Tip

Avoid using implied topic sentences in an informational document. Readers often lose patience if they are unable to quickly grasp what the writer is trying to say. The clearest and most efficient way to communicate in an informational document is to position the topic sentence at the beginning of the paragraph.

\section{Exercise 4}

Identify the topic sentence, supporting sentences, and concluding sentence in the following paragraph.

The desert provides a harsh environment in which few mammals are able to adapt. Of these hardy creatures, the kangaroo rat is possibly the most fascinating. Able to live in some of the most arid parts of the southwest, the kangaroo rat neither sweats nor pants to keep cool. Its specialized kidneys enable it to survive on a miniscule amount of water. Unlike other desert creatures, the kangaroo rat does not store water in its body but instead is able to convert the dry seeds it eats into moisture. Its ability to adapt to such a hostile environment makes the kangaroo rat a truly amazing creature.

Collaboration

Please share with a classmate and compare your answers.

\section{Supporting Sentences}

If you think of a paragraph as a hamburger, the supporting sentences are the meat inside the bun. They make up the body of the paragraph by explaining, proving, or enhancing the controlling idea in the topic sentence. Most paragraphs contain three to six supporting sentences depending on the audience and purpose for writing. A supporting sentence usually offers one of the following:

\section{- Reason}

Sentence: The refusal of the baby boom generation to retire is contributing to the current lack of available jobs.

\section{- Fact}

Sentence: Many families now rely on older relatives to support them financially.

\section{- Statistic}

Sentence: Nearly 10 percent of adults are currently unemployed in the United States.

\section{- Quotation}


Sentence: "We will not allow this situation to continue,” stated Senator Johns.

\section{- Example}

Sentence: Last year, Bill was asked to retire at the age of fifty-five.

The type of supporting sentence you choose will depend on what you are writing and why you are writing. For example, if you are attempting to persuade your audience to take a particular position you should rely on facts, statistics, and concrete examples, rather than personal opinions. Read the following example:

\section{There are numerous advantages to owning a hybrid car. (Topic sentence)}

First, they get 20 percent to 35 percent more miles to the gallon than a fuel-efficient gas-powered vehicle. (Supporting sentence 1: statistic)

Second, they produce very few emissions during low speed city driving. (Supporting sentence 2: fact)

Because they do not require gas, hybrid cars reduce dependency on fossil fuels, which helps lower prices at the pump. (Supporting sentence 3: reason)

Alex bought a hybrid car two years ago and has been extremely impressed with its performance. (Supporting sentence 4: example)

"It's the cheapest car I've ever had," she said. "The running costs are far lower than previous gas powered vehicles I've owned.” (Supporting sentence 5: quotation)

Given the low running costs and environmental benefits of owning a hybrid car, it is likely that many more people will follow Alex's example in the near future. (Concluding sentence)

To find information for your supporting sentences, you might consider using one of the following sources:

- Reference book

- Encyclopedia

- Website

- Biography/autobiography

- Map

- Dictionary

- Newspaper/magazine

- Interview

- Previous experience

- Personal research

To read more about sources and research, see Chapter 11 "Writing from Research: What Will I Learn?”. 


\section{Tip}

When searching for information on the Internet, remember that some websites are more reliable than others. websites ending in .gov or .edu are generally more reliable than websites ending in .com or .org. Wikis and blogs are not reliable sources of information because they are subject to inaccuracies.

\section{Concluding Sentences}

An effective concluding sentence draws together all the ideas you have raised in your paragraph. It reminds readers of the main point - the topic sentence-without restating it in exactly the same words. Using the hamburger example, the top bun (the topic sentence) and the bottom bun (the concluding sentence) are very similar. They frame the "meat" or body of the paragraph. Compare the topic sentence and concluding sentence from the previous example:

Topic sentence: There are numerous advantages to owning a hybrid car.

Concluding sentence: Given the low running costs and environmental benefits of owning a hybrid car, it is likely that many more people will follow Alex’s example in the near future.

Notice the use of the synonyms advantages and benefits. The concluding sentence reiterates the idea that owning a hybrid is advantageous without using the exact same words. It also summarizes two examples of the advantages covered in the supporting sentences: low running costs and environmental benefits.

You should avoid introducing any new ideas into your concluding sentence. A conclusion is intended to provide the reader with a sense of completion. Introducing a subject that is not covered in the paragraph will confuse the reader and weaken your writing.

A concluding sentence may do any of the following:

- Restate the main idea.

Example: Childhood obesity is a growing problem in the United States.

- Summarize the key points in the paragraph.

Example: A lack of healthy choices, poor parenting, and an addiction to video games are among the many factors contributing to childhood obesity.

- Draw a conclusion based on the information in the paragraph.

Example: These statistics indicate that unless we take action, childhood obesity rates will 
continue to rise.

- Make a prediction, suggestion, or recommendation about the information in the paragraph.

Example: Based on this research, more than 60 percent of children in the United States will be morbidly obese by the year 2030 unless we take evasive action.

- Offer an additional observation about the controlling idea.

Example: Childhood obesity is an entirely preventable tragedy.

\section{Exercise 5}

On your own paper, write one example of each type of concluding sentence based on a topic of your choice.

\section{Transitions}

A strong paragraph moves seamlessly from the topic sentence into the supporting sentences and on to the concluding sentence. To help organize a paragraph and ensure that ideas logically connect to one another, writers use transitional words and phrases. A transition is a connecting word that describes a relationship between ideas. Take another look at the earlier example:

There are numerous advantages to owning a hybrid car. First, they get 20 percent to 35 percent more miles to the gallon than a fuel-efficient gas-powered vehicle. Second, they produce very few emissions during low speed city driving. Because they do not require gas, hybrid cars reduce dependency on fossil fuels, which helps lower prices at the pump. Alex bought a hybrid car two years ago and has been extremely impressed with its performance. "It's the cheapest car I’ve ever had," she said. "The running costs are far lower than previous gas-powered vehicles I've owned.” Given the low running costs and environmental benefits of owning a hybrid car, it is likely that many more people will follow Alex's example in the near future.

Each of the underlined words is a transition word. Words such as first and second are transition words that show sequence or clarify order. They help organize the writer's ideas by showing that he or she has another point to make in support of the topic sentence. Other transition words that show order include third, also, and furthermore.

The transition word because is a transition word of consequence that continues a line of thought. It indicates that the writer will provide an explanation of a result. In this sentence, the writer explains why hybrid cars will reduce dependency on fossil fuels (because they do not require gas). Other transition words of consequence include as a result, so that, since, or for this reason.

To include a summarizing transition in her concluding sentence, the writer could rewrite the final 
sentence as follows:

In conclusion, given the low running costs and environmental benefits of owning a hybrid car, it is likely that many more people will follow Alex's example in the near future.

The following chart provides some useful transition words to connect supporting sentences and concluding sentences. See Chapter 8 "The Writing Process: How Do I Begin?" for a more comprehensive look at transitional words and phrases.

Table 6.1 Useful Transitional Words and Phrases

\section{For Supporting Sentences}

\begin{tabular}{|l|l|l|l|l|l|}
\hline above all & but & for instance & in particular & moreover & subsequently \\
\hline also & conversely & furthermore & later on & nevertheless & therefore \\
\hline aside from & correspondingly & however & likewise & on one hand & to begin with \\
\hline at the same time & for example & in addition & meanwhile & on the contrary & \\
\hline For Concluding & Sentences & & & & \\
\hline after all & all things considered & in brief & in summary & on the whole & to sum up \\
\hline all in all & finally & in conclusion & on balance & thus & \\
\hline
\end{tabular}

\section{Exercise 6}

Using your own paper, write a paragraph on a topic of your choice. Be sure to include a topic sentence, supporting sentences, and a concluding sentence and to use transitional words and phrases to link your ideas together.

\section{Collaboration}

Please share with a classmate and compare your answers.

\section{Writing at Work}

Transitional words and phrases are useful tools to incorporate into workplace documents. They guide the reader through the document, clarifying relationships between sentences and paragraphs so that the reader understands why they have been written in that particular order. 
For example, when writing an instructional memo, it may be helpful to consider the following transitional words and phrases: before you begin, first, next, then, finally, after you have completed. Using these transitions as a template to write your memo will provide readers with clear, logical instructions about a particular process and the order in which steps are supposed to be completed.

\section{Key Takeaways}

- A good paragraph contains three distinct components: a topic sentence, body, and concluding sentence.

- The topic sentence expresses the main idea of the paragraph combined with the writer's attitude or opinion about the topic.

- Good topic sentences contain both a main idea and a controlling idea, are clear and easy to follow, use engaging vocabulary, and provide an accurate indication of what will follow in the rest of the paragraph.

- Topic sentences may be placed at the beginning, middle, or end of a paragraph. In most academic essays, the topic sentence is placed at the beginning of a paragraph.

- Supporting sentences help explain, prove, or enhance the topic sentence by offering facts, reasons, statistics, quotations, or examples.

- Concluding sentences summarize the key points in a paragraph and reiterate the main idea without repeating it word for word.

- Transitional words and phrases help organize ideas in a paragraph and show how these ideas relate to one another. 


\subsection{Writing Paragraphs: End-of-Chapter Exercises}

\section{Exercises}

1. Select one of the following topics or choose a topic of your choice:

- Drilling for oil in Alaska

- Health care reform

- Introducing a four-day work week

- Bringing pets to work

- Charging airline passengers to use the in-flight bathroom

Create a topic sentence based on the topic you chose, remembering to include both a main idea and a controlling idea. Next, write an alternative topic sentence using the same main idea but a different controlling idea. Explain how each fully developed paragraph might differ in tone and content.

\section{Collaboration}

Please share with a classmate and compare your answers.

2. At some point during your career, you may be asked to write a report or complete a presentation. Imagine that you have been asked to report on the issue of health and safety in the workplace. Using the information in Section 6.1.2 "Identifying the Audience", complete an analysis of your intended audience-your fellow office workers. Consider how demographics, education, prior knowledge, and expectations will influence your report and explain how you will tailor it to your audience accordingly.

\section{Collaboration}

Please share with a classmate and compare your answers.

3. Group activity. Working in a group of four or five, assign each group member the task of collecting one document each. These documents might include magazine or newspaper articles, workplace documents, academic essays, chapters from a reference book, film or book reviews, or any other type of writing. As a group, read through each document and discuss the author's purpose for writing. Use the information you have learned in this chapter to decide whether the main purpose is to summarize, analyze, synthesize, or evaluate. Write a brief report on the purpose of each document, using supporting evidence from the text.

4. Group activity. Working in a small group, select a workplace document or academic essay that has a clear thesis. Examine each paragraph and identify the topic sentence, supporting sentences, and concluding sentence. Then, choose one particular paragraph and discuss the following questions:

- Is the topic sentence clearly identifiable or is it implied?

- Do all the supporting sentences relate to the topic sentence?

- Does the writer use effective transitions to link his or her ideas?

- Does the concluding sentence accurately summarize the main point of the paragraph? 
As a group, identify the weakest areas of the paragraph and rewrite them. Focus on the relationship among the topic sentence, supporting sentences, and concluding sentence. Use transitions to illustrate the connection between each sentence in the paragraph.

5. Peer activity. Using the information you have learned in this chapter, write a paragraph about a current event. Underline the topic sentence in your paragraph. Now, rewrite the paragraph, placing the topic sentence in a different part of the paragraph. Read the two paragraphs aloud to a peer and have him or her identify the topic sentence. Discuss which paragraph is more effective and why.

\section{Collaboration}

Please share with a classmate, compare your answers, and discuss the contrasting results. 


\section{Chapter 7: Refining Your Writing: How Do I Improve My Writing Technique?}

7.1 Sentence Variety

7.2 Coordination and Subordination

7.3 Parallelism

7.4 Refining Your Writing: End-of-Chapter Exercises 


\subsection{Sentence Variety}

\section{Learning Objectives}

1. Identify ways to vary sentence structure.

2. Write and revise sentence structure at the beginning of sentences.

3. Write and revise sentence structure by connecting ideas.

Have you ever ordered a dish in a restaurant and been not happy with its taste, even though it contained most of your favorite ingredients? Just as a meal might lack the finishing touches needed to spice it up, so too might a paragraph contain all the basic components but still lack the stylistic finesse required to engage a reader. Sometimes writers have a tendency to reuse the same sentence pattern throughout their writing. Like any repetitive task, reading text that contains too many sentences with the same length and structure can become monotonous and boring. Experienced writers mix it up by using an assortment of sentence patterns, rhythms, and lengths.

In this chapter, you will follow a student named Naomi who has written a draft of an essay but needs to refine her writing. This section discusses how to introduce sentence variety into writing, how to open sentences using a variety of techniques, and how to use different types of sentence structure when connecting ideas. You can use these techniques when revising a paper to bring life and rhythm to your work. They will also make reading your work more enjoyable.

\section{Incorporating Sentence Variety}

Experienced writers incorporate sentence variety into their writing by varying sentence style and structure. Using a mixture of different sentence structures reduces repetition and adds emphasis to important points in the text. Read the following example:

During my time in office I have achieved several goals. I have helped increase funding for local schools. I have reduced crime rates in the neighborhood. I have encouraged young people to get involved in their community. My competitor argues that she is the better choice in the upcoming election. I argue that it is ridiculous to fix something that isn't broken. If you reelect me this year, I promise to continue to serve this community.

In this extract from an election campaign, the writer uses short, simple sentences of a similar length and 
style. Writers often mistakenly believe that this technique makes the text more clear for the reader, but the result is a choppy, unsophisticated paragraph that does not grab the audience's attention. Now read the revised paragraph with sentence variety:

During my time in office, I have helped increase funding for local schools, reduced crime rates in the neighborhood, and encouraged young people to get involved in their community. Why fix what isn't broken? If you reelect me this year, I will continue to achieve great things for this community. Don't take a chance on an unknown contender; vote for the proven success.

Notice how introducing a short rhetorical question among the longer sentences in the paragraph is an effective means of keeping the reader's attention. In the revised version, the writer combines the choppy sentences at the beginning into one longer sentence, which adds rhythm and interest to the paragraph.

\section{Tip}

Effective writers often implement the "rule of three," which is basically the thought that things that contain three elements are more memorable and more satisfying to readers than any other number. Try to use a series of three when providing examples, grouping adjectives, or generating a list.

\section{Exercise 1}

Combine each set of simple sentences into a compound or a complex sentence. Write the combined sentence on your own sheet of paper.

1. Heroin is an extremely addictive drug. Thousands of heroin addicts die each year.

2. Shakespeare's writing is still relevant today. He wrote about timeless themes. These themes include love, hate, jealousy, death, and destiny.

3. Gay marriage is now legal in six states. Iowa, Massachusetts, Connecticut, Vermont, New Hampshire, and Maine all permit same-sex marriage. Other states are likely to follow their example.

4. Prewriting is a vital stage of the writing process. Prewriting helps you organize your ideas. Types of prewriting include outlining, brainstorming, and idea mapping.

5. Mitch Bancroft is a famous writer. He also serves as a governor on the local school board. Mitch's two children attend the school.

\section{Collaboration}

Please share with a classmate and compare your answers. 


\section{Using Sentence Variety at the Beginning of Sentences}

Read the following sentences and consider what they all have in common:

John and Amanda will be analyzing this week’s financial report.

The car screeched to a halt just a few inches away from the young boy.

Students rarely come to the exam adequately prepared.

If you are having trouble figuring out why these sentences are similar, try underlining the subject in each. You will notice that the subject is positioned at the beginning of each sentence-John and Amanda, the car, students. Since the subject-verb-object pattern is the simplest sentence structure, many writers tend to overuse this technique, which can result in repetitive paragraphs with little sentence variety.

Naomi wrote an essay about the 2008 government bailout. Read this excerpt from Naomi’s essay:

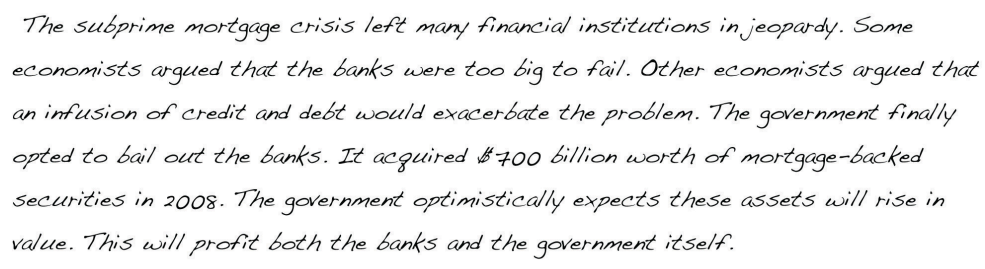

This section examines several ways to introduce sentence variety at the beginning of sentences, using Naomi’s essay as an example.

\section{Starting a Sentence with an Adverb}

One technique you can use so as to avoid beginning a sentence with the subject is to use an adverb. An adverb is a word that describes a verb, adjective, or other adverb and often ends in -ly. Examples of adverbs include quickly, softly, quietly, angrily, and timidly. Read the following sentences:

She slowly turned the corner and peered into the murky basement. 
Slowly, she turned the corner and peered into the murky basement.

In the second sentence, the adverb slowly is placed at the beginning of the sentence. If you read the two sentences aloud, you will notice that moving the adverb changes the rhythm of the sentence and slightly alters its meaning. The second sentence emphasizes how the subject moves—slowly_creating a buildup of tension. This technique is effective in fictional writing.

Note that an adverb used at the beginning of a sentence is usually followed by a comma. A comma indicates that the reader should pause briefly, which creates a useful rhetorical device. Read the following sentences aloud and consider the effect of pausing after the adverb:

Cautiously, he unlocked the kennel and waited for the dog's reaction.

Solemnly, the policeman approached the mayor and placed him under arrest.

Suddenly, he slammed the door shut and sprinted across the street.

In an academic essay, moving an adverb to the beginning of a sentence serves to vary the rhythm of a paragraph and increase sentence variety.

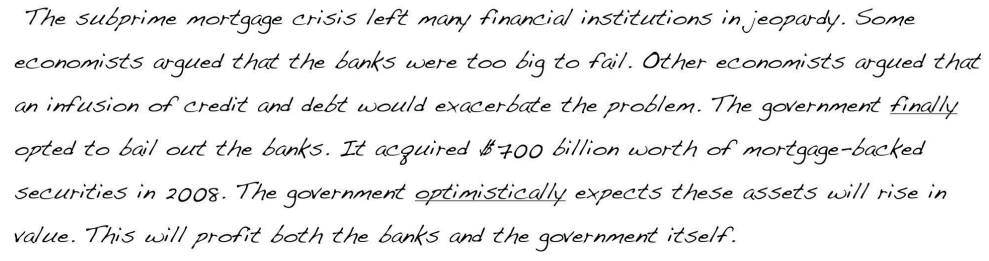

Naomi has used two adverbs in her essay that could be moved to the beginning of their respective sentences. Notice how the following revised version creates a more varied paragraph: 


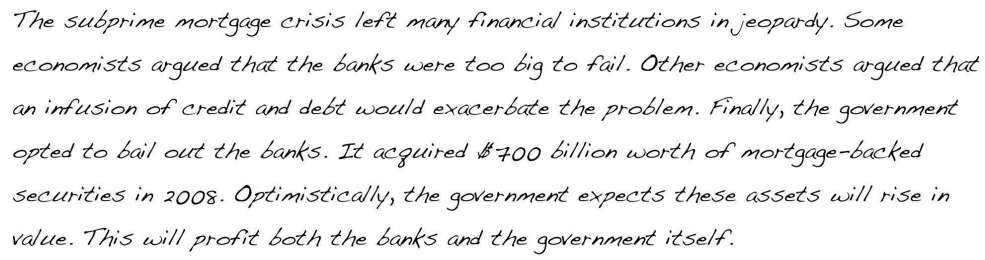

Tip

Adverbs of time-adverbs that indicate when an action takes place-do not always require a comma when used at the beginning of a sentence. Adverbs of time include words such as yesterday, today, later, sometimes, often, and now.

\section{Exercise 2}

On your own sheet of paper, rewrite the following sentences by moving the adverbs to the beginning.

1. The red truck sped furiously past the camper van, blaring its horn.

2. Jeff snatched at the bread hungrily, polishing off three slices in under a minute.

3. Underage drinking typically results from peer pressure and lack of parental attention.

4. The firefighters bravely tackled the blaze, but they were beaten back by flames.

5. Mayor Johnson privately acknowledged that the budget was excessive and that further discussion was needed.

\section{Collaboration}

Please share with a classmate and compare your answers.

\section{Starting a Sentence with a Prepositional Phrase}

A prepositional phrase is a group of words that behaves as an adjective or an adverb, modifying a noun or a verb. Prepositional phrases contain a preposition (a word that specifies place, direction, or time) and an object of the preposition (a noun phrase or pronoun that follows the preposition). 
Table 7.1 Common Prepositions

\begin{tabular}{|l|l|l|l|}
\hline above & beneath & into & till \\
\hline across & beside & like & toward \\
\hline against & between & near & under \\
\hline after & beyond & off & underneath \\
\hline among & by & on & until \\
\hline around & despite & over & up \\
\hline at & except & past & with \\
\hline before & for & since & without \\
\hline behind & from & through & \\
\hline below & inside & throughout & \\
\hline
\end{tabular}

Read the following sentence:

The terrified child hid underneath the table.

In this sentence, the prepositional phrase is underneath the table. The preposition underneath relates to the object that follows the preposition — the table. Adjectives may be placed between the preposition and the object in a prepositional phrase.

The terrified child hid underneath the heavy wooden table.

Some prepositional phrases can be moved to the beginning of a sentence in order to create variety in a piece of writing. Look at the following revised sentence:

Underneath the heavy wooden table, the terrified child hid.

Notice that when the prepositional phrase is moved to the beginning of the sentence, the emphasis shifts from the subject - the terrified child — to the location in which the child is hiding. Words that are placed at the beginning or end of a sentence generally receive the greatest emphasis. Take a look at the following examples. The prepositional phrase is underlined in each: 
The bandaged man waited in the doctor's office.

In the doctor's office, the bandaged man waited.

My train leaves the station at 6:45 a.m.

At 6:45 a.m., my train leaves the station.

Teenagers exchange drugs and money under the railway bridge.

Under the railway bridge, teenagers exchange drugs and money.

Prepositional phrases are useful in any type of writing. Take another look at Naomi's essay on the government bailout.

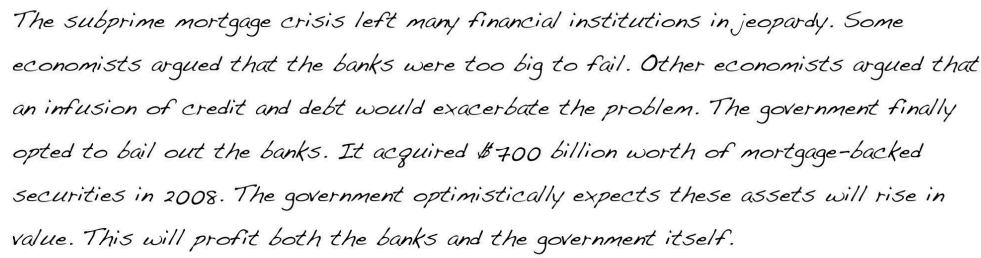

Now read the revised version.

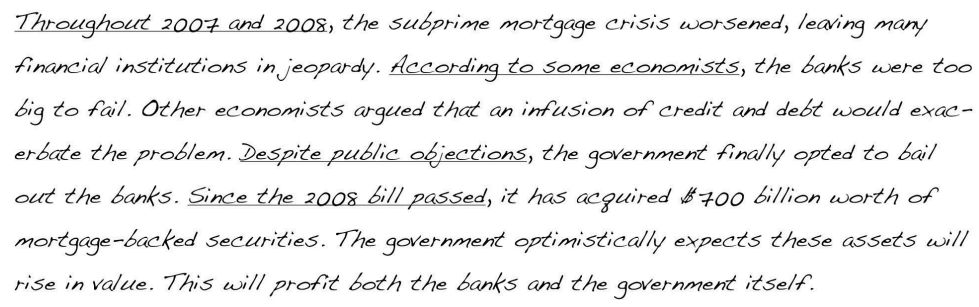

The underlined words are all prepositional phrases. Notice how they add additional information to the text and provide a sense of flow to the essay, making it less choppy and more pleasurable to read.

\section{Unmovable Prepositional Phrases}


Not all prepositional phrases can be placed at the beginning of a sentence. Read the following sentence:

I would like a chocolate sundae without whipped cream.

In this sentence, without whipped cream is the prepositional phrase. Because it describes the chocolate sundae, it cannot be moved to the beginning of the sentence. "Without whipped cream I would like a chocolate sundae" does not make as much (if any) sense. To determine whether a prepositional phrase can be moved, we must determine the meaning of the sentence.

\section{Overuse of Prepositional Phrases}

Experienced writers often include more than one prepositional phrase in a sentence; however, it is important not to overload your writing. Using too many modifiers in a paragraph may create an unintentionally comical effect as the following example shows:

The treasure lay buried under the old oak tree, behind the crumbling fifteenth-century wall, near the schoolyard, where children played merrily during their lunch hour, unaware of the riches that remained hidden beneath their feet.

A sentence is not necessarily effective just because it is long and complex. If your sentence appears cluttered with prepositional phrases, divide it into two shorter sentences. The previous sentence is far more effective when written as two simpler sentences:

The treasure lay buried under the old oak tree, behind the crumbling fifteenth-century wall. In the nearby schoolyard, children played merrily during their lunch hour, unaware of the riches that remained hidden beneath their feet.

\section{Writing at Work}

The overuse of prepositional phrases often occurs when our thoughts are jumbled and we are unsure how concepts or ideas relate to one another. If you are preparing a report or a proposal, take the time to organize your thoughts in an outline before writing a rough draft. Read the draft aloud, either to yourself or to a colleague, and identify areas that are rambling or unclear. If you notice that a particular part of your report contains several sentences over twenty words, you should double check that particular section to make certain that it is coherent and does not contain unnecessary prepositional phrases. Reading aloud sometimes helps detect unclear and wordy sentences. You can also ask a colleague to paraphrase your main points to ensure that the meaning is clear. 


\section{Starting a Sentence by Inverting Subject and Verb}

As we noted earlier, most writers follow the subject-verb-object sentence structure. In an inverted sentence, the order is reversed so that the subject follows the verb. Read the following sentence pairs:

1. A truck was parked in the driveway.

2. Parked in the driveway was a truck.

1. A copy of the file is attached.

2. Attached is a copy of the file.

Notice how the second sentence in each pair places more emphasis on the subject-a truck in the first example and the file in the second. This technique is useful for drawing the reader's attention to your primary area of focus. We can apply this method to an academic essay. Take another look at Naomi's paragraph.

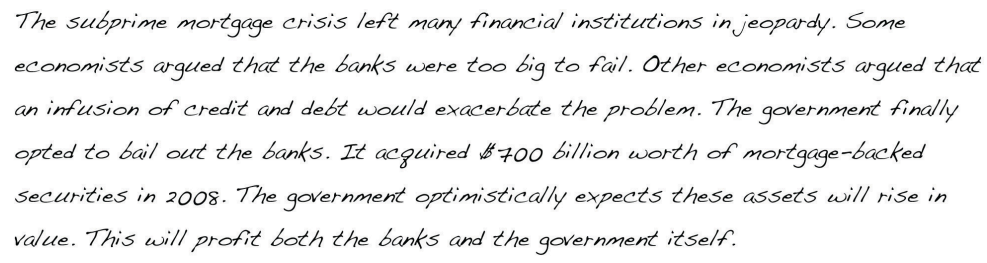

To emphasize the subject in certain sentences, Naomi can invert the traditional sentence structure. Read her revised paragraph: 


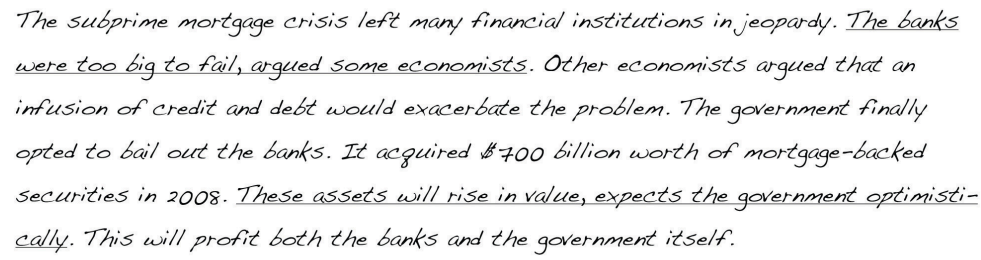

Notice that in the first underlined sentence, the subject (some economists) is placed after the verb (argued). In the second underlined sentence, the subject (the government) is placed after the verb (expects).

\section{Exercise 3}

On your own sheet of paper, rewrite the following sentences as inverted sentences.

1. Teresa will never attempt to run another marathon.

2. A detailed job description is enclosed with this letter.

3. Bathroom facilities are across the hall to the left of the water cooler.

4. The well-dressed stranger stumbled through the doorway.

5. My colleagues remain unconvinced about the proposed merger.

\section{Collaboration}

Please share with a classmate and compare your answers.

\section{Connecting Ideas to Increase Sentence Variety}

Reviewing and rewriting the beginning of sentences is a good way of introducing sentence variety into your writing. Another useful technique is to connect two sentences using a modifier, a relative clause, or an appositive. This section examines how to connect ideas across several sentences in order to increase sentence variety and improve writing. 


\section{Joining Ideas Using an -ing Modifier}

Sometimes it is possible to combine two sentences by converting one of them into a modifier using the -ing verb form-singing, dancing, swimming. A modifier is a word or phrase that qualifies the meaning of another element in the sentence. Read the following example:

Original sentences: Steve checked the computer system. He discovered a virus.

Revised sentence: Checking the computer system, Steve discovered a virus.

To connect two sentences using an -ing modifier, add -ing to one of the verbs in the sentences (checking) and delete the subject (Steve). Use a comma to separate the modifier from the subject of the sentence. It is important to make sure that the main idea in your revised sentence is contained in the main clause, not in the modifier. In this example, the main idea is that Steve discovered a virus, not that he checked the computer system.

In the following example, an -ing modifier indicates that two actions are occurring at the same time:

1. Noticing the police car, she shifted gears and slowed down.

This means that she slowed down at the same time she noticed the police car.

2. Barking loudly, the dog ran across the driveway.

This means that the dog barked as it ran across the driveway.

You can add an -ing modifier to the beginning or the end of a sentence, depending on which fits best.

Beginning: Conducting a survey among her friends, Amanda found that few were happy in their jobs.

End: Maria filed the final report, meeting her deadline.

\section{Dangling Modifiers}

A common mistake when combining sentences using the -ing verb form is to misplace the modifier so that it is not logically connected to the rest of the sentence. This creates a dangling modifier. Look at the following example: 
Jogging across the parking lot, my breath grew ragged and shallow.

In this sentence, jogging across the parking lot seems to modify my breath. Since breath cannot jog, the sentence should be rewritten so that the subject is placed immediately after the modifier or added to the dangling phrase.

Jogging across the parking lot, I felt my breath grow ragged and shallow.

For more information on dangling modifiers, see Chapter 2 "Writing Basics: What Makes a Good Sentence?”.

\section{Joining Ideas Using an -ed Modifier}

Some sentences can be combined using an -ed verb form—stopped, finished, played. To use this method, one of the sentences must contain a form of be as a helping verb in addition to the -ed verb form. Take a look at the following example:

Original sentences: The Jones family was delayed by a traffic jam. They arrived several hours after the party started.

Revised sentence: Delayed by a traffic jam, the Jones family arrived several hours after the party started.

In the original version, was acts as a helping verb-it has no meaning by itself, but it serves a grammatical function by placing the main verb (delayed) in the perfect tense.

To connect two sentences using an -ed modifier, drop the helping verb (was) and the subject (the Jones family) from the sentence with an -ed verb form. This forms a modifying phrase (delayed by a traffic jam) that can be added to the beginning or end of the other sentence according to which fits best. As with the -ing modifier, be careful to place the word that the phrase modifies immediately after the phrase in order to avoid a dangling modifier.

Using -ing or -ed modifiers can help streamline your writing by drawing obvious connections between two sentences. Take a look at how Naomi might use modifiers in her paragraph. 


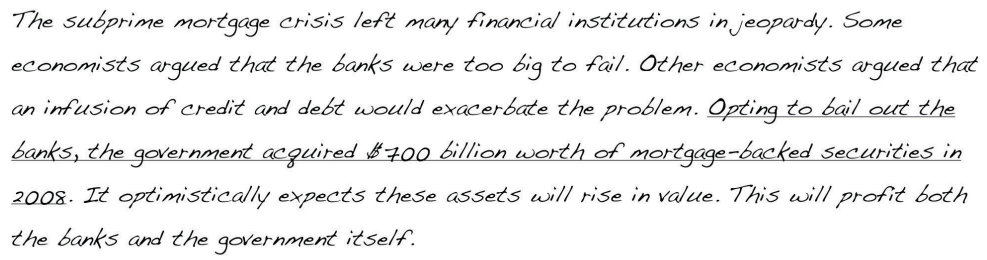

The revised version of the essay uses the -ing modifier opting to draw a connection between the government's decision to bail out the banks and the result of that decision-the acquisition of the mortgage-backed securities.

\section{Joining Ideas Using a Relative Clause}

Another technique that writers use to combine sentences is to join them using a relative clause. A relative clause is a group of words that contains a subject and a verb and describes a noun. Relative clauses function as adjectives by answering questions such as which one? or what kind? Relative clauses begin with a relative pronoun, such as who, which, where, why, or when. Read the following examples:

Original sentences: The managing director is visiting the company next week. He lives in Seattle.

Revised sentence: The managing director, who lives in Seattle, is visiting the company next week.

To connect two sentences using a relative clause, substitute the subject of one of the sentences (he) for a relative pronoun (who). This gives you a relative clause (who lives in Seattle) that can be placed next to the noun it describes (the managing director). Make sure to keep the sentence you want to emphasize as the main clause. For example, reversing the main clause and subordinate clause in the preceding sentence emphasizes where the managing director lives, not the fact that he is visiting the company.

Revised sentence: The managing director, who is visiting the company next week, lives in Seattle.

Relative clauses are a useful way of providing additional, nonessential information in a sentence. Take a look at how Naomi might incorporate relative clauses into her essay. 


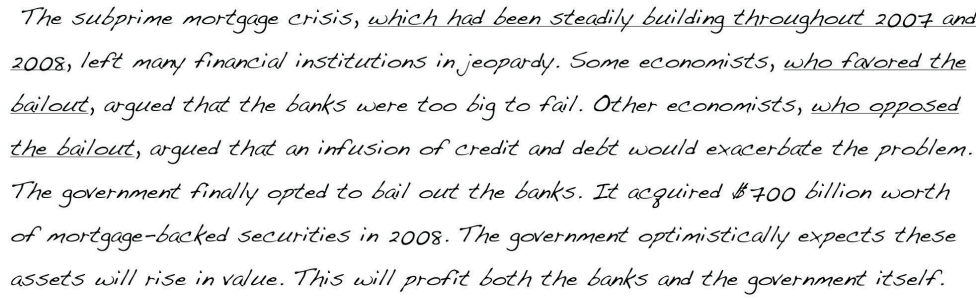

Notice how the underlined relative clauses can be removed from Naomi's essay without changing the meaning of the sentence.

Tip

To check the punctuation of relative clauses, assess whether or not the clause can be taken out of the sentence without changing its meaning. If the relative clause is not essential to the meaning of the sentence, it should be placed in commas. If the relative clause is essential to the meaning of the sentence, it does not require commas around it.

\section{Joining Ideas Using an Appositive}

An appositive is a word or group of words that describes or renames a noun or pronoun. Incorporating appositives into your writing is a useful way of combining sentences that are too short and choppy. Take a look at the following example:

Original sentences: Harland Sanders began serving food for hungry travelers in 1930. He is Colonel Sanders or "the Colonel."

Revised sentence: Harland Sanders, “the Colonel,” began serving food for hungry travelers in 1930.

In the revised sentence, "the Colonel" is an appositive because it renames Harland Sanders. To combine two sentences using an appositive, drop the subject and verb from the sentence that renames the noun and turn it into a phrase. Note that in the previous example, the appositive is positioned immediately after the noun it describes. An appositive may be placed anywhere in a sentence, but it must come directly before or after the noun to which it refers: 
Appositive after noun: Scott, a poorly trained athlete, was not expected to win the race.

Appositive before noun: A poorly trained athlete, Scott was not expected to win the race.

Unlike relative clauses, appositives are always punctuated by a comma or a set commas. Take a look at the way Naomi uses appositives to include additional facts in her essay.

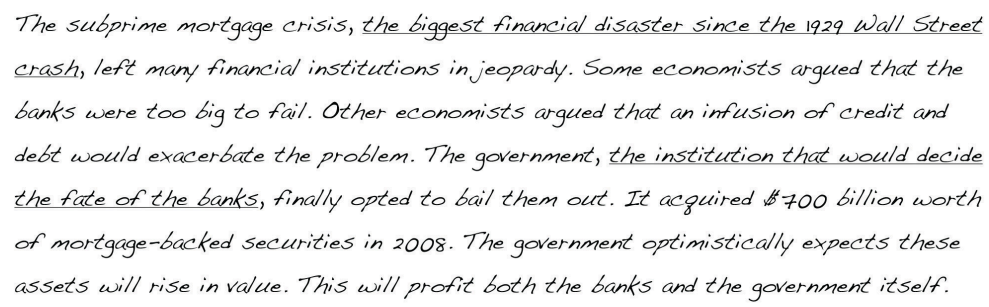

\section{Exercise 4}

On your own sheet of paper, rewrite the following sentence pairs as one sentence using the techniques you have learned in this section.

1. Baby sharks are called pups. Pups can be born in one of three ways.

2. The Pacific Ocean is the world's largest ocean. It extends from the Arctic in the north to the Southern Ocean in the south.

3. Michael Phelps won eight gold medals in the 2008 Olympics. He is a champion swimmer.

4. Ashley introduced her colleague Dan to her husband, Jim. She speculated that the two of them would have a lot in common.

5. Cacao is harvested by hand. It is then sold to chocolate-processing companies at the Coffee, Sugar, and Cocoa Exchange.

\section{Collaboration}

Please share with a classmate and compare your answers. 


\section{Writing at Work}

In addition to varying sentence structure, consider varying the types of sentences you are using in a report or other workplace document. Most sentences are declarative, but a carefully placed question, exclamation, or command can pique colleagues' interest, even if the subject material is fairly dry. Imagine that you are writing a budget analysis. Beginning your report with a rhetorical question, such as "Where is our money going?” or "How can we increase sales?” encourages people to continue reading to find out the answers. Although they should be used sparingly in academic and professional writing, questions or commands are effective rhetorical devices.

\section{Key Takeaways}

- Sentence variety reduces repetition in a piece of writing and adds emphasis to important points in the text.

- Sentence variety can be introduced to the beginning of sentences by starting a sentence with an adverb, starting a sentence with a prepositional phrase, or by inverting the subject and verb.

- Combine ideas, using modifiers, relative clauses, or appositives, to achieve sentence variety. 


\subsection{Coordination and Subordination}

\section{Learning Objectives}

1. Identify coordination and subordination in writing.

2. Combine sentences and ideas using coordination.

3. Combine sentences and ideas using subordination.

In the previous section, we learned how to use different patterns to create sentence variety and to add emphasis to important points in our writing. Next, we will examine two ways in which we can join sentences with related ideas:

- Coordination. Joining two related ideas of equal importance.

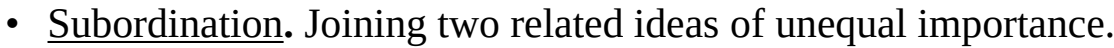

Connecting sentences with coordinate or subordinate clauses creates more coherent paragraphs, and in turn, produces more effective writing. In this section, you will read excerpts from Naomi's classmate named Joshua, who drafted an essay about wine production. Read this excerpt from Joshua's essay.

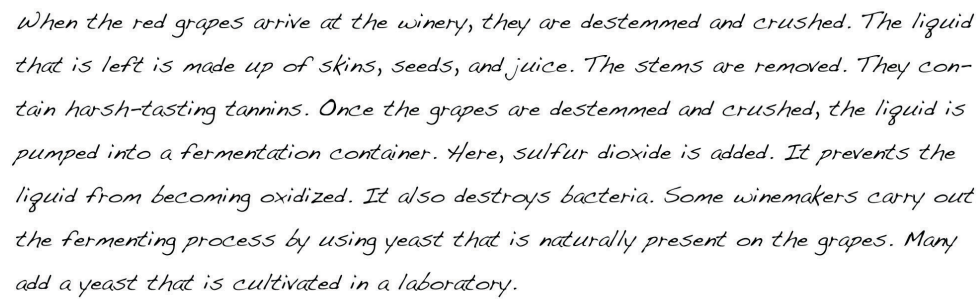

This section examines several ways to combine sentences with coordination and subordination, using Joshua’s essay as an example. 


\section{Coordination}

Coordination joins two independent clauses that contain related ideas of equal importance.

Original sentences: I spent my entire paycheck last week. I am staying home this weekend.

In their current form, these sentences contain two separate ideas that may or may not be related. Am I staying home this week because I spent my paycheck, or is there another reason for my lack of enthusiasm to leave the house? To indicate a relationship between the two ideas, we can use the coordinating conjunction so:

Revised sentence: I spent my entire paycheck last week, so I am staying home this weekend.

The revised sentence illustrates that the two ideas are connected. Notice that the sentence retains two independent clauses (I spent my entire paycheck; I am staying home this weekend) because each can stand alone as a complete idea.

\section{Coordinating Conjunctions}

A coordinating conjunction is a word that joins two independent clauses. The most common coordinating conjunctions are for, and, nor, but, or, yet, and so. Note that a comma precedes the coordinating conjunction when joining two clauses. 


\begin{tabular}{|l|l|l|l|}
\hline Independent Clause & $\begin{array}{l}\text { Coordinating } \\
\text { Conjunction }\end{array}$ & $\begin{array}{l}\text { Independent } \\
\text { Clause }\end{array}$ & Revised Sentence \\
\hline $\begin{array}{l}\text { I will not be attending the } \\
\text { dance. }\end{array}$ & $\begin{array}{l}\text { for (indicates } \\
\text { a reason or } \\
\text { cause) }\end{array}$ & $\begin{array}{l}\text { I have no one to } \\
\text { go with. }\end{array}$ & $\begin{array}{l}\text { I will not be attending the dance, for I have } \\
\text { no one to go with. }\end{array}$ \\
\hline I plan to stay home. & $\begin{array}{l}\text { and (joins two } \\
\text { ideas) }\end{array}$ & $\begin{array}{l}\text { I will complete } \\
\text { an essay for } \\
\text { class. }\end{array}$ & $\begin{array}{l}\text { I plan to stay home, and I will complete an } \\
\text { essay for class. }\end{array}$ \\
\hline $\begin{array}{l}\text { Jessie isn't going to be at } \\
\text { the dance }\end{array}$ & $\begin{array}{l}\text { nor (indicates } \\
\text { a negative) }\end{array}$ & $\begin{array}{l}\text { Tom won't be } \\
\text { there either. }\end{array}$ & $\begin{array}{l}\text { Jessie isn't going to be at the dance, nor will } \\
\text { Tom be there. }\end{array}$ \\
\hline $\begin{array}{l}\text { The fundraisers are hoping } \\
\text { for a record-breaking } \\
\text { attendance. }\end{array}$ & $\begin{array}{l}\text { but (indicates } \\
\text { a contrast) }\end{array}$ & $\begin{array}{l}\text { I don't think } \\
\text { many people are } \\
\text { going. }\end{array}$ & $\begin{array}{l}\text { The fundraisers are hoping for a } \\
\text { record-breaking attendance, but I don't think } \\
\text { many people are going. }\end{array}$ \\
\hline $\begin{array}{l}\text { I might go to the next } \\
\text { fundraising event. }\end{array}$ & $\begin{array}{l}\text { or (offers an } \\
\text { alternative) }\end{array}$ & $\begin{array}{l}\text { I might donate } \\
\text { some money to } \\
\text { the cause. }\end{array}$ & $\begin{array}{l}\text { I might go to the next fundraising event, or I } \\
\text { might donate some money to the cause. }\end{array}$ \\
\hline $\begin{array}{l}\text { My parents are worried } \\
\text { that I am antisocial. }\end{array}$ & $\begin{array}{l}\text { yet (indicates } \\
\text { a reason) }\end{array}$ & $\begin{array}{l}\text { I have many } \\
\text { friends at school. }\end{array}$ & $\begin{array}{l}\text { My parents are worried that I am antisocial, } \\
\text { yet I have many friends at school. }\end{array}$ \\
\hline $\begin{array}{l}\text { Buying a new dress is } \\
\text { expensive. }\end{array}$ & $\begin{array}{l}\text { so (indicates a } \\
\text { result) }\end{array}$ & $\begin{array}{l}\text { By staying home } \\
\text { I will save } \\
\text { money. }\end{array}$ & $\begin{array}{l}\text { Buying a new dress is expensive, so by } \\
\text { staying home I will save money. }\end{array}$ \\
\hline
\end{tabular}

Tip

To help you remember the seven coordinating conjunctions, think of the acronym FANBOYS: for, and, nor, but, or, yet, so. Remember that when you use a coordinating conjunction in a sentence, a comma should precede it.

\section{Conjunctive Adverbs}

Another method of joining two independent clauses with related and equal ideas is to use a conjunctive adverb and a semicolon (see Chapter 2 "Writing Basics: What Makes a Good Sentence?” for information on semicolon usage). A conjunctive adverb is a linking word that demonstrates a relationship between two clauses. Read the following sentences:

Original sentences: Bridget wants to take part in the next Olympics. She trains every day. 
Since these sentences contain two equal and related ideas, they may be joined using a conjunctive adverb. Now, read the revised sentence:

Revised sentence: Bridget wants to take part in the next Olympics; therefore, she trains every day.

The revised sentence explains the relationship between Bridget's desire to take part in the next Olympics and her daily training. Notice that the conjunctive adverb comes after a semicolon that separates the two clauses and is followed by a comma.

Review the following chart of some common conjunctive adverbs with examples of how they are used:

\begin{tabular}{|c|c|c|}
\hline Function & $\begin{array}{l}\text { Conjunctive } \\
\text { Adverb }\end{array}$ & Example \\
\hline Addition & $\begin{array}{l}\text { also, furthermore, } \\
\text { moreover, besides }\end{array}$ & $\begin{array}{l}\text { Alicia was late for class and stuck in traffic; furthermore, her shoe heel } \\
\text { had broken and she had forgotten her lunch. }\end{array}$ \\
\hline Comparison & similarly, likewise & $\begin{array}{l}\text { Recycling aluminum cans is beneficial to the environment; similarly, } \\
\text { reusing plastic bags and switching off lights reduces waste. }\end{array}$ \\
\hline Contrast & $\begin{array}{l}\text { instead, however, } \\
\text { conversely }\end{array}$ & Most people do not walk to work; instead, they drive or take the train. \\
\hline Emphasis & $\begin{array}{l}\text { namely, certainly, } \\
\text { indeed }\end{array}$ & $\begin{array}{l}\text { The Siberian tiger is a rare creature; indeed, there are fewer than five } \\
\text { hundred left in the wild. }\end{array}$ \\
\hline $\begin{array}{l}\text { Cause and } \\
\text { Effect }\end{array}$ & $\begin{array}{l}\text { accordingly, } \\
\text { consequently, hence, } \\
\text { thus }\end{array}$ & I missed my train this morning; consequently, I was late for my meeting. \\
\hline Time & $\begin{array}{l}\text { finally, next, } \\
\text { subsequently, then }\end{array}$ & $\begin{array}{l}\text { Tim crossed the barrier, jumped over the wall, and pushed through the } \\
\text { hole in the fence; finally, he made it to the station. }\end{array}$ \\
\hline
\end{tabular}

Take a look at Joshua's essay on wine production and identify some areas in which he might use coordination. 


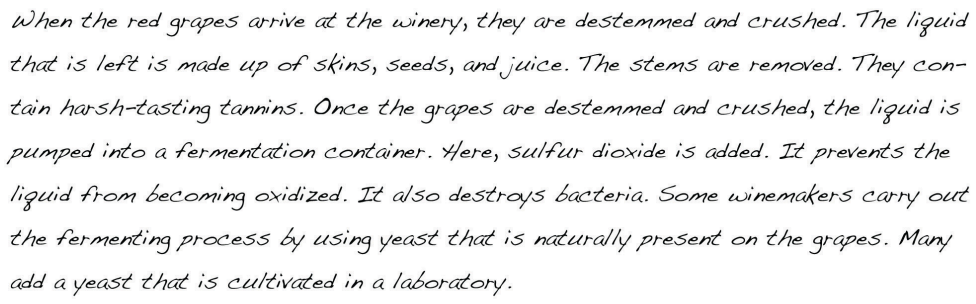

Now look at Joshua's revised essay. Did you coordinate the same sentences? You may find that your answers are different because there are usually several ways to join two independent clauses.

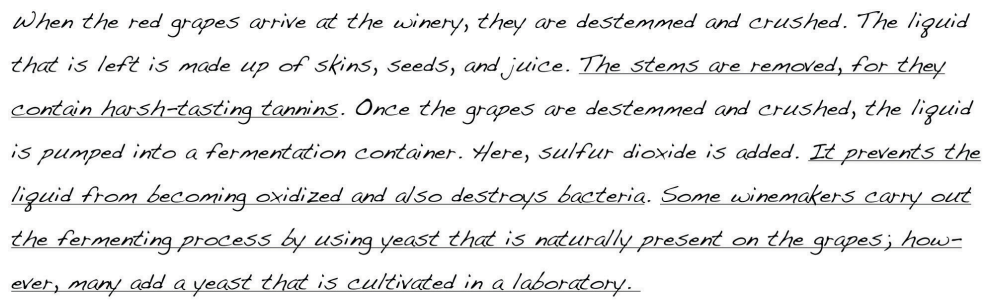

\section{Exercise 1}

Combine each sentence pair into a single sentence using either a coordinating conjunction or a conjunctive adverb. Then copy the combined sentence onto your own sheet of paper.

1. Pets are not allowed in Mr. Taylor's building. He owns several cats and a parrot.

2. New legislation prevents drivers from sending or reading text messages while driving. Many people continue to use their phones illegally.

3. The coroner concluded that the young man had taken a lethal concoction of drugs. By the time his relatives found him, nothing could be done.

4. Amphibians are vertebrates that live on land and in the water. Flatworms are invertebrates that live only in water.

5. Ashley carefully fed and watered her tomato plants all summer. The tomatoes grew juicy and ripe. 
6. When he lost his car key, Simon attempted to open the door with a wire hanger, a credit card, and a paper clip. He called the manufacturer for advice.

\section{Collaboration}

Please share with a classmate and compare your answers.

\section{Writing at Work}

When writing an essay or a report, it is important that you do not use excessive coordination. Workplace documents should be clear and concise, so only join two clauses that are logically connected and can work together to make one main point. If you repeat the same coordinating conjunction several times in a sentence, you are probably including more than one idea. This may make it difficult for readers to pick out the most important information in each sentence.

\section{Subordination}

Subordination joins two sentences with related ideas by merging them into a main clause (a complete sentence) and a dependent clause (a construction that relies on the main clause to complete its meaning). Coordination allows a writer to give equal weight to the two ideas that are being combined, and subordination enables a writer to emphasize one idea over the other. Take a look at the following sentences:

Original sentences: Tracy stopped to help the injured man. She would be late for work.

To illustrate that these two ideas are related, we can rewrite them as a single sentence using the subordinating conjunction even though.

Revised sentence: Even though Tracy would be late for work, she stopped to help the injured man.

In the revised version, we now have an independent clause (she stopped to help the injured man) that stands as a complete sentence and a dependent clause (even though Tracy would be late for work) that is subordinate to the main clause. Notice that the revised sentence emphasizes the fact that Tracy stopped to help the injured man, rather than the fact she would be late for work. We could also write the sentence this way: 
Revised sentence: Tracy stopped to help the injured man even though she would be late for work.

The meaning remains the same in both sentences, with the subordinating conjunction even though introducing the dependent clause.

\section{Tip}

To punctuate sentences correctly, look at the position of the main clause and the subordinate clause. If a subordinate clause precedes the main clause, use a comma. If the subordinate clause follows the main cause, no punctuation is required.

\section{Subordinating Conjunctions}

A subordinating conjunction is a word that joins a subordinate (dependent) clause to a main (independent) clause. Review the following chart of some common subordinating conjunctions and examples of how they are used:

\begin{tabular}{|l|l|l|}
\hline Function & Subordinating Conjunction & Example \\
\hline Concession & $\begin{array}{l}\text { although, while, though, } \\
\text { whereas, even though }\end{array}$ & $\begin{array}{l}\text { Sarah completed her report even though she had to stay late to get } \\
\text { it done. }\end{array}$ \\
\hline Condition & if, unless, until & $\begin{array}{l}\text { Until we know what is causing the problem, we will not be able to } \\
\text { fix it. }\end{array}$ \\
\hline Manner & as if, as, though & $\begin{array}{l}\text { Everyone in the conference room stopped talking at once, as } \\
\text { though they had been stunned into silence. }\end{array}$ \\
\hline Place & where, wherever & $\begin{array}{l}\text { Rita is in San Jose where she has several important client } \\
\text { meetings. }\end{array}$ \\
\hline Reason & $\begin{array}{l}\text { because, since, so that, in } \\
\text { order that }\end{array}$ & $\begin{array}{l}\text { Because the air conditioning was turned up so high, everyone in } \\
\text { the office wore sweaters. }\end{array}$ \\
\hline Time & $\begin{array}{l}\text { after, before, while, once, } \\
\text { when }\end{array}$ & After the meeting had finished, we all went to lunch. \\
\hline
\end{tabular}

Take a look at the excerpt from Joshua's essay and identify some areas in which he might use subordination. 


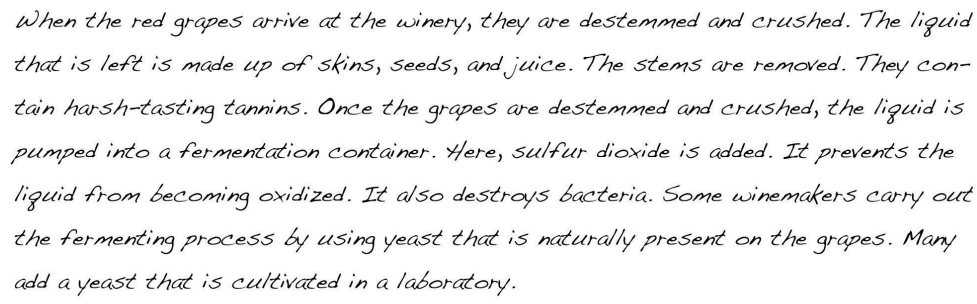

Now look at Joshua's revised essay and compare your answers. You will probably notice that there are many different ways to subordinate sentences.

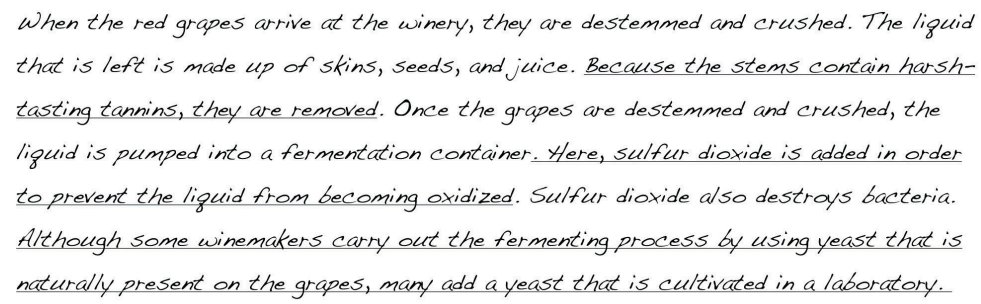

\section{Exercise 2}

Combine each sentence pair into a single sentence using a subordinating conjunction and then copy the combined sentence onto your own sheet of paper.

1. Jake is going to Mexico. There are beautiful beaches in Mexico.

2. A snowstorm disrupted traffic all over the east coast. There will be long delivery delays this week.

3. My neighbor had his television volume turned up too high. I banged on his door and asked him to keep the noise down.

4. Jessica prepared the potato salad and the sautéed vegetables. Ashley marinated the chicken.

5. Romeo poisons himself. Juliet awakes to find Romeo dead and stabs herself with a dagger. 


\section{Exercise 3}

Copy the paragraph from Joshua's essay onto your own sheet of paper. Then edit using the techniques you have learned in this section. Join the underlined sentences using coordination or subordination. Check your revised sentences for punctuation.

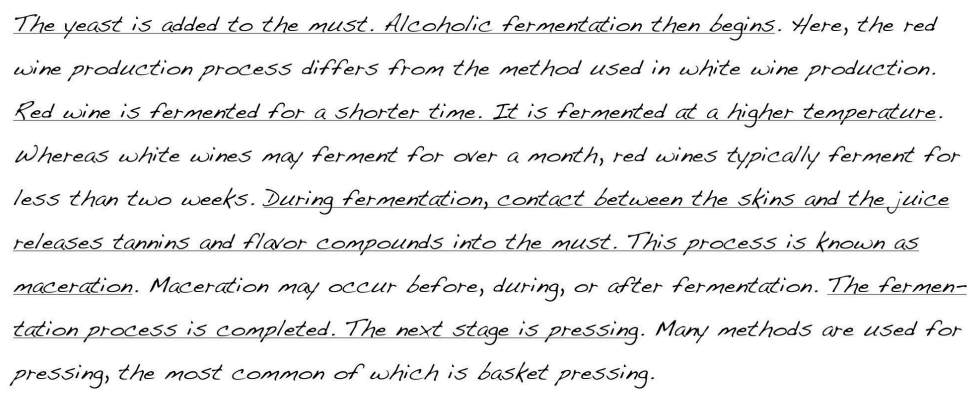

\section{Key Takeaways}

- Coordination and subordination join two sentences with related ideas.

- Coordination joins sentences with related and equal ideas, whereas subordination joins sentences with related but unequal ideas.

- Sentences can be coordinated using either a coordinating conjunction and a comma or a conjunctive adverb and a semicolon.

- Subordinate sentences are characterized by the use of a subordinate conjunction.

- In a subordinate sentence, a comma is used to separate the main clause from the dependent clause if the dependent clause is placed at the beginning of the sentence. 


\subsection{Parallelism}

\section{Learning Objectives}

1. Identify sentences that are parallel and not parallel.

2. Identify ways to create parallelism in writing.

3. Write and revise sentences using parallelism.

Earlier in this chapter, we learned that increasing sentence variety adds interest to a piece of writing and makes the reading process more enjoyable for others. Using a mixture of sentence lengths and patterns throughout an essay is an important writing technique. However, it is equally important to avoid introducing variation within individual sentences. A strong sentence is composed of balanced parts that all have the same structure. In this section, we will examine how to create a balanced sentence structure by using parallelism.

\section{Using Parallelism}

Parallelism is the use of similar structure in related words, clauses, or phrases. It creates a sense of rhythm and balance within a sentence. As readers, we often correct faulty parallelism-a lack of parallel structure-intuitively because an unbalanced sentence sounds awkward and poorly constructed. Read the following sentences aloud:

Faulty parallelism: Kelly had to iron, do the washing, and shopping before her parents arrived.

Faulty parallelism: Driving a car requires coordination, patience, and to have good eyesight.

Faulty parallelism: Ali prefers jeans to wearing a suit.

All of these sentences contain faulty parallelism. Although they are factually correct, the construction is clunky and confusing. In the first example, three different verb forms are used. In the second and third examples, the writer begins each sentence by using a noun (coordination, jeans), but ends with a phrase (to have good eyesight, wearing a suit). Now read the same three sentences that have correct parallelism.

Correct parallelism: Kelly had to do the ironing, washing, and shopping before her parents arrived. 
Correct parallelism: Driving a car requires coordination, patience, and good eyesight.

Correct parallelism: Ali prefers wearing jeans to wearing a suit.

When these sentences are written using a parallel structure, they sound more aesthetically pleasing because they are balanced. Repetition of grammatical construction also minimizes the amount of work the reader has to do to decode the sentence. This enables the reader to focus on the main idea in the sentence and not on how the sentence is put together.

Tip

A simple way to check for parallelism in your writing is to make sure you have paired nouns with nouns, verbs with verbs, prepositional phrases with prepositional phrases, and so on. Underline each element in a sentence and check that the corresponding element uses the same grammatical form.

\section{Creating Parallelism Using Coordinating Conjunctions}

When you connect two clauses using a coordinating conjunction (for, and, nor, but, or, yet, so), make sure that the same grammatical structure is used on each side of the conjunction. Take a look at the following example:

Faulty parallelism: When I walk the dog, I like to listen to music and talking to friends on the phone.

Correct parallelism: When I walk the dog, I like listening to music and talking to friends on the phone.

The first sentence uses two different verb forms (to listen, talking). In the second sentence, the grammatical construction on each side of the coordinating conjunction (and) is the same, creating a parallel sentence.

The same technique should be used for joining items or lists in a series:

Faulty parallelism: This committee needs to decide whether the company should reduce its workforce, cut its benefits, or lowering workers' wages.

Correct parallelism: This committee needs to decide whether the company should reduce its workforce, cut its benefits, or lower workers' wages.

The first sentence contains two items that use the same verb construction (reduce, cut) and a third item 
that uses a different verb form (lowering). The second sentence uses the same verb construction in all three items, creating a parallel structure.

\section{Exercise 1}

On your own sheet of paper, revise each of the following sentences to create parallel structure using coordinating conjunctions.

1. Mr. Holloway enjoys reading and to play his guitar at weekends.

2. The doctor told Mrs. Franklin that she should either eat less or should exercise more.

3. Breaking out of the prison compound, the escapees moved carefully, quietly, and were quick on their feet.

4. I have read the book, but I have not watched the movie version.

5. Deal with a full inbox first thing in the morning, or by setting aside short periods of time in which to answer e-mail queries.

\section{Collaboration}

Please share with a classmate and compare your answers.

\section{Creating Parallelism Using Than or As}

When you are making a comparison, the two items being compared should have a parallel structure. Comparing two items without using parallel structure can lead to confusion about what is being compared. Comparisons frequently use the words than or as, and the items on each side of these comparison words should be parallel. Take a look at the following example:

Faulty parallelism: Swimming in the ocean is much tougher than a pool.

Correct parallelism: Swimming in the ocean is much tougher than swimming in a pool.

In the first sentence, the elements before the comparison word (than) are not equal to the elements after the comparison word. It appears that the writer is comparing an action (swimming) with a noun ( $a$ pool). In the second sentence, the writer uses the same grammatical construction to create a parallel structure. This clarifies that an action is being compared with another action.

To correct some instances of faulty parallelism, it may be necessary to add or delete words in a sentence.

Faulty parallelism: A brisk walk is as beneficial to your health as going for a run. 
Correct parallelism: Going for a brisk walk is as beneficial to your health as going for a run.

In this example, it is necessary to add the verb phrase going for to the sentence in order to clarify that the act of walking is being compared to the act of running.

\section{Exercise 2}

On your own sheet of paper, revise each of the following sentences to create parallel structure using than or as.

1. I would rather work at a second job to pay for a new car than a loan.

2. How you look in the workplace is just as important as your behavior.

3. The firefighter spoke more of his childhood than he talked about his job.

4. Indian cuisine is far tastier than the food of Great Britain.

5. Jim's opponent was as tall as Jim and he carried far more weight.

\section{Collaboration}

Please share with a classmate and compare your answers.

\section{Creating Parallelism Using Correlative Conjunctions}

A correlative conjunction is a paired conjunction that connects two equal parts of a sentence and shows the relationship between them. Common correlative conjunctions include the following:

- either...or

- not only...but also

- neither...nor

- whether...or

- rather...than

- both... and

Correlative conjunctions should follow the same grammatical structure to create a parallel sentence. Take a look at the following example:

Faulty parallelism: We can neither wait for something to happen nor can we take evasive action. 
Correct parallelism: We can neither wait for something to happen nor take evasive action.

When using a correlative conjunction, the words, phrases, or clauses following each part should be parallel. In the first sentence, the construction of the second part of the sentence does not match the construction of the first part. In the second sentence, omitting needless words and matching verb constructions create a parallel structure. Sometimes, rearranging a sentence corrects faulty parallelism.

Faulty parallelism: It was both a long movie and poorly written.

Correct parallelism: The movie was both long and poorly written.

\section{Tip}

To see examples of parallelism in use, read some of the great historical speeches by rhetoricians such as Abraham Lincoln and Martin Luther King Jr. Notice how they use parallel structures to emphasize important points and to create a smooth, easily understandable oration.

Here is a link to text, audio, video, and the music of Martin Luther King's speech "I Have a Dream”: http://www.mlkonline.net/dream.html.

\section{Writing at Work}

Speechwriters use parallelism not only within sentences but also throughout paragraphs and beyond.

Repeating particular key phrases throughout a speech is an effective way of tying a paragraph together as a cohesive whole and creating a sense of importance. This technique can be adapted to any piece of writing, but it may be especially useful for creating a proposal or other type of persuasive workplace document.

Note that the spelling and grammar checker on most word processors will not draw attention to faulty parallelism. When proofreading a document, read it aloud and listen for sentences that sound awkward or poorly phrased.

\section{Exercise 3}

On your own sheet of paper, revise each of the following sentences to create parallel structure using correlative conjunctions.

1. The cyclist owns both a mountain bike and has a racing bike. 
2. The movie not only contained lots of action, but also it offered an important lesson.

3. My current job is neither exciting nor is it meaningful.

4. Jason would rather listen to his father than be taking advice from me.

5. We are neither interested in buying a vacuum cleaner nor do we want to utilize your carpet cleaning service.

\section{Collaboration}

Please share with a classmate and compare your answers.

\section{Exercise 4}

Read through the following excerpt from Alex's essay and revise any instances of faulty parallelism. Rewrite the sentences to create a parallel structure.

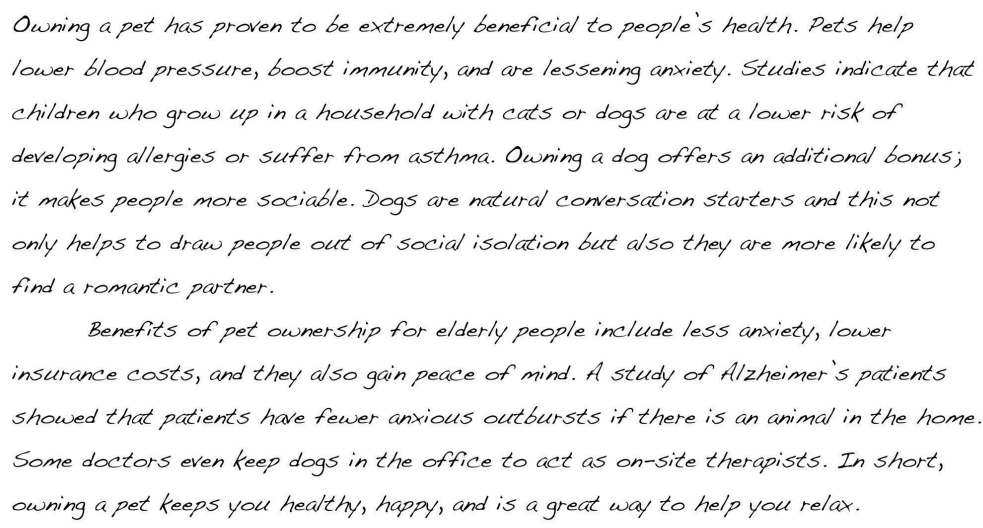

\section{Key Takeaways}

- Parallelism creates a sense of rhythm and balance in writing by using the same grammatical structure to express equal ideas.

- Faulty parallelism occurs when elements of a sentence are not balanced, causing the sentence to sound clunky and awkward. 
- Parallelism may be created by connecting two clauses or making a list using coordinating conjunctions; by comparing two items using than or as; or by connecting two parts of a sentence using correlative conjunctions. 


\subsection{Refining Your Writing: End-of-Chapter Exercises}

\section{Learning Objectives}

1. Use the skills you have learned in the chapter.

2. Work collaboratively with other students.

3. Work with a variety of academic and on-the-job, real-world examples.

\section{Exercises}

1. Children's stories are deliberately written in short, simple sentences to avoid confusion. Most sentences are constructed using the standard subject-verb-object format. Choose a children's story that is suitable for eightto ten-year-olds. Rewrite a chapter of the story so that it appeals to a slightly older age group, by editing for sentence variety. Experiment with the techniques you learned in Section 7.1 "Sentence Variety", including the three different ways to vary sentence structure at the beginning of a sentence and the three different ways to connect ideas between sentences. Compare the revised chapter with the original version and consider how sentence variety can be used to target a particular audience.

\section{Collaboration}

Please share with a classmate and compare your answers.

2. Compile a selection of real-life writing samples from the workplace or around the home. You might like to choose one of the following: e-mail, junk mail, personal letter, company report, social networking page, local newspaper, bulletin-board posting, or public notice. Choose two samples that lack sentence variety. Highlight areas of each writing sample that you would edit for sentence variety and explain why. Replace any recognizable name with a pseudonym, or a fictitious name.

\section{Collaboration}

Please share with a classmate and compare your answers.

3. Group activity. Choose a well-known speech, such as Martin Luther King’s “I Have a Dream” speech, Winston Churchill's “Blood, Toil, Tears, and Sweat” speech, or Barack Obama's inaugural address. Make a copy of the speech and, as a group, underline examples of parallelism. Discuss the effects of using parallelism and consider whether it is always used to achieve the same result or whether the writer manipulates parallelism to create a variety of responses among his or her audience.

4. Group activity. Working in a small group, select a workplace document or academic essay. Examine each paragraph and identify examples of sentence variety, coordination and subordination, and parallelism. Then, choose one particular paragraph and discuss the following questions:

- Does the writer use sentence variety effectively? 
- Does the writer connect his or her ideas effectively?

- Does the writer use subordination and coordination correctly?

- Does the writer use parallelism to emphasize his or her points?

As a group, identify the weaker areas of the paragraph and rewrite them. Focus on sentence structure and sentence variation. Use coordinating conjunctions and subordinating conjunctions to join sentences.

5. Choose a college essay or a recent piece of writing from your work or everyday life. Use the techniques you have learned throughout this chapter to edit your writing for sentence variety, appropriate coordination and subordination, and parallelism. When you have finished, compare the two versions and write a brief analysis of how sentence variety, coordination and subordination, and parallelism help refine a piece of writing.

\section{Collaboration}

Please share with a classmate and compare your answers. 


\title{
Chapter 8: The Writing Process: How Do I Begin?
}

\author{
8.1 Apply Prewriting Models \\ 8.2 Outlining \\ 8.3 Drafting \\ 8.4 Revising and Editing \\ 8.5 The Writing Process: End-of-Chapter Exercises
}




\subsection{Apply Prewriting Models}

\section{Learning Objective}

1. Use prewriting strategies to choose a topic and narrow the focus.

If you think that a blank sheet of paper or a blinking cursor on the computer screen is a scary sight, you are not alone. Many writers, students, and employees find that beginning to write can be intimidating. When faced with a blank page, however, experienced writers remind themselves that writing, like other everyday activities, is a process. Every process, from writing to cooking, bike riding, and learning to use a new cell phone, will get significantly easier with practice.

Just as you need a recipe, ingredients, and proper tools to cook a delicious meal, you also need a plan, resources, and adequate time to create a good written composition. In other words, writing is a process that requires following steps and using strategies to accomplish your goals.

These are the five steps in the writing process:

1. Prewriting

2. Outlining the structure of ideas

3. Writing a rough draft

4. Revising

5. Editing

Effective writing can be simply described as good ideas that are expressed well and arranged in the proper order. This chapter will give you the chance to work on all these important aspects of writing. Although many more prewriting strategies exist, this chapter covers six: using experience and observations, freewriting, asking questions, brainstorming, mapping, and searching the Internet. Using the strategies in this chapter can help you overcome the fear of the blank page and confidently begin the writing process.

\section{Prewriting}

Prewriting is the stage of the writing process during which you transfer your abstract thoughts into more 
concrete ideas in ink on paper (or in type on a computer screen). Although prewriting techniques can be helpful in all stages of the writing process, the following four strategies are best used when initially deciding on a topic:

1. Using experience and observations

2. Reading

3. Freewriting

4. Asking questions

At this stage in the writing process, it is OK if you choose a general topic. Later you will learn more prewriting strategies that will narrow the focus of the topic.

\section{Choosing a Topic}

In addition to understanding that writing is a process, writers also understand that choosing a good general topic for an assignment is an essential step. Sometimes your instructor will give you an idea to begin an assignment, and other times your instructor will ask you to come up with a topic on your own. A good topic not only covers what an assignment will be about but also fits the assignment's purpose and its audience.

In this chapter, you will follow a writer named Mariah as she prepares a piece of writing. You will also be planning one of your own. The first important step is for you to tell yourself why you are writing (to inform, to explain, or some other purpose) and for whom you are writing. Write your purpose and your audience on your own sheet of paper, and keep the paper close by as you read and complete exercises in this chapter.

My purpose:

My audience:

\section{Using Experience and Observations}

When selecting a topic, you may also want to consider something that interests you or something based on your own life and personal experiences. Even everyday observations can lead to interesting topics. After writers think about their experiences and observations, they often take notes on paper to better develop their thoughts. These notes help writers discover what they have to say about their topic. 
Tip

Have you seen an attention-grabbing story on your local news channel? Many current issues appear on television, in magazines, and on the Internet. These can all provide inspiration for your writing.

\section{Reading}

Reading plays a vital role in all the stages of the writing process, but it first figures in the development of ideas and topics. Different kinds of documents can help you choose a topic and also develop that topic. For example, a magazine advertising the latest research on the threat of global warming may catch your eye in the supermarket. This cover may interest you, and you may consider global warming as a topic. Or maybe a novel's courtroom drama sparks your curiosity of a particular lawsuit or legal controversy.

After you choose a topic, critical reading is essential to the development of a topic. While reading almost any document, you evaluate the author's point of view by thinking about his main idea and his support. When you judge the author's argument, you discover more about not only the author's opinion but also your own. If this step already seems daunting, remember that even the best writers need to use prewriting strategies to generate ideas.

Tip

The steps in the writing process may seem time consuming at first, but following these steps will save you time in the future. The more you plan in the beginning by reading and using prewriting strategies, the less time you may spend writing and editing later because your ideas will develop more swiftly.

Prewriting strategies depend on your critical reading skills. Reading prewriting exercises (and outlines and drafts later in the writing process) will further develop your topic and ideas. As you continue to follow the writing process, you will see how Mariah uses critical reading skills to assess her own prewriting exercises.

\section{Freewriting}

Freewriting is an exercise in which you write freely about any topic for a set amount of time (usually three to five minutes). During the time limit, you may jot down any thoughts that come to your mind. Try not to worry about grammar, spelling, or punctuation. Instead, write as quickly as you can without stopping. If you get stuck, just copy the same word or phrase over and over until you come up with a new thought. 
Writing often comes easier when you have a personal connection with the topic you have chosen. Remember, to generate ideas in your freewriting, you may also think about readings that you have enjoyed or that have challenged your thinking. Doing this may lead your thoughts in interesting directions.

Quickly recording your thoughts on paper will help you discover what you have to say about a topic. When writing quickly, try not to doubt or question your ideas. Allow yourself to write freely and unselfconsciously. Once you start writing with few limitations, you may find you have more to say than you first realized. Your flow of thoughts can lead you to discover even more ideas about the topic. Freewriting may even lead you to discover another topic that excites you even more.

Look at Mariah's example. The instructor allowed the members of the class to choose their own topics, and Mariah thought about her experiences as a communications major. She used this freewriting exercise to help her generate more concrete ideas from her own experience.

\section{Tip}

Some prewriting strategies can be used together. For example, you could use experience and observations to come up with a topic related to your course studies. Then you could use freewriting to describe your topic in more detail and figure out what you have to say about it.

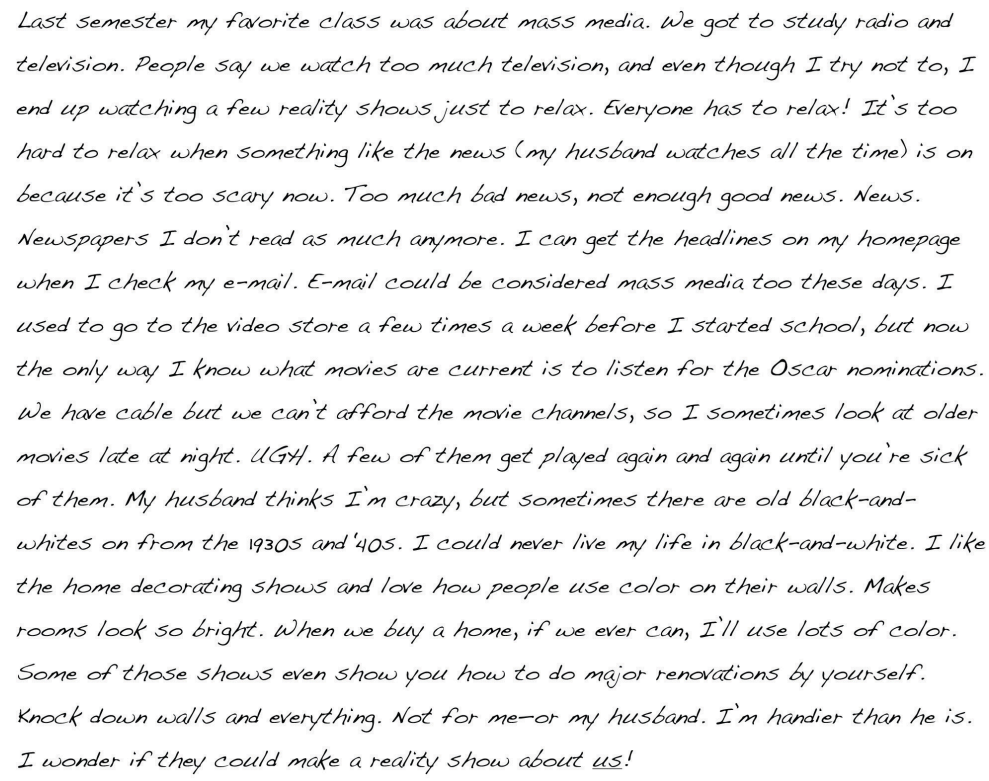




\section{Exercise 1}

Freewrite about one event you have recently experienced. With this event in mind, write without stopping for five minutes. After you finish, read over what you wrote. Does anything stand out to you as a good general topic to write about?

\section{Asking Questions}

Who? What? Where? When? Why? How? In everyday situations, you pose these kinds of questions to get more information. Who will be my partner for the project? When is the next meeting? Why is my car making that odd noise? Even the title of this chapter begins with the question "How do I begin?"

You seek the answers to these questions to gain knowledge, to better understand your daily experiences, and to plan for the future. Asking these types of questions will also help you with the writing process. As you choose your topic, answering these questions can help you revisit the ideas you already have and generate new ways to think about your topic. You may also discover aspects of the topic that are unfamiliar to you and that you would like to learn more about. All these idea-gathering techniques will help you plan for future work on your assignment.

When Mariah reread her freewriting notes, she found she had rambled and her thoughts were disjointed. She realized that the topic that interested her most was the one she started with, the media. She then decided to explore that topic by asking herself questions about it. Her purpose was to refine media into a topic she felt comfortable writing about. To see how asking questions can help you choose a topic, take a look at the following chart that Mariah completed to record her questions and answers. She asked herself the questions that reporters and journalists use to gather information for their stories. The questions are often called the $\underline{5 \mathrm{WH} \text { questions, }}$ after their initial letters.

Figure 8.1 Asking Questions

\begin{tabular}{|l|l|}
\hline $\begin{array}{l}\text { Questions } \\
\text { Who? }\end{array}$ & Answers \\
\hline What? & The media can be a lot of things. Television, radio, e-mail (I think), newspapers, magazines, books. \\
\hline Where? & The media is almost everywhere now. It's in homes, at work, in cars, even on cell phones! \\
\hline When? & Media has been around for a long time, but seems a lot more important now. \\
\hline When? & $\begin{array}{l}\text { Hmm. This is a good question. I don’t know why there is mass media. Maybe we have it because we have the technology now. } \\
\text { Or people live far away from their families and they have to stay in touch. }\end{array}$ \\
\hline How? & Well, edia is possible because of the technology inventions, but I don't know how they all work! \\
\hline
\end{tabular}




\section{Tip}

Prewriting is very purpose driven; it does not follow a set of hard-and-fast rules. The purpose of prewriting is to find and explore ideas so that you will be prepared to write. A prewriting technique like asking questions can help you both find a topic and explore it. The key to effective prewriting is to use the techniques that work best for your thinking process. Freewriting may not seem to fit your thinking process, but keep an open mind. It may work better than you think. Perhaps brainstorming a list of topics might better fit your personal style. Mariah found freewriting and asking questions to be fruitful strategies to use. In your own prewriting, use the $5 \mathrm{WH}$ questions in any way that benefits your planning.

\section{Exercise 2}

Choose a general topic idea from the prewriting you completed in Note 8.9 "Exercise 1". Then read each question and use your own paper to answer the 5WH questions. As with Mariah when she explored her writing topic for more detail, it is OK if you do not know all the answers. If you do not know an answer, use your own opinion to speculate, or guess. You may also use factual information from books or articles you previously read on your topic. Later in the chapter, you will read about additional ways (like searching the Internet) to answer your questions and explore your guesses.

5WH Questions

1. Who?

2. What?

3. Where?

4. When?

5. Why?

6. How?

Now that you have completed some of the prewriting exercises, you may feel less anxious about starting a paper from scratch. With some ideas down on paper (or saved on a computer), writers are often more comfortable continuing the writing process. After identifying a good general topic, you, too, are ready 
to continue the process.

\section{Exercise}

Write your general topic on your own sheet of paper, under where you recorded your purpose and audience. Choose it from among the topics you listed or explored during the prewriting you have done so far. Make sure it is one you feel comfortable with and feel capable of writing about.

My general topic:

Tip

You may find that you need to adjust your topic as you move through the writing stages (and as you complete the exercises in this chapter). If the topic you have chosen is not working, you can repeat the prewriting activities until you find a better one.

\section{More Prewriting Techniques}

The prewriting techniques of freewriting and asking questions helped Mariah think more about her topic, but the following prewriting strategies can help her (and you) narrow the focus of the topic:

- Brainstorming

- Idea mapping

- Searching the Internet

\section{Narrowing the Focus}

Narrowing the focus means breaking up the topic into subtopics, or more specific points. Generating lots of subtopics will help you eventually select the ones that fit the assignment and appeal to you and your audience.

After rereading her syllabus, Mariah realized her general topic, mass media, is too broad for her class's short paper requirement. Three pages are not enough to cover all the concerns in mass media today. Mariah also realized that although her readers are other communications majors who are interested in the topic, they may want to read a paper about a particular issue in mass media. 


\section{Brainstorming}

Brainstorming is similar to list making. You can make a list on your own or in a group with your classmates. Start with a blank sheet of paper (or a blank computer document) and write your general topic across the top. Underneath your topic, make a list of more specific ideas. Think of your general topic as a broad category and the list items as things that fit in that category. Often you will find that one item can lead to the next, creating a flow of ideas that can help you narrow your focus to a more specific paper topic.

The following is Mariah's brainstorming list: 
Writing for Success 308

Mass Media

Magazines

Newspapers

Broadcasting

Radio

Television

DVd

Gaming/video games

Internet

Cell phones

Smartphones

Text messages

Tiny cameras

GPS 
309 [Author removed at request of original publisher]

From this list, Mariah could narrow her focus to a particular technology under the broad category of mass media.

Writing at Work 


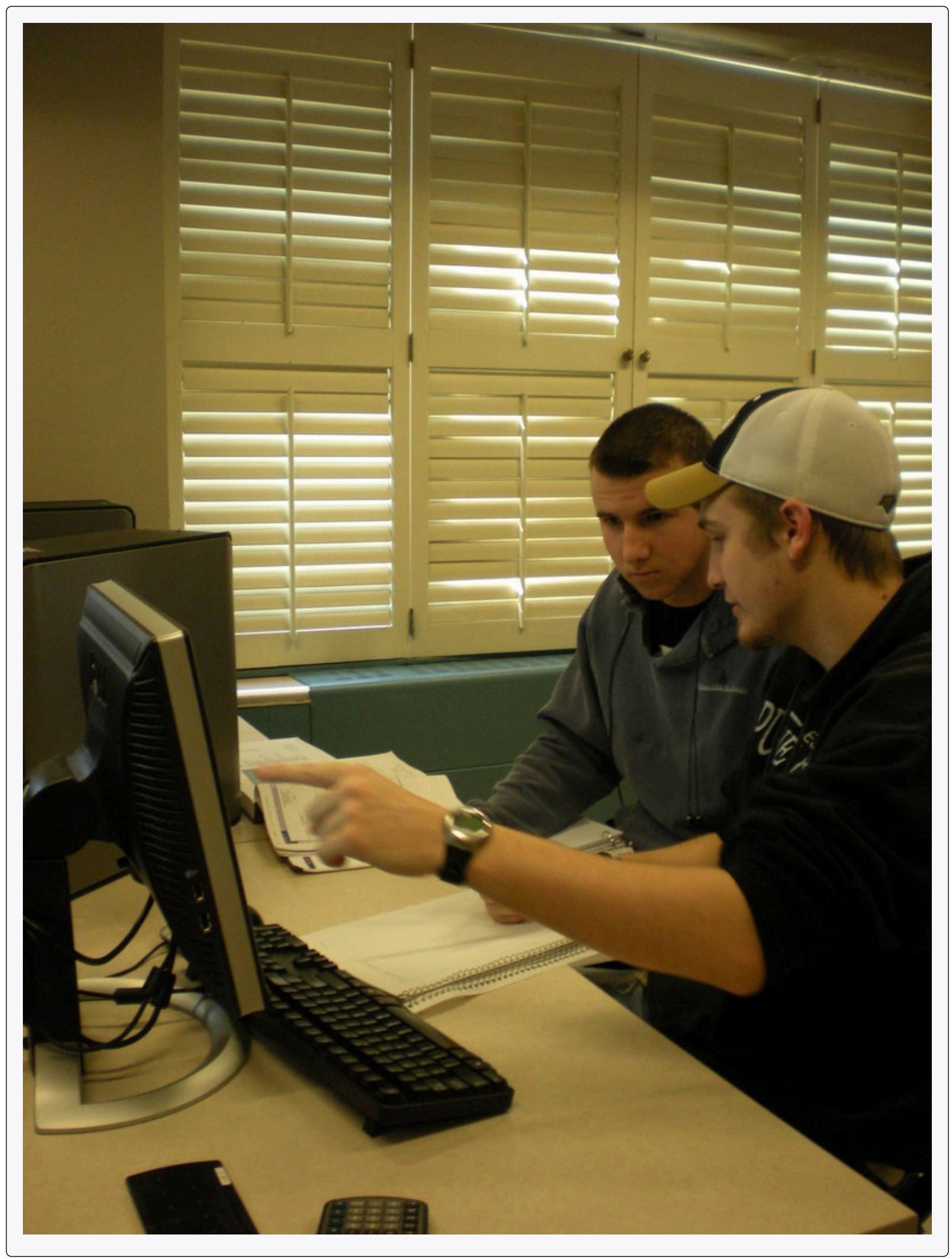


Imagine you have to write an e-mail to your current boss explaining your prior work experience, but you do not know where to start. Before you begin the e-mail, you can use the brainstorming technique to generate a list of employers, duties, and responsibilities that fall under the general topic "work experience.”

\section{Idea Mapping}

Idea mapping allows you to visualize your ideas on paper using circles, lines, and arrows. This technique is also known as clustering because ideas are broken down and clustered, or grouped together. Many writers like this method because the shapes show how the ideas relate or connect, and writers can find a focused topic from the connections mapped. Using idea mapping, you might discover interesting connections between topics that you had not thought of before.

To create an idea map, start with your general topic in a circle in the center of a blank sheet of paper. Then write specific ideas around it and use lines or arrows to connect them together. Add and cluster as many ideas as you can think of.

In addition to brainstorming, Mariah tried idea mapping. Review the following idea map that Mariah created:

Figure 8.2 Idea Map

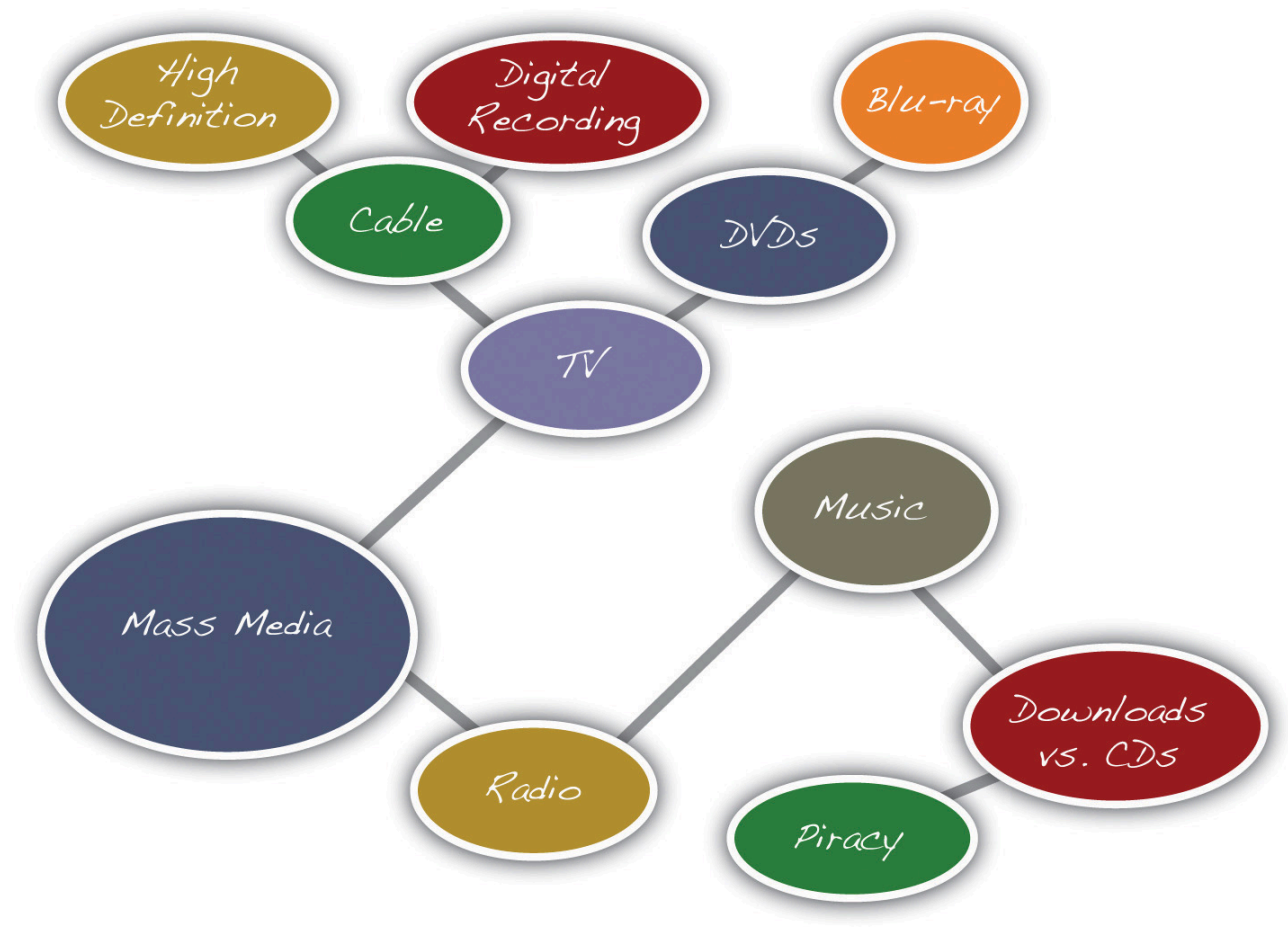


Notice Mariah’s largest circle contains her general topic, mass media. Then, the general topic branches into two subtopics written in two smaller circles: television and radio. The subtopic television branches into even more specific topics: cable and DVDs. From there, Mariah drew more circles and wrote more specific ideas: high definition and digital recording from cable and Blu-ray from DVDs. The radio topic led Mariah to draw connections between music, downloads versus CDs, and, finally, piracy.

From this idea map, Mariah saw she could consider narrowing the focus of her mass media topic to the more specific topic of music piracy.

\section{Searching the Internet}

Using search engines on the Internet is a good way to see what kinds of websites are available on your topic. Writers use search engines not only to understand more about the topic's specific issues but also to get better acquainted with their audience.

\section{Tip}

Look back at the chart you completed in Note 8.12 "Exercise 2". Did you guess at any of the answers? Searching the Internet may help you find answers to your questions and confirm your guesses. Be choosy about the websites you use. Make sure they are reliable sources for the kind of information you seek.

When you search the Internet, type some key words from your broad topic or words from your narrowed focus into your browser's search engine (many good general and specialized search engines are available for you to try). Then look over the results for relevant and interesting articles.

Results from an Internet search show writers the following information:

- Who is talking about the topic

- How the topic is being discussed

- What specific points are currently being discussed about the topic

\section{Tip}

If the search engine results are not what you are looking for, revise your key words and search again. Some search engines also offer suggestions for related searches that may give you better results.

Mariah typed the words music piracy from her idea map into the search engine Google. 
Figure 8.3 Useful Search Engine Results

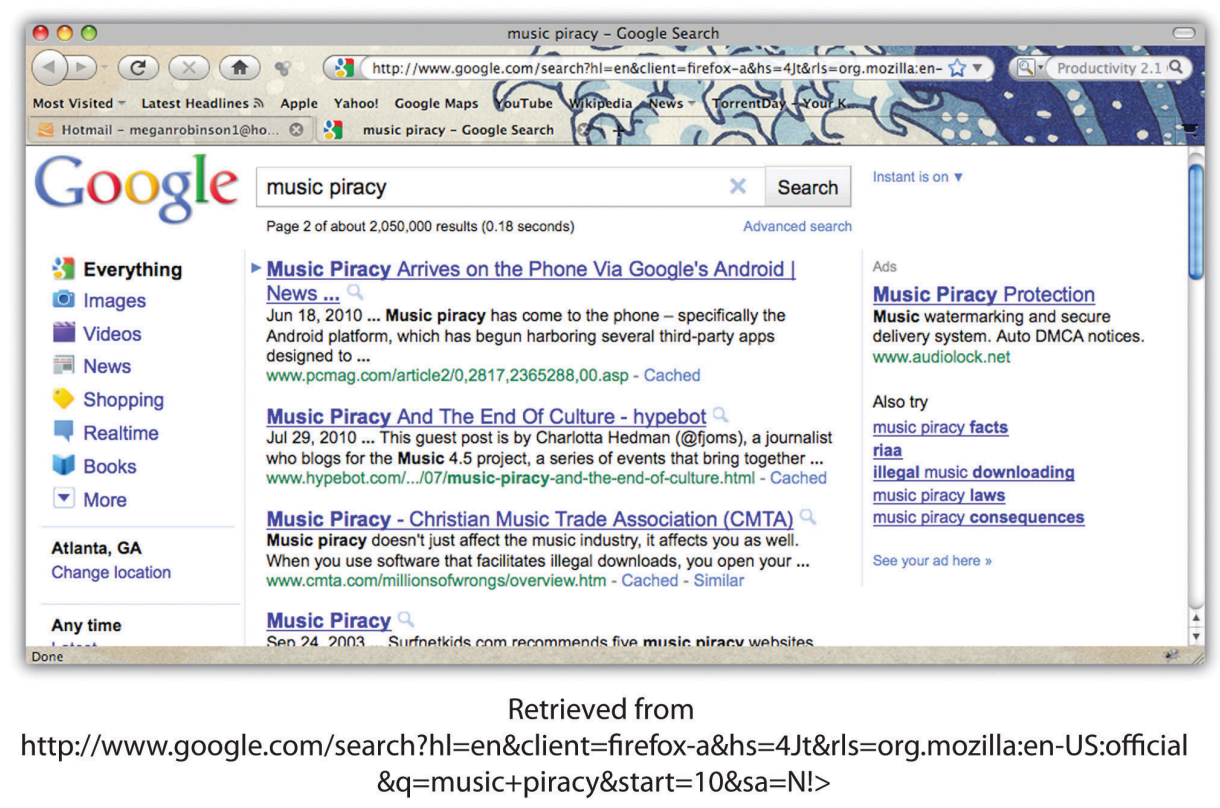

Not all the results online search engines return will be useful or reliable. Give careful consideration to the reliability of an online source before selecting a topic based on it. Remember that factual information can be verified in other sources, both online and in print. If you have doubts about any information you find, either do not use it or identify it as potentially unreliable.

The results from Mariah's search included websites from university publications, personal blogs, online news sources, and lots of legal cases sponsored by the recording industry. Reading legal jargon made Mariah uncomfortable with the results, so she decided to look further. Reviewing her map, she realized that she was more interested in consumer aspects of mass media, so she refocused her search to media technology and the sometimes confusing array of expensive products that fill electronics stores. Now, Mariah considers a paper topic on the products that have fed the mass media boom in everyday lives.

\section{Exercise 3}

In Note 8.12 "Exercise 2", you chose a possible topic and explored it by answering questions about it using the 5WH questions. However, this topic may still be too broad. Here, in Note 8.21 "Exercise 3", choose and complete one of the prewriting strategies to narrow the focus. Use either brainstorming, idea mapping, or searching the Internet.

\section{Collaboration}

Please share with a classmate and compare your answers. Share what you found and what interests you about the possible topic(s).

Prewriting strategies are a vital first step in the writing process. First, they help you first choose a broad topic and then they help you narrow the focus of the topic to a more specific idea. An effective topic ensures that you are ready for the next step. 


\section{Topic Checklist}

Developing a Good Topic

The following checklist can help you decide if your narrowed topic is a good topic for your assignment.

- Am I interested in this topic?

- Would my audience be interested?

- Do I have prior knowledge or experience with this topic? If so, would I be comfortable exploring this topic and sharing my experiences?

- Do I want to learn more about this topic?

- Is this topic specific?

- Does it fit the length of the assignment?

With your narrowed focus in mind, answer the bulleted questions in the checklist for developing a good topic. If you can answer "yes" to all the questions, write your topic on the line. If you answer "no" to any of the questions, think about another topic or adjust the one you have and try the prewriting strategies again.

My narrowed topic:

\section{Key Takeaways}

- All writers rely on steps and strategies to begin the writing process.

- The steps in the writing process are prewriting, outlining, writing a rough draft, revising, and editing.

- Prewriting is the transfer of ideas from abstract thoughts into words, phrases, and sentences on paper.

- A good topic interests the writer, appeals to the audience, and fits the purpose of the assignment.

- Writers often choose a general topic first and then narrow the focus to a more specific topic. 


\subsection{Outlining}

\section{Learning Objectives}

1. Identify the steps in constructing an outline.

2. Construct a topic outline and a sentence outline.

Your prewriting activities and readings have helped you gather information for your assignment. The more you sort through the pieces of information you found, the more you will begin to see the connections between them. Patterns and gaps may begin to stand out. But only when you start to organize your ideas will you be able to translate your raw insights into a form that will communicate meaning to your audience.

\section{Tip}

Longer papers require more reading and planning than shorter papers do. Most writers discover that the more they know about a topic, the more they can write about it with intelligence and interest.

\section{Organizing Ideas}

When you write, you need to organize your ideas in an order that makes sense. The writing you complete in all your courses exposes how analytically and critically your mind works. In some courses, the only direct contact you may have with your instructor is through the assignments you write for the course. You can make a good impression by spending time ordering your ideas.

Order refers to your choice of what to present first, second, third, and so on in your writing. The order you pick closely relates to your purpose for writing that particular assignment. For example, when telling a story, it may be important to first describe the background for the action. Or you may need to first describe a 3-D movie projector or a television studio to help readers visualize the setting and scene. You may want to group your support effectively to convince readers that your point of view on an issue is well reasoned and worthy of belief.

In longer pieces of writing, you may organize different parts in different ways so that your purpose stands out clearly and all parts of the paper work together to consistently develop your main point. 


\section{Methods of Organizing Writing}

The three common methods of organizing writing are chronological order, spatial order, and order of importance. You will learn more about these in Chapter 9 "Writing Essays: From Start to Finish"; however, you need to keep these methods of organization in mind as you plan how to arrange the information you have gathered in an outline. An outline is a written plan that serves as a skeleton for the paragraphs you write. Later, when you draft paragraphs in the next stage of the writing process, you will add support to create "flesh" and "muscle" for your assignment.

When you write, your goal is not only to complete an assignment but also to write for a specific purpose-perhaps to inform, to explain, to persuade, or for a combination of these purposes. Your purpose for writing should always be in the back of your mind, because it will help you decide which pieces of information belong together and how you will order them. In other words, choose the order that will most effectively fit your purpose and support your main point.

Table 8.1 "Order versus Purpose" shows the connection between order and purpose.

Table 8.1 Order versus Purpose

\begin{tabular}{|l|l|}
\hline Order & Purpose \\
\hline \multirow{2}{*}{ Chronological Order } & To explain the history of an event or a topic \\
\cline { 2 - 2 } & To tell a story or relate an experience \\
\cline { 2 - 2 } & To explain how to do or make something \\
\hline Spatial Order & To explain the steps in a process \\
\hline Order of Importance & To help readers visualize something as you want them to see it \\
\hline & To create a main impression using the senses (sight, touch, taste, smell, and sound) \\
\hline To rank items by their importance, benefit, or significance
\end{tabular}

\section{Writing a Thesis Statement}

One legitimate question readers always ask about a piece of writing is "What is the big idea?" (You may even ask this question when you are the reader, critically reading an assignment or another document.) Every nonfiction writing task-from the short essay to the ten-page term paper to the lengthy senior thesis - needs a big idea, or a controlling idea, as the spine for the work. The controlling idea is the main idea that you want to present and develop. 


\section{Tip}

For a longer piece of writing, the main idea should be broader than the main idea for a shorter piece of writing. Be sure to frame a main idea that is appropriate for the length of the assignment. Ask yourself, "How many pages will it take for me to explain and explore this main idea in detail?” Be reasonable with your estimate. Then expand or trim it to fit the required length.

The big idea, or controlling idea, you want to present in an essay is expressed in a thesis statement. A thesis statement is often one sentence long, and it states your point of view. The thesis statement is not the topic of the piece of writing but rather what you have to say about that topic and what is important to tell readers.

Table 8.2 "Topics and Thesis Statements" compares topics and thesis statements.

Table 8.2 Topics and Thesis Statements

\section{Topic}

Music piracy

The number of consumer choices available in media gear

E-books and online newspapers increasing their share of the market

Online education and the new media

\section{Thesis Statement}

The recording industry fears that so-called music piracy will diminish profits and destroy markets, but it cannot be more wrong.

Everyone wants the newest and the best digital technology, but the choices are extensive, and the specifications are often confusing.

E-books and online newspapers will bring an end to print media as we know it.

Someday, students and teachers will send avatars to their online classrooms.

The first thesis statement you write will be a preliminary thesis statement, or a working thesis statement. You will need it when you begin to outline your assignment as a way to organize it. As you continue to develop the arrangement, you can limit your working thesis statement if it is too broad or expand it if it proves too narrow for what you want to say.

\section{Exercise 1}

Using the topic you selected in Section 8.1 "Apply Prewriting Models”, develop a working thesis statement that states your controlling idea for the piece of writing you are doing. On a sheet of paper, write your working thesis statement. 


\section{Tip}

You will make several attempts before you devise a working thesis statement that you think is effective. Each draft of the thesis statement will bring you closer to the wording that expresses your meaning exactly.

\section{Writing an Outline}

For an essay question on a test or a brief oral presentation in class, all you may need to prepare is a short, informal outline in which you jot down key ideas in the order you will present them. This kind of outline reminds you to stay focused in a stressful situation and to include all the good ideas that help you explain or prove your point.

For a longer assignment, like an essay or a research paper, many college instructors require students to submit a formal outline before writing a major paper as a way to be sure you are on the right track and are working in an organized manner. A formal outline is a detailed guide that shows how all your supporting ideas relate to each other. It helps you distinguish between ideas that are of equal importance and ones that are of lesser importance. You build your paper based on the framework created by the outline.

\section{Tip}

Instructors may also require you to submit an outline with your final draft to check the direction of the assignment and the logic of your final draft. If you are required to submit an outline with the final draft of a paper, remember to revise the outline to reflect any changes you made while writing the paper.

There are two types of formal outlines: the topic outline and the sentence outline. You format both types of formal outlines in the same way.

- Place your introduction and thesis statement at the beginning, under roman numeral I.

- Use roman numerals (II, III, IV, V, etc.) to identify main points that develop the thesis statement.

- Use capital letters (A, B, C, D, etc.) to divide your main points into parts.

- Use arabic numerals (1, 2, 3, 4, 5, etc.) if you need to subdivide any As, Bs, or Cs into smaller parts.

- End with the final roman numeral expressing your idea for your conclusion.

Here is what the skeleton of a traditional formal outline looks like. The indention helps clarify how the ideas are related. 
1. Introduction

Thesis statement

2. Main point $1 \rightarrow$ becomes the topic sentence of body paragraph 1

Main point $2 \rightarrow$ becomes the topic sentence of body paragraph 2

Main point $3 \rightarrow$ becomes the topic sentence of body paragraph 3

Conclusion

Tip

In an outline, any supporting detail can be developed with subpoints. For simplicity, the model shows them only under the first main point.

Tip

Formal outlines are often quite rigid in their organization. As many instructors will specify, you cannot subdivide one point if it is only one part. For example, for every roman numeral I, there must be a For every A, there must be a B. For every arabic numeral 1, there must be a 2. See for yourself on the sample outlines that follow.

\section{Constructing Topic Outlines}

A topic outline is the same as a sentence outline except you use words or phrases instead of complete sentences. Words and phrases keep the outline short and easier to comprehend. All the headings, however, must be written in parallel structure. (For more information on parallel structure, see Chapter 7 “Refining Your Writing: How Do I Improve My Writing Technique?”.)

Here is the topic outline that Mariah constructed for the essay she is developing. Her purpose is to inform, and her audience is a general audience of her fellow college students. Notice how Mariah begins with her thesis statement. She then arranges her main points and supporting details in outline form using short phrases in parallel grammatical structure. 


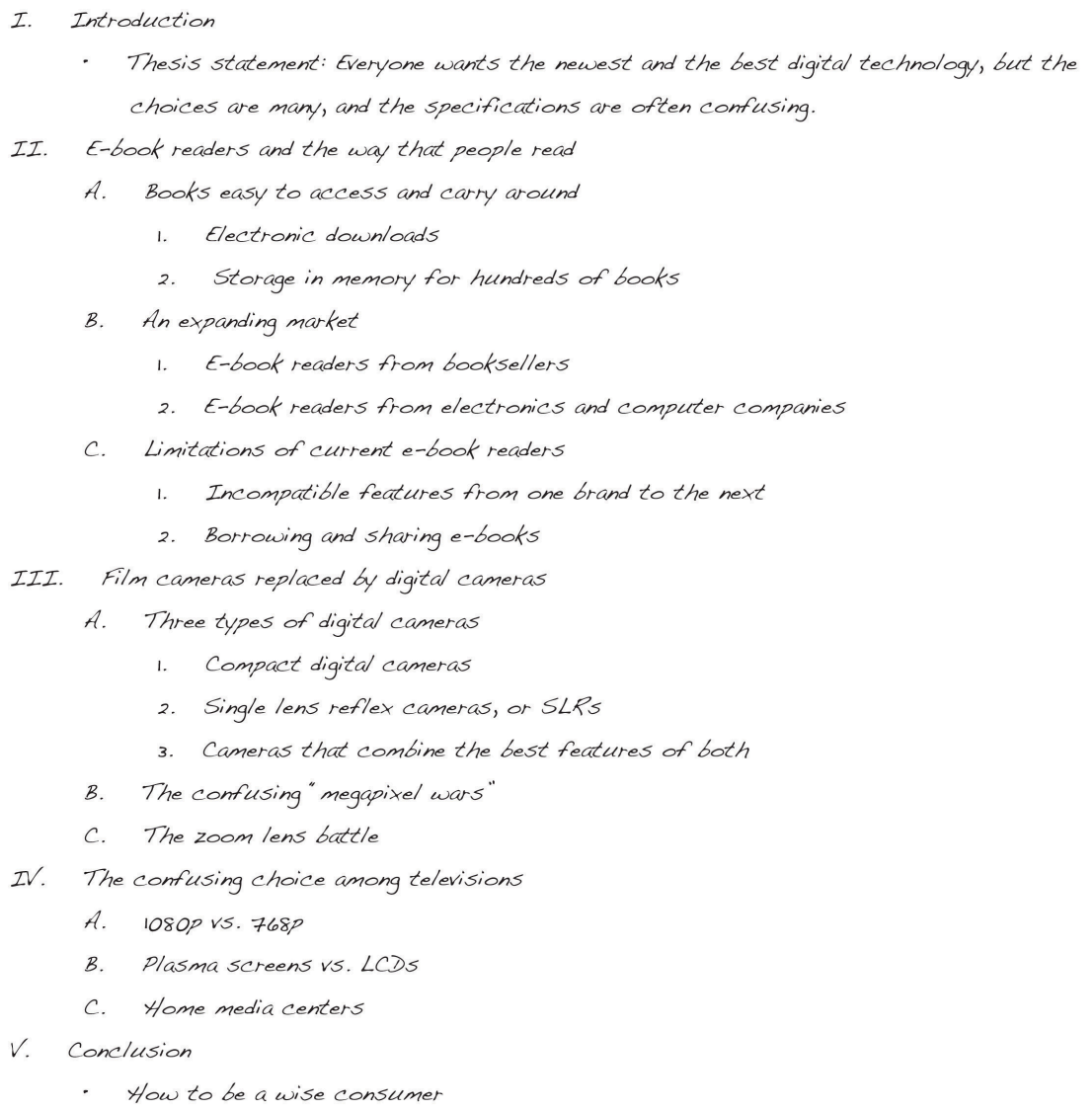

\section{Checklist}

\section{Writing an Effective Topic Outline}

This checklist can help you write an effective topic outline for your assignment. It will also help you discover where you may need to do additional reading or prewriting.

- Do I have a controlling idea that guides the development of the entire piece of writing?

- Do I have three or more main points that I want to make in this piece of writing? Does each main point connect to my controlling idea?

- Is my outline in the best order — chronological order, spatial order, or order of importance — for me to present my main points? Will this order help me get my main point across?

- Do I have supporting details that will help me inform, explain, or prove my main points?

- Do I need to add more support? If so, where? 
- Do I need to make any adjustments in my working thesis statement before I consider it the final version?

\section{Writing at Work}

Word processing programs generally have an automatic numbering feature that can be used to prepare outlines. This feature automatically sets indents and lets you use the tab key to arrange information just as you would in an outline. Although in business this style might be acceptable, in college your instructor might have different requirements. Teach yourself how to customize the levels of outline numbering in your wordprocessing program to fit your instructor's preferences.

\section{Exercise 2}

Using the working thesis statement you wrote in Note 8.32 "Exercise 1" and the reading you did in Section 8.1 "Apply Prewriting Models", construct a topic outline for your essay. Be sure to observe correct outline form, including correct indentions and the use of Roman and arabic numerals and capital letters.

\section{Collaboration}

Please share with a classmate and compare your outline. Point out areas of interest from their outline and what you would like to learn more about.

\section{Constructing Sentence Outlines}

A sentence outline is the same as a topic outline except you use complete sentences instead of words or phrases. Complete sentences create clarity and can advance you one step closer to a draft in the writing process.

Here is the sentence outline that Mariah constructed for the essay she is developing. 
I. Introduction

- Thesis statement: Everyone wants the newest and the best digital

technology, but the choices are many, and the specifications are often

confusing.

II. E-book readers are changing the way people read.

A. E-book readers make books easy to access and to carry.

1. Books can be downloaded electronically.

2. Devices can store hundreds of books in memory.

B. The market expands as a variety of companies enter it.

I. Booksellers sell their own e-book readers.

2. Electronics and computer companies also sell e-book readers.

c. Current e-book readers have significant limitations.

1. The devices are owned by different brands and may not be compatible.

2. Few programs have been made to fit the other way Americans read: by borrowing books from libraries.

III. Digital cameras have almost totally replaced film cameras.

A. The first major choice is the type of digital camera.

1. Compact digital cameras are light but have fewer megapixels.

2. Single lens reflex cameras, or SLRS, may be large and heary but can be used for many functions.

3. Some cameras combine the best features of compacts and SLRS.

B. Choosing the camera type involves the confusing "megapixel wars."

C. The zoom lens battle also determines the camera you will buy.

IV. Nothing is more confusing to me than choosing among televisions.

A. In the resolution wars, what are the benefits of $1080 \mathrm{p}$ and $768 \mathrm{p}$ ?

B. In the screen-size wars, what do plasma screens and LCD screens offer?

C. Does every home really need a media center?

V. Conclusion

- The solution for many people should be to avoid buying on impulse. consumers should think about what they really need, not what is advertised.

\section{Tip}

The information compiled under each roman numeral will become a paragraph in your final paper. In the previous example, the outline follows the standard five-paragraph essay arrangement, but longer essays will require more paragraphs and thus more roman numerals. If you think that a paragraph might become too long or stringy, add an additional paragraph to your outline, renumbering the main points appropriately. 


\section{Writing at Work}

PowerPoint presentations, used both in schools and in the workplace, are organized in a way very similar to formal outlines. PowerPoint presentations often contain information in the form of talking points that the presenter develops with more details and examples than are contained on the PowerPoint slide.

\section{Exercise 3}

Expand the topic outline you prepared in Note 8.41 "Exercise 2" to make it a sentence outline. In this outline, be sure to include multiple supporting points for your main topic even if your topic outline does not contain them. Be sure to observe correct outline form, including correct indentions and the use of Roman and arabic numerals and capital letters.

\section{Key Takeaways}

- Writers must put their ideas in order so the assignment makes sense. The most common orders are chronological order, spatial order, and order of importance.

- After gathering and evaluating the information you found for your essay, the next step is to write a working, or preliminary, thesis statement.

- The working thesis statement expresses the main idea that you want to develop in the entire piece of writing. It can be modified as you continue the writing process.

- Effective writers prepare a formal outline to organize their main ideas and supporting details in the order they will be presented.

- A topic outline uses words and phrases to express the ideas.

- A sentence outline uses complete sentences to express the ideas.

- The writer's thesis statement begins the outline, and the outline ends with suggestions for the concluding paragraph. 


\subsection{Drafting}

\section{Learning Objectives}

1. Identify drafting strategies that improve writing.

2. Use drafting strategies to prepare the first draft of an essay.

Drafting is the stage of the writing process in which you develop a complete first version of a piece of writing.

Even professional writers admit that an empty page scares them because they feel they need to come up with something fresh and original every time they open a blank document on their computers. Because you have completed the first two steps in the writing process, you have already recovered from empty page syndrome. You have hours of prewriting and planning already done. You know what will go on that blank page: what you wrote in your outline.

\section{Getting Started: Strategies For Drafting}

Your objective for this portion of Chapter 8 “The Writing Process: How Do I Begin?” is to draft the body paragraphs of a standard five-paragraph essay. A five-paragraph essay contains an introduction, three body paragraphs, and a conclusion. If you are more comfortable starting on paper than on the computer, you can start on paper and then type it before you revise. You can also use a voice recorder to get yourself started, dictating a paragraph or two to get you thinking. In this lesson, Mariah does all her work on the computer, but you may use pen and paper or the computer to write a rough draft.

\section{Making the Writing Process Work for You}

What makes the writing process so beneficial to writers is that it encourages alternatives to standard practices while motivating you to develop your best ideas. For instance, the following approaches, done alone or in combination with others, may improve your writing and help you move forward in the writing process:

- Begin writing with the part you know the most about. You can start with the third paragraph in your outline if ideas come easily to mind. You can start with the second paragraph or the first paragraph, too. Although paragraphs may vary in length, keep in mind 
that short paragraphs may contain insufficient support. Readers may also think the writing is abrupt. Long paragraphs may be wordy and may lose your reader's interest. As a guideline, try to write paragraphs longer than one sentence but shorter than the length of an entire double-spaced page.

- Write one paragraph at a time and then stop. As long as you complete the assignment on time, you may choose how many paragraphs you complete in one sitting. Pace yourself. On the other hand, try not to procrastinate. Writers should always meet their deadlines.

- Take short breaks to refresh your mind. This tip might be most useful if you are writing a multipage report or essay. Still, if you are antsy or cannot concentrate, take a break to let your mind rest. But do not let breaks extend too long. If you spend too much time away from your essay, you may have trouble starting again. You may forget key points or lose momentum.

Try setting an alarm to limit your break, and when the time is up, return to your desk to write.

- Be reasonable with your goals. If you decide to take ten-minute breaks, try to stick to that goal. If you told yourself that you need more facts, then commit to finding them. Holding yourself to your own goals will create successful writing assignments.

- Keep your audience and purpose in mind as you write. These aspects of writing are just as important when you are writing a single paragraph for your essay as when you are considering the direction of the entire essay.

Of all of these considerations, keeping your purpose and your audience at the front of your mind is the most important key to writing success. If your purpose is to persuade, for example, you will present your facts and details in the most logical and convincing way you can.

Your purpose will guide your mind as you compose your sentences. Your audience will guide word choice. Are you writing for experts, for a general audience, for other college students, or for people who know very little about your topic? Keep asking yourself what your readers, with their background and experience, need to be told in order to understand your ideas. How can you best express your ideas so they are totally clear and your communication is effective?

Tip

You may want to identify your purpose and audience on an index card that you clip to your paper (or keep next to your computer). On that card, you may want to write notes to yourself-perhaps about what that audience might not know or what it needs to know - so that you will be sure to address those issues when you write. It may be a good idea to also state exactly what you want to explain to that audience, or to inform them of, or to persuade them about.

\section{Writing at Work}

Many of the documents you produce at work target a particular audience for a particular purpose. You may 
find that it is highly advantageous to know as much as you can about your target audience and to prepare your message to reach that audience, even if the audience is a coworker or your boss. Menu language is a common example. Descriptions like "organic romaine" and "free-range chicken" are intended to appeal to a certain type of customer though perhaps not to the same customer who craves a thick steak. Similarly, mail-order companies research the demographics of the people who buy their merchandise. Successful vendors customize product descriptions in catalogs to appeal to their buyers' tastes. For example, the product descriptions in a skateboarder catalog will differ from the descriptions in a clothing catalog for mature adults.

\section{Exercise 1}

Using the topic for the essay that you outlined in Section 8.2 “Outlining”, describe your purpose and your audience as specifically as you can. Use your own sheet of paper to record your responses. Then keep these responses near you during future stages of the writing process.

My purpose:

My audience:

\section{Setting Goals for Your First Draft}

A draft is a complete version of a piece of writing, but it is not the final version. The step in the writing process after drafting, as you may remember, is revising. During revising, you will have the opportunity to make changes to your first draft before you put the finishing touches on it during the editing and proofreading stage. A first draft gives you a working version that you can later improve.

\section{Writing at Work}

Workplace writing in certain environments is done by teams of writers who collaborate on the planning, writing, and revising of documents, such as long reports, technical manuals, and the results of scientific research. Collaborators do not need to be in the same room, the same building, or even the same city. Many collaborations are conducted over the Internet.

In a perfect collaboration, each contributor has the right to add, edit, and delete text. Strong communication skills, in addition to strong writing skills, are important in this kind of writing situation because disagreements over style, content, process, emphasis, and other issues may arise. 
The collaborative software, or document management systems, that groups use to work on common projects is sometimes called groupware or workgroup support systems.

The reviewing tool on some word-processing programs also gives you access to a collaborative tool that many smaller workgroups use when they exchange documents. You can also use it to leave comments to yourself.

\section{Tip}

If you invest some time now to investigate how the reviewing tool in your word processor works, you will be able to use it with confidence during the revision stage of the writing process. Then, when you start to revise, set your reviewing tool to track any changes you make, so you will be able to tinker with text and commit only those final changes you want to keep.

\section{Discovering the Basic Elements of a First Draft}

If you have been using the information in this chapter step by step to help you develop an assignment, you already have both a formal topic outline and a formal sentence outline to direct your writing. Knowing what a first draft looks like will help you make the creative leap from the outline to the first draft. A first draft should include the following elements:

- An introduction that piques the audience's interest, tells what the essay is about, and motivates readers to keep reading.

- A thesis statement that presents the main point, or controlling idea, of the entire piece of writing.

- A topic sentence in each paragraph that states the main idea of the paragraph and implies how that main idea connects to the thesis statement.

- Supporting sentences in each paragraph that develop or explain the topic sentence. These can be specific facts, examples, anecdotes, or other details that elaborate on the topic sentence.

- A conclusion that reinforces the thesis statement and leaves the audience with a feeling of completion.

These elements follow the standard five-paragraph essay format, which you probably first encountered in high school. This basic format is valid for most essays you will write in college, even much longer ones. For now, however, Mariah focuses on writing the three body paragraphs from her outline. Chapter 9 "Writing Essays: From Start to Finish" covers writing introductions and conclusions, and you will read Mariah's introduction and conclusion in Chapter 9 "Writing Essays: From Start to Finish". 


\section{The Role of Topic Sentences}

Topic sentences make the structure of a text and the writer's basic arguments easy to locate and comprehend. In college writing, using a topic sentence in each paragraph of the essay is the standard rule. However, the topic sentence does not always have to be the first sentence in your paragraph even if it the first item in your formal outline.

Tip

When you begin to draft your paragraphs, you should follow your outline fairly closely. After all, you spent valuable time developing those ideas. However, as you begin to express your ideas in complete sentences, it might strike you that the topic sentence might work better at the end of the paragraph or in the middle. Try it. Writing a draft, by its nature, is a good time for experimentation.

The topic sentence can be the first, middle, or final sentence in a paragraph. The assignment's audience and purpose will often determine where a topic sentence belongs. When the purpose of the assignment is to persuade, for example, the topic sentence should be the first sentence in a paragraph. In a persuasive essay, the writer's point of view should be clearly expressed at the beginning of each paragraph.

Choosing where to position the topic sentence depends not only on your audience and purpose but also on the essay's arrangement, or order. When you organize information according to order of importance, the topic sentence may be the final sentence in a paragraph. All the supporting sentences build up to the topic sentence. Chronological order may also position the topic sentence as the final sentence because the controlling idea of the paragraph may make the most sense at the end of a sequence.

When you organize information according to spatial order, a topic sentence may appear as the middle sentence in a paragraph. An essay arranged by spatial order often contains paragraphs that begin with descriptions. A reader may first need a visual in his or her mind before understanding the development of the paragraph. When the topic sentence is in the middle, it unites the details that come before it with the ones that come after it.

Tip

As you read critically throughout the writing process, keep topic sentences in mind. You may discover topic sentences that are not always located at the beginning of a paragraph. For example, fiction writers customarily use topic ideas, either expressed or implied, to move readers through their texts. In nonfiction writing, such as popular magazines, topic sentences are often used when the author thinks it is appropriate (based on the audience and the purpose, of course). A single topic sentence might even control the development of a number of paragraphs. For more information on topic sentences, please see Chapter 6 "Writing Paragraphs: Separating Ideas and Shaping Content". 
Developing topic sentences and thinking about their placement in a paragraph will prepare you to write the rest of the paragraph.

\section{Paragraphs}

The paragraph is the main structural component of an essay as well as other forms of writing. Each paragraph of an essay adds another related main idea to support the writer's thesis, or controlling idea. Each related main idea is supported and developed with facts, examples, and other details that explain it. By exploring and refining one main idea at a time, writers build a strong case for their thesis.

\section{Paragraph Length}

How long should a paragraph be?

One answer to this important question may be "long enough"-long enough for you to address your points and explain your main idea. To grab attention or to present succinct supporting ideas, a paragraph can be fairly short and consist of two to three sentences. A paragraph in a complex essay about some abstract point in philosophy or archaeology can be three-quarters of a page or more in length. As long as the writer maintains close focus on the topic and does not ramble, a long paragraph is acceptable in college-level writing. In general, try to keep the paragraphs longer than one sentence but shorter than one full page of double-spaced text.

\section{Tip}

Journalistic style often calls for brief two- or three-sentence paragraphs because of how people read the news, both online and in print. Blogs and other online information sources often adopt this paragraphing style, too. Readers often skim the first paragraphs of a great many articles before settling on the handful of stories they want to read in detail.

You may find that a particular paragraph you write may be longer than one that will hold your audience's interest. In such cases, you should divide the paragraph into two or more shorter paragraphs, adding a topic statement or some kind of transitional word or phrase at the start of the new paragraph. Transition words or phrases show the connection between the two ideas.

In all cases, however, be guided by what you instructor wants and expects to find in your draft. Many instructors will expect you to develop a mature college-level style as you progress through the semester's assignments. 


\section{Exercise 2}

To build your sense of appropriate paragraph length, use the Internet to find examples of the following items. Copy them into a file, identify your sources, and present them to your instructor with your annotations, or notes.

- A news article written in short paragraphs. Take notes on, or annotate, your selection with your observations about the effect of combining paragraphs that develop the same topic idea. Explain how effective those paragraphs would be.

- A long paragraph from a scholarly work that you identify through an academic search engine. Annotate it with your observations about the author's paragraphing style.

\section{Starting Your First Draft}

Now we are finally ready to look over Mariah's shoulder as she begins to write her essay about digital technology and the confusing choices that consumers face. As she does, you should have in front of you your outline, with its thesis statement and topic sentences, and the notes you wrote earlier in this lesson on your purpose and audience. Reviewing these will put both you and Mariah in the proper mind-set to start.

The following is Mariah's thesis statement.

Everyone wants the newest and the best digital technology, but the choices are many,

and the specifications are often confusing.

Here are the notes that Mariah wrote to herself to characterize her purpose and audience. 


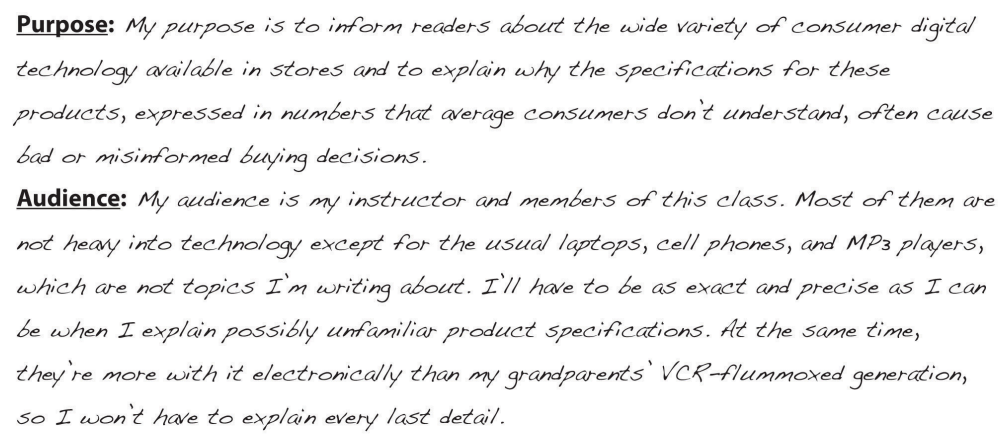

Mariah chose to begin by writing a quick introduction based on her thesis statement. She knew that she would want to improve her introduction significantly when she revised. Right now, she just wanted to give herself a starting point. You will read her introduction again in Section 8.4 "Revising and Editing" when she revises it.

\section{Tip}

Remember Mariah’s other options. She could have started directly with any of the body paragraphs.

You will learn more about writing attention-getting introductions and effective conclusions in $\underline{\text { Chapter } 9}$ "Writing Essays: From Start to Finish".

With her thesis statement and her purpose and audience notes in front of her, Mariah then looked at her sentence outline. She chose to use that outline because it includes the topic sentences. The following is the portion of her outline for the first body paragraph. The roman numeral II identifies the topic sentence for the paragraph, capital letters indicate supporting details, and arabic numerals label subpoints. 
II. E-book readers are changing the way people read.

A. E-book readers make books easy to access and to carry.

1. Books can be downloaded electronically.

2. Devices can store hundreds of books in memory.

B. The market expands as a variety of companies enter it.

1. Booksellers sell their own e-book readers.

2. Electronics and computer companies also sell e-book readers.

c. Current e-book readers have significant limitations.

1. The devices are owned by different brands and may not be compatible.

2. Few programs have been made to fit the other way Americans read: by borrowing books from libraries

Mariah then began to expand the ideas in her outline into a paragraph. Notice how the outline helped her guarantee that all her sentences in the body of the paragraph develop the topic sentence.

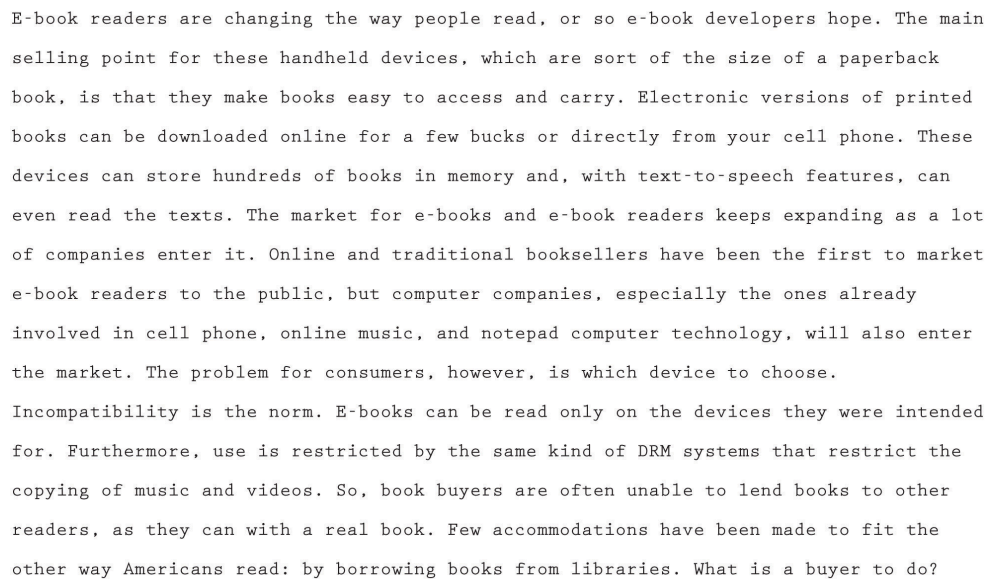

Tip

If you write your first draft on the computer, consider creating a new file folder for each course with a set of subfolders inside the course folders for each assignment you are given. Label the folders clearly with the course names, and label each assignment folder and word processing document with a title that you will 
easily recognize. The assignment name is a good choice for the document. Then use that subfolder to store all the drafts you create. When you start each new draft, do not just write over the last one. Instead, save the draft with a new tag after the title-draft 1, draft 2, and so on—-so that you will have a complete history of drafts in case your instructor wishes you to submit them.

In your documents, observe any formatting requirements—-for margins, headers, placement of page numbers, and other layout matters- that your instructor requires.

\section{Exercise 3}

Study how Mariah made the transition from her sentence outline to her first draft. First, copy her outline onto your own sheet of paper. Leave a few spaces between each part of the outline. Then copy sentences from Mariah’s paragraph to align each sentence with its corresponding entry in her outline.

\section{Continuing the First Draft}

Mariah continued writing her essay, moving to the second and third body paragraphs. She had supporting details but no numbered subpoints in her outline, so she had to consult her prewriting notes for specific information to include.

\section{Tip}

If you decide to take a break between finishing your first body paragraph and starting the next one, do not start writing immediately when you return to your work. Put yourself back in context and in the mood by rereading what you have already written. This is what Mariah did. If she had stopped writing in the middle of writing the paragraph, she could have jotted down some quick notes to herself about what she would write next.

Preceding each body paragraph that Mariah wrote is the appropriate section of her sentence outline. Notice how she expanded roman numeral III from her outline into a first draft of the second body paragraph. As you read, ask yourself how closely she stayed on purpose and how well she paid attention to the needs of her audience. 
III. Digital cameras have almost totally replaced film cameras.

A. The first major choice is the type of digital camera.

1. Compact digital cameras are light but lack the megapixels.

2. Single lens reflex cameras, or SLRS, may be large but can be used for many functions.

3. Some cameras combine the best features of compacts and SLRS.

B. Choosing the camera type involves the confusing "megapixel wars."

C. The zoom lens battle also determines the camera you will buy.

Digital cameras have almost totally replaced film cameras in amateur photographers. gadget bags. My father took hundreds of slides when his children were growing up, but he had more and more trouble getting them developed. So, he decided to go modern. But, what kind of camera should he buy? The small compact digital cameras could slip right in his pocket, but if he tried to print a photograph larger than an $8 \times 10$, the quality would be poor. When he investigated buying a single lens reflex camera, or SLR, he discovered that they were as versatile as his old film camera, also an SLR, but they were big and bulky. Then he discovered yet a third type, which combined the smaller size of the compact digital cameras with the zoom lenses available for SLRs. His first thought was to buy one of those, but then he realized he had a lot of decisions to make. How many megapixels should the camera be? Five? Ten? What is the advantage of each? Then came the size of the zoom lens. He knew that $3 \mathrm{x}$ was too sma11, but what about $25 \mathrm{x}$ ? Could he hold a lens that long without causing camera shake? He read hundreds of photography magazines and buying guides, and he still wasn't sure he was right.

Mariah then began her third and final body paragraph using roman numeral IV from her outline.

IV. Nothing is more confusing to me than choosing anong televisions.

A. In the resolution wars, what are the benefits of $1080 \mathrm{p}$ and $768 \mathrm{p}$ ?

$B$. In the screen-size wars, what do plasma screens and $L C D$ screens offer?

c. Does every home really need a media center? 


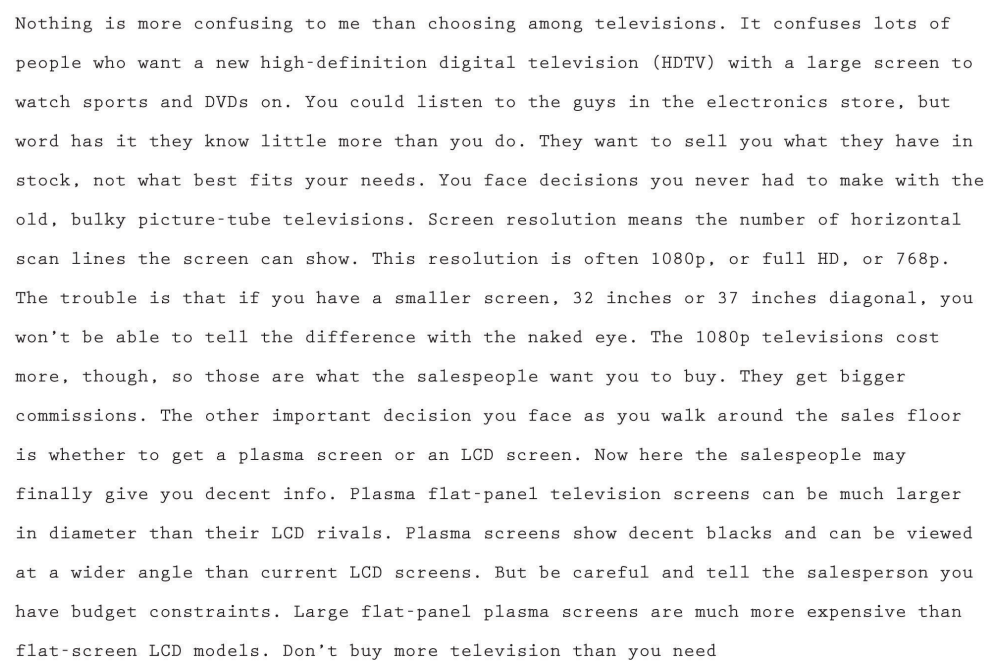

\section{Exercise 4}

Reread body paragraphs two and three of the essay that Mariah is writing. Then answer the questions on your own sheet of paper.

1. In body paragraph two, Mariah decided to develop her paragraph as a nonfiction narrative. Do you agree with her decision? Explain. How else could she have chosen to develop the paragraph? Why is that better?

2. Compare the writing styles of paragraphs two and three. What evidence do you have that Mariah was getting tired or running out of steam? What advice would you give her? Why?

3. Choose one of these two body paragraphs. Write a version of your own that you think better fits Mariah's audience and purpose.

\section{Writing a Title}

A writer's best choice for a title is one that alludes to the main point of the entire essay. Like the headline in a newspaper or the big, bold title in a magazine, an essay's title gives the audience a first peek at the content. If readers like the title, they are likely to keep reading.

Following her outline carefully, Mariah crafted each paragraph of her essay. Moving step by step in the writing process, Mariah finished the draft and even included a brief concluding paragraph (you will read 
her conclusion in Chapter 9 "Writing Essays: From Start to Finish”). She then decided, as the final touch for her writing session, to add an engaging title.

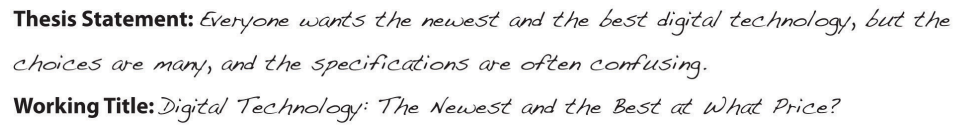

\section{Writing Your Own First Draft}

Now you may begin your own first draft, if you have not already done so. Follow the suggestions and the guidelines presented in this section.

\section{Key Takeaways}

- Make the writing process work for you. Use any and all of the strategies that help you move forward in the writing process.

- Always be aware of your purpose for writing and the needs of your audience. Cater to those needs in every sensible way.

- Remember to include all the key structural parts of an essay: a thesis statement that is part of your introductory paragraph, three or more body paragraphs as described in your outline, and a concluding paragraph. Then add an engaging title to draw in readers.

- Write paragraphs of an appropriate length for your writing assignment. Paragraphs in collegelevel writing can be a page long, as long as they cover the main topics in your outline.

- Use your topic outline or your sentence outline to guide the development of your paragraphs and the elaboration of your ideas. Each main idea, indicated by a roman numeral in your outline, becomes the topic of a new paragraph. Develop it with the supporting details and the subpoints of those details that you included in your outline.

- Generally speaking, write your introduction and conclusion last, after you have fleshed out the body paragraphs. 


\subsection{Revising and Editing}

\section{Learning Objectives}

1. Identify major areas of concern in the draft essay during revising and editing.

2. Use peer reviews and editing checklists to assist revising and editing.

3. Revise and edit the first draft of your essay and produce a final draft.

Revising and editing are the two tasks you undertake to significantly improve your essay. Both are very important elements of the writing process. You may think that a completed first draft means little improvement is needed. However, even experienced writers need to improve their drafts and rely on peers during revising and editing. You may know that athletes miss catches, fumble balls, or overshoot goals. Dancers forget steps, turn too slowly, or miss beats. For both athletes and dancers, the more they practice, the stronger their performance will become. Web designers seek better images, a more clever design, or a more appealing background for their web pages. Writing has the same capacity to profit from improvement and revision.

\section{Understanding the Purpose of Revising and Editing}

Revising and editing allow you to examine two important aspects of your writing separately, so that you can give each task your undivided attention.

- When you revise, you take a second look at your ideas. You might add, cut, move, or change information in order to make your ideas clearer, more accurate, more interesting, or more convincing.

- When you edit, you take a second look at how you expressed your ideas. You add or change words. You fix any problems in grammar, punctuation, and sentence structure. You improve your writing style. You make your essay into a polished, mature piece of writing, the end product of your best efforts.

Tip

How do you get the best out of your revisions and editing? Here are some strategies that writers have developed to look at their first drafts from a fresh perspective. Try them over the course of this semester; then 
keep using the ones that bring results.

- Take a break. You are proud of what you wrote, but you might be too close to it to make changes. Set aside your writing for a few hours or even a day until you can look at it objectively.

- Ask someone you trust for feedback and constructive criticism.

- Pretend you are one of your readers. Are you satisfied or dissatisfied? Why?

- Use the resources that your college provides. Find out where your school's writing lab is located and ask about the assistance they provide online and in person.

Many people hear the words critic, critical, and criticism and pick up only negative vibes that provoke feelings that make them blush, grumble, or shout. However, as a writer and a thinker, you need to learn to be critical of yourself in a positive way and have high expectations for your work. You also need to train your eye and trust your ability to fix what needs fixing. For this, you need to teach yourself where to look.

\section{Creating Unity and Coherence}

Following your outline closely offers you a reasonable guarantee that your writing will stay on purpose and not drift away from the controlling idea. However, when writers are rushed, are tired, or cannot find the right words, their writing may become less than they want it to be. Their writing may no longer be clear and concise, and they may be adding information that is not needed to develop the main idea.

When a piece of writing has unity, all the ideas in each paragraph and in the entire essay clearly belong and are arranged in an order that makes logical sense. When the writing has coherence, the ideas flow smoothly. The wording clearly indicates how one idea leads to another within a paragraph and from paragraph to paragraph.

Tip

Reading your writing aloud will often help you find problems with unity and coherence. Listen for the clarity and flow of your ideas. Identify places where you find yourself confused, and write a note to yourself about possible fixes.

\section{Creating Unity}

Sometimes writers get caught up in the moment and cannot resist a good digression. Even though you might enjoy such detours when you chat with friends, unplanned digressions usually harm a piece of writing. 
Mariah stayed close to her outline when she drafted the three body paragraphs of her essay she tentatively titled “Digital Technology: The Newest and the Best at What Price?” But a recent shopping trip for an HDTV upset her enough that she digressed from the main topic of her third paragraph and included comments about the sales staff at the electronics store she visited. When she revised her essay, she deleted the off-topic sentences that affected the unity of the paragraph.

Read the following paragraph twice, the first time without Mariah's changes, and the second time with them.

Nothing is more confusing to me than choosing among televisions. It confuses lots of people who want a new high-definition digital television (HDTV) with a large screen to watch sports and DVDs on. You could listen to the guys in the electronics store, but word has it they know little more than you do. They want to sell what they have in stock, not what best fits your needs. You face decisions you never had to make with the old, bulky picture-tube televisions. Screen resolution means the number of horizontal scan lines the screen can show. This resolution is often 1080p, or full HD, or 768p. The trouble is that if you have a smaller screen, 32 inches or 37 inches diagonal, you won't be able to tell the difference with the naked eye. The 1080p televisions cost more, though, so those are what the salespeople want you to buy. They get bigger commissions. The other important decision you face as you walk around the sales floor is whether to get a plasma screen or an LCD screen. Now here the salespeople may finally give you decent info. Plasma flatpanel television screens can be much larger in diameter than their LCD rivals. Plasma screens show truer blacks and can be viewed at a wider angle than current LCD screens. But be careful and tell the salesperson you have budget constraints. Large flat-panel plasma screens are much more expensive than flat-screen LCD models. Don’t let someone make you by more television than you need!

\section{Exercise 1}

1. Answer the following two questions about Mariah’s paragraph:

\section{Collaboration}

Please share with a classmate and compare your answers.

2. Now start to revise the first draft of the essay you wrote in Section 8 "Writing Your Own First Draft". Reread it to find any statements that affect the unity of your writing. Decide how best to revise.

\section{Tip}

When you reread your writing to find revisions to make, look for each type of problem in a separate sweep. Read it straight through once to locate any problems with unity. Read it straight through a second time to find problems with coherence. You may follow this same practice during many stages of the writing process. 


\section{Writing at Work}

Many companies hire copyeditors and proofreaders to help them produce the cleanest possible final drafts of large writing projects. Copyeditors are responsible for suggesting revisions and style changes; proofreaders check documents for any errors in capitalization, spelling, and punctuation that have crept in. Many times, these tasks are done on a freelance basis, with one freelancer working for a variety of clients.

\section{Creating Coherence}

Careful writers use transitions to clarify how the ideas in their sentences and paragraphs are related. These words and phrases help the writing flow smoothly. Adding transitions is not the only way to improve coherence, but they are often useful and give a mature feel to your essays. Table 8.3 "Common Transitional Words and Phrases” groups many common transitions according to their purpose.

Table 8.3 Common Transitional Words and Phrases 


\section{Transitions That Show Sequence or Time}

\begin{tabular}{|c|c|c|}
\hline after & before & later \\
\hline afterward & before long & meanwhile \\
\hline as soon as & finally & next \\
\hline at first & first, second, third & soon \\
\hline at last & in the first place & then \\
\hline \multicolumn{3}{|l|}{ Transitions That Show Position } \\
\hline above & across & at the bottom \\
\hline at the top & behind & below \\
\hline beside & beyond & inside \\
\hline near & next to & opposite \\
\hline to the left, to the right, to the side & under & where \\
\hline \multicolumn{3}{|c|}{ Transitions That Show a Conclusion } \\
\hline indeed & hence & in conclusion \\
\hline in the final analysis & therefore & thus \\
\hline \multicolumn{3}{|c|}{ Transitions That Continue a Line of Thought } \\
\hline consequently & furthermore & additionally \\
\hline because & besides the fact & following this idea further \\
\hline in addition & in the same way & moreover \\
\hline looking further & considering..., it is clear that & \\
\hline \multicolumn{3}{|c|}{ Transitions That Change a Line of Thought } \\
\hline but & yet & however \\
\hline nevertheless & on the contrary & on the other hand \\
\hline \multicolumn{3}{|l|}{ Transitions That Show Importance } \\
\hline above all & best & especially \\
\hline in fact & more important & most important \\
\hline most & worst & \\
\hline \multicolumn{3}{|c|}{ Transitions That Introduce the Final Thoughts in a Paragraph or Essay } \\
\hline finally & last & in conclusion \\
\hline most of all & least of all & last of all \\
\hline
\end{tabular}




\begin{tabular}{|l|l|l|}
\hline \begin{tabular}{l} 
All-Purpose Transitions to Open Paragraphs or to Connect Ideas Inside Paragraphs \\
\hline admittedly
\end{tabular} & at this point & certainly \\
\hline granted & it is true & generally speaking \\
\hline in general & in this situation & no doubt \\
\hline no one denies & obviously & of course \\
\hline to be sure & undoubtedly & \\
\hline Transitions that Introduce Examples & for example & \\
\hline for instance & generally, furthermore, finally & in the first place, also, last \\
\hline Transitions That Clarify the Order of Events or Steps & \\
\hline first, second, third & in the first place, likewise, lastly & \\
\hline in the first place, furthermore, finally &
\end{tabular}

After Maria revised for unity, she next examined her paragraph about televisions to check for coherence. She looked for places where she needed to add a transition or perhaps reword the text to make the flow of ideas clear. In the version that follows, she has already deleted the sentences that were off topic.

Tip

Many writers make their revisions on a printed copy and then transfer them to the version on-screen. They conventionally use a small arrow called a caret $(\wedge)$ to show where to insert an addition or correction.

\footnotetext{
Finally, is mothing confusing to me than choosing among televisions. It confuses lots of people who want a new high-definition digital television (HDtelevision) with a large There's good reason for this confusion:
screen to watch sports and DVDs on. ^You face decisions you never had to make with the old, bulky picture-tube televisions. Ascreen resolution means the number of horizontal scan lines the screen can show. This resolution is often 1080p, or full HD, or 768p. The trouble is that if you have a smaller screen, 32 inches or 37 inches diagonal, you won't be able to tell the difference with the naked eye. The ^ ^ you face as you walk around the sales floor is whether to get a plasma screen or an LCD
Along with the choice of display type, a further decision buyers face is screen size and feat LCD rivals. Plasma screens show truer blacks and can be viewed at a wider angle than current LCD screens. Howerer, Large flat-panel plasma screens are much more expensive than flat-screen LCD models. Don't buy more television than you need!
} 


\section{Exercise 2}

1. Answer the following questions about Mariah’s revised paragraph.

2. Now return to the first draft of the essay you wrote in Section 8 "Writing Your Own First Draft" and revise it for coherence. Add transition words and phrases where they are needed, and make any other changes that are needed to improve the flow and connection between ideas.

\section{Being Clear and Concise}

Some writers are very methodical and painstaking when they write a first draft. Other writers unleash a lot of words in order to get out all that they feel they need to say. Do either of these composing styles match your style? Or is your composing style somewhere in between? No matter which description best fits you, the first draft of almost every piece of writing, no matter its author, can be made clearer and more concise.

If you have a tendency to write too much, you will need to look for unnecessary words. If you have a tendency to be vague or imprecise in your wording, you will need to find specific words to replace any overly general language.

\section{Identifying Wordiness}

Sometimes writers use too many words when fewer words will appeal more to their audience and better fit their purpose. Here are some common examples of wordiness to look for in your draft. Eliminating wordiness helps all readers, because it makes your ideas clear, direct, and straightforward.

- Sentences that begin with There is or There are.

Wordy: There are two major experiments that the Biology Department sponsors.

Revised: The Biology Department sponsors two major experiments.

\section{- Sentences with unnecessary modifiers.}

Wordy: Two extremely famous and well-known consumer advocates spoke eloquently in favor of the proposed important legislation.

Revised: Two well-known consumer advocates spoke in favor of the proposed legislation.

- Sentences with deadwood phrases that add little to the meaning. Be judicious when you use phrases such as in terms of, with a mind to, on the subject of, as to whether or not, 
more or less, as far as...is concerned, and similar expressions. You can usually find a more straightforward way to state your point.

Wordy: As a world leader in the field of green technology, the company plans to focus its efforts in the area of geothermal energy.

A report as to whether or not to use geysers as an energy source is in the process of preparation.

Revised: As a world leader in green technology, the company plans to focus on geothermal energy.

A report about using geysers as an energy source is in preparation.

- Sentences in the passive voice or with forms of the verb to be. Sentences with passive-voice verbs often create confusion, because the subject of the sentence does not perform an action. Sentences are clearer when the subject of the sentence performs the action and is followed by a strong verb. Use strong active-voice verbs in place of forms of to be, which can lead to wordiness. Avoid passive voice when you can.

Wordy: It might perhaps be said that using a GPS device is something that is a benefit to drivers who have a poor sense of direction.

Revised: Using a GPS device benefits drivers who have a poor sense of direction.

\section{- Sentences with constructions that can be shortened.}

Wordy: The e-book reader, which is a recent invention, may become as commonplace as the cell phone.

My over-sixty uncle bought an e-book reader, and his wife bought an e-book reader, too.

Revised: The e-book reader, a recent invention, may become as commonplace as the cell phone.

My over-sixty uncle and his wife both bought e-book readers.

\section{Exercise 3}

Now return once more to the first draft of the essay you have been revising. Check it for unnecessary words. Try making your sentences as concise as they can be. 


\section{Choosing Specific, Appropriate Words}

Most college essays should be written in formal English suitable for an academic situation. Follow these principles to be sure that your word choice is appropriate. For more information about word choice, see Chapter 4 "Working with Words: Which Word Is Right?".

- Avoid slang. Find alternatives to bummer, kewl, and rad.

- Avoid language that is overly casual. Write about "men and women" rather than "girls and guys" unless you are trying to create a specific effect. A formal tone calls for formal language.

- Avoid contractions. Use do not in place of don't, I am in place of I'm, have not in place of haven't, and so on. Contractions are considered casual speech.

- Avoid clichés. Overused expressions such as green with envy, face the music, better late than never, and similar expressions are empty of meaning and may not appeal to your audience.

- Be careful when you use words that sound alike but have different meanings. Some examples are allusion/illusion, complement/compliment, council/counsel, concurrent/ consecutive, founder/flounder, and historic/historical. When in doubt, check a dictionary.

- Choose words with the connotations you want. Choosing a word for its connotations is as important in formal essay writing as it is in all kinds of writing. Compare the positive connotations of the word proud and the negative connotations of arrogant and conceited.

- Use specific words rather than overly general words. Find synonyms for thing, people, nice, good, bad, interesting, and other vague words. Or use specific details to make your exact meaning clear.

Now read the revisions Mariah made to make her third paragraph clearer and more concise. She has already incorporated the changes she made to improve unity and coherence. 
confuses buyers more than purchasing

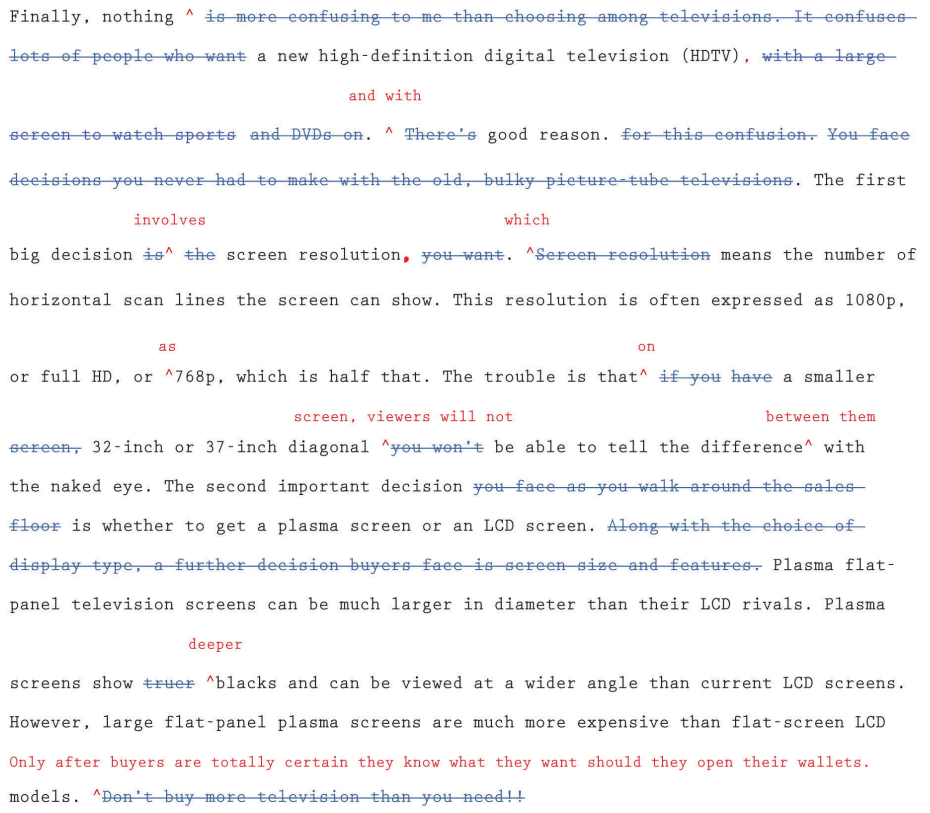

\section{Exercise 4}

1. Answer the following questions about Mariah’s revised paragraph:

2. Now return once more to your essay in progress. Read carefully for problems with word choice. Be sure that your draft is written in formal language and that your word choice is specific and appropriate.

\section{Completing a Peer Review}

After working so closely with a piece of writing, writers often need to step back and ask for a more objective reader. What writers most need is feedback from readers who can respond only to the words on the page. When they are ready, writers show their drafts to someone they respect and who can give an honest response about its strengths and weaknesses.

You, too, can ask a peer to read your draft when it is ready. After evaluating the feedback and assessing what is most helpful, the reader's feedback will help you when you revise your draft. This process is called peer review. 
You can work with a partner in your class and identify specific ways to strengthen each other's essays. Although you may be uncomfortable sharing your writing at first, remember that each writer is working toward the same goal: a final draft that fits the audience and the purpose. Maintaining a positive attitude when providing feedback will put you and your partner at ease. The box that follows provides a useful framework for the peer review session.

\section{Questions for Peer Review}

Title of essay:

Date:

Writer's name:

Peer reviewer's name:

1. This essay is about

2. Your main points in this essay are

3. What I most liked about this essay is

4. These three points struck me as your strongest:

b. Point:

Why:

c. Point:

Why:

These places in your essay are not clear to me:

a. Where:

Needs improvement because

b. Where:

Needs improvement because

c. Where:

Needs improvement because

The one additional change you could make that would improve this essay significantly is 


\section{Writing at Work}

One of the reasons why word-processing programs build in a reviewing feature is that workgroups have become a common feature in many businesses. Writing is often collaborative, and the members of a workgroup and their supervisors often critique group members' work and offer feedback that will lead to a better final product.

\section{Exercise 5}

Exchange essays with a classmate and complete a peer review of each other's draft in progress. Remember to give positive feedback and to be courteous and polite in your responses. Focus on providing one positive comment and one question for more information to the author.

\section{Using Feedback Objectively}

The purpose of peer feedback is to receive constructive criticism of your essay. Your peer reviewer is your first real audience, and you have the opportunity to learn what confuses and delights a reader so that you can improve your work before sharing the final draft with a wider audience (or your intended audience).

It may not be necessary to incorporate every recommendation your peer reviewer makes. However, if you start to observe a pattern in the responses you receive from peer reviewers, you might want to take that feedback into consideration in future assignments. For example, if you read consistent comments about a need for more research, then you may want to consider including more research in future assignments.

\section{Using Feedback from Multiple Sources}

You might get feedback from more than one reader as you share different stages of your revised draft. In this situation, you may receive feedback from readers who do not understand the assignment or who lack your involvement with and enthusiasm for it.

You need to evaluate the responses you receive according to two important criteria:

1. Determine if the feedback supports the purpose of the assignment.

2. Determine if the suggested revisions are appropriate to the audience. 
Then, using these standards, accept or reject revision feedback.

\section{Exercise 6}

Work with two partners. Go back to Note 8.81 "Exercise 4" in this lesson and compare your responses to Activity A, about Mariah’s paragraph, with your partners’. Recall Mariah’s purpose for writing and her audience. Then, working individually, list where you agree and where you disagree about revision needs.

\section{Editing Your Draft}

If you have been incorporating each set of revisions as Mariah has, you have produced multiple drafts of your writing. So far, all your changes have been content changes. Perhaps with the help of peer feedback, you have made sure that you sufficiently supported your ideas. You have checked for problems with unity and coherence. You have examined your essay for word choice, revising to cut unnecessary words and to replace weak wording with specific and appropriate wording.

The next step after revising the content is editing. When you edit, you examine the surface features of your text. You examine your spelling, grammar, usage, and punctuation. You also make sure you use the proper format when creating your finished assignment.

\section{Tip}

Editing often takes time. Budgeting time into the writing process allows you to complete additional edits after revising. Editing and proofreading your writing helps you create a finished work that represents your best efforts. Here are a few more tips to remember about your readers:

- Readers do not notice correct spelling, but they do notice misspellings.

- Readers look past your sentences to get to your ideas - unless the sentences are awkward, poorly constructed, and frustrating to read.

- Readers notice when every sentence has the same rhythm as every other sentence, with no variety.

- Readers do not cheer when you use there, their, and they're correctly, but they notice when you do not.

- Readers will notice the care with which you handled your assignment and your attention to detail in the delivery of an error-free document..

The first section of this book offers a useful review of grammar, mechanics, and usage. Use it to help you eliminate major errors in your writing and refine your understanding of the conventions of language. Do not hesitate to ask for help, too, from peer tutors in your academic department or in the college's writing lab. In the meantime, use the checklist to help you edit your writing. 


\section{Checklist}

Editing Your Writing

\section{Grammar}

- Are some sentences actually sentence fragments?

- Are some sentences run-on sentences? How can I correct them?

- Do some sentences need conjunctions between independent clauses?

- Does every verb agree with its subject?

- Is every verb in the correct tense?

- Are tense forms, especially for irregular verbs, written correctly?

- Have I used subject, object, and possessive personal pronouns correctly?

- Have I used who and whom correctly?

- Is the antecedent of every pronoun clear?

- Do all personal pronouns agree with their antecedents?

- Have I used the correct comparative and superlative forms of adjectives and adverbs?

- Is it clear which word a participial phrase modifies, or is it a dangling modifier?

\section{Sentence Structure}

- Are all my sentences simple sentences, or do I vary my sentence structure?

- Have I chosen the best coordinating or subordinating conjunctions to join clauses?

- Have I created long, overpacked sentences that should be shortened for clarity?

- Do I see any mistakes in parallel structure?

\section{Punctuation}

- Does every sentence end with the correct end punctuation?

- Can I justify the use of every exclamation point?

- Have I used apostrophes correctly to write all singular and plural possessive forms?

- Have I used quotation marks correctly?

\section{Mechanics and Usage}

- Can I find any spelling errors? How can I correct them?

- Have I used capital letters where they are needed?

- Have I written abbreviations, where allowed, correctly?

- Can I find any errors in the use of commonly confused words, such as to/too/two? 


\section{Tip}

Be careful about relying too much on spelling checkers and grammar checkers. A spelling checker cannot recognize that you meant to write principle but wrote principal instead. A grammar checker often queries constructions that are perfectly correct. The program does not understand your meaning; it makes its check against a general set of formulas that might not apply in each instance. If you use a grammar checker, accept the suggestions that make sense, but consider why the suggestions came up.

\section{Tip}

Proofreading requires patience; it is very easy to read past a mistake. Set your paper aside for at least a few hours, if not a day or more, so your mind will rest. Some professional proofreaders read a text backward so they can concentrate on spelling and punctuation. Another helpful technique is to slowly read a paper aloud, paying attention to every word, letter, and punctuation mark.

If you need additional proofreading help, ask a reliable friend, a classmate, or a peer tutor to make a final pass on your paper to look for anything you missed.

\section{Formatting}

Remember to use proper format when creating your finished assignment. Sometimes an instructor, a department, or a college will require students to follow specific instructions on titles, margins, page numbers, or the location of the writer's name. These requirements may be more detailed and rigid for research projects and term papers, which often observe the American Psychological Association (APA) or Modern Language Association (MLA) style guides, especially when citations of sources are included.

To ensure the format is correct and follows any specific instructions, make a final check before you submit an assignment.

\section{Exercise 7}

With the help of the checklist, edit and proofread your essay. 


\section{Key Takeaways}

- Revising and editing are the stages of the writing process in which you improve your work before producing a final draft.

- During revising, you add, cut, move, or change information in order to improve content.

- During editing, you take a second look at the words and sentences you used to express your ideas and fix any problems in grammar, punctuation, and sentence structure.

- Unity in writing means that all the ideas in each paragraph and in the entire essay clearly belong together and are arranged in an order that makes logical sense.

- Coherence in writing means that the writer's wording clearly indicates how one idea leads to another within a paragraph and between paragraphs.

- Transitional words and phrases effectively make writing more coherent.

- Writing should be clear and concise, with no unnecessary words.

- Effective formal writing uses specific, appropriate words and avoids slang, contractions, clichés, and overly general words.

- Peer reviews, done properly, can give writers objective feedback about their writing. It is the writer's responsibility to evaluate the results of peer reviews and incorporate only useful feedback.

- Remember to budget time for careful editing and proofreading. Use all available resources, including editing checklists, peer editing, and your institution's writing lab, to improve your editing skills. 


\subsection{The Writing Process: End-of-Chapter Exercises}

\section{Learning Objectives}

1. Use the skills you have learned in the chapter.

2. Work collaboratively with other students.

3. Work with a variety of academic and on-the-job, real-world examples.

\section{Exercises}

1. In this chapter, you have thought and read about the topic of mass media. Starting with the title "The Future of Information: How It Will Be Created, Transmitted, and Consumed," narrow the focus of the topic until it is suitable for a two- to three-page paper. Then narrow your topic with the help of brainstorming, idea mapping, and searching the Internet until you select a final topic to explore. Keep a journal or diary in which you record and comment on everything you did to choose a final topic. Then record what you will do next to explore the idea and create a thesis statement.

2. Write a thesis statement and a formal sentence outline for an essay about the writing process. Include separate paragraphs for prewriting, drafting, and revising and editing. Your audience will be a general audience of educated adults who are unfamiliar with how writing is taught at the college level. Your purpose is to explain the stages of the writing process so that readers will understand its benefits.

\section{Collaboration}

Please share with a classmate and compare your answers.

3. Pieces of writing in a variety of real-life and work-related situations would benefit from revising and editing. Consider the following list of real-life and work-related pieces of writing: e-mails, greeting card messages, junk mail, late-night television commercials, social networking pages, local newspapers, bulletin-board postings, and public notices. Find and submit at least two examples of writing that needs revision. Explain what changes you would make. Replace any recognizable names with pseudonyms.

4. Group activity. At work, an employer might someday ask you to contribute to the research base for an essay such as the one Mariah wrote or the one you wrote while working through this chapter. Choosing either her topic or your own, compile a list of at least five sources. Then, working in a group of four students, bring in printouts or PDF files of Internet sources or paper copies of non-Internet sources for the other group members to examine. In a group report, rate the reliability of each other's sources. 
5. Group activity. Working in a peer-review group of four, go to Section 8.3 "Drafting" and reread the draft of the first two body paragraphs of Mariah's essay, "Digital Technology: The Newest and the Best at What Price?” Review those two paragraphs using the same level of inspection given to the essay's third paragraph in Section 8.4 "Revising and Editing". Suggest and agree on changes to improve unity and coherence, eliminate unneeded words, and refine word choice. Your purpose is to help Mariah produce two effective paragraphs for a formal college-level essay about her topic. 


\section{Chapter 9: Writing Essays: From Start to Finish}

9.1 Developing a Strong, Clear Thesis Statement

9.2 Writing Body Paragraphs

9.3 Organizing Your Writing

9.4 Writing Introductory and Concluding Paragraphs

9.5 Writing Essays: End-of-Chapter Exercises 


\subsection{Developing a Strong, Clear Thesis Statement}

\section{Learning Objectives}

1. Develop a strong, clear thesis statement with the proper elements.

2. Revise your thesis statement.

Have you ever known a person who was not very good at telling stories? You probably had trouble following his train of thought as he jumped around from point to point, either being too brief in places that needed further explanation or providing too many details on a meaningless element. Maybe he told the end of the story first, then moved to the beginning and later added details to the middle. His ideas were probably scattered, and the story did not flow very well. When the story was over, you probably had many questions.

Just as a personal anecdote can be a disorganized mess, an essay can fall into the same trap of being out of order and confusing. That is why writers need a thesis statement to provide a specific focus for their essay and to organize what they are about to discuss in the body.

Just like a topic sentence summarizes a single paragraph, the thesis statement summarizes an entire essay. It tells the reader the point you want to make in your essay, while the essay itself supports that point. It is like a signpost that signals the essay's destination. You should form your thesis before you begin to organize an essay, but you may find that it needs revision as the essay develops.

\section{Elements of a Thesis Statement}

For every essay you write, you must focus on a central idea. This idea stems from a topic you have chosen or been assigned or from a question your teacher has asked. It is not enough merely to discuss a general topic or simply answer a question with a yes or no. You have to form a specific opinion, and then articulate that into a controlling idea - the main idea upon which you build your thesis.

Remember that a thesis is not the topic itself, but rather your interpretation of the question or subject. For whatever topic your professor gives you, you must ask yourself, "What do I want to say about it?" Asking and then answering this question is vital to forming a thesis that is precise, forceful and confident.

A thesis is one sentence long and appears toward the end of your introduction. It is specific and focuses on one to three points of a single idea-points that are able to be demonstrated in the body. It forecasts the content of the essay and suggests how you will organize your information. Remember that a thesis 
statement does not summarize an issue but rather dissects it.

\section{A Strong Thesis Statement}

A strong thesis statement contains the following qualities.

Specificity. A thesis statement must concentrate on a specific area of a general topic. As you may recall, the creation of a thesis statement begins when you choose a broad subject and then narrow down its parts until you pinpoint a specific aspect of that topic. For example, health care is a broad topic, but a proper thesis statement would focus on a specific area of that topic, such as options for individuals without health care coverage.

Precision. A strong thesis statement must be precise enough to allow for a coherent argument and to remain focused on the topic. If the specific topic is options for individuals without health care coverage, then your precise thesis statement must make an exact claim about it, such as that limited options exist for those who are uninsured by their employers. You must further pinpoint what you are going to discuss regarding these limited effects, such as whom they affect and what the cause is.

Ability to be argued. A thesis statement must present a relevant and specific argument. A factual statement often is not considered arguable. Be sure your thesis statement contains a point of view that can be supported with evidence.

Ability to be demonstrated. For any claim you make in your thesis, you must be able to provide reasons and examples for your opinion. You can rely on personal observations in order to do this, or you can consult outside sources to demonstrate that what you assert is valid. A worthy argument is backed by examples and details.

Forcefulness. A thesis statement that is forceful shows readers that you are, in fact, making an argument. The tone is assertive and takes a stance that others might oppose.

Confidence. In addition to using force in your thesis statement, you must also use confidence in your claim. Phrases such as I feel or I believe actually weaken the readers' sense of your confidence because these phrases imply that you are the only person who feels the way you do. In other words, your stance has insufficient backing. Taking an authoritative stance on the matter persuades your readers to have faith in your argument and open their minds to what you have to say.

\section{Tip}

Even in a personal essay that allows the use of first person, your thesis should not contain phrases such as in my opinion or I believe. These statements reduce your credibility and weaken your argument. Your opinion is more convincing when you use a firm attitude. 


\section{Exercise 1}

On a separate sheet of paper, write a thesis statement for each of the following topics. Remember to make each statement specific, precise, demonstrable, forceful and confident.

Topics

- Texting while driving

- The legal drinking age in the United States

- Steroid use among professional athletes

- Abortion

- Racism

\section{Examples of Appropriate Thesis Statements}

Each of the following thesis statements meets several of the following requirements:

- Specificity

- Precision

- Ability to be argued

- Ability to be demonstrated

- Forcefulness

- Confidence

1. The societal and personal struggles of Troy Maxon in the play Fences symbolize the challenge of black males who lived through segregation and integration in the United States.

2. Closing all American borders for a period of five years is one solution that will tackle illegal immigration.

3. Shakespeare's use of dramatic irony in Romeo and Juliet spoils the outcome for the audience and weakens the plot.

4. J. D. Salinger's character in Catcher in the Rye, Holden Caulfield, is a confused rebel who voices his disgust with phonies, yet in an effort to protect himself, he acts like a phony on many occasions.

5. Compared to an absolute divorce, no-fault divorce is less expensive, promotes fairer settlements, and reflects a more realistic view of the causes for marital breakdown.

6. Exposing children from an early age to the dangers of drug abuse is a sure method of preventing future drug addicts. 
7. In today’s crumbling job market, a high school diploma is not significant enough education to land a stable, lucrative job.

\section{Tip}

You can find thesis statements in many places, such as in the news; in the opinions of friends, coworkers or teachers; and even in songs you hear on the radio. Become aware of thesis statements in everyday life by paying attention to people's opinions and their reasons for those opinions. Pay attention to your own everyday thesis statements as well, as these can become material for future essays.

Now that you have read about the contents of a good thesis statement and have seen examples, take a look at the pitfalls to avoid when composing your own thesis:

- A thesis is weak when it is simply a declaration of your subject or a description of what you will discuss in your essay.

Weak thesis statement: My paper will explain why imagination is more important than knowledge.

- A thesis is weak when it makes an unreasonable or outrageous claim or insults the opposing side.

Weak thesis statement: Religious radicals across America are trying to legislate their Puritanical beliefs by banning required high school books.

- A thesis is weak when it contains an obvious fact or something that no one can disagree with or provides a dead end.

Weak thesis statement: Advertising companies use sex to sell their products.

- A thesis is weak when the statement is too broad.

Weak thesis statement: The life of Abraham Lincoln was long and challenging.

\section{Exercise 2}

Read the following thesis statements. On a separate piece of paper, identify each as weak or strong. For those that are weak, list the reasons why. Then revise the weak statements so that they conform to the requirements of a strong thesis.

1. The subject of this paper is my experience with ferrets as pets.

2. The government must expand its funding for research on renewable energy resources in order to 
prepare for the impending end of oil.

3. Edgar Allan Poe was a poet who lived in Baltimore during the nineteenth century.

4. In this essay, I will give you lots of reasons why slot machines should not be legalized in Baltimore.

5. Despite his promises during his campaign, President Kennedy took few executive measures to support civil rights legislation.

6. Because many children's toys have potential safety hazards that could lead to injury, it is clear that not all children's toys are safe.

7. My experience with young children has taught me that I want to be a disciplinary parent because I believe that a child without discipline can be a parent's worst nightmare.

\section{Writing at Work}

Often in your career, you will need to ask your boss for something through an e-mail. Just as a thesis statement organizes an essay, it can also organize your e-mail request. While your e-mail will be shorter than an essay, using a thesis statement in your first paragraph quickly lets your boss know what you are asking for, why it is necessary, and what the benefits are. In short body paragraphs, you can provide the essential information needed to expand upon your request.

\section{Thesis Statement Revision}

Your thesis will probably change as you write, so you will need to modify it to reflect exactly what you have discussed in your essay. Remember from Chapter 8 “The Writing Process: How Do I Begin?” that your thesis statement begins as a working thesis statement, an indefinite statement that you make about your topic early in the writing process for the purpose of planning and guiding your writing.

Working thesis statements often become stronger as you gather information and form new opinions and reasons for those opinions. Revision helps you strengthen your thesis so that it matches what you have expressed in the body of the paper.

\section{Tip}

The best way to revise your thesis statement is to ask questions about it and then examine the answers to those questions. By challenging your own ideas and forming definite reasons for those ideas, you grow closer to a more precise point of view, which you can then incorporate into your thesis statement. 


\section{Ways to Revise Your Thesis}

You can cut down on irrelevant aspects and revise your thesis by taking the following steps:

1. Pinpoint and replace all nonspecific words, such as people, everything, society, or life, with more precise words in order to reduce any vagueness.

Working thesis: Young people have to work hard to succeed in life.

Revised thesis: Recent college graduates must have discipline and persistence in order to find and maintain a stable job in which they can use and be appreciated for their talents.

The revised thesis makes a more specific statement about success and what it means to work hard. The original includes too broad a range of people and does not define exactly what success entails. By replacing those general words like people and work hard, the writer can better focus his or her research and gain more direction in his or her writing.

2. Clarify ideas that need explanation by asking yourself questions that narrow your thesis.

Working thesis: The welfare system is a joke.

Revised thesis: The welfare system keeps a socioeconomic class from gaining employment by alluring members of that class with unearned income, instead of programs to improve their education and skill sets.

A joke means many things to many people. Readers bring all sorts of backgrounds and perspectives to the reading process and would need clarification for a word so vague. This expression may also be too informal for the selected audience. By asking questions, the writer can devise a more precise and appropriate explanation for joke. The writer should ask himself or herself questions similar to the $5 \mathrm{WH}$ questions. (See Chapter 8 “The Writing Process: How Do I Begin?” for more information on the 5WH questions.) By incorporating the answers to these questions into a thesis statement, the writer more accurately defines his or her stance, which will better guide the writing of the essay.

3. Replace any linking verbs with action verbs. Linking verbs are forms of the verb to be, a verb that simply states that a situation exists.

Working thesis: Kansas City schoolteachers are not paid enough.

Revised thesis: The Kansas City legislature cannot afford to pay its educators, resulting in job cuts and resignations in a district that sorely needs highly qualified and dedicated teachers.

The linking verb in this working thesis statement is the word are. Linking verbs often make thesis statements weak because they do not express action. Rather, they connect words and phrases to the second half of the sentence. Readers might wonder, "Why are they not paid enough?” But this statement does not compel them to ask many more questions. The writer should ask himself or herself questions in order to replace the linking verb with an action verb, thus forming a stronger thesis statement, one that takes a more definitive stance on the issue: 
- Who is not paying the teachers enough?

- What is considered “enough”?

- What is the problem?

- What are the results

4. Omit any general claims that are hard to support.

Working thesis: Today’s teenage girls are too sexualized.

Revised thesis: Teenage girls who are captivated by the sexual images on MTV are conditioned to believe that a woman's worth depends on her sensuality, a feeling that harms their self-esteem and behavior.

It is true that some young women in today's society are more sexualized than in the past, but that is not true for all girls. Many girls have strict parents, dress appropriately, and do not engage in sexual activity while in middle school and high school. The writer of this thesis should ask the following questions:

- Which teenage girls?

- What constitutes “too” sexualized?

- Why are they behaving that way?

- Where does this behavior show up?

- What are the repercussions?

\section{Exercise 3}

In the first section of Chapter 8 “The Writing Process: How Do I Begin?”, you determined your purpose for writing and your audience. You then completed a freewriting exercise about an event you recently experienced and chose a general topic to write about. Using that general topic, you then narrowed it down by answering the $5 \mathrm{WH}$ questions. After you answered these questions, you chose one of the three methods of prewriting and gathered possible supporting points for your working thesis statement.

Now, on a separate sheet of paper, write down your working thesis statement. Identify any weaknesses in this sentence and revise the statement to reflect the elements of a strong thesis statement. Make sure it is specific, precise, arguable, demonstrable, forceful, and confident.

\section{Collaboration}

Please share with a classmate and compare your answers. 


\section{Writing at Work}

In your career you may have to write a project proposal that focuses on a particular problem in your company, such as reinforcing the tardiness policy. The proposal would aim to fix the problem; using a thesis statement would clearly state the boundaries of the problem and tell the goals of the project. After writing the proposal, you may find that the thesis needs revision to reflect exactly what is expressed in the body. Using the techniques from this chapter would apply to revising that thesis.

\section{Key Takeaways}

- Proper essays require a thesis statement to provide a specific focus and suggest how the essay will be organized.

- A thesis statement is your interpretation of the subject, not the topic itself.

- A strong thesis is specific, precise, forceful, confident, and is able to be demonstrated.

- A strong thesis challenges readers with a point of view that can be debated and can be supported with evidence.

- A weak thesis is simply a declaration of your topic or contains an obvious fact that cannot be argued.

- Depending on your topic, it may or may not be appropriate to use first person point of view.

- Revise your thesis by ensuring all words are specific, all ideas are exact, and all verbs express action. 


\subsection{Writing Body Paragraphs}

\section{Learning Objectives}

1. Select primary support related to your thesis.

2. Support your topic sentences.

If your thesis gives the reader a roadmap to your essay, then body paragraphs should closely follow that map. The reader should be able to predict what follows your introductory paragraph by simply reading the thesis statement.

The body paragraphs present the evidence you have gathered to confirm your thesis. Before you begin to support your thesis in the body, you must find information from a variety of sources that support and give credit to what you are trying to prove.

\section{Select Primary Support for Your Thesis}

Without primary support, your argument is not likely to be convincing. Primary support can be described as the major points you choose to expand on your thesis. It is the most important information you select to argue for your point of view. Each point you choose will be incorporated into the topic sentence for each body paragraph you write. Your primary supporting points are further supported by supporting details within the paragraphs.

Tip

Remember that a worthy argument is backed by examples. In order to construct a valid argument, good writers conduct lots of background research and take careful notes. They also talk to people knowledgeable about a topic in order to understand its implications before writing about it.

\section{Identify the Characteristics of Good Primary Support}

In order to fulfill the requirements of good primary support, the information you choose must meet the following standards: 
- Be specific. The main points you make about your thesis and the examples you use to expand on those points need to be specific. Use specific examples to provide the evidence and to build upon your general ideas. These types of examples give your reader something narrow to focus on, and if used properly, they leave little doubt about your claim. General examples, while they convey the necessary information, are not nearly as compelling or useful in writing because they are too obvious and typical.

- Be relevant to the thesis. Primary support is considered strong when it relates directly to the thesis. Primary support should show, explain, or prove your main argument without delving into irrelevant details. When faced with lots of information that could be used to prove your thesis, you may think you need to include it all in your body paragraphs. But effective writers resist the temptation to lose focus. Choose your examples wisely by making sure they directly connect to your thesis.

- Be detailed. Remember that your thesis, while specific, should not be very detailed. The body paragraphs are where you develop the discussion that a thorough essay requires. Using detailed support shows readers that you have considered all the facts and chosen only the most precise details to enhance your point of view.

\section{Prewrite to Identify Primary Supporting Points for a Thesis Statement}

Recall that when you prewrite you essentially make a list of examples or reasons why you support your stance. Stemming from each point, you further provide details to support those reasons. After prewriting, you are then able to look back at the information and choose the most compelling pieces you will use in your body paragraphs.

\section{Exercise 1}

Choose one of the following working thesis statements. On a separate sheet of paper, write for at least five minutes using one of the prewriting techniques you learned in Chapter 8 "The Writing Process: How Do I Begin?”.

1. Unleashed dogs on city streets are a dangerous nuisance.

2. Students cheat for many different reasons.

3. Drug use among teens and young adults is a problem.

4. The most important change that should occur at my college or university is

\section{Select the Most Effective Primary Supporting Points for a}




\section{Thesis Statement}

After you have prewritten about your working thesis statement, you may have generated a lot of information, which may be edited out later. Remember that your primary support must be relevant to your thesis. Remind yourself of your main argument, and delete any ideas that do not directly relate to it. Omitting unrelated ideas ensures that you will use only the most convincing information in your body paragraphs. Choose at least three of only the most compelling points. These will serve as the topic sentences for your body paragraphs.

\section{Exercise 2}

Refer to the previous exercise and select three of your most compelling reasons to support the thesis statement. Remember that the points you choose must be specific and relevant to the thesis. The statements you choose will be your primary support points, and you will later incorporate them into the topic sentences for the body paragraphs.

\section{Collaboration}

Please share with a classmate and compare your answers.

When you support your thesis, you are revealing evidence. Evidence includes anything that can help support your stance. The following are the kinds of evidence you will encounter as you conduct your research:

1. Facts. Facts are the best kind of evidence to use because they often cannot be disputed. They can support your stance by providing background information on or a solid foundation for your point of view. However, some facts may still need explanation. For example, the sentence "The most populated state in the United States is California" is a pure fact, but it may require some explanation to make it relevant to your specific argument.

2. Judgments. Judgments are conclusions drawn from the given facts. Judgments are more credible than opinions because they are founded upon careful reasoning and examination of a topic.

3. Testimony. Testimony consists of direct quotations from either an eyewitness or an expert witness. An eyewitness is someone who has direct experience with a subject; he adds authenticity to an argument based on facts. An expert witness is a person who has extensive experience with a topic. This person studies the facts and provides commentary based on either facts or judgments, or both. An expert witness adds authority and credibility to an argument.

4. Personal observation. Personal observation is similar to testimony, but personal observation consists of your testimony. It reflects what you know to be true because you have experiences and have formed either opinions or judgments about them. For instance, if you are one of five children and your thesis states that being part of a large family is beneficial to a child's social development, you could use your own experience to support your thesis. 


\section{Writing at Work}

In any job where you devise a plan, you will need to support the steps that you lay out. This is an area in which you would incorporate primary support into your writing. Choosing only the most specific and relevant information to expand upon the steps will ensure that your plan appears well-thought-out and precise.

\section{Tip}

You can consult a vast pool of resources to gather support for your stance. Citing relevant information from reliable sources ensures that your reader will take you seriously and consider your assertions. Use any of the following sources for your essay: newspapers or news organization websites, magazines, encyclopedias, and scholarly journals, which are periodicals that address topics in a specialized field.

\section{Choose Supporting Topic Sentences}

Each body paragraph contains a topic sentence that states one aspect of your thesis and then expands upon it. Like the thesis statement, each topic sentence should be specific and supported by concrete details, facts, or explanations.

Each body paragraph should comprise the following elements.

topic sentence + supporting details (examples, reasons, or arguments)

As you read in Chapter 8 “The Writing Process: How Do I Begin?”, topic sentences indicate the location and main points of the basic arguments of your essay. These sentences are vital to writing your body paragraphs because they always refer back to and support your thesis statement. Topic sentences are linked to the ideas you have introduced in your thesis, thus reminding readers what your essay is about. A paragraph without a clearly identified topic sentence may be unclear and scattered, just like an essay without a thesis statement.

\section{Tip}

Unless your teacher instructs otherwise, you should include at least three body paragraphs in your essay. A five-paragraph essay, including the introduction and conclusion, is commonly the standard for exams and essay assignments. 
Consider the following the thesis statement:

Author J.D. Salinger relied primarily on his personal life and belief system as the foundation for the themes in the majority of his works.

The following topic sentence is a primary support point for the thesis. The topic sentence states exactly what the controlling idea of the paragraph is. Later, you will see the writer immediately provide support for the sentence.

Salinger, a World War II veteran, suffered from posttraumatic stress disorder, a disorder that influenced themes in many of his works.

\section{Exercise 3}

In Note 9.19 "Exercise 2", you chose three of your most convincing points to support the thesis statement you selected from the list. Take each point and incorporate it into a topic sentence for each body paragraph.

Supporting point 1 :

Topic sentence:

Supporting point 2:

Topic sentence:

Supporting point 3:

Topic sentence:

\section{Collaboration}

Please share with a classmate and compare your answers.

\section{Draft Supporting Detail Sentences for Each Primary Support Sentence}

After deciding which primary support points you will use as your topic sentences, you must add details to clarify and demonstrate each of those points. These supporting details provide examples, facts, or evidence that support the topic sentence. 
The writer drafts possible supporting detail sentences for each primary support sentence based on the thesis statement:

Thesis statement: Unleashed dogs on city streets are a dangerous nuisance.

Supporting point 1: Dogs can scare cyclists and pedestrians.

Supporting details:

1. Cyclists are forced to zigzag on the road.

2. School children panic and turn wildly on their bikes.

3. People who are walking at night freeze in fear.

\section{Supporting point 2:}

Loose dogs are traffic hazards.

Supporting details:

1. Dogs in the street make people swerve their cars.

2. To avoid dogs, drivers run into other cars or pedestrians.

3. Children coaxing dogs across busy streets create danger.

Supporting point 3: Unleashed dogs damage gardens.

Supporting details:

1. They step on flowers and vegetables.

2. They destroy hedges by urinating on them.

3. They mess up lawns by digging holes.

The following paragraph contains supporting detail sentences for the primary support sentence (the topic sentence), which is underlined.

Salinger, a World War II veteran, suffered from posttraumatic stress disorder, a disorder that influenced the themes in many of his works. He did not hide his mental anguish over the horrors of war and once told his daughter, "You never really get the smell of burning flesh out of your nose, no matter how long you live.” His short story "A Perfect Day for a Bananafish" details a day in the life of a WWII veteran who was recently released from an army hospital for psychiatric problems. The man acts questionably with a little girl he meets on the beach before he returns to his hotel room and commits suicide. Another short story, "For Esmé - with Love and Squalor," is narrated by a traumatized soldier who sparks an unusual relationship with a young girl he meets before he departs to partake in D-Day. Finally, in Salinger's only novel, The Catcher in the Rye, he continues with the theme of posttraumatic stress, though not directly related to war. From a rest home for the mentally ill, sixteen-year-old Holden Caulfield narrates the story of his nervous breakdown following the death of his younger brother. 


\section{Exercise 4}

Using the three topic sentences you composed for the thesis statement in Note 9.18 "Exercise 1", draft at least three supporting details for each point.

Thesis statement:

Primary supporting point 1 :

Supporting details:

Primary supporting point 2:

Supporting details:

Primary supporting point 3:

Supporting details:

\section{Tip}

You have the option of writing your topic sentences in one of three ways. You can state it at the beginning of the body paragraph, or at the end of the paragraph, or you do not have to write it at all. This is called an implied topic sentence. An implied topic sentence lets readers form the main idea for themselves. For beginning writers, it is best to not use implied topic sentences because it makes it harder to focus your writing. Your instructor may also want to clearly identify the sentences that support your thesis. For more information on the placement of thesis statements and implied topic statements, see Chapter 8 "The Writing Process: How Do I Begin?”.

\section{Tip}

Print out the first draft of your essay and use a highlighter to mark your topic sentences in the body paragraphs. Make sure they are clearly stated and accurately present your paragraphs, as well as accurately reflect your thesis. If your topic sentence contains information that does not exist in the rest of the paragraph, rewrite it to more accurately match the rest of the paragraph.

\section{Key Takeaways}

- Your body paragraphs should closely follow the path set forth by your thesis statement.

- Strong body paragraphs contain evidence that supports your thesis. 
- Primary support comprises the most important points you use to support your thesis.

- Strong primary support is specific, detailed, and relevant to the thesis.

- Prewriting helps you determine your most compelling primary support.

- Evidence includes facts, judgments, testimony, and personal observation.

- Reliable sources may include newspapers, magazines, academic journals, books, encyclopedias, and firsthand testimony.

- A topic sentence presents one point of your thesis statement while the information in the rest of the paragraph supports that point.

- A body paragraph comprises a topic sentence plus supporting details. 


\subsection{Organizing Your Writing}

\section{Learning Objectives}

1. Understand how and why organizational techniques help writers and readers stay focused.

2. Assess how and when to use chronological order to organize an essay.

3. Recognize how and when to use order of importance to organize an essay.

4. Determine how and when to use spatial order to organize an essay.

The method of organization you choose for your essay is just as important as its content. Without a clear organizational pattern, your reader could become confused and lose interest. The way you structure your essay helps your readers draw connections between the body and the thesis, and the structure also keeps you focused as you plan and write the essay. Choosing your organizational pattern before you outline ensures that each body paragraph works to support and develop your thesis.

This section covers three ways to organize body paragraphs:

1. Chronological order

2. Order of importance

3. Spatial order

When you begin to draft your essay, your ideas may seem to flow from your mind in a seemingly random manner. Your readers, who bring to the table different backgrounds, viewpoints, and ideas, need you to clearly organize these ideas in order to help process and accept them.

A solid organizational pattern gives your ideas a path that you can follow as you develop your draft. Knowing how you will organize your paragraphs allows you to better express and analyze your thoughts. Planning the structure of your essay before you choose supporting evidence helps you conduct more effective and targeted research.

\section{Chronological Order}

In Chapter 8 “The Writing Process: How Do I Begin?”, you learned that chronological arrangement has the following purposes:

- To explain the history of an event or a topic 
- To tell a story or relate an experience

- To explain how to do or to make something

- To explain the steps in a process

Chronological order is mostly used in expository writing, which is a form of writing that narrates, describes, informs, or explains a process. When using chronological order, arrange the events in the order that they actually happened, or will happen if you are giving instructions. This method requires you to use words such as first, second, then, after that, later, and finally. These transition words guide you and your reader through the paper as you expand your thesis.

For example, if you are writing an essay about the history of the airline industry, you would begin with its conception and detail the essential timeline events up until present day. You would follow the chain of events using words such as first, then, next, and so on.

\section{Writing at Work}

At some point in your career you may have to file a complaint with your human resources department. Using chronological order is a useful tool in describing the events that led up to your filing the grievance. You would logically lay out the events in the order that they occurred using the key transition words. The more logical your complaint, the more likely you will be well received and helped.

\section{Exercise 1}

Choose an accomplishment you have achieved in your life. The important moment could be in sports, schooling, or extracurricular activities. On your own sheet of paper, list the steps you took to reach your goal. Try to be as specific as possible with the steps you took. Pay attention to using transition words to focus your writing.

Keep in mind that chronological order is most appropriate for the following purposes:

- Writing essays containing heavy research

- Writing essays with the aim of listing, explaining, or narrating

- Writing essays that analyze literary works such as poems, plays, or books

\section{Tip}

When using chronological order, your introduction should indicate the information you will cover and in what 
order, and the introduction should also establish the relevance of the information. Your body paragraphs should then provide clear divisions or steps in chronology. You can divide your paragraphs by time (such as decades, wars, or other historical events) or by the same structure of the work you are examining (such as a line-by-line explication of a poem).

\section{Exercise 2}

On a separate sheet of paper, write a paragraph that describes a process you are familiar with and can do well. Assume that your reader is unfamiliar with the procedure. Remember to use the chronological key words, such as first, second, then, and finally.

\section{Order of Importance}

Recall from Chapter 8 “The Writing Process: How Do I Begin?” that order of importance is best used for the following purposes:

- Persuading and convincing

- Ranking items by their importance, benefit, or significance

- Illustrating a situation, problem, or solution

Most essays move from the least to the most important point, and the paragraphs are arranged in an effort to build the essay's strength. Sometimes, however, it is necessary to begin with your most important supporting point, such as in an essay that contains a thesis that is highly debatable. When writing a persuasive essay, it is best to begin with the most important point because it immediately captivates your readers and compels them to continue reading.

For example, if you were supporting your thesis that homework is detrimental to the education of high school students, you would want to present your most convincing argument first, and then move on to the less important points for your case.

Some key transitional words you should use with this method of organization are most importantly, almost as importantly, just as importantly, and finally.

\section{Writing at Work}

During your career, you may be required to work on a team that devises a strategy for a specific goal of your company, such as increasing profits. When planning your strategy you should organize your steps in order of 
importance. This demonstrates the ability to prioritize and plan. Using the order of importance technique also shows that you can create a resolution with logical steps for accomplishing a common goal.

\section{Exercise 3}

On a separate sheet of paper, write a paragraph that discusses a passion of yours. Your passion could be music, a particular sport, filmmaking, and so on. Your paragraph should be built upon the reasons why you feel so strongly. Briefly discuss your reasons in the order of least to greatest importance.

\section{Spatial Order}

As stated in Chapter 8 “The Writing Process: How Do I Begin?”, spatial order is best used for the following purposes:

- Helping readers visualize something as you want them to see it

- Evoking a scene using the senses (sight, touch, taste, smell, and sound)

- Writing a descriptive essay

Spatial order means that you explain or describe objects as they are arranged around you in your space, for example in a bedroom. As the writer, you create a picture for your reader, and their perspective is the viewpoint from which you describe what is around you.

The view must move in an orderly, logical progression, giving the reader clear directional signals to follow from place to place. The key to using this method is to choose a specific starting point and then guide the reader to follow your eye as it moves in an orderly trajectory from your starting point.

Pay attention to the following student's description of her bedroom and how she guides the reader through the viewing process, foot by foot.

Attached to my bedroom wall is a small wooden rack dangling with red and turquoise necklaces that shimmer as you enter. Just to the right of the rack is my window, framed by billowy white curtains. The peace of such an image is a stark contrast to my desk, which sits to the right of the window, layered in textbooks, crumpled papers, coffee cups, and an overflowing ashtray. Turning my head to the right, I see a set of two bare windows that frame the trees outside the glass like a 3D painting. Below the windows is an oak chest from which blankets and scarves are protruding. Against the wall opposite the billowy curtains is an antique dresser, on top of which sits a jewelry box and a few picture frames. A tall mirror attached to the dresser takes up most of the wall, which is the color of lavender. 
The paragraph incorporates two objectives you have learned in this chapter: using an implied topic sentence and applying spatial order. Often in a descriptive essay, the two work together.

The following are possible transition words to include when using spatial order:

- Just to the left or just to the right

- Behind

- Between

- On the left or on the right

- Across from

- A little further down

- To the south, to the east, and so on

- A few yards away

- Turning left or turning right

\section{Exercise 4}

On a separate sheet of paper, write a paragraph using spatial order that describes your commute to work, school, or another location you visit often.

\section{Collaboration}

Please share with a classmate and compare your answers.

\section{Key Takeaways}

- The way you organize your body paragraphs ensures you and your readers stay focused on and draw connections to, your thesis statement.

- A strong organizational pattern allows you to articulate, analyze, and clarify your thoughts.

- Planning the organizational structure for your essay before you begin to search for supporting evidence helps you conduct more effective and directed research.

- Chronological order is most commonly used in expository writing. It is useful for explaining the history of your subject, for telling a story, or for explaining a process.

- Order of importance is most appropriate in a persuasion paper as well as for essays in which you rank things, people, or events by their significance.

- Spatial order describes things as they are arranged in space and is best for helping readers visualize something as you want them to see it; it creates a dominant impression. 


\subsection{Writing Introductory and Concluding Paragraphs}

\section{Learning Objectives}

1. Recognize the importance of strong introductory and concluding paragraphs.

2. Learn to engage the reader immediately with the introductory paragraph.

3. Practice concluding your essays in a more memorable way.

Picture your introduction as a storefront window: You have a certain amount of space to attract your customers (readers) to your goods (subject) and bring them inside your store (discussion). Once you have enticed them with something intriguing, you then point them in a specific direction and try to make the sale (convince them to accept your thesis).

Your introduction is an invitation to your readers to consider what you have to say and then to follow your train of thought as you expand upon your thesis statement.

An introduction serves the following purposes:

1. Establishes your voice and tone, or your attitude, toward the subject

2. Introduces the general topic of the essay

3. States the thesis that will be supported in the body paragraphs

First impressions are crucial and can leave lasting effects in your reader's mind, which is why the introduction is so important to your essay. If your introductory paragraph is dull or disjointed, your reader probably will not have much interest in continuing with the essay.

\section{Attracting Interest in Your Introductory Paragraph}

Your introduction should begin with an engaging statement devised to provoke your readers' interest. In the next few sentences, introduce them to your topic by stating general facts or ideas about the subject. As you move deeper into your introduction, you gradually narrow the focus, moving closer to your thesis. Moving smoothly and logically from your introductory remarks to your thesis statement can be achieved using a funnel technique, as illustrated in the diagram in Figure 9.1 "Funnel Technique”. 


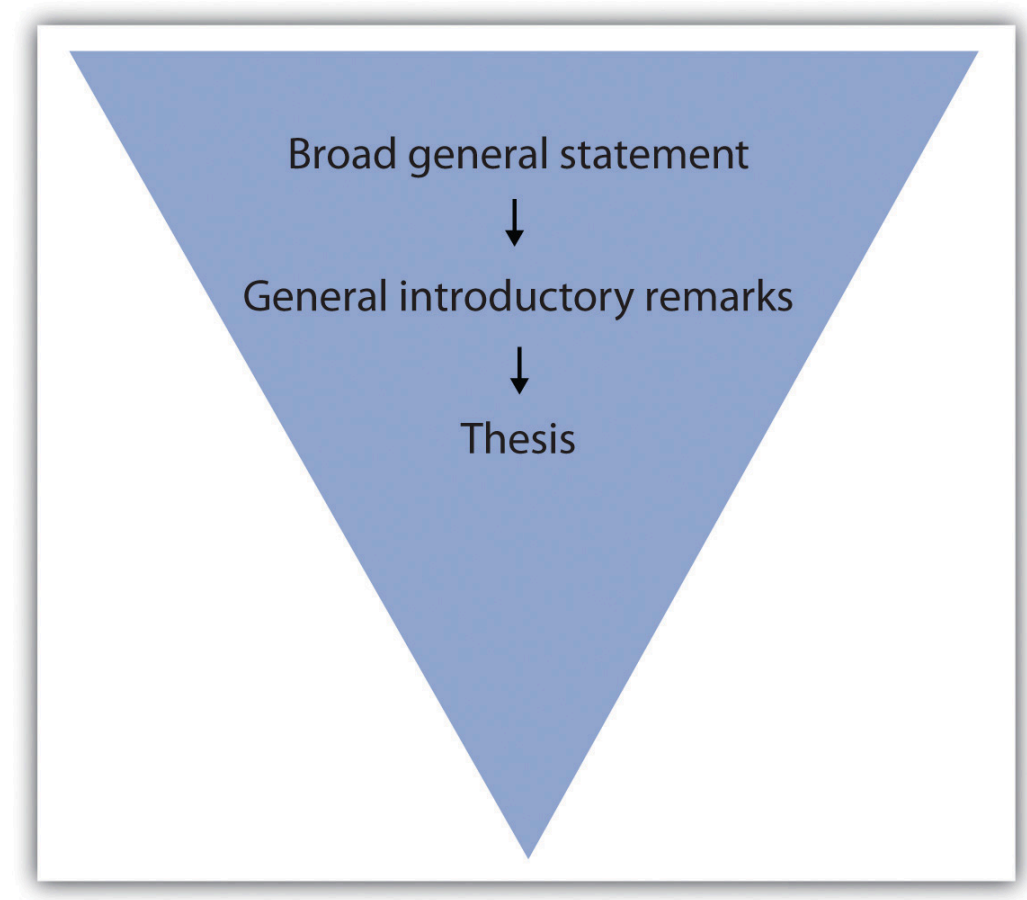

General introductory remarks -> Thesis)" style="max-width: 400px;"/>

\section{Exercise 1}

On a separate sheet of paper, jot down a few general remarks that you can make about the topic for which you formed a thesis in Section 9.1 "Developing a Strong, Clear Thesis Statement".

Immediately capturing your readers' interest increases the chances of having them read what you are about to discuss. You can garner curiosity for your essay in a number of ways. Try to get your readers personally involved by doing any of the following:

- Appealing to their emotions

- Using logic

- Beginning with a provocative question or opinion

- Opening with a startling statistic or surprising fact

- Raising a question or series of questions

- Presenting an explanation or rationalization for your essay

- Opening with a relevant quotation or incident

- Opening with a striking image 
- Including a personal anecdote

Tip

Remember that your diction, or word choice, while always important, is most crucial in your introductory paragraph. Boring diction could extinguish any desire a person might have to read through your discussion. Choose words that create images or express action. For more information on diction, see Chapter 4 "Working with Words: Which Word Is Right?”.

In Chapter 8 “The Writing Process: How Do I Begin?”, you followed Mariah as she moved through the writing process. In this chapter, Mariah writes her introduction and conclusion for the same essay. Mariah incorporates some of the introductory elements into her introductory paragraph, which she previously outlined in Chapter 8 "The Writing Process: How Do I Begin?". Her thesis statement is underlined.

Play Atari on a General Electric brand television set? Maybe watch Dynasty? Or read old newspaper articles on microfiche at the library? Twenty-five years ago, the average college student did not have many options when it came to entertainment in the form of technology. Fast-forward to the twenty-first century, and the digital age has digital technology, consumers are bombarded with endless options for how they do most everything-from buying and reading books to taking and developing photographs. In a society that is obsessed with digital means of entertainment, it is easy for the average person to become baffled. Everyone wants the newest and best digital technology, but the choices are many and the specifications are often confusing.

\section{Tip}

If you have trouble coming up with a provocative statement for your opening, it is a good idea to use a relevant, attention-grabbing quote about your topic. Use a search engine to find statements made by historical or significant figures about your subject.

\section{Writing at Work}

In your job field, you may be required to write a speech for an event, such as an awards banquet or a dedication ceremony. The introduction of a speech is similar to an essay because you have a limited amount of space to attract your audience's attention. Using the same techniques, such as a provocative quote or an interesting statistic, is an effective way to engage your listeners. Using the funnel approach also introduces your audience to your topic and then presents your main idea in a logical manner. 


\section{Exercise 2}

Reread each sentence in Mariah's introductory paragraph. Indicate which techniques she used and comment on how each sentence is designed to attract her readers' interest.

\section{Writing a Conclusion}

It is not unusual to want to rush when you approach your conclusion, and even experienced writers may fade. But what good writers remember is that it is vital to put just as much attention into the conclusion as in the rest of the essay. After all, a hasty ending can undermine an otherwise strong essay.

A conclusion that does not correspond to the rest of your essay, has loose ends, or is unorganized can unsettle your readers and raise doubts about the entire essay. However, if you have worked hard to write the introduction and body, your conclusion can often be the most logical part to compose.

\section{The Anatomy of a Strong Conclusion}

Keep in mind that the ideas in your conclusion must conform to the rest of your essay. In order to tie these components together, restate your thesis at the beginning of your conclusion. This helps you assemble, in an orderly fashion, all the information you have explained in the body. Repeating your thesis reminds your readers of the major arguments you have been trying to prove and also indicates that your essay is drawing to a close. A strong conclusion also reviews your main points and emphasizes the importance of the topic.

The construction of the conclusion is similar to the introduction, in which you make general introductory statements and then present your thesis. The difference is that in the conclusion you first paraphrase, or state in different words, your thesis and then follow up with general concluding remarks. These sentences should progressively broaden the focus of your thesis and maneuver your readers out of the essay.

Many writers like to end their essays with a final emphatic statement. This strong closing statement will cause your readers to continue thinking about the implications of your essay; it will make your conclusion, and thus your essay, more memorable. Another powerful technique is to challenge your readers to make a change in either their thoughts or their actions. Challenging your readers to see the subject through new eyes is a powerful way to ease yourself and your readers out of the essay. 
Tip

When closing your essay, do not expressly state that you are drawing to a close. Relying on statements such as in conclusion, it is clear that, as you can see, or in summation is unnecessary and can be considered trite.

\section{Tip}

It is wise to avoid doing any of the following in your conclusion:

- Introducing new material

- Contradicting your thesis

- Changing your thesis

- Using apologies or disclaimers

Introducing new material in your conclusion has an unsettling effect on your reader. When you raise new points, you make your reader want more information, which you could not possibly provide in the limited space of your final paragraph.

Contradicting or changing your thesis statement causes your readers to think that you do not actually have a conviction about your topic. After all, you have spent several paragraphs adhering to a singular point of view. When you change sides or open up your point of view in the conclusion, your reader becomes less inclined to believe your original argument.

By apologizing for your opinion or stating that you know it is tough to digest, you are in fact admitting that even you know what you have discussed is irrelevant or unconvincing. You do not want your readers to feel this way. Effective writers stand by their thesis statement and do not stray from it.

\section{Exercise 3}

On a separate sheet of a paper, restate your thesis from Note 9.52 "Exercise 2" of this section and then make some general concluding remarks. Next, compose a final emphatic statement. Finally, incorporate what you have written into a strong conclusion paragraph for your essay.

\section{Collaboration}

Please share with a classmate and compare your answers

Mariah incorporates some of these pointers into her conclusion. She has paraphrased her thesis statement in the first sentence. 
In a society fixated on the latest and smartest digital technology, a consumer can easily become confused by the countless options and specifications. The ever-changing state of digital technology challenges consumers with its updates and add-ons and expanding markets and incompatible formats and restrictions-a fact that is complicated by salesmen who want to sell them anything. In a world that is increasingly driven by instant gratification, it's easy for people to buy the first thing they see. The solution for many people should be to avoid buying on impulse. Consumers should think about what they really need, not what is advertised.

Tip

Make sure your essay is balanced by not having an excessively long or short introduction or conclusion. Check that they match each other in length as closely as possible, and try to mirror the formula you used in each. Parallelism strengthens the message of your essay.

\section{Writing at Work}

On the job you will sometimes give oral presentations based on research you have conducted. A concluding statement to an oral report contains the same elements as a written conclusion. You should wrap up your presentation by restating the purpose of the presentation, reviewing its main points, and emphasizing the importance of the material you presented. A strong conclusion will leave a lasting impression on your audience.

\section{Key Takeaways}

- A strong opening captures your readers' interest and introduces them to your topic before you present your thesis statement.

- An introduction should restate your thesis, review your main points, and emphasize the importance of the topic.

- The funnel technique to writing the introduction begins with generalities and gradually narrows your focus until you present your thesis.

- A good introduction engages people's emotions or logic, questions or explains the subject, or provides a striking image or quotation.

- Carefully chosen diction in both the introduction and conclusion prevents any confusing or boring ideas.

- A conclusion that does not connect to the rest of the essay can diminish the effect of your paper.

- The conclusion should remain true to your thesis statement. It is best to avoid changing your tone or your main idea and avoid introducing any new material. 
383 [Author removed at request of original publisher]

- Closing with a final emphatic statement provides closure for your readers and makes your essay more memorable. 


\subsection{Writing Essays: End-of-Chapter Exercises}

\section{Exercises}

1. On a separate sheet of paper, choose one of the examples of a proper thesis statement from this chapter (one that interests you) and form three supporting points for that statement. After you have formed your three points, write a topic sentence for each body paragraph. Make sure that your topic sentences can be backed up with examples and details.

2. Group activity. Choose one of the topics from Note 9.5 "Exercise 1" in Section 9.1 "Developing a Strong, Clear Thesis Statement" and form a yes-or-no question about that topic. Then, take a survey of the people in your class to find out how they feel about the subject. Using the majority vote, ask those people to write on slips of paper the reasons for their opinion. Using the data you collect, form a thesis statement based on your classmates' perspectives on the topic and their reasons.

3. On a separate sheet of a paper, write an introduction for an essay based on the thesis statement from the group activity using the techniques for introductory paragraphs that you learned in this chapter.

4. Start a journal in which you record "spoken" thesis statements. Start listening closely to the opinions expressed by your teachers, classmates, friends, and family members. Ask them to provide at least three reasons for their opinion and record them in the journal. Use this as material for future essays.

5. Open a magazine and read a lengthy article. See if you can pinpoint the thesis statement as well as the topic sentence for each paragraph and its supporting details. 


\section{Chapter 10: Rhetorical Modes}

10.1 Narration

10.2 Illustration

10.3 Description

10.4 Classification

10.5 Process Analysis

10.6 Definition

10.7 Comparison and Contrast

10.8 Cause and Effect

10.9 Persuasion

10.10 Rhetorical Modes: End-of-Chapter Exercises 


\subsection{Narration}

\section{Learning Objectives}

1. Determine the purpose and structure of narrative writing.

2. Understand how to write a narrative essay.

Rhetorical modes simply mean the ways in which we can effectively communicate through language. This chapter covers nine common rhetorical modes. As you read about these nine modes, keep in mind that the rhetorical mode a writer chooses depends on his or her purpose for writing. Sometimes writers incorporate a variety of modes in any one essay. In covering the nine modes, this chapter also emphasizes the rhetorical modes as a set of tools that will allow you greater flexibility and effectiveness in communicating with your audience and expressing your ideas.

\section{The Purpose of Narrative Writing}

Narration means the art of storytelling, and the purpose of narrative writing is to tell stories. Any time you tell a story to a friend or family member about an event or incident in your day, you engage in a form of narration. In addition, a narrative can be factual or fictional. A factual story is one that is based on, and tries to be faithful to, actual events as they unfolded in real life. A fictional story is a made-up, or imagined, story; the writer of a fictional story can create characters and events as he or she sees fit.

The big distinction between factual and fictional narratives is based on a writer's purpose. The writers of factual stories try to recount events as they actually happened, but writers of fictional stories can depart from real people and events because the writers' intents are not to retell a real-life event. Biographies and memoirs are examples of factual stories, whereas novels and short stories are examples of fictional stories.

\section{Tip}

Because the line between fact and fiction can often blur, it is helpful to understand what your purpose is from the beginning. Is it important that you recount history, either your own or someone else's? Or does your interest lie in reshaping the world in your own image-either how you would like to see it or how you imagine it could be? Your answers will go a long way in shaping the stories you tell. 
Ultimately, whether the story is fact or fiction, narrative writing tries to relay a series of events in an emotionally engaging way. You want your audience to be moved by your story, which could mean through laughter, sympathy, fear, anger, and so on. The more clearly you tell your story, the more emotionally engaged your audience is likely to be.

\section{Exercise 1}

On a separate sheet of paper, start brainstorming ideas for a narrative. First, decide whether you want to write a factual or fictional story. Then, freewrite for five minutes. Be sure to use all five minutes, and keep writing the entire time. Do not stop and think about what to write.

The following are some topics to consider as you get going:

1. Childhood

2. School

3. Adventure

4. Work

5. Love

6. Family

7. Friends

8. Vacation

9. Nature

10. Space

\section{The Structure of a Narrative Essay}

Major narrative events are most often conveyed in chronological order, the order in which events unfold from first to last. Stories typically have a beginning, a middle, and an end, and these events are typically organized by time. Certain transitional words and phrases aid in keeping the reader oriented in the sequencing of a story. Some of these phrases are listed in Table 10.1 "Transition Words and Phrases for Expressing Time”. For more information about chronological order, see Chapter 8 "The Writing Process: How Do I Begin?” and Chapter 9 “Writing Essays: From Start to Finish”. 


\begin{tabular}{|l|l|l|l|}
\hline after/afterward & as soon as & at last & before \\
\hline currently & during & eventually & meanwhile \\
\hline next & now & since & soon \\
\hline finally & later & still & then \\
\hline until & when/whenever & while & first, second, third \\
\hline
\end{tabular}

The following are the other basic components of a narrative:

- Plot. The events as they unfold in sequence.

- Characters. The people who inhabit the story and move it forward. Typically, there are minor characters and main characters. The minor characters generally play supporting roles to the main character, or the protagonist.

- Conflict. The primary problem or obstacle that unfolds in the plot that the protagonist must solve or overcome by the end of the narrative. The way in which the protagonist resolves the conflict of the plot results in the theme of the narrative.

- Theme. The ultimate message the narrative is trying to express; it can be either explicit or implicit.

\section{Writing at Work}

When interviewing candidates for jobs, employers often ask about conflicts or problems a potential employee has had to overcome. They are asking for a compelling personal narrative. To prepare for this question in a job interview, write out a scenario using the narrative mode structure. This will allow you to troubleshoot rough spots, as well as better understand your own personal history. Both processes will make your story better and your self-presentation better, too.

\section{Exercise 2}

Take your freewriting exercise from the last section and start crafting it chronologically into a rough plot summary. To read more about a summary, see Chapter 6 "Writing Paragraphs: Separating Ideas and Shaping Content". Be sure to use the time transition words and phrases listed in Table 10.1 "Transition Words and Phrases for Expressing Time” to sequence the events.

\section{Collaboration}

Please share with a classmate and compare your rough plot summary. 


\section{Writing a Narrative Essay}

When writing a narrative essay, start by asking yourself if you want to write a factual or fictional story. Then freewrite about topics that are of general interest to you. For more information about freewriting, see Chapter 8 “The Writing Process: How Do I Begin?”.

Once you have a general idea of what you will be writing about, you should sketch out the major events of the story that will compose your plot. Typically, these events will be revealed chronologically and climax at a central conflict that must be resolved by the end of the story. The use of strong details is crucial as you describe the events and characters in your narrative. You want the reader to emotionally engage with the world that you create in writing.

\section{Tip}

To create strong details, keep the human senses in mind. You want your reader to be immersed in the world that you create, so focus on details related to sight, sound, smell, taste, and touch as you describe people, places, and events in your narrative.

As always, it is important to start with a strong introduction to hook your reader into wanting to read more. Try opening the essay with an event that is interesting to introduce the story and get it going. Finally, your conclusion should help resolve the central conflict of the story and impress upon your reader the ultimate theme of the piece. See Chapter 15 "Readings: Examples of Essays" to read a sample narrative essay.

\section{Exercise 3}

On a separate sheet of paper, add two or three paragraphs to the plot summary you started in the last section. Describe in detail the main character and the setting of the first scene. Try to use all five senses in your descriptions.

\section{Key Takeaways}

- Narration is the art of storytelling.

- Narratives can be either factual or fictional. In either case, narratives should emotionally engage the reader.

- Most narratives are composed of major events sequenced in chronological order. 
- Time transition words and phrases are used to orient the reader in the sequence of a narrative.

- The four basic components to all narratives are plot, character, conflict, and theme.

- The use of sensory details is crucial to emotionally engaging the reader.

- A strong introduction is important to hook the reader. A strong conclusion should add resolution to the conflict and evoke the narrative's theme. 


\subsection{Illustration}

\section{Learning Objectives}

1. Determine the purpose and structure of the illustration essay.

2. Understand how to write an illustration essay.

\section{The Purpose of Illustration in Writing}

To illustrate means to show or demonstrate something clearly. An effective illustration essay clearly demonstrates and supports a point through the use of evidence.

As you learned in Chapter 9 "Writing Essays: From Start to Finish", the controlling idea of an essay is called a thesis. A writer can use different types of evidence to support his or her thesis. Using scientific studies, experts in a particular field, statistics, historical events, current events, analogies, and personal anecdotes are all ways in which a writer can illustrate a thesis. Ultimately, you want the evidence to help the reader "see" your point, as one would see a good illustration in a magazine or on a website. The stronger your evidence is, the more clearly the reader will consider your point.

Using evidence effectively can be challenging, though. The evidence you choose will usually depend on your subject and who your reader is (your audience). When writing an illustration essay, keep in mind the following:

- Use evidence that is appropriate to your topic as well as appropriate for your audience.

- Assess how much evidence you need to adequately explain your point depending on the complexity of the subject and the knowledge of your audience regarding that subject.

For example, if you were writing about a new communication software and your audience was a group of English-major undergrads, you might want to use an analogy or a personal story to illustrate how the software worked. You might also choose to add a few more pieces of evidence to make sure the audience understands your point. However, if you were writing about the same subject and you audience members were information technology (IT) specialists, you would likely use more technical evidence because they would be familiar with the subject.

Keeping in mind your subject in relation to your audience will increase your chances of effectively illustrating your point. 
Tip

You never want to insult your readers' intelligence by overexplaining concepts the audience members may already be familiar with, but it may be necessary to clearly articulate your point. When in doubt, add an extra example to illustrate your idea.

\section{Exercise 1}

On a separate piece of paper, form a thesis based on each of the following three topics. Then list the types of evidence that would best explain your point for each of the two audiences.

1. Topic: Combat and mental health

Audience: family members of veterans, doctors

2. Topic: Video games and teen violence

Audience: parents, children

3. Topic: Architecture and earthquakes

Audience: engineers, local townspeople

\section{The Structure of an Illustration Essay}

The controlling idea, or thesis, belongs at the beginning of the essay. Evidence is then presented in the essay's body paragraphs to support the thesis. You can start supporting your main point with your strongest evidence first, or you can start with evidence of lesser importance and have the essay build to increasingly stronger evidence. This type of organization-order of importance-you learned about in Chapter 8 "The Writing Process: How Do I Begin?" and Chapter 9 "Writing Essays: From Start to Finish".

The time transition words listed in Table 10.1 “Transition Words and Phrases for Expressing Time" are also helpful in ordering the presentation of evidence. Words like first, second, third, currently, next, and finally all help orient the reader and sequence evidence clearly. Because an illustration essay uses so many examples, it is also helpful to have a list of words and phrases to present each piece of evidence. Table 10.2 "Phrases of Illustration" provides a list of phrases for illustration. 


\begin{tabular}{|l|l|}
\hline case in point & for example \\
\hline for instance & in particular \\
\hline in this case & one example/another example \\
\hline specifically & to illustrate \\
\hline
\end{tabular}

\section{Tip}

Vary the phrases of illustration you use. Do not rely on just one. Variety in choice of words and phrasing is critical when trying to keep readers engaged in your writing and your ideas.

\section{Writing at Work}

In the workplace, it is often helpful to keep the phrases of illustration in mind as a way to incorporate them whenever you can. Whether you are writing out directives that colleagues will have to follow or requesting a new product or service from another company, making a conscious effort to incorporate a phrase of illustration will force you to provide examples of what you mean.

\section{Exercise 2}

On a separate sheet of paper, form a thesis based on one of the following topics. Then support that thesis with three pieces of evidence. Make sure to use a different phrase of illustration to introduce each piece of evidence you choose.

1. Cooking

2. Baseball

3. Work hours

4. Exercise

5. Traffic

\section{Collaboration}

Please share with a classmate and compare your answers. Discuss which topic you like the best or would like to learn more about. Indicate which thesis statement you perceive as the most effective. 


\section{Writing an Illustration Essay}

First, decide on a topic that you feel interested in writing about. Then create an interesting introduction to engage the reader. The main point, or thesis, should be stated at the end of the introduction.

Gather evidence that is appropriate to both your subject and your audience. You can order the evidence in terms of importance, either from least important to most important or from most important to least important. Be sure to fully explain all of your examples using strong, clear supporting details. See Chapter 15 "Readings: Examples of Essays" to read a sample illustration essay.

\section{Exercise 3}

On a separate sheet of paper, write a five-paragraph illustration essay. You can choose one of the topics from Note 10.23 "Exercise 1" or Note 10.27 "Exercise 2", or you can choose your own.

\section{Key Takeaways}

- An illustration essay clearly explains a main point using evidence.

- When choosing evidence, always gauge whether the evidence is appropriate for the subject as well as the audience.

- Organize the evidence in terms of importance, either from least important to most important or from most important to least important.

- Use time transitions to order evidence.

- Use phrases of illustration to call out examples. 


\subsection{Description}

\section{Learning Objectives}

1. Determine the purpose and structure of the description essay.

2. Understand how to write a description essay.

\section{The Purpose of Description in Writing}

Writers use description in writing to make sure that their audience is fully immersed in the words on the page. This requires a concerted effort by the writer to describe his or her world through the use of sensory details.

As mentioned earlier in this chapter, sensory details are descriptions that appeal to our sense of sight, sound, smell, taste, and touch. Your descriptions should try to focus on the five senses because we all rely on these senses to experience the world. The use of sensory details, then, provides you the greatest possibility of relating to your audience and thus engaging them in your writing, making descriptive writing important not only during your education but also during everyday situations.

\section{Tip}

Avoid empty descriptors if possible. Empty descriptors are adjectives that can mean different things to different people. Good, beautiful, terrific, and nice are examples. The use of such words in descriptions can lead to misreads and confusion. A good day, for instance, can mean far different things depending on one's age, personality, or tastes.

\section{Writing at Work}

Whether you are presenting a new product or service to a client, training new employees, or brainstorming ideas with colleagues, the use of clear, evocative detail is crucial. Make an effort to use details that express your thoughts in a way that will register with others. Sharp, concise details are always impressive. 


\section{Exercise 1}

On a separate sheet of paper, describe the following five items in a short paragraph. Use at least three of the five senses for each description.

1. Night

2. Beach

3. City

4. Dinner

5. Stranger

\section{The Structure of a Description Essay}

Description essays typically describe a person, a place, or an object using sensory details. The structure of a descriptive essay is more flexible than in some of the other rhetorical modes. The introduction of a description essay should set up the tone and point of the essay. The thesis should convey the writer's overall impression of the person, place, or object described in the body paragraphs.

The organization of the essay may best follow spatial order, an arrangement of ideas according to physical characteristics or appearance. Depending on what the writer describes, the organization could move from top to bottom, left to right, near to far, warm to cold, frightening to inviting, and so on.

For example, if the subject were a client's kitchen in the midst of renovation, you might start at one side of the room and move slowly across to the other end, describing appliances, cabinetry, and so on. Or you might choose to start with older remnants of the kitchen and progress to the new installations. Maybe start with the floor and move up toward the ceiling.

\section{Exercise 2}

On a separate sheet of paper, choose an organizing strategy and then execute it in a short paragraph for three of the following six items:

1. Train station

2. Your office

3. Your car

4. A coffee shop

5. Lobby of a movie theater 
6. Mystery Option*

*Choose an object to describe but do not indicate it. Describe it, but preserve the mystery.

\section{Writing a Description Essay}

Choosing a subject is the first step in writing a description essay. Once you have chosen the person, place, or object you want to describe, your challenge is to write an effective thesis statement to guide your essay.

The remainder of your essay describes your subject in a way that best expresses your thesis. Remember, you should have a strong sense of how you will organize your essay. Choose a strategy and stick to it.

Every part of your essay should use vivid sensory details. The more you can appeal to your readers' senses, the more they will be engaged in your essay. See Chapter 15 "Readings: Examples of Essays" to read a sample description essay.

\section{Exercise 3}

On a separate sheet of paper, choose one of the topics that you started in Note 10.37 "Exercise 2", and expand it into a five-paragraph essay. Expanding on ideas in greater detail can be difficult. Sometimes it is helpful to look closely at each of the sentences in a summary paragraph. Those sentences can often serve as topic sentences to larger paragraphs.

Mystery Option: Here is an opportunity to collaborate. Please share with a classmate and compare your thoughts on the mystery descriptions. Did your classmate correctly guess your mystery topic? If not, how could you provide more detail to describe it and lead them to the correct conclusion?

\section{Key Takeaways}

- Description essays should describe something vividly to the reader using strong sensory details.

- Sensory details appeal to the five human senses: sight, sound, smell, taste, and touch.

- A description essay should start with the writer's main impression of a person, a place, or an object.

- Use spatial order to organize your descriptive writing. 


\subsection{Classification}

\section{Learning Objectives}

1. Determine the purpose and structure of the classification essay.

2. Understand how to write a classification essay.

\section{The Purpose of Classification in Writing}

The purpose of classification is to break down broad subjects into smaller, more manageable, more specific parts. We classify things in our daily lives all the time, often without even thinking about it. Cell phones, for example, have now become part of a broad category. They can be classified as feature phones, media phones, and smartphones.

Smaller categories, and the way in which these categories are created, help us make sense of the world. Keep both of these elements in mind when writing a classification essay.

Tip

Choose topics that you know well when writing classification essays. The more you know about a topic, the more you can break it into smaller, more interesting parts. Adding interest and insight will enhance your classification essays.

\section{Exercise 1}

On a separate sheet of paper, break the following categories into smaller classifications.

1. The United States

2. Colleges and universities

3. Beverages

4. Fashion 


\section{The Structure of a Classification Essay}

The classification essay opens with an introductory paragraph that introduces the broader topic. The thesis should then explain how that topic is divided into subgroups and why. Take the following introductory paragraph, for example:

When people think of New York, they often think of only New York City. But New York is actually a diverse state with a full range of activities to do, sights to see, and cultures to explore. In order to better understand the diversity of New York state, it is helpful to break it into these five separate regions: Long Island, New York City, Western New York, Central New York, and Northern New York.

The underlined thesis explains not only the category and subcategory but also the rationale for breaking it into those categories. Through this classification essay, the writer hopes to show his or her readers a different way of considering the state.

Each body paragraph of a classification essay is dedicated to fully illustrating each of the subcategories. In the previous example, then, each region of New York would have its own paragraph.

The conclusion should bring all the categories and subcategories back together again to show the reader the big picture. In the previous example, the conclusion might explain how the various sights and activities of each region of New York add to its diversity and complexity.

\section{Tip}

To avoid settling for an overly simplistic classification, make sure you break down any given topic at least three different ways. This will help you think outside the box and perhaps even learn something entirely new about a subject.

\section{Exercise 2}

Using your classifications from Note 10.43 "Exercise 1", write a brief paragraph explaining why you chose to organize each main category in the way that you did.

\section{Writing a Classification Essay}

Start with an engaging opening that will adequately introduce the general topic that you will be dividing 
into smaller subcategories. Your thesis should come at the end of your introduction. It should include the topic, your subtopics, and the reason you are choosing to break down the topic in the way that you are. Use the following classification thesis equation:

topic + subtopics + rationale for the subtopics $=$ thesis.

The organizing strategy of a classification essay is dictated by the initial topic and the subsequent subtopics. Each body paragraph is dedicated to fully illustrating each of the subtopics. In a way, coming up with a strong topic pays double rewards in a classification essay. Not only do you have a good topic, but you also have a solid organizational structure within which to write.

Be sure you use strong details and explanations for each subcategory paragraph that help explain and support your thesis. Also, be sure to give examples to illustrate your points. Finally, write a conclusion that links all the subgroups together again. The conclusion should successfully wrap up your essay by connecting it to your topic initially discussed in the introduction. See Chapter 15 "Readings: Examples of Essays" to read a sample classification essay.

\section{Exercise 3}

Building on Note 10.43 "Exercise 1" and Note 10.46 "Exercise 2", write a five-paragraph classification essay about one of the four original topics. In your thesis, make sure to include the topic, subtopics, and rationale for your breakdown. And make sure that your essay is organized into paragraphs that each describes a subtopic.

\section{Key Takeaways}

- The purpose of classification is to break a subject into smaller, more manageable, more specific parts.

- Smaller subcategories help us make sense of the world, and the way in which these subcategories are created also helps us make sense of the world.

- A classification essay is organized by its subcategories. 


\subsection{Process Analysis}

\section{Learning Objectives}

1. Determine the purpose and structure of the process analysis essay.

2. Understand how to write a process analysis essay.

\section{The Purpose of Process Analysis in Writing}

The purpose of a process analysis essay is to explain how to do something or how something works. In either case, the formula for a process analysis essay remains the same. The process is articulated into clear, definitive steps.

Almost everything we do involves following a step-by-step process. From riding a bike as children to learning various jobs as adults, we initially needed instructions to effectively execute the task. Likewise, we have likely had to instruct others, so we know how important good directions are-and how frustrating it is when they are poorly put together.

\section{Writing at Work}

The next time you have to explain a process to someone at work, be mindful of how clearly you articulate each step. Strong communication skills are critical for workplace satisfaction and advancement. Effective process analysis plays a critical role in developing that skill set.

\section{Exercise 1}

On a separate sheet of paper, make a bulleted list of all the steps that you feel would be required to clearly illustrate three of the following four processes:

1. Tying a shoelace

2. Parallel parking

3. Planning a successful first date 
4. Being an effective communicator

\section{The Structure of a Process Analysis Essay}

The process analysis essay opens with a discussion of the process and a thesis statement that states the goal of the process.

The organization of a process analysis essay typically follows chronological order. The steps of the process are conveyed in the order in which they usually occur. Body paragraphs will be constructed based on these steps. If a particular step is complicated and needs a lot of explaining, then it will likely take up a paragraph on its own. But if a series of simple steps is easier to understand, then the steps can be grouped into a single paragraph.

The time transition phrases covered in the Narration and Illustration sections are also helpful in organizing process analysis essays (see Table 10.1 "Transition Words and Phrases for Expressing Time" and Table 10.2 "Phrases of Illustration"). Words such as first, second, third, next, and finally are helpful cues to orient reader and organize the content of essay.

Tip

Always have someone else read your process analysis to make sure it makes sense. Once we get too close to a subject, it is difficult to determine how clearly an idea is coming across. Having a friend or coworker read it over will serve as a good way to troubleshoot any confusing spots.

\section{Exercise 2}

Choose two of the lists you created in Note 10.52 "Exercise 1" and start writing out the processes in paragraph form. Try to construct paragraphs based on the complexity of each step. For complicated steps, dedicate an entire paragraph. If less complicated steps fall in succession, group them into a single paragraph.

\section{Writing a Process Analysis Essay}

Choose a topic that is interesting, is relatively complex, and can be explained in a series of steps. As with other rhetorical writing modes, choose a process that you know well so that you can more easily 
describe the finer details about each step in the process. Your thesis statement should come at the end of your introduction, and it should state the final outcome of the process you are describing.

Body paragraphs are composed of the steps in the process. Each step should be expressed using strong details and clear examples. Use time transition phrases to help organize steps in the process and to orient readers. The conclusion should thoroughly describe the result of the process described in the body paragraphs. See Chapter 15 "Readings: Examples of Essays" to read an example of a process analysis essay.

\section{Exercise 3}

Choose one of the expanded lists from Note 10.54 "Exercise 2". Construct a full process analysis essay from the work you have already done. That means adding an engaging introduction, a clear thesis, time transition phrases, body paragraphs, and a solid conclusion.

\section{Key Takeaways}

- A process analysis essay explains how to do something, how something works, or both.

- The process analysis essay opens with a discussion of the process and a thesis statement that states the outcome of the process.

- The organization of a process analysis essay typically follows a chronological sequence.

- Time transition phrases are particularly helpful in process analysis essays to organize steps and orient reader. 


\subsection{Definition}

\section{Learning Objectives}

1. Determine the purpose and structure of the definition essay.

2. Understand how to write a definition essay.

\section{The Purpose of Definition in Writing}

The purpose of a definition essay may seem self-explanatory: the purpose of the definition essay is to simply define something. But defining terms in writing is often more complicated than just consulting a dictionary. In fact, the way we define terms can have far-reaching consequences for individuals as well as collective groups.

Take, for example, a word like alcoholism. The way in which one defines alcoholism depends on its legal, moral, and medical contexts. Lawyers may define alcoholism in terms of its legality; parents may define alcoholism in terms of its morality; and doctors will define alcoholism in terms of symptoms and diagnostic criteria. Think also of terms that people tend to debate in our broader culture. How we define words, such as marriage and climate change, has enormous impact on policy decisions and even on daily decisions. Think about conversations couples may have in which words like commitment, respect, or love need clarification.

Defining terms within a relationship, or any other context, can at first be difficult, but once a definition is established between two people or a group of people, it is easier to have productive dialogues. Definitions, then, establish the way in which people communicate ideas. They set parameters for a given discourse, which is why they are so important.

\section{Tip}

When writing definition essays, avoid terms that are too simple, that lack complexity. Think in terms of concepts, such as hero, immigration, or loyalty, rather than physical objects. Definitions of concepts, rather than objects, are often fluid and contentious, making for a more effective definition essay. 


\section{Writing at Work}

Definitions play a critical role in all workplace environments. Take the term sexual harassment, for example. Sexual harassment is broadly defined on the federal level, but each company may have additional criteria that define it further. Knowing how your workplace defines and treats all sexual harassment allegations is important. Think, too, about how your company defines lateness, productivity, or contributions.

\section{Exercise 1}

On a separate sheet of paper, write about a time in your own life in which the definition of a word, or the lack of a definition, caused an argument. Your term could be something as simple as the category of an all-star in sports or how to define a good movie. Or it could be something with higher stakes and wider impact, such as a political argument. Explain how the conversation began, how the argument hinged on the definition of the word, and how the incident was finally resolved.

\section{Collaboration}

Please share with a classmate and compare your responses.

\section{The Structure of a Definition Essay}

The definition essay opens with a general discussion of the term to be defined. You then state as your thesis your definition of the term.

The rest of the essay should explain the rationale for your definition. Remember that a dictionary's definition is limiting, and you should not rely strictly on the dictionary entry. Instead, consider the context in which you are using the word. Context identifies the circumstances, conditions, or setting in which something exists or occurs. Often words take on different meanings depending on the context in which they are used. For example, the ideal leader in a battlefield setting could likely be very different than a leader in an elementary school setting. If a context is missing from the essay, the essay may be too short or the main points could be confusing or misunderstood.

The remainder of the essay should explain different aspects of the term's definition. For example, if you were defining a good leader in an elementary classroom setting, you might define such a leader according to personality traits: patience, consistency, and flexibility. Each attribute would be explained in its own paragraph. 
Tip

For definition essays, try to think of concepts that you have a personal stake in. You are more likely to write a more engaging definition essay if you are writing about an idea that has personal value and importance.

\section{Writing at Work}

It is a good idea to occasionally assess your role in the workplace. You can do this through the process of definition. Identify your role at work by defining not only the routine tasks but also those gray areas where your responsibilities might overlap with those of others. Coming up with a clear definition of roles and responsibilities can add value to your résumé and even increase productivity in the workplace.

\section{Exercise 2}

On a separate sheet of paper, define each of the following items in your own terms. If you can, establish a context for your definition.

1. Bravery

2. Adulthood

3. Consumer culture

4. Violence

5. Art

\section{Writing a Definition Essay}

Choose a topic that will be complex enough to be discussed at length. Choosing a word or phrase of personal relevance often leads to a more interesting and engaging essay.

After you have chosen your word or phrase, start your essay with an introduction that establishes the relevancy of the term in the chosen specific context. Your thesis comes at the end of the introduction, and it should clearly state your definition of the term in the specific context. Establishing a functional context from the beginning will orient readers and minimize misunderstandings.

The body paragraphs should each be dedicated to explaining a different facet of your definition. Make sure to use clear examples and strong details to illustrate your points. Your concluding paragraph should 
pull together all the different elements of your definition to ultimately reinforce your thesis. See Chapter 15 "Readings: Examples of Essays" to read a sample definition essay.

\section{Exercise 3}

Create a full definition essay from one of the items you already defined in Note 10.64 "Exercise 2". Be sure to include an interesting introduction, a clear thesis, a well-explained context, distinct body paragraphs, and a conclusion that pulls everything together.

\section{Key Takeaways}

- Definitions establish the way in which people communicate ideas. They set parameters for a given discourse.

- Context affects the meaning and usage of words.

- The thesis of a definition essay should clearly state the writer's definition of the term in the specific context.

- Body paragraphs should explain the various facets of the definition stated in the thesis.

- The conclusion should pull all the elements of the definition together at the end and reinforce the thesis. 


\subsection{Comparison and Contrast}

\section{Learning Objectives}

1. Determine the purpose and structure of comparison and contrast in writing.

2. Explain organizational methods used when comparing and contrasting.

3. Understand how to write a compare-and-contrast essay.

\section{The Purpose of Comparison and Contrast in Writing}

Comparison in writing discusses elements that are similar, while contrast in writing discusses elements that are different. A compare-and-contrast essay, then, analyzes two subjects by comparing them, contrasting them, or both.

The key to a good compare-and-contrast essay is to choose two or more subjects that connect in a meaningful way. The purpose of conducting the comparison or contrast is not to state the obvious but rather to illuminate subtle differences or unexpected similarities. For example, if you wanted to focus on contrasting two subjects you would not pick apples and oranges; rather, you might choose to compare and contrast two types of oranges or two types of apples to highlight subtle differences. For example, Red Delicious apples are sweet, while Granny Smiths are tart and acidic. Drawing distinctions between elements in a similar category will increase the audience's understanding of that category, which is the purpose of the compare-and-contrast essay.

Similarly, to focus on comparison, choose two subjects that seem at first to be unrelated. For a comparison essay, you likely would not choose two apples or two oranges because they share so many of the same properties already. Rather, you might try to compare how apples and oranges are quite similar. The more divergent the two subjects initially seem, the more interesting a comparison essay will be.

\section{Writing at Work}

Comparing and contrasting is also an evaluative tool. In order to make accurate evaluations about a given topic, you must first know the critical points of similarity and difference. Comparing and contrasting is a primary tool for many workplace assessments. You have likely compared and contrasted yourself to other colleagues. Employee advancements, pay raises, hiring, and firing are typically conducted using comparison and contrast. Comparison and contrast could be used to evaluate companies, departments, or individuals. 


\section{Exercise 1}

Brainstorm an essay that leans toward contrast. Choose one of the following three categories. Pick two examples from each. Then come up with one similarity and three differences between the examples.

1. Romantic comedies

2. Internet search engines

3. Cell phones

\section{Exercise 2}

Brainstorm an essay that leans toward comparison. Choose one of the following three items. Then come up with one difference and three similarities.

1. Department stores and discount retail stores

2. Fast food chains and fine dining restaurants

3. Dogs and cats

\section{The Structure of a Comparison and Contrast Essay}

The compare-and-contrast essay starts with a thesis that clearly states the two subjects that are to be compared, contrasted, or both and the reason for doing so. The thesis could lean more toward comparing, contrasting, or both. Remember, the point of comparing and contrasting is to provide useful knowledge to the reader. Take the following thesis as an example that leans more toward contrasting.

Thesis statement: Organic vegetables may cost more than those that are conventionally grown, but when put to the test, they are definitely worth every extra penny.

Here the thesis sets up the two subjects to be compared and contrasted (organic versus conventional vegetables), and it makes a claim about the results that might prove useful to the reader.

You may organize compare-and-contrast essays in one of the following two ways:

1. According to the subjects themselves, discussing one then the other

2. According to individual points, discussing each subject in relation to each point 
See Figure 10.1 “Comparison and Contrast Diagram”, which diagrams the ways to organize our organic versus conventional vegetables thesis.

Figure 10.1 Comparison and Contrast Diagram

\section{Organize by Subject:}

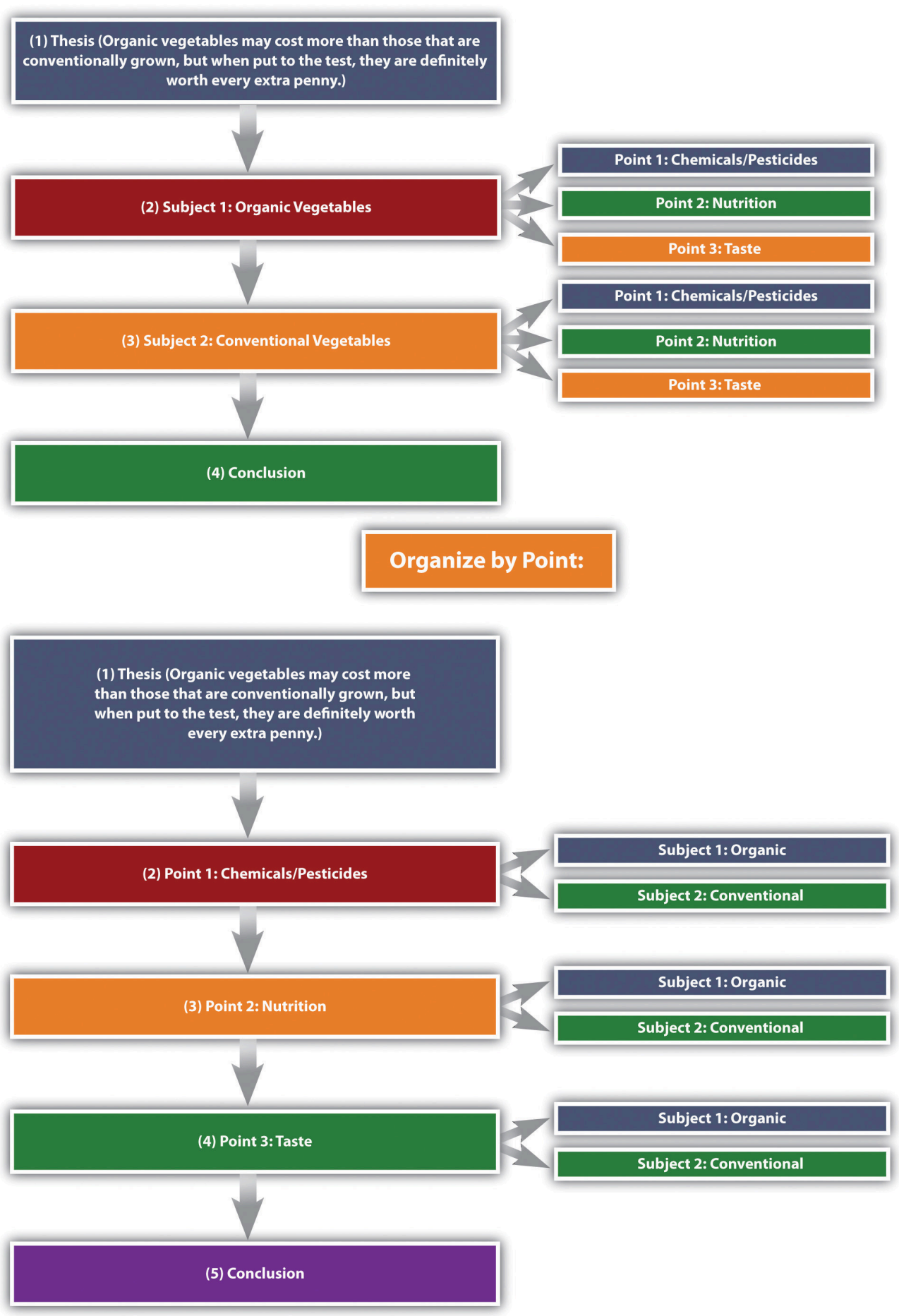

The organizational structure you choose depends on the nature of the topic, your purpose, and your 
audience.

Given that compare-and-contrast essays analyze the relationship between two subjects, it is helpful to have some phrases on hand that will cue the reader to such analysis. See Table 10.3 "Phrases of Comparison and Contrast” for examples.

Table 10.3 Phrases of Comparison and Contrast

\begin{tabular}{|l|l|}
\hline Comparison & Contrast \\
\hline one similarity & one difference \\
\hline another similarity & another difference \\
\hline both & conversely \\
\hline like & in contrast \\
\hline likewise & unlike \\
\hline similarly & while \\
\hline in a similar fashion & whereas \\
\hline
\end{tabular}

\section{Exercise 3}

Create an outline for each of the items you chose in Note 10.72 "Exercise 1" and Note 10.73 "Exercise 2". Use the point-by-point organizing strategy for one of them, and use the subject organizing strategy for the other.

\section{Writing a Comparison and Contrast Essay}

First choose whether you want to compare seemingly disparate subjects, contrast seemingly similar subjects, or compare and contrast subjects. Once you have decided on a topic, introduce it with an engaging opening paragraph. Your thesis should come at the end of the introduction, and it should establish the subjects you will compare, contrast, or both as well as state what can be learned from doing so.

The body of the essay can be organized in one of two ways: by subject or by individual points. The organizing strategy that you choose will depend on, as always, your audience and your purpose. You may also consider your particular approach to the subjects as well as the nature of the subjects themselves; some subjects might better lend themselves to one structure or the other. Make sure to use comparison and contrast phrases to cue the reader to the ways in which you are analyzing the relationship between the subjects. 
After you finish analyzing the subjects, write a conclusion that summarizes the main points of the essay and reinforces your thesis. See Chapter 15 "Readings: Examples of Essays" to read a sample compareand-contrast essay.

\section{Writing at Work}

Many business presentations are conducted using comparison and contrast. The organizing strategies-by subject or individual points - could also be used for organizing a presentation. Keep this in mind as a way of organizing your content the next time you or a colleague have to present something at work.

\section{Exercise 4}

Choose one of the outlines you created in Note 10.75 "Exercise 3", and write a full compare-and-contrast essay. Be sure to include an engaging introduction, a clear thesis, well-defined and detailed paragraphs, and a fitting conclusion that ties everything together.

\section{Key Takeaways}

- A compare-and-contrast essay analyzes two subjects by either comparing them, contrasting them, or both.

- The purpose of writing a comparison or contrast essay is not to state the obvious but rather to illuminate subtle differences or unexpected similarities between two subjects.

- The thesis should clearly state the subjects that are to be compared, contrasted, or both, and it should state what is to be learned from doing so.

- There are two main organizing strategies for compare-and-contrast essays.

1. Organize by the subjects themselves, one then the other.

2. Organize by individual points, in which you discuss each subject in relation to each point.

- Use phrases of comparison or phrases of contrast to signal to readers how exactly the two subjects are being analyzed. 


\subsection{Cause and Effect}

\section{Learning Objectives}

1. Determine the purpose and structure of cause and effect in writing.

2. Understand how to write a cause-and-effect essay.

\section{The Purpose of Cause and Effect in Writing}

It is often considered human nature to ask, "why?” and "how?” We want to know how our child got sick so we can better prevent it from happening in the future, or why our colleague a pay raise because we want one as well. We want to know how much money we will save over the long term if we buy a hybrid car. These examples identify only a few of the relationships we think about in our lives, but each shows the importance of understanding cause and effect.

A cause is something that produces an event or condition; an effect is what results from an event or condition. The purpose of the cause-and-effect essay is to determine how various phenomena relate in terms of origins and results. Sometimes the connection between cause and effect is clear, but often determining the exact relationship between the two is very difficult. For example, the following effects of a cold may be easily identifiable: a sore throat, runny nose, and a cough. But determining the cause of the sickness can be far more difficult. A number of causes are possible, and to complicate matters, these possible causes could have combined to cause the sickness. That is, more than one cause may be responsible for any given effect. Therefore, cause-and-effect discussions are often complicated and frequently lead to debates and arguments.

Tip

Use the complex nature of cause and effect to your advantage. Often it is not necessary, or even possible, to find the exact cause of an event or to name the exact effect. So, when formulating a thesis, you can claim one of a number of causes or effects to be the primary, or main, cause or effect. As soon as you claim that one cause or one effect is more crucial than the others, you have developed a thesis. 


\section{Exercise 1}

Consider the causes and effects in the following thesis statements. List a cause and effect for each one on your own sheet of paper.

1. The growing childhood obesity epidemic is a result of technology.

2. Much of the wildlife is dying because of the oil spill.

3. The town continued programs that it could no longer afford, so it went bankrupt.

4. More young people became politically active as use of the Internet spread throughout society.

5. While many experts believed the rise in violence was due to the poor economy, it was really due to the summer-long heat wave.

\section{Exercise 2}

Write three cause-and-effect thesis statements of your own for each of the following five broad topics.

1. Health and nutrition

2. Sports

3. Media

4. Politics

5. History

\section{The Structure of a Cause-and-Effect Essay}

The cause-and-effect essay opens with a general introduction to the topic, which then leads to a thesis that states the main cause, main effect, or various causes and effects of a condition or event.

The cause-and-effect essay can be organized in one of the following two primary ways:

1. Start with the cause and then talk about the effects.

2. Start with the effect and then talk about the causes.

For example, if your essay were on childhood obesity, you could start by talking about the effect of childhood obesity and then discuss the cause or you could start the same essay by talking about the cause of childhood obesity and then move to the effect.

Regardless of which structure you choose, be sure to explain each element of the essay fully and 
completely. Explaining complex relationships requires the full use of evidence, such as scientific studies, expert testimony, statistics, and anecdotes.

Because cause-and-effect essays determine how phenomena are linked, they make frequent use of certain words and phrases that denote such linkage. See Table 10.4 "Phrases of Causation" for examples of such terms.

Table 10.4 Phrases of Causation

\begin{tabular}{|l|l|}
\hline as a result & consequently \\
\hline because & due to \\
\hline hence & since \\
\hline thus & therefore \\
\hline
\end{tabular}

The conclusion should wrap up the discussion and reinforce the thesis, leaving the reader with a clear understanding of the relationship that was analyzed.

Tip

Be careful of resorting to empty speculation. In writing, speculation amounts to unsubstantiated guessing. Writers are particularly prone to such trappings in cause-and-effect arguments due to the complex nature of finding links between phenomena. Be sure to have clear evidence to support the claims that you make.

\section{Exercise 3}

Look at some of the cause-and-effect relationships from Note 10.83 "Exercise 2". Outline the links you listed. Outline one using a cause-then-effect structure. Outline the other using the effect-then-cause structure.

\section{Writing a Cause-and-Effect Essay}

Choose an event or condition that you think has an interesting cause-and-effect relationship. Introduce your topic in an engaging way. End your introduction with a thesis that states the main cause, the main effect, or both.

Organize your essay by starting with either the cause-then-effect structure or the effect-then-cause structure. Within each section, you should clearly explain and support the causes and effects using a full range of evidence. If you are writing about multiple causes or multiple effects, you may choose to 
sequence either in terms of order of importance. In other words, order the causes from least to most important (or vice versa), or order the effects from least important to most important (or vice versa).

Use the phrases of causation when trying to forge connections between various events or conditions. This will help organize your ideas and orient the reader. End your essay with a conclusion that summarizes your main points and reinforces your thesis. See Chapter 15 "Readings: Examples of Essays” to read a sample cause-and-effect essay.

\section{Exercise 4}

Choose one of the ideas you outlined in Note 10.85 "Exercise 3" and write a full cause-and-effect essay. Be sure to include an engaging introduction, a clear thesis, strong evidence and examples, and a thoughtful conclusion.

\section{Key Takeaways}

- The purpose of the cause-and-effect essay is to determine how various phenomena are related.

- The thesis states what the writer sees as the main cause, main effect, or various causes and effects of a condition or event.

- The cause-and-effect essay can be organized in one of these two primary ways:

1. Start with the cause and then talk about the effect.

2. Start with the effect and then talk about the cause.

- Strong evidence is particularly important in the cause-and-effect essay due to the complexity of determining connections between phenomena.

- Phrases of causation are helpful in signaling links between various elements in the essay. 


\subsection{Persuasion}

\section{Learning Objectives}

1. Determine the purpose and structure of persuasion in writing.

2. Identify bias in writing.

3. Assess various rhetorical devices.

4. Distinguish between fact and opinion.

5. Understand the importance of visuals to strengthen arguments.

6. Write a persuasive essay.

\section{The Purpose of Persuasive Writing}

The purpose of persuasion in writing is to convince, motivate, or move readers toward a certain point of view, or opinion. The act of trying to persuade automatically implies more than one opinion on the subject can be argued.

The idea of an argument often conjures up images of two people yelling and screaming in anger. In writing, however, an argument is very different. An argument is a reasoned opinion supported and explained by evidence. To argue in writing is to advance knowledge and ideas in a positive way. Written arguments often fail when they employ ranting rather than reasoning.

\section{Tip}

Most of us feel inclined to try to win the arguments we engage in. On some level, we all want to be right, and we want others to see the error of their ways. More times than not, however, arguments in which both sides try to win end up producing losers all around. The more productive approach is to persuade your audience to consider your opinion as a valid one, not simply the right one.

\section{The Structure of a Persuasive Essay}

The following five features make up the structure of a persuasive essay: 
1. Introduction and thesis

2. Opposing and qualifying ideas

3. Strong evidence in support of claim

4. Style and tone of language

5. A compelling conclusion

\section{Creating an Introduction and Thesis}

The persuasive essay begins with an engaging introduction that presents the general topic. The thesis typically appears somewhere in the introduction and states the writer's point of view.

\section{Tip}

Avoid forming a thesis based on a negative claim. For example, "The hourly minimum wage is not high enough for the average worker to live on.” This is probably a true statement, but persuasive arguments should make a positive case. That is, the thesis statement should focus on how the hourly minimum wage is low or insufficient.

\section{Acknowledging Opposing Ideas and Limits to Your Argument}

Because an argument implies differing points of view on the subject, you must be sure to acknowledge those opposing ideas. Avoiding ideas that conflict with your own gives the reader the impression that you may be uncertain, fearful, or unaware of opposing ideas. Thus it is essential that you not only address counterarguments but also do so respectfully.

Try to address opposing arguments earlier rather than later in your essay. Rhetorically speaking, ordering your positive arguments last allows you to better address ideas that conflict with your own, so you can spend the rest of the essay countering those arguments. This way, you leave your reader thinking about your argument rather than someone else’s. You have the last word.

Acknowledging points of view different from your own also has the effect of fostering more credibility between you and the audience. They know from the outset that you are aware of opposing ideas and that you are not afraid to give them space.

It is also helpful to establish the limits of your argument and what you are trying to accomplish. In effect, you are conceding early on that your argument is not the ultimate authority on a given topic. Such humility can go a long way toward earning credibility and trust with an audience. Audience members will know from the beginning that you are a reasonable writer, and audience members will trust your argument as a result. For example, in the following concessionary statement, the writer advocates for 
stricter gun control laws, but she admits it will not solve all of our problems with crime:

Although tougher gun control laws are a powerful first step in decreasing violence in our streets, such legislation alone cannot end these problems since guns are not the only problem we face.

Such a concession will be welcome by those who might disagree with this writer's argument in the first place. To effectively persuade their readers, writers need to be modest in their goals and humble in their approach to get readers to listen to the ideas. See Table 10.5 "Phrases of Concession" for some useful phrases of concession.

Table 10.5 Phrases of Concession

\begin{tabular}{|l|l|}
\hline although & granted that \\
\hline of course & still \\
\hline though & yet \\
\hline
\end{tabular}

\section{Exercise 1}

Try to form a thesis for each of the following topics. Remember the more specific your thesis, the better.

1. Foreign policy

2. Television and advertising

3. Stereotypes and prejudice

4. Gender roles and the workplace

5. Driving and cell phones

\section{Collaboration}

Please share with a classmate and compare your answers. Choose the thesis statement that most interests you and discuss why.

\section{Bias in Writing}

Everyone has various biases on any number of topics. For example, you might have a bias toward wearing black instead of brightly colored clothes or wearing jeans rather than formal wear. You might have a bias toward working at night rather than in the morning, or working by deadlines rather than getting tasks done in advance. These examples identify minor biases, of course, but they still indicate preferences and opinions. 
Handling bias in writing and in daily life can be a useful skill. It will allow you to articulate your own points of view while also defending yourself against unreasonable points of view. The ideal in persuasive writing is to let your reader know your bias, but do not let that bias blind you to the primary components of good argumentation: sound, thoughtful evidence and a respectful and reasonable address of opposing sides.

The strength of a personal bias is that it can motivate you to construct a strong argument. If you are invested in the topic, you are more likely to care about the piece of writing. Similarly, the more you care, the more time and effort you are apt to put forth and the better the final product will be.

The weakness of bias is when the bias begins to take over the essay-when, for example, you neglect opposing ideas, exaggerate your points, or repeatedly insert yourself ahead of the subject by using $I$ too often. Being aware of all three of these pitfalls will help you avoid them.

\section{The Use of I in Writing}

The use of $I$ in writing is often a topic of debate, and the acceptance of its usage varies from instructor to instructor. It is difficult to predict the preferences for all your present and future instructors, but consider the effects it can potentially have on your writing.

Be mindful of the use of $I$ in your writing because it can make your argument sound overly biased. There are two primary reasons:

1. Excessive repetition of any word will eventually catch the reader's attention — and usually not in a good way. The use of $I$ is no different.

2. The insertion of $I$ into a sentence alters not only the way a sentence might sound but also the composition of the sentence itself. $I$ is often the subject of a sentence. If the subject of the essay is supposed to be, say, smoking, then by inserting yourself into the sentence, you are effectively displacing the subject of the essay into a secondary position. In the following example, the subject of the sentence is underlined:

Smoking is bad.

I think smoking is bad.

In the first sentence, the rightful subject, smoking, is in the subject position in the sentence. In the second sentence, the insertion of $I$ and think replaces smoking as the subject, which draws attention to $I$ and away from the topic that is supposed to be discussed. Remember to keep the message (the subject) and the messenger (the writer) separate. 


\section{Checklist}

Developing Sound Arguments

Does my essay contain the following elements?

- An engaging introduction

- A reasonable, specific thesis that is able to be supported by evidence

- A varied range of evidence from credible sources

- Respectful acknowledgement and explanation of opposing ideas

- A style and tone of language that is appropriate for the subject and audience

- Acknowledgement of the argument's limits

- A conclusion that will adequately summarize the essay and reinforce the thesis

\section{Fact and Opinion}

$\underline{\text { Facts }}$ are statements that can be definitely proven using objective data. The statement that is a fact is absolutely valid. In other words, the statement can be pronounced as true or false. For example, $2+2=$ 4. This expression identifies a true statement, or a fact, because it can be proved with objective data.

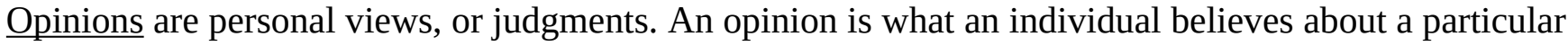
subject. However, an opinion in argumentation must have legitimate backing; adequate evidence and credibility should support the opinion. Consider the credibility of expert opinions. Experts in a given field have the knowledge and credentials to make their opinion meaningful to a larger audience.

For example, you seek the opinion of your dentist when it comes to the health of your gums, and you seek the opinion of your mechanic when it comes to the maintenance of your car. Both have knowledge and credentials in those respective fields, which is why their opinions matter to you. But the authority of your dentist may be greatly diminished should he or she offer an opinion about your car, and vice versa.

In writing, you want to strike a balance between credible facts and authoritative opinions. Relying on one or the other will likely lose more of your audience than it gains.

\section{Tip}

The word prove is frequently used in the discussion of persuasive writing. Writers may claim that one piece of evidence or another proves the argument, but proving an argument is often not possible. No evidence proves a debatable topic one way or the other; that is why the topic is debatable. Facts can be proved, but opinions can only be supported, explained, and persuaded. 


\section{Exercise 2}

On a separate sheet of paper, take three of the theses you formed in Note 10.94 "Exercise 1", and list the types of evidence you might use in support of that thesis.

\section{Exercise 3}

Using the evidence you provided in support of the three theses in Note 10.100 "Exercise 2", come up with at least one counterargument to each. Then write a concession statement, expressing the limits to each of your three arguments.

\section{Using Visual Elements to Strengthen Arguments}

Adding visual elements to a persuasive argument can often strengthen its persuasive effect. There are two main types of visual elements: quantitative visuals and qualitative visuals.

Quantitative visuals present data graphically. They allow the audience to see statistics spatially. The purpose of using quantitative visuals is to make logical appeals to the audience. For example, sometimes it is easier to understand the disparity in certain statistics if you can see how the disparity looks graphically. Bar graphs, pie charts, Venn diagrams, histograms, and line graphs are all ways of presenting quantitative data in spatial dimensions.

Qualitative visuals present images that appeal to the audience's emotions. Photographs and pictorial images are examples of qualitative visuals. Such images often try to convey a story, and seeing an actual example can carry more power than hearing or reading about the example. For example, one image of a child suffering from malnutrition will likely have more of an emotional impact than pages dedicated to describing that same condition in writing.

\section{Writing at Work}

When making a business presentation, you typically have limited time to get across your idea. Providing visual elements for your audience can be an effective timesaving tool. Quantitative visuals in business presentations serve the same purpose as they do in persuasive writing. They should make logical appeals by showing numerical data in a spatial design. Quantitative visuals should be pictures that might appeal to your audience's emotions. You will find that many of the rhetorical devices used in writing are the same ones used in the workplace. For more information about visuals in presentations, see Chapter 14 "Creating Presentations: Sharing Your Ideas". 


\section{Writing a Persuasive Essay}

Choose a topic that you feel passionate about. If your instructor requires you to write about a specific topic, approach the subject from an angle that interests you. Begin your essay with an engaging introduction. Your thesis should typically appear somewhere in your introduction.

Start by acknowledging and explaining points of view that may conflict with your own to build credibility and trust with your audience. Also state the limits of your argument. This too helps you sound more reasonable and honest to those who may naturally be inclined to disagree with your view. By respectfully acknowledging opposing arguments and conceding limitations to your own view, you set a measured and responsible tone for the essay.

Make your appeals in support of your thesis by using sound, credible evidence. Use a balance of facts and opinions from a wide range of sources, such as scientific studies, expert testimony, statistics, and personal anecdotes. Each piece of evidence should be fully explained and clearly stated.

Make sure that your style and tone are appropriate for your subject and audience. Tailor your language and word choice to these two factors, while still being true to your own voice.

Finally, write a conclusion that effectively summarizes the main argument and reinforces your thesis. See Chapter 15 "Readings: Examples of Essays” to read a sample persuasive essay.

\section{Exercise 4}

Choose one of the topics you have been working on throughout this section. Use the thesis, evidence, opposing argument, and concessionary statement as the basis for writing a full persuasive essay. Be sure to include an engaging introduction, clear explanations of all the evidence you present, and a strong conclusion.

\section{Key Takeaways}

- The purpose of persuasion in writing is to convince or move readers toward a certain point of view, or opinion.

- An argument is a reasoned opinion supported and explained by evidence. To argue, in writing, is to advance knowledge and ideas in a positive way.

- A thesis that expresses the opinion of the writer in more specific terms is better than one that is vague.

- It is essential that you not only address counterarguments but also do so respectfully.

- It is also helpful to establish the limits of your argument and what you are trying to accomplish through a concession statement. 
- To persuade a skeptical audience, you will need to use a wide range of evidence. Scientific studies, opinions from experts, historical precedent, statistics, personal anecdotes, and current events are all types of evidence that you might use in explaining your point.

- Make sure that your word choice and writing style is appropriate for both your subject and your audience.

- You should let your reader know your bias, but do not let that bias blind you to the primary components of good argumentation: sound, thoughtful evidence and respectfully and reasonably addressing opposing ideas.

- You should be mindful of the use of $I$ in your writing because it can make your argument sound more biased than it needs to.

- Facts are statements that can be proven using objective data.

- Opinions are personal views, or judgments, that cannot be proven.

- In writing, you want to strike a balance between credible facts and authoritative opinions.

- Quantitative visuals present data graphically. The purpose of using quantitative visuals is to make logical appeals to the audience.

- Qualitative visuals present images that appeal to the audience's emotions. 


\subsection{Rhetorical Modes: End-of-Chapter Exercises}

\section{Exercises}

1. The thesis statement is a fundamental element of writing regardless of what rhetorical mode you are writing in. Formulate one more thesis for each of the modes discussed in this chapter.

2. Which rhetorical mode seems most aligned with who you are as a person? That is, which mode seems most useful to you? Explain why in a paragraph.

3. Over the next week, look closely at the texts and articles you read. Document in a journal exactly what type of rhetorical mode is being used. Sometimes it might be for an entire article, but sometimes you might see different modes within one article. The more you can detect various ways of communicating ideas, the easier it will be to do yourself. 


\section{Chapter 11: Writing from Research: What Will I Learn?}

11.1 The Purpose of Research Writing

11.2 Steps in Developing a Research Proposal

11.3 Managing Your Research Project

11.4 Strategies for Gathering Reliable Information

11.5 Critical Thinking and Research Applications

11.6 Writing from Research: End-of-Chapter Exercises 


\subsection{The Purpose of Research Writing}

\section{Learning Objectives}

1. Identify reasons to research writing projects.

2. Outline the steps of the research writing process.

Why was the Great Wall of China built? What have scientists learned about the possibility of life on Mars? What roles did women play in the American Revolution? How does the human brain create, store, and retrieve memories? Who invented the game of football, and how has it changed over the years?

You may know the answers to these questions off the top of your head. If you are like most people, however, you find answers to tough questions like these by searching the Internet, visiting the library, or asking others for information. To put it simply, you perform research.

Whether you are a scientist, an artist, a paralegal, or a parent, you probably perform research in your everyday life. When your boss, your instructor, or a family member asks you a question that you do not know the answer to, you locate relevant information, analyze your findings, and share your results. Locating, analyzing, and sharing information are key steps in the research process, and in this chapter, you will learn more about each step. By developing your research writing skills, you will prepare yourself to answer any question no matter how challenging.

\section{Reasons for Research}

When you perform research, you are essentially trying to solve a mystery-you want to know how something works or why something happened. In other words, you want to answer a question that you (and other people) have about the world. This is one of the most basic reasons for performing research.

But the research process does not end when you have solved your mystery. Imagine what would happen if a detective collected enough evidence to solve a criminal case, but she never shared her solution with the authorities. Presenting what you have learned from research can be just as important as performing the research. Research results can be presented in a variety of ways, but one of the most popular-and effective-presentation forms is the research paper. A research paper presents an original thesis, or purpose statement, about a topic and develops that thesis with information gathered from a variety of sources.

If you are curious about the possibility of life on Mars, for example, you might choose to research the topic. What will you do, though, when your research is complete? You will need a way to put your 
thoughts together in a logical, coherent manner. You may want to use the facts you have learned to create a narrative or to support an argument. And you may want to show the results of your research to your friends, your teachers, or even the editors of magazines and journals. Writing a research paper is an ideal way to organize thoughts, craft narratives or make arguments based on research, and share your newfound knowledge with the world.

\section{Exercise 1}

Write a paragraph about a time when you used research in your everyday life. Did you look for the cheapest way to travel from Houston to Denver? Did you search for a way to remove gum from the bottom of your shoe? In your paragraph, explain what you wanted to research, how you performed the research, and what you learned as a result.

\section{Research Writing and the Academic Paper}

No matter what field of study you are interested in, you will most likely be asked to write a research paper during your academic career. For example, a student in an art history course might write a research paper about an artist's work. Similarly, a student in a psychology course might write a research paper about current findings in childhood development.

Having to write a research paper may feel intimidating at first. After all, researching and writing a long paper requires a lot of time, effort, and organization. However, writing a research paper can also be a great opportunity to explore a topic that is particularly interesting to you. The research process allows you to gain expertise on a topic of your choice, and the writing process helps you remember what you have learned and understand it on a deeper level.

\section{Research Writing at Work}

Knowing how to write a good research paper is a valuable skill that will serve you well throughout your career. Whether you are developing a new product, studying the best way to perform a procedure, or learning about challenges and opportunities in your field of employment, you will use research techniques to guide your exploration. You may even need to create a written report of your findings. And because effective communication is essential to any company, employers seek to hire people who can write clearly and professionally. 


\section{Writing at Work}

Take a few minutes to think about each of the following careers. How might each of these professionals use researching and research writing skills on the job?

- Medical laboratory technician

- Small business owner

- Information technology professional

- Freelance magazine writer

A medical laboratory technician or information technology professional might do research to learn about the latest technological developments in either of these fields. A small business owner might conduct research to learn about the latest trends in his or her industry. A freelance magazine writer may need to research a given topic to write an informed, up-to-date article.

\section{Exercise 2}

Think about the job of your dreams. How might you use research writing skills to perform that job? Create a list of ways in which strong researching, organizing, writing, and critical thinking skills could help you succeed at your dream job. How might these skills help you obtain that job?

\section{Steps of the Research Writing Process}

How does a research paper grow from a folder of brainstormed notes to a polished final draft? No two projects are identical, but most projects follow a series of six basic steps.

These are the steps in the research writing process:

1. Choose a topic.

2. Plan and schedule time to research and write.

3. Conduct research.

4. Organize research and ideas.

5. Draft your paper.

6. Revise and edit your paper.

Each of these steps will be discussed in more detail later in this chapter. For now, though, we will take a brief look at what each step involves. 


\section{Step 1: Choosing a Topic}

As you may recall from Chapter 8 "The Writing Process: How Do I Begin?", to narrow the focus of your topic, you may try freewriting exercises, such as brainstorming. You may also need to ask a specific research question - a broad, open-ended question that will guide your research—as well as propose a possible answer, or a working thesis. You may use your research question and your working thesis to create a research proposal. In a research proposal, you present your main research question, any related subquestions you plan to explore, and your working thesis.

\section{Step 2: Planning and Scheduling}

Before you start researching your topic, take time to plan your researching and writing schedule. Research projects can take days, weeks, or even months to complete. Creating a schedule is a good way to ensure that you do not end up being overwhelmed by all the work you have to do as the deadline approaches.

During this step of the process, it is also a good idea to plan the resources and organizational tools you will use to keep yourself on track throughout the project. Flowcharts, calendars, and checklists can all help you stick to your schedule. See Chapter 11 "Writing from Research: What Will I Learn?”, $\underline{\text { Section }}$ 11.2 "Steps in Developing a Research Proposal” for an example of a research schedule.

\section{Step 3: Conducting Research}

When going about your research, you will likely use a variety of sources-anything from books and periodicals to video presentations and in-person interviews.

Your sources will include both primary sources and secondary sources. Primary sources provide firsthand information or raw data. For example, surveys, in-person interviews, and historical documents are primary sources. Secondary sources, such as biographies, literary reviews, or magazine articles, include some analysis or interpretation of the information presented. As you conduct research, you will

take detailed, careful notes about your discoveries. You will also evaluate the reliability of each source you find.

\section{Step 4: Organizing Research and the Writer's Ideas}

When your research is complete, you will organize your findings and decide which sources to cite in your paper. You will also have an opportunity to evaluate the evidence you have collected and determine whether it supports your thesis, or the focus of your paper. You may decide to adjust your thesis or conduct additional research to ensure that your thesis is well supported. 
Tip

Remember, your working thesis is not set in stone. You can and should change your working thesis throughout the research writing process if the evidence you find does not support your original thesis. Never try to force evidence to fit your argument. For example, your working thesis is "Mars cannot support lifeforms." Yet, a week into researching your topic, you find an article in the New York Times detailing new findings of bacteria under the Martian surface. Instead of trying to argue that bacteria are not life forms, you might instead alter your thesis to "Mars cannot support complex life-forms."

\section{Step 5: Drafting Your Paper}

Now you are ready to combine your research findings with your critical analysis of the results in a rough draft. You will incorporate source materials into your paper and discuss each source thoughtfully in relation to your thesis or purpose statement.

When you cite your reference sources, it is important to pay close attention to standard conventions for citing sources in order to avoid plagiarism, or the practice of using someone else's words without acknowledging the source. Later in this chapter, you will learn how to incorporate sources in your paper and avoid some of the most common pitfalls of attributing information.

\section{Step 6: Revising and Editing Your Paper}

In the final step of the research writing process, you will revise and polish your paper. You might reorganize your paper's structure or revise for unity and cohesion, ensuring that each element in your paper flows into the next logically and naturally. You will also make sure that your paper uses an appropriate and consistent tone.

Once you feel confident in the strength of your writing, you will edit your paper for proper spelling, grammar, punctuation, mechanics, and formatting. When you complete this final step, you will have transformed a simple idea or question into a thoroughly researched and well-written paper you can be proud of!

\section{Exercise 3}

Review the steps of the research writing process. Then answer the questions on your own sheet of paper.

1. In which steps of the research writing process are you allowed to change your thesis? 
2. In step 2, which types of information should you include in your project schedule?

3. What might happen if you eliminated step 4 from the research writing process?

\section{Key Takeaways}

- People undertake research projects throughout their academic and professional careers in order to answer specific questions, share their findings with others, increase their understanding of challenging topics, and strengthen their researching, writing, and analytical skills.

- The research writing process generally comprises six steps: choosing a topic, scheduling and planning time for research and writing, conducting research, organizing research and ideas, drafting a paper, and revising and editing the paper. 


\subsection{Steps in Developing a Research Proposal}

\section{Learning Objectives}

1. Identify the steps in developing a research proposal.

2. Choose a topic and formulate a research question and working thesis.

3. Develop a research proposal.

Writing a good research paper takes time, thought, and effort. Although this assignment is challenging, it is manageable. Focusing on one step at a time will help you develop a thoughtful, informative, wellsupported research paper.

Your first step is to choose a topic and then to develop research questions, a working thesis, and a written research proposal. Set aside adequate time for this part of the process. Fully exploring ideas will help you build a solid foundation for your paper.

\section{Choosing a Topic}

When you choose a topic for a research paper, you are making a major commitment. Your choice will help determine whether you enjoy the lengthy process of research and writing - and whether your final paper fulfills the assignment requirements. If you choose your topic hastily, you may later find it difficult to work with your topic. By taking your time and choosing carefully, you can ensure that this assignment is not only challenging but also rewarding.

Writers understand the importance of choosing a topic that fulfills the assignment requirements and fits the assignment's purpose and audience. (For more information about purpose and audience, see Chapter 6 "Writing Paragraphs: Separating Ideas and Shaping Content".) Choosing a topic that interests you is also crucial. You instructor may provide a list of suggested topics or ask that you develop a topic on your own. In either case, try to identify topics that genuinely interest you.

After identifying potential topic ideas, you will need to evaluate your ideas and choose one topic to pursue. Will you be able to find enough information about the topic? Can you develop a paper about this topic that presents and supports your original ideas? Is the topic too broad or too narrow for the scope of the assignment? If so, can you modify it so it is more manageable? You will ask these questions during this preliminary phase of the research process. 


\section{Identifying Potential Topics}

Sometimes, your instructor may provide a list of suggested topics. If so, you may benefit from identifying several possibilities before committing to one idea. It is important to know how to narrow down your ideas into a concise, manageable thesis. You may also use the list as a starting point to help you identify additional, related topics. Discussing your ideas with your instructor will help ensure that you choose a manageable topic that fits the requirements of the assignment.

In this chapter, you will follow a writer named Jorge, who is studying health care administration, as he prepares a research paper. You will also plan, research, and draft your own research paper.

Jorge was assigned to write a research paper on health and the media for an introductory course in health care. Although a general topic was selected for the students, Jorge had to decide which specific issues interested him. He brainstormed a list of possibilities.

\section{Tip}

If you are writing a research paper for a specialized course, look back through your notes and course activities. Identify reading assignments and class discussions that especially engaged you. Doing so can help you identify topics to pursue.

\section{$\underline{\text { Possible Topics }}$}

1. Health Maintenance Organizations (HMOs) in the news

2. Sexual education programs

3. Hollywood and eating disorders

4. Americans' access to public health information

5. Media portrayal of health care reform bill

6. Depictions of drugs on television

7. The effect of the Internet on mental health

8. Popularized diets (such as low-carbohydrate diets)

9. Fear of pandemics (bird flu, HINI, SARS)

10. Electronic entertainment and obesity

11. Advertisements for prescription drugs

12. Public education and disease prevention 


\section{Exercise 1}

Set a timer for five minutes. Use brainstorming or idea mapping to create a list of topics you would be interested in researching for a paper about the influence of the Internet on social networking. Do you closely follow the media coverage of a particular website, such as Twitter? Would you like to learn more about a certain industry, such as online dating? Which social networking sites do you and your friends use? List as many ideas related to this topic as you can.

\section{Narrowing Your Topic}

Once you have a list of potential topics, you will need to choose one as the focus of your essay. You will also need to narrow your topic. Most writers find that the topics they listed during brainstorming or idea mapping are broad - too broad for the scope of the assignment. Working with an overly broad topic, such as sexual education programs or popularized diets, can be frustrating and overwhelming. Each topic has so many facets that it would be impossible to cover them all in a college research paper. However, more specific choices, such as the pros and cons of sexual education in kids' television programs or the physical effects of the South Beach diet, are specific enough to write about without being too narrow to sustain an entire research paper.

A good research paper provides focused, in-depth information and analysis. If your topic is too broad, you will find it difficult to do more than skim the surface when you research it and write about it. Narrowing your focus is essential to making your topic manageable. To narrow your focus, explore your topic in writing, conduct preliminary research, and discuss both the topic and the research with others.

\section{Exploring Your Topic in Writing}

“How am I supposed to narrow my topic when I haven’t even begun researching yet?” In fact, you may already know more than you realize. Review your list and identify your top two or three topics. Set aside some time to explore each one through freewriting. (For more information about freewriting, see Chapter 8 “The Writing Process: How Do I Begin?".) Simply taking the time to focus on your topic may yield fresh angles.

Jorge knew that he was especially interested in the topic of diet fads, but he also knew that it was much too broad for his assignment. He used freewriting to explore his thoughts so he could narrow his topic. Read Jorge's ideas.

Our instructors are always saying that accurate, up-to-date information is crucial in encouraging people to make better choices about their health. I don’t think the media does a very good job of providing that, though. Every time I go on the Internet, I see tons of ads for the latest “miracle food." One week it’s acai berries, the 
next week it's green tea, and then six months later I see a news story saying all the fabulous claims about acai berries and green tea are overblown! Advice about weight loss is even worse. Think about all the diet books that are out there! Some say that a low-fat diet is best; some say you should cut down on carbs; and some make bizarre recommendations like eating half a grapefruit with every meal. I don't know how anyone is supposed to make an informed decision about what to eat when there's so much confusing, contradictory information. I bet even doctors, nurses, and dietcians have trouble figuring out what information is reliable and what is just the latest hype.

\section{Conducting Preliminary Research}

Another way writers may focus a topic is to conduct preliminary research. Like freewriting, exploratory reading can help you identify interesting angles. Surfing the web and browsing through newspaper and magazine articles are good ways to start. Find out what people are saying about your topic on blogs and online discussion groups. Discussing your topic with others can also inspire you. Talk about your ideas with your classmates, your friends, or your instructor.

Jorge's freewriting exercise helped him realize that the assigned topic of health and the media intersected with a few of his interests - diet, nutrition, and obesity. Preliminary online research and discussions with his classmates strengthened his impression that many people are confused or misled by media coverage of these subjects.

Jorge decided to focus his paper on a topic that had garnered a great deal of media attention-lowcarbohydrate diets. He wanted to find out whether low-carbohydrate diets were as effective as their proponents claimed.

\section{Writing at Work}

At work, you may need to research a topic quickly to find general information. This information can be useful in understanding trends in a given industry or generating competition. For example, a company may research a competitor's prices and use the information when pricing their own product. You may find it useful to skim a variety of reliable sources and take notes on your findings.

\section{Tip}

The reliability of online sources varies greatly. In this exploratory phase of your research, you do not need to evaluate sources as closely as you will later. However, use common sense as you refine your paper topic. If you read a fascinating blog comment that gives you a new idea for your paper, be sure to check out other, more reliable sources as well to make sure the idea is worth pursuing. 


\section{Exercise 2}

Review the list of topics you created in Note 11.18 "Exercise 1" and identify two or three topics you would like to explore further. For each of these topics, spend five to ten minutes writing about the topic without stopping. Then review your writing to identify possible areas of focus.

Set aside time to conduct preliminary research about your potential topics. Then choose a topic to pursue for your research paper.

\section{Collaboration}

Please share your topic list with a classmate. Select one or two topics on his or her list that you would like to learn more about and return it to him or her. Discuss why you found the topics interesting, and learn which of your topics your classmate selected and why.

\section{A Plan for Research}

Your freewriting and preliminary research have helped you choose a focused, manageable topic for your research paper. To work with your topic successfully, you will need to determine what exactly you want to learn about it-and later, what you want to say about it. Before you begin conducting in-depth research, you will further define your focus by developing a research question, a working thesis, and a research proposal.

\section{Formulating a Research Question}

In forming a research question, you are setting a goal for your research. Your main research question should be substantial enough to form the guiding principle of your paper-but focused enough to guide your research. A strong research question requires you not only to find information but also to put together different pieces of information, interpret and analyze them, and figure out what you think. As you consider potential research questions, ask yourself whether they would be too hard or too easy to answer.

To determine your research question, review the freewriting you completed earlier. Skim through books, articles, and websites and list the questions you have. (You may wish to use the 5WH strategy to help you formulate questions. See Chapter 8 “The Writing Process: How Do I Begin?” for more information about 5WH questions.) Include simple, factual questions and more complex questions that would require analysis and interpretation. Determine your main question - the primary focus of your paper-and several subquestions that you will need to research to answer your main question.

Here are the research questions Jorge will use to focus his research. Notice that his main research question has no obvious, straightforward answer. Jorge will need to research his subquestions, which address narrower topics, to answer his main question. 
Topic:Main question: Are low-carbohydrate diets as effective as they have been portrayed to be by media sources?

\section{Subquestions:}

Who can benefit from following a low-carbohydrate diet?

What are the supposed advantages to following a low-carbohydrate diet?

When did low-carb diets become a "hot" topic in the media?

Where do average consumers get information about diet and nutrition?

Why has the low-carb approach received so much media attention?

How do low-carb diets work?

\section{Exercise 3}

Using the topic you selected in Note 11.24 "Exercise 2", write your main research question and at least four to five subquestions. Check that your main research question is appropriately complex for your assignment.

\section{Constructing a Working Thesls}

A working thesis concisely states a writer's initial answer to the main research question. It does not merely state a fact or present a subjective opinion. Instead, it expresses a debatable idea or claim that you hope to prove through additional research. Your working thesis is called a working thesis for a reason-it is subject to change. As you learn more about your topic, you may change your thinking in light of your research findings. Let your working thesis serve as a guide to your research, but do not be afraid to modify it based on what you learn.

Jorge began his research with a strong point of view based on his preliminary writing and research. Read his working thesis statement, which presents the point he will argue. Notice how it states Jorge's tentative answer to his research question.

Main research question: Are low-carb diets as effective as they have sometimes been portrayed to be by the mass media?

Working thesis statement: Low-car diets do not live up to the media hype surrounding them.

\section{Tip}

One way to determine your working thesis is to consider how you would complete sentences such as I believe or My opinion is. However, keep in mind that academic writing generally does not use first-person pronouns. These statements are useful starting points, but formal research papers use an objective voice. 


\section{Exercise 4}

Write a working thesis statement that presents your preliminary answer to the research question you wrote in Note 11.27 "Exercise 3". Check that your working thesis statement presents an idea or claim that could be supported or refuted by evidence from research.

\section{Creating a Research Proposal}

A research proposal is a brief document-no more than one typed page-that summarizes the preliminary work you have completed. Your purpose in writing it is to formalize your plan for research and present it to your instructor for feedback. In your research proposal, you will present your main research question, related subquestions, and working thesis. You will also briefly discuss the value of researching this topic and indicate how you plan to gather information.

When Jorge began drafting his research proposal, he realized that he had already created most of the pieces he needed. However, he knew he also had to explain how his research would be relevant to other future health care professionals. In addition, he wanted to form a general plan for doing the research and identifying potentially useful sources. Read Jorge’s research proposal. 


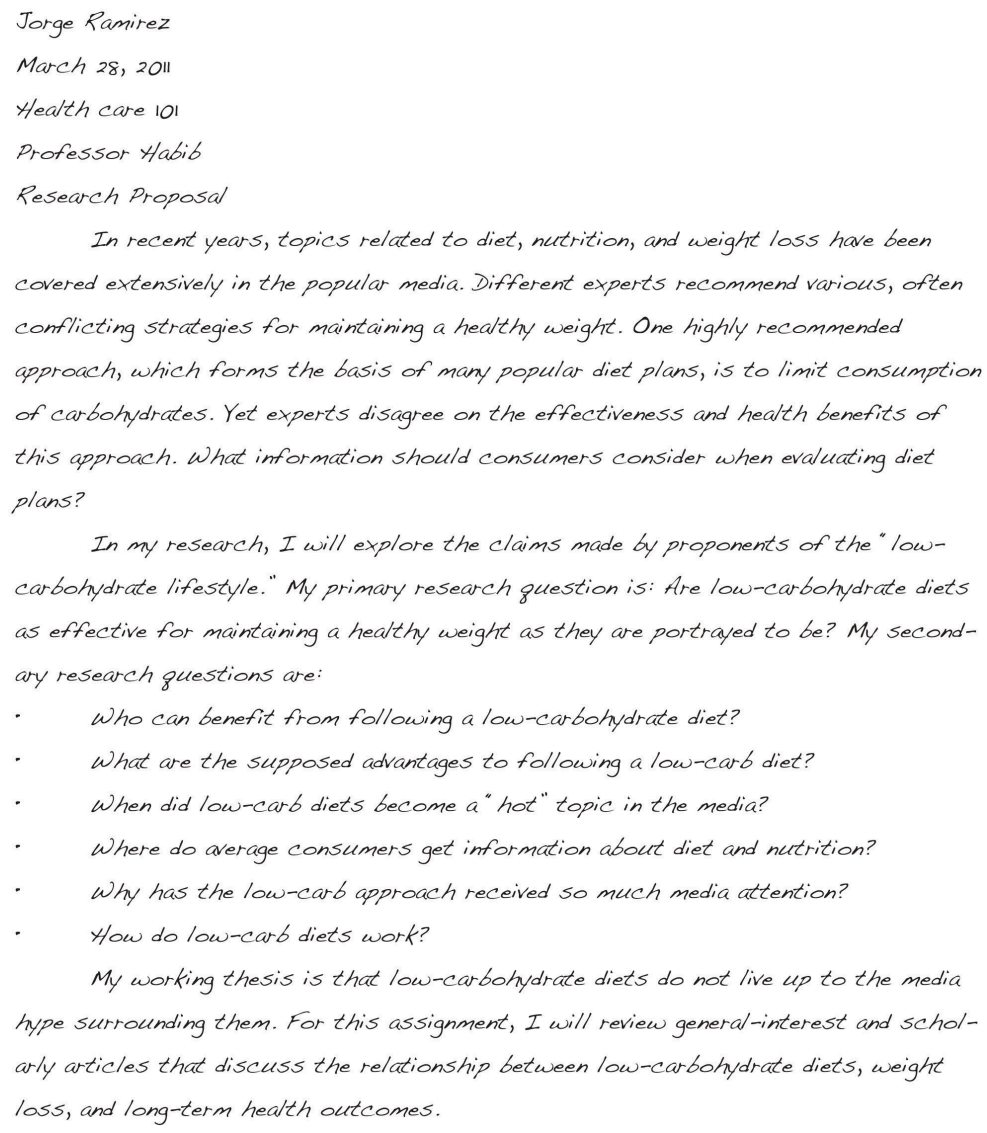

\section{Writing at Work}

Before you begin a new project at work, you may have to develop a project summary document that states the purpose of the project, explains why it would be a wise use of company resources, and briefly outlines the steps involved in completing the project. This type of document is similar to a research proposal. Both documents define and limit a project, explain its value, discuss how to proceed, and identify what resources you will use.

\section{Writing Your Own Research Proposal}

Now you may write your own research proposal, if you have not done so already. Follow the guidelines provided in this lesson. 


\section{Key Takeaways}

- Developing a research proposal involves the following preliminary steps: identifying potential ideas, choosing ideas to explore further, choosing and narrowing a topic, formulating a research question, and developing a working thesis.

- A good topic for a research paper interests the writer and fulfills the requirements of the assignment.

- Defining and narrowing a topic helps writers conduct focused, in-depth research.

- Writers conduct preliminary research to identify possible topics and research questions and to develop a working thesis.

- A good research question interests readers, is neither too broad nor too narrow, and has no obvious answer.

- A good working thesis expresses a debatable idea or claim that can be supported with evidence from research.

- Writers create a research proposal to present their topic, main research question, subquestions, and working thesis to an instructor for approval or feedback. 


\subsection{Managing Your Research Project}

\section{Learning Objectives}

1. Identify reasons for outlining the scope and sequence of a research project.

2. Recognize the steps of the research writing process.

3. Develop a plan for managing time and resources to complete the research project on time.

4. Identify organizational tools and strategies to use in managing the project.

The prewriting you have completed so far has helped you begin to plan the content of your research paper-your topic, research questions, and preliminary thesis. It is equally important to plan out the process of researching and writing the paper. Although some types of writing assignments can be completed relatively quickly, developing a good research paper is a complex process that takes time. Breaking it into manageable steps is crucial. Review the steps outlined at the beginning of this chapter.

Steps to Writing a Research Paper

1. Choose a topic.

2. Schedule and plan time for research and writing.

3. Conduct research.

4. Organize research

5. Draft your paper.

6. Revise and edit your paper.

You have already completed step 1 . In this section, you will complete step 2. The remaining steps fall under two broad categories - the research phase of the project (steps 3 and 4) and the writing phase (steps 5 and 6). Both phases present challenges. Understanding the tasks involved and allowing enough time to complete each task will help you complete your research paper on time with a minimal amount of stress.

\section{Planning Your Project}

Each step of a research project requires time and attention. Careful planning helps ensure that you will 
keep your project running smoothly and produce your best work. Set up a project schedule that shows when you will complete each step. Think about how you will complete each step and what project resources you will use. Resources may include anything from library databases and word-processing software to interview subjects and writing tutors.

To develop your schedule, use a calendar and work backward from the date your final draft is due. Generally, it is wise to divide half of the available time on the research phase of the project and half on the writing phase. For example, if you have a month to work, plan for two weeks for each phase. If you have a full semester, plan to begin research early and to start writing by the middle of the term. You might think that no one really works that far ahead, but try it. You will probably be pleased with the quality of your work and with the reduction in your stress level.

As you plan, break down major steps into smaller tasks if necessary. For example, step 3, conducting research, involves locating potential sources, evaluating their usefulness and reliability, reading, and taking notes. Defining these smaller tasks makes the project more manageable by giving you concrete goals to achieve.

Jorge had six weeks to complete his research project. Working backward from a due date of May 2, he mapped out a schedule for completing his research by early April so that he would have ample time to write. Jorge chose to write his schedule in his weekly planner to help keep himself on track.

Review Jorge's schedule. Key target dates are shaded. Note that Jorge planned times to use available resources by visiting the library and writing center and by meeting with his instructor.

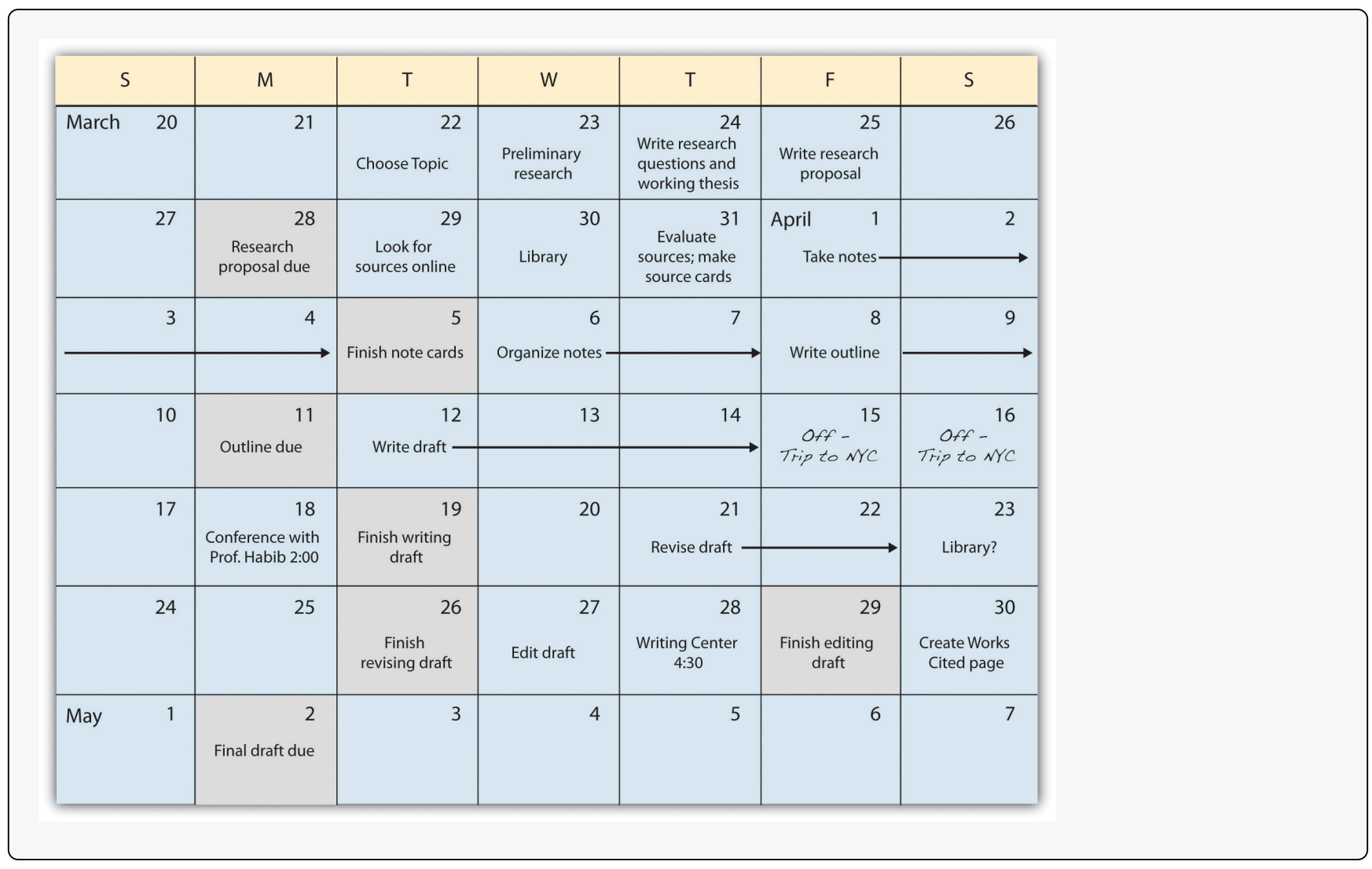




\section{Exercise 1}

1. Working backward from the date your final draft is due, create a project schedule. You may choose to write a sequential list of tasks or record tasks on a calendar.

2. Check your schedule to be sure that you have broken each step into smaller tasks and assigned a target completion date to each key task.

3. Review your target dates to make sure they are realistic. Always allow a little more time than you think you will actually need.

Tip

Plan your schedule realistically, and consider other commitments that may sometimes take precedence. A business trip or family visit may mean that you are unable to work on the research project for a few days. Make the most of the time you have available. Plan for unexpected interruptions, but keep in mind that a short time away from the project may help you come back to it with renewed enthusiasm. Another strategy many writers find helpful is to finish each day's work at a point when the next task is an easy one. That makes it easier to start again.

\section{Writing at Work}

When you create a project schedule at work, you set target dates for completing certain tasks and identify the resources you plan to use on the project. It is important to build in some flexibility. Materials may not be received on time because of a shipping delay. An employee on your team may be called away to work on a higher-priority project. Essential equipment may malfunction. You should always plan for the unexpected.

\section{Staying Organized}

Although setting up a schedule is easy, sticking to one is challenging. Even if you are the rare person who never procrastinates, unforeseen events may interfere with your ability to complete tasks on time. A self-imposed deadline may slip your mind despite your best intentions. Organizational tools_-calendars, checklists, note cards, software, and so forth—can help you stay on track.

Throughout your project, organize both your time and your resources systematically. Review your schedule frequently and check your progress. It helps to post your schedule in a place where you will see it every day. Both personal and workplace e-mail systems usually include a calendar feature where you can record tasks, arrange to receive daily reminders, and check off completed tasks. Electronic devices 
such as smartphones have similar features.

Organize project documents in a binder or electronic folder, and label project documents and folders clearly. Use note cards or an electronic document to record bibliographical information for each source you plan to use in your paper. Tracking this information throughout the research process can save you hours of time when you create your references page.

\section{Exercise 2}

Revisit the schedule you created in Note 11.42 "Exercise 1". Transfer it into a format that will help you stay on track from day to day. You may wish to input it into your smartphone, write it in a weekly planner, post it by your desk, or have your e-mail account send you daily reminders. Consider setting up a buddy system with a classmate that will help you both stay on track.

\section{Tip}

Some people enjoy using the most up-to-date technology to help them stay organized. Other people prefer simple methods, such as crossing off items on a checklist. The key to staying organized is finding a system you like enough to use daily. The particulars of the method are not important as long as you are consistent.

\section{Anticipating Challenges}

Do any of these scenarios sound familiar? You have identified a book that would be a great resource for your project, but it is currently checked out of the library. You planned to interview a subject matter expert on your topic, but she calls to reschedule your meeting. You have begun writing your draft, but now you realize that you will need to modify your thesis and conduct additional research. Or you have finally completed your draft when your computer crashes, and days of hard work disappear in an instant.

These troubling situations are all too common. No matter how carefully you plan your schedule, you may encounter a glitch or setback. Managing your project effectively means anticipating potential problems, taking steps to minimize them where possible, and allowing time in your schedule to handle any setbacks.

Many times a situation becomes a problem due only to lack of planning. For example, if a book is checked out of your local library, it might be available through interlibrary loan, which usually takes a few days for the library staff to process. Alternatively, you might locate another, equally useful source. If you have allowed enough time for research, a brief delay will not become a major setback.

You can manage other potential problems by staying organized and maintaining a take-charge attitude. Take a minute each day to save a backup copy of your work on a portable hard drive. Maintain detailed 
note cards and source cards as you conduct research-doing so will make citing sources in your draft infinitely easier. If you run into difficulties with your research or your writing, ask your instructor for help, or make an appointment with a writing tutor.

\section{Exercise 3}

Identify five potential problems you might encounter in the process of researching and writing your paper. Write them on a separate sheet of paper. For each problem, write at least one strategy for solving the problem or minimizing its effect on your project.

\section{Writing at Work}

In the workplace, documents prepared at the beginning of a project often include a detailed plan for risk management. When you manage a project, it makes sense to anticipate and prepare for potential setbacks. For example, to roll out a new product line, a software development company must strive to complete tasks on a schedule in order to meet the new product release date. The project manager may need to adjust the project plan if one or more tasks fall behind schedule.

\section{Key Takeaways}

- To complete a research project successfully, a writer must carefully manage each phase of the process and break major steps into smaller tasks.

- Writers can plan a research project by setting up a schedule based on the deadline and by identifying useful project resources.

- Writers stay focused by using organizational tools that suit their needs.

- Anticipating and planning for potential setbacks can help writers avoid those setbacks or minimize their effect on the project schedule. 


\subsection{Strategies for Gathering Reliable Information}

\section{Learning Objectives}

1. Distinguish between primary and secondary sources.

2. Identify strategies for locating relevant print and electronic resources efficiently.

3. Identify instances when it is appropriate to use human sources, such as interviews or eyewitness testimony.

4. Identify criteria for evaluating research resources.

5. Understand why many electronic resources are not reliable.

Now that you have planned your research project, you are ready to begin the research. This phase can be both exciting and challenging. As you read this section, you will learn ways to locate sources efficiently, so you have enough time to read the sources, take notes, and think about how to use the information.

Of course, the technological advances of the past few decades-particularly the rise of online media - mean that, as a twenty-first-century student, you have countless sources of information available at your fingertips. But how can you tell whether a source is reliable? This section will discuss strategies for evaluating sources critically so that you can be a media-savvy researcher.

In this section, you will locate and evaluate resources for your paper and begin taking notes. As you read, begin gathering print and electronic resources, identify at least eight to ten sources by the time you finish the chapter, and begin taking notes on your research findings.

\section{Locating Useful Resources}

When you chose a paper topic and determined your research questions, you conducted preliminary research to stimulate your thinking. Your research proposal included some general ideas for how to go about your research - for instance, interviewing an expert in the field or analyzing the content of popular magazines. You may even have identified a few potential sources. Now it is time to conduct a more focused, systematic search for informative primary and secondary sources.

\section{Using Primary and Secondary Sources}

Writers classify research resources in two categories: primary sources and secondary sources. Primary 
sources are direct, firsthand sources of information or data. For example, if you were writing a paper about the First Amendment right to freedom of speech, the text of the First Amendment in the Bill of Rights would be a primary source.

Other primary sources include the following:

- Research articles

- Literary texts

- Historical documents such as diaries or letters

- Autobiographies or other personal accounts

Secondary sources discuss, interpret, analyze, consolidate, or otherwise rework information from primary sources. In researching a paper about the First Amendment, you might read articles about legal cases that involved First Amendment rights, or editorials expressing commentary on the First Amendment. These sources would be considered secondary sources because they are one step removed from the primary source of information.

The following are examples of secondary sources:

- Magazine articles

- Biographical books

- Literary and scientific reviews

- Television documentaries

Your topic and purpose determine whether you must cite both primary and secondary sources in your paper. Ask yourself which sources are most likely to provide the information that will answer your research questions. If you are writing a research paper about reality television shows, you will need to use some reality shows as a primary source, but secondary sources, such as a reviewer's critique, are also important. If you are writing about the health effects of nicotine, you will probably want to read the published results of scientific studies, but secondary sources, such as magazine articles discussing the outcome of a recent study, may also be helpful.

Once you have thought about what kinds of sources are most likely to help you answer your research questions, you may begin your search for print and electronic resources. The challenge here is to conduct your search efficiently. Writers use strategies to help them find the sources that are most relevant and reliable while steering clear of sources that will not be useful.

\section{Finding Print Resources}

Print resources include a vast array of documents and publications. Regardless of your topic, you will consult some print resources as part of your research. (You will use electronic sources as well, but it is not wise to limit yourself to electronic sources only, because some potentially useful sources may be available only in print form.) Table 11.1 "Library Print Resources” lists different types of print resources 
449 [Author removed at request of original publisher]

available at public and university libraries.

Table 11.1 Library Print Resources 


\begin{tabular}{|c|c|c|}
\hline $\begin{array}{l}\text { Resource } \\
\text { Type }\end{array}$ & Description & Example(s) \\
\hline $\begin{array}{l}\text { Reference } \\
\text { works }\end{array}$ & $\begin{array}{l}\text { Reference works provide a summary of information about a particular topic. } \\
\text { Almanacs, encyclopedias, atlases, medical reference books, and scientific abstracts are } \\
\text { examples of reference works. In some cases, reference books may not be checked out } \\
\text { of a library. } \\
\text { Note that reference works are many steps removed from original primary sources and } \\
\text { are often brief, so these should be used only as a starting point when you gather } \\
\text { information. }\end{array}$ & $\begin{array}{l}\text { - The World } \\
\text { Almanac and } \\
\text { Book of Facts } \\
2010 \\
\text { - Diagnostic and } \\
\text { Statistical } \\
\text { Manual } \\
\text { published by } \\
\text { the American } \\
\text { Psychiatric } \\
\text { Association }\end{array}$ \\
\hline $\begin{array}{l}\text { Nonfiction } \\
\text { books }\end{array}$ & $\begin{array}{l}\text { Nonfiction books provide in-depth coverage of a topic. Trade books, } \\
\text { biographies, and how-to guides are usually written for a general } \\
\text { audience. Scholarly books and scientific studies are usually written } \\
\text { for an audience that has specialized knowledge of a topic. }\end{array}$ & $\begin{array}{l}\text { - The Low-Carb } \\
\text { Solution: A } \\
\text { Slimmer You in } \\
30 \text { Days } \\
\text { - Carbohydrates, } \\
\text { Fats and } \\
\text { Proteins: } \\
\text { Exploring the } \\
\text { Relationship } \\
\text { Between } \\
\text { Macronutrient } \\
\text { Ratios and } \\
\text { Health } \\
\text { Outcomes }\end{array}$ \\
\hline $\begin{array}{l}\text { Periodicals } \\
\text { and news } \\
\text { sources }\end{array}$ & $\begin{array}{l}\text { These sources are published at regular intervals_-daily, weekly, } \\
\text { monthly, or quarterly. Newspapers, magazines, and academic } \\
\text { journals are examples. Some periodicals provide articles on subjects } \\
\text { of general interest, while others are more specialized. }\end{array}$ & $\begin{array}{l}\text { - New York } \\
\text { Times } \\
\text { - PC Magazine } \\
\text { - JAMA, The } \\
\text { Journal of the } \\
\text { American } \\
\text { Medical } \\
\text { Association }\end{array}$ \\
\hline
\end{tabular}




\begin{tabular}{|c|c|c|}
\hline $\begin{array}{l}\text { Resource } \\
\text { Type }\end{array}$ & Description & Example(s) \\
\hline $\begin{array}{l}\text { Government } \\
\text { publications }\end{array}$ & $\begin{array}{l}\text { Federal, state, and local government agencies publish information on } \\
\text { a variety of topics. Government publications include reports, } \\
\text { legislation, court documents, public records, statistics, studies, } \\
\text { guides, programs, and forms. }\end{array}$ & $\begin{array}{l}\text { - The Census } \\
2000 \text { Profile } \\
\text { - The Business } \\
\text { Relocation } \\
\text { Package } \\
\text { published by } \\
\text { the } \\
\text { Philadelphia } \\
\text { Chamber of } \\
\text { Commerce }\end{array}$ \\
\hline $\begin{array}{l}\text { Business } \\
\text { and } \\
\text { nonprofit } \\
\text { publications }\end{array}$ & $\begin{array}{l}\text { Businesses and nonprofit organizations produce publications } \\
\text { designed to market a product, provide background about the } \\
\text { organization, provide information on topics connected to the } \\
\text { organization, or promote a cause. These publications include reports, } \\
\text { newsletters, advertisements, manuals, brochures, and other print } \\
\text { documents. }\end{array}$ & $\begin{array}{l}\text { - A company's } \\
\text { instruction } \\
\text { manual } \\
\text { explaining how } \\
\text { to use a } \\
\text { specific } \\
\text { software } \\
\text { program } \\
\text { - A news release } \\
\text { published by } \\
\text { the Sierra Club }\end{array}$ \\
\hline
\end{tabular}

Some of these resources are also widely available in electronic format. In addition to the resources noted in the table, library holdings may include primary texts such as historical documents, letters, and diaries.

\section{Writing at Work}

Businesses, government organizations, and nonprofit organizations produce published materials that range from brief advertisements and brochures to lengthy, detailed reports. In many cases, producing these publications requires research. A corporation's annual report may include research about economic or industry trends. A charitable organization may use information from research in materials sent to potential donors.

Regardless of the industry you work in, you may be asked to assist in developing materials for publication. Often, incorporating research in these documents can make them more effective in informing or persuading readers. 


\section{Tip}

As you gather information, strive for a balance of accessible, easy-to-read sources and more specialized, challenging sources. Relying solely on lightweight books and articles written for a general audience will drastically limit the range of useful, substantial information. On the other hand, restricting oneself to dense, scholarly works could make the process of researching extremely time-consuming and frustrating.

\section{Exercise 1}

Make a list of five types of print resources you could use to find information about your research topic. Include at least one primary source. Be as specific as possible-if you have a particular resource or type of resource in mind, describe it.

To find print resources efficiently, first identify the major concepts and terms you will use to conduct your search - that is, your keywords. These, along with the research questions you identified in $\underline{\text { Chapter }}$ 11 "Writing from Research: What Will I Learn?", Section 11.2 "Steps in Developing a Research Proposal”, will help you find sources using any of the following methods:

- Using the library's online catalog or card catalog

- Using periodicals indexes and databases

- Consulting a reference librarian

You probably already have some keywords in mind based on your preliminary research and writing. Another way to identify useful keywords is to visit the Library of Congress's website at http://id.loc.gov/ authorities. This site allows you to search for a topic and see the related subject headings used by the Library of Congress, including broader terms, narrower terms, and related terms. Other libraries use these terms to classify materials. Knowing the most-used terms will help you speed up your keyword search.

Jorge used the Library of Congress site to identify general terms he could use to find resources about low-carb dieting. His search helped him identify potentially useful keywords and related topics, such as carbohydrates in human nutrition, glycemic index, and carbohydrates-metabolism. These terms helped Jorge refine his search.

\section{Tip}

Knowing the right keywords can sometimes make all the difference in conducting a successful search. If you have trouble finding sources on a topic, consult a librarian to see whether you need to modify your search 
terms.

\section{Exercise 2}

Visit the Library of Congress's website at http://id.loc.gov/authorities and conduct searches on a few terms related to your topic.

1. Review your search results and identify six to eight additional terms you might use when you conduct your research.

2. Print out the search results or save the results to your research folder on your computer or portable storage device.

\section{Using Periodicals, Indexes, and Databases}

Library catalogs can help you locate book-length sources, as well as some types of nonprint holdings, such as CDs, DVDs, and audio books. To locate shorter sources, such as magazine and journal articles, you will need to use a periodical index or an online periodical database. These tools index the articles that appear in newspapers, magazines, and journals. Like catalogs, they provide publication information about an article and often allow users to access a summary or even the full text of the article.

Print indexes may be available in the periodicals section of your library. Increasingly, libraries use online databases that users can access through the library website. A single library may provide access to multiple periodical databases. These can range from general news databases to specialized databases. Table 11.2 "Commonly Used Indexes and Databases" describes some commonly used indexes and databases.

Table 11.2 Commonly Used Indexes and Databases 


\begin{tabular}{|c|c|c|}
\hline Resource & Format & Contents \\
\hline New York Times Index & Print & Guide to articles published in the New York Times \\
\hline ProQuest & Online & $\begin{array}{l}\text { Database that archives content from newspapers, magazines, and } \\
\text { dissertations }\end{array}$ \\
\hline Psychlit, PsycINFO & Online & $\begin{array}{l}\text { Databases that archive content from journals in psychology and } \\
\text { psychiatry }\end{array}$ \\
\hline $\begin{array}{l}\text { Business Source } \\
\text { Complete }\end{array}$ & Online & $\begin{array}{l}\text { Database that archives business-related content from magazines and } \\
\text { journals }\end{array}$ \\
\hline MEDLINE, PubMed & Online & Databases that archive articles in medicine and health \\
\hline EBSCOhost & Online & $\begin{array}{l}\text { General database that provides access to articles on a wide variety of } \\
\text { topics }\end{array}$ \\
\hline
\end{tabular}

\section{Reading Popular and Scholarly Periodicals}

When you search for periodicals, be sure to distinguish among different types. Mass-market publications, such as newspapers and popular magazines, differ from scholarly publications in their accessibility, audience, and purpose.

Newspapers and magazines are written for a broader audience than scholarly journals. Their content is usually quite accessible and easy to read. Trade magazines that target readers within a particular industry may presume the reader has background knowledge, but these publications are still reader-friendly for a broader audience. Their purpose is to inform and, often, to entertain or persuade readers as well.

Scholarly or academic journals are written for a much smaller and more expert audience. The creators of these publications assume that most of their readers are already familiar with the main topic of the journal. The target audience is also highly educated. Informing is the primary purpose of a scholarly journal. While a journal article may advance an agenda or advocate a position, the content will still be presented in an objective style and formal tone. Entertaining readers with breezy comments and splashy graphics is not a priority.

Because of these differences, scholarly journals are more challenging to read. That doesn't mean you should avoid them. On the contrary, they can provide in-depth information unavailable elsewhere. Because knowledgeable professionals carefully review the content before publication, scholarly journals are far more reliable than much of the information available in popular media. Seek out academic journals along with other resources. Just be prepared to spend a little more time processing the information. 


\section{Writing at Work}

Periodicals databases are not just for students writing research papers. They also provide a valuable service to workers in various fields. The owner of a small business might use a database such as Business Source Premiere to find articles on management, finance, or trends within a particular industry. Health care professionals might consult databases such as MedLine to research a particular disease or medication. Regardless of what career path you plan to pursue, periodicals databases can be a useful tool for researching specific topics and identifying periodicals that will help you keep up with the latest news in your industry.

\section{Consulting a Reference Librarian}

Sifting through library stacks and database search results to find the information you need can be like trying to find a needle in a haystack. If you are not sure how you should begin your search, or if it is yielding too many or too few results, you are not alone. Many students find this process challenging, although it does get easier with experience. One way to learn better search strategies is to consult a reference librarian.

Reference librarians are intimately familiar with the systems libraries use to organize and classify information. They can help you locate a particular book in the library stacks, steer you toward useful reference works, and provide tips on how to use databases and other electronic research tools. Take the time to see what resources you can find on your own, but if you encounter difficulties, ask for help. Many university librarians hold virtual office hours and are available for online chatting.

\section{Exercise 3}

Visit your library's website or consult with a reference librarian to determine what periodicals indexes or databases would be useful for your research. Depending on your topic, you may rely on a general news index, a specialized index for a particular subject area, or both. Search the catalog for your topic and related keywords. Print out or bookmark your search results.

1. Identify at least one to two relevant periodicals, indexes, or databases.

2. Conduct a keyword search to find potentially relevant articles on your topic.

3. Save your search results. If the index you are using provides article summaries, read these to determine how useful the articles are likely to be.

4. Identify at least three to five articles to review more closely. If the full article is available online, set aside time to read it. If not, plan to visit our library within the next few days to locate the articles you need. 
Tip

One way to refine your keyword search is to use Boolean operators. These operators allow you to combine keywords, find variations on a word, and otherwise expand or limit your results. Here are some of the ways you can use Boolean operators:

- Combine keywords with and or + to limit results to citations that include both keywords—-for example, diet + nutrition.

- Combine keywords with not or - to search for the first word without the second. This can help you eliminate irrelevant results based on words that are similar to your search term. For example, searching for obesity not childhood locates materials on obesity but excludes materials on childhood obesity.

- Enclose a phrase in quotation marks to search for an exact phrase, such as "morbid obesity."

- Use parentheses to direct the order of operations in a search string. For example, since Type II diabetes is also known as adult-onset diabetes, you could search (Type II or adult-onset) and diabetes to limit your search results to articles on this form of the disease.

- Use a wildcard symbol such as \#, ?, or \$ after a word to search for variations on a term. For instance, you might type diabet\# to search for information on diabetes and diabetics. The specific symbol used varies with different databases.

\section{Finding and Using Electronic Resources}

With the expansion of technology and media over the past few decades, a wealth of information is available to you in electronic format. Some types of resources, such as a television documentary, may only be available electronically. Other resources-for instance, many newspapers and magazines-may be available in both print and electronic form. The following are some of the electronic sources you might consult:

- Online databases

- CD-ROMs

- Popular web search engines

- Websites maintained by businesses, universities, nonprofit organizations, or government agencies

- Newspapers, magazines, and journals published on the web

- E-books

- Audio books

- Industry blogs

- Radio and television programs and other audio and video recordings 
- Online discussion groups

The techniques you use to locate print resources can also help you find electronic resources efficiently. Libraries usually include CD-ROMs, audio books, and audio and video recordings among their holdings. You can locate these materials in the catalog using a keyword search. The same Boolean operators used to refine database searches can help you filter your results in popular search engines.

\section{Using Internet Search Engines Efficiently}

When faced with the challenge of writing a research paper, some students rely on popular search engines as their first source of information. Typing a keyword or phrase into a search engine instantly pulls up links to dozens, hundreds, or even thousands of related websites - what could be easier? Unfortunately, despite its apparent convenience, this research strategy has the following drawbacks to consider:

- Results do not always appear in order of reliability. The first few hits that appear in search results may include sites whose content is not always reliable, such as online encyclopedias that can be edited by any user. Because websites are created by third parties, the search engine cannot tell you which sites have accurate information.

- Results may be too numerous for you to use. The amount of information available on the web is far greater than the amount of information housed within a particular library or database. Realistically, if your web search pulls up thousands of hits, you will not be able to visit every site- and the most useful sites may be buried deep within your search results.

- Search engines are not connected to the results of the search. Search engines find websites that people visit often and list the results in order of popularity. The search engine, then, is not connected to any of the results. When you cite a source found through a search engine, you do not need to cite the search engine. Only cite the source.

A general web search can provide a helpful overview of a topic and may pull up genuinely useful resources. To get the most out of a search engine, however, use strategies to make your search more efficient. Use multiple keywords and Boolean operators to limit your results. Click on the Advanced Search link on the homepage to find additional options for streamlining your search. Depending on the specific search engine you use, the following options may be available:

- Limit results to websites that have been updated within a particular time frame.

- Limit results by language or country.

- Limit results to scholarly works available online.

- Limit results by file type.

- Limit results to a particular domain type, such as .edu (school and university sites) or .gov (government sites). This is a quick way to filter out commercial sites, which can often lead to more objective results.

Use the Bookmarks or Favorites feature of your web browser to save and organize sites that look 
promising.

\section{Using Other Information Sources: Interviews}

With so many print and electronic media readily available, it is easy to overlook another valuable information resource: other people. Consider whether you could use a person or group as a primary source. For instance, you might interview a professor who has expertise in a particular subject, a worker within a particular industry, or a representative from a political organization. Interviews can be a great way to get firsthand information.

To get the most out of an interview, you will need to plan ahead. Contact your subject early in the research process and explain your purpose for requesting an interview. Prepare detailed questions. Openended questions, rather than questions with simple yes-or-no answers, are more likely to lead to an indepth discussion. Schedule a time to meet, and be sure to obtain your subject's permission to record the interview. Take careful notes and be ready to ask follow-up questions based on what you learn.

Tip

If scheduling an in-person meeting is difficult, consider arranging a telephone interview or asking your subject to respond to your questions via e-mail. Recognize that any of these formats takes time and effort. Be prompt and courteous, avoid going over the allotted interview time, and be flexible if your subject needs to reschedule.

\section{Evaluating Research Resources}

As you gather sources, you will need to examine them with a critical eye. Smart researchers continually ask themselves two questions: "Is this source relevant to my purpose?" and "Is this source reliable?" The first question will help you avoid wasting valuable time reading sources that stray too far from your specific topic and research questions. The second question will help you find accurate, trustworthy sources.

\section{Determining Whether a Source Is Relevant}

At this point in your research process, you may have identified dozens of potential sources. It is easy for writers to get so caught up in checking out books and printing out articles that they forget to ask themselves how they will use these resources in their research. Now is a good time to get a little ruthless. Reading and taking notes takes time and energy, so you will want to focus on the most relevant sources. 
To weed through your stack of books and articles, skim their contents. Read quickly with your research questions and subtopics in mind. Table 11.3 “Tips for Skimming Books and Articles” explains how to skim to get a quick sense of what topics are covered. If a book or article is not especially relevant, put it aside. You can always come back to it later if you need to.

Table 11.3 Tips for Skimming Books and Articles

\section{Tips for Skimming Books}

1. Read the dust jacket and table of contents for a broad overview of the topics covered.

2. Use the index to locate more specific topics and see how thoroughly they are covered.

3. Flip through the book and look for subtitles or key terms that correspond to your research.

\section{Tips for Skimming Articles}

1. Skim the introduction and conclusion for summary material.

2. Skim through subheadings and text features such as sidebars.

3. Look for keywords related to your topic.

4. Journal articles often begin with an abstract or summary of the contents. Read it to determine the article's relevance to your research.

\section{Determining Whether a Source Is Reliable}

All information sources are not created equal. Sources can vary greatly in terms of how carefully they are researched, written, edited, and reviewed for accuracy. Common sense will help you identify obviously questionable sources, such as tabloids that feature tales of alien abductions, or personal websites with glaring typos. Sometimes, however, a source's reliability—or lack of it—is not so obvious. For more information about source reliability, see Chapter 12 "Writing a Research Paper".

To evaluate your research sources, you will use critical thinking skills consciously and deliberately. You will consider criteria such as the type of source, its intended purpose and audience, the author's (or authors') qualifications, the publication's reputation, any indications of bias or hidden agendas, how current the source is, and the overall quality of the writing, thinking, and design.

\section{Evaluating Types of Sources}

The different types of sources you will consult are written for distinct purposes and with different audiences in mind. This accounts for other differences, such as the following:

- How thoroughly the writers cover a given topic

- How carefully the writers research and document facts

- How editors review the work 
- What biases or agendas affect the content

A journal article written for an academic audience for the purpose of expanding scholarship in a given field will take an approach quite different from a magazine feature written to inform a general audience. Textbooks, hard news articles, and websites approach a subject from different angles as well. To some extent, the type of source provides clues about its overall depth and reliability. Table 11.4 "Source Rankings” ranks different source types.

Table 11.4 Source Rankings 


\section{High-Quality Sources}

These sources provide the most in-depth information. They are researched and written by subject matter experts and are carefully reviewed.
- Scholarly books and articles in scholarly journals

- Trade books and magazines geared toward an educated general audience, such as Smithsonian Magazine or Nature

- Government documents, such as books, reports, and web pages

- Documents posted online by reputable organizations, such as universities and research institutes

- Textbooks and reference books, which are usually reliable but may not cover a topic in great depth

\section{Varied-Quality Sources}

These sources are often useful. However, they do not cover subjects in as much depth as high-quality sources, and they are not always rigorously researched and reviewed. Some, such as popular magazine articles or company brochures, may be written to market a product or a cause. Use them with caution.
- News stories and feature articles (print or online) from reputable newspapers, magazines, or organizations, such as Newsweek or the Public Broadcasting Service

- Popular magazine articles, which may or may not be carefully researched and fact checked

- Documents published by businesses and nonprofit organizations

\section{Questionable Sources}

These sources should be avoided. They are often written primarily to attract a large readership or present the author's opinions and are not subject to careful review.
- Loosely regulated or unregulated media content, such as Internet discussion boards, blogs, free online encyclopedias, talk radio shows, television news shows with obvious political biases, personal websites, and chat rooms

\section{Tip}

Free online encyclopedias and wikis may seem like a great source of information. They usually appear among 
the first few results of a web search. They cover thousands of topics, and many articles use an informal, straightforward writing style. Unfortunately, these sites have no control system for researching, writing, and reviewing articles. Instead, they rely on a community of users to police themselves. At best, these sites can be a starting point for finding other, more trustworthy sources. Never use them as final sources.

\section{Evaluating Credibility and Reputability}

Even when you are using a type of source that is generally reliable, you will still need to evaluate the author's credibility and the publication itself on an individual basis. To examine the author's credibility - that is, how much you can believe of what the author has to say-examine his or her credentials. What career experience or academic study shows that the author has the expertise to write about this topic?

Keep in mind that expertise in one field is no guarantee of expertise in another, unrelated area. For instance, an author may have an advanced degree in physiology, but this credential is not a valid qualification for writing about psychology. Check credentials carefully.

Just as important as the author's credibility is the publication's overall reputability. Reputability refers to a source's standing and reputation as a respectable, reliable source of information. An established and well-known newspaper, such as the New York Times or the Wall Street Journal, is more reputable than a college newspaper put out by comparatively inexperienced students. A website that is maintained by a well-known, respected organization and regularly updated is more reputable than one created by an unknown author or group.

If you are using articles from scholarly journals, you can check databases that keep count of how many times each article has been cited in other articles. This can be a rough indication of the article's quality or, at the very least, of its influence and reputation among other scholars.

\section{Checking for Biases and Hidden Agendas}

Whenever you consult a source, always think carefully about the author's or authors' purpose in presenting the information. Few sources present facts completely objectively. In some cases, the source's content and tone are significantly influenced by biases or hidden agendas.

$\underline{\text { Bias }}$ refers to favoritism or prejudice toward a particular person or group. For instance, an author may be biased against a certain political party and present information in a way that subtly-or not so subtly-makes that organization look bad. Bias can lead an author to present facts selectively, edit quotations to misrepresent someone's words, and distort information.

Hidden agendas are goals that are not immediately obvious but influence how an author presents the facts. For instance, an article about the role of beef in a healthy diet would be questionable if it were written by a representative of the beef industry_or by the president of an animal-rights organization. In 
both cases, the author would likely have a hidden agenda.

As Jorge conducted his research, he read several research studies in which scientists found significant benefits to following a low-carbohydrate diet. He also noticed that many studies were sponsored by a foundation associated with the author of a popular series of low-carbohydrate diet books. Jorge read these studies with a critical eye, knowing that a hidden agenda might be shaping the researchers' conclusions.

\section{Using Current Sources}

Be sure to seek out sources that are current, or up to date. Depending on the topic, sources may become outdated relatively soon after publication, or they may remain useful for years. For instance, online social networking sites have evolved rapidly over the past few years. An article published in 2002 about this topic will not provide current information. On the other hand, a research paper on elementary education practices might refer to studies published decades ago by influential child psychologists.

When using websites for research, check to see when the site was last updated. Many sites publish this information on the homepage, and some, such as news sites, are updated daily or weekly. Many nonfunctioning links are a sign that a website is not regularly updated. Do not be afraid to ask your professor for suggestions if you find that many of your most relevant sources are not especially reliable—or that the most reliable sources are not relevant.

\section{Evaluating Overall Quality by Asking Questions}

When you evaluate a source, you will consider the criteria previously discussed as well as your overall impressions of its quality. Read carefully, and notice how well the author presents and supports his or her statements. Stay actively engaged - do not simply accept an author's words as truth. Ask questions to determine each source's value. Checklist 11.1 lists ten questions to ask yourself as a critical reader.

\section{Checklist 11.1}

Source Evaluation

- Is the type of source appropriate for my purpose? Is it a high-quality source or one that needs to be looked at more critically?

- Can I establish that the author is credible and the publication is reputable?

- Does the author support ideas with specific facts and details that are carefully documented? Is the source of the author's information clear? (When you use secondary sources, look for sources that are not too removed from primary research.)

- Does the source include any factual errors or instances of faulty logic? 
- Does the author leave out any information that I would expect to see in a discussion of this topic?

- Do the author's conclusions logically follow from the evidence that is presented? Can I see how the author got from one point to another?

- Is the writing clear and organized, and is it free from errors, clichés, and empty buzzwords? Is the tone objective, balanced, and reasonable? (Be on the lookout for extreme, emotionally charged language.)

- Are there any obvious biases or agendas? Based on what I know about the author, are there likely to be any hidden agendas?

- Are graphics informative, useful, and easy to understand? Are websites organized, easy to navigate, and free of clutter like flashing ads and unnecessary sound effects?

- Is the source contradicted by information found in other sources? (If so, it is possible that your sources are presenting similar information but taking different perspectives, which requires you to think carefully about which sources you find more convincing and why. Be suspicious, however, of any source that presents facts that you cannot confirm elsewhere.)

\section{Writing at Work}

The critical thinking skills you use to evaluate research sources as a student are equally valuable when you conduct research on the job. If you follow certain periodicals or websites, you have probably identified publications that consistently provide reliable information. Reading blogs and online discussion groups is a great way to identify new trends and hot topics in a particular field, but these sources should not be used for substantial research.

\section{Exercise 4}

Use a search engine to conduct a web search on your topic. Refer to the tips provided earlier to help you streamline your search. Evaluate your search results critically based on the criteria you have learned. Identify and bookmark one or more websites that are reliable, reputable, and likely to be useful in your research.

\section{Managing Source Information}

As you determine which sources you will rely on most, it is important to establish a system for keeping track of your sources and taking notes. There are several ways to go about it, and no one system is necessarily superior. What matters is that you keep materials in order; record bibliographical information you will need later; and take detailed, organized notes. 


\section{Keeping Track of Your Sources}

Think ahead to a moment a few weeks from now, when you've written your research paper and are almost ready to submit it for a grade. There is just one task left—writing your list of sources.

As you begin typing your list, you realize you need to include the publication information for a book you cited frequently. Unfortunately, you already returned it to the library several days ago. You do not remember the URLs for some of the websites you used or the dates you accessed them-information that also must be included in your bibliography. With a sinking feeling, you realize that finding this information and preparing your bibliography will require hours of work.

This stressful scenario can be avoided. Taking time to organize source information now will ensure that you are not scrambling to find it at the last minute. Throughout your research, record bibliographical information for each source as soon as you begin using it. You may use pen-and-paper methods, such as a notebook or note cards, or maintain an electronic list. (If you prefer the latter option, many office software packages include separate programs for recording bibliographic information.)

Table 11.5 "Details for Commonly Used Source Types" shows the specific details you should record for commonly used source types. Use these details to develop a working bibliography — a preliminary list of sources that you will later use to develop the references section of your paper. You may wish to record information using the formatting system of the American Psychological Association (APA) or the Modern Language Association (MLA), which will save a step later on. (For more information on APA and MLA formatting, see Chapter 13 “APA and MLA Documentation and Formatting”.)

Table 11.5 Details for Commonly Used Source Types

\begin{tabular}{|l|l|}
\hline Source Type & Necessary Information \\
\hline Book & Author(s), title and subtitle, publisher, city of publication, year of publication \\
\hline $\begin{array}{l}\text { Essay or article } \\
\text { published in a } \\
\text { book }\end{array}$ & $\begin{array}{l}\text { Include all the information you would for any other book. Additionally, record the essay's or } \\
\text { article’s title, author(s), the pages on which it appears, and the name of the book’s editor(s). }\end{array}$ \\
\hline Periodical & $\begin{array}{l}\text { Author(s), article title, publication title, date of publication, volume and issue number, and } \\
\text { page numbers }\end{array}$ \\
\hline Online source & $\begin{array}{l}\text { Author(s) (if available), article or document title, organization that sponsors the site, } \\
\text { database name (if applicable), date of publication, date you accessed the site, and URL }\end{array}$ \\
\hline Interview & Name of person interviewed, method of communication, date of interview \\
\hline
\end{tabular}

Your research may involve less common types of sources not listed in Table 11.5 "Details for Commonly Used Source Types”. For additional information on citing different sources, see Chapter 13 "APA and MLA Documentation and Formatting”. 


\section{Exercise 5}

Create a working bibliography using the format that is most convenient for you. List at least five sources you plan to use. Continue to add sources to your working bibliography throughout the research process.

Tip

To make your working bibliography even more complete, you may wish to record additional details, such as a book's call number or contact information for a person you interviewed. That way, if you need to locate a source again, you have all the information you need right at your fingertips. You may also wish to assign each source a code number to use when taking notes $(1,2,3$, or a similar system).

\section{Taking Notes Efficiently}

Good researchers stay focused and organized as they gather information from sources. Before you begin taking notes, take a moment to step back and think about your goal as a researcher - to find information that will help you answer your research question. When you write your paper, you will present your conclusions about the topic supported by research. That goal will determine what information you record and how you organize it.

Writers sometimes get caught up in taking extensive notes, so much so that they lose sight of how their notes relate to the questions and ideas they started out with. Remember that you do not need to write down every detail from your reading. Focus on finding and recording details that will help you answer your research questions. The following strategies will help you take notes efficiently.

\section{Use Headings to Organize Ideas}

Whether you use old-fashioned index cards or organize your notes using word-processing software, record just one major point from each source at a time, and use a heading to summarize the information covered. Keep all your notes in one file, digital or otherwise. Doing so will help you identify connections among different pieces of information. It will also help you make connections between your notes and the research questions and subtopics you identified earlier.

\section{Know When to Summarize, Paraphrase, or Directly Quote a}




\section{Source}

Your notes will fall under three categories-summary notes, paraphrased information, and direct quotations from your sources. Effective researchers make choices about which type of notes is most appropriate for their purpose.

- Summary notes sum up the main ideas in a source in a few sentences or a short paragraph. A summary is considerably shorter than the original text and captures only the major ideas. Use summary notes when you do not need to record specific details but you intend to refer to broad concepts the author discusses.

- Paraphrased notes restate a fact or idea from a source using your own words and sentence structure.

- Direct quotations use the exact wording used by the original source and enclose the quoted material in quotation marks. It is a good strategy to copy direct quotations when an author expresses an idea in an especially lively or memorable way. However, do not rely exclusively on direct quotations in your note taking.

Most of your notes should be paraphrased from the original source. Paraphrasing as you take notes is usually a better strategy than copying direct quotations, because it forces you to think through the information in your source and understand it well enough to restate it. In short, it helps you stay engaged with the material instead of simply copying and pasting. Synthesizing will help you later when you begin planning and drafting your paper. (For detailed guidelines on summarizing, paraphrasing, and quoting, see Chapter 11 "Writing from Research: What Will I Learn?”, Section 11.6 "Writing from Research: End-of-Chapter Exercises”.)

\section{Maintain Complete, Accurate Notes}

Regardless of the format used, any notes you take should include enough information to help you organize ideas and locate them instantly in the original text if you need to review them. Make sure your notes include the following elements:

- Heading summing up the main topic covered

- Author's name, a source code, or an abbreviated source title

- Page number

- Full URL of any pages buried deep in a website

Throughout the process of taking notes, be scrupulous about making sure you have correctly attributed each idea to its source. Always include source information so you know exactly which ideas came from which sources. Use quotation marks to set off any words for phrases taken directly from the original text. If you add your own responses and ideas, make sure they are distinct from ideas you quoted or paraphrased. 
Finally, make sure your notes accurately reflect the content of the original text. Make sure quoted material is copied verbatim. If you omit words from a quotation, use ellipses to show the omission and make sure the omission does not change the author's meaning. Paraphrase ideas carefully, and check your paraphrased notes against the original text to make sure that you have restated the author's ideas accurately in your own words.

\section{Use a System That Works for You}

There are several formats you can use to take notes. No technique is necessarily better than the others-it is more important to choose a format you are comfortable using. Choosing the format that works best for you will ensure your notes are organized, complete, and accurate. Consider implementing one of these formats when you begin taking notes:

- Use index cards. This traditional format involves writing each note on a separate index card. It takes more time than copying and pasting into an electronic document, which encourages you to be selective in choosing which ideas to record. Recording notes on separate cards makes it easy to later organize your notes according to major topics. Some writers color-code their cards to make them still more organized.

- Use note-taking software. Word-processing and office software packages often include different types of note-taking software. Although you may need to set aside some time to learn the software, this method combines the speed of typing with the same degree of organization associated with handwritten note cards.

- Maintain a research notebook. Instead of using index cards or electronic note cards, you may wish to keep a notebook or electronic folder, allotting a few pages (or one file) for each of your sources. This method makes it easy to create a separate column or section of the document where you add your responses to the information you encounter in your research.

- Annotate your sources. This method involves making handwritten notes in the margins of sources that you have printed or photocopied. If using electronic sources, you can make comments within the source document. For example, you might add comment boxes to a PDF version of an article. This method works best for experienced researchers who have already thought a great deal about the topic because it can be difficult to organize your notes later when starting your draft.

Choose one of the methods from the list to use for taking notes. Continue gathering sources and taking notes. In the next section, you will learn strategies for organizing and synthesizing the information you have found.

\section{Key Takeaways}

- A writer's use of primary and secondary sources is determined by the topic and purpose of the research. Sources used may include print sources, such as books and journals; electronic sources, 
such as websites and articles retrieved from databases; and human sources of information, such as interviews.

- Strategies that help writers locate sources efficiently include conducting effective keyword searches, understanding how to use online catalogs and databases, using strategies to narrow web search results, and consulting reference librarians.

- Writers evaluate sources based on how relevant they are to the research question and how reliable their content is.

- Skimming sources can help writers determine their relevance efficiently.

- Writers evaluate a source's reliability by asking questions about the type of source (including its audience and purpose); the author's credibility, the publication's reputability, the source's currency, and the overall quality of the writing, research, logic, and design in the source.

- In their notes, effective writers record organized, complete, accurate information. This includes bibliographic information about each source as well as summarized, paraphrased, or quoted information from the source. 


\subsection{Critical Thinking and Research Applications}

\section{Learning Objectives}

1. Analyze source materials to determine how they support or refute the working thesis.

2. Identify connections between source materials and eliminate redundant or irrelevant source materials.

3. Identify instances when it is appropriate to use human sources, such as interviews or eyewitness testimony.

4. Select information from sources to begin answering the research questions.

5. Determine an appropriate organizational structure for the research paper that uses critical analysis to connect the writer's ideas and information taken from sources.

At this point in your project, you are preparing to move from the research phase to the writing phase. You have gathered much of the information you will use, and soon you will be ready to begin writing your draft. This section helps you transition smoothly from one phase to the next.

Beginning writers sometimes attempt to transform a pile of note cards into a formal research paper without any intermediary step. This approach presents problems. The writer's original question and thesis may be buried in a flood of disconnected details taken from research sources. The first draft may present redundant or contradictory information. Worst of all, the writer's ideas and voice may be lost.

An effective research paper focuses on the writer's ideas-from the question that sparked the research process to how the writer answers that question based on the research findings. Before beginning a draft, or even an outline, good writers pause and reflect. They ask themselves questions such as the following:

- How has my thinking changed based on my research? What have I learned?

- Was my working thesis on target? Do I need to rework my thesis based on what I have learned?

- How does the information in my sources mesh with my research questions and help me answer those questions? Have any additional important questions or subtopics come up that I will need to address in my paper?

- How do my sources complement each other? What ideas or facts recur in multiple sources?

- Where do my sources disagree with each other, and why?

In this section, you will reflect on your research and review the information you have gathered. You will determine what you now think about your topic. You will synthesize, or put together, different pieces of information that help you answer your research questions. Finally, you will determine the organizational 
structure that works best for your paper and begin planning your outline.

\section{Exercise 1}

Review the research questions and working thesis you developed in Chapter 11 "Writing from Research: What Will I Learn?", Section 11.2 "Steps in Developing a Research Proposal”. Set a timer for ten minutes and write about your topic, using your questions and thesis to guide your writing. Complete this exercise without looking over your notes or sources. Base your writing on the overall impressions and concepts you have absorbed while conducting research. If additional, related questions come to mind, jot them down.

\section{Selecting Useful Information}

At this point in the research process, you have gathered information from a wide variety of sources. Now it is time to think about how you will use this information as a writer.

When you conduct research, you keep an open mind and seek out many promising sources. You take notes on any information that looks like it might help you answer your research questions. Often, new ideas and terms come up in your reading, and these, too, find their way into your notes. You may record facts or quotations that catch your attention even if they did not seem immediately relevant to your research question. By now, you have probably amassed an impressively detailed collection of notes.

You will not use all of your notes in your paper.

Good researchers are thorough. They look at multiple perspectives, facts, and ideas related to their topic, and they gather a great deal of information. Effective writers, however, are selective. They determine which information is most relevant and appropriate for their purpose. They include details that develop or explain their ideas - and they leave out details that do not. The writer, not the pile of notes, is the controlling force. The writer shapes the content of the research paper.

While working through Chapter 11 “Writing from Research: What Will I Learn?”, Section 11.4 "Strategies for Gathering Reliable Information", you used strategies to filter out unreliable or irrelevant sources and details. Now you will apply your critical-thinking skills to the information you recorded-analyzing how it is relevant, determining how it meshes with your ideas, and finding how it forms connections and patterns.

\section{Writing at Work}

When you create workplace documents based on research, selectivity remains important. A project team may spend months conducting market surveys to prepare for rolling out a new product, but few managers have time to read the research in its entirety. Most employees want the research distilled into a few well-supported 
points. Focused, concise writing is highly valued in the workplace.

\section{Identify Information That Supports Your Thesis}

In Note 11.81 "Exercise 1", you revisited your research questions and working thesis. The process of writing informally helped you see how you might begin to pull together what you have learned from your research. Do not feel anxious, however, if you still have trouble seeing the big picture. Systematically looking through your notes will help you.

Begin by identifying the notes that clearly support your thesis. Mark or group these, either physically or using the cut-and-paste function in your word-processing program. As you identify the crucial details that support your thesis, make sure you analyze them critically. Ask the following questions to focus your thinking:

- Is this detail from a reliable, high-quality source? Is it appropriate for me to cite this source in an academic paper? The bulk of the support for your thesis should come from reliable, reputable sources. If most of the details that support your thesis are from lessreliable sources, you may need to do additional research or modify your thesis.

- Is the link between this information and my thesis obvious —or will I need to explain it to my readers? Remember, you have spent more time thinking and reading about this topic than your audience. Some connections might be obvious to both you and your readers. More often, however, you will need to provide the analysis or explanation that shows how the information supports your thesis. As you read through your notes, jot down ideas you have for making those connections clear.

- What personal biases or experiences might affect the way I interpret this information? No researcher is 100 percent objective. We all have personal opinions and experiences that influence our reactions to what we read and learn. Good researchers are aware of this human tendency. They keep an open mind when they read opinions or facts that contradict their beliefs.

Tip

It can be tempting to ignore information that does not support your thesis or that contradicts it outright. However, such information is important. At the very least, it gives you a sense of what has been written about the issue. More importantly, it can help you question and refine your own thinking so that writing your research paper is a true learning process. 


\section{Find Connections between Your Sources}

As you find connections between your ideas and information in your sources, also look for information that connects your sources. Do most sources seem to agree on a particular idea? Are some facts mentioned repeatedly in many different sources? What key terms or major concepts come up in most of your sources regardless of whether the sources agree on the finer points? Identifying these connections will help you identify important ideas to discuss in your paper.

Look for subtler ways your sources complement one another, too. Does one author refer to another's book or article? How do sources that are more recent build upon the ideas developed in earlier sources?

Be aware of any redundancies in your sources. If you have amassed solid support from a reputable source, such as a scholarly journal, there is no need to cite the same facts from an online encyclopedia article that is many steps removed from any primary research. If a given source adds nothing new to your discussion and you can cite a stronger source for the same information, use the stronger source.

Determine how you will address any contradictions found among different sources. For instance, if one source cites a startling fact that you cannot confirm anywhere else, it is safe to dismiss the information as unreliable. However, if you find significant disagreements among reliable sources, you will need to review them and evaluate each source. Which source presents a sounder argument or more solid evidence? It is up to you to determine which source is the most credible and why.

Finally, do not ignore any information simply because it does not support your thesis. Carefully consider how that information fits into the big picture of your research. You may decide that the source is unreliable or the information is not relevant, or you may decide that it is an important point you need to bring up. What matters is that you give it careful consideration.

As Jorge reviewed his research, he realized that some of the information was not especially useful for his purpose. His notes included several statements about the relationship between soft drinks that are high in sugar and childhood obesity — a subtopic that was too far outside of the main focus of the paper. Jorge decided to cut this material.

\section{Reevaluate Your Working Thesis}

A careful analysis of your notes will help you reevaluate your working thesis and determine whether you need to revise it. Remember that your working thesis was the starting point-not necessarily the end point — of your research. You should revise your working thesis if your ideas changed based on what you read. Even if your sources generally confirmed your preliminary thinking on the topic, it is still a good idea to tweak the wording of your thesis to incorporate the specific details you learned from research.

Jorge realized that his working thesis oversimplified the issues. He still believed that the media was exaggerating the benefits of low-carb diets. However, his research led him to conclude that these diets did have some advantages. Read Jorge’s revised thesis. 
Although following a low-carbohydrate diet can benefit some people, these diets are not necessarily the best option for everyone who wants to lose weight or improve their health.

\section{Synthesizing and Organizing Information}

By now your thinking on your topic is taking shape. You have a sense of what major ideas to address in your paper, what points you can easily support, and what questions or subtopics might need a little more thought. In short, you have begun the process of synthesizing information-that is, of putting the pieces together into a coherent whole.

It is normal to find this part of the process a little difficult. Some questions or concepts may still be unclear to you. You may not yet know how you will tie all of your research together. Synthesizing information is a complex, demanding mental task, and even experienced researchers struggle with it at times. A little uncertainty is often a good sign! It means you are challenging yourself to work thoughtfully with your topic instead of simply restating the same information.

\section{Use Your Research Questions to Synthesize Information}

You have already considered how your notes fit with your working thesis. Now, take your synthesis a step further. Analyze how your notes relate to your major research question and the subquestions you identified in Chapter 11 "Writing from Research: What Will I Learn?”, Section 11.2 “Steps in Developing a Research Proposal”. Organize your notes with headings that correspond to those questions. As you proceed, you might identify some important subtopics that were not part of your original plan, or you might decide that some questions are not relevant to your paper.

Categorize information carefully and continue to think critically about the material. Ask yourself whether the sources are reliable and whether the connections between ideas are clear.

Remember, your ideas and conclusions will shape the paper. They are the glue that holds the rest of the content together. As you work, begin jotting down the big ideas you will use to connect the dots for your reader. (If you are not sure where to begin, try answering your major research question and subquestions. Add and answer new questions as appropriate.) You might record these big ideas on sticky notes or type and highlight them within an electronic document.

Jorge looked back on the list of research questions that he had written down earlier. He changed a few to match his new thesis, and he began a rough outline for his paper. 


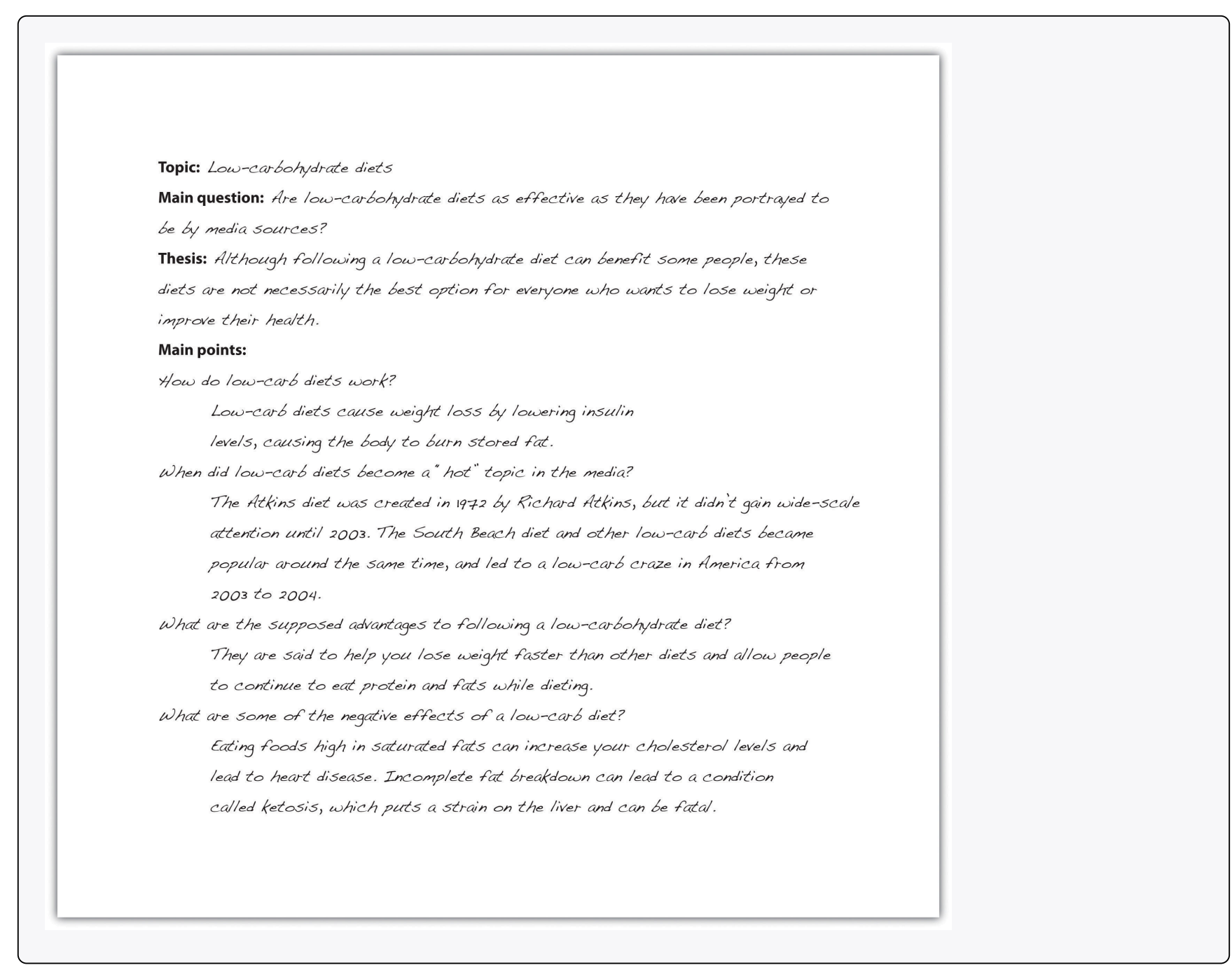

\section{Exercise 2}

Review your research questions and working thesis again. This time, keep them nearby as you review your research notes.

1. Identify information that supports your working thesis.

2. Identify details that call your thesis into question. Determine whether you need to modify your thesis.

3. Use your research questions to identify key ideas in your paper. Begin categorizing your notes according to which topics are addressed. (You may find yourself adding important topics or deleting unimportant ones as you proceed.)

4. Write out your revised thesis and at least two or three big ideas.

You may be wondering how your ideas are supposed to shape the paper, especially since you are writing a research paper based on your research. Integrating your ideas and your information from research is a 
complex process, and sometimes it can be difficult to separate the two.

Some paragraphs in your paper will consist mostly of details from your research. That is fine, as long as you explain what those details mean or how they are linked. You should also include sentences and transitions that show the relationship between different facts from your research by grouping related ideas or pointing out connections or contrasts. The result is that you are not simply presenting information; you are synthesizing, analyzing, and interpreting it.

\section{Plan How to Organize Your Paper}

The final step to complete before beginning your draft is to choose an organizational structure. For some assignments, this may be determined by the instructor's requirements. For instance, if you are asked to explore the impact of a new communications device, a cause-and-effect structure is obviously appropriate. In other cases, you will need to determine the structure based on what suits your topic and purpose. For more information about the structures used in writing, see Chapter 10 "Rhetorical Modes".

The purpose of Jorge's paper was primarily to persuade. With that in mind, he planned the following outline.

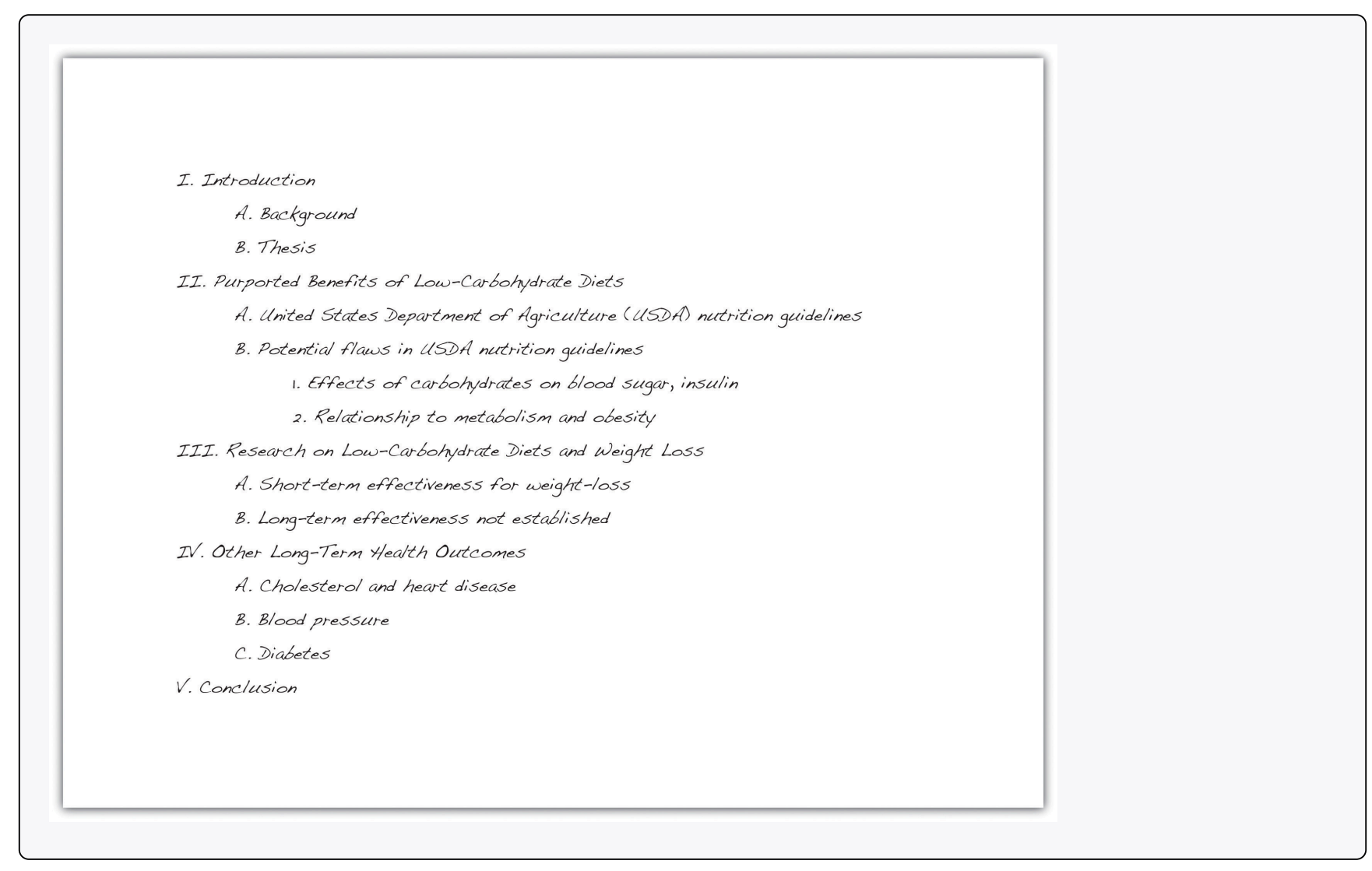




\section{Exercise 3}

Review the organizational structures discussed in this section and Chapter 10 "Rhetorical Modes". Working with the notes you organized earlier, follow these steps to begin planning how to organize your paper.

1. Create an outline that includes your thesis, major subtopics, and supporting points.

2. The major headings in your outline will become sections or paragraphs in your paper. Remember that your ideas should form the backbone of the paper. For each major section of your outline, write out a topic sentence stating the main point you will make in that section.

3. As you complete step 2, you may find that some points are too complex to explain in a sentence. Consider whether any major sections of your outline need to be broken up and jot down additional topic sentences as needed.

4. Review your notes and determine how the different pieces of information fit into your outline as supporting points.

\section{Collaboration}

Please share the outline you created with a classmate. Examine your classmate's outline and see if any questions come to mind or if you see any area that would benefit from an additional point or clarification. Return the outlines to each other and compare observations.

\section{Writing at Work}

The structures described in this section and Chapter 10 "Rhetorical Modes" can also help you organize information in different types of workplace documents. For instance, medical incident reports and police reports follow a chronological structure. If the company must choose between two vendors to provide a service, you might write an e-mail to your supervisor comparing and contrasting the choices. Understanding when and how to use each organizational structure can help you write workplace documents efficiently and effectively.

\section{Key Takeaways}

- An effective research paper focuses on presenting the writer's ideas using information from research as support.

- Effective writers spend time reviewing, synthesizing, and organizing their research notes before they begin drafting a research paper.

- It is important for writers to revisit their research questions and working thesis as they transition from the research phase to the writing phrase of a project. Usually, the working thesis will need at least minor adjustments. 
- To organize a research paper, writers choose a structure that is appropriate for the topic and purpose. Longer papers may make use of more than one structure. 


\subsection{Writing from Research: End-of-Chapter Exercises}

\section{Exercises}

1. In this chapter, you learned strategies for generating and narrowing a topic for a research paper. Review the following list of five general topics. Use freewriting and preliminary research to narrow three of these topics to manageable size for a five- to seven-page research paper. Save your list of topics in a print or electronic file, and add to it periodically as you identify additional areas of interest.

- Illegal immigration in the United States

- Bias in the media

- The role of religion in educational systems

- The possibility of life in outer space

- Modern-day slavery around the world

2. Working with one of the topics you have identified, use the research skills you learned in this chapter to locate three to five potentially useful print or electronic sources of information about the topic. Create a list that includes the following:

- One subject-specific periodicals database likely to include relevant articles on your topic

- Two articles about your topic written for an educated general audience

- At least one article about your topic written for an audience with specialized knowledge

3. Organize your list of resources into primary and secondary sources. What makes them such? Pick one primary source and one secondary source and write a sentence or two summarizing the information that they provide. Then answer these questions:

- What type of primary source did you choose? Who wrote it, and why? Do you think this source provides accurate information, or is it biased in some way?

- Where did the information in the secondary source come from? Was the author citing an initial study, piece of literature, or work of art? Where could you find the primary source? 


\section{Chapter 12: Writing a Research Paper}

12.1 Creating a Rough Draft for a Research Paper

12.2 Developing a Final Draft of a Research Paper

12.3 Writing a Research Paper: End-of-Chapter Exercises 


\subsection{Creating a Rough Draft for a Research Paper}

\section{Learning Objectives}

1. Apply strategies for drafting an effective introduction and conclusion.

2. Identify when and how to summarize, paraphrase, and directly quote information from research sources.

3. Apply guidelines for citing sources within the body of the paper and the bibliography.

4. Use primary and secondary research to support ideas.

5. Identify the purposes for which writers use each type of research.

At last, you are ready to begin writing the rough draft of your research paper. Putting your thinking and research into words is exciting. It can also be challenging. In this section, you will learn strategies for handling the more challenging aspects of writing a research paper, such as integrating material from your sources, citing information correctly, and avoiding any misuse of your sources.

\section{The Structure of a Research Paper}

Research papers generally follow the same basic structure: an introduction that presents the writer's thesis, a body section that develops the thesis with supporting points and evidence, and a conclusion that revisits the thesis and provides additional insights or suggestions for further research.

Your writing voice will come across most strongly in your introduction and conclusion, as you work to attract your readers' interest and establish your thesis. These sections usually do not cite sources at length. They focus on the big picture, not specific details. In contrast, the body of your paper will cite sources extensively. As you present your ideas, you will support your points with details from your research.

\section{Writing Your Introduction}

There are several approaches to writing an introduction, each of which fulfills the same goals. The introduction should get readers' attention, provide background information, and present the writer's thesis. Many writers like to begin with one of the following catchy openers:

- A surprising fact 
- A thought-provoking question

- An attention-getting quote

- A brief anecdote that illustrates a larger concept

- A connection between your topic and your readers' experiences

The next few sentences place the opening in context by presenting background information. From there, the writer builds toward a thesis, which is traditionally placed at the end of the introduction. Think of your thesis as a signpost that lets readers know in what direction the paper is headed.

Jorge decided to begin his research paper by connecting his topic to readers' daily experiences. Read the first draft of his introduction. The thesis is underlined. Note how Jorge progresses from the opening sentences to background information to his thesis.

\section{Beyond the Hype: Evaluating Low-Carb Diets}

\section{Introduction}

Over the past decade, increasing numbers of Americans have jumped on the low-carb bandwagon. Some studies estimate that approximately 40 million Americans, or about 20 percent of the population, are attempting to restrict their intake of food high in carbohydrates (Sanders and Katz, 2004; Hirsch, 2004). Proponents of low-carb diets say they are not only the most effective way to lose weight, but they also yield health benefits such as lower blood pressure and improved cholesterol levels. Meanwhile, some doctors claim that low-carb diets are overrated and caution that their long-term effects are unknown. Although following a low-carbohydrate diet can benefit some people, these diets are not necessarily the best option for everyone who wants to lose weight or improve their health.

\section{Exercise 1}

Write the introductory paragraph of your research paper. Try using one of the techniques listed in this section to write an engaging introduction. Be sure to include background information about the topic that leads to your thesis.

\section{Tip}

Writers often work out of sequence when writing a research paper. If you find yourself struggling to write an engaging introduction, you may wish to write the body of your paper first. Writing the body sections first will help you clarify your main points. Writing the introduction should then be easier. You may have a better sense of how to introduce the paper after you have drafted some or all of the body. 


\section{Writing Your Conclusion}

In your introduction, you tell readers where they are headed. In your conclusion, you recap where they have been. For this reason, some writers prefer to write their conclusions soon after they have written their introduction. However, this method may not work for all writers. Other writers prefer to write their conclusion at the end of the paper, after writing the body paragraphs. No process is absolutely right or absolutely wrong; find the one that best suits you.

No matter when you compose the conclusion, it should sum up your main ideas and revisit your thesis. The conclusion should not simply echo the introduction or rely on bland summary statements, such as "In this paper, I have demonstrated that...." In fact, avoid repeating your thesis verbatim from the introduction. Restate it in different words that reflect the new perspective gained through your research. That helps keep your ideas fresh for your readers. An effective writer might conclude a paper by asking a new question the research inspired, revisiting an anecdote presented earlier, or reminding readers of how the topic relates to their lives.

\section{Writing at Work}

If your job involves writing or reading scientific papers, it helps to understand how professional researchers use the structure described in this section. A scientific paper begins with an abstract that briefly summarizes the entire paper. The introduction explains the purpose of the research, briefly summarizes previous research, and presents the researchers' hypothesis. The body provides details about the study, such as who participated in it, what the researchers measured, and what results they recorded. The conclusion presents the researchers' interpretation of the data, or what they learned.

\section{Using Source Material in Your Paper}

One of the challenges of writing a research paper is successfully integrating your ideas with material from your sources. Your paper must explain what you think, or it will read like a disconnected string of facts and quotations. However, you also need to support your ideas with research, or they will seem insubstantial. How do you strike the right balance?

You have already taken a step in the right direction by writing your introduction. The introduction and conclusion function like the frame around a picture. They define and limit your topic and place your research in context.

In the body paragraphs of your paper, you will need to integrate ideas carefully at the paragraph level and at the sentence level. You will use topic sentences in your paragraphs to make sure readers understand the significance of any facts, details, or quotations you cite. You will also include sentences that transition between ideas from your research, either within a paragraph or between paragraphs. At the sentence level, you will need to think carefully about how you introduce paraphrased and quoted 
material.

Earlier you learned about summarizing, paraphrasing, and quoting when taking notes. In the next few sections, you will learn how to use these techniques in the body of your paper to weave in source material to support your ideas.

\section{Summarizing Sources}

When you summarize material from a source, you zero in on the main points and restate them concisely in your own words. This technique is appropriate when only the major ideas are relevant to your paper or when you need to simplify complex information into a few key points for your readers.

Be sure to review the source material as you summarize it. Identify the main idea and restate it as concisely as you can-preferably in one sentence. Depending on your purpose, you may also add another sentence or two condensing any important details or examples. Check your summary to make sure it is accurate and complete.

In his draft, Jorge summarized research materials that presented scientists' findings about lowcarbohydrate diets. Read the following passage from a trade magazine article and Jorge's summary of the article.

\section{Assessing the Efficacy of Low-Carbohydrate Diets}

Adrienne Howell, Ph.D.

Over the past few years, a number of clinical studies have explored whether high-protein, low-carbohydrate diets are more effective for weight loss than other frequently recommended diet plans, such as diets that drastically curtail fat intake (Pritikin) or that emphasize consuming lean meats, grains, vegetables, and a moderate amount of unsaturated fats (the Mediterranean diet). A 2009 study found that obese teenagers who followed a low-carbohydrate diet lost an average of 15.6 kilograms over a six-month period, whereas teenagers following a low-fat diet or a Mediterranean diet lost an average of 11.1 kilograms and 9.3 kilograms respectively. Two 2010 studies that measured weight loss for obese adults following these same three diet plans found similar results. Over three months, subjects on the low-carbohydrate diet plan lost anywhere from four to six kilograms more than subjects who followed other diet plans.

\section{Summary}

In three recent studies, researchers compared outcomes for obese subjects who followed either a lowcarbohydrate diet, a low-fat diet, or a Mediterranean diet and found that subjects following a lowcarbohydrate diet lost more weight in the same time (Howell, 2010). 


\section{Tip}

A summary restates ideas in your own words-but for specialized or clinical terms, you may need to use terms that appear in the original source. For instance, Jorge used the term obese in his summary because related words such as heavy or overweight have a different clinical meaning.

\section{Exercise 2}

On a separate sheet of paper, practice summarizing by writing a one-sentence summary of the same passage that Jorge already summarized.

\section{Paraphrasing Sources}

When you paraphrase material from a source, restate the information from an entire sentence or passage in your own words, using your own original sentence structure. A paraphrased source differs from a summarized source in that you focus on restating the ideas, not condensing them.

Again, it is important to check your paraphrase against the source material to make sure it is both accurate and original. Inexperienced writers sometimes use the thesaurus method of paraphrasing-that is, they simply rewrite the source material, replacing most of the words with synonyms. This constitutes a misuse of sources. A true paraphrase restates ideas using the writer's own language and style.

In his draft, Jorge frequently paraphrased details from sources. At times, he needed to rewrite a sentence more than once to ensure he was paraphrasing ideas correctly. Read the passage from a website. Then read Jorge's initial attempt at paraphrasing it, followed by the final version of his paraphrase.

\section{Source}

Dieters nearly always get great results soon after they begin following a low-carbohydrate diet, but these results tend to taper off after the first few months, particularly because many dieters find it difficult to follow a low-carbohydrate diet plan consistently. 


\section{Summary}

People usually see encouraging outcomes shortly after they go on a low-carbohydrate diet, but their progress slows down after a short while, especially because most discover that it is a challenge to adhere to the diet strictly (Heinz, 2009).

After reviewing the paraphrased sentence, Jorge realized he was following the original source too closely. He did not want to quote the full passage verbatim, so he again attempted to restate the idea in his own style.

\section{Summary}

Because it is hard for dieters to stick to a low-carbohydrate eating plan, the initial success of these diets is short-lived (Heinz, 2009).

\section{Exercise 3}

On a separate sheet of paper, follow these steps to practice paraphrasing.

1. Choose an important idea or detail from your notes.

2. Without looking at the original source, restate the idea in your own words.

3. Check your paraphrase against the original text in the source. Make sure both your language and your sentence structure are original.

4. Revise your paraphrase if necessary.

\section{Quoting Sources Directly}

Most of the time, you will summarize or paraphrase source material instead of quoting directly. Doing so shows that you understand your research well enough to write about it confidently in your own words. However, direct quotes can be powerful when used sparingly and with purpose.

Quoting directly can sometimes help you make a point in a colorful way. If an author's words are especially vivid, memorable, or well phrased, quoting them may help hold your reader's interest. Direct quotations from an interviewee or an eyewitness may help you personalize an issue for readers. And when you analyze primary sources, such as a historical speech or a work of literature, quoting extensively is often necessary to illustrate your points. These are valid reasons to use quotations. 
Less experienced writers, however, sometimes overuse direct quotations in a research paper because it seems easier than paraphrasing. At best, this reduces the effectiveness of the quotations. At worst, it results in a paper that seems haphazardly pasted together from outside sources. Use quotations sparingly for greater impact.

When you do choose to quote directly from a source, follow these guidelines:

- Make sure you have transcribed the original statement accurately.

- Represent the author's ideas honestly. Quote enough of the original text to reflect the author's point accurately.

- Never use a stand-alone quotation. Always integrate the quoted material into your own sentence.

- Use ellipses (...) if you need to omit a word or phrase. Use brackets [ ] if you need to replace a word or phrase.

- Make sure any omissions or changed words do not alter the meaning of the original text. Omit or replace words only when absolutely necessary to shorten the text or to make it grammatically correct within your sentence.

- Remember to include correctly formatted citations that follow the assigned style guide.

Jorge interviewed a dietician as part of his research, and he decided to quote her words in his paper. Read an excerpt from the interview and Jorge's use of it, which follows.

\section{Source}

Personally, I don’t really buy into all of the hype about low-carbohydrate miracle diets like Atkins and so on. Sure, for some people, they are great, but for most, any sensible eating and exercise plan would work just as well.

\section{Summary}

Registered dietician Dana Kwon (2010) admits, “Personally, I don’t really buy into all of the hype....Sure, for some people, [low-carbohydrate diets] are great, but for most, any sensible eating and exercise plan would work just as well.”

Notice how Jorge smoothly integrated the quoted material by starting the sentence with an introductory phrase. His use of ellipses and brackets did not change the source's meaning. 


\section{Documenting Source Material}

Throughout the writing process, be scrupulous about documenting information taken from sources. The purpose of doing so is twofold:

1. To give credit to other writers or researchers for their ideas

2. To allow your reader to follow up and learn more about the topic if desired

You will cite sources within the body of your paper and at the end of the paper in your bibliography. For this assignment, you will use the citation format used by the American Psychological Association (also known as APA style). For information on the format used by the Modern Language Association (MLA style), see Chapter 13 "APA and MLA Documentation and Formatting".

\section{Citing Sources in the Body of Your Paper}

In-text citations document your sources within the body of your paper. These include two vital pieces of information: the author's name and the year the source material was published. When quoting a print source, also include in the citation the page number where the quoted material originally appears. The page number will follow the year in the in-text citation. Page numbers are necessary only when content has been directly quoted, not when it has been summarized or paraphrased.

Within a paragraph, this information may appear as part of your introduction to the material or as a parenthetical citation at the end of a sentence. Read the examples that follow. For more information about in-text citations for other source types, see Chapter 13 "APA and MLA Documentation and Formatting”.

\section{Summary}

Leibowitz (2008) found that low-carbohydrate diets often helped subjects with Type II diabetes maintain a healthy weight and control blood-sugar levels.

The introduction to the source material includes the author's name followed by the year of publication in parentheses.

\section{Summary}

Low-carbohydrate diets often help subjects with Type II diabetes maintain a healthy weight and control blood-sugar levels (Leibowitz, 2008). 
The parenthetical citation at the end of the sentence includes the author's name, a comma, and the year the source was published. The period at the end of the sentence comes after the parentheses.

\section{Creating a List of References}

Each of the sources you cite in the body text will appear in a references list at the end of your paper. While in-text citations provide the most basic information about the source, your references section will include additional publication details. In general, you will include the following information:

- The author's last name followed by his or her first (and sometimes middle) initial

- The year the source was published

- The source title

- For articles in periodicals, the full name of the periodical, along with the volume and issue number and the pages where the article appeared

Additional information may be included for different types of sources, such as online sources. For a detailed guide to APA or MLA citations, see Chapter 13 "APA and MLA Documentation and Formatting”. A sample reference list is provided with the final draft of Jorge's paper later in this chapter.

\section{Using Primary and Secondary Research}

As you write your draft, be mindful of how you are using primary and secondary source material to support your points. Recall that primary sources present firsthand information. Secondary sources are one step removed from primary sources. They present a writer's analysis or interpretation of primary source materials. How you balance primary and secondary source material in your paper will depend on the topic and assignment.

\section{Using Primary Sources Effectively}

Some types of research papers must use primary sources extensively to achieve their purpose. Any paper that analyzes a primary text or presents the writer's own experimental research falls in this category. Here are a few examples:

- A paper for a literature course analyzing several poems by Emily Dickinson

- A paper for a political science course comparing televised speeches delivered by two presidential candidates

- A paper for a communications course discussing gender biases in television commercials

- A paper for a business administration course that discusses the results of a survey the writer 
conducted with local businesses to gather information about their work-from-home and flextime policies

- A paper for an elementary education course that discusses the results of an experiment the writer conducted to compare the effectiveness of two different methods of mathematics instruction

For these types of papers, primary research is the main focus. If you are writing about a work (including nonprint works, such as a movie or a painting), it is crucial to gather information and ideas from the original work, rather than relying solely on others' interpretations. And, of course, if you take the time to design and conduct your own field research, such as a survey, a series of interviews, or an experiment, you will want to discuss it in detail. For example, the interviews may provide interesting responses that you want to share with your reader.

\section{Using Secondary Sources Effectively}

For some assignments, it makes sense to rely more on secondary sources than primary sources. If you are not analyzing a text or conducting your own field research, you will need to use secondary sources extensively.

As much as possible, use secondary sources that are closely linked to primary research, such as a journal article presenting the results of the authors' scientific study or a book that cites interviews and case studies. These sources are more reliable and add more value to your paper than sources that are further removed from primary research. For instance, a popular magazine article on junk-food addiction might be several steps removed from the original scientific study on which it is loosely based. As a result, the article may distort, sensationalize, or misinterpret the scientists’ findings.

Even if your paper is largely based on primary sources, you may use secondary sources to develop your ideas. For instance, an analysis of Alfred Hitchcock's films would focus on the films themselves as a primary source, but might also cite commentary from critics. A paper that presents an original experiment would include some discussion of similar prior research in the field.

Jorge knew he did not have the time, resources, or experience needed to conduct original experimental research for his paper. Because he was relying on secondary sources to support his ideas, he made a point of citing sources that were not far removed from primary research.

\section{Tip}

Some sources could be considered primary or secondary sources, depending on the writer's purpose for using them. For instance, if a writer's purpose is to inform readers about how the No Child Left Behind legislation has affected elementary education, a Time magazine article on the subject would be a secondary source.

However, suppose the writer's purpose is to analyze how the news media has portrayed the effects of the No Child Left Behind legislation. In that case, articles about the legislation in news magazines like Time, 
Newsweek, and US News \& World Report would be primary sources. They provide firsthand examples of the media coverage the writer is analyzing.

\section{Avoiding Plagiarism}

Your research paper presents your thinking about a topic, supported and developed by other people's ideas and information. It is crucial to always distinguish between the two-as you conduct research, as you plan your paper, and as you write. Failure to do so can lead to plagiarism.

\section{Intentional and Accidental Plagiarism}

Plagiarism is the act of misrepresenting someone else's work as your own. Sometimes a writer plagiarizes work on purpose-for instance, by purchasing an essay from a website and submitting it as original course work. In other cases, a writer may commit accidental plagiarism due to carelessness, haste, or misunderstanding. To avoid unintentional plagiarism, follow these guidelines:

- Understand what types of information must be cited.

- Understand what constitutes fair use of a source.

- Keep source materials and notes carefully organized.

- Follow guidelines for summarizing, paraphrasing, and quoting sources.

\section{When to Cite}

Any idea or fact taken from an outside source must be cited, in both the body of your paper and the references list. The only exceptions are facts or general statements that are common knowledge. Common-knowledge facts or general statements are commonly supported by and found in multiple sources. For example, a writer would not need to cite the statement that most breads, pastas, and cereals are high in carbohydrates; this is well known and well documented. However, if a writer explained in detail the differences among the chemical structures of carbohydrates, proteins, and fats, a citation would be necessary. When in doubt, cite.

\section{Fair Use}

In recent years, issues related to the fair use of sources have been prevalent in popular culture. Recording artists, for example, may disagree about the extent to which one has the right to sample another's music. 
For academic purposes, however, the guidelines for fair use are reasonably straightforward.

Writers may quote from or paraphrase material from previously published works without formally obtaining the copyright holder's permission. Fair use means that the writer legitimately uses brief excerpts from source material to support and develop his or her own ideas. For instance, a columnist may excerpt a few sentences from a novel when writing a book review. However, quoting or paraphrasing another's work at excessive length, to the extent that large sections of the writing are unoriginal, is not fair use.

As he worked on his draft, Jorge was careful to cite his sources correctly and not to rely excessively on any one source. Occasionally, however, he caught himself quoting a source at great length. In those instances, he highlighted the paragraph in question so that he could go back to it later and revise. Read the example, along with Jorge’s revision.

\section{Summary}

Heinz (2009) found that "subjects in the low-carbohydrate group (30\% carbohydrates; $40 \%$ protein, $30 \%$ fat) had a mean weight loss of $10 \mathrm{~kg}$ (22 lbs) over a 4-month period." These results were "noticeably better than results for subjects on a low-fat diet (45\% carbohydrates, 35\% protein, $20 \%$ fat)" whose average weight loss was only "7 kg (15.4 lbs) in the same period." From this, it can be concluded that "low-carbohydrate diets obtain more rapid results." Other researchers agree that "at least in the short term, patients following lowcarbohydrate diets enjoy greater success” than those who follow alternative plans (Johnson \& Crowe, 2010).

After reviewing the paragraph, Jorge realized that he had drifted into unoriginal writing. Most of the paragraph was taken verbatim from a single article. Although Jorge had enclosed the material in quotation marks, he knew it was not an appropriate way to use the research in his paper.

\section{Summary}

Low-carbohydrate diets may indeed be superior to other diet plans for short-term weight loss. In a study comparing low-carbohydrate diets and low-fat diets, Heinz (2009) found that subjects who followed a lowcarbohydrate plan (30\% of total calories) for 4 months lost, on average, about 3 kilograms more than subjects who followed a low-fat diet for the same time. Heinz concluded that these plans yield quick results, an idea supported by a similar study conducted by Johnson and Crowe (2010). What remains to be seen, however, is whether this initial success can be sustained for longer periods.

As Jorge revised the paragraph, he realized he did not need to quote these sources directly. Instead, he paraphrased their most important findings. He also made sure to include a topic sentence stating the main idea of the paragraph and a concluding sentence that transitioned to the next major topic in his essay. 


\section{Working with Sources Carefully}

Disorganization and carelessness sometimes lead to plagiarism. For instance, a writer may be unable to provide a complete, accurate citation if he didn't record bibliographical information. A writer may cut and paste a passage from a website into her paper and later forget where the material came from. A writer who procrastinates may rush through a draft, which easily leads to sloppy paraphrasing and inaccurate quotations. Any of these actions can create the appearance of plagiarism and lead to negative consequences.

Carefully organizing your time and notes is the best guard against these forms of plagiarism. Maintain a detailed working bibliography and thorough notes throughout the research process. Check original sources again to clear up any uncertainties. Allow plenty of time for writing your draft so there is no temptation to cut corners.

\section{Writing at Work}

Citing other people's work appropriately is just as important in the workplace as it is in school. If you need to consult outside sources to research a document you are creating, follow the general guidelines already discussed, as well as any industry-specific citation guidelines. For more extensive use of others' work-for instance, requesting permission to link to another company's website on your own corporate website—always follow your employer's established procedures.

\section{Academic Integrity}

The concepts and strategies discussed in this section of Chapter 12 "Writing a Research Paper" connect to a larger issue-academic integrity. You maintain your integrity as a member of an academic community by representing your work and others' work honestly and by using other people's work only in legitimately accepted ways. It is a point of honor taken seriously in every academic discipline and career field.

Academic integrity violations have serious educational and professional consequences. Even when cheating and plagiarism go undetected, they still result in a student's failure to learn necessary research and writing skills. Students who are found guilty of academic integrity violations face consequences ranging from a failing grade to expulsion from the university. Employees may be fired for plagiarism and do irreparable damage to their professional reputation. In short, it is never worth the risk. 


\section{Key Takeaways}

- An effective research paper focuses on the writer's ideas. The introduction and conclusion present and revisit the writer's thesis. The body of the paper develops the thesis and related points with information from research.

- Ideas and information taken from outside sources must be cited in the body of the paper and in the references section.

- Material taken from sources should be used to develop the writer's ideas. Summarizing and paraphrasing are usually most effective for this purpose.

- A summary concisely restates the main ideas of a source in the writer's own words.

- A paraphrase restates ideas from a source using the writer's own words and sentence structures.

- Direct quotations should be used sparingly. Ellipses and brackets must be used to indicate words that were omitted or changed for conciseness or grammatical correctness.

- Always represent material from outside sources accurately.

- Plagiarism has serious academic and professional consequences. To avoid accidental plagiarism, keep research materials organized, understand guidelines for fair use and appropriate citation of sources, and review the paper to make sure these guidelines are followed. 


\subsection{Developing a Final Draft of a Research Paper}

\section{Learning Objectives}

1. Revise your paper to improve organization and cohesion.

2. Determine an appropriate style and tone for your paper.

3. Revise to ensure that your tone is consistent.

4. Edit your paper to ensure that language, citations, and formatting are correct.

Given all the time and effort you have put into your research project, you will want to make sure that your final draft represents your best work. This requires taking the time to revise and edit your paper carefully.

You may feel like you need a break from your paper before you revise and edit it. That is understandable - but leave yourself with enough time to complete this important stage of the writing process. In this section, you will learn the following specific strategies that are useful for revising and editing a research paper:

- How to evaluate and improve the overall organization and cohesion

- How to maintain an appropriate style and tone

- How to use checklists to identify and correct any errors in language, citations, and formatting

\section{Revising Your Paper: Organization and Cohesion}

When writing a research paper, it is easy to become overly focused on editorial details, such as the proper format for bibliographical entries. These details do matter. However, before you begin to address them, it is important to spend time reviewing and revising the content of the paper.

A good research paper is both organized and cohesive. Organization means that your argument flows logically from one point to the next. Cohesion means that the elements of your paper work together smoothly and naturally. In a cohesive research paper, information from research is seamlessly integrated with the writer's ideas. 


\section{Revise to Improve Organization}

When you revise to improve organization, you look at the flow of ideas throughout the essay as a whole and within individual paragraphs. You check to see that your essay moves logically from the introduction to the body paragraphs to the conclusion, and that each section reinforces your thesis. Use Checklist 12.1 to help you.

\section{Checklist 12.1}

Revision: Organization

At the essay level

- Does my introduction proceed clearly from the opening to the thesis?

- Does each body paragraph have a clear main idea that relates to the thesis?

- Do the main ideas in the body paragraphs flow in a logical order? Is each paragraph connected to the one before it?

- Do I need to add or revise topic sentences or transitions to make the overall flow of ideas clearer?

- Does my conclusion summarize my main ideas and revisit my thesis?

\section{At the paragraph level}

- Does the topic sentence clearly state the main idea?

- Do the details in the paragraph relate to the main idea?

- Do I need to recast any sentences or add transitions to improve the flow of sentences?

Jorge reread his draft paragraph by paragraph. As he read, he highlighted the main idea of each paragraph so he could see whether his ideas proceeded in a logical order. For the most part, the flow of ideas was clear. However, he did notice that one paragraph did not have a clear main idea. It interrupted the flow of the writing. During revision, Jorge added a topic sentence that clearly connected the paragraph to the one that had preceded it. He also added transitions to improve the flow of ideas from sentence to sentence.

Read the following paragraphs twice, the first time without Jorge's changes, and the second time with them. 


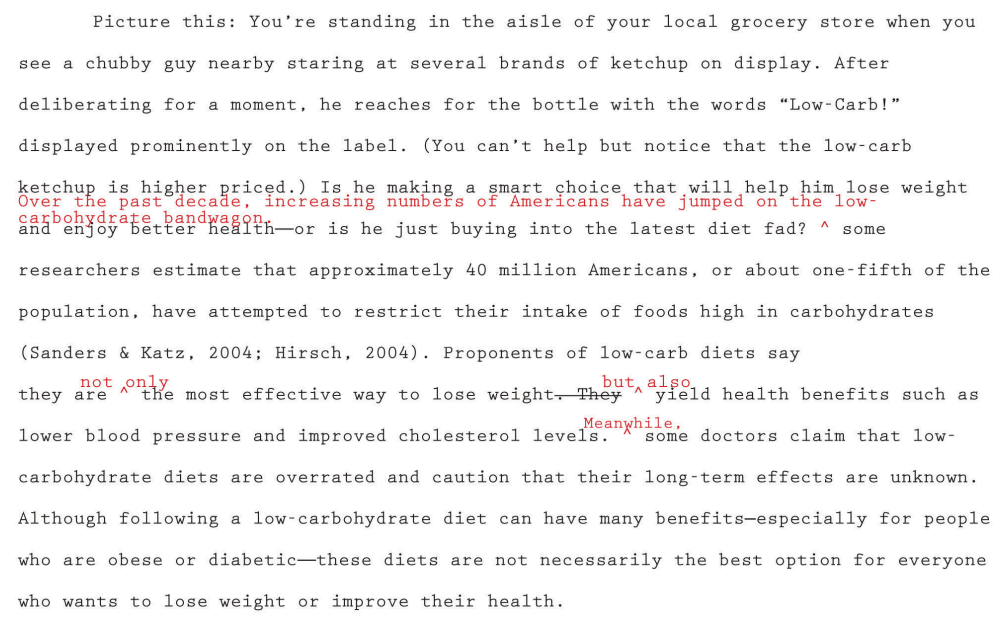

\section{Exercise 1}

Follow these steps to begin revising your paper's overall organization.

1. Print out a hard copy of your paper.

2. Read your paper paragraph by paragraph. Highlight your thesis and the topic sentence of each paragraph.

3. Using the thesis and topic sentences as starting points, outline the ideas you presented-just as you would do if you were outlining a chapter in a textbook. Do not look at the outline you created during prewriting. You may write in the margins of your draft or create a formal outline on a separate sheet of paper.

4. Next, reread your paper more slowly, looking for how ideas flow from sentence to sentence. Identify places where adding a transition or recasting a sentence would make the ideas flow more logically.

5. Review the topics on your outline. Is there a logical flow of ideas? Identify any places where you may need to reorganize ideas.

6. Begin to revise your paper to improve organization. Start with any major issues, such as needing to move an entire paragraph. Then proceed to minor revisions, such as adding a transitional phrase or tweaking a topic sentence so it connects ideas more clearly.

\section{Collaboration}

Please share your paper with a classmate. Repeat the six steps and take notes on a separate piece of paper. Share and compare notes. 


\section{Tip}

Writers choose transitions carefully to show the relationships between ideas-for instance, to make a comparison or elaborate on a point with examples. Make sure your transitions suit your purpose and avoid overusing the same ones. For an extensive list of transitions, see Chapter 8 "The Writing Process: How Do I Begin?", Section 8.4 "Revising and Editing”.

\section{Revise to Improve Cohesion}

When you revise to improve cohesion, you analyze how the parts of your paper work together. You look for anything that seems awkward or out of place. Revision may involve deleting unnecessary material or rewriting parts of the paper so that the out-of-place material fits in smoothly.

In a research paper, problems with cohesion usually occur when a writer has trouble integrating source material. If facts or quotations have been awkwardly dropped into a paragraph, they distract or confuse the reader instead of working to support the writer's point. Overusing paraphrased and quoted material has the same effect. Use Checklist 12.2 to review your essay for cohesion.

\section{Checklist 12.2}

Revision: Cohesion

- Does the opening of the paper clearly connect to the broader topic and thesis? Make sure entertaining quotes or anecdotes serve a purpose.

- Have I included support from research for each main point in the body of my paper?

- Have I included introductory material before any quotations? Quotations should never stand alone in a paragraph.

- Does paraphrased and quoted material clearly serve to develop my own points?

- Do I need to add to or revise parts of the paper to help the reader understand how certain information from a source is relevant?

- Are there any places where I have overused material from sources?

- Does my conclusion make sense based on the rest of the paper? Make sure any new questions or suggestions in the conclusion are clearly linked to earlier material.

As Jorge reread his draft, he looked to see how the different pieces fit together to prove his thesis. He realized that some of his supporting information needed to be integrated more carefully and decided to omit some details entirely. Read the following paragraph, first without Jorge's revisions and then with them. 


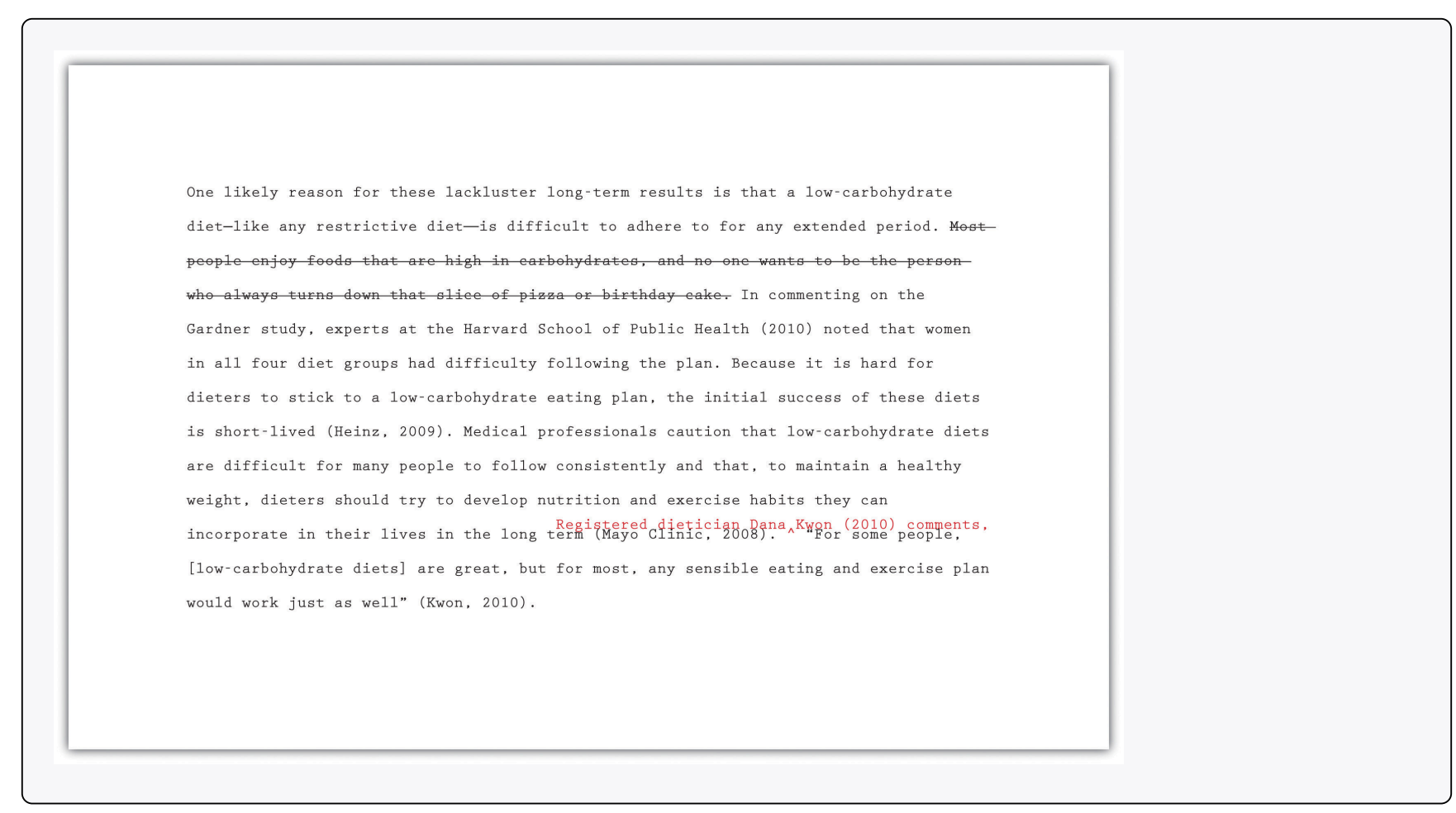

Jorge decided that his comment about pizza and birthday cake came across as subjective and was not necessary to make his point, so he deleted it. He also realized that the quotation at the end of the paragraph was awkward and ineffective. How would his readers know who Kwon was or why her opinion should be taken seriously? Adding an introductory phrase helped Jorge integrate this quotation smoothly and establish the credibility of his source.

\section{Exercise 2}

Follow these steps to begin revising your paper to improve cohesion.

1. Print out a hard copy of your paper, or work with your printout from Note 12.33 "Exercise 1".

2. Read the body paragraphs of your paper first. Each time you come to a place that cites information from sources, ask yourself what purpose this information serves. Check that it helps support a point and that it is clearly related to the other sentences in the paragraph.

3. Identify unnecessary information from sources that you can delete.

4. Identify places where you need to revise your writing so that readers understand the significance of the details cited from sources.

5. Skim the body paragraphs once more, looking for any paragraphs that seem packed with citations. Review these paragraphs carefully for cohesion.

6. Review your introduction and conclusion. Make sure the information presented works with ideas in the body of the paper.

7. Revise the places you identified in your paper to improve cohesion.

\section{Collaboration}


Please exchange papers with a classmate. Complete step four. On a separate piece of paper, note any areas that would benefit from clarification. Return and compare notes.

\section{Writing at Work}

Understanding cohesion can also benefit you in the workplace, especially when you have to write and deliver a presentation. Speakers sometimes rely on cute graphics or funny quotations to hold their audience's attention. If you choose to use these elements, make sure they work well with the substantive content of your presentation. For example, if you are asked to give a financial presentation, and the financial report shows that the company lost money, funny illustrations would not be relevant or appropriate for the presentation.

\section{Using a Consistent Style and Tone}

Once you are certain that the content of your paper fulfills your purpose, you can begin revising to improve style and tone. Together, your style and tone create the voice of your paper, or how you come across to readers. Style refers to the way you use language as a writer-the sentence structures you use and the word choices you make. Tone is the attitude toward your subject and audience that you convey through your word choice.

\section{Determining an Appropriate Style and Tone}

Although accepted writing styles will vary within different disciplines, the underlying goal is the same-to come across to your readers as a knowledgeable, authoritative guide. Writing about research is like being a tour guide who walks readers through a topic. A stuffy, overly formal tour guide can make readers feel put off or intimidated. Too much informality or humor can make readers wonder whether the tour guide really knows what he or she is talking about. Extreme or emotionally charged language comes across as unbalanced.

To help prevent being overly formal or informal, determine an appropriate style and tone at the beginning of the research process. Consider your topic and audience because these can help dictate style and tone. For example, a paper on new breakthroughs in cancer research should be more formal than a paper on ways to get a good night's sleep.

A strong research paper comes across as straightforward, appropriately academic, and serious. It is generally best to avoid writing in the first person, as this can make your paper seem overly subjective and opinion based. Use Checklist 12.3 on style to review your paper for other issues that affect style and tone. You can check for consistency at the end of the writing process. Checking for consistency is discussed later in this section. 


\section{Checklist 12.3}

Style

- My paper avoids excessive wordiness.

- My sentences are varied in length and structure.

- I have avoided using first-person pronouns such as $I$ and we.

- I have used the active voice whenever possible.

- I have defined specialized terms that might be unfamiliar to readers.

- I have used clear, straightforward language whenever possible and avoided unnecessary jargon.

- My paper states my point of view using a balanced tone-neither too indecisive nor too forceful.

\section{Word Choice}

Note that word choice is an especially important aspect of style. In addition to checking the points noted on Checklist 12.3, review your paper to make sure your language is precise, conveys no unintended connotations, and is free of biases. Here are some of the points to check for:

- Vague or imprecise terms

- Slang

- Repetition of the same phrases (“Smith states..., Jones states...”) to introduce quoted and paraphrased material (For a full list of strong verbs to use with in-text citations, see Chapter 13 “APA and MLA Documentation and Formatting”.)

- Exclusive use of masculine pronouns or awkward use of he or she

- Use of language with negative connotations, such as haughty or ridiculous

- Use of outdated or offensive terms to refer to specific ethnic, racial, or religious groups

\section{Tip}

Using plural nouns and pronouns or recasting a sentence can help you keep your language gender neutral while avoiding awkwardness. Consider the following examples.

- Gender-biased: When a writer cites a source in the body of his paper, he must list it on his references page.

- Awkward: When a writer cites a source in the body of his or her paper, he or she must list it on 
his or her references page.

- Improved: Writers must list any sources cited in the body of a paper on the references page.

\section{Keeping Your Style Consistent}

As you revise your paper, make sure your style is consistent throughout. Look for instances where a word, phrase, or sentence just does not seem to fit with the rest of the writing. It is best to reread for style after you have completed the other revisions so that you are not distracted by any larger content issues. Revising strategies you can use include the following:

- Read your paper aloud. Sometimes your ears catch inconsistencies that your eyes miss.

- Share your paper with another reader whom you trust to give you honest feedback. It is often difficult to evaluate one's own style objectively-especially in the final phase of a challenging writing project. Another reader may be more likely to notice instances of wordiness, confusing language, or other issues that affect style and tone.

- Line-edit your paper slowly, sentence by sentence. You may even wish to use a sheet of paper to cover everything on the page except the paragraph you are editing - that forces you to read slowly and carefully. Mark any areas where you notice problems in style or tone, and then take time to rework those sections.

On reviewing his paper, Jorge found that he had generally used an appropriately academic style and tone. However, he noticed one glaring exception-his first paragraph. He realized there were places where his overly informal writing could come across as unserious or, worse, disparaging. Revising his word choice and omitting a humorous aside helped Jorge maintain a consistent tone. Read his revisions.

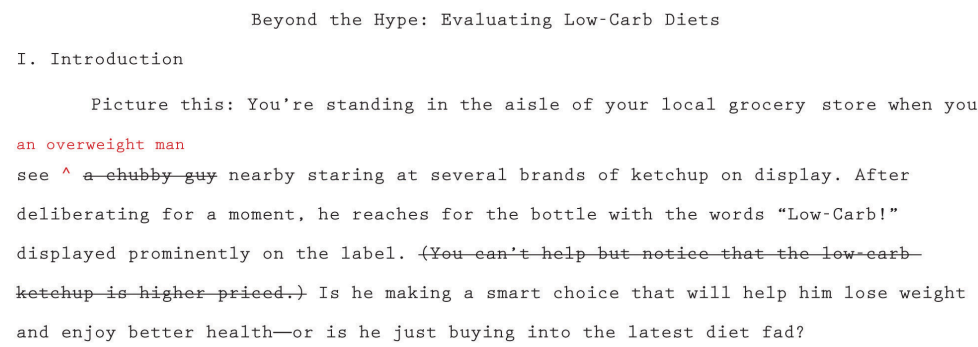




\section{Exercise 3}

Using Checklist 12.3, line-edit your paper. You may use either of these techniques:

1. Print out a hard copy of your paper, or work with your printout from Note 12.33 "Exercise 1". Read it line by line. Check for the issues noted on Checklist 12.3, as well as any other aspects of your writing style you have previously identified as areas for improvement. Mark any areas where you notice problems in style or tone, and then take time to rework those sections.

2. If you prefer to work with an electronic document, use the menu options in your word-processing program to enlarge the text to 150 or 200 percent of the original size. Make sure the type is large enough that you can focus on only one paragraph at a time. Read the paper line by line as described in step 1. Highlight any areas where you notice problems in style or tone, and then take time to rework those sections.

\section{Collaboration}

Please exchange papers with a classmate. On a separate piece of paper, note places where the essay does not seem to flow or you have questions about what was written. Return the essay and compare notes.

\section{Editing Your Paper}

After revising your paper to address problems in content or style, you will complete one final editorial review. Perhaps you already have caught and corrected minor mistakes during previous revisions. Nevertheless, give your draft a final edit to make sure it is error-free. Your final edit should focus on two broad areas:

1. Errors in grammar, mechanics, usage, and spelling

2. Errors in citing and formatting sources

For in-depth information on these two topics, see Chapter 2 "Writing Basics: What Makes a Good Sentence?” and Chapter 13 “APA and MLA Documentation and Formatting”.

\section{Correcting Errors}

Given how much work you have put into your research paper, you will want to check for any errors that could distract or confuse your readers. Using the spell-checking feature in your word-processing program can be helpful-but this should not replace a full, careful review of your document. Be sure to check for any errors that may have come up frequently for you in the past. Use Checklist 12.4 to help you as you edit: 


\section{Checklist 12.4}

Grammar, Mechanics, Punctuation, Usage, and Spelling

- My paper is free of grammatical errors, such as errors in subject-verb agreement and sentence fragments. (For additional guidance on grammar, see Chapter 2 "Writing Basics: What Makes a Good Sentence?”.)

- My paper is free of errors in punctuation and mechanics, such as misplaced commas or incorrectly formatted source titles. (For additional guidance on punctuation and mechanics, see Chapter 3 "Punctuation".)

- My paper is free of common usage errors, such as alot and alright. (For additional guidance on correct usage, see Chapter 4 "Working with Words: Which Word Is Right?".)

- My paper is free of spelling errors. I have proofread my paper for spelling in addition to using the spell-checking feature in my word-processing program.

- I have checked my paper for any editing errors that I know I tend to make frequently.

\section{Checking Citations and Formatting}

When editing a research paper, it is also important to check that you have cited sources properly and formatted your document according to the specified guidelines. There are two reasons for this. First and foremost, citing sources correctly ensures that you have given proper credit to other people for ideas and information that helped you in your work. Second, using correct formatting establishes your paper as one student's contribution to the work developed by and for a larger academic community. Increasingly, American Psychological Association (APA) style guidelines are the standard for many academic fields. Modern Language Association (MLA) is also a standard style in many fields. Use Checklist 12.5 to help you check citations and formatting.

\section{Checklist 12.5}

Citations and Formatting

- Within the body of my paper, each fact or idea taken from a source is credited to the correct source.

- Each in-text citation includes the source author's name (or, where applicable, the organization name or source title) and year of publication. I have used the correct format of in-text and parenthetical citations.

- Each source cited in the body of my paper has a corresponding entry in the references section of my paper. 
- My references section includes a heading and double-spaced, alphabetized entries.

- Each entry in my references section is indented on the second line and all subsequent lines.

- Each entry in my references section includes all the necessary information for that source type, in the correct sequence and format.

- My paper includes a title page.

- My paper includes a running head.

- The margins of my paper are set at one inch. Text is double spaced and set in a standard 12-point font.

For detailed guidelines on APA and MLA citation and formatting, see Chapter 13 "APA and MLA Documentation and Formatting”.

\section{Writing at Work}

Following APA or MLA citation and formatting guidelines may require time and effort. However, it is good practice for learning how to follow accepted conventions in any professional field. Many large corporations create a style manual with guidelines for editing and formatting documents produced by that corporation. Employees follow the style manual when creating internal documents and documents for publication.

During the process of revising and editing, Jorge made changes in the content and style of his paper. He also gave the paper a final review to check for overall correctness and, particularly, correct APA or MLA citations and formatting. Read the final draft of his paper. 
Writing for Success 506

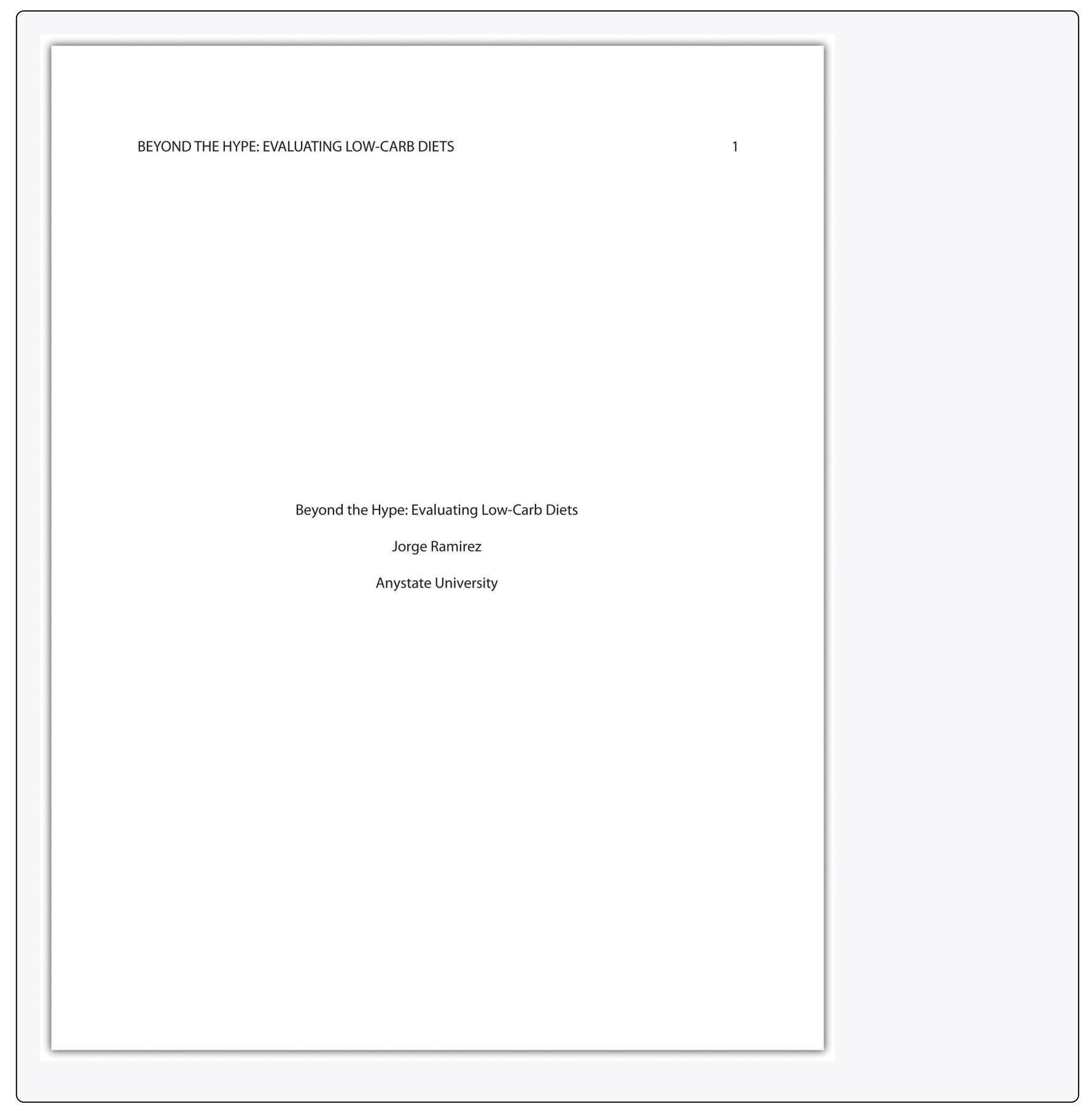




\section{Beyond the Hype: Evaluating Low-Carb Diets}

Picture this: You're standing in the aisle of your local grocery store when you see an overweight man nearby staring at several brands of ketchup on display. After deliberating for a moment, he reaches for the bottle with the words "Low-Carb!" displayed prominently on the label. Is he making a smart choice that will help him lose weight and enjoy better health —or is he just buying into the latest diet fad?

Over the past decade, increasing numbers of Americans have jumped on the low-carb bandwagon. As of 2004, researchers estimated that approximately 40 million Americans, or about one-fifth of the population, were attempting to restrict their intake of food high in carbohydrates (Sanders \& Katz, 2004; Hirsch, 2004). Proponents of low-carb diets say they not only are the most effective way to lose weight but also yield health benefits such as lower blood pressure and improved cholesterol levels. Meanwhile, some doctors claim that low-carb diets are overrated and caution that their long-term effects are unknown. Although following a low-carbohydrate diet can benefit some people, these diets are not necessarily the best option for everyone who wants to lose weight or improve their health.

\section{Purported Benefits of Low-Carbohydrate Diets}

To make sense of the popular enthusiasm for low-carbohydrate diets, it is important to understand proponents' claims about how they work. Any eating plan includes a balance of the three macronutrients - proteins, fats, and carbohydrates — each of which is essential for human health. Different foods provide these macronutrients in different proportions; a steak is primarily a source of protein, and a plate of pasta is primarily a source of carbohydrates. No one recommends eliminating any of these three macronutrient groups entirely. 
However, experts disagree on what protein : fats : carbohydrate ratio is best for optimum health and for maintaining a healthy weight. Since the 1970s, the USDA has recommended that the greatest proportion of one's daily calories should come from carbohydratesbreads, pastas, and cereals - with moderate consumption of proteins and minimal consumption of fats. High-carbohydrate foods form the base of the "food pyramid" familiar to nutrition students.

Those who subscribe to the low-carb philosophy, however, argue that this approach is flawed. They argue that excess weight stems from disordered metabolism, which in turn can be traced to overconsumption of foods high in carbohydrates-especially refined carbohydrates like white flour and sugar (Atkins, 2002; Sears, 1995; Agatson, 2003). The body quickly absorbs sugars from these foods, increasing the level of glucose in the blood. This triggers the release of insulin, delivering energy-providing glucose to cells and storing some of the excess as glycogen. Unfortunately, the liver turns the rest of this excess glucose into fat. Thus, adherents of the low-carb approach often classify foods according to their glycemic index (GI)_ a measurement of how quickly a given food raises blood glucose levels when consumed. Foods high in refined carbohydrates — sugar, potatoes, white breads, and pasta, for instance-have a high glycemic index. '

Dieters who focus solely on reducing fat intake may fail to realize that consuming refined carbohydrates contributes to weight problems. Atkins (2002) notes that low-fat diets recommended to many who wish to lose weight are, by definition, usually high in carbohydrates, and thus unlikely to succeed.

Even worse, consuming high-carbohydrate foods regularly can, over time, wreak havoc with the body's systems for regulating blood sugar levels and insulin production. In some individuals, frequent spikes in blood sugar and insulin levels cause the body to become insulin-resistantless able to use glucose for energy and more likely to convert it to fat (Atkins, 2002). This in turn 
helps to explain the link between obesity and Type 2 diabetes. In contrast, reducing carbohydrate intake purportedly helps the body use food more efficiently for energy. Additional benefits associated with these diets include reduced risk of cardiovascular disease (Atkins, 2002), lowered blood pressure (Bell, 2006; Atkins, 2002), and reduced risk of developing certain cancers (Atkins, 2002).

Given the experts' conflicting recommendations, it is no wonder that patients are confused about how to eat for optimum health. Some may assume that even moderate carbohydrate consumption should be avoided (Harvard School of Public Health, 2010). Others may use the low-carb approach to justify consuming large amounts of foods high in saturated fats-eggs, steak, bacon, and so forth. Meanwhile, low-carb diet plans and products have become a multibillion-dollar industry (Hirsch, 2004). Does this approach live up to its adherents' promises?

\section{Research on Low-Carbohydrate Diets and Weight Loss}

A number of clinical studies have found that low-carbohydrate diet plans are indeed highly effective for weight loss. Gardner et al. (2007) compared outcomes among overweight and obese women who followed one of four popular diet plans: Atkins, The Zone, LEARN, or Ornish. After 12 months, the group that had followed the low-carb Atkins plan had lost significantly more weight than those in the other three groups. McMillan-Price et al. (2006) compared results among overweight and obese young adults who followed one of four plans, all of which were low in fat but had varying proportions of proteins and carbohydrates. They found that, over a 12-week period, the most significant body-fat loss occurred on plans that were high in protein and/or low in "high glycemic index" foods. More recently, the American Heart Association (2010) reported on an Israeli study that found that subjects who followed a low-carbohydrate, high-protein diet lost more weight than those who followed a low-fat plan 
or a Mediterranean plan based on vegetables, grains, and minimal consumption of meats and healthy fats. ${ }^{2}$ Other researchers have also found that low-carbohydrate diets resulted in increased weight loss (Ebbeling, Leidig, Feldman, Lovesky, \& Ludwig, 2007; Bell, 2006; HealthDay, 2010).

Although these results are promising, they may be short-lived. Dieters who succeed in losing weight often struggle to keep the weight off-and unfortunately, low-carb diets are no exception to the rule. HealthDay News (2010) cites a study recently published in the Annals of Internal Medicine that compared obese subjects who followed a low-carbohydrate diet and a low-fat diet. The former group lost more weight in the first six months of the diet, but three years later, only the latter group continued to lose weight steadily — and both groups had difficulty keeping weight off. Similarly, Swiss researchers found that, although low-carb dieters initially lost more weight than those who followed other plans, the differences tended to even out over time (Bell, 2006). This suggests that low-carb diets may be no more effective than other diets for maintaining a healthy weight in the long term.

One likely reason is that a low-carbohydrate diet-like any restrictive diet - is difficult to adhere to for any extended period of time. In commenting on the Gardner study, experts at the Harvard School of Public Health (2010) noted that women in all four diet groups had difficulty following the plan. Because it is hard for dieters to stick to a low-carbohydrate eating plan, the initial success of these diets is short-lived (Heinz, 2009). Medical professionals caution that lowcarb diets are difficult for many people to follow consistently and that, to maintain a healthy weight, dieters should try to develop nutrition and exercise habits they can incorporate in their lives in the long term (Mayo Clinic, 2008). Registered dietician Dana Kwon (2010) comments,

"for some people, [low-carbohydrate diets] are great, but for most, any sensible eating and exercise plan would work just as well." 


\section{Other Long-Term Health Outcomes}

Regardless of whether low-carb diets are most effective for weight loss, their potential benefits for weight loss must be weighed against other long-term health outcomes such as hypertension, the risk of heart disease, and cholesterol levels. Research findings in these areas are mixed. For this reason, people considering following a low-carbohydrate diet to lose weight should be advised of the potential risks in doing so.

Research on how low-carbohydrate diets affect cholesterol levels is inconclusive. Some researchers have found that low-carbohydrate diets raise levels of HDL, or "good" cholesterol (Ebbeling et al., 2007; Seppa, 2008). Unfortunately, they may also raise levels of LDL, or "bad" cholesterol, which is associated with heart disease (Ebbeling et al., 2007; Reuters, 2010). A particular concern is that as dieters on a low-carbohydrate plan increase their intake of meats and dairy products - foods that are high in protein and fat - they are also likely to consume increased amounts of saturated fats, resulting in clogged arteries and again increasing the risk of heart disease. Studies of humans (Bradley et al., 2009) and mice (Foo et al., 2009) have identified possible risks to cardiovascular health associated with low-carb diets. The American Heart Association (2010) and the Harvard School of Public Health (2010) caution that doctors cannot yet assess how following a low-carbohydrate diet affects patients' health over a longterm period.

Some studies (Bell, 2006) have found that following a low-carb diet helped lower patients blood pressure. Again, however, excessive consumption of foods high in saturated fats may, over time, lead to the development of clogged arteries and increase risk of hypertension. Choosing lean meats over those high in fat and supplementing the diet with high-fiber, low-glycemicindex carbohydrates, such as leafy green vegetables, is a healthier plan for dieters to follow. 
Perhaps most surprisingly, low-carbohydrate diets are not necessarily advantageous for patients with Type 2 diabetes. Bradley et al. (2009) found that patients who followed a low-carb or a low-fat diet had comparable outcomes for both weight loss and insulin resistance. The National Diabetes Information Clearinghouse (2010) advises diabetics to monitor blood sugar levels carefully and to consult with their health care provider to develop a plan for healthy eating. Nevertheless, the nutritional guidelines it provides as a dietary starting point closely follow the USDA food pyramid.

\section{Conclusion}

Low-carb diets have garnered a great deal of positive attention, and it isn't entirely undeserved. These diets do lead to rapid weight loss, and they often result in greater weight loss over a period of months than other diet plans. Significantly overweight or obese people may find low-carb eating plans the most effective for losing weight and reducing the risks associated with carrying excess body fat. However, because these diets are difficult for some people to adhere to and because their potential long-term health effects are still being debated, they are not necessarily the ideal choice for anyone who wants to lose weight. A moderately overweight person who wants to lose a only few pounds is best advised to choose whatever plan will help him stay active and consume fewer calories consistently—whether or not it involves eating low-carb ketchup. 
513 [Author removed at request of original publisher]

\section{References}

Agatson, A. (2003). The South Beach diet. New York, NY: St. Martin's Griffin.

The American Heart Association. (2010). American Heart Association comments on

weight loss study comparing low carbohydrate/high protein, Mediterranean style and

low fat diets. http://americanheart.mediaroom.com/index.php?s=43\&item $=473$

Atkins, R. C. (2002). Dr. Atkins' diet revolution. New York, NY: M. Evans and Company.

Bell, J. R. (2006). Low-carb beats low-fat diet for early losses but not long term. OBGYN News, 41(12), 32. doi:10.1016/S0029-7437(06)71905-X

Bradley, U., Spence, M., Courtney, C. H., McKinley, M. C., Ennis, C. N., McCance, D. R.... Hunter, S. J. (2009). Low-fat versus low-carbohydrate weight reduction diets: effects on weight loss, insulin resistance, and cardiovascular risk: A randomized control trial [Abstract]. Diabetes, 58(12), 2741-2748. http://diabetes.diabetesjournals.org/content/early/2009/08/ 23/db09-0098.abstract

Ebbeling, C. B., Leidig, M. M., Feldman, H. A., Lovesky, M. M., \& Ludwig, D. S. (2007). Effects of a low-glycemic load vs low-fat diet in obese young adults: A randomized trial. Journal of the American Medical Association, 297(19), 2092-2102. http://jama.ama-assn.org/cgi/ content/full/297/19/2092? maxtoshow=\&hits=10\&RESULTFORMAT=\&fulltext=ebbeling \&searchid $=1 \&$ FIRSTINDEX $=0$ \&resourcetype $=$ HWCIT

Foo, S. Y., Heller, E. R., Wykrzykowska, J., Sullivan, C. J., Manning-Tobin, J. J., Moore, K. J.... Rosenzweigac, A. (2009). Vascular effects of a low-carbohydrate high-protein diet. Proceedings of the National Academy of Sciences of America, 106(36), 15418-15423. doi: $10.1073 /$ pnas.0907995106

Gardner, C. D., Kiazand, A., Alhassan, S., Kim, S., Stafford, R. S., Balise, R. R....King, A. C. (2007), Comparison of the Atkins, Zone, Ornish, and LEARN Diets for change in weight and related risk factors among overweight premenopausal women. Journal of the American Medical Association, 297(9), 969-977. http://jama.ama-assn.org/cgi/content/full/297/9/ 
969\#AUTHINFO

Harvard School of Public Health. (2010). The Nutrition Source. Carbohydrates: Good carbs guide the way. http://www.hsph.harvard.edu/nutritionsource/what-should-you-eat/ carbohydrates-full-story/index.html\#good-carbs-not-no-carbs

HealthDay. (2010). Low-fat diets beat low-carb regimen long term. http://www.nlm.nih.gov/ medlineplus/news/fullstory_95861.html

Hirsch, J. (2004). The low-carb evolution: Be reactive with low-carb products but proactive with nutrition. Nutraceuticals World. http://www.nutraceuticalsworld.com/contents/view/ 13321

Mayo Foundation for Medical Education and Research (MFMER). (2010). Weight-loss options: 6 common diet plans. http://www.mayoclinic.com/print/weight-loss/NU00616/ METHOD=print

McMillan-Price, J., Petocz, P., Atkinson, F., O'Neill, K., Samman, S., Steinbeck, K....Brand-Miller, J. (2006, July). Comparison of 4 diets of varying glycemic load on weight loss and cardiovascular risk reduction in overweight and obese young adults: A randomized controlled trial. Archives of Internal Medicine, 166(14), 1466-1475. http://archinte.amaassn.org/cgi/content/full/166/14/1466

National Institute of Diabetes and Digestive and Kidney Diseases. (2010). National Diabetes Information Clearinghouse: What I need to know about eating and diabetes. http:// diabetes.niddk.nih.gov/dm/pubs/eating_ez/index.htm

Reuters Health. (2010). Low-carb diet can increase bad cholesterol levels. http://www.nlm.nih. gov/medlineplus/news/fullstory_95708.html

Seppa, N. (2008). Go against the grains, diet study suggests: Low-carb beats low-fat in weight loss, cholesterol. Science News, 174(4), 25. http://www.sciencenews.org/view/issue/id/ 34757

\section{Key Takeaways}

- Organization in a research paper means that the argument proceeds logically from the introduction to the body to the conclusion. It flows logically from one point to the next. When revising a research paper, evaluate the organization of the paper as a whole and the organization of individual paragraphs.

- In a cohesive research paper, the elements of the paper work together smoothly and naturally. When revising a research paper, evaluate its cohesion. In particular, check that information from research is smoothly integrated with your ideas. 
- An effective research paper uses a style and tone that are appropriately academic and serious. When revising a research paper, check that the style and tone are consistent throughout.

- Editing a research paper involves checking for errors in grammar, mechanics, punctuation, usage, spelling, citations, and formatting. 


\subsection{Writing a Research Paper: End-of-Chapter Exercises}

\section{Exercises}

1. In this chapter, you learned strategies for generating and narrowing a topic for a research paper. Brainstorm to create a list of five general topics of personal or professional interest to you that you would like to research. Then use freewriting and preliminary research to narrow three of these topics to manageable size for a five- to seven-page research paper. Save your list of topics in a print or electronic file and add to it periodically as you identify additional areas of interest. Use your topic list as a starting point the next time a research paper is assigned.

2. Working with one of the topics you just identified, use the research skills you learned in this chapter to locate three to five potentially useful print or electronic sources of information about the topic. Create a list that includes the following:

- One subject-specific periodicals database likely to include relevant articles on your topic

- Two articles about your topic written for an educated general audience

- At least one article about your topic written for an audience with specialized knowledge

3. In real-life and work-related contexts, people consult a wide range of different information sources every day, without always making conscious judgments about whether the source is reliable and why. Identify one media source of information you use at least once a week-for instance, a website you visit regularly, or a newspaper or magazine to which you subscribe. Write two paragraphs explaining the following:

- What topics you learn about by reading or viewing this source

- Whether you consider this source reliable and why

In addressing the latter point, be sure to consider details that help you evaluate the source's credibility and reputability, as well as the presence or absence of bias.

4. Different professional communities develop their own standards about the writing style people in that community use when creating documents to share with others. In some cases, these standards may apply to a very broad group of professionals-for example, researchers in many different social sciences use APA style in academic writing. MLA style is commonly used in the humanities, including English classes. In other cases, style guidelines are specific to a particular company or organization. Find a document, such as a newsletter or brochure, that was produced by an organization to which you belong. (Make sure it is a document you have permission to share.) Review the document and answer the following questions:

- What are the purpose, intended audience, and message of this document?

- How does the writing style function to fulfill the purpose, appeal to a particular audience, and convey a message? Consider elements of style, such as word choice, the use of active or passive voice, sentence length, and sentence structure. If your document includes graphics, consider their effectiveness as well.

- Are there any places where the style is inconsistent? 
517 [Author removed at request of original publisher]

- Is the writing style of this document effective for achieving the document's purpose? Why or why not? If it is not effective, explain why. 


\section{Chapter 13: APA and MLA Documentation and Formatting}

13.1 Formatting a Research Paper

13.2 Citing and Referencing Techniques

13.3 Creating a References Section

13.4 Using Modern Language Association (MLA) Style

13.5 APA and MLA Documentation and Formatting: End-of-Chapter Exercises 


\subsection{Formatting a Research Paper}

\section{Learning Objectives}

1. Identify the major components of a research paper written using American Psychological Association (APA) style.

2. Apply general APA style and formatting conventions in a research paper.

In this chapter, you will learn how to use APA style, the documentation and formatting style followed by the American Psychological Association, as well as MLA style, from the Modern Language Association. There are a few major formatting styles used in academic texts, including AMA, Chicago, and Turabian:

- AMA (American Medical Association) for medicine, health, and biological sciences

- APA (American Psychological Association) for education, psychology, and the social sciences

- Chicago-a common style used in everyday publications like magazines, newspapers, and books

- MLA (Modern Language Association) for English, literature, arts, and humanities

- Turabian-another common style designed for its universal application across all subjects and disciplines

While all the formatting and citation styles have their own use and applications, in this chapter we focus our attention on the two styles you are most likely to use in your academic studies: APA and MLA.

If you find that the rules of proper source documentation are difficult to keep straight, you are not alone. Writing a good research paper is, in and of itself, a major intellectual challenge. Having to follow detailed citation and formatting guidelines as well may seem like just one more task to add to an alreadytoo-long list of requirements.

Following these guidelines, however, serves several important purposes. First, it signals to your readers that your paper should be taken seriously as a student's contribution to a given academic or professional field; it is the literary equivalent of wearing a tailored suit to a job interview. Second, it shows that you respect other people's work enough to give them proper credit for it. Finally, it helps your reader find additional materials if he or she wishes to learn more about your topic.

Furthermore, producing a letter-perfect APA-style paper need not be burdensome. Yes, it requires careful attention to detail. However, you can simplify the process if you keep these broad guidelines in mind: 
- Work ahead whenever you can. Chapter 11 “Writing from Research: What Will I Learn?” includes tips for keeping track of your sources early in the research process, which will save time later on.

- Get it right the first time. Apply APA guidelines as you write, so you will not have much to correct during the editing stage. Again, putting in a little extra time early on can save time later.

- Use the resources available to you. In addition to the guidelines provided in this chapter, you may wish to consult the APA website at http://www.apa.org or the Purdue University Online Writing lab at http://owl.english.purdue.edu, which regularly updates its online style guidelines.

\section{General Formatting Guidelines}

This chapter provides detailed guidelines for using the citation and formatting conventions developed by the American Psychological Association, or APA. Writers in disciplines as diverse as astrophysics, biology, psychology, and education follow APA style. The major components of a paper written in APA style are listed in the following box.

These are the major components of an APA-style paper:

1. Title page

2. Abstract

3. Body, which includes the following:

- Headings and, if necessary, subheadings to organize the content

- In-text citations of research sources

4. References page

All these components must be saved in one document, not as separate documents.

\section{Title Page}

The title page of your paper includes the following information:

- Title of the paper

- Author's name

- Name of the institution with which the author is affiliated 
521 [Author removed at request of original publisher]

- Header at the top of the page with the paper title (in capital letters) and the page number (If the title is lengthy, you may use a shortened form of it in the header.)

List the first three elements in the order given in the previous list, centered about one third of the way down from the top of the page. Use the headers and footers tool of your word-processing program to add the header, with the title text at the left and the page number in the upper-right corner. Your title page should look like the following example.

BEYOND THE HYPE: EVALUATING LOW-CARBOHYDRATE DIETS

Beyond the Hype: Evaluating Low-Carb Diets

Jorge Ramirez

Anystate University 


\section{Abstract}

The next page of your paper provides an abstract, or brief summary of your findings. An abstract does not need to be provided in every paper, but an abstract should be used in papers that include a hypothesis. A good abstract is concise-about one hundred fifty to two hundred fifty words - and is written in an objective, impersonal style. Your writing voice will not be as apparent here as in the body of your paper. When writing the abstract, take a just-the-facts approach, and summarize your research question and your findings in a few sentences.

In Chapter 12 "Writing a Research Paper", you read a paper written by a student named Jorge, who researched the effectiveness of low-carbohydrate diets. Read Jorge's abstract. Note how it sums up the major ideas in his paper without going into excessive detail. 


\section{Abstract}

Low-carbohydrate diets have become increasingly popular. Supporters claim they are notably more effective than other diets for weight loss and provide other health benefits such as lower blood pressure and improved cholesterol levels; however, some doctors believe these diets carry potential long-term health risks. A review of the available research literature indicates that low-carbohydrate diets are highly effective for short-term weight loss but that their long-term effectiveness is not significantly greater than other common diet plans. Their long-term effects on cholesterol levels and blood pressure are unknown; research literature suggests some potential for negative health outcomes associated with increased consumption of saturated fat. This conclusion points to the importance of following a balanced, moderate diet appropriate for the individual, as well as the need for further research.

\section{Exercise 1}

Write an abstract summarizing your paper. Briefly introduce the topic, state your findings, and sum up what conclusions you can draw from your research. Use the word count feature of your word-processing program to make sure your abstract does not exceed one hundred fifty words. 
Tip

Depending on your field of study, you may sometimes write research papers that present extensive primary research, such as your own experiment or survey. In your abstract, summarize your research question and your findings, and briefly indicate how your study relates to prior research in the field.

\section{Margins, Pagination, and Headings}

APA style requirements also address specific formatting concerns, such as margins, pagination, and heading styles, within the body of the paper. Review the following APA guidelines.

Use these general guidelines to format the paper:

1. Set the top, bottom, and side margins of your paper at 1 inch.

2. Use double-spaced text throughout your paper.

3. Use a standard font, such as Times New Roman or Arial, in a legible size (10- to 12-point).

4. Use continuous pagination throughout the paper, including the title page and the references section. Page numbers appear flush right within your header.

5. Section headings and subsection headings within the body of your paper use different types of formatting depending on the level of information you are presenting. Additional details from Jorge's paper are provided. 
525 [Author removed at request of original publisher]

BEYOND THE HYPE: EVALUATING LOW-CARBOHYDRATE DIETS

Beyond the Hype: Evaluating Low-Carbohydrate Diets

Jorge Ramirez

Anystate University 


\section{Abstract}

Low-carbohydrate diets have become increasingly popular. Supporters claim they are notably more effective than other diets for weight loss and provide other health benefits such as lower blood pressure and improved cholesterol levels; however, some doctors believe these diets carry potential long-term health risks. A review of the available research literature indicates that low-carbohydrate diets are highly effective for short-term weight loss but that their long-term effectiveness is not significantly greater than other common diet plans. Their long-term effects on cholesterol levels and blood pressure are unknown; research literature suggests some potential for negative health outcomes associated with increased consumption of saturated fat. This conclusion points to the importance of following a balanced, moderate diet appropriate for the individual, as well as the need for further research.

\section{Exercise 2}

Begin formatting the final draft of your paper according to APA guidelines. You may work with an existing document or set up a new document if you choose. Include the following:

- Your title page 
- The abstract you created in Note 13.8 "Exercise 1"

- Correct headers and page numbers for your title page and abstract

\section{Headings}

APA style uses section headings to organize information, making it easy for the reader to follow the writer's train of thought and to know immediately what major topics are covered. Depending on the length and complexity of the paper, its major sections may also be divided into subsections, subsubsections, and so on. These smaller sections, in turn, use different heading styles to indicate different levels of information. In essence, you are using headings to create a hierarchy of information.

The following heading styles used in APA formatting are listed in order of greatest to least importance:

1. Section headings use centered, boldface type. Headings use title case, with important words in the heading capitalized.

2. Subsection headings use left-aligned, boldface type. Headings use title case.

3. The third level uses left-aligned, indented, boldface type. Headings use a capital letter only for the first word, and they end in a period.

4. The fourth level follows the same style used for the previous level, but the headings are boldfaced and italicized.

5. The fifth level follows the same style used for the previous level, but the headings are italicized and not boldfaced.

Visually, the hierarchy of information is organized as indicated in Table 13.1 “Section Headings”.

Table 13.1 Section Headings

\begin{tabular}{|c|c|}
\hline Level of Information & Text Example \\
\hline Level 1 & Heart Disease \\
\hline Level 2 & Lifestyle Factors That Reduce Heart Disease Risk \\
\hline Level 3 & Exercising regularly. \\
\hline Level 4 & Aerobic exercise. \\
\hline Level 5 & Country line dancing. \\
\hline
\end{tabular}

A college research paper may not use all the heading levels shown in Table 13.1 "Section Headings", but 
you are likely to encounter them in academic journal articles that use APA style. For a brief paper, you may find that level 1 headings suffice. Longer or more complex papers may need level 2 headings or other lower-level headings to organize information clearly. Use your outline to craft your major section headings and determine whether any subtopics are substantial enough to require additional levels of headings.

\section{Exercise 3}

Working with the document you developed in Note 13.11 "Exercise 2", begin setting up the heading structure of the final draft of your research paper according to APA guidelines. Include your title and at least two to three major section headings, and follow the formatting guidelines provided above. If your major sections should be broken into subsections, add those headings as well. Use your outline to help you.

Because Jorge used only level 1 headings, his Exercise 3 would look like the following:

\section{Level of Information Text Example}

Level $1 \quad$ Purported Benefits of Low-Carbohydrate Diets

Level $1 \quad$ Research on Low-Carbohydrate Diets and Weight Loss

Level 1 Other Long-Term Health Outcomes

Level $1 \quad$ Conclusion

\section{Citation Guidelines}

\section{In-Text Citations}

Throughout the body of your paper, include a citation whenever you quote or paraphrase material from your research sources. As you learned in Chapter 11 "Writing from Research: What Will I Learn?", the purpose of citations is twofold: to give credit to others for their ideas and to allow your reader to follow up and learn more about the topic if desired. Your in-text citations provide basic information about your source; each source you cite will have a longer entry in the references section that provides more detailed information.

In-text citations must provide the name of the author or authors and the year the source was published. (When a given source does not list an individual author, you may provide the source title or the name of the organization that published the material instead.) When directly quoting a source, it is also required that you include the page number where the quote appears in your citation.

This information may be included within the sentence or in a parenthetical reference at the end of the sentence, as in these examples. 
Epstein (2010) points out that “junk food cannot be considered addictive in the same way that we think of psychoactive drugs as addictive” (p. 137).

Here, the writer names the source author when introducing the quote and provides the publication date in parentheses after the author's name. The page number appears in parentheses after the closing quotation marks and before the period that ends the sentence.

Addiction researchers caution that "junk food cannot be considered addictive in the same way that we think of psychoactive drugs as addictive” (Epstein, 2010, p. 137).

Here, the writer provides a parenthetical citation at the end of the sentence that includes the author's name, the year of publication, and the page number separated by commas. Again, the parenthetical citation is placed after the closing quotation marks and before the period at the end of the sentence.

As noted in the book Junk Food, Junk Science (Epstein, 2010, p. 137), “junk food cannot be considered addictive in the same way that we think of psychoactive drugs as addictive.”

Here, the writer chose to mention the source title in the sentence (an optional piece of information to include) and followed the title with a parenthetical citation. Note that the parenthetical citation is placed before the comma that signals the end of the introductory phrase.

David Epstein's book Junk Food, Junk Science (2010) pointed out that “junk food cannot be considered addictive in the same way that we think of psychoactive drugs as addictive” (p. 137).

Another variation is to introduce the author and the source title in your sentence and include the publication date and page number in parentheses within the sentence or at the end of the sentence. As long as you have included the essential information, you can choose the option that works best for that particular sentence and source.

Citing a book with a single author is usually a straightforward task. Of course, your research may require that you cite many other types of sources, such as books or articles with more than one author or sources with no individual author listed. You may also need to cite sources available in both print and online and nonprint sources, such as websites and personal interviews. Chapter 13 "APA and MLA Documentation and Formatting", Section 13.2 "Citing and Referencing Techniques" and Section 13.3 “Creating a References Section” provide extensive guidelines for citing a variety of source types. 


\section{Writing at Work}

APA is just one of several different styles with its own guidelines for documentation, formatting, and language usage. Depending on your field of interest, you may be exposed to additional styles, such as the following:

- MLA style. Determined by the Modern Languages Association and used for papers in literature, languages, and other disciplines in the humanities.

- Chicago style. Outlined in the Chicago Manual of Style and sometimes used for papers in the humanities and the sciences; many professional organizations use this style for publications as well.

- Associated Press (AP) style. Used by professional journalists.

\section{References List}

The brief citations included in the body of your paper correspond to the more detailed citations provided at the end of the paper in the references section. In-text citations provide basic information-the author's name, the publication date, and the page number if necessary-while the references section provides more extensive bibliographical information. Again, this information allows your reader to follow up on the sources you cited and do additional reading about the topic if desired.

The specific format of entries in the list of references varies slightly for different source types, but the entries generally include the following information:

- The name(s) of the author(s) or institution that wrote the source

- The year of publication and, where applicable, the exact date of publication

- The full title of the source

- For books, the city of publication

- For articles or essays, the name of the periodical or book in which the article or essay appears

- For magazine and journal articles, the volume number, issue number, and pages where the article appears

- For sources on the web, the URL where the source is located

The references page is double spaced and lists entries in alphabetical order by the author's last name. If an entry continues for more than one line, the second line and each subsequent line are indented five spaces. Review the following example. (Chapter 13 "APA and MLA Documentation and Formatting”, Section 13.3 "Creating a References Section" provides extensive guidelines for formatting reference entries for different types of sources.) 


\section{References}

Agatson, A. (2003). The South Beach diet. New York, NY: St. Martin's Griffin.

The American Heart Association. (2010). American Heart Association comments on weight loss study comparing low carbohydrate/high protein, Mediterranean style and low fat diets. http://americanheart.mediaroom.com/index.php?s=43\&item=473

Atkins, R. C. (2002). Dr. Atkins' diet revolution. New York, NY: M. Evans and Company.

Bell, J. R. (2006). Low-carb beats low-fat diet for early losses but not long term. OBGYN News, 41(12), 32. doi:10.1016/S0029-7437(06)71905-X

Bradley, U., Spence, M., Courtney, C. H., McKinley, M. C., Ennis, C. N., McCance, D. R.... Hunter, S. J. (2009). Low-fat versus low-carbohydrate weight reduction diets: effects on weight loss, insulin resistance, and cardiovascular risk: A randomized control trial [Abstract]. Diabetes, 58(12), 2741-2748. Recieved from http://diabetes.diabetesjournals.org/content/ early/2009/08/23/db09-0098.abstract

Ebbeling, C. B., Leidig, M. M., Feldman, H. A., Lovesky, M. M., \& Ludwig, D. S. (2007). Effects of a low-glycemic load vs low-fat diet in obese young adults: A randomized trial. Journal of the American Medical Association, 297(19), 2092-2102.

Foo, S. Y., Heller, E. R., Wykrzykowska, J., Sullivan, C. J., Manning-Tobin, J. J., Moore,

K. J....Rosenzweigac, A. (2009). Vascular effects of a low-carbohydrate high-protein diet. Proceedings of the National Academy of Sciences of America, 106(36), 15418-15423. doi:10.1073/pnas.0907995106

Gardner, C. D., Kiazand, A., Alhassan, S., Kim, S., Stafford, R. S., Balise, R. R....King, A. C. (2007). Comparison of the Atkins, Zone, Ornish, and LEARN Diets for change in weight and related risk factors among overweight premenopausal women. Journal of the American Medical Association, 297(9), 969-977. http://jama.ama-assn.org/cgi/content/full/297/ 9/969\#AUTHINFO

Harvard School of Public Health. (2010). The Nutrition Source. Carbohydrates: Good carbs guide 
the way. In The Nutrition Source. Retrieved from http://www.hsph.harvard.edu/ nutritionsource/what-should-you-eat/carbohydrates-full-story/index.html\#good-carbs -not-no-carbs

HealthDay. (2010). Low-fat diets beat low-carb regimen long term. http://www.nlm.nih.gov/ medlineplus/news/fullstory_95861.html

Hirsch, J. (2004). The low-carb evolution: Be reactive with low-carb products but proactive with nutrition. Nutraceuticals World. Retrved from http://www.nutraceuticalsworld.com/ contents/view/13321

Mayo Foundation for Medical Education and Research (MFMER). (2010). Weight-loss options: 6 common diet plans. http://www.mayoclinic.com/print/weight-loss/NU00616/ METHOD=print

McMillan-Price, J., Petocz, P., Atkinson, F., O'Neill, K., Samman, S., Steinbeck, K....Brand-Miller, J. (2006, July). Comparison of 4 diets of varying glycemic load on weight loss and cardiovascular risk reduction in overweight and obese young adults: $\mathrm{A}$ randomized controlled trial. Archives of Internal Medicine, 166(14), 1466-1475. Retrieved from http:// archinte.ama-assn.org/cgi/content/full/166/14/1466

National Institute of Diabetes and Digestive and Kidney Diseases. (2010). What I need to know about eating and diabetes. In National Diabetes Information Clearinghouse. Retrieved from http://diabetes.niddk.nih.gov/dm/pubs/eating_ez/index.htm

Reuters Health. (2010). Low-carb diet can increase bad cholesterol levels. Retrieved from http:// www.nlm.nih.gov/medlineplus/news/fullstory_95708.html

Seppa, N. (2008). Go against the grains, diet study suggests: Low-carb beats low-fat in weight loss, cholesterol. Science News, 174(4), 25. http://www.sciencenews.org/view/issue/id/ 34757 
National Institute of Diabetes and Digestive and Kidney Diseases. (2010). What I need to know about eating and diabetes. In National Diabetes Information Clearinghouse. Retrieved from http://diabetes.niddk.nih.gov/dm/pubs/eating_ez/index.htm

Reuters Health. (2010). Low-carb diet can increase bad cholesterol levels. Retrieved from http://www.nlm.nih.gov/medlineplus/news/fullstory_95708.html

Seppa, N. (2008). Go against the grains, diet study suggests: Low-carb beats low-fat in weight loss, cholesterol. Science News. 174(4), 25. http://www.sciencenews.org/view/ issue/id/34757

\section{Tip}

In APA style, book and article titles are formatted in sentence case, not title case. Sentence case means that only the first word is capitalized, along with any proper nouns. 


\section{Key Takeaways}

- Following proper citation and formatting guidelines helps writers ensure that their work will be taken seriously, give proper credit to other authors for their work, and provide valuable information to readers.

- Working ahead and taking care to cite sources correctly the first time are ways writers can save time during the editing stage of writing a research paper.

- APA papers usually include an abstract that concisely summarizes the paper.

- APA papers use a specific headings structure to provide a clear hierarchy of information.

- In APA papers, in-text citations usually include the name(s) of the author(s) and the year of publication.

- In-text citations correspond to entries in the references section, which provide detailed bibliographical information about a source. 


\subsection{Citing and Referencing Techniques}

\section{Learning Objective}

1. Apply American Psychological Association (APA) style formatting guidelines for citations.

This section covers the nitty-gritty details of in-text citations. You will learn how to format citations for different types of source materials, whether you are citing brief quotations, paraphrasing ideas, or quoting longer passages. You will also learn techniques you can use to introduce quoted and paraphrased material effectively. Keep this section handy as a reference to consult while writing the body of your paper.

\section{Formatting Cited Material: The Basics}

As noted in previous sections of this book, in-text citations usually provide the name of the author(s) and the year the source was published. For direct quotations, the page number must also be included. Use past-tense verbs when introducing a quote_- "Smith found..." and not "Smith finds...."

\section{Formatting Brief Quotations}

For brief quotations-fewer than forty words-use quotation marks to indicate where the quoted material begins and ends, and cite the name of the author(s), the year of publication, and the page number where the quotation appears in your source. Remember to include commas to separate elements within the parenthetical citation. Also, avoid redundancy. If you name the author(s) in your sentence, do not repeat the name(s) in your parenthetical citation. Review following the examples of different ways to cite direct quotations.

Chang (2008) emphasized that "engaging in weight-bearing exercise consistently is one of the single best things women can do to maintain good health” (p. 49).

The author's name can be included in the body of the sentence or in the parenthetical citation. Note that when a parenthetical citation appears at the end of the sentence, it comes after the closing quotation marks and before the period. The elements within parentheses are separated by commas. 
Weight Training for Women (Chang, 2008) claimed that "engaging in weight-bearing exercise consistently is one of the single best things women can do to maintain good health" (p. 49).

Weight Training for Women claimed that "engaging in weight-bearing exercise consistently is one of the single best things women can do to maintain good health” (Chang, 2008, p. 49).

Including the title of a source is optional.

In Chang's 2008 text Weight Training for Women, she asserts, "Engaging in weight-bearing exercise is one of the single best things women can do to maintain good health" (p. 49).

The author's name, the date, and the title may appear in the body of the text. Include the page number in the parenthetical citation. Also, notice the use of the verb asserts to introduce the direct quotation.

"Engaging in weight-bearing exercise," Chang asserts, "is one of the single best things women can do to maintain good health” (2008, p. 49).

You may begin a sentence with the direct quotation and add the author's name and a strong verb before continuing the quotation.

\section{Formatting Paraphrased and Summarized Material}

When you paraphrase or summarize ideas from a source, you follow the same guidelines previously provided, except that you are not required to provide the page number where the ideas are located. If you are summing up the main findings of a research article, simply providing the author's name and publication year may suffice, but if you are paraphrasing a more specific idea, consider including the page number.

Read the following examples.

Chang (2008) pointed out that weight-bearing exercise has many potential benefits for women. 
Here, the writer is summarizing a major idea that recurs throughout the source material. No page reference is needed.

Chang (2008) found that weight-bearing exercise could help women maintain or even increase bone density through middle age and beyond, reducing the likelihood that they will develop osteoporosis in later life (p. 86).

Although the writer is not directly quoting the source, this passage paraphrases a specific detail, so the writer chose to include the page number where the information is located.

Tip

Although APA style guidelines do not require writers to provide page numbers for material that is not directly quoted, your instructor may wish you to do so when possible.

Check with your instructor about his or her preferences.

\section{Formatting Longer Quotations}

When you quote a longer passage from a source — forty words or more — use a different format to set off the quoted material. Instead of using quotation marks, create a block quotation by starting the quotation on a new line and indented five spaces from the margin. Note that in this case, the parenthetical citation comes after the period that ends the sentence. Here is an example:

In recent years, many writers within the fitness industry have emphasized the ways in which women can benefit from weight-bearing exercise, such as weightlifting, karate, dancing, stair climbing, hiking, and jogging. Chang (2008) found that engaging in weight-bearing exercise regularly significantly reduces women's risk of developing osteoporosis. Additionally, these exercises help women maintain muscle mass and overall strength, and many common forms of weight-bearing exercise, such as brisk walking or stair climbing, also provide noticeable cardiovascular benefits. (p. 93)

\section{Exercise 1}

Review the places in your paper where you cited, quoted, and paraphrased material from a source with a single author. Edit your citations to ensure that 
- each citation includes the author's name, the date of publication, and, where appropriate, a page reference;

- parenthetical citations are correctly formatted;

- longer quotations use the block-quotation format.

If you are quoting a passage that continues into a second paragraph, indent five spaces again in the first line of the second paragraph. Here is an example:

In recent years, many writers within the fitness industry have emphasized the ways in which women can benefit from weight-bearing exercise, such as weightlifting, karate, dancing, stair climbing, hiking, and jogging. Chang (2008) found that engaging in weight-bearing exercise regularly significantly reduces women's risk of developing osteoporosis. Additionally, these exercises help women maintain muscle mass and overall strength, and many common forms of weight-bearing exercise, such as brisk walking or stair climbing, also provide noticeable cardiovascular benefits.

It is important to note that swimming cannot be considered a weight-bearing exercise, since the water supports and cushions the swimmer. That doesn't mean swimming isn't great exercise, but it should be considered one part of an integrated fitness program. (p. 93)

Tip

Be wary of quoting from sources at length. Remember, your ideas should drive the paper, and quotations should be used to support and enhance your points. Make sure any lengthy quotations that you include serve a clear purpose. Generally, no more than 10-15 percent of a paper should consist of quoted material.

\section{Introducing Cited Material Effectively}

Including an introductory phrase in your text, such as “Jackson wrote” or "Copeland found,” often helps you integrate source material smoothly. This citation technique also helps convey that you are actively engaged with your source material. Unfortunately, during the process of writing your research paper, it is easy to fall into a rut and use the same few dull verbs repeatedly, such as "Jones said," "Smith stated," and so on.

Punch up your writing by using strong verbs that help your reader understand how the source material presents ideas. There is a world of difference between an author who "suggests" and one who "claims," one who "questions" and one who "criticizes." You do not need to consult your thesaurus every time you cite a source, but do think about which verbs will accurately represent the ideas and make your writing more engaging. The following chart shows some possibilities. 


\begin{tabular}{|l|l|l|}
\hline \multicolumn{2}{|l|}{ Strong Verbs for Introducing Cited Material } \\
\hline ask & suggest & question \\
\hline explain & assert & claim \\
\hline recommend & compare & contrast \\
\hline propose & hypothesize & believe \\
\hline insist & argue & find \\
\hline determine & measure & assess \\
\hline evaluate & conclude & study \\
\hline warn & point out & sum up \\
\hline
\end{tabular}

\section{Exercise 2}

Review the citations in your paper once again. This time, look for places where you introduced source material using a signal phrase in your sentence.

1. Highlight the verbs used in your signal phrases, and make note of any that seem to be overused throughout the paper.

2. Identify at least three places where a stronger verb could be used.

3. Make the edits to your draft.

\section{Writing at Work}

It is important to accurately represent a colleague's ideas or communications in the workplace. When writing professional or academic papers, be mindful of how the words you use to describe someone's tone or ideas carry certain connotations. Do not say a source argues a particular point unless an argument is, in fact, presented. Use lively language, but avoid language that is emotionally charged. Doing so will ensure you have represented your colleague's words in an authentic and accurate way.

\section{Formatting In-Text Citations for Other Source Types}

These sections discuss the correct format for various types of in-text citations. Read them through quickly to get a sense of what is covered, and then refer to them again as needed. 


\section{Print Sources}

This section covers books, articles, and other print sources with one or more authors.

\section{A Work by One Author}

For a print work with one author, follow the guidelines provided in Chapter 13 "APA and MLA Documentation and Formatting", Section 13.1 "Formatting a Research Paper". Always include the author's name and year of publication. Include a page reference whenever you quote a source directly. (See also the guidelines presented earlier in this chapter about when to include a page reference for paraphrased material.)

Chang (2008) emphasized that "engaging in weight-bearing exercise consistently is one of the single best things women can do to maintain good health" (p. 49).

Chang (2008) pointed out that weight-bearing exercise has many potential benefits for women.

\section{Two or More Works by the Same Author}

At times, your research may include multiple works by the same author. If the works were published in different years, a standard in-text citation will serve to distinguish them. If you are citing multiple works by the same author published in the same year, include a lowercase letter immediately after the year. Rank the sources in the order they appear in your references section. The source listed first includes an $a$ after the year, the source listed second includes a $b$, and so on.

Rodriguez (2009a) criticized the nutrition-supplement industry for making unsubstantiated and sometimes misleading claims about the benefits of taking supplements. Additionally, he warned that consumers frequently do not realize the potential harmful effects of some popular supplements (Rodriguez, 2009b). 
Tip

If you have not yet created your references section, you may not be sure which source will appear first. See Chapter 13 "APA and MLA Documentation and Formatting", Section 13.3 "Creating a References Section" for guidelines - or assign each source a temporary code and highlight the in-text citations so you remember to double-check them later on.

\section{Works by Authors with the Same Last Name}

If you are citing works by different authors with the same last name, include each author's initials in your citation, whether you mention them in the text or in parentheses. Do so even if the publication years are different.

J. S. Williams (2007) believes nutritional supplements can be a useful part of some diet and fitness regimens.

C. D. Williams (2008), however, believes these supplements are overrated.

According to two leading researchers, the rate of childhood obesity exceeds the rate of adult obesity (K.

Connelley, 2010; O. Connelley, 2010).

Studies from both A. Wright (2007) and C. A. Wright (2008) confirm the benefits of diet and exercise on weight loss.

\section{A Work by Two Authors}

When two authors are listed for a given work, include both authors' names each time you cite the work. If you are citing their names in parentheses, use an ampersand (\&) between them. (Use the word and, however, if the names appear in your sentence.)

As Garrison and Gould (2010) pointed out, "It is never too late to quit smoking. The health risks associated with this habit begin to decrease soon after a smoker quits” (p. 101). 
As doctors continue to point out, "It is never too late to quit smoking. The health risks associated with this habit begin to decrease soon after a smoker quits” (Garrison \& Gould, 2010, p. 101).

\section{A Work by Three to Five Authors}

If the work you are citing has three to five authors, list all the authors' names the first time you cite the source. In subsequent citations, use the first author's name followed by the abbreviation et al. (Et al. is short for et alia, the Latin phrase for "and others.")

Henderson, Davidian, and Degler (2010) surveyed 350 smokers aged 18 to 30.

One survey, conducted among 350 smokers aged 18 to 30, included a detailed questionnaire about participants’ motivations for smoking (Henderson, Davidian, \& Degler, 2010).

Note that these examples follow the same ampersand conventions as sources with two authors. Again, use the ampersand only when listing authors' names in parentheses.

As Henderson et al. (2010) found, some young people, particularly young women, use smoking as a means of appetite suppression.

Disturbingly, some young women use smoking as a means of appetite suppression (Henderson et al., 2010).

Note how the phrase et al. is punctuated. No period comes after et, but al. gets a period because it is an abbreviation for a longer Latin word. In parenthetical references, include a comma after et al. but not before. Remember this rule by mentally translating the citation to English: "Henderson and others, 2010.”

\section{A Work by Six or More Authors}

If the work you are citing has six or more authors, list only the first author's name, followed by et al., in 
your in-text citations. The other authors' names will be listed in your references section.

Researchers have found that outreach work with young people has helped reduce tobacco use in some communities (Costello et al., 2007).

\section{A Work Authored by an Organization}

When citing a work that has no individual author(s) but is published by an organization, use the organization's name in place of the author's name. Lengthy organization names with well-known abbreviations can be abbreviated. In your first citation, use the full name, followed by the abbreviation in square brackets. Subsequent citations may use the abbreviation only.

It is possible for a patient to have a small stroke without even realizing it (American Heart Association [AHA], 2010).

Another cause for concern is that even if patients realize that they have had a stroke and need medical attention, they may not know which nearby facilities are best equipped to treat them (AHA, 2010).

\section{Exercise 3}

1. Review the places in your paper where you cited material from a source with multiple authors or with an organization as the author. Edit your citations to ensure that each citation follows APA guidelines for the inclusion of the authors' names, the use of ampersands and et al., the date of publication, and, where appropriate, a page reference.

2. Mark any additional citations within your paper that you are not sure how to format based on the guidelines provided so far. You will revisit these citations after reading the next few sections.

\section{A Work with No Listed Author}

If no author is listed and the source cannot be attributed to an organization, use the title in place of the author's name. You may use the full title in your sentence or use the first few words-enough to convey the key ideas - in a parenthetical reference. Follow standard conventions for using italics or quotations 
marks with titles:

- Use italics for titles of books or reports.

- Use quotation marks for titles of articles or chapters.

“Living With Diabetes: Managing Your Health” (2009) recommends regular exercise for patients with diabetes.

Regular exercise can benefit patients with diabetes (“Living with Diabetes,” 2009).

Rosenhan (1973) had mentally healthy study participants claim to be experiencing hallucinations so they would be admitted to psychiatric hospitals.

\section{A Work Cited within Another Work}

To cite a source that is referred to within another secondary source, name the first source in your sentence. Then, in parentheses, use the phrase as cited in and the name of the second source author.

Rosenhan’s study “On Being Sane in Insane Places” (as cited in Spitzer, 1975) found that psychiatrists diagnosed schizophrenia in people who claimed to be experiencing hallucinations and sought treatment—even though these patients were, in fact, imposters.

\section{Two or More Works Cited in One Reference}

At times, you may provide more than one citation in a parenthetical reference, such as when you are discussing related works or studies with similar results. List the citations in the same order they appear in your references section, and separate the citations with a semicolon.

Some researchers have found serious flaws in the way Rosenhan's study was conducted (Dawes, 2001; Spitzer, 1975). 
Both of these researchers authored works that support the point being made in this sentence, so it makes sense to include both in the same citation.

\section{A Famous Text Published in Multiple Editions}

In some cases, you may need to cite an extremely well-known work that has been repeatedly republished or translated. Many works of literature and sacred texts, as well as some classic nonfiction texts, fall into this category. For these works, the original date of publication may be unavailable. If so, include the year of publication or translation for your edition. Refer to specific parts or chapters if you need to cite a specific section. Discuss with your instructor whether he or she would like you to cite page numbers in this particular instance.

In New Introductory Lectures on Psycho-Analysis, Freud explains that the "manifest content" of a dream — what literally takes place-is separate from its "latent content," or hidden meaning (trans. 1965, lecture XXIX).

Here, the student is citing a classic work of psychology, originally written in German and later translated to English. Since the book is a collection of Freud's lectures, the student cites the lecture number rather than a page number.

\section{An Introduction, Foreword, Preface, or Afterword}

To cite an introduction, foreword, preface, or afterword, cite the author of the material and the year, following the same format used for other print materials.

\section{Electronic Sources}

Whenever possible, cite electronic sources as you would print sources, using the author, the date, and where appropriate, a page number. For some types of electronic sources-for instance, many online articles - this information is easily available. Other times, however, you will need to vary the format to reflect the differences in online media.

\section{Online Sources without Page Numbers}

If an online source has no page numbers but you want to refer to a specific portion of the source, try to locate other information you can use to direct your reader to the information cited. Some websites 
number paragraphs within published articles; if so, include the paragraph number in your citation. Precede the paragraph number with the abbreviation for the word paragraph and the number of the paragraph (e.g., para. 4).

As researchers have explained, “Incorporating fresh fruits and vegetables into one’s diet can be a challenge for residents of areas where there are few or no easily accessible supermarkets” (Smith \& Jones, 2006, para. 4).

Even if a source does not have numbered paragraphs, it is likely to have headings that organize the content. In your citation, name the section where your cited information appears, followed by a paragraph number.

The American Lung Association (2010) noted, “After smoking, radon exposure is the second most common cause of lung cancer” (What Causes Lung Cancer? section, para. 2).

This student cited the appropriate section heading within the website and then counted to find the specific paragraph where the cited information was located.

If an online source has no listed author and no date, use the source title and the abbreviation n.d. in your parenthetical reference.

It has been suggested that electromagnetic radiation from cellular telephones may pose a risk for developing certain cancers (“Cell Phones and Cancer,” n.d.).

\section{Personal Communication}

For personal communications, such as interviews, letters, and e-mails, cite the name of the person involved, clarify that the material is from a personal communication, and provide the specific date the communication took place. Note that while in-text citations correspond to entries in the references section, personal communications are an exception to this rule. They are cited only in the body text of your paper.

J. H. Yardley, M.D., believes that available information on the relationship between cell phone use and cancer is inconclusive (personal communication, May 1, 2009). 


\section{Writing at Work}

At work, you may sometimes share information resources with your colleagues by photocopying an interesting article or forwarding the URL of a useful website. Your goal in these situations and in formal research citations is the same. The goal is to provide enough information to help your professional peers locate and follow up on potentially useful information. Provide as much specific information as possible to achieve that goal, and consult with your professor as to what specific style he or she may prefer.

\section{Exercise 4}

Revisit the problem citations you identified in Note 13.55 "Exercise 3"-for instance, sources with no listed author or other oddities. Review the guidelines provided in this section and edit your citations for these kinds of sources according to APA guidelines.

\section{Key Takeaways}

- In APA papers, in-text citations include the name of the author(s) and the year of publication whenever possible.

- Page numbers are always included when citing quotations. It is optional to include page numbers when citing paraphrased material; however, this should be done when citing a specific portion of a work.

- When citing online sources, provide the same information used for print sources if it is available.

- When a source does not provide information that usually appears in a citation, in-text citations should provide readers with alternative information that would help them locate the source material. This may include the title of the source, section headings and paragraph numbers for websites, and so forth.

- When writing a paper, discuss with your professor what particular standards he or she would like you to follow. 


\subsection{Creating a References Section}

\section{Learning Objective}

1. Apply American Psychological Association (APA) style and formatting guidelines for a references section.

This section provides detailed information about how to create the references section of your paper. You will review basic formatting guidelines and learn how to format bibliographical entries for various types of sources. This section of Chapter 13 “APA and MLA Documentation and Formatting”, like the previous section, is meant to be used as a reference tool while you write.

\section{Formatting the References Section: The Basics}

At this stage in the writing process, you may already have begun setting up your references section. This section may consist of a single page for a brief research paper or may extend for many pages in professional journal articles. As you create this section of your paper, follow the guidelines provided here.

\section{Formatting the References Section}

To set up your references section, use the insert page break feature of your word-processing program to begin a new page. Note that the header and margins will be the same as in the body of your paper, and pagination continues from the body of your paper. (In other words, if you set up the body of your paper correctly, the correct header and page number should appear automatically in your references section.)

See additional guidelines below.

\section{Formatting Reference Entries}

Reference entries should include the following information:

- The name of the author(s)

- The year of publication and, where applicable, the exact date of publication 
549 [Author removed at request of original publisher]

- The full title of the source

- For books, the city of publication

- For articles or essays, the name of the periodical or book in which the article or essay appears

- For magazine and journal articles, the volume number, issue number, and pages where the article appears

- For sources on the web, the URL where the source is located

See the following examples for how to format a book or journal article with a single author.

\section{Sample Book Entry}

$$
\begin{aligned}
& \text { Use } \\
& \text { author's } \\
& \text { last name } \\
& \text { and initials } \\
& \text { followed }
\end{aligned}
$$

byperiods.

Use a single space between parts of

the entry. Include periods and other

punctuation as indicated.

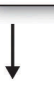

Use standard postal abbreviations

for the state where the source

was published.

Use a colon between the city of publication, and the publisher.

\section{Sample Journal Article Entry}




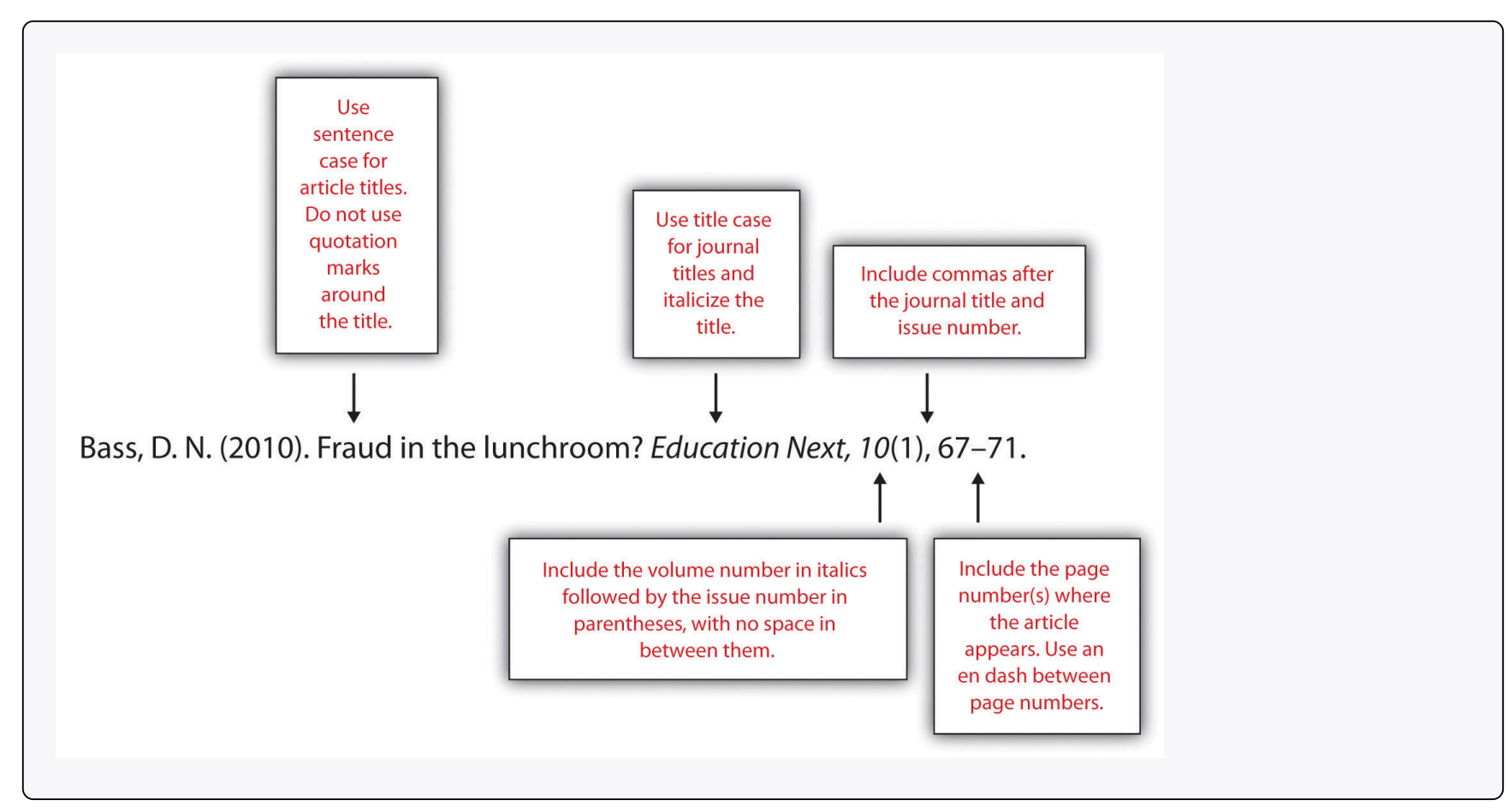

The following box provides general guidelines for formatting the reference page. For the remainder of this chapter, you will learn about how to format bibliographical entries for different source types, including multiauthor and electronic sources.

\section{Formatting the References Section: APA General Guidelines}

1. Include the heading References, centered at the top of the page. The heading should not be boldfaced, italicized, or underlined.

2. Use double-spaced type throughout the references section, as in the body of your paper.

3. Use hanging indentation for each entry. The first line should be flush with the left margin, while any lines that follow should be indented five spaces. Note that hanging indentation is the opposite of normal indenting rules for paragraphs.

4. List entries in alphabetical order by the author's last name. For a work with multiple authors, use the last name of the first author listed.

5. List authors' names using this format: Smith, J. C.

6. For a work with no individual author(s), use the name of the organization that published the work or, if this is unavailable, the title of the work in place of the author's name.

7. For works with multiple authors, follow these guidelines:

- For works with up to seven authors, list the last name and initials for each author.

- For works with more than seven authors, list the first six names, followed by ellipses, and then the name of the last author listed.

- Use an ampersand before the name of the last author listed.

8. Use title case for journal titles. Capitalize all important words in the title.

9. Use sentence case for all other titles—books, articles, web pages, and other source titles. Capitalize the first 
word of the title. Do not capitalize any other words in the title except for the following:

- Proper nouns

- First word of a subtitle

- First word after a colon or dash

10. Use italics for book and journal titles. Do not use italics, underlining, or quotation marks for titles of shorter works, such as articles.

\section{Exercise 1}

Set up the first page of your references section and begin adding entries, following the APA formatting guidelines provided in this section.

1. If there are any simple entries that you can format completely using the general guidelines, do so at this time.

2. For entries you are unsure of how to format, type in as much information as you can, and highlight the entries so you can return to them later.

\section{Formatting Reference Entries for Different Source Types}

As is the case for in-text citations, formatting reference entries becomes more complicated when you are citing a source with multiple authors, citing various types of online media, or citing sources for which you must provide additional information beyond the basics listed in the general guidelines. The following guidelines show how to format reference entries for these different situations.

\section{Print Sources: Books}

For book-length sources and shorter works that appear in a book, follow the guidelines that best describes your source.

\section{A Book by Two or More Authors}

List the authors' names in the order they appear on the book's title page. Use an ampersand before the last author's name. 
Campbell, D. T., \& Stanley, J. C. (1963). Experimental and quasi-experimental designs for research. Boston, MA: Houghton Mifflin.

\section{An Edited Book with No Author}

List the editor or editors' names in place of the author's name, followed by Ed. or Eds. in parentheses.

Myers, C., \& Reamer, D. (Eds.). (2009). 2009 nutrition index. San Francisco, CA: HealthSource, Inc.

\section{An Edited Book with an Author}

List the author's name first, followed by the title and the editor or editors. Note that when the editor is listed after the title, you list the initials before the last name.

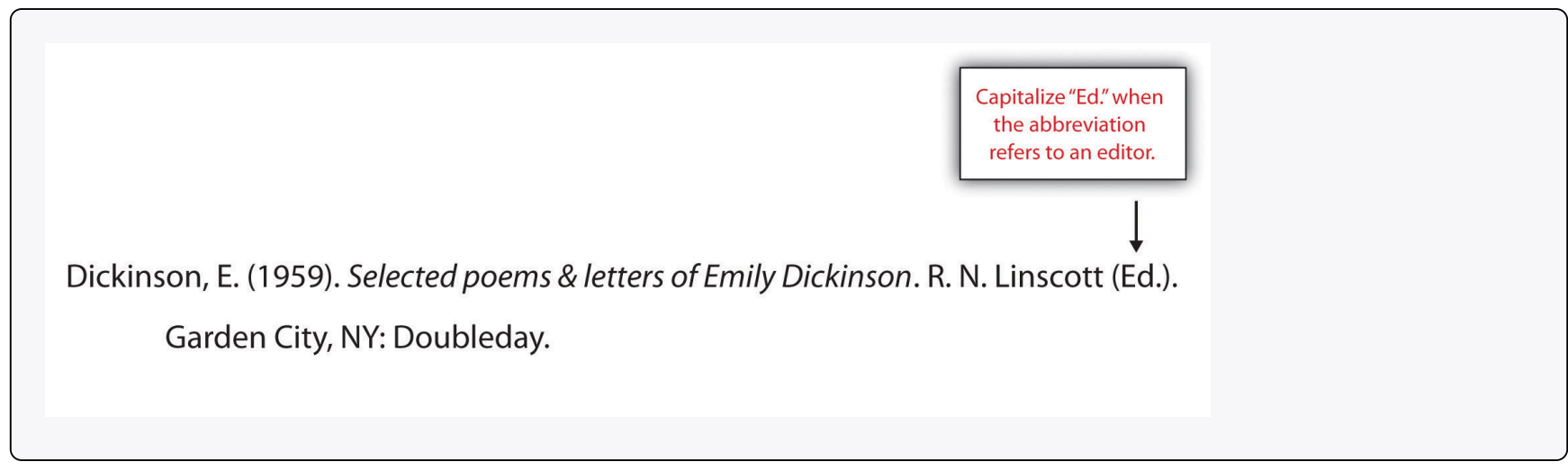

Tip

The previous example shows the format used for an edited book with one author-for instance, a collection of a famous person's letters that has been edited. This type of source is different from an anthology, which is a collection of articles or essays by different authors. For citing works in anthologies, see the guidelines later in this section. 


\section{A Translated Book}

Include the translator's name after the title, and at the end of the citation, list the date the original work was published. Note that for the translator's name, you list the initials before the last name.

Freud, S. (1965). New introductory lectures on psycho-analysis (J. Strachey, Trans.). New York, NY: W. W. Norton. (Original work published 1933).

\section{A Book Published in Multiple Editions}

If you are using any edition other than the first edition, include the edition number in parentheses after the title.

Do not capitalize "ed." when the

abbreviation refers to an edition of a book.

Berk, L. (2001). Development through the lifespan (2nd ed.). Needham Heights, MA:

Allyn \& Bacon.

\section{A Chapter in an Edited Book}

List the name of the author(s) who wrote the chapter, followed by the chapter title. Then list the names of the book editor(s) and the title of the book, followed by the page numbers for the chapter and the usual information about the book's publisher.

Hughes, J. R., \& Pierattini, R. A. (1992). An introduction to pharmacotherapy for mental disorders. In J. Grabowski \& G. VandenBos (Eds.), Psychopharmacology (pp. 97-125). Washington, DC: American Psychological Association. 


\section{A Work That Appears in an Anthology}

Follow the same process you would use to cite a book chapter, substituting the article or essay title for the chapter title.

Beck, A. T., \& Young, J. (1986). College blues. In D. Goleman \& D. Heller (Eds.), The pleasures of psychology (pp. 309-323). New York, NY: New American Library.

Include the abbreviation "pp." when listing the pages where a chapter or article appears in a book.

\section{An Article in a Reference Book}

List the author's name if available; if no author is listed, provide the title of the entry where the author's name would normally be listed. If the book lists the name of the editor(s), include it in your citation. Indicate the volume number (if applicable) and page numbers in parentheses after the article title.

The census. (2006). In J. W. Wright (Ed.), The New York Times 2006 almanac (pp. 268-

275). New York, NY: Penguin.

Capitalize proper nouns

that appear in a

book title.

\section{Two or More Books by the Same Author}

List the entries in order of their publication year, beginning with the work published first.

Swedan, N. (2001). Women's sports medicine and rehabilitation. Gaithersburg, MD: Aspen Publishers.

Swedan, N. (2003). The active woman's health and fitness handbook. New York, NY: Perigee.

If two books have multiple authors, and the first author is the same but the others are different, 
alphabetize by the second author's last name (or the third or fourth, if necessary).

Carroll, D., \& Aaronson, F. (2008). Managing type II diabetes. Chicago, IL: Southwick Press.

Carroll, D., \& Zuckerman, N. (2008). Gestational diabetes. Chicago, IL: Southwick Press.

\section{Books by Different Authors with the Same Last Name}

Alphabetize entries by the authors' first initial.

Smith, I. K. (2008). The 4-day diet. New York, NY: St. Martin's Press.

Capitalize the first word of a subtitle.

Smith, S. (2008). The complete guide to Navy Seal fitness: Updated for today's warrior elite (3rd ed.). Long Island City, NY: Hatherleigh Press.

\section{A Book Authored by an Organization}

Treat the organization name as you would an author's name. For the purposes of alphabetizing, ignore words like The in the organization's name. (That is, a book published by the American Heart Association would be listed with other entries whose authors’ names begin with A.)

American Psychiatric Association. (1994). Diagnostic and statistical manual of mental disorders DSM-IV (4th ed.). Arlington, VA: American Psychiatric Publishing.

\section{A Book-Length Report}

Format technical and research reports as you would format other book-length sources. If the organization that issued the report assigned it a number, include the number in parentheses after the title. (See also the guidelines provided for citing works produced by government agencies.) 
Jameson, R., \& Dewey, J. (2009). Preliminary findings from an evaluation of the president's physical fitness program in Pleasantville school district. Pleasantville, WA: Pleasantville Board of Education.

\section{A Book Authored by a Government Agency}

Treat these as you would a book published by a nongovernment organization, but be aware that these works may have an identification number listed. If so, include it in parentheses after the publication year.

U.S. Census Bureau. (2002). The decennial censuses from 1790 to 2000 (Publication No. POL/02-MA).

Washington, DC: US Government Printing Offices.

\section{Exercise 2}

Revisit the references section you began to compile in Note 13.73 "Exercise 1". Use the guidelines provided to format any entries for book-length print sources that you were unable to finish earlier.

Review how Jorge formatted these book-length print sources:

Atkins, R. C. (2002). Dr. Atkins' diet revolution. New York, NY: M. Evans and Company.

Agatson, A. (2003). The South Beach diet. New York, NY: St. Martin’s Griffin.

\section{Print Sources: Periodicals}

\section{An Article in a Scholarly Journal}

Include the following information:

- Author or authors' names

- Publication year

- Article title (in sentence case, without quotation marks or italics)

- Journal title (in title case and in italics)

- Volume number (in italics) 
557 [Author removed at request of original publisher]

- Issue number (in parentheses)

- Page number(s) where the article appears

DeMarco, R. F. (2010). Palliative care and African American women living with HIV. Journal of Nursing Education, 49(5), 1-4.

\section{An Article in a Journal Paginated by Volume}

In these types of journals, page numbers for one volume continue across all the issues in that volume. For instance, the winter issue may begin with page 1 , and in the spring issue that follows, the page numbers pick up where the previous issue left off. (If you have ever wondered why a print journal did not begin on page 1, or wondered why the page numbers of a journal extend into four digits, this is why.) Omit the issue number from your reference entry.

Wagner, J. (2009). Rethinking school lunches: A review of recent literature. American School Nurses' Journal, 47, 1123-1127.

\section{An Abstract of a Scholarly Article}

At times you may need to cite an abstract — the summary that appears at the beginning — of a published article. If you are citing the abstract only, and it was published separately from the article, provide the following information:

- Publication information for the article

- Information about where the abstract was published (for instance, another journal or a collection of abstracts)

Use this format for

abstracts published in

a collection of abstracts.

$\downarrow$

Romano, S. (2005). Parental involvement in raising standardized test scores. [Abstract]. Elementary Education Abstracts, 19, 36. 
Use this format for

abstracts published

in another journal.

$\downarrow$

Simpson, M. J. (2008). Assessing educational progress: Beyond standardized testing. Journal of the Association for School Administrative Professionals, 35(4), 32-40. Abstract obtained from Assessment in Education, 2009, 73(6), Abstract No. 537892.

\section{A Journal Article with Two to Seven Authors}

List all the authors' names in the order they appear in the article. Use an ampersand before the last name listed.

Barker, E. T., \& Bornstein, M. H. (2010). Global self-esteem, appearance satisfaction, and self-reported dieting in early adolescence. Journal of Early Adolescence, 30(2), 205-224.

Tremblay, M. S., Shields, M., Laviolette, M., Craig, C. L., Janssen, I., \& Gorber, S. C. (2010). Fitness of Canadian children and youth: Results from the 2007-2009 Canadian Health Measures Survey. Health Reports, 21(1), 7-20.

\section{A Journal Article with More Than Seven Authors}

List the first six authors' names, followed by a comma, an ellipsis, and the name of the last author listed. The article in the following example has sixteen listed authors; the reference entry lists the first six authors and the sixteenth, omitting the seventh through the fifteenth. 
Straznicky, N. E., Lambert, E. A., Nestel, P. J., McGrane, M. T., Dawood, T., Schlaich,

M. P., ... Lambert, G. W. (2010). Sympathetic neural adaptation to hypocaloric diet with or without exercise training in obese metabolic syndrome subjects. Diabetes, 59(1),

$71-79$.

Because some names are omitted, use a comma

and an ellipsis, rather than an ampersand,

before the final name listed.

\section{Writing at Work}

The idea of an eight-page article with sixteen authors may seem strange to you-especially if you are in the midst of writing a ten-page research paper on your own. More often than not, articles in scholarly journals list multiple authors. Sometimes, the authors actually did collaborate on writing and editing the published article. In other instances, some of the authors listed may have contributed to the research in some way while being only minimally involved in the process of writing the article. Whenever you collaborate with colleagues to produce a written product, follow your profession's conventions for giving everyone proper credit for their contribution.

\section{A Magazine Article}

After the publication year, list the issue date. Otherwise, treat these as you would journal articles. List the volume and issue number if both are available.

List the month after the year.

For weekly magazines, list the

full date, e.g. "March 8, 2010."

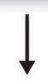

Marano, H. E. (2010, March/April). Keen cuisine: Dairy queen. Psychology Today, 43(2), 58.

\section{A Newspaper Article}

Treat these as you would magazine and journal articles, with one important difference: precede the page 
number(s) with the abbreviation $p$. (for a single-page article) or pp. (for a multipage article). For articles whose pagination is not continuous, list all the pages included in the article. For example, an article that begins on page A1 and continues on pages A4 would have the page reference A1, A4. An article that begins on page A1 and continues on pages A4 and A5 would have the page reference A1, A4-A5.

Corwin, C. (2009, January 24). School board votes to remove soda machines from county

schools. Rockwood Gazette, pp. A1-A2. $\longleftarrow \quad$ Include the section in

your page reference.

\section{A Letter to the Editor}

After the title, indicate in brackets that the work is a letter to the editor.

Jones, J. (2009, January 31). Food police in our schools [Letter to the editor]. Rockwood Gazette, p. A8.

\section{A Review}

After the title, indicate in brackets that the work is a review and state the name of the work being reviewed. (Note that even if the title of the review is the same as the title of the book being reviewed, as in the following example, you should treat it as an article title. Do not italicize it.)

Penhollow, T. M., \& Jackson, M.A. (2009). Drug abuse: Concepts, prevention, and cessation [Review of the book Drug abuse: Concepts, prevention, and cessation]. American Journal of Health Behavior, 33(5), 620-622.

Italicize the title of the reviewed book only where

it appears in brackets.

\section{Exercise 3}

Revisit the references section you began to compile in Note 13.73 "Exercise 1". Use the guidelines provided 
above to format any entries for periodicals and other shorter print sources that you were unable to finish earlier.

\section{Electronic Sources}

\section{Citing Articles from Online Periodicals: URLs and Digital Object Identifiers (DOIs)}

Whenever you cite online sources, it is important to provide the most up-to-date information available to help readers locate the source. In some cases, this means providing an article's URL, or web address. (The letters $U R L$ stand for uniform resource locator.) Always provide the most complete URL possible. Provide a link to the specific article used, rather than a link to the publication's homepage.

As you know, web addresses are not always stable. If a website is updated or reorganized, the article you accessed in April may move to a different location in May. The URL you provided may become a dead link. For this reason, many online periodicals, especially scholarly publications, now rely on DOIs rather than URLs to keep track of articles.

A DOI is a Digital Object Identifier - an identification code provided for some online documents, typically articles in scholarly journals. Like a URL, its purpose is to help readers locate an article. However, a DOI is more stable than a URL, so it makes sense to include it in your reference entry when possible. Follow these guidelines:

- If you are citing an online article with a DOI, list the DOI at the end of the reference entry.

- If the article appears in print as well as online, you do not need to provide the URL. However, include the words Electronic version after the title in brackets.

- In other respects, treat the article as you would a print article. Include the volume number and issue number if available. (Note, however, that these may not be available for some online periodicals).

\section{An Article from an Online Periodical with a DOI}

List the DOI if one is provided. There is no need to include the URL if you have listed the DOI.

Bell, J. R. (2006). Low-carb beats low-fat diet for early losses but not long term. OBGYN News, 41(12), 32. doi:10.1016/S0029-7437(06)71905-X 


\section{An Article from an Online Periodical with No DOI}

List the URL. Include the volume and issue number for the periodical if this information is available. (For some online periodicals, it may not be.)

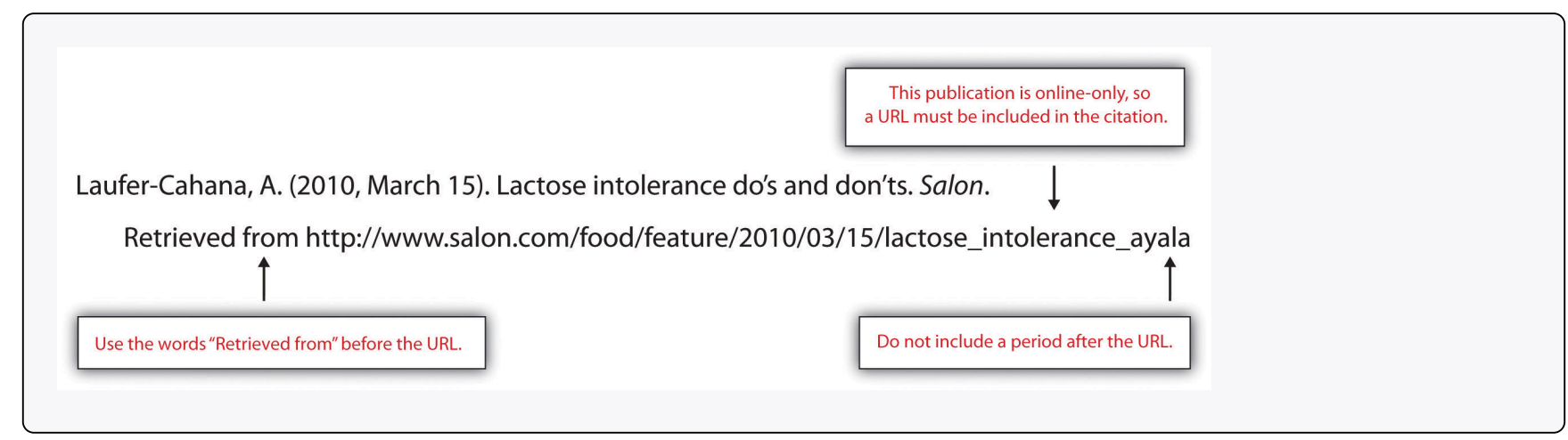

Note that if the article appears in a print version of the publication, you do not need to list the URL, but do indicate that you accessed the electronic version.

Robbins, K. (2010, March/April). Nature’s bounty: A heady feast [Electronic version]. Psychology Today, 43(2), 58.

\section{A Newspaper Article}

Provide the URL of the article.

McNeil, D. G. (2010, May 3). Maternal health: A new study challenges benefits of vitamin A for women and babies. The New York Times. Retrieved from http://www.nytimes.com/2010/05/04/health/

04glob.html?ref=health

\section{An Article Accessed through a Database}

Cite these articles as you would normally cite a print article. Provide database information only if the article is difficult to locate. 


\section{Tip}

APA style does not require writers to provide the item number or accession number for articles retrieved from databases. You may choose to do so if the article is difficult to locate or the database is an obscure one. Check with your professor to see if this is something he or she would like you to include.

\section{An Abstract of an Article}

Format these as you would an article citation, but add the word Abstract in brackets after the title.

Bradley, U., Spence, M., Courtney, C. H., McKinley, M. C., Ennis, C. N., McCance, D. R....Hunter, S. J. (2009). Low-fat versus low-carbohydrate weight reduction diets: Effects on weight loss, insulin resistance, and cardiovascular risk: A randomized control trial [Abstract]. Diabetes, 58(12), 2741-2748.

http://diabetes.diabetesjournals.org/content/early/2009/08/23/db00098.abstract

\section{A Nonperiodical Web Document}

The ways you cite different nonperiodical web documents may vary slightly from source to source, depending on the information that is available. In your citation, include as much of the following information as you can:

- Name of the author(s), whether an individual or organization

- Date of publication (Use n.d. if no date is available.)

- Title of the document

- Address where you retrieved the document

If the document consists of more than one web page within the site, link to the homepage or the entry page for the document.

American Heart Association. (2010). Heart attack, stroke, and cardiac arrest warning signs. Retrieved from http://www.americanheart.org/presenter.jhtml?identifier=3053 


\section{An Entry from an Online Encyclopedia or Dictionary}

Because these sources often do not include authors' names, you may list the title of the entry at the beginning of the citation. Provide the URL for the specific entry.

Addiction. (n.d.) In Merriam-Webster's online dictionary. Retrieved from http://www.merriam-webster.com/ dictionary/addiction

\section{Data Sets}

If you cite raw data compiled by an organization, such as statistical data, provide the URL where you retrieved the information. Provide the name of the organization that sponsors the site.

US Food and Drug Administration. (2009). Nationwide evaluation of X-ray trends: NEXT surveys performed [Data file]. Retrieved from http://www.fda.gov/Radiation-EmittingProducts/RadiationSafety/

NationwideEvaluationofX- RayTrendsNEXT/ucm116508.htm

\section{Graphic Data}

When citing graphic data — such as maps, pie charts, bar graphs, and so on-include the name of the organization that compiled the information, along with the publication date. Briefly describe the contents in brackets. Provide the URL where you retrieved the information. (If the graphic is associated with a specific project or document, list it after your bracketed description of the contents.)

US Food and Drug Administration. (2009). [Pie charts showing the percentage breakdown of the FDA's budget for fiscal year 2005]. 2005 FDA budget summary. Retrieved from mhttp://www.fda.gov/AboutFDA/ ReportsManualsForms/Reports/BudgetReports/2005FDABudgetSummary/ucm117231.htm

\section{An Online Interview (Audio File or Transcript)}

List the interviewer, interviewee, and date. After the title, include bracketed text describing the interview as an "Interview transcript" or "Interview audio file," depending on the format of the interview you 
accessed. List the name of the website and the URL where you retrieved the information. Use the following format.

Davies, D. (Interviewer), \& Pollan, M. (Interviewee). (2008). Michael Pollan offers president food for thought [Interview transcript]. Retrieved from National Public Radio website: http://www.npr.org/templates/ transcript/transcript.php?storyId=100755362

\section{An Electronic Book}

Electronic books may include books available as text files online or audiobooks. If an electronic book is easily available in print, cite it as you would a print source. If it is unavailable in print (or extremely difficult to find), use the format in the example. (Use the words Available from in your citation if the book must be purchased or is not available directly.)

Chisholm, L. (n.d.). Celtic tales. Retrieved from http://www.childrenslibrary.org/icdl/BookReader?bookid= chicelt_00150014\&twoPage=false\&route=text\&size=0\&fullscreen=false\&pnum1=1\&lang= English\&ilang=English

\section{A Chapter from an Online Book or a Chapter or Section of a Web Document}

These are treated similarly to their print counterparts with the addition of retrieval information. Include the chapter or section number in parentheses after the book title.

Hart, A. M. (1895). Restoratives - Coffee, cocoa, chocolate. In Diet in sickness and in health (VI). Retrieved from http://www.archive.org/details/dietinsicknessin00hartrich

\section{A Dissertation or Thesis from a Database}

Provide the author, date of publication, title, and retrieval information. If the work is numbered within the database, include the number in parentheses at the end of the citation. 
Italicize the titles of

theses and dissertations.

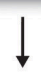

Coleman, M. D. (2004). Effect of a low-carbohydrate, high-protein diet on bone mineral

density, biomarkers of bone turnover, and calcium metabolism in healthy pre-

menopausal females. Retrieved from Virginia Tech Digital Library \& Archives: Electronic

Theses and Dissertations. (etd-07282004-174858)

\section{Computer Software}

For commonly used office software and programming languages, it is not necessary to provide a citation. Cite software only when you are using a specialized program, such as the nutrition tracking software in the following example. If you download software from a website, provide the version and the year if available.

Internet Brands, Inc. (2009). FitDay PC (Version 2) [Software]. Available from http://www.fitday.com/Pc/ PcHome.html?gcid=14

\section{A Post on a Blog or Video Blog}

Citation guidelines for these sources are similar to those used for discussion forum postings. Briefly describe the type of source in brackets after the title.

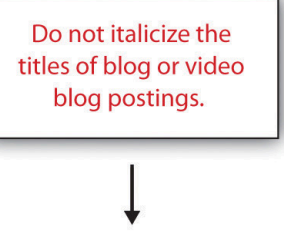

Fazio, M. (2010, April 5). Exercising in my eighth month of pregnancy [Web log comment]. Retrieved from http://somanyblogs.com/ faziom/postID=67 


\section{Writing at Work}

Because the content may not be carefully reviewed for accuracy, discussion forums and blogs should not be relied upon as a major source of information. However, it may be appropriate to cite these sources for some types of research. You may also participate in discussion forums or comment on blogs that address topics of personal or professional interest. Always keep in mind that when you post, you are making your thoughts public — and in many cases, available through search engines. Make sure any posts that can easily be associated with your name are appropriately professional, because a potential employer could view them.

\section{A Television or Radio Broadcast}

Include the name of the producer or executive producer; the date, title, and type of broadcast; and the associated company and location.

West, Ty. (Executive producer). (2009, September 24). PBS special report: Health care reform [Television broadcast]. New York, NY, and Washington, DC: Public Broadcasting Service.

\section{A Television or Radio Series or Episode}

Include the producer and the type of series if you are citing an entire television or radio series.

Couture, D., Nabors, S., Pinkard, S., Robertson, N., \& Smith, J. (Producers). (1979). The Diane Rehm show [Radio series]. Washington, DC: National Public Radio.

To cite a specific episode of a radio or television series, list the name of the writer or writers (if available), the date the episode aired, its title, and the type of series, along with general information about the series.

Bernanke, J., \& Wade, C. (2010, January 10). Hummingbirds: Magic in the air [Television series episode]. In F. Kaufman (Executive producer), Nature. New York, NY: WNET. 


\section{A Motion Picture}

Name the director or producer (or both), year of release, title, country of origin, and studio.

Spurlock, M. (Director/producer), Morley, J. (Executive producer), \& Winters. H. M. (Executive producer). (2004). Super size me. United States: Kathbur Pictures in association with Studio on Hudson.

\section{A Recording}

Name the primary contributors and list their role. Include the recording medium in brackets after the title. Then list the location and the label.

Smith, L. W. (Speaker). (1999). Meditation and relaxation [CD]. New York, NY: Earth, Wind, \& Sky Productions.

Székely, I. (Pianist), Budapest Symphony Orchestra (Performers), \& Németh, G. (Conductor). (1988). Chopin piano concertos no. 1 and 2 [CD]. Hong Kong: Naxos.

\section{A Podcast}

Provide as much information as possible about the writer, director, and producer; the date the podcast aired; its title; any organization or series with which it is associated; and where you retrieved the podcast.

Kelsey, A. R. (Writer), Garcia, J. (Director), \& Kim, S. C. (Producer). (2010, May 7). Lies food labels tell us. Savvy consumer podcasts [Audio podcast]. Retrieved from http://www.savvyconsumer.org/podcasts/050710 


\section{Exercise 4}

Revisit the references section you began to compile in Note 13.73 "Exercise 1".

1. Use the APA guidelines provided in this section to format any entries for electronic sources that you were unable to finish earlier.

2. If your sources include a form of media not covered in the APA guidelines here, consult with a writing tutor or review a print or online reference book. You may wish to visit the website of the American Psychological Association at http://www.apa.org or the Purdue University Online Writing lab at http://owl.english.purdue.edu, which regularly updates its online style guidelines.

3. Give your paper a final edit to check the references section.

\section{Key Takeaways}

- In APA papers, entries in the references section include as much of the following information as possible:

- Print sources. Author(s), date of publication, title, publisher, page numbers (for shorter works), editors (if applicable), and periodical title (if applicable).

- Online sources (text-based). Author(s), date of publication, title, publisher or sponsoring organization, and DOI or URL (if applicable).

- Electronic sources (non-text-based). Provide details about the creator(s) of the work, title, associated company or series, and date the work was produced or broadcast. The specific details provided will vary depending on the medium and the information that is available.

- Electronic sources (text-based). If an electronic source is also widely available in print form, it is sometimes unnecessary to provide details about how to access the electronic version. Check the guidelines for the specific source type. 


\subsection{Using Modern Language Association (MLA) Style}

\section{Learning Objectives}

1. Identify the major components of a research paper written using MLA style.

2. Apply general Modern Language Association (MLA) style and formatting conventions in a research paper.

We have addressed American Psychological Association (APA) style, as well as the importance of giving credit where credit is due, so now let's turn our attention to the formatting and citation style of the Modern Language Association, known as MLA style.

MLA style is often used in the liberal arts and humanities. Like APA style, it provides a uniform framework for consistency across a document in several areas. MLA style provides a format for the manuscript text and parenthetical citations, or in-text citations. It also provides the framework for the works cited area for references at the end of the essay. MLA style emphasizes brevity and clarity. As a student writer, it is to your advantage to be familiar with both major styles, and this section will outline the main points of MLA as well as offer specific examples of commonly used references. Remember that your writing represents you in your absence. The correct use of a citation style demonstrates your attention to detail and ability to produce a scholarly work in an acceptable style, and it can help prevent the appearance or accusations of plagiarism.

If you are taking an English, art history, or music appreciation class, chances are that you will be asked to write an essay in MLA format. One common question goes something like "What's the difference?" referring to APA and MLA style, and it deserves our consideration. The liberal arts and humanities often reflect works of creativity that come from individual and group effort, but they may adapt, change, or build on previous creative works. The inspiration to create something new, from a song to a music video, may contain elements of previous works. Drawing on your fellow artists and authors is part of the creative process, and so is giving credit where credit is due.

A reader interested in your subject wants not only to read what you wrote but also to be aware of the works that you used to create it. Readers want to examine your sources to see if you know your subject, to see if you missed anything, or if you offer anything new and interesting. Your new or up-to-date sources may offer the reader additional insight on the subject being considered. It also demonstrates that you, as the author, are up-to-date on what is happening in the field or on the subject. Giving credit where it is due enhances your credibility, and the MLA style offers a clear format to use.

Uncredited work that is incorporated into your own writing is considered plagiarism. In the professional world, plagiarism results in loss of credibility and often compensation, including future opportunities. In a classroom setting, plagiarism results in a range of sanctions, from loss of a grade to expulsion from 
a school or university. In both professional and academic settings, the penalties are severe. MLA offers artists and authors a systematic style of reference, again giving credit where credit is due, to protect MLA users from accusations of plagiarism.

MLA style uses a citation in the body of the essay that links to the works cited page at the end. The intext citation is offset with parentheses, clearly calling attention to itself for the reader. The reference to the author or title is like a signal to the reader that information was incorporated from a separate source. It also provides the reader with information to then turn to the works cited section of your essay (at the end) where they can find the complete reference. If you follow the MLA style, and indicate your source both in your essay and in the works cited section, you will prevent the possibility of plagiarism. If you follow the MLA guidelines, pay attention to detail, and clearly indicate your sources, then this approach to formatting and citation offers a proven way to demonstrate your respect for other authors and artists.

\section{Five Reasons to Use MLA Style}

1. To demonstrate your ability to present a professional, academic essay in the correct style

2. To gain credibility and authenticity for your work

3. To enhance the ability of the reader to locate information discussed in your essay

4. To give credit where credit is due and prevent plagiarism

5. To get a good grade or demonstrate excellence in your writing

Before we transition to specifics, please consider one word of caution: consistency. If you are instructed to use the MLA style and need to indicate a date, you have options. For example, you could use an international or a US style:

- International style: 18 May 1980 (day/month/year)

- US style: May 18, 1980 (month/day/year)

If you are going to the US style, be consistent in its use. You'll find you have the option on page 83 of the MLA Handbook for Writers of Research Papers, 7th edition. You have many options when writing in English as the language itself has several conventions, or acceptable ways of writing particular parts of speech or information. For example, on the next page our MLA Handbook addresses the question:

Which convention is preferred in MLA style:

twentieth century

Twentieth Century

20th century

20th Century

You are welcome to look in the MLA Handbook and see there is one preferred style or convention (you will also find the answer at end of this section marked by an asterisk [*]). Now you may say to yourself 
that you won't write that term and it may be true, but you will come to a term or word that has more than one way it can be written. In that case, what convention is acceptable in MLA style? This is where the MLA Handbook serves as an invaluable resource. Again, your attention to detail and the professional presentation of your work are aspects of learning to write in an academic setting.

Now let's transition from a general discussion on the advantages of MLA style to what we are required to do to write a standard academic essay. We will first examine a general "to do" list, then review a few “do not” suggestions, and finally take a tour through a sample of MLA features. Links to sample MLA papers are located at the end of this section.

\section{General MLA List}

1. Use standard white paper $(8.5 \times 11$ inches $)$.

2. Double space the essay and quotes.

3. Use Times New Roman 12-point font.

4. Use one-inch margins on all sides

5. Indent paragraphs (five spaces or 1.5 inches).

6. Include consecutive page numbers in the upper-right corner.

7. Use italics to indicate a title, as in Writing for Success.

8. On the first page, place your name, course, date, and instructor's name in the upper-left corner.

9. On the first page, place the title centered on the page, with no bold or italics and all words capitalized.

10. On all pages, place the header, student's name + one space + page number, 1.5 inches from the top, aligned on the right.

Tip

Depending on your field of study, you may sometimes write research papers in either APA or MLA style. Recognize that each has its advantages and preferred use in fields and disciplines. Learn to write and reference in both styles with proficiency.

\section{Title Block Format}

You never get a second chance to make a first impression, and your title block (not a separate title page; just a section at the top of the first page) makes an impression on the reader. If correctly formatted with 
each element of information in its proper place, form, and format, it says to the reader that you mean business, that you are a professional, and that you take your work seriously, so it should, in turn, be seriously considered. Your title block in MLA style contributes to your credibility. Remember that your writing represents you in your absence, and the title block is the tailored suit or outfit that represents you best. That said, sometimes a separate title page is necessary, but it is best both to know how to properly format a title block or page in MLA style and to ask your instructor if it is included as part of the assignment.

Your name

Instructor

Course number

Date

Title of Paper

\section{Paragraphs and Indentation}

Make sure you indent five spaces (from the left margin). You'll see that the indent offsets the beginning of a new paragraph. We use paragraphs to express single ideas or topics that reinforce our central purpose or thesis statement. Paragraphs include topic sentences, supporting sentences, and conclusion or transitional sentences that link paragraphs together to support the main focus of the essay.

\section{Tables and Illustrations}

Place tables and illustrations as close as possible to the text they reinforce or complement. Here's an example of a table in MLA.

Table 13.2

\begin{tabular}{|l|l|}
\hline Sales Figures by Year & Sales Amount (\$) \\
\hline 2007 & 100,000 \\
\hline 2008 & 125,000 \\
\hline 2009 & 185,000 \\
\hline 2010 & 215,000 \\
\hline
\end{tabular}


As we can see in Table 13.2, we have experienced significant growth since 2008.

This example demonstrates that the words that you write and the tables, figures, illustrations, or images that you include should be next to each other in your paper.

\section{Parenthetical Citations}

You must cite your sources as you use them. In the same way that a table or figure should be located right next to the sentence that discusses it (see the previous example), parenthetical citations, or citations enclosed in parenthesis that appear in the text, are required. You need to cite all your information. If someone else wrote it, said it, drew it, demonstrated it, or otherwise expressed it, you need to cite it. The exception to this statement is common, widespread knowledge. For example, if you search online for MLA resources, and specifically MLA sample papers, you will find many similar discussions on MLA style. MLA is a style and cannot be copyrighted because it is a style, but the seventh edition of the MLA Handbook can be copyright protected. If you reference a specific page in that handbook, you need to indicate it. If you write about a general MLA style issue that is commonly covered or addressed in multiple sources, you do not. When in doubt, reference the specific resource you used to write your essay.

Your in-text, or parenthetical, citations should do the following:

- Clearly indicate the specific sources also referenced in the works cited

- Specifically identify the location of the information that you used

- Keep the citation clear and concise, always confirming its accuracy

\section{Works Cited Page}

After the body of your paper comes the works cited page. It features the reference sources used in your essay. List the sources alphabetically by last name, or list them by title if the author is not known as is often the case of web-based articles. You will find links to examples of the works cited page in several of the sample MLA essays at the end of this section.

As a point of reference and comparison to our APA examples, let's examine the following three citations and the order of the information needed. 


\section{Citation \\ Type \\ MLA Style \\ Author's Last Name, First Name. Title of the website. \\ Website Publication Date. Name of Organization (if applicable). Date you accessed the website. $<$ URL $>$. \\ Online \\ article \\ Author's Last Name, First Name. “Title of Article.” Title of the website. Date of publication. Organization that provides the website. Date you accessed the website. \\ Book \\ Author's Last Name, First Name. Title of the Book. Place of Publication: Publishing Company, Date of publication.}

\section{APA Style}

Author's Last Name, First Initial. (Date of publication). Title of document. Retrieved from URL

Author's Last name, First Initial. (Date of publication). Title of article. Title of Journal, Volume(Issue). Retrieved from URL

Author's Last Name, First Initial. (Date of publication). Title of the book. Place of Publication: Publishing Company.

Note: The items listed include proper punctuation and capitalization according to the style's guidelines.

\section{Exercise 1}

In Chapter 13 "APA and MLA Documentation and Formatting", Section 13.1 "Formatting a Research Paper", you created a sample essay in APA style. After reviewing this section and exploring the resources linked at the end of the section (including California State University-Sacramento's clear example of a paper in MLA format), please convert your paper to MLA style using the formatting and citation guidelines. You may find it helpful to use online applications that quickly, easily, and at no cost convert your citations to MLA format.

\section{Exercise 2}

Please convert the APA-style citations to MLA style. You may find that online applications can quickly, easily, and at no cost convert your citations to MLA format. There are several websites and applications available free (or as a free trial) that will allow you to input the information and will produce a correct citation in the style of your choice. Consider these two sites:

- http://www.noodletools.com

- http://citationmachine.net

Hint: You may need access to the Internet to find any missing information required to correctly cite in MLA style. This demonstrates an important difference between APA and MLA style — the information provided to the reader. 


\section{Sample Student Reference List in APA Style}

1 Brent, D. A., Poling, K. D., \& Goldstein, T. R. (2010). Treating depressed and suicidal adolescents: A clinician's guide. New York, NY: Guilford Press.

MLA

2 Dewan, S. (2007, September 17). Using crayons to exorcise Katrina. The New York Times. Retrieved from http://www.nytimes.com/2007/09/17/arts/design/17ther.html

MLA

3 Freud, S. (1955). Beyond the pleasure principle. In The Complete Works of Sigmund Freud. (Vol. XVII, pp.

3-66). London, England: Hogarth.

MLA

$4 \quad$ Henley, D. (2007). Naming the enemy: An art therapy intervention for children with bipolar and comorbid disorders. Art Therapy: Journal of the American Art Therapy Association, 24(3), 104-110.

MLA

5 Hutson, M. (2008). Art therapy: The healing arts. Psychology Today. Retrieved from

http://www.psychologytoday.com/articles/200705/art-therapy-the-healing-arts

MLA

Isis, P. D., Bus, J., Siegel, C. A., \& Ventura, Y. (2010). Empowering students through creativity: Art therapy in

6 Miami-Dade County Public Schools. Art Therapy: Journal of the American Art Therapy Association, 27(2), $56-61$.

MLA

7 Johnson, D. (1987). The role of the creative arts therapies in the diagnosis and treatment of psychological trauma. The Arts in Psychotherapy, 14, 7-13.

MLA

8 Malchiodi, C. (2006). Art therapy sourcebook. New York, NY: McGraw-Hill.

MLA

9 Markel, R. (Producer). (2010). I’m an artist [Motion picture]. United States: Red Pepper Films.

MLA

10 Kelley, S. J. (1984). The use of art therapy with sexually abused children. Journal of Psychosocial Nursing and Mental Health, 22(12), 12-28.

MLA

11 Pifalo, T. (2008). Why art therapy? Darkness to light: Confronting child abuse with courage. Retrieved from http://www.darkness2light.org/KnowAbout/articles_art_therapy.asp

MLA

12 Rubin, J. A. (2005). Child art therapy (25th ed.). New York, NY: Wiley.

MLA 


\section{Sample Student Reference List in APA Style}

13 Schimek, J. (1975). A critical re-examination of Freud's concept of unconscious mental representation. International Review of Psychoanalysis, 2, 171-187.

MLA

14 Strauss, M. B. (1999). No talk therapy for children and adolescents. New York, NY: Norton.

MLA

Thompson, T. (2008). Freedom from meltdowns: Dr. Thompson's solutions for children with autism. Baltimore, MD: Paul H. Brookes.

MLA

\section{Useful Sources of Examples of MLA Style}

- Arizona State University Libraries offers an excellent resource with clear examples.

- http://libguides.asu.edu/content.php?pid=122697\&sid=1132964

- Purdue Online Writing Lab includes sample pages and works cited.

- http://owl.english.purdue.edu/owl/resource/747/01

- California State University-Sacramento's Online Writing Lab has an excellent visual description and example of an MLA paper.

- http://www.csus.edu/owl/index/mla/mla format.htm

- SUNY offers an excellent, brief, side-by-side comparison of MLA and APA citations.

- http://www.sunywcc.edu/LIBRARY/research/MLA APA 08.03.10.pdf

- Cornell University Library provides comprehensive MLA information on its Citation Management website.

- http://www.library.cornell.edu/resrch/citmanage/mla

- The University of Kansas Writing Center is an excellent resource.

- http://www.writing.ku.edu/guides

* (a) is the correct answer to the question at the beginning of this section. The MLA Handbook prefers

"twentieth century." 


\section{Key Takeaways}

- MLA style is often used in the liberal arts and humanities.

- MLA style emphasizes brevity and clarity.

- A reader interested in your subject wants not only to read what you wrote but also to be informed of the works you used to create it.

- MLA style uses a citation in the body of the essay that refers to the works cited section at the end.

- If you follow MLA style, and indicate your source both in your essay and in the works cited section, you will prevent the possibility of plagiarism. 


\subsection{APA and MLA Documentation and Formatting: End-of-Chapter Exercises}

\section{Exercises}

1. In this chapter, you learned strategies for using APA and MLA style documentation and formatting in a research paper. Locate a source that uses APA or MLA style, such as an article in a professional journal in the sciences or social sciences. Identify these key components of an APA or MLA paper in your example: the abstract, section heads, in-text citations, and references list.

2. Check one of your assignments for correct APA or MLA formatting and citations. (You may wish to conduct this activity in two sessions - one to edit the body of the paper and one to edit the references section.) Check for the following:

- All components of an APA or MLA paper are included.

- The title page (or title block) and body of the paper are correctly formatted.

- In-text, or parenthetical, citations are complete and correctly formatted.

- Sources cited within the paper match the sources listed in the references or works cited section.

- The references or works cited section uses correct formatting and lists entries in alphabetical order.

3. As electronic media continually change, guidelines for citing electronic sources are continually updated. Identify three new or emerging forms of electronic media not listed in this text-for instance, virtual communities, such as Second Life, or social networking sites, such as LinkedIn, Facebook, and MySpace. Answer the following questions:

- Under what circumstances would this media be a useful source of information for a research paper? How might students use these sources to conduct research five or ten years from now?

- What information would a student need to provide if citing this source? Why?

- Develop brief guidelines for how to cite the emerging media source types you identified. 


\section{Chapter 14: Creating Presentations: Sharing Your Ideas}

14.1 Organizing a Visual Presentation

14.2 Incorporating Effective Visuals into a Presentation

14.3 Giving a Presentation

14.4 Creating Presentations: End-of-Chapter Exercises 


\subsection{Organizing a Visual Presentation}

\section{Learning Objectives}

1. Identify key ideas and details to create a concise, engaging presentation.

2. Identify the steps involved in planning a comprehensive presentation.

Until now, you have interacted with your audience of readers indirectly, on the page. You have tried to anticipate their reactions and questions as all good writers do. Anticipating the audience's needs can be tough, especially when you are sitting alone in front of your computer.

When you give a presentation, you connect directly with your audience. For most people, making a presentation is both exciting and stressful. The excitement comes from engaging in a two-way interaction about your ideas. The stress comes from the pressure of presenting your ideas without having a delete button to undo mistakes. Outside the classroom, you may be asked to give a presentation, often at the last minute, and the show must go on. Presentations can be stressful, but planning and preparation, when the time and opportunity are available, can make all the difference.

This chapter covers how to plan and deliver an effective, engaging presentation. By planning carefully, applying some time-honored presentation strategies, and practicing, you can make sure that your presentation comes across as confident, knowledgeable, and interesting-and that your audience actually learns from it. The specific tasks involved in creating a presentation may vary slightly depending on your purpose and your assignment. However, these are the general steps.

Follow these steps to create a presentation based on your ideas:

1. Determine your purpose and identify the key ideas to present.

2. Organize your ideas in an outline.

3. Identify opportunities to incorporate visual or audio media, and create or locate these media aids.

4. Rehearse your presentation in advance.

5. Deliver your presentation to your audience. 


\section{Getting Started: Identifying and Organizing Key Ideas}

To deliver a successful presentation, you need to develop content suitable for an effective presentation. Your ideas make up your presentation, but to deliver them effectively, you will need to identify key ideas and organize them carefully. Read the following considerations, which will help you first identify and then organize key ideas:

- Be concise. You will include the most important ideas and leave out others. Some concepts may need to be simplified.

- Employ more than one medium of expression. You should incorporate other media, such as charts, graphs, photographs, video or audio recordings, or websites.

- Prepare for a face-to-face presentation. If you must deliver a face-to-face presentation, it is important to project yourself as a serious and well-informed speaker. You will often speak extemporaneously, or in a rehearsed but not memorized manner, which allows for flexibility given the context or audience. You will need to know your points and keep your audience engaged.

\section{Determine Your Purpose}

As with a writing assignment, determining the purpose of your presentation early on is crucial. You want to inform your readers about the topic, but think about what else you hope to achieve.

Are you presenting information intended to move your audience to adopt certain beliefs or take action on a particular issue? If so, you are speaking not only to inform but also to persuade your listeners. Do you want your audience to come away from your presentation knowing how to do something they that they did not know before? In that case, you are not only informing them but also explaining or teaching a process.

\section{Writing at Work}

Schoolteachers are trained to structure lessons around one or more lesson objectives. Usually the objective, the mission or purpose, states what students should know or be able to do after they complete the lesson. For example, an objective might state, "Students will understand the specific freedoms guaranteed by the First Amendment" or "Students will be able to add two three-digit numbers correctly."

As a manager, mentor, or supervisor, you may sometimes be required to teach or train other employees as part of your job. Determining the desired outcome of a training session will help you plan effectively. Identify your teaching objectives. What, specifically, do you want your audience to know (for instance, details of a new workplace policy) or be able to do (for instance, use a new software program)? Plan your teaching or training session to meet your objectives. 


\section{Identify Key Ideas}

To plan your presentation, think in terms of three or four key points you want to get across. In a paper, you have the space to develop ideas at length and delve into complex details. In a presentation, however, you must convey your ideas more concisely.

One strategy you might try is to create an outline. What is your main idea? Would your main idea work well as key points for a brief presentation? How would you condense topics that might be too lengthy, or should you eliminate topics that may be too complicated to address in your presentation?

\section{Exercise 1}

1. Revisit your presentation assignment, or think of a topic for your presentation. On your own sheet of notebook paper, write a list of at least three to five key ideas. Keep the following questions in mind when listing your key ideas:

- What is your purpose?

- Who is your audience?

- How will you engage your audience?

2. On the same paper, identify the steps you must complete before you begin creating your presentation.

\section{Use an Outline to Organize Ideas}

After you determine which ideas are most appropriate for your presentation, you will create an outline of those ideas. Your presentation, like a written assignment, should include an introduction, body, and conclusion. These components serve much the same purpose as they do in a written assignment.

- The introduction engages the audience's attention, introduces the topic, and sets the tone for what is to come.

- The body develops your point of view with supporting ideas, details, and examples presented in a logical order.

- The conclusion restates your point of view, sums up your main points, and leaves your audience with something to think about.

Jorge, who wrote the research paper featured in Chapter 11 "Writing from Research: What Will I Learn?", developed the following outline. Jorge relied heavily on this outline to plan his presentation, but he adjusted it to suit the new format. 
Beyond the Hype: Evaluating Low-Carbohydrate Diets

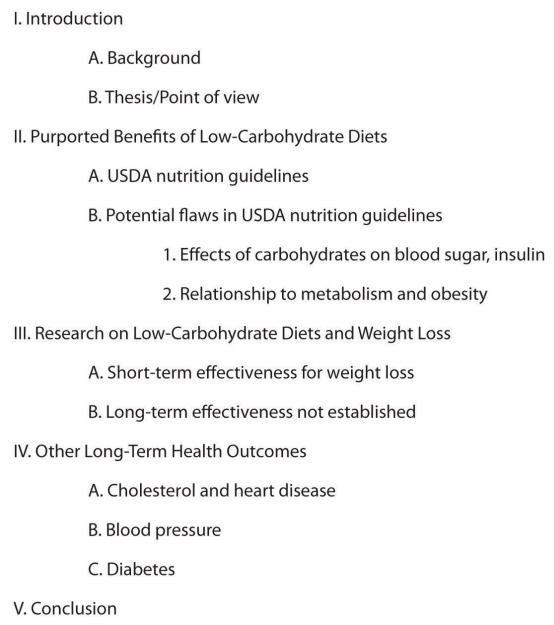

\section{Planning Your Introduction}

In Chapter 12 "Writing a Research Paper", you learned techniques for writing an interesting introduction, such as beginning with a surprising fact or statistic, a thought-provoking question or quotation, a brief anecdote that illustrates a larger concept or connects your topic to your audience's experiences. You can use these techniques effectively in presentations as well. You might also consider actively engaging your audience by having members respond to questions or complete a brief activity related to your topic. For example, you may have your audience respond to a survey or tell about an experience related to your topic.

Incorporating media can also be an effective way to get your audience's attention. Visual images such as a photograph or a cartoon can invoke an immediate emotional response. A graph or chart can highlight startling findings in research data or statistical information. Brief video or audio clips that clearly reinforce your message and do not distract or overwhelm your audience can provide a sense of immediacy when you plan to discuss an event or a current issue. A PowerPoint presentation allows you to integrate many of these different media sources into one presentation. 


\section{Tip}

With the accessibility provided by the Internet, you can find interesting and appropriate audio and video with little difficulty. However, the clip alone will not sustain the presentation. To keep the audience interested and engaged, you must frame the beginning and end of the clip with your own words.

Jorge completed the introduction part of his outline by listing the key points he would use to open his presentation. He also planned to show various web links early on to illustrate the popularity of the lowcarbohydrate diet trend.

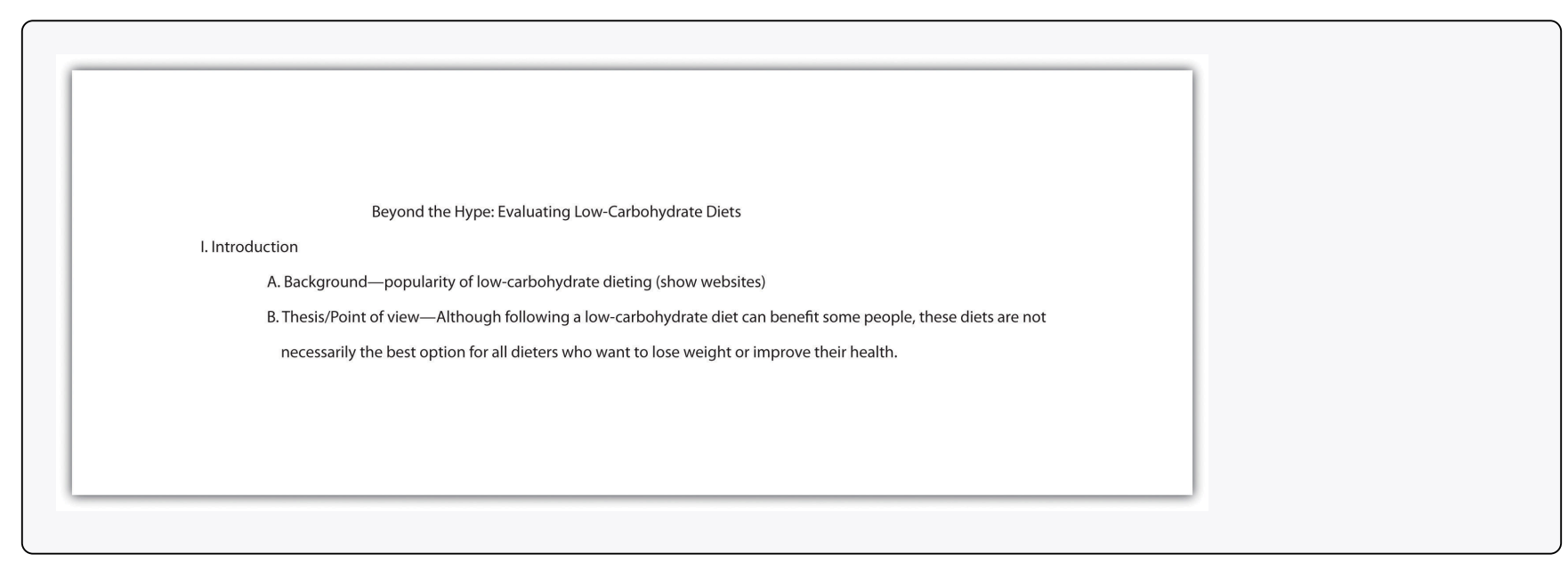

\section{Planning the Body of Your Presentation}

The next step is to work with the key ideas you identified earlier. Determine the order in which you want to present these ideas, and flesh them out with important details. Chapter 10 "Rhetorical Modes” discusses several organizational structures you might work with, such as chronological order, comparison-and-contrast structure, or cause-and-effect structure.

How much detail you include will depend on the time allotted for your presentation. Your instructor will most likely give you a specific time limit or a specific slide limit, such as eight to ten slides. If the time limit is very brief (two to three minutes, for instance), you will need to focus on communicating your point of view, main supporting points, and only the most relevant details. Three minutes can feel like an eternity if you are speaking before a group, but the time will pass very quickly. It is important to use it well.

If you have more time to work with — ten minutes or half an hour-you will be able to discuss your topic in greater detail. More time also means you must devote more thought into how you will hold your audience's interest. If your presentation is longer than five minutes, introduce some variety so the audience is not bored. Incorporate multimedia, invite the audience to complete an activity, or set aside time for a question-and-answer session. 
Jorge was required to limit his presentation to five to seven minutes. In his outline, he made a note about where he would need to condense some complicated material to stay within his time limit. He also decided to focus only on cholesterol and heart disease in his discussion of long-term health outcomes. The research on other issues was inconclusive, so Jorge decided to omit this material. Jorge's notes on his outline show the revisions he has made to his presentation.

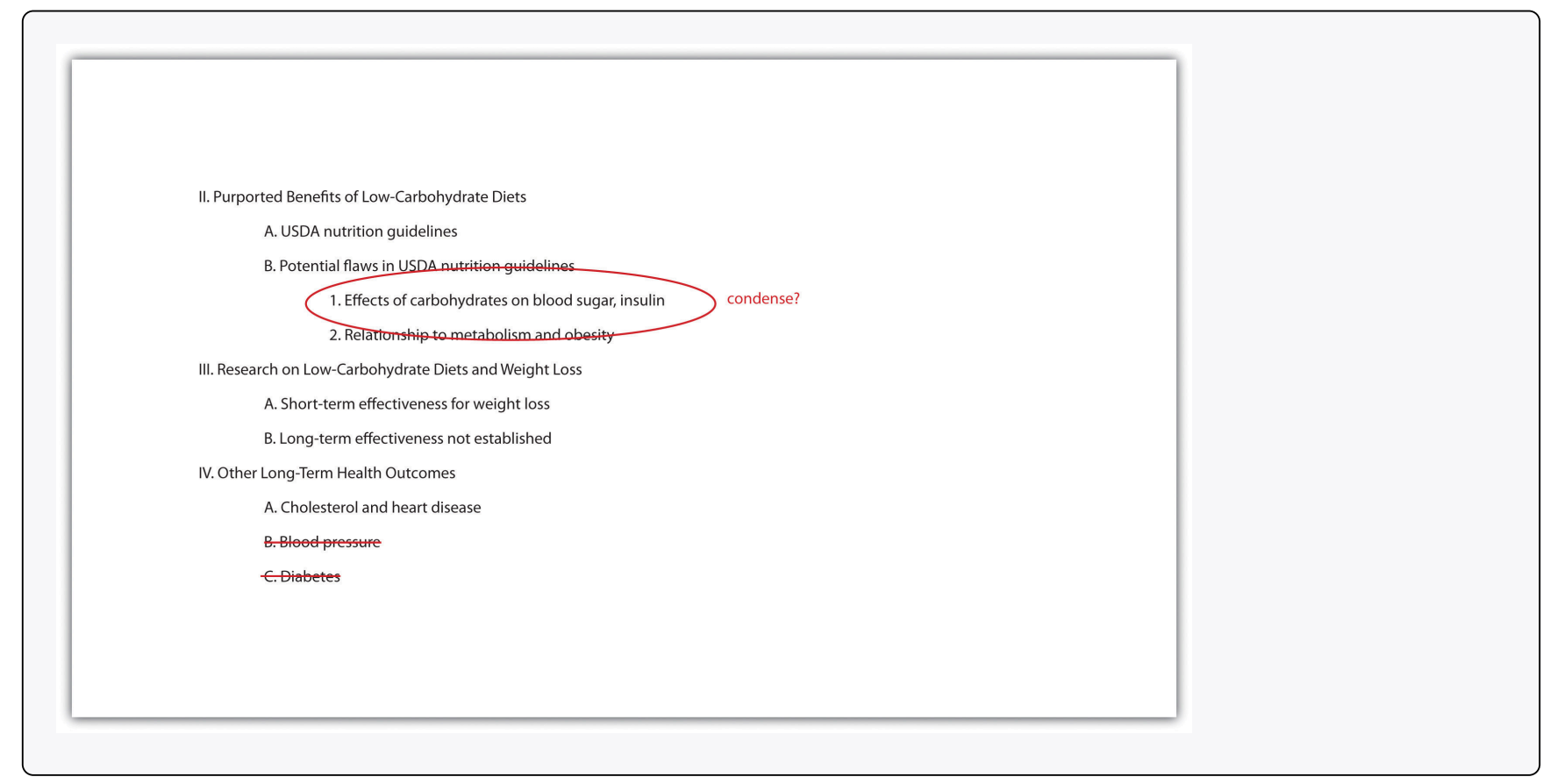

Tip

You are responsible for using your presentation time effectively to inform your audience. You show respect for your audience by following the expected time limit. However, that does not mean you must fill all of that time with talk if you are giving a face-to-face presentation. Involving your audience can take some of the pressure off you while also keeping them engaged. Have them respond to a few brief questions to get them thinking. Display a relevant photograph, document, or object and ask your classmates to comment. In some presentations, if time allows, you may choose to have your classmates complete an individual or group activity.

\section{Planning Your Conclusion}

The conclusion should briefly sum up your main idea and leave your audience with something to think about. As in a written paper, you are essentially revisiting your thesis. Depending on your topic, you may also ask the audience to reconsider their thinking about an issue, to take action, or to think about a related issue. If you presented an attention-getting fact or anecdote in your introduction, consider revisiting it in your conclusion. Just as you have learned about an essay's conclusion, do not add new content to the presentation's conclusion. 
No matter how you choose to structure your conclusion, make sure it is well planned so that you are not tempted to wrap up your presentation too quickly. Inexperienced speakers, in a face-to-face presentation, sometimes rush through the end of a presentation to avoid exceeding the allotted time or to end the stressful experience of presenting in public. Unfortunately, a hurried conclusion makes the presentation as a whole less memorable.

\section{Tip}

Time management is the key to delivering an effective presentation whether it is face-to-face or in PowerPoint. As you develop your outline, think about the amount of time you will devote to each section. For instance, in a five-minute face-to-face presentation, you might plan to spend one minute on the introduction, three minutes on the body, and one minute on the conclusion. Later, when you rehearse, you can time yourself to determine whether you need to adjust your content or delivery.

In a PowerPoint presentation, it is important that your presentation is visually stimulating, avoids information overload by limiting the text per slide, uses speaker notes effectively, and uses a font that is visible on the background (e.g., avoid white letters on a light background or black letters on a dark background).

\section{Exercise 2}

Work with the list you created in Note 14.4 "Exercise 1" to develop a more complete outline for your presentation. Make sure your outline includes the following:

- An introduction that uses strategies to capture your audience's attention

- A body section that summarizes your main points and supporting details

- A conclusion that will help you end on a memorable note

- Brief notes about how much time you plan to spend on each part of the presentation (you may adjust the timing later as needed)

\section{Identifying Opportunities to Incorporate Visual and Audio Media}

You may already have some ideas for how to incorporate visual and audio media in your presentation. If not, review your outline and begin thinking about where to include media. Presenting information in a variety of formats will help you keep your audience's interest. 


\section{Use Presentation Software}

Delivering your presentation as a slideshow is one way to use media to your advantage. As you speak, you use a computer and an attached projector to display a slideshow of text and graphics that complement the speech. Your audience will follow your ideas more easily, because you are communicating with them through more than one sense. The audience hears your words and also sees the corresponding visuals. A listener who momentarily loses track of what you are saying can rely on the slide to cue his or her memory.

To set up your presentation, you will need to work with the content of your outline to develop individual slides. Each slide should focus on just a few bullet points (or a similar amount of content presented in a graphic). Remember that your audience must be able to read the slides easily, whether the members sit in the front or the back of the room. Avoid overcrowding the slides with too much text.

Using presentation software, such as PowerPoint, allows you to incorporate graphics, sounds, and even web links directly into your slides. You can also work with available styles, color schemes, and fonts to give your presentation a polished, consistent appearance. Different slide templates make it easy to organize information to suit your purpose. Be sure your font is visible to you audience. Avoid using small font or colored font that is not visible against your background.

\section{Use PowerPoint as a Visual Aid}

PowerPoint and similar visual representation programs can be effective tools to help audiences remember your message, but they can also be an annoying distraction to your speech. How you prepare your slides and use the tool will determine your effectiveness.

PowerPoint is a slideware program that you have no doubt seen used in class, seen in a presentation at work, or perhaps used yourself to support a presentation. PowerPoint and similar slideware programs provide templates for creating electronic slides to present visual information to the audience, reinforcing the verbal message. You will be able to import or cut and paste words from text files, images, or video clips to create slides to represent your ideas. You can even incorporate web links. When using any software program, it is always a good idea to experiment with it long before you intend to use it; explore its many options and functions, and see how it can be an effective tool for you.

At first, you might be overwhelmed by the possibilities, and you might be tempted to use all the bells, whistles, and sound effects, not to mention the tumbling, flying, and animated graphics. If used wisely, a dissolve or key transition can be like a well-executed scene from a major motion picture and lead your audience to the next point. But if used indiscriminately, it can annoy the audience to the point where they cringe in anticipation of the sound effect at the start of each slide. This danger is inherent in the tool, but you are in charge of it and can make wise choices that enhance the understanding and retention of your information.

The first point to consider is which visual aid is the most important. The answer is you, the speaker. You will facilitate the discussion, give life to the information, and help the audience correlate the content to 
your goal or purpose. You do not want to be in a position where the PowerPoint presentation is the focus and you are on the side of the stage simply helping the audience follow along. Slides should support you in your presentation, rather than the other way around. Just as there is a number one rule for handouts (do not pass them out at the start of your presentation), there is also one for PowerPoint presentations: do not use PowerPoint slides as a read-aloud script for your speech. The PowerPoint slides should amplify and illustrate your main points, not reproduce everything you are going to say.

Your pictures are the second area of emphasis you will want to consider. The tool will allow you to show graphs, charts and illustrate relationships that words may only approach in terms of communication, but your verbal support of the visual images will make all the difference. Dense pictures or complicated graphics will confuse more than they clarify. Choose clear images that have an immediate connection to both your content and the audience, tailored to their specific needs. After the images, consider using only key words that can be easily read to accompany your pictures. The fewer words the better. Try to keep each slide to a total word count of less than ten words. Do not use full sentences. Using key words provides support for your verbal discussion, guiding you as well as your audience. The key words can serve as signposts or signal words related to key ideas.

A natural question at this point is, How do I communicate complex information simply? The answer comes with several options. The visual representation on the screen is for support and illustration. Should you need to communicate more technical, complex, or in-depth information in a visual way, consider preparing a handout to distribute at the conclusion of your speech. You may also consider using a printout of your slide show with a section for taking notes, but if you distribute it at the beginning of your speech, you run the risk of turning your presentation into a guided reading exercise and possibly distracting or losing members of the audience. Everyone reads at a different pace and takes notes in their own way. You do not want to be in the position of going back and forth between slides to help people follow along.

Another point to consider is how you want to use the tool to support your speech and how your audience will interpret its presentation. Most audiences wouldn't want to read a page of text-as you might see in this book - on the big screen. They will be far more likely to glance at the screen and assess the information you present in relation to your discussion. Therefore, it is key to consider one main idea, relationship, or point per slide. The use of the tool should be guided with the idea that its presentation is for the audience's benefit, not yours. People often understand pictures and images more quickly and easily than text, and you can use this to your advantage, using the knowledge that a picture is worth a thousand words.

\section{Incorporate Visual Media}

Even if you do not use a slideshow to complement your presentation, you can include visual media to support and enhance your content. Visual media are divided into two major categories: images and informational graphics.

Image-based media, such as photographs or videos, often have little or no accompanying text. Often these media are more powerful than words in getting a message across. Within the past decade, the images associated with major news stories, such as the Indian Ocean tsunami of 2004, the Abu Ghraib 
prison abuses from 2004 to 2006, and the 2010 earthquake in Haiti, have powerfully affected viewers’ emotions and drawn their attention to these news stories.

Figure 14.1

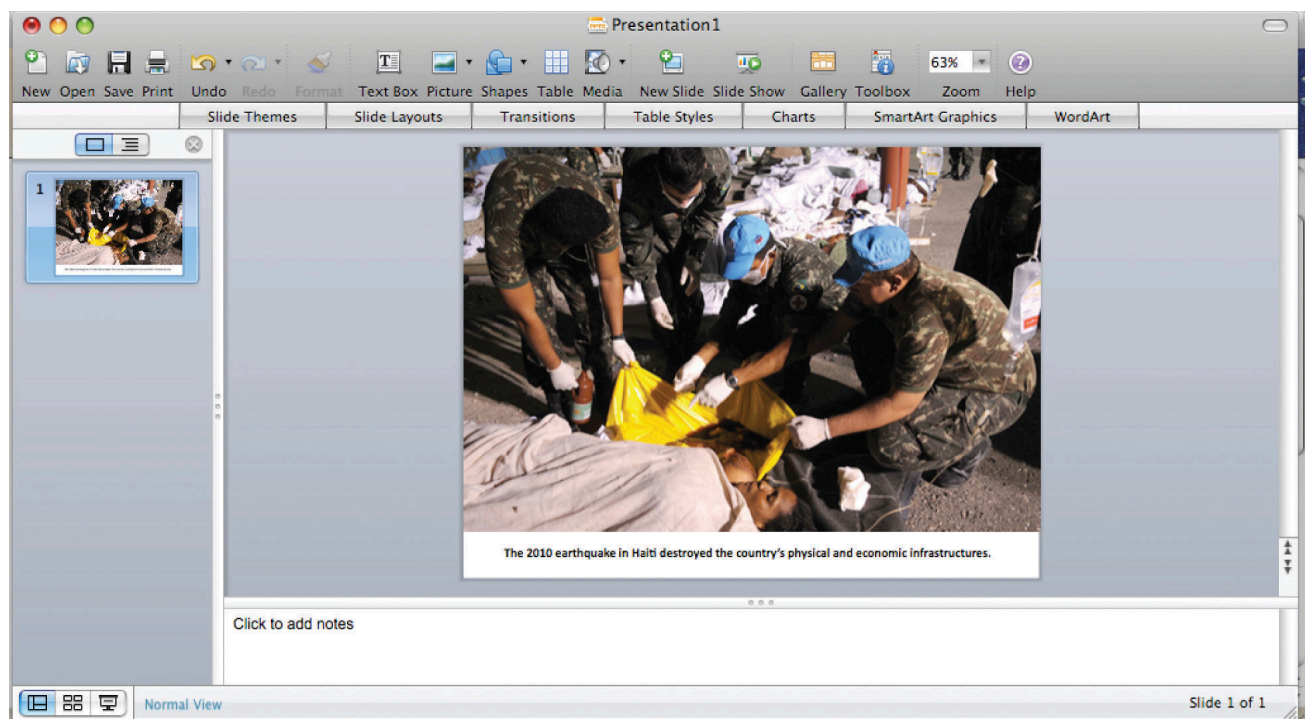

Even if your presentation addresses a less dramatic subject, you can still use images to draw in your audience. Consider how photographs, an illustration, or a video might help your audience connect with a particular person or place or bring a historical event to life. Use visual images to support descriptions of natural or man-made phenomena. What ideas lend themselves to being explained primarily through images?

In addition, consider how you might incorporate informational graphics in your presentation. Informational graphics include diagrams, tables, pie charts, bar and line graphs, and flow charts. Informational graphics usually include some text and often work well to present numerical information. Consider using them if you are presenting statistics, comparing facts or data about several different groups, describing changes over time, or presenting a process.

\section{Incorporate Audio Media}

Although audio media are not as versatile as visual media, you may wish to use them if they work well with your particular topic. If your presentation discusses trends in pop music or analyzes political speeches, playing an audio clip is an obvious and effective choice. Clips from historical speeches, radio talk shows, and interviews can also be used, but extended clips may be ineffective with modern audiences. Always assess your audience's demographics and expectations before selecting and including audio media. 


\section{Exercise 3}

Review the outline you created in Note 14.11 "Exercise 2". Complete the following steps:

1. Identify at least two to three places in your presentation where you might incorporate visual or audio media. Brainstorm ideas for what media would be effective, and create a list of ideas. (In Chapter 14 "Creating Presentations: Sharing Your Ideas", Section 14.2 "Incorporating Effective Visuals into a Presentation”, you will explore different media options in greater depth. For now, focus on coming up with a few general ideas.)

2. Determine whether you will use presentation software to deliver your presentation as a slideshow. If you plan to do so, begin using your outline to draft your slides.

Figure 14.2

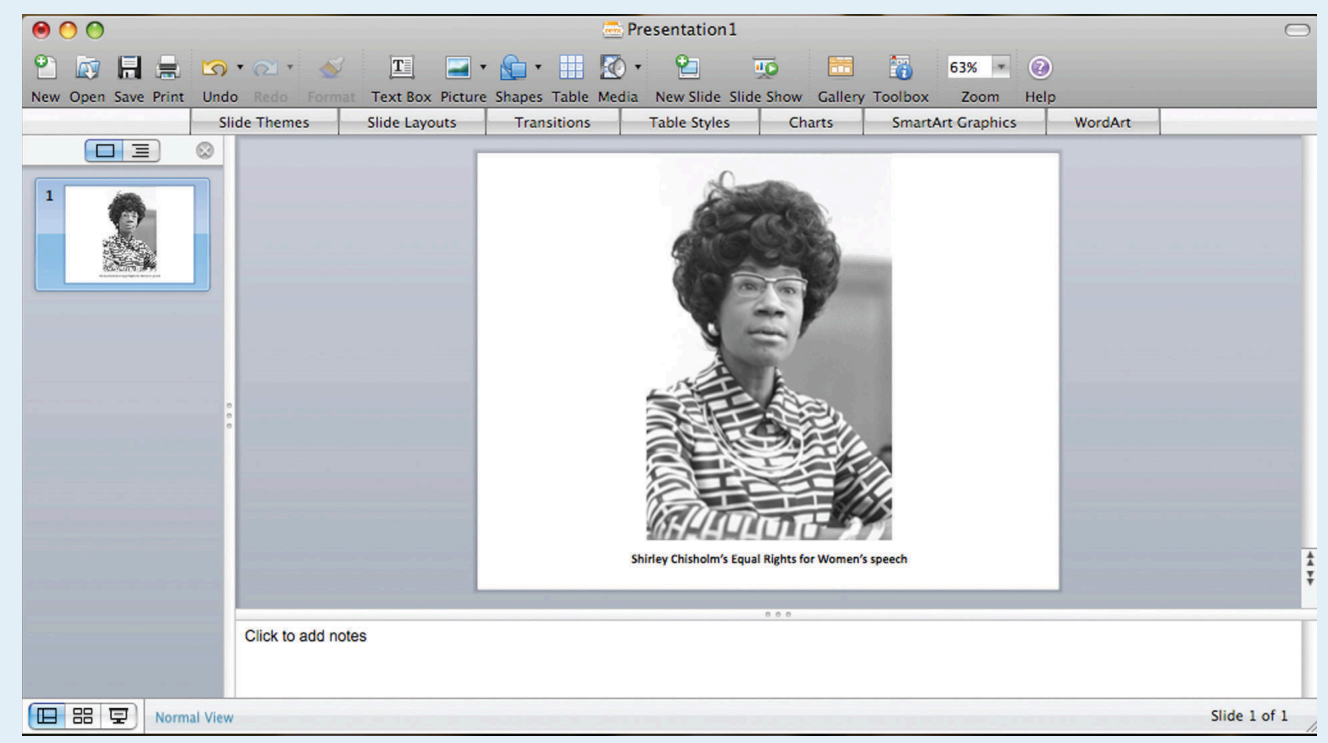

Source: $\underline{\text { http://www.agenciabrasil.gov.br/media/imagens/2010/01/14/14.01.10RP5978.jpg/view }}$

\section{Planning Ahead: Annotating Your Presentation}

When you make a presentation, you are giving a performance of sorts. It may not be as dramatic as a play or a movie, but it requires smooth coordination of several elements-your words, your gestures, and any media you include. One way to ensure that the performance goes smoothly is to annotate your presentation ahead of time.

To annotate means to add comments or notes to a document. You can use this technique to plan how the different parts of your presentation will flow together. For instance, if you are working with slides, add notes to your outline indicating when you will show each slide. If you have other visual or audio media to include, make a note of that, too. Be as detailed as necessary. Jotting "Start video at 3:14" can spare you the awkwardness of searching for the right clip during your presentation. 


\section{Writing at Work}

In the workplace, employees are often asked to deliver presentations or conduct a meeting using standard office presentation software. If you are using presentation software, you can annotate your presentation easily as you create your slides. Use the notes feature at the bottom of the page to add notes for each slide. As you deliver your presentation, your notes will be visible to you on the computer screen but not to your audience on the projector screen.

In a face-to-face presentation, make sure your final annotated outline is easy to read. It will serve to cue you during your presentation, so it does not need to look polished, as long as it is clear to you. Double space the text. Use a larger-than-normal font size (14 or 16 points) if that will make it easier for you to read. Boldface or italics will set off text that should be emphasized or delivered with greater emotion. Write out main points, as well as your opening and closing remarks, in complete sentences, along with any material you want to quote verbatim. Use shorter phrases for supporting details. Using your speaker notes effectively will help you deliver an effective presentation. Highlighting, all capital letters, or different-colored font will help you easily distinguish notes from the text of your speech. Read Jorge's annotated outline. 


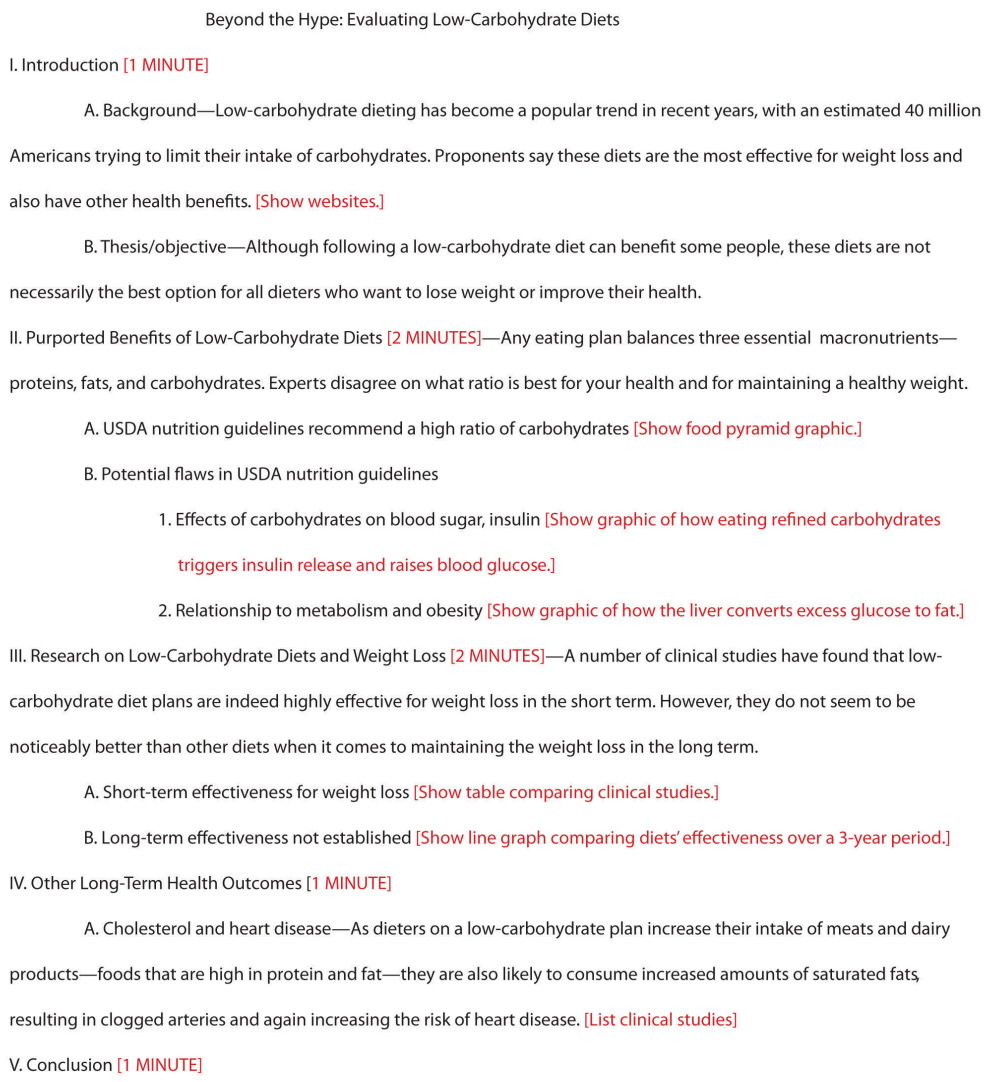

\section{Tip}

Some students prefer to write out the full text of their face-to-face presentation. This can be a useful strategy when you are practicing your delivery. However, keep in mind that reading your text aloud, word for word, will not help you capture and hold your audience's attention. Write out and read your speech if that helps you rehearse. After a few practice sessions, when you are more comfortable with your material, switch to working from an outline. That will help you sound more natural when you speak to an audience.

In a PowerPoint presentation, remember to have your slides in logical sequential order. Annotating your presentation before submitting it to your audience or your instructor will help you check for order and logical transitions. Too much text or data may confuse your audience; strive for clarity and avoid unnecessary details. Let the pictures or graphics tell the story but do not overload your slideshow with visuals. Be sure your font is visible. Look for consistency in the time limit of your presentation to gauge your level of preparedness. 


\section{Exercise 4}

Begin to annotate your outline. (You will probably add more notes as you proceed, but including some annotations now will help you begin pulling your ideas together.) Mark your outline with the following information:

1. Write notes in brackets to any sections where you definitely plan to incorporate visual or audio media.

2. If you are presenting a slideshow, add notes in brackets indicating which slides go with each section of your outline.

3. Identify and set off any text that should be emphasized.

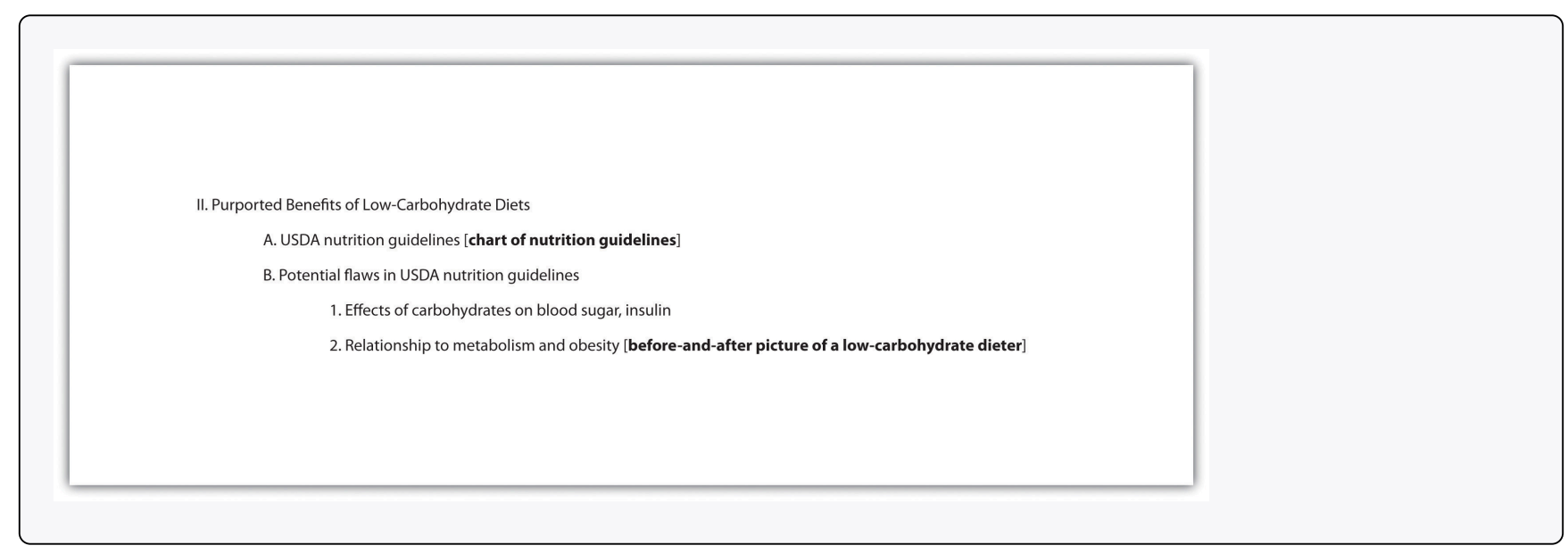

\section{Key Takeaways}

- An effective presentation presents ideas more concisely than a written document and uses media to explain ideas and hold the audience's interest.

- Like an essay, a presentation should have a clear beginning, middle, and end.

- Good writers structure their presentations on the thesis, or point of view; main ideas; and key supporting details and create a presentation outline to organize their ideas.

- Annotating a presentation outline is a useful way to coordinate different parts of the presentation and manage time effectively. 


\subsection{Incorporating Effective Visuals into a Presentation}

\section{Learning Objectives}

1. Recognize the characteristics of effective visual aids.

2. Analyze different types of visual aids and appropriate ways to use them.

3. Determine how to create original visual aids and how to locate visual aids created by others.

Good communication is a multisensory experience. Children first learning how to read often gravitate toward books with engaging pictures. As adults, we graduate to denser books without pictures, yet we still visualize ideas to help us understand the text. Advertisers favor visual media-television, magazines, and billboards-because they are the best way to hook an audience. Websites rely on color, graphics, icons, and a clear system of visual organization to engage Internet surfers.

Bringing visuals into a presentation adds color, literally and figuratively. There is an art to doing it well. This section covers how to use different kinds of visual aids effectively.

\section{Using Visual Aids: The Basics}

Good writers make conscious choices. They understand their purpose and audience. Every decision they make on the page, from organizing an essay to choosing a word with just the right connotations, is made with their purpose and audience in mind.

The same principle applies to visual communication. As a presenter, you choose the following:

- When to show images or video for maximum impact

- Which images will best produce the effect you want

- When to present information using a table, chart, or other graphic

- How much text to include in slides or informational graphics

- How to organize graphics so they present information clearly

Your goal is to use visual media to support and enhance your presentation. At the same time, you must make sure these media do not distract your audience or interfere with getting your point across. Your ideas, not your visuals, should be the focus.

As you develop the visual side of your presentation, you will follow a process much like the process you 
follow when you write. You will brainstorm ideas, form an organizational plan, develop drafts, and then refine and edit your work. The following sections provide guidelines to help you make good decisions throughout the process.

\section{What Makes Visual Aids Effective?}

To help you get a sense of what makes visual media work, think about what does not work. Try to recall occasions when you have witnessed the following visual media failures:

- Websites crammed with so many images, flashing phrases, and clashing colors that they are almost unreadable

- Assembly instructions with illustrations or diagrams that are impossible to follow

- Photographs that are obviously (and badly) altered with photo-editing software

- Distracting typos or other errors in signs, advertisements, or headlines

- Tables, charts, or graphs with tiny, dense text or missing labels

In each case, the problem is that the media creator did not think carefully enough about the purpose and audience. The purpose of images, color, or flashing text on a website is to attract attention. Overusing these elements defeats the purpose because the viewer may become overwhelmed or distracted. Tables, charts, and graphs are intended to simplify complex information, but without clear labels and legible text, they will confuse the audience.

In contrast, effective visual elements are chosen or created with the purpose and audience in mind. Although a photo shoot for a magazine article might result in dozens of images, editors choose those few that work best with the article. Web designers and video game creators have an audience test their products before they are released, to ensure that people will understand how to use them. Understanding the function of different visual aids will help you use them with purpose.

\section{Types of Visual Aids}

Visual aids fall into two main categories-images and informational graphics. Images include photographs, illustrations and clip art, and video footage. Informational graphics include tables, charts, bar graphs, and line graphs.

These visual aids serve two purposes: to add emotional impact to your presentation and to organize information more clearly. With that in mind, read to find out how specific types of visual aids achieve those purposes. 


\section{Photographs}

A striking photograph can capture your audience's attention far more successfully than words can. Consider including photographs at the beginning or end of your presentation to emphasize your main ideas or to accompany a particularly important point in the body of your presentation. Remember that, as with other types of graphics, less is often more. Two or three well-chosen photographs are more effective than a dozen mediocre ones.

When you choose photographs, ask yourself these questions:

- What purpose does this image serve? Will it surprise the audience? Will it provoke a strong emotional response? Does it support an important point?

- Will this photograph be more effective if shown with only a caption, or does it need additional text?

- Will the audience understand what is happening in the photograph? Is the meaning immediately evident, or does the photo need some context?

- Would editing the image make it more effective? Consider using image-editing software to crop the photo, change the brightness, or make other cosmetic changes. (Do not go overboard, though. A slightly imperfect but authentic image is preferable to one that has been obviously altered.)

To illustrate the sense of helplessness people felt in the midst of tragedy, a student could use a photograph that shows fear, weariness, or defeat on the face of the photograph's subject. 


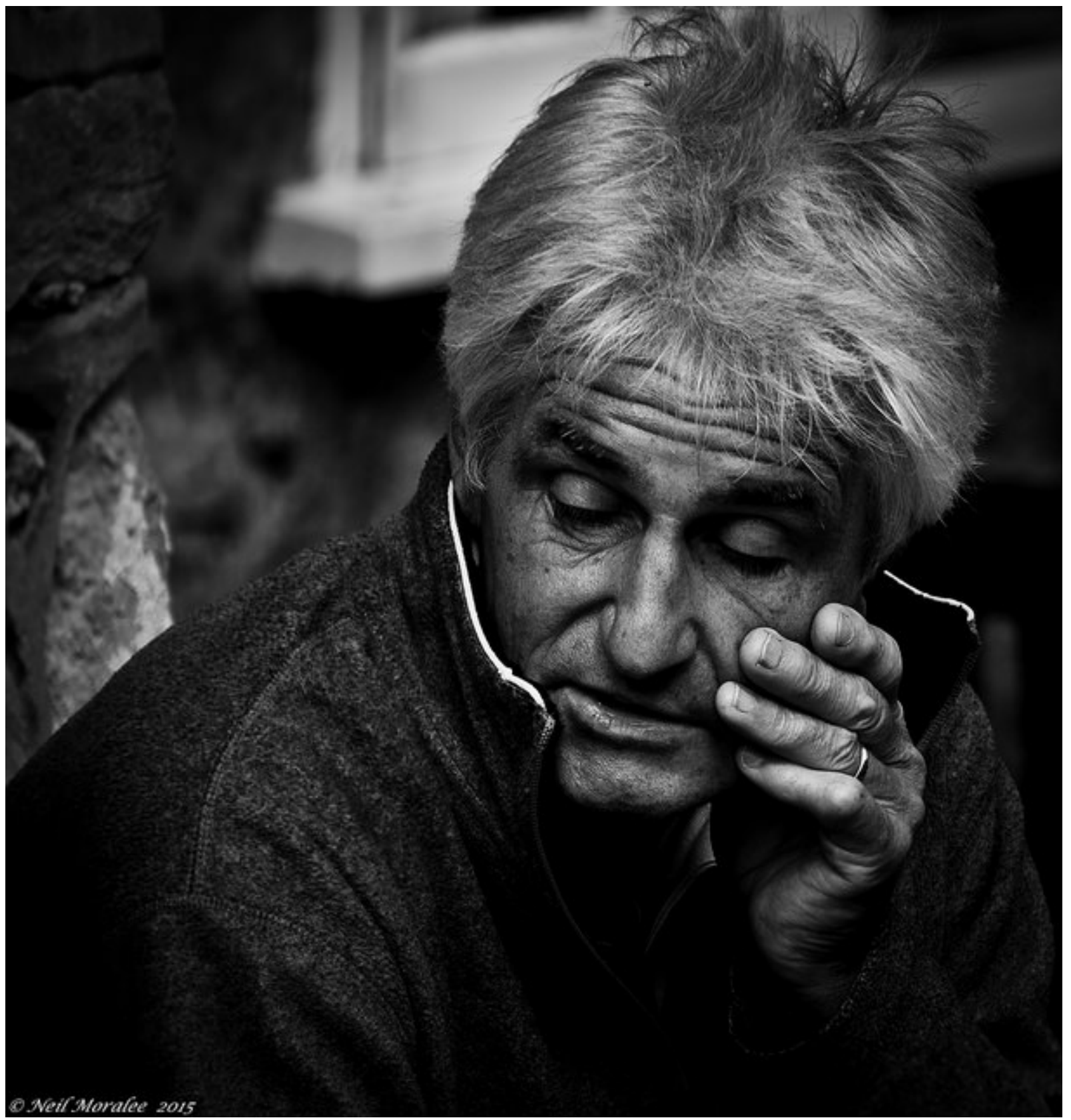

Neil Moralee - On The Scrap Heap . - CC BY-NC-ND 2.0.

\section{Illustrations}

Illustrations, such as editorial or political cartoons, serve much the same purpose as photographs. Because an illustration does not capture a moment in time the way a photo does, it may have less impact. However, depending on your topic and the effect you want to achieve, illustrations can still be very useful. Use the same criteria for choosing photographs to help you choose illustrations. 


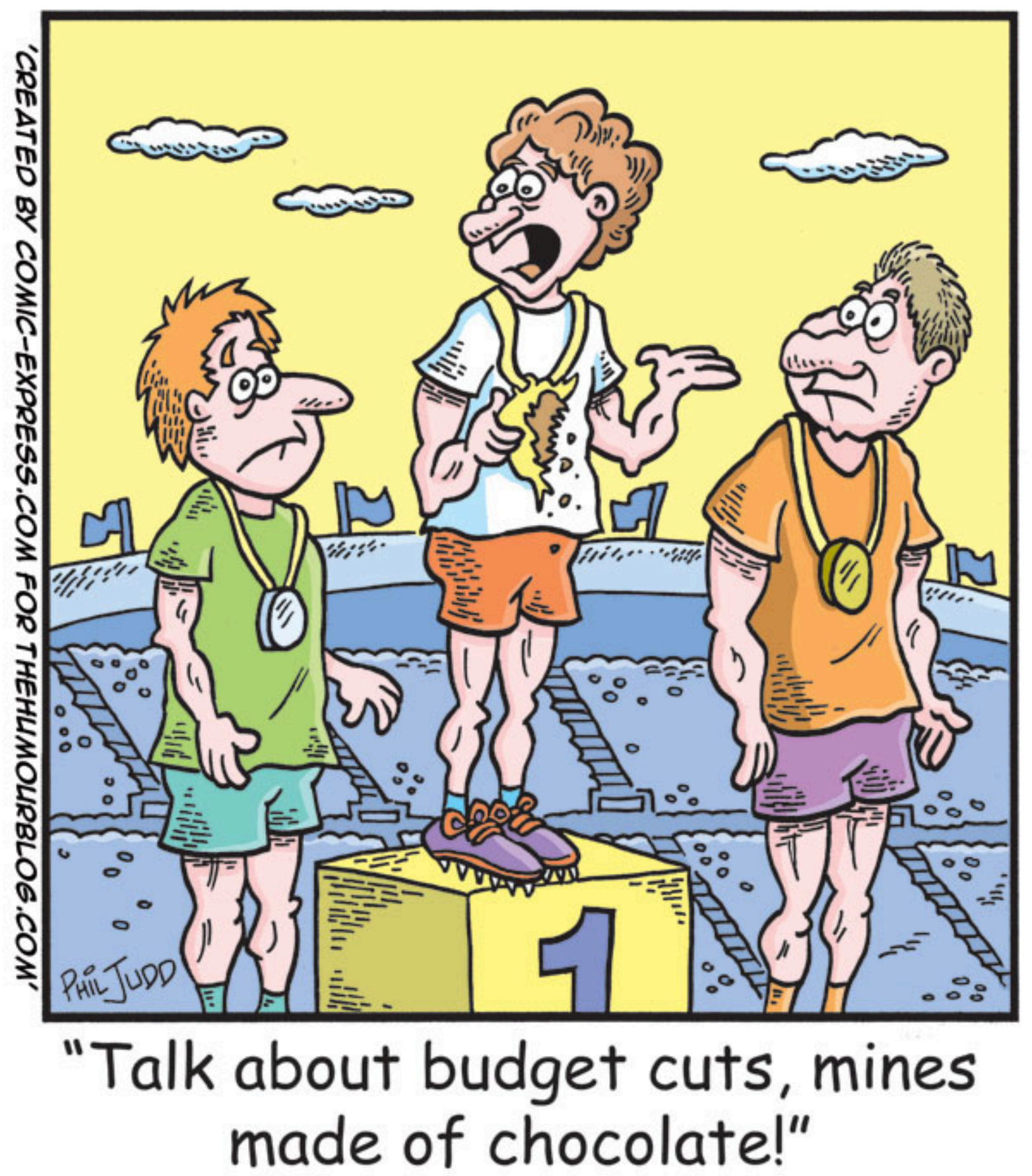

Humor Blog - Political Cartoon about Budget Cuts - CC BY 2.0.

Tip

The style of an illustration or photograph affects viewers just as the content does. Keep this in mind if you are working with the stock images available in office software programs. Many of these images have a comical tone. This may be fine for some topics - for instance, a presentation on television shows for children. 
However, if you need to project a more serious tone, make sure you choose images to suit that purpose. Many free (or reasonably priced) image banks are available online.

\section{Video Footage}

Even more than photographs, video footage can create a sense of immediacy, especially if your video includes sound. Showing a brief video clip can help your audience feel as if they are present at an important event, connect with a person being interviewed, or better understand a process. Again, ask yourself the following questions to ensure you are using the footage well:

- What purpose does this video serve? (Never rely on video clips just to fill time.)

- How much footage should be shown to achieve your purpose?

- What will need to be explained, before or after showing the video, to ensure that your audience understands its significance?

- Will it be necessary to edit the video to stay within time requirements or to focus on the most important parts?

\section{Tables}

Informational graphics, such as tables, charts, and graphs, do not provoke the same response that images do. Nevertheless, these graphics can have a powerful impact. Their primary purpose is to organize and simplify information.

Tables are effective when you must classify information and organize it in categories. Tables are an especially good choice when you are presenting qualitative data that are not strictly numerical. Table 14.1 "Example of Qualitative Data Table" was created for a presentation discussing the subprime mortgage crisis. It presents information about people who have held powerful positions both in the government and at one of the investment banking firms involved in the subprime mortgage market. 


\begin{tabular}{|c|c|c|c|c|}
\hline Name & $\begin{array}{l}\text { Role(s) at Goldman } \\
\text { Sachs }\end{array}$ & $\begin{array}{l}\text { Years } \\
\text { Active }\end{array}$ & Government Role(s) & $\begin{array}{l}\text { Years } \\
\text { Active }\end{array}$ \\
\hline \multirow{2}{*}{$\begin{array}{l}\text { Henry } \\
\text { Paulson }\end{array}$} & Chief operating officer & 1994-98 & \multirow{2}{*}{ US secretary of the treasury } & \multirow{2}{*}{$2006-9$} \\
\hline & Chief executive officer & 1998-2006 & & \\
\hline \multirow{2}{*}{$\begin{array}{l}\text { Robert } \\
\text { Rubin }\end{array}$} & $\begin{array}{l}\text { Vice chairman and } \\
\text { co-chief operating } \\
\text { officer }\end{array}$ & 1987-90 & $\begin{array}{l}\text { Assistant to the president for economic policy } \\
\text { and director, National Economic Council }\end{array}$ & 1993-95 \\
\hline & $\begin{array}{l}\text { Co-chairman and } \\
\text { co-senior partner }\end{array}$ & 1990-92 & US secretary of the treasury & 1995-99 \\
\hline \multirow{3}{*}{$\begin{array}{l}\text { Stephen } \\
\text { Friedman }\end{array}$} & $\begin{array}{l}\text { Co-chief operating } \\
\text { officer }\end{array}$ & 1987-90 & \multirow{3}{*}{$\begin{array}{l}\text { Assistant to the president for economic policy } \\
\text { and director, National Economic Council }\end{array}$} & \multirow{3}{*}{$2002-5$} \\
\hline & Co-chairman & 1990-92 & & \\
\hline & Chairman & 1992-94 & & \\
\hline
\end{tabular}

Sources: $\quad$ http://www.rollingstone.com/politics/news/\%3Bkw=\%5B3351,11459\%5D; http://www.nytimes.com/2008/10/19/ business/19gold.html; http://topics.nytimes.com/top/reference/timestopics/people/p/henry m jr_paulson/index.html?inline=nytper; $\quad$ http://topics.nytimes.com/top/reference/timestopics/people/r/robert e rubin/index.html?inline=nyt-per, http://www.nytimes.com/2002/12/13/us/man-in-the-news-economic-adviser-from-other-side-of-the-deficit-stephenfriedman.html; http://news.bbc.co.uk/2/hi/business/342086.stm.

Tip

If you are working with numerical information, consider whether a pie chart, bar graph, or line graph might be an effective way to present the content. A table can help you organize numerical information, but it is not the most effective way to emphasize contrasting data or to show changes over time.

\section{Pie Charts}

Pie charts are useful for showing numerical information in percentages. For example, you can use a pie chart to represent presidential election results by showing what percentage of voters voted for the Democratic presidential candidate, the Republican candidate, and candidates from other political parties. 


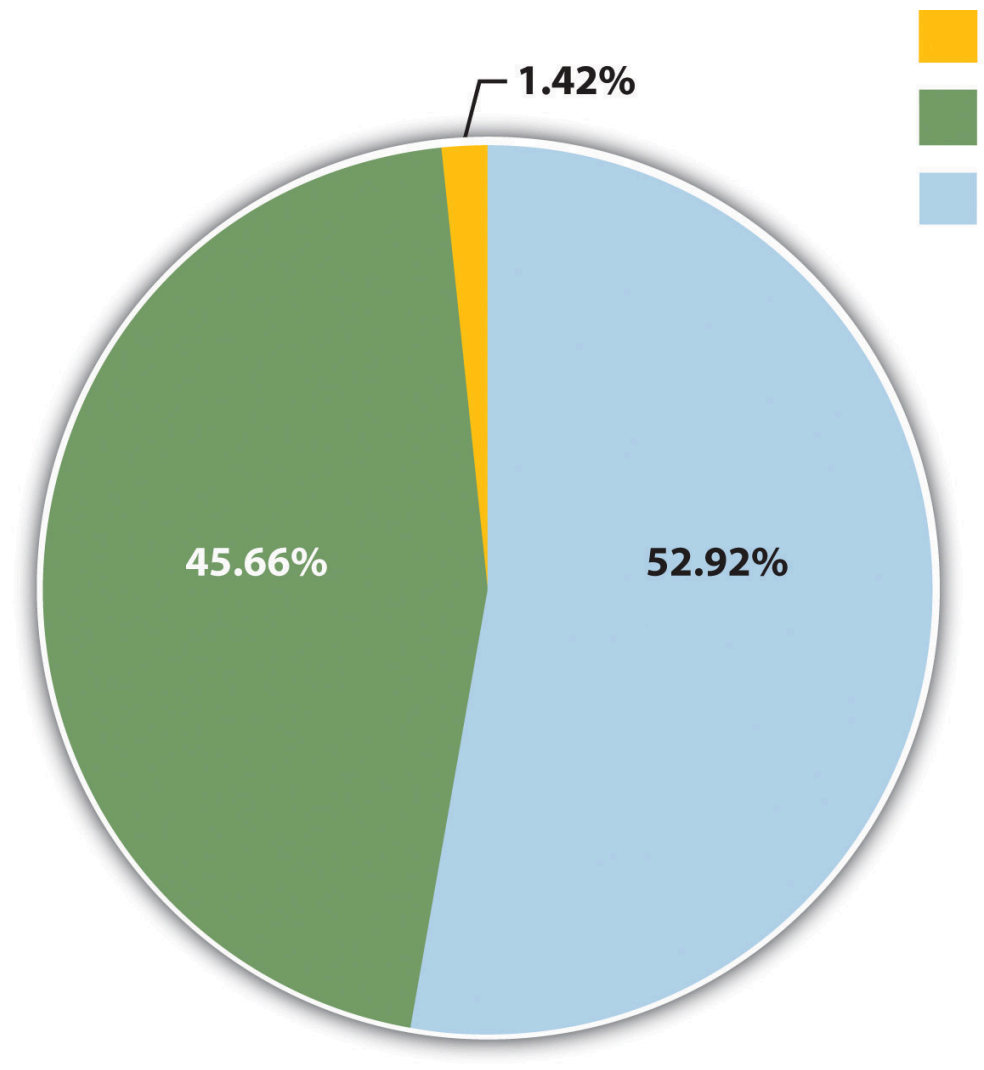

Other Candidates

John McCain

Barack Obama

Source: http://www.fec.gov/pubrec/fe2008/2008presgeresults.pdf

\section{Bar Graphs}

Bar graphs work well when you want to show similarities and differences in numerical data. Horizontal or vertical bars help viewers compare data from different groups, different time periods, and so forth. For instance, the bar graph in Figure 14.6 allows the viewer to compare data on the five countries that have won the most Olympic medals since the modern games began in 1924: Norway, the United States, the former Soviet Union, Germany, and Austria. Bar graphs can effectively show trends or patterns in data as well.

Figure 14.6 


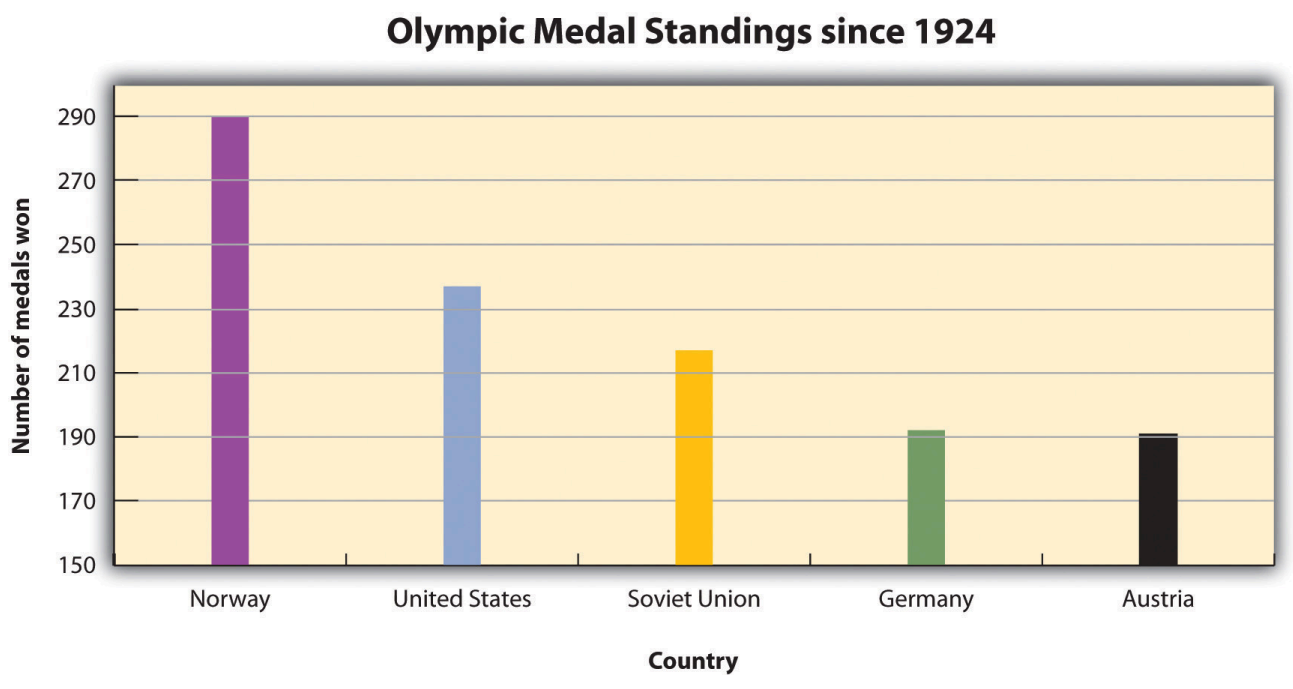

Source: http://www.nbcolympics.com/medals/all-time-standings/index.html

\section{Line Graphs}

Like bar graphs, line graphs show trends in data. Line graphs are usually used to show trends in data over time. For example, the line graph in Figure 14.7 shows changes in the Dow Jones Industrial Average-an economic index based on trading information about thirty large, US-based public companies. This graph shows where the Dow closed at the end of each business day over a period of five days.

Figure 14.7

\section{Down Jones Industrial Average at Market Closing}

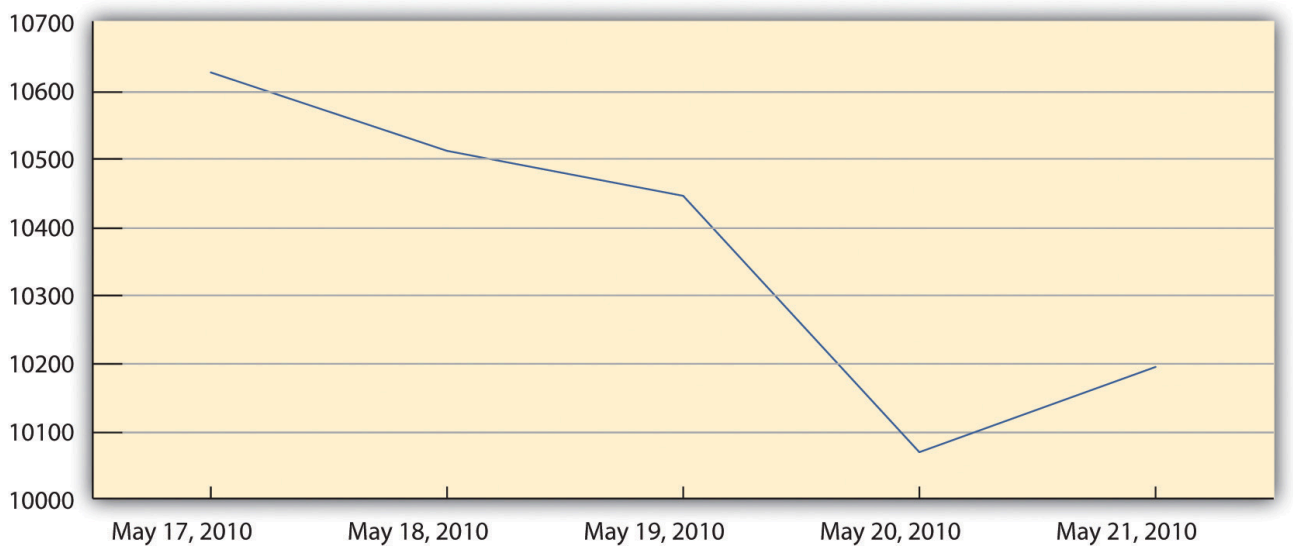




\section{Exercise 1}

In this exercise, you will begin to refine your ideas for incorporating media into your presentation. Complete the following steps on your own sheet of paper.

1. Revisit the list you brainstormed for Note 14.12 "Exercise 3" in Chapter 14 "Creating Presentations: Sharing Your Ideas", Section 14.1 "Organizing a Visual Presentation" and the annotated outline you developed for Note 14.17 "Exercise 4".

2. Analyze the two different types of visual aids: images and informational graphics. Identify at least two places in your presentation where you might incorporate visual aids.

3. Evaluate the purpose of the visual aid. Does it create emotional impact, or does it organize information? Is the visual effective?

4. Determine whether you will be able to create the visual aid yourself or will need to find it.

\section{Creating Original Visual Aids}

You will include original visual aids in your presentation to add interest, present complex information or data more clearly, or appeal to your audience's emotions. You may wish to create some visual aids by hand-for instance, by mounting photographs on poster board for display. More likely, however, you will use computer-generated graphics.

Computer-generated visual aids are easy to create once you learn how to use certain office software. They also offer greater versatility. You can print hard copies and display them large or include them in a handout for your audience. Or, if you are working with presentation software, you can simply insert the graphics in your slides.

Regardless of how you proceed, keep the following guidelines in mind:

- Create visual aids with purpose. Think carefully about how they will enhance your message, and choose a form that is appropriate for your content.

- Strive for quality. You do not need the skills of a professional photographer or designer, but do take time to make sure your visual aids are neat, attractive, and legible. Proofread for errors, too.

\section{Using Software to Create Visual Aids}

You can use standard office software to create simple graphics easily. The following guidelines describe how to work with word-processing software and presentation software. 


\section{Working with Photographs}

Most personal computers come equipped with some basic image-editing software, and many people choose to purchase more advanced programs as well. You can upload photographs from a digital camera (or in some cases, a cell phone) or scan and upload printed photographs. The images can then be edited and incorporated into your presentation. Be sure to save all of your images in one folder for easy access.

\section{Creating Tables}

To create a table within a word-processing document consult your software program's help feature or an online tutorial. Once you have created the table, you can edit and make any additional changes. Be sure that the table has no more than six to seven rows or columns because you do not want to compromise the size of the text or the readability. Aligning with precision will help your table look less crowded. Also, the row and column titles should spell out their contents.

\section{Creating Graphs}

Figure 14.8 

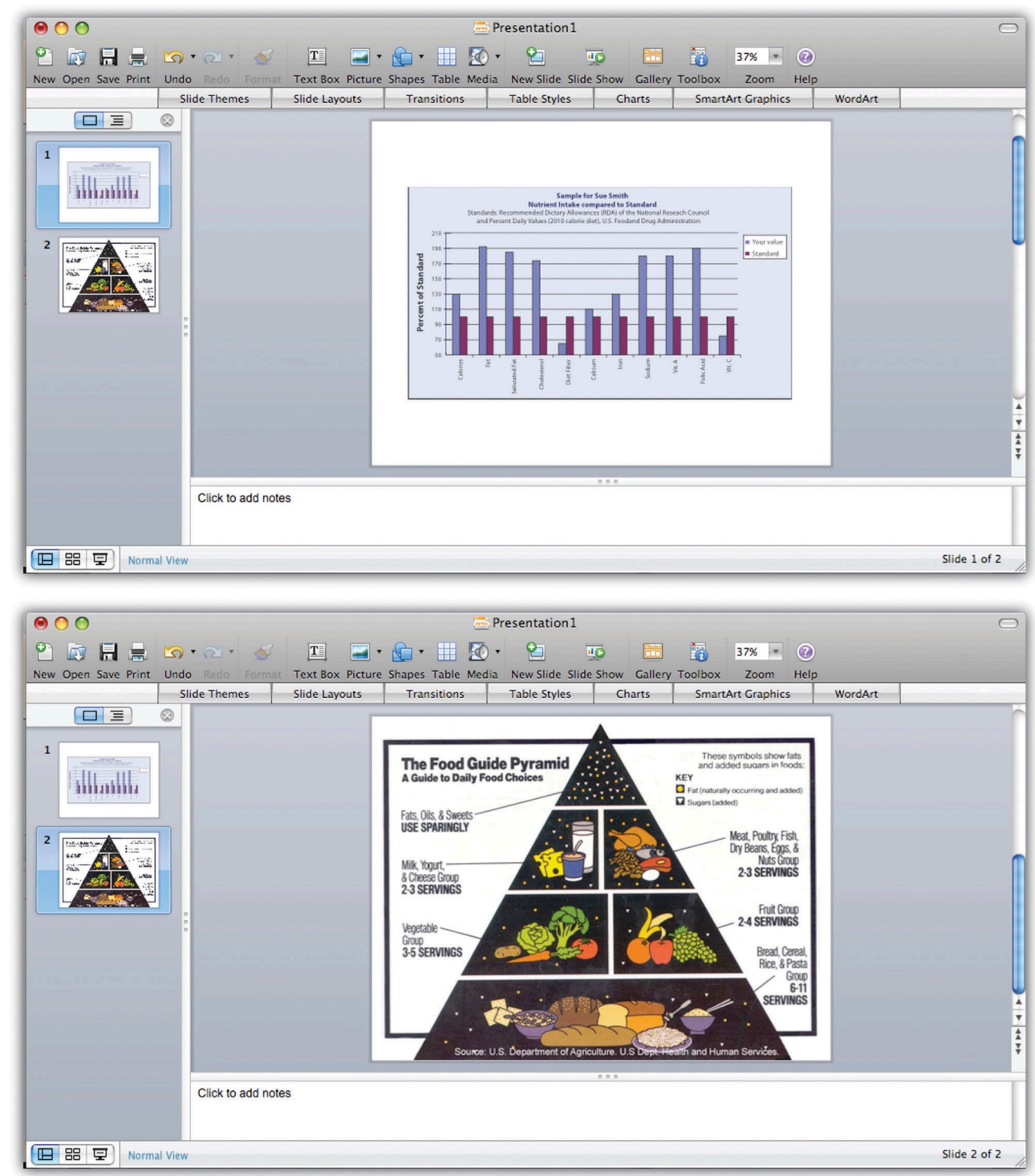

Pie charts and bar and line graphs can also be created using standard office software. Although you can create these graphics within a document, you will need to work with both your word-processing application and your spreadsheet application to do so. The graph should visually explain the data using colors, titles, and labels. The use of color will help the audience distinguish information; however, avoid colors that are hard on the eyes, such as lime green or hot pink. The title should clearly state what the graph explains. Lastly, avoid using acronyms in the titles and other labels.

\section{Creating Graphics in an Electronic Presentation}

If you plan to work only with hard copy graphics during your presentation, you may choose to create them as word-processing documents. However, if you are using presentation software, you will need to choose one of the following options:

- Create your graphics using the presentation software program. 
- Create your graphics within another program and import them.

Standard office presentation software allows you to create informational graphics in much the same way you would create them within a word-processing application. Keep the formatting palette, a menu option that allows you to customize the graphic, open while you use the software. The formatting menu provides options for inserting other types of graphics, such as pictures and video. You may insert pictures from an image bank available within the program, or insert images or video from your own desktop files. Shape your use of multimedia in accordance with the message your presentation is trying to convey, the purpose, and your audience.

\section{Creating Visual Aids by Hand}

Most of the time, using computer-generated graphics is more efficient than creating them by hand. Using office software programs helps give your graphics a polished appearance while also teaching you skills that are useful in a variety of jobs. However, it may make sense to use hand-created visual aids in some cases-for instance, when showing a 3-D model would be effective. If you follow this route, be sure to devote extra time to making sure your visual aids are neat, legible, and professional.

Flip charts are inexpensive and quick visual aids used during face-to-face presentations. The flip chart can be prepared before, as well as during, the presentation. Each sheet of paper should contain one theme, idea, or sketch and must be penned in large letters to be seen by audience members farthest away from the speaker.

\section{Writing Captions}

Any media you incorporate should include a caption or other explanatory text. A caption is a brief, oneto two-sentence description or explanation of a visual image. Make sure your captions are clear, accurate, and to the point. Use full sentences when you write them.

Captions should always be used with photographs, and in some cases, they can be useful for clarifying informational graphics, which represent qualitative data visually. However, informational graphics may not require a caption if the title and labels are sufficiently clear. For other visual media, such as video footage, providing explanatory text before or after the footage will suffice. The important thing is to make sure you always include some explanation of the media.

\section{Exercise 2}

In this exercise, you will begin to develop visual aids for your presentation. Complete the steps in this exercise-and enjoy the chance to be creative. Working with visuals can be a pleasant way to take a break from the demands of writing. 
1. Revisit the ideas you developed in Note 14.24 "Exercise 1". Choose at least two ideas that you can create. (Note: If you are using software to develop a slideshow presentation, count this as one of your self-created visual aids. Include at least one other self-created visual aid, such as an original photograph, within your slideshow.)

2. Get creative! Take your photographs, construct a 3-D model, create informational graphics, or work on your presentation slides. Develop good working drafts.

3. After you have completed drafts of your visual aids, set them aside for a while. Then revisit them with a critical eye. First, check any text included with the graphic. Make sure your facts are correct, your words are clear and concise, and your language is free of errors.

4. Next, evaluate how well your aids work visually. Are they large enough to be seen and read from a distance? Are captions and labels easy to find? Are photographs of reasonably high quality? Ask someone else for feedback, too.

5. Begin making any needed changes. As you proceed through the rest of this section, continue to revisit your work to improve it as needed.

\section{Collaboration}

Please share the first version of your visual aids with a classmate. Examine what they have produced. On a separate piece of paper, note both the elements that catch your attention and those that would benefit from clarification. Return and compare notes.

\section{Testing and Evaluating Visual Aids}

Regardless of how you create your visual aids, be sure to test-drive them before you deliver your presentation. Edit and proofread them, and if possible, show them to someone who can give you objective feedback. Use the following checklist.

\section{Checklist 14.1}

Visual Aid Evaluation Checklist

- Visual aids are clearly integrated with the content of the presentation

- Photographs and illustrations suit the overall tone of the presentation

- Images and text are large and clear enough for the viewer to see or read

- Images are shown with explanatory text or a caption

- Informational graphics include clear, easy-to-read labels and headings

- Text within informational graphics is easy to read (Watch out for wordiness and crowded text or a font that is too small and hard to read.)

- Formatting choices (color, different fonts, etc.) organize information effectively 
- Any text within graphics is free of errors

- Hyperlinks within slides function properly

- Display text for hyperlinks is concise and informative (Never paste a link into a slide without modifying the display text.)

\section{Writing at Work}

Office software includes many options for personalizing a presentation. For instance, you can choose or create a theme and color scheme, modify how one slide transitions to the next, or even include sound effects. With so many options, students and employees sometimes get carried away. The result can seem amateurish and detract from, rather than enhance, your presentation.

Remember, you are delivering a presentation, not producing a movie. Use the customization options to help give your presentations a consistent, polished, appearance. However, do not let these special effects detract from the substance of your slides.

\section{Using Existing Visual Media}

Depending on your topic, you may be able to find images and other graphics you can use instead of creating your own. For instance, you might use photographs from a reputable news source or informational graphics created by a government agency. If you plan to use visual aids created by others, keep the following guidelines in mind:

- Set a purpose before you begin your search. You will search more efficiently if you start with a general idea of what you are looking for-a line graph of unemployment rates for the past twelve months, for example, or a video clip of the most recent State of the Union address.

- Filter out visual aids that are not relevant. You may come across eye-catching graphics and be tempted to use them even if they are only loosely related to your topic, simply because they are attention getting. Resist the temptation. If the graphic is not clearly connected to your point, it does not belong in your presentation.

- Read carefully. In addition to reading labels, headings, and captions, read any text that accompanies the visual. Make sure you understand the visual in its original context. For informational graphics, make sure you understand exactly what information is being represented. (This may seem obvious, but it is easy to misread graphic information. Take the time to examine it carefully.)

- Evaluate sources carefully and record source information. When you look for visual media to complement your presentation, you are conducting research. Apply the same 
standards you used for your research paper. Choose reliable sources, such as reputable news organizations, government and nonprofit organizations, and educational institutions. Verify data in additional sources. Finally, be sure to document all source information as you proceed.

\section{Searching Efficiently for Visual Media}

You will probably find it most efficient to use the Internet to search for visual aids. Many students begin by typing keywords into a search engine to locate related images. However, this search technique is not necessarily efficient, for several reasons:

- It often pulls up hundreds or even thousands of images, which may be only loosely related to your search terms.

- It can sometimes be difficult to understand the image in its original context.

- It can be hard to find copyright information about how you may use the image.

A more efficient strategy is to identify a few sources that are likely to have what you are looking for, and then search within those sites. For instance, if you need a table showing average life expectancy in different countries, you might begin with the website of the World Health Organization. If you hope to find images related to current events, news publications are an obvious choice. The Library of Congress website includes many media related to American history, culture, and politics.

Searching this way has the following advantages:

- You will often find what you are looking for faster because you are not wasting time scrolling through many irrelevant results.

- If you have chosen your sources well, you can be reasonably certain that you are getting accurate, up-to-date information.

- Images and informational graphics produced by reputable sources are likely to be high quality — easy to read and well designed.

If you do choose to use a search engine to help you locate visual media, make sure you use it wisely. Begin with a clear idea of what you are looking for. Use the advanced search settings to narrow your search. When you locate a relevant image, do not download it immediately. Read the page or site to make sure you understand the image in context. Finally, read the site's copyright or terms of use policy - usually found at the bottom of the home page - to make sure you may use the material.

If you are unable to find what you are looking for on the Internet consider using print sources of visual media. You may choose to mount these for display or scan them and incorporate the files into an electronic presentation. (Scanning printed pages may lower the quality of the image. However, if you are skilled at using photo-editing software, you may be able to improve the quality of the scanned image.) 


\section{Inserting Hyperlinks in an Electronic Presentation}

If you are working with images, audio, or video footage available online, you may wish to insert a link within your presentation. Then, during your presentation, you can simply click the link to open the website in a separate window and toggle between windows to return to your presentation slides.

To insert a hyperlink within your presentation, click on insert in the toolbar and then select hyperlink from the menu. Doing so will open a dialogue box where you can paste your link and modify the accompanying display text shown on your slide.

\section{Copyright and Fair Use}

Before you download (or scan) any visual media, make sure you have the right to use it. Most websites state their copyright and terms of use policy on their home page. In general, you may not use other people's visual media for any commercial purpose without contacting the copyright holder to obtain permission and pay any specified fees.

Copyright restrictions are somewhat more ambiguous when you wish to download visual media for educational uses. Some educational uses of copyrighted materials are generally considered fair use-meaning that it is legally and ethically acceptable to use the material in your work. However, do not assume that because you are using the media for an educational purpose, you are automatically in the clear. Make sure your work meets the guidelines in the following checklist. If it does, you can be reasonably confident that it would be considered fair use in a court of law and always give credit to the source.

\section{Checklist 14.2}

Media Fair Use Checklist

- You are using the media for educational purposes only.

- You will make the work available only for a short period and to a limited audience. For instance, showing a copyrighted image in a classroom presentation is acceptable. Posting a presentation with copyrighted images online is problematic. In addition, avoid any uses that would allow other people to easily access and reproduce the work.

- You have used only as much of the work as needed for your purposes. For video and audio footage, limit your use to no more than 10 percent of the media-five minutes of an hour-long television show, for example. Image use is harder to quantify, but you should avoid using many images from the same source.

- You are using the media to support your own ideas, not replace them. Your use should include some commentary or place the media in context. It should be a supporting player in your presentation —not the star of the show. 
- You have obtained the material legally. Purchase the media if necessary rather than using illegally pirated material.

- Your use of the media will not affect the copyright holder or benefit you financially.

By following these guidelines, you are respecting the copyright holder's right to control the distribution of the work and to profit from it.

\section{Writing at Work}

In some fields, such as teaching, job applicants often submit a professional portfolio to a prospective employer. Recent college graduates may include relevant course work in their portfolios or in applications to graduate school. What should you do if your course work uses copyrighted visual media?

This use of media is acceptable according to fair use guidelines. Even though you are using the work for your personal professional advancement, it is not considered an infringement on copyright as long as you follow the additional guidelines listed in the previous checklist.

\section{Crediting Sources}

As you conduct your research, make sure you document sources as you proceed. Follow the guidelines when you download images, video, or other media from the Internet or capture media from other sources. Keep track of where you accessed the media and where you can find additional information about it. You may also provide a references page at the end of the presentation to cite not only media and images but also the information in the text of your presentation. See Chapter 13 "APA and MLA Documentation and Formatting” for more information on creating a reference page.

Write captions or other explanatory text for visual media created by others, just as you would for media you created. Doing so helps keep your audience informed. It also helps ensure that you are following fair use guidelines by presenting the media with your commentary, interpretation, or analysis. In your caption or elsewhere in your presentation, note the source of any media you did not create yourself. You do not need to provide a full bibliographical citation, but do give credit where it is due.

\section{Exercise 3}

In this exercise, you will locate visual aids created by others and continue developing the work you began earlier. Complete these steps.

1. Revisit the ideas you developed in Note 14.24 "Exercise 1". Choose at least two ideas for which it would make more sense to find the visual aid than to create it yourself. 
2. Use the search tips provided in this section to locate at least two visual aids from reputable sources that you can use. Prepare them for your presentation by adding clarifying text as needed. Be sure to credit your source. 3. Incorporate the visual aids you created in Note 14.26 "Exercise 2" and Note 14.32 "Exercise 3" into your presentation. This may involve preparing physical copies for display or inserting graphic files into an electronic presentation.

4. Take some time now to review how you will integrate the visual and verbal components of your presentation.

- If you are working with presentation software, refine your slides. Make sure the visual approach is consistent and suits your topic. Give your text a final proofread.

- If you are not using presentation software, review the annotated outline you created in Note 14.24 "Exercise 1". Update it as needed to reflect your current plan. Also, determine how you will physically set up your visual aids.

\section{Key Takeaways}

- Visual aids are most effective when they are chosen with the purpose and audience in mind. They serve to add emotional impact to a presentation and to organize information more clearly.

- Visual aids should always be clearly related to the presenter's ideas. Captions, labels, and other explanatory text help make the connection clear for the audience.

- Like writing, developing the visual components of a presentation is a process. It involves generating ideas, working with them in a draft format, and then revising and editing one's work.

- Visual aids can be divided into two broad categories-image-based media and informational graphics.

- Widely available software programs make it relatively easy to create visual aids electronically, such as photo images, charts, and graphs.

- When using visual aids created by others, it is important to apply good research skills, follow guidelines for fair use, and credit sources appropriately. 


\subsection{Giving a Presentation}

\section{Learning Objectives}

1. Recognize characteristics of effective speakers.

2. Identify the benefits of rehearsing a presentation in advance.

3. Plan for parts of the presentation that cannot be fully rehearsed in advance, such as a questionand-answer session.

4. Apply strategies for reducing anxiety about public speaking.

By this time, you have already completed much of the preparation for your presentation. You have organized your ideas and planned both the textual and visual components of your presentation. Still, you may not feel quite ready to speak in front of a group.

Public speaking is stressful. In fact, some researchers have found that a large percentage of people surveyed rate public speaking as their number one fear. Most people feel at least a little bit nervous at the prospect of public speaking.

At the same time, it is an increasingly necessary skill in the workplace. A human resource manager presents company policies and benefits plans to large groups of employees. An entrepreneur presents the idea for a new business to potential investors. A nurse might chair a staff meeting to introduce new hospital procedures. A police officer might present crime-prevention tips at a community meeting. In some fields, such as training and teaching, speaking in public is a regular job requirement.

In this section, you will learn strategies for becoming a confident, effective speaker. You have already taken the major steps toward making your presentation successful, as a result of the content planning you did in Chapter 14 "Creating Presentations: Sharing Your Ideas", Section 14.1 "Organizing a Visual Presentation" and Section 14.2 "Incorporating Effective Visuals into a Presentation". Now, it is time to plan and practice your delivery.

\section{What Makes a Speaker Effective?}

Think about times you have been part of the audience for a speech, lecture, or other presentation. You have probably noticed how certain traits and mannerisms work to engage you and make the experience enjoyable. Effective speakers project confidence and interest in both their audience and their subject matter. They present ideas clearly and come across as relaxed but in control.

In contrast, less effective speakers may seem anxious or, worse, apathetic. They may be difficult to hear 
or understand, or their body language may distract from their message. They have trouble making a connection with their audience. This can happen even when the speaker knows his or her material and has prepared effective visual aids.

In both cases, two factors contribute to your overall impression of the speaker: voice and body language. The following sections discuss specific points to focus on.

\section{Finding Your Voice}

Most people do not think much about how their voices come across in everyday conversations. Talking to other people feels natural. Unfortunately, speaking in public does not, and that can affect your voice. For instance, many people talk faster when they give presentations, because they are nervous and want to finish quickly. In addition, some traits that do not matter too much in ordinary conversation, such as a tendency to speak quietly, can be a problem when speaking to a group. Think about the characteristics discussed in the following section and how your own voice might come across.

\section{Resonance}

One quality of a good speaking voice is resonance, meaning strength, depth, and force. This word is related to the word resonate. Resonant speech begins at the speaker's vocal cords and resonates throughout the upper body. The speaker does not simply use his or her mouth to form words, but instead projects from the lungs and chest. (That is why having a cold can make it hard to speak clearly.)

Some people happen to have powerful, resonant voices. But even if your voice is naturally softer or higher pitched, you can improve it with practice.

- Take a few deep breaths before you begin rehearsing.

- Hum a few times, gradually lowering the pitch so that you feel the vibration not only in your throat but also in your chest and diaphragm.

- Try to be conscious of that vibration and of your breathing while you speak. You may not feel the vibration as intensely, but you should feel your speech resonate in your upper body, and you should feel as though you are breathing easily.

- Keep practicing until it feels natural.

\section{Enunciation}

Enunciation refers to how clearly you articulate words while speaking. Try to pronounce words as clearly and accurately as you can, enunciating each syllable. Avoid mumbling or slurring words. As you rehearse your presentation, practice speaking a little more slowly and deliberately. Ask someone you 
know to give you feedback.

\section{Volume}

Volume is simply how loudly or softly you speak. Shyness, nervousness, or overenthusiasm can cause people to speak too softly or too loudly, which may make the audience feel frustrated or put off. Here are some tips for managing volume effectively:

- Afraid of being too loud, many people speak too quietly. As a rule, aim to use a slightly louder volume for public speaking than you use in conversation.

- Consider whether you might be an exception to the rule. If you know you tend to be loud, you might be better off using your normal voice or dialing back a bit.

- Think about volume in relation to content. Main points should usually be delivered with more volume and force. However, lowering your voice at crucial points can also help draw in your audience or emphasize serious content.

\section{Pitch}

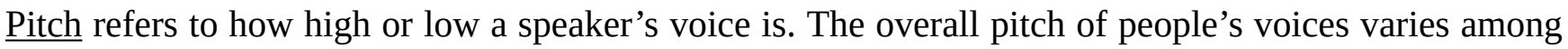
individuals. We also naturally vary our pitch when speaking. For instance, our pitch gets higher when we ask a question and often when we express excitement. It often gets lower when we give a command or want to convey seriousness.

A voice that does not vary in pitch sounds monotonous, like a musician playing the same note repeatedly. Keep these tips in mind to manage pitch:

- Pitch, like volume, should vary with your content. Evaluate your voice to make sure you are not speaking at the same pitch throughout your presentation.

- It is fine to raise your pitch slightly at the end of a sentence when you ask a question. However, some speakers do this for every sentence, and as a result, they come across as tentative and unsure. Notice places where your pitch rises, and make sure the change is appropriate to the content.

- Lower your pitch when you want to convey authority. But do not overdo it. Questions should sound different from statements and commands.

- Chances are, your overall pitch falls within a typical range. However, if your voice is very high or low, consciously try to lower or raise it slightly. 


\section{Pace}

Pace is the speed or rate at which you speak. Speaking too fast makes it hard for an audience to follow the presentation. The audience may become impatient.

Many less experienced speakers tend to talk faster when giving a presentation because they are nervous, want to get the presentation over with, or fear that they will run out of time. If you find yourself rushing during your rehearsals, try these strategies:

- Take a few deep breaths before you speak. Make sure you are not forgetting to breathe during your presentation.

- Identify places where a brief, strategic pause is appropriate-for instance, when transitioning from one main point to the next. Build these pauses into your presentation.

- If you still find yourself rushing, you may need to edit your presentation content to ensure that you stay within the allotted time.

If, on the other hand, your pace seems sluggish, you will need to liven things up. A slow pace may stem from uncertainty about your content. If that is the case, additional practice should help you. It also helps to break down how much time you plan to spend on each part of the presentation and then make sure you are adhering to your plan.

\section{Tip}

Pace affects not only your physical presentation but also the point of view; slowing down the presentation may allow your audience to further comprehend and consider your topic. Pace may also refer to the rate at which PowerPoint slides appear. If either the slide or the animation on the slide automatically appears, make sure the audience has adequate time to read the information or view the animation before the presentation continues.

\section{Tone}

Tone is the emotion you convey when speaking - excitement, annoyance, nervousness, lightheartedness, and so forth. Various factors, such as volume, pitch, and body language, affect how your tone comes across to your audience.

Before you begin rehearsing your presentation, think about what tone is appropriate for the content. Should you sound forceful, concerned, or matter-of-fact? Are there places in your presentation where a more humorous or more serious tone is appropriate? Think about the tone you should project, and practice setting that tone. 


\section{Exercise 1}

In this exercise, you will work on refining the oral delivery of the annotated outline you developed in Note 14.17 "Exercise 4" of Section 14.1 "Organizing a Visual Presentation".

1. Set up a microphone to record yourself. (You may use a webcam if you wish.) For this exercise, assess yourself on your verbal delivery only, not your body language.)

2. Rehearse and record your presentation.

3. Replay the recording and assess yourself using the following criteria: resonance, enunciation, volume, pitch, pace, and tone. Rate yourself from one to five on each criterion, with five being the highest rating. Determine which areas are strengths and which areas you need to improve.

4. If you wish, ask another person to evaluate your presentation.

\section{The Power of Body Language}

The nonverbal content of a presentation is just as important as the verbal delivery. A person's body language - eye contact, facial expressions, posture, gestures, and movement—communicates a powerful message to an audience before any words are spoken.

People interpret and respond to each other's body language instinctively. When you talk to someone, you notice whether the other person is leaning forward or hanging back, nodding in agreement or disagreement, looking at you attentively or looking away. If your listener slouches, fidgets, or stares into space, you interpret these nonverbal cues as signs of discomfort or boredom. In everyday conversations, people often communicate through body language without giving it much conscious thought. Mastering this aspect of communication is a little more challenging, however, when you are giving a presentation. As a speaker, you are onstage. It is not easy to see yourself as your audience sees you.

Think about times you have been part of a speaker's audience. You have probably seen some presenters who seemed to own the room, projecting confidence and energy and easily connecting with the audience. Other presenters may have come across as nervous, gloomy, or disengaged. How did body language make a difference?

Three factors work together powerfully to convey a nonverbal message: eye contact, posture, and movement.

\section{Eye Contact and Facial Expressions}

"Maintain eye contact" is a common piece of public-speaking advice-so common it may sound elementary and clichéd. Why is that simple piece of advice so hard to follow? 
Maintaining eye contact may not be as simple as it sounds. In everyday conversation, people establish eye contact but then look away from time to time, because staring into someone's eyes continuously feels uncomfortably intense. Two or three people conversing can establish a comfortable pattern of eye contact. But how do you manage that when you are addressing a group?

The trick is to focus on one person at a time. Zero in on one person, make eye contact, and maintain it just long enough to establish a connection. (A few seconds will suffice.) Then move on. This way, you connect with your audience, one person at a time. As you proceed, you may find that some people hold your gaze and others look away quickly. That is fine, as long as you connect with people in different parts of the room.

Pay attention to your facial expressions as well. If you have thought about how you want to convey emotion during different parts of your presentation, you are probably already monitoring your facial expressions as you rehearse. Be aware that the pressure of presenting can make your expression serious or tense without your realizing it.

Tip

If you are speaking to a very large group, it may be difficult to make eye contact with each individual. Instead, focus on a smaller group of persons or one row of people at time. Look in their direction for a few seconds and then shift your gaze to another small group in the room.

\section{Posture}

While eye contact establishes a connection with your audience, your posture establishes your confidence. Stand straight and tall with your head held high to project confidence and authority. Slouching or drooping, on the other hand, conveys timidity, uncertainty, or lack of interest in your own presentation.

It will not seem natural, but practice your posture in front of a mirror. Take a deep breath and let it out. Stand upright and imagine a straight line running from your shoulders to your hips to your feet. Rock back and forth slightly on the balls of your feet until your weight feels balanced. You should not be leaning forward, backward, or to either side. Let your arms and hands hang loosely at your sides, relaxed but not limp. Then lift your chin slightly and look into your own eyes. Do you feel more confident?

You might not just yet. In fact, you may feel overly self-conscious or downright silly. In time, however, maintaining good posture will come more naturally, and it will improve your effectiveness as a speaker. 


\section{Tip}

Nervousness affects posture. When feeling tense, people often hunch up their shoulders without realizing it. (Doing so just makes them feel even tenser and may inhibit breathing, which can affect your delivery.) As you rehearse, relax your shoulders so they are not hunched forward or pushed back unnaturally far. Stand straight but not rigid. Do not try to suck in your stomach or push out your chest unnaturally. You do not need to stand like a military officer, just a more confident version of yourself.

\section{Movement and Gestures}

The final piece of body language that helps tie your presentation together is your use of gestures and movement. A speaker who barely moves may come across as wooden or lacking energy and emotion. Excessive movement and gestures, on the other hand, are distracting. Strive for balance.

A little movement can do a lot to help you connect with your audience and add energy to your presentation. Try stepping forward toward your audience at key moments where you really want to establish that personal connection. Consider where you might use gestures such as pointing, holding up your hand, or moving your hands for emphasis. Avoid putting your hands in your pockets or clasping them in front of or behind you.

\section{Writing at Work}

When you give a presentation at work, wearing the right outfit can help you feel more poised and confident. The right attire can also help you avoid making distracting gestures. While you talk, you do not want to be tugging on necktie tied too tight or wobbling on flimsy high-heeled shoes. Choose clothing that is appropriately professional and comfortable.

\section{Exercise 2}

In this exercise, present the same oral presentation from Note 14.41 "Exercise 1", but this time, evaluate your body language.

1. Set up a video camera to record yourself, or ask someone else to evaluate you.

2. Rehearse and, if applicable, record your presentation.

3. Replay the recording and assess yourself (or have your companion assess you) on the following criteria: eye contact, facial expressions, posture, movement, and gestures. Rate yourself from one 
to five on each criterion, with five being the highest rating. Determine in which areas you have strength and in which areas you need to improve.

\section{Rehearsing Your Presentation and Making Final Preparations}

Practice is essential if you want your presentation to be effective. Speaking in front of a group is a complicated task because there are so many components to stay on top of-your words, your visual aids, your voice, and your body language. If you are new to public speaking, the task can feel like juggling eggs while riding a unicycle. With experience, it gets easier, but even experienced speakers benefit from practice.

Take the time to rehearse your presentation more than once. Each time you go through it, pick another element to refine. For instance, once you are comfortable with the overall verbal content, work on integrating your visuals. Then focus on your vocal delivery and your body language. Multiple practice sessions will help you integrate all of these components into a smooth, effective presentation.

Practice in front of another person (or a small group) at least once. Practicing with a test audience will help you grow accustomed to interacting with other people as you talk, and it will give you a chance to get feedback from someone else's perspective. Your audience can help you identify areas to improve.

Just as important as identifying areas for improvement, your audience can encourage you not to be too hard on yourself. When preparing for an oral presentation, many people are their own worst critics. They are hyperconscious of any flaws in their presentation, real or imagined. A test audience can provide honest feedback from a neutral observer who can provide support and constructive critique.

\section{Managing Your Environment}

Part of being a good presenter is managing your environment effectively. Your environment may be the space, the sound levels, and any tools or equipment you will use. Take these factors into account as you rehearse. Consider the following questions:

- Will you have enough space to move around in? Consider whether you might need to rearrange chairs or tables in the room in advance.

- Do you have enough space to display your visual aids? If you are using slides, where will you project the images?

- Will the lighting in the room need to be adjusted for your presentation? If so, where are the light switches located? How are window coverings opened or closed?

- Will your audience be able to hear you? Does the environment have any distracting noises, such as heating or cooling vents, outside traffic, or noisy equipment or machines? If so, how 
can you minimize the problem? Will you need a microphone?

- Do you have access to any technical equipment you need, such as a laptop computer, a projector, or a CD or DVD player? Are electrical outlets conveniently placed and functional?

You may not be able to control every aspect of the environment to your liking. However, by thinking ahead, you can make the best of the space you have to work in. If you have a chance to rehearse in that environment, do so.

\section{Engaging Your Audience: Planning a Question-and-Answer Session}

Rehearsing your presentation will help you feel confident and in control. The most effective presenters do not simply rehearse the content they will deliver. They also think about how they will interact with their audience and respond effectively to audience input.

An effective way to interact is to plan a brief question-and-answer (Q\&A) session to follow your presentation. Set aside a few minutes of your allotted time to address audience questions. Plan ahead. Try to anticipate what questions your audience might have, so you can be prepared to answer them. You probably will not have enough time to cover everything you know about the topic in your presentation. A Q\&A session can give you an opportunity to fill in any gaps for your audience.

Finally, accept that interacting with your audience means going with the flow and giving up a little of your control. If someone asks a question you were not anticipating and cannot answer, simply admit you do not know and make a note to follow up.

\section{Writing at Work}

Increasingly, employees need to manage a virtual environment when giving presentations in the workplace. You might need to conduct a webinar, a live presentation, meeting, workshop, or lecture delivered over the web; run an online Q\&A chat session; or coordinate a conference call involving multiple time zones.

Preparation and rehearsal can help ensure that a virtual presentation goes smoothly. Complete a test run of any software you will use. Ask a coworker to assist you to ensure that both you and the audience have all the tools needed and that the tools are in working order. Make sure you have contact information for all the key meeting attendees. Finally, know whom to call if something goes wrong, and have a backup plan.

\section{Exercise 3}

If you have not yet rehearsed in front of an audience, now is the time. Ask a peer (or a small group of people) 
to observe your presentation, provide a question-and-answer session, and have your audience provide feedback on the following:

- The overall quality of your content (clarity, organization, level of detail)

- The effectiveness of your visual aids

- Your vocal delivery (resonance, enunciation, volume, pitch, pace, and tone)

- The effectiveness of your body language (eye contact, facial expressions, posture, movement, and gestures)

- Your response to questions the audience posed during the question-and-answer session

Use your audience's feedback to make any final adjustments to your presentation. For example, could you clarify your presentation to reduce the number of questions - or enhance the quality of the questions - the audience asked during the question-and-answer session?

\section{Coping with Public-Speaking Anxiety}

The tips in this chapter should help you reduce any nervousness you may feel about public speaking. Although most people are a little anxious about talking to a group, the task usually becomes less intimidating with experience and practice.

Preparation and practice are the best defenses against public-speaking anxiety. If you have made a serious effort to prepare and rehearse, you can be confident that your efforts will pay off. If you still feel shaky, try the following strategies:

- Take care of your health. In the days leading up to your presentation, make sure you get plenty of sleep and eat right. Exercise to help cope with tension. Avoid caffeine if it makes you jittery.

- Use relaxation techniques such as meditation, deep breathing, and stretching to help you feel calm and focused on the day of your presentation.

- Visualize yourself giving a successful presentation. Image yourself succeeding. It will make you feel more confident.

- Put things into perspective. What is the worst that could happen if anything went wrong? Many people have given less-than-perfect presentations and lived to tell about it! Of course, you should make your best effort, but if something does go wrong, you can use it as a learning experience.

- Understand that you may not be able to overcome your nervousness completely. Feeling a little anxious can help you stay alert and focused. If you do not feel confident, try to "fake it until you make it.” 


\section{Exercise 4}

To practice overcoming public-speaking anxiety, ask a family member, coworker, or peer to view a rehearsal of the presentation. Schedule the rehearsal at a time that works for you, and plan to get plenty of rest the night before. After the presentation, answer the following questions.

1. When did you feel most nervous during the presentation? Make a note on your outline of the most nervous moments. Next to this note, add one strategy that may ease your anxiety. For example, you could add a reminder to relax, such as, “Take a deep breath here!” or a few words of encouragement, such as, "You are doing a great job!"

2. Ask your rehearsal audience for feedback on which moments of the presentation seemed most nerve wrecking for you. What nonverbal or verbal clues indicated to your audience that you were nervous? Which were most distracting to the audience? Make a note of these clues and practice the presentation again; be aware of how you show your anxiety and try to lessen these distractions.

\section{Key Takeaways}

- Delivering an effective speech requires paying attention to both verbal delivery and body language.

- Good speakers rehearse their presentation and, if necessary, get feedback from others to help them refine their presentation before they deliver it.

- Monitoring one's vocal delivery involves paying attention to resonance, enunciation, volume, pitch, pace, and tone.

- Monitoring one's body language involves paying attention to eye contact, facial expressions, posture, movement, and gestures.

- Good speakers plan ahead to help them manage the presentation effectively. 


\subsection{Creating Presentations: End-of-Chapter Exercises}

\section{Exercises}

1. Identify a topic of personal interest to you that you would enjoy presenting. (It is best to choose a topic you already know something about.) Create a brief, informal presentation-about three minutes and no more than five to six slides. You may conduct some research if necessary, but this exercise does not need to be extensively researched. Instead, focus on summarizing your main points concisely and using visuals effectively. If possible, share your presentation with a partner and evaluate each other's work.

2. Conduct an Internet search to find examples of strong and weak slideshow presentations. Determine the reasons why each presentation is or is not successful. Consider the following elements:

- The number of slides and the amount of information presented overall

- The amount of information on each slide and how well it is organized

- The ratio of text to graphics

- The clarity and appropriateness of the graphics

- The use of special formatting, sounds, slide transitions, and so on

3. It is sometimes difficult to evaluate one's own speaking skills. It is very helpful to rehearse and record yourself. Use the questions from the following list that to determine if your presentation needs additional work. If possible, have a partner evaluate your presentation.

- Is the presentation clear, concise, and organized? Would your audience understand your main point and supporting points?

- Are your visual aids relevant, appropriate, and effective? What changes (if any) are needed?

- Is your vocal delivery effective? If possible, have a partner evaluate your presentation on the following criteria: resonance, enunciation, volume, pitch, pace, and tone.

- Are you using your body language effectively? If possible, have a partner evaluate your eye contact, facial expressions, posture, movement, and gestures.

4. View one or more television infomercials. Evaluate the presentations using the following questions:

- Does the presenter deliver information clearly and engage the audience? Does the infomercial fulfill its purpose - to convince the audience to buy the product?

- Does the presenter use visual aids effectively? How?

- Is the presenter's vocal delivery effective? Why or why not?

- Is the presenter's body language effective? How does the presenter use body language to connect with the television audience and to emphasize the product's value? 


\section{Chapter 15: Readings: Examples of Essays}

15.1 Introduction to Sample Essays

15.2 Narrative Essay

15.3 Illustration Essay

15.4 Descriptive Essay

15.5 Classification Essay

15.6 Process Analysis Essay

15.7 Definition Essay

15.8 Compare-and-Contrast Essay

15.9 Cause-and-Effect Essay

15.10 Persuasive Essay 


\subsection{Introduction to Sample Essays}

\section{Learning Objectives}

1. Identify the role of reading in the writing process.

2. Read examples of the rhetorical modes.

This chapter contains quality samples of the rhetorical modes described in Chapter 10 "Rhetorical Modes". While you read these essays, remember the purpose of the writing and pay attention to the following:

- Thesis statement. What is the author's main point of the essay? Identify the sentence and see how well it is supported throughout the essay.

- Topic sentence. How well does each topic sentence support the thesis, and how well does it describe the main idea of the following paragraph?

- Supporting evidence. Identify the evidence that the author uses to support the essay's main ideas, and gauge their credibility.

The best way to become a better writer is to become a closer reader. As you read each essay carefully take note of the content and the structure as well as the thesis statement, topic sentences, and supporting evidence. These should shape your response to the essay and should also shape your writing. 


\subsection{Narrative Essay}

\section{Learning Objective}

1. Read an example of the narrative rhetorical mode.

\section{My College Education}

The first class I went to in college was philosophy, and it changed my life forever. Our first assignment was to write a short response paper to the Albert Camus essay "The Myth of Sisyphus.” I was extremely nervous about the assignment as well as college. However, through all the confusion in philosophy class, many of my questions about life were answered.

I entered college intending to earn a degree in engineering. I always liked the way mathematics had right and wrong answers. I understood the logic and was very good at it. So when I received my first philosophy assignment that asked me to write my interpretation of the Camus essay, I was instantly confused. What is the right way to do this assignment, I wondered? I was nervous about writing an incorrect interpretation and did not want to get my first assignment wrong. Even more troubling was that the professor refused to give us any guidelines on what he was looking for; he gave us total freedom. He simply said, "I want to see what you come up with.”

Full of anxiety, I first set out to read Camus's essay several times to make sure I really knew what was it was about. I did my best to take careful notes. Yet even after I took all these notes and knew the essay inside and out, I still did not know the right answer. What was my interpretation? I could think of a million different ways to interpret the essay, but which one was my professor looking for? In math class, I was used to examples and explanations of solutions. This assignment gave me nothing; I was completely on my own to come up with my individual interpretation.

Next, when I sat down to write, the words just did not come to me. My notes and ideas were all present, but the words were lost. I decided to try every prewriting strategy I could find. I brainstormed, made idea maps, and even wrote an outline. Eventually, after a lot of stress, my ideas became more organized and the words fell on the page. I had my interpretation of "The Myth of Sisyphus," and I had my main reasons for interpreting the essay. I remember being unsure of myself, wondering if what I was saying made sense, or if I was even on the right track. Through all the uncertainty, I continued writing the best I could. I finished the conclusion paragraph, had my spouse proofread it for errors, and turned it in the next day simply hoping for the best.

Then, a week or two later, came judgment day. The professor gave our papers back to us with grades and comments. I remember feeling simultaneously afraid and eager to get the paper back in my hands. It turned out, however, that I had nothing to worry about. The professor gave me an A on the paper, and his notes suggested that I wrote an effective essay overall. He wrote that my reading of the essay was very original and that my thoughts were well organized. My relief and newfound confidence upon reading his comments could 
not be overstated.

What I learned through this process extended well beyond how to write a college paper. I learned to be open to new challenges. I never expected to enjoy a philosophy class and always expected to be a math and science person. This class and assignment, however, gave me the self-confidence, critical-thinking skills, and courage to try a new career path. I left engineering and went on to study law and eventually became a lawyer. More important, that class and paper helped me understand education differently. Instead of seeing college as a direct stepping stone to a career, I learned to see college as a place to first learn and then seek a career or enhance an existing career. By giving me the space to express my own interpretation and to argue for my own values, my philosophy class taught me the importance of education for education's sake. That realization continues to pay dividends every day.

\section{Online Narrative Essay Alternatives}

Sandra Cisneros offers an example of a narrative essay in Only Daughter that captures her sense of her Chicana-Mexican heritage as the only daughter in a family of seven children.

Her complete essay is available on:

- http://chawkinsteaching.weebly.com/uploads/1/2/9/7/12977279/only daughter.pdf

Gary Shteyngart came to the United States when he was seven years old. The son of Russian Jewish parents who struggled to provide a better life for their son, he reflects on his struggles, including becoming “American,” in Sixty-Nine Cents:

- http://www.newyorker.com/reporting/2007/09/03/ $\underline{070903 f a \text { fact shteyngart?printable=true\#ixzz0pihck7DS }}$

Sherman Alexie grew up on the Spokane Reservation in Washington State. He chronicles his challenges in school, starting in first grade, in Indian Education:

- https://www.cengage.com/custom/static content/OLC/s76656 76218lf/alexie.pdf 


\subsection{Illustration Essay}

\section{Learning Objective}

1. Read an example of the illustration rhetorical mode.

\section{Letter to the City}

To: Lakeview Department of Transportation

From: A Concerned Citizen

The intersection of Central Avenue and Lake Street is dangerous and demands immediate consideration for the installation of a controlling mechanism. I have lived in Lakeview my entire life, and during that time I have witnessed too many accidents and close calls at that intersection. I would like the Department of Transportation to answer this question: how many lives have to be lost on the corner of Central Avenue and Lake Street before a street light or stop sign is placed there?

Over the past twenty years, the population of Lakeview has increased dramatically. This population growth has put tremendous pressure on the city's roadways, especially Central Avenue and its intersecting streets. At the intersection of Central Avenue and Lake Street it is easy to see how serious this problem is. For example, when I try to cross Central Avenue as a pedestrian, I frequently wait over ten minutes for the cars to clear, and even then I must rush to the median. I will then have to continue to wait until I can finally run to the other side of the street. On one hand, even as a physically fit adult, I can run only with significant effort and care. Expecting a senior citizen or a child to cross this street, on the other hand, is extremely dangerous and irresponsible. Does the city have any plans to do anything about this?

Recent data show that the intersection of Central Avenue and Lake Street has been especially dangerous. According to the city's own statistics, three fatalities occurred at that intersection in the past year alone. Over the past five years, the intersection witnessed fourteen car accidents, five of which were fatal. These numbers officially qualify the intersection as the most fatal and dangerous in the entire state. It should go without saying that fatalities and accidents are not the clearest way of measuring the severity of this situation because for each accident that happens, countless other close calls never contribute to city data. I hope you will agree that these numbers alone are sufficient evidence that the intersection at Central Avenue and Lake Street is hazardous and demands immediate attention.

Nearly all accidents mentioned are caused by vehicles trying to cross Central Avenue while driving on Lake Street. I think the City of Lakeview should consider placing a traffic light there to control the traffic going both ways. While I do not have access to any resources or data that can show precisely how much a traffic light can improve the intersection, I think you will agree that a controlled busy intersection is much safer than an uncontrolled one. Therefore, at a minimum, the city must consider making the intersection a four-way stop.

Each day that goes by without attention to this issue is a lost opportunity to save lives and make the community a safer, more enjoyable place to live. Because the safety of citizens is the priority of every 
government, I can only expect that the Department of Transportation and the City of Lakeview will act on this matter immediately. For the safety and well-being of Lakeview citizens, please do not let bureaucracy or money impede this urgent project.

Sincerely,

A Concerned Citizen

\section{Online Illustration Essay Alternatives}

Lewis Thomas provides several illustrative examples in On Natural Death:

- http://thefloatinglibrary.com/2009/03/05/on-natural-death-lewis-thomas

Jessica Bennett, a senior writer for Newsweek, offers an example of an illustration essay when she presents The Flip Side of Internet Fame:

- http://www.newsweek.com/2008/02/21/the-flip-side-of-internet-fame.html 


\subsection{Descriptive Essay}

\section{Learning Objective}

1. Read an example of the descriptive rhetorical mode.

\section{America's Pastime}

As the sun hits my face and I breathe in the fresh air, I temporarily forget that I am at a sporting event. But when I open my eyes and look around, I am reminded of all things American. From the national anthem to the international players on the field, all the sights and sounds of a baseball game come together like a slice of Americana pie.

First, the entrance turnstiles click and clank, and then a hallway of noise bombards me. All the fans voices coalesce in a chorus of sound, rising to a humming clamor. The occasional, "Programs, get your programs, here!" jumps out through the hum to get my attention. I navigate my way through the crowded walkways of the stadium, moving to the right of some people, to the left of others, and I eventually find the section number where my seat is located. As I approach my seat I hear the announcer's voice echo around the ball park, "Attention fans. In honor of our country, please remove your caps for the singing of the national anthem." His deep voice echoes around each angle of the park, and every word is heard again and again. The crowd sings and hums "The Star-Spangled Banner," and I feel a surprising amount of national pride through the voices. I take my seat as the umpire shouts, "Play ball!" and the game begins.

In the fifth inning of the game, I decide to find a concessions stand. Few tastes are as American as hot dogs and soda pop, and they cannot be missed at a ball game. The smell of hot dogs carries through the park, down every aisle, and inside every concourse. They are always as unhealthy as possible, dripping in grease, while the buns are soft and always too small for the dog. The best way to wash down the Ball Park Frank is with a large soda pop, so I order both. Doing my best to balance the cold pop in one hand and the wrapped-up dog in the other, I find the nearest condiments stand to load up my hot dog. A dollop of bright green relish and chopped onions, along with two squirts of the ketchup and mustard complete the dog. As I continue the balancing act between the loaded hot dog and pop back to my seat, a cheering fan bumps into my pop hand. The pop splashes out of the cup and all over my shirt, leaving me drenched. I make direct eye contact with the man who bumped into me and he looks me in the eye, looks at my shirt, tells me how sorry he is, and then I just shake my head and keep walking. "It’s all just part of the experience,” I tell myself.

Before I am able to get back to my seat, I hear the crack of a bat, followed by an uproar from the crowd. Everyone is standing, clapping, and cheering. I missed a home run. I find my aisle and ask everyone to excuse me as I slip past them to my seat. "Excuse me. Excuse me. Thank you. Thank you. Sorry," is all I can say as I inch past each fan. Halfway to my seat I can hear discarded peanut shells crunch beneath my feet, and each step is marked with a pronounced crunch.

When I finally get to my seat I realize it is the start of the seventh inning stretch. I quickly eat my hot dog and 
wash it down with what is left of my soda pop. The organ starts playing and everyone begins to sing "Take Me Out to the Ball Game.” While singing the song, putting my arms around friends and family with me, I watch all the players taking the field. It is wonderful to see the overwhelming amount of players on one team from around the world: Japan, the Dominican Republic, the United States, Canada, and Venezuela. I cannot help but feel a bit of national pride at this realization. Seeing the international representation on the field reminds me of the ways that Americans, though from many different backgrounds and places, still come together under common ideals. For these reasons and for the whole experience in general, going to a Major League Baseball game is the perfect way to glimpse a slice of Americana.

\section{Online Descriptive Essay Alternatives}

Suzanne Berne visits New York and describes her impressions in Where Nothing Says Everything, also called Ground Zero:

- http://hepurpleenglishteacher.files.wordpress.com/2010/10/groundzero.pdf

- http://www.nytimes.com/2002/04/21/travel/where-nothing-says-everything.html

Heather Rogers provides a detailed description (book excerpt) of a landfill that challenges the reader to consider his or her own consumption and waste in The Hidden Life of Garbage:

- http://books.google.com/books?id=efUymAhM tAC\&pg=PA12\&lpg=PA12\&dq= the+hidden+life+of+garbage+by+heather+rogers+\%22in+the+dark+chill+of+early+ morning\%22\&source=bl\&ots=7c4hoFLhTp\&sig=ngecGSS27blb9zoy8wLaJX8la o\&hl= en\&ei=Vi7xTKDKG4zSsAP2hdGtCw\&sa=X\&oi=book result\&ct=result\&resnum= $\underline{1 \& \text { ved }=0 \text { CBgQ6AEwAA\#v=onepage } \& \mathrm{q} \& \mathrm{f}=\text { false }}$ 


\subsection{Classification Essay}

\section{Learning Objective}

1. Read an example of the classification rhetorical mode.

Types of Higher Education Programs

Today's students have many choices when it comes to pursuing a degree: four-year programs, two-year programs, large or small classroom settings, and even daytime or evening classes. With all the different options to consider, potential students should learn about the different types of colleges so they can find a school that best fits their personality, budget, and educational goals.

One type of higher education program for students to consider is a liberal arts college. These schools tend to be small in size and offer a range of undergraduate degrees in subjects like English, history, psychology, and education. Students may choose a liberal arts college if they want a more intimate classroom setting rather than large lecture-style classes. Students may also consider a liberal arts college if they want to gain knowledge from a variety of disciplines, rather than focus on a single area of study. Many liberal arts schools are privately owned, and some have religious affiliations. Liberal arts schools can come with a hefty price tag, and their high cost presents an obstacle for students on a tight budget; moreover, while some students might appreciate a liberal arts school's intimate atmosphere, others might encounter a lack of diversity in the student body. Still, students seeking a well-rounded education in the humanities will find liberal arts colleges to be one option.

Universities, another type of higher education program, offer both undergraduate and graduate degrees. Usually universities are larger than colleges and can accommodate tens of thousands of students in many different majors and areas of study. A large student body means that class sizes are often larger, and some classes may be taught by graduate students rather than professors. Students will feel at home at a university if they want a focused academic program and state-of-the-art research facilities. While some universities are private, many are public, which means they receive funding from the government, so tuition is more affordable and some even offer discounted in-state tuition for state residents. Also, universities attract many international students, so those looking for a variety of campus cultural groups and clubs will appreciate a greater sense of diversity among the student body. Universities can be overwhelming for some, but they are the right fit for students who seek research opportunities and academic studies, especially in the fields of mathematics and science.

Community college is a type of higher education program popular with students on a limited budget who want to take college courses but may not know what they want to major in. Most schools offer degrees after two years of study, usually an associate's degree that prepares students to enter the work force; many students choose to study at a community college for two years and then transfer to a four-year college to complete their undergraduate degree. Like liberal arts schools, classes are small and allow instructors to pay more 
attention to their students. Community college allows students to live at home rather than in a dormitory, which also keeps costs down. While some young people might not like the idea of living at home for school, many adults choose to attend community college so they can advance their education while working and living with their families.

Online universities are another type of higher education program that are gaining popularity as technology improves. These schools offer many of the same degree programs as traditional liberal arts colleges and universities. Unlike traditional programs, which require students to attend classes and lectures, online universities offer greater academic flexibility and are a great option for students wishing to pursue a degree while still working full time. At online universities, students access course materials, such as video lectures and assessments, remotely using a personal computer and are able to speed up or slow down their progress to complete their degree at their own pace. Students may attend classes in the comfort of their own home or a local library, but students hoping for the social community of higher education might not enjoy this aspect of higher education.

With so many colleges and universities to choose from, it may be difficult for a student to narrow down his or her selection, but once a student knows what he or she is looking for, the process may become much easier. It is very important for students to learn about the different types of higher education programs available before making their selections.

\section{Online Classification Essay Alternatives}

Amy Tan describes relationship with her heritage, her mother, and her languages in Mother Tongue

- http://theessayexperiencefall2013.qwriting.qc.cuny.edu/files/2013/09/Mother-Tongue-byAmy-Tan.pdf 


\subsection{Process Analysis Essay}

\section{Learning Objective}

1. Read an example of the process analysis rhetorical mode.

How to Grow Tomatoes from a Seedling

Growing tomatoes is a simple and rewarding task, and more people should be growing them. This paper walks readers through the main steps for growing and maintaining patio tomatoes from a seedling.

The first step in growing tomatoes is determining if you have the appropriate available space and sunlight to grow them. All tomato varieties require full sunlight, which means at least six hours of direct sun every day. If you have south-facing windows or a patio or backyard that receives direct sunlight, you should be able to grow tomatoes. Choose the location that receives the most sun.

Next, you need to find the right seedling. Growing tomatoes and other vegetables from seeds can be more complicated (though it is not difficult), so I am only discussing how to grow tomatoes from a seedling. A seedling, for those who do not know, is typically understood as a young plant that has only recently started growing from the seed. It can be anything from a newly germinated plant to a fully flowering plant. You can usually find tomato seedlings at your local nursery for an affordable price. Less than five dollars per plant is a common price. When choosing the best seedling, look for a plant that is short with healthy, full leaves and no flowers. This last point tends to be counterintuitive, but it is extremely important. You do not want a vegetable plant that has already started flowering in the nursery because it will have a more difficult time adapting to its new environment when you replant it. Additionally, choose a plant with one strong main stem. This is important because the fewer stems that a tomato plant has, the more easily it can transport nutrients to the fruit. Multiple stems tend to divide nutrients in less efficient ways, often resulting in either lower yields or smaller fruit.

Once you have found the right seedlings to plant back home, you need to find the best way of planting them. I recommend that you plant your tomatoes in containers. If you have the space and sunlight, then you can certainly plant them in the ground, but a container has several advantages and is usually most manageable for the majority of gardeners. The containers can be used in the house, on a patio, or anywhere in the backyard, and they are portable. Containers also tend to better regulate moisture and drain excess water. Choose a container that is at least 10 inches in diameter and at least 1 foot deep. This will provide sufficient room for root development.

In addition to the container, you also need the appropriate soil mixture and draining mechanisms. For the best drainage, fill the bottom of your container with 2 or 3 inches of gravel. On top of the gravel, fill $3 / 4$ of the container with soil. Choose a well-balanced organic soil. The three main ingredients you will find described on soil bags are N-P-K - that is, nitrogen, phosphorus, and potassium. Without going into too much detail about the role of each element in plant growth, I will tell you that an average vegetable will grow fine in a 
10-5-5 mixture. This ratio, too, will be easy to find at your local nursery.

Once you have the gravel in the bottom of the container and the soil on top, you are ready to transplant the tomato. Pick up the tomato in the plastic container it comes in from the nursery. Turn it upside down, and holding the stem between your fingers, pat the bottom lightly several times, and the plant should fall into your hand. Next, you should gently break up the root ball that formed in the nursery container with your hands. Be gentle, but be sure to rip them up a bit; this helps generate new root growth in the new container. Be careful not to damage the roots too much, as this could stunt the growth or even destroy the plant altogether.

Next, carve out a hole in the soil to make space for the plant. Make it deep enough to go about an inch higher than it was previously buried and wide enough so all the roots can comfortably fit within and beneath it. Place the seedling in the hole and push the removed soil back on top to cover the base of the plant. After that, the final step in planting your tomato is mulch. Mulch is not necessary for growing plants, but it can be very helpful in maintaining moisture, keeping out weeds, and regulating soil temperature. Place 2-3 inches of mulch above the soil and spread it out evenly.

Once the mulch is laid, you are mostly done. The rest is all watering, waiting, and maintenance. After you lay the mulch, pour the plant a heavy amount of water. Water the plant at its base until you see water coming through the bottom of the container. Wait ten minutes, and repeat. This initial watering is very important for establishing new roots. You should continue to keep the soil moist, but never soaking wet. One healthy watering each morning should be sufficient for days without rain. You can often forego watering on days with moderate rainfall. Watering in the morning is preferable to the evening because it lessens mold and bacteria growth.

Choosing to grow the patio variety of tomatoes is easiest because patio tomatoes do not require staking or training around cages. They grow in smaller spaces and have a determinate harvest time. As you continue to water and monitor your plant, prune unhealthy looking leaves to the main stem, and cut your tomatoes down at the stem when they ripen to your liking. As you can see, growing tomatoes can be very easy and manageable for even novice gardeners. The satisfaction of picking and eating fresh food, and doing it yourself, outweighs all the effort you put in over the growing season.

\section{Online Process Analysis Essay Alternatives:}

Stanley Fish, a professor of humanities and law at Florida International University, tells us why Getting Coffee Is Hard to Do:

- http://www.nytimes.com/2007/08/06/opinion/06iht-edfish.1.7000425.html

- http://opinionator.blogs.nytimes.com/2007/08/04/getting-coffee-is-hard-to-do

Arthur Miller takes a humorous look at a gruesome process in Get It Right: Privatize Executions:

- http://www.davidglensmith.com/lonestar/1301/PDFs/miller.pdf

- http://www.nytimes.com/1992/05/08/opinion/get-it-right-privatize-executions.html 


\subsection{Definition Essay}

\section{Learning Objective}

1. Read an example of the definition rhetorical mode.

Defining Good Students Means More Than Just Grades

Many people define good students as those who receive the best grades. While it is true that good students often earn high grades, I contend that grades are just one aspect of how we define a good student. In fact, even poor students can earn high grades sometimes, so grades are not the best indicator of a student's quality. Rather, a good student pursues scholarship, actively participates in class, and maintains a positive, professional relationship with instructors and peers.

Good students have a passion for learning that drives them to fully understand class material rather than just worry about what grades they receive in the course. Good students are actively engaged in scholarship, which means they enjoy reading and learning about their subject matter not just because readings and assignments are required. Of course, good students will complete their homework and all assignments, and they may even continue to perform research and learn more on the subject after the course ends. In some cases, good students will pursue a subject that interests them but might not be one of their strongest academic areas, so they will not earn the highest grades. Pushing oneself to learn and try new things can be difficult, but good students will challenge themselves rather than remain at their educational comfort level for the sake of a high grade. The pursuit of scholarship and education rather than concern over grades is the hallmark of a good student.

Class participation and behavior are another aspect of the definition of a good student. Simply attending class is not enough; good students arrive punctually because they understand that tardiness disrupts the class and disrespects the professors. They might occasionally arrive a few minutes early to ask the professor questions about class materials or mentally prepare for the day's work. Good students consistently pay attention during class discussions and take notes in lectures rather than engage in off-task behaviors, such as checking their cell phones or daydreaming. Excellent class participation requires a balance between speaking and listening, so good students will share their views when appropriate but also respect their classmates' views when they differ from their own. It is easy to mistake quantity of class discussion comments with quality, but good students know the difference and do not try to dominate the conversation. Sometimes class participation is counted toward a student's grade, but even without such clear rewards, good students understand how to perform and excel among their peers in the classroom.

Finally, good students maintain a positive and professional relationship with their professors. They respect their instructor's authority in the classroom as well as the instructor's privacy outside of the classroom. Prying into a professor's personal life is inappropriate, but attending office hours to discuss course material is an appropriate, effective way for students to demonstrate their dedication and interest in learning. Good 
students go to their professor's office during posted office hours or make an appointment if necessary. While instructors can be very busy, they are usually happy to offer guidance to students during office hours; after all, availability outside the classroom is a part of their job. Attending office hours can also help good students become memorable and stand out from the rest, particularly in lectures with hundreds enrolled. Maintaining positive, professional relationships with professors is especially important for those students who hope to attend graduate school and will need letters of recommendation in the future.

Although good grades often accompany good students, grades are not the only way to indicate what it means to be a good student. The definition of a good student means demonstrating such traits as engaging with course material, participating in class, and creating a professional relationship with professors. While every professor will have different criteria for earning an A in their course, most would agree on these characteristics for defining good students.

\section{Online Definition Essay Alternatives}

Judy Brady provides a humorous look at responsibilities and relationships in I Want a Wife:

- http://www.columbia.edu/ sss31/rainbow/wife.html

Gayle Rosenwald Smith shares her dislike of the name for a sleeveless T-shirt, The Wife-Beater:

- http://faculty.gordonstate.edu/cperkowski/1101/WifeBeater.pdf

Philip Levine defines What Work Is:

- http://www.ibiblio.org/ipa/poems/levine/what work is.php

- http://www.poemhunter.com/poem/what-work-is 


\subsection{Compare-and-Contrast Essay}

\section{Learning Objective}

1. Read an example of the compare-and-contrast rhetorical mode.

Comparing and Contrasting London and Washington, DC

Both Washington, DC, and London are capital cities of English-speaking countries, and yet they offer vastly different experiences to their residents and visitors. Comparing and contrasting the two cities based on their history, their culture, and their residents show how different and similar the two are.

Both cities are rich in world and national history, though they developed on very different time lines. London, for example, has a history that dates back over two thousand years. It was part of the Roman Empire and known by the similar name, Londinium. It was not only one of the northernmost points of the Roman Empire but also the epicenter of the British Empire where it held significant global influence from the early sixteenth century on through the early twentieth century. Washington, DC, on the other hand, has only formally existed since the late eighteenth century. Though Native Americans inhabited the land several thousand years earlier, and settlers inhabited the land as early as the sixteenth century, the city did not become the capital of the United States until the 1790s. From that point onward to today, however, Washington, DC, has increasingly maintained significant global influence. Even though both cities have different histories, they have both held, and continue to hold, significant social influence in the economic and cultural global spheres.

Both Washington, DC, and London offer a wide array of museums that harbor many of the world's most prized treasures. While Washington, DC, has the National Gallery of Art and several other Smithsonian galleries, London's art scene and galleries have a definite edge in this category. From the Tate Modern to the British National Gallery, London's art ranks among the world's best. This difference and advantage has much to do with London and Britain's historical depth compared to that of the United States. London has a much richer past than Washington, DC, and consequently has a lot more material to pull from when arranging its collections. Both cities have thriving theater districts, but again, London wins this comparison, too, both in quantity and quality of theater choices. With regard to other cultural places like restaurants, pubs, and bars, both cities are very comparable. Both have a wide selection of expensive, elegant restaurants as well as a similar amount of global and national chains. While London may be better known for its pubs and taste in beer, DC offers a different bar-going experience. With clubs and pubs that tend to stay open later than their British counterparts, the DC night life tend to be less reserved overall.

Both cities also share and differ in cultural diversity and cost of living. Both cities share a very expensive cost of living-both in terms of housing and shopping. A downtown one-bedroom apartment in DC can easily cost $\$ 1,800$ per month, and a similar "flat" in London may double that amount. These high costs create socioeconomic disparity among the residents. Although both cities' residents are predominantly wealthy, both have a significantly large population of poor and homeless. Perhaps the most significant difference between 
the resident demographics is the racial makeup. Washington, DC, is a "minority majority" city, which means the majority of its citizens are races other than white. In 2009, according to the US Census, 55 percent of DC residents were classified as "Black or African American" and 35 percent of its residents were classified as "white.” London, by contrast, has very few minorities - in 2006, 70 percent of its population was "white," while only 10 percent was "black." The racial demographic differences between the cities is drastic.

Even though Washington, DC, and London are major capital cities of English-speaking countries in the Western world, they have many differences along with their similarities. They have vastly different histories, art cultures, and racial demographics, but they remain similar in their cost of living and socioeconomic disparity.

\section{Online Compare-and-Contrast Essay Alternatives}

Ellen Laird compares and contrasts traditional and distance education in I'm Your Teacher, Not Your Internet-Service Provider:

- http://celt.cui.edu/celt/webct for instructors/Laird Article.htm

Deborah Tannen compares and contrasts conversation styles in Sex, Lies and Conversation: Why Is It So Hard for Men and Women to Talk to Each Other?

- https://static1.squarespace.com/static/5523ffe4e4b012b2c4ebd8fc/t/ 5627dc4de4b00c9587e32fa0/1445452877014/Sex\%2C+Lies+and+Conversation.PDF

Alex Wright examines communication patterns, old and new, in Friending, Ancient or Otherwise:

- http://www.nytimes.com/2007/12/02/weekinreview/02wright.html 


\subsection{Cause-and-Effect Essay}

\section{Learning Objective}

1. Read an example of the cause-and-effect rhetorical mode.

\section{Effects of Video Game Addiction}

Video game addition is a serious problem in many parts of the world today and deserves more attention. It is no secret that children and adults in many countries throughout the world, including Japan, China, and the United States, play video games every day. Most players are able to limit their usage in ways that do not interfere with their daily lives, but many others have developed an addiction to playing video games and suffer detrimental effects.

An addiction can be described in several ways, but generally speaking, addictions involve unhealthy attractions to substances or activities that ultimately disrupt the ability of a person to keep up with regular daily responsibilities. Video game addiction typically involves playing games uncontrollably for many hours at a time-some people will play only four hours at a time while others cannot stop for over twenty-four hours. Regardless of the severity of the addiction, many of the same effects will be experienced by all.

One common effect of video game addiction is isolation and withdrawal from social experiences. Video game players often hide in their homes or in Internet cafés for days at a time-only reemerging for the most pressing tasks and necessities. The effect of this isolation can lead to a breakdown of communication skills and often a loss in socialization. While it is true that many games, especially massive multiplayer online games, involve a very real form of e-based communication and coordination with others, and these virtual interactions often result in real communities that can be healthy for the players, these communities and forms of communication rarely translate to the types of valuable social interaction that humans need to maintain typical social functioning. As a result, the social networking in these online games often gives the users the impression that they are interacting socially, while their true social lives and personal relations may suffer.

Another unfortunate product of the isolation that often accompanies video game addiction is the disruption of the user's career. While many players manage to enjoy video games and still hold their jobs without problems, others experience challenges at their workplace. Some may only experience warnings or demerits as a result of poorer performance, or others may end up losing their jobs altogether. Playing video games for extended periods of time often involves sleep deprivation, and this tends to carry over to the workplace, reducing production and causing habitual tardiness.

Video game addiction may result in a decline in overall health and hygiene. Players who interact with video games for such significant amounts of time can go an entire day without eating and even longer without basic hygiene tasks, such as using the restroom or bathing. The effects of this behavior pose significant danger to their overall health. 
The causes of video game addiction are complex and can vary greatly, but the effects have the potential to be severe. Playing video games can and should be a fun activity for all to enjoy. But just like everything else, the amount of time one spends playing video games needs to be balanced with personal and social responsibilities.

\section{Online Cause-and-Effective Essay Alternatives}

Lawrence Otis Graham examines racism, and whether it has changed since the 1970s, in The "Black Table” Is Still There:

- http://scremeens.googlepages.com/TheBlackTableessay.rtf

Robin Tolmach Lakoff discusses the power of language to dehumanize in From Ancient Greece to Iraq: The Power of Words in Wartime:

- http://www.nytimes.com/2004/05/18/science/essay-from-ancient-greece-to-iraq-the-powerof-words-in-wartime.html

Alan Weisman examines the human impact on the planet and its effects in Earth without People:

- http://discovermagazine.com/2005/feb/earth-without-people 


\subsection{Persuasive Essay}

\section{Learning Objective}

1. Read an example of the persuasive rhetorical mode.

Universal Health Care Coverage for the United States

The United States is the only modernized Western nation that does not offer publicly funded health care to all its citizens; the costs of health care for the uninsured in the United States are prohibitive, and the practices of insurance companies are often more interested in profit margins than providing health care. These conditions are incompatible with US ideals and standards, and it is time for the US government to provide universal health care coverage for all its citizens. Like education, health care should be considered a fundamental right of all US citizens, not simply a privilege for the upper and middle classes.

One of the most common arguments against providing universal health care coverage (UHC) is that it will cost too much money. In other words, UHC would raise taxes too much. While providing health care for all US citizens would cost a lot of money for every tax-paying citizen, citizens need to examine exactly how much money it would cost, and more important, how much money is "too much" when it comes to opening up health care for all. Those who have health insurance already pay too much money, and those without coverage are charged unfathomable amounts. The cost of publicly funded health care versus the cost of current insurance premiums is unclear. In fact, some Americans, especially those in lower income brackets, could stand to pay less than their current premiums.

However, even if UHC would cost Americans a bit more money each year, we ought to reflect on what type of country we would like to live in, and what types of morals we represent if we are more willing to deny health care to others on the basis of saving a couple hundred dollars per year. In a system that privileges capitalism and rugged individualism, little room remains for compassion and love. It is time that Americans realize the amorality of US hospitals forced to turn away the sick and poor. UHC is a health care system that aligns more closely with the core values that so many Americans espouse and respect, and it is time to realize its potential.

Another common argument against UHC in the United States is that other comparable national health care systems, like that of England, France, or Canada, are bankrupt or rife with problems. UHC opponents claim that sick patients in these countries often wait in long lines or long wait lists for basic health care. Opponents also commonly accuse these systems of being unable to pay for themselves, racking up huge deficits year after year. A fair amount of truth lies in these claims, but Americans must remember to put those problems in context with the problems of the current US system as well. It is true that people often wait to see a doctor in countries with UHC, but we in the United States wait as well, and we often schedule appointments weeks in advance, only to have onerous waits in the doctor's "waiting rooms."

Critical and urgent care abroad is always treated urgently, much the same as it is treated in the United States. 
The main difference there, however, is cost. Even health insurance policy holders are not safe from the costs of health care in the United States. Each day an American acquires a form of cancer, and the only effective treatment might be considered "experimental" by an insurance company and thus is not covered. Without medical coverage, the patient must pay for the treatment out of pocket. But these costs may be so prohibitive that the patient will either opt for a less effective, but covered, treatment; opt for no treatment at all; or attempt to pay the costs of treatment and experience unimaginable financial consequences. Medical bills in these cases can easily rise into the hundreds of thousands of dollars, which is enough to force even wealthy families out of their homes and into perpetual debt. Even though each American could someday face this unfortunate situation, many still choose to take the financial risk. Instead of gambling with health and financial welfare, US citizens should press their representatives to set up UHC, where their coverage will be guaranteed and affordable.

Despite the opponents' claims against UHC, a universal system will save lives and encourage the health of all Americans. Why has public education been so easily accepted, but not public health care? It is time for Americans to start thinking socially about health in the same ways they think about education and police services: as rights of US citizens.

\section{Online Persuasive Essay Alternatives}

Martin Luther King Jr. writes persuasively about civil disobedience in Letter from Birmingham Jail:

- http://www.stanford.edu/group/King/frequentdocs/birmingham.pdf

- http://web.cn.edu/kwheeler/documents/Letter Birmingham Jail.pdf

- http://www.oak-tree.us/stuff/King-Birmingham.pdf

Michael Levin argues The Case for Torture:

- http://people.brandeis.edu/ teuber/torture.html

Alan Dershowitz argues The Case for Torture Warrants:

- http://blogs.reuters.com/great-debate/2011/09/07/the-case-for-torture-warrants/

Alisa Solomon argues The Case against Torture:

- http://www.villagevoice.com/2001-11-27/news/the-case-against-torture/1 